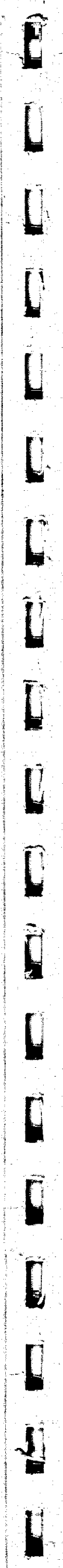

\title{
Hot Isostatic Press Waste Option Study Report
}

\section{RECEIVED \\ MAR 131998 \\ OSTI}

\begin{abstract}
N. E. Russell
D. D. Taylor
\end{abstract}

EETMIBUTION OF THIS DOCUMENT IS UNLMMTID

LOCKHEE MATTIN/7 MASTER 


\title{
Hot Isostatic Press Waste Option Study Report
}

\author{
N. E. Russell \\ D. D. Taylor
}

Published February 1998

Idaho National Engineering and Environmental Laboratory Applied Engineering and Development Laboratory Department

Lockheed Martin Idaho Technologies Company Idaho Falls, Idaho 83415

Prepared for the

U.S. Department of Energy

Assistant Secretary for Environmental Management

Under DOE Idaho Operations Office

Contract DE-AC07-94ID13223 


\begin{abstract}
A Settlement Agreement between the Department of Energy and the State of Idaho mandates that all high-level radioactive waste now stored at the Idaho Chemical Processing Plant be treated so that it is ready to move out of Idaho for disposal by the target date of 2035. This study investigates the immobilization of all Idaho Chemical Processing Plant calcine, including calcined sodium bearing waste, via the process known as hot isostatic press, which produces compact solid waste forms by means of high temperature and pressure $\left(1,050^{\circ} \mathrm{C}\right.$ and $20,000 \mathrm{psi})$, as the treatment method for complying with the settlement agreement. The final waste product would be contained in stainless-steel canisters, the same type used at the Savannah River Site for vitrified waste, and stored at the Idaho National Engineering and Environmental Laboratory until a national geological repository becomes available for its disposal. The waste processing period is from 2013 through 2032, and disposal at the High Level Waste repository will probably begin sometime after 2065 .
\end{abstract}

\title{
DISCLAIMER
}

This report was prepared as an account of work sponsored by an agency of the United States This report was prepared as an aned employees, makes any warranty, express or implied, or assumes any legal liability or responsibility for the accuracy, completeness, or usefulness of any information, apparatus, product, or process disclosed, or represents that its use would not infringe privately owned rights. Reference herein to any specific commercial product, process, or service by trade name, trademark, manufacturer, or otherwise does not necessarily constitute or imply its endorsement, recommendation, or favoring by the United States Government or any agency thereof. The views mendation, or favoring by the United States Government or any agences the herein do not necessarily state or reflect those of the United States Government or any agency thereof. 



\section{DISCLAIMER}

Portions of this document may be illegible electronic image products. Images are produced from the best available original document. 


\section{SUMMARY}

Treatment of high-level radioactive wastes at the Idaho Chemical Processing Plant (ICPP) on the Idaho National Engineering and Environmental Laboratory (INEEL) is mandated under a Settlement Agreement between the U.S. Department of Energy (DOE) and the State of Idaho. Among other things, the Settlement Agreement requires that this treated radioactive high-level waste (HLW) be ready to move out of Idaho for disposal by a target date of 2035. To comply, INEEL proposes a treatment called the Hot Isostatic Press (HIP) Waste Option (HWO), where the existing liquid sodium-bearing waste (SBW) would be calcined and added to the other calcine presently in the Calcined Solids Storage Facility (CSSF) at ICPP. The calcine would be mixed with amorphous silica and titanium powder, and then hot isostatically pressed (HIPed) in special cans to form a glass-ceramic product. The HIPed product would be packaged in Savannah River Site (SRS) canisters for interim storage and disposal in a HLW national repository. This option will not process any waste generated after 2012. The SRS canister was selected for use in this report.

Design bases and criteria, requirements, regulations, and codes, and standard studies were conducted and corresponding engineering design files (EDFs) were issued. These studies included requirements of DOE, U.S. Environmental Protection Agency (EPA), the State of Idaho, Nuclear Regulatory Commission (NRC), and U.S. Department of Transportation (DOT) that were applicable to all Non-Separations Alternatives including the HWO. The operating period for the HIP facility is from 2013 through 2032 , and $5,400 \mathrm{~m}^{3}$ of calcine will be processed, resulting in 5,700 SRS canisters of HIPed waste produced and stored in the HWO interim storage facility (ISF). Costs for analytical support, costs to ship the SRS canisters to the repository, and the costs to dispose of the SRS canisters at the repository are outside the scope of this report.

The major processes involved in the HWO are to (1) obtain calcine from the ICPP CSSF using a Calcine Retrieval and Transport System (CRTS), (2) blend and size the calcine received from the CRTS, (3) sample the calcine to determine chemistry, (4) receive amorphous silica and titanium powder from trucks or rail cars to mix with the calcine, (5) mix the calcine and additives in the proper ratio, (7) deliver the mix to the HIP can fill station and fill the HIP cans, (8) devolatilize the calcine and additives, (9) seal the can lids, (10) HIP the cans, (11) place the HIPed cans in suitable canisters, (12) decontaminate the filled canisters, (13) transport the canisters to an Interim Storage Facility (ISF) and place them in interim storage, and (14) process the devolatilization off-gas. All the processes, except 1 and 13, will be accomplished in the HIP facility.

A process chemical engineer first formulated the basic HIP facility processes necessary to successfully HIP the calcine into an acceptable glassceramic. The process engineer also calculated, and documented, qualitative parameters of the processes that would allow treating all calcined waste by the end of 2032. A design team of specialists then implemented that process, and documented the work in this report. The CRTS, the ISF, and the Utilities Support necessary to support the HIP facility were studied, and similar but separate documents were issued for these studies. The HWO consists of the HIP facility, CRTS, ISF, and the Utilities Support. The latter three systems are 
described briefly in this report and their documents are either included or referenced. The CRTS, ISF, and Utilities Support cost estimates are each included in their respective reports and their cost summaries are combined with the HIP facility costs in Section 3 of this report to arrive at the total HWO costs.

In the performance of this study, various processing methods were researched and assumptions made about the composition and quantity of the HIPed waste, the types of remote equipment needed in the HIP facility, the layout of the HIP facility, the utilities required, and the requirements and regulations that will apply.

The majority of the main text of this report describes the HWO HIP facility in detail. The facility will be located in the northeast comer of the ICPP. Utilities for the facility are detailed in a separate report. The HIP facility will be a multistory building that extends from $20 \mathrm{ft}$ below, to $60 \mathrm{ft}$ above grade elevation, and has a floor plan occupying an area measuring approximately $302 \times 320 \mathrm{ft}$. It will be designed to house the equipment and operations for nonseparations processing of HLW calcine while providing essential features for safe and efficient operation and maintenance. The HIP facility layout is based on centrally located process cell complexes with limited personnel access and heavy concrete walls for shielding. The remotely operated cells will house equipment that requires minimal maintenance. The periphery of the facility contains office space, support areas, and nonradioactive operation areas. The facility will have a separate system for processing devolatilization off-gas and reclaiming mercury waste. The building will comply with requirements of DOE Order 6430.1A1325, "Laboratory Facilities including Hot Laboratories." In addition to the offgas system, the HIP facility will have separate primary, secondary, and office ventilation zones. Airflow will be from areas of lower contamination to areas of higher contamination where areas of higher potential airborne contamination will be kept at less than ambient pressure.

To facilitate equipment changeout and maintenance, the facility is based on the canyon design approach using hatches in the cell ceilings that can be removed to provide access to cell equipment by a large remotely operated bridge crane. Above the ceiling hatches is a large, open maintenance area that can be used for laydown, maintenance, sizing, packaging, and removal and retrieval of equipment.

The heart of the HIP facility is the devolatilization and HIPing processes. The HIP facility receives calcine, amorphous silica, and titanium powder from two different systems. The calcine is pneumatically transferred into large blending tanks in the HIP facility by two parallel lines from the CRTS. The calcine is then sized and blended with the additives. A loading system delivers the calcine and additives mixture to the HIP can fill station where HIP cans are filled. The HIP cans are then transferred to the devolatilization cell where the devolatilization process takes place. The devolatilization ovens are designed to develop a centerline temperature of the HIP can and its contents of $650^{\circ} \mathrm{C}$ and maintain this temperature for 24 hours. The resulting off-gases are removed in the off-gas treatment system. Following the devolatilization process, the HIP cans are transported to the HIP furnaces. 
The electrically heated and argon-gas-pressurized HIP furnaces are designed to operate at about $1,050^{\circ} \mathrm{C}$ and 20,000 psi. The HIP cans and contents, while exposed to this environment, transform into a dense, non-leaching, glassceramic waste form. The HIPed cans are removed from the furnaces and placed into SRS canisters. The canisters are capped, decontaminated, and transferred to the IFS for storage.

The electrical utility is provided by the facilities described in the Utilities and Infrastructure Study. Automatic wet-pipe sprinkler systems in the operating galleries and office areas, and high efficiency particulate air (HEPA) deluge systems will provide fire protection. The hot cells will be provided with either limited water, or gaseous extinguishing systems. The information regarding the calcine transfer system is provided in EDF-WTS-002 (see Appendix A) and information for the Interim Storage Facility is provided.'

Cost estimates were performed on the HIP facility and HWO. The total costs for the HWO are summarized as follows and include costs for the CRTF, the ISF, and the Utility Service:

Total Cost (unescalated) is $\$ 2,263,435,000$

Total Cost (with escalation, management reserve, and contingency) is $\$ 5,763,998,000$

Discounted Cost (escalated) is $\$ 1,572,040,000$.

The maturity of the HWO technology was evaluated and determined to be between the Engineering Development and the Implementation stage. The risk associated with the HIP facility technical key assumptions were evaluated.

Failure modes were listed and discussed in general, but detailed effects analyses were beyond the scope of this report.

The Project Data Sheet and its supporting data were completed for the HIP facility and are included. A list of recommended future studies that will be needed to support future design efforts, but was beyond the scope of this report, is included.

In conclusion, about 5,700 SRS canisters of HIPed HLW would be produced by the HWO from 2013 through 2032. That schedule would require two 10-hourper-day shifts, four days per week of operation, and $50 \%$ down time for maintenance. The HWO technology is considered to be at the engineering development phase and the risk of failure due to the maturity of technology is perceived as low to medium. 


\section{CONCLUSIONS}

The Non-separations Alternative HWO consists of the CRTS, the Vitrification Facility, the ISF, and Utilities Support. Designs were based on existing feasibility and conceptual designs for other facilities having similar requirements. This report concentrates on the HIP facility portion of the HWO.

The HIP facility in this report will produce approximately 5,700 SRS canisters for the non-separations alternative during its 20-yr operating life (from 2013 through 2032). This assumes two 10 hour-per-day shifts, 4 days per week operation, with a $50 \%$ process up time. The SRS canister design will be an acceptable waste form for eventual transportation offsite and storage at the repository. The planned date for all HLW to be stored in a road-ready condition, at the ISF, is the end of 2032, which is two years ahead of the 2035 date targeted by DOE and the State of Idaho in the Settlement Agreement. The HWO HIP facility is designed for dry calcine from the ICPP Calcined Solid Storage Facility (CSSF) only. This is because of the assumption that all SBW will have been calcined and placed in the CSSF before the start of HIP facility operation.

The HWO technology is considered to be at the engineering development phase and the risk of failure due to the maturity of technology is perceived as low to medium.

The total costs for the HWO are summarized as follows and include costs for the CRTF, the ISF, and the Utility Service:

Total Cost (unescalated) is $\$ 2,263,435,000$

Total Cost (with escalation, management reserve, and contingency) is $\$ 5,763,998,000$

Discounted Cost (escalated) is $\$ 1,572,040,000$. 


\section{RECOMMENDATIONS}

Communication should be initiated with the NRC, State of Idaho, EPA, repository, and each state and EPA Region through which the waste will be transported for disposal. Future studies are recommended in section 9.2 of this report. 


\section{ACKNOWLEDGMENTS}

The following team of people made significant contributions of their time and expertise to this study. Their work is reflected throughout this report and its appendices:

Rick Adams

Stephanie Austad

Jila Banaee

Phil Rice

Doug Stacey

Mike Berry

Charlie Cox

John Duggan

Rich Eagle

Eloise Snell

Sara Gifford

Dan James

Rod Kimmett

Barry King

Dave Lord

Tom McDonald

Pat Pinto

Doug Stacey

Jack Prendergast

Neal Russell

Ted Reed

Brad Schrader

Dean Taylor

Bob Turk

Mark VanSickle

Gary Wilson
Schedule

AE Facility design and development of site, plot, and floor plans, sections, and elevations, Report writing, and Design Requirements.

Applicable regulations, requirements

Remote Systems Design

Electrical Design

Facility Drawings and P\&ID Drafting

Calcine Retrieval and Transfer System

Construction cost estimate

Project Data Sheets

Technical Editing

Instrumentation and control

Report Writing, Information input and development, overall support in many areas.

Mechanical Equipment Design, Devolatilization Equipment, HIP Furnace, Report

Writing, Risk Analysis

Industrial design, Manpower requirements

Technical team lead, mechanical design, report writing

Recycling Cell and Equipment Design

Radiological Evaluation

Process and off-gas system design, Information input and development, Project Data Sheets, overall support in many areas.

Life cycle cost estimate

Nuclear and Building HVAC

Information input and development Project Data Sheets. 


\section{CONTENTS}

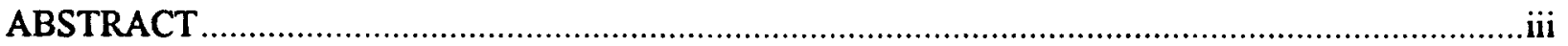

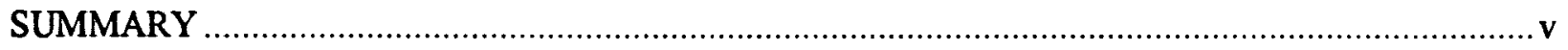

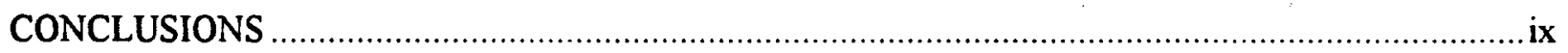

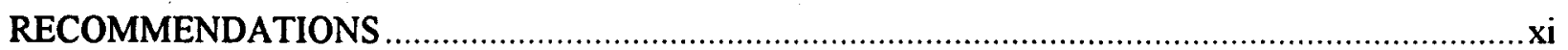

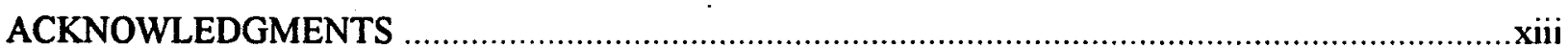

ACRONYMS

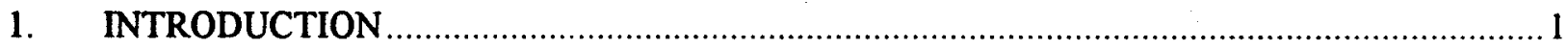

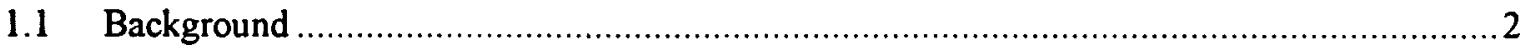

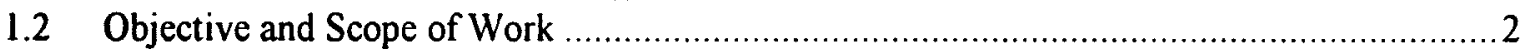

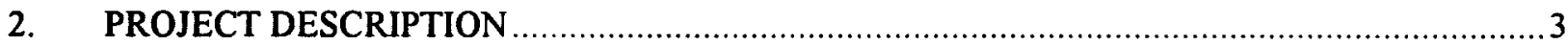

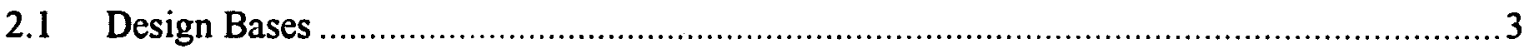

2.1.1 HIP Cans and SRS HLW Canisters .......................................................... 3

2.1.2 Calcine Retrieval and Transportation System ............................................. 3

2.1.3 Interim Storage Facility ................................................................

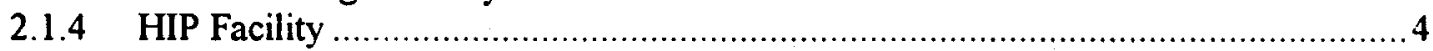

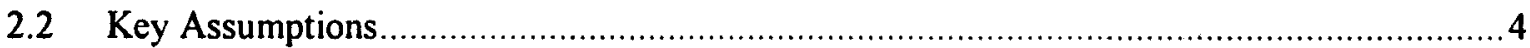

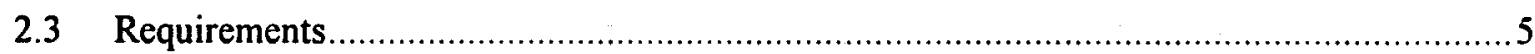

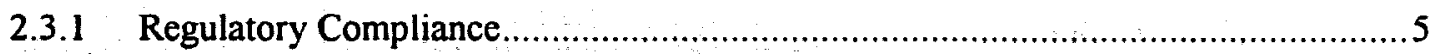

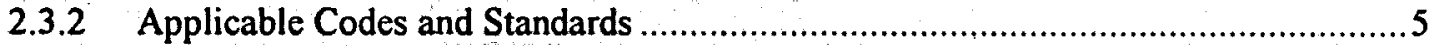

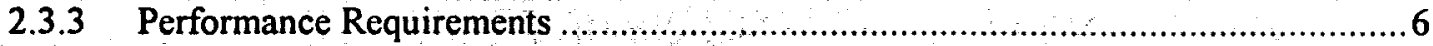

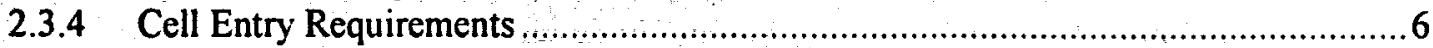

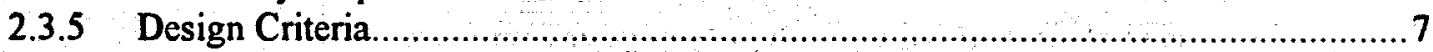

2.3.6 National HLW Geological Repository ...........................................................

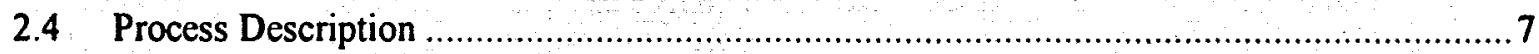

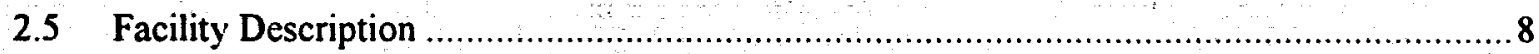

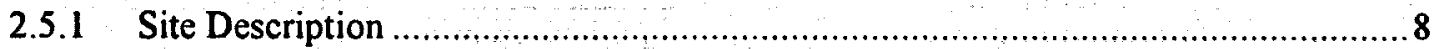

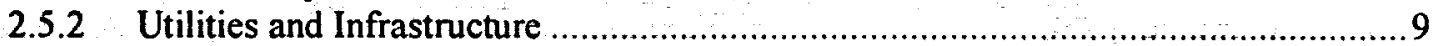

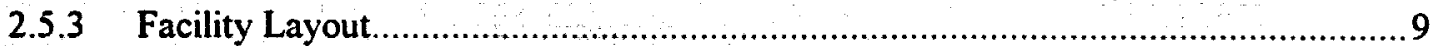

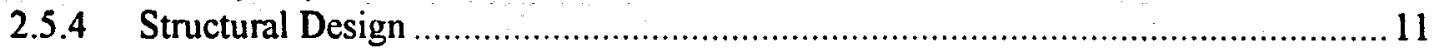

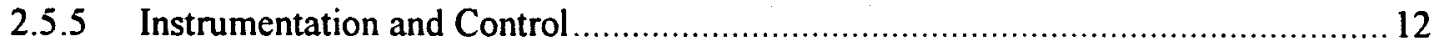




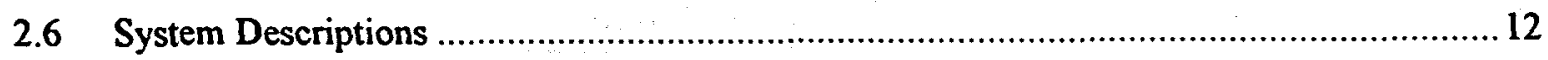

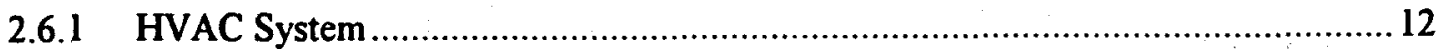

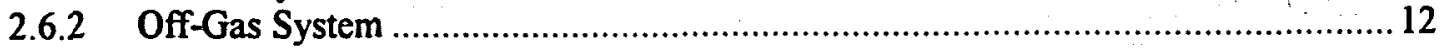

2.6.3 Calcine Retrieval and Transportation System .......................................... 12

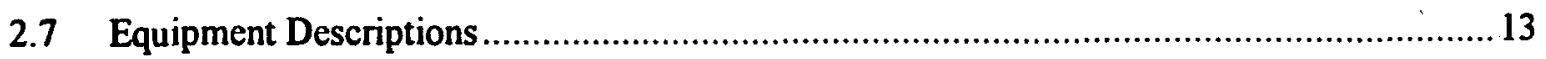

2.7.1 Radiological Monitoring Equipment …................................................... 13

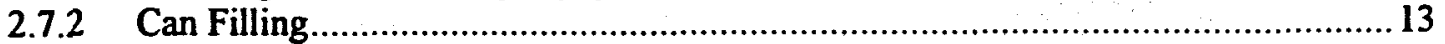

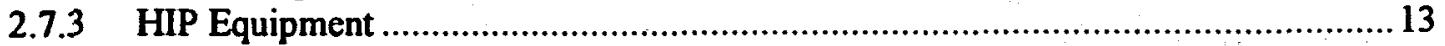

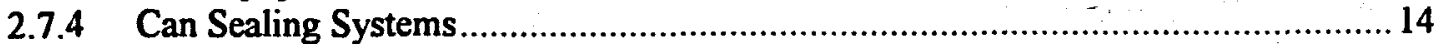

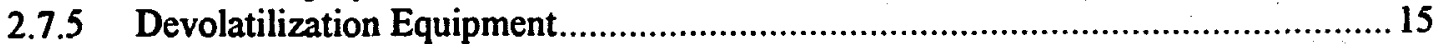

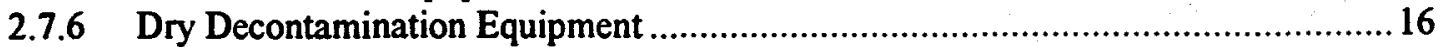

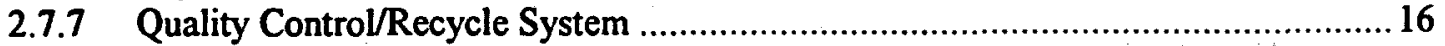

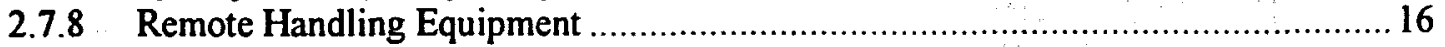

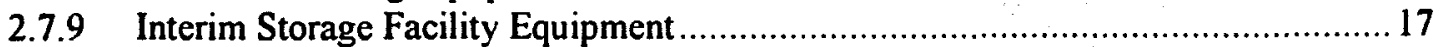

2.8 Utility and Infrastructure Requirements...................................................... 17

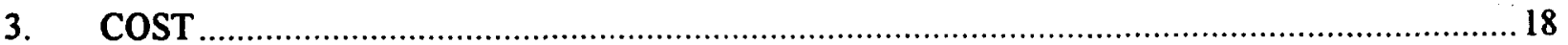

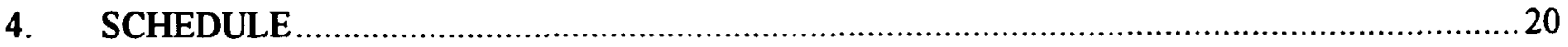

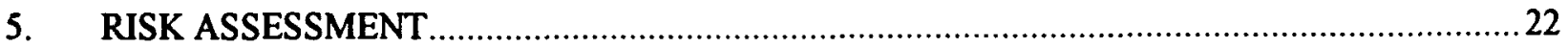

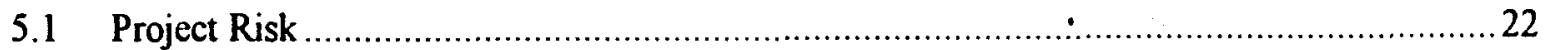

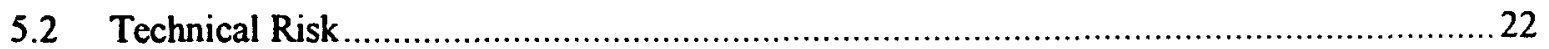

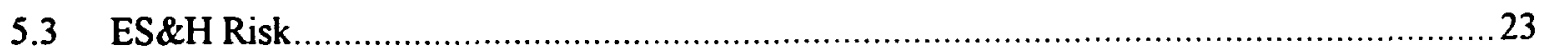

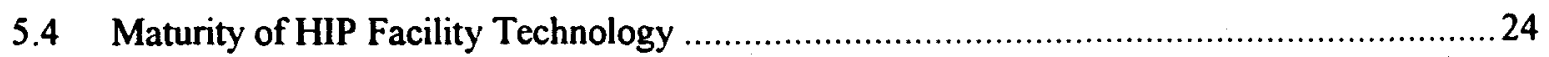

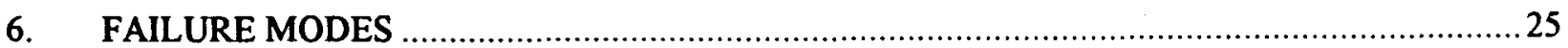

7. PROJECT DATA SHEETS—SUMMARY OF IMPACTS ...............................................27

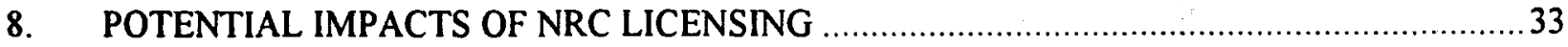

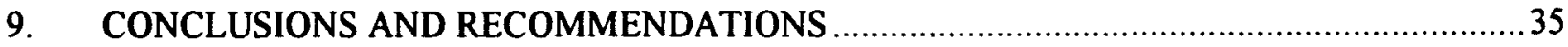

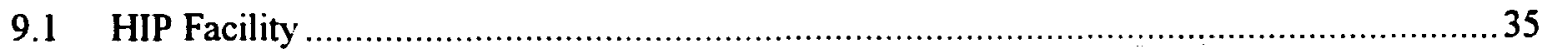

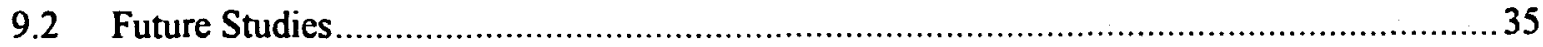

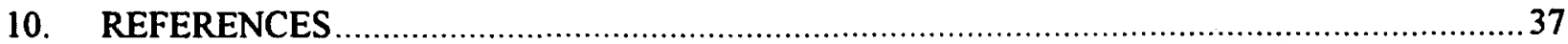

Appendix A-Referenced Engineering Design Files 
Appendix B-Drawings and Sketches

Appendix C-Additional Assumptions

Appendix D-Detailed Cost Estimates

Appendix E-Backup Information for Project Data Sheet

FIGURES

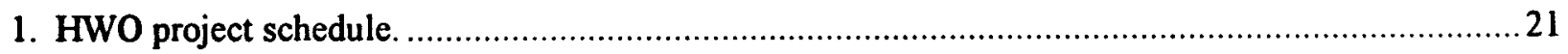

TABLES

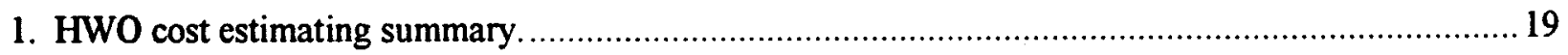

2. Project data sheet for HWO 
xviii 


\section{ACRONYMS}

CRTS Calcine Retrieval and Transportation System

CSSF Calcined Solids Storage Facility

DOE U.S. Department of Energy

DOT U.S. Department of Transportation

EDF Engineering Design File

EIS Environmental Impact Statement

EPA U.S. Environmental Protection Agency

ES\&H Environmental Safety and Health

HAW high-activity waste

HIP hot isostatic press

HLW high-level radioactive waste

HWO HIP Waste Option

GC glass canister

ICPP Idaho Chemical Processing Plant

INEEL Idaho National Engineering and Environmental Laboratory

ISF Interim Storage Facility

ITS Intermediate Transport Station

LAW low-activity waste

LCC life-cycle cost

LDR Land Disposal Restriction

NRC Nuclear Regulatory Commission

OPC Other Project Cost

RCRA Resource Conservation and Recovery Act

SBW sodium-bearing waste 
SRS

Savannah River Site

TRU

transuranic

TEC

total estimated cost

VWO

vitrified waste option

WAC waste acceptance criteria

WAPS waste acceptance product specifications

WIPP Waste Isolation Pilot Plant

WTS Waste Treatment Studies 


\section{Hot Isostatic Press Waste Option Study Report}

\section{INTRODUCTION}

From 1953 until 1992, the Idaho National Engineering and Environmental Laboratory (INEEL) reprocessed spent nuclear fuel, primarily from the U.S. Navy, to recover uranium-235. This activity produced a quantity of mixed, high-level-liquid waste that was then converted into a granular, solid form of mixed, high-level radioactive waste (HLW) called calcine, which is now in the Calcined Solids Storage Facility (CSSF, more commonly referred to as bin sets) on-site. Routine decontamination of the calcining equipment produced a mixed, incidental, liquid waste called sodium-bearing waste (SBW), because it contains sodium hydroxide in addition to a variety of dissolved radioactive and hazardous materials in a nitric-acid solution. The SBW is stored in tanks in an on-site facility called the Tank Farm. All Tank Farm wastes contain both hazardous, as defined in the Resource Conservation and Recovery Act (RCRA), and radioactive wastes that must meet stringent requirements prior to disposal. These requirements include site-specific waste acceptance criteria, and the land disposal restrictions (LDR) established and regulated by the Environmental Protection Agency (EPA) for the hazardous waste components.

In 1995 the U.S. Department of Energy (DOE) signed a Settlement Agreement ${ }^{2}$ with the State of Idaho stating that the DOE would convert all SBW to calcine by the end of 2012 and would prepare all HLW for disposal outside of Idaho by a target date of 2035. By an act of Congress, the disposal of all HLW must be in a characterized, geologic repository; however, only Yucca Mountain is being proposed as the repository for HLW, and may not have enough space for DOE's wastes because of its commitments to commercial nuclear-power plants. Yucca Mountain's criteria require that the HLW contain no untreated hazardous wastes, and that it be immobilized by a process called vitrification (blending the HLW with molten glass) or by an approved, equivalent process. Another geologic repository, the Waste Isolation Pilot Plant (WIPP) in New Mexico, accepts only defense-related transuranic (TRU) wastes.

In addition to radioactive waste, mixed HLW also contains both listed and characteristic categories of RCRA-hazardous waste that are subject to Land Disposal Restrictions (LDRs) under 40 CFR 268 prior to disposal. ${ }^{3}$ The hazardous wastes must be treated in accordance with the methods defined in the LDR $^{3}$; otherwise, they must be treated by techniques approved as the equivalents to the specified treatment standards. Vitrification satisfies the LDR, ${ }^{3}$ but the process evaluated in this report might also satisfy the LDR and the repository's acceptance criteria after further development and testing. After the wastes have been treated, the listed wastes must be delisted before they can be disposed. This report assumes that the waste form from the proposed process would meet the HLW repository's acceptance criteria for radioactive wastes and would satisfy the EPA's treatment standards for hazardous wastes.

The following alternatives are being considered:

- Three separations options-In the separations options, the TRU and high-activity isotopes (Cs-137 and Sr-90) would be removed from the SBW and dissolved HLW-calcine and disposed in a geologic repository outside of Idaho; the remaining low-level waste (LLW) would be disposed onsite (at the INEEL) in a mixture of concrete or grout. Because the volume of high-activity waste is small compared to the total, the volume of waste sent offsite for disposal would be minimized.

- Four nonseparations options-In the nonseparations options, the SBW would be converted to calcine and then all of the calcine would be immobilized in materials like glass, cement, 
and ceramic for disposal at the HLW repository or an approved alternate (there is no approved alternate yet).

- No action-In the no-action alternative, the SBW would be calcined and stored in the CSSF with the existing HLW calcine. After a few hundred years, the radiation field strength would have been rendered harmless through radioactive decay, at which time disposal of the longlived isotopes could begin.

In all three alternatives, various amounts of mercury would be recovered and then amalgamated for on-site disposal.

All of the waste forms requiring disposal in the HLW repository would have to be stored at the INEEL until space became available at the existing repository or at a new HLW repository, probably sometime after 2065. That INEEL storage site, which does not currently exist, is referred to in this report as the Interim Storage Facility.

A proposed HLW treatment, known as the Hot Isostatic Press (HIP) Waste Option (HWO), involves mixing the calcine with amorphous silica and titanium powder in special cans, then applying a HIP technology to produce a glass-ceramic. The resulting product is then packed into Savannah River Site (SRS) canisters for ultimate disposal in a national geological repository. A number of other possible non-separations HLW treatments are also being considered. These options are Direct Vitrified Waste Option, Cementitious Waste Option, and Direct Cementitious Waste Option.

This report investigates a HLW treatment process that mix HLW calcine with amorphous silica and titanium powder in special cans for hot isostatic pressing (HIPing). Volatile materials are eliminated by heating the mixture to moderate temperatures prior to the actual HIPing operation. A HIP furnace, operating at $1,050^{\circ} \mathrm{C}$ and $20,000 \mathrm{psi}$, compresses the can and its contents to form a glass-ceramic product. The hot isostatically pressed (HIPed) cans are then placed in stainless-steel canisters for interim storage and ultimate disposal at a HLW repository.

\subsection{Background}

Calcination is a heat treatment process performed at the Idaho Chemical Processing Plant (ICPP) to transform liquid waste to a more stable granular solid waste form. Past calcining activities produced large calcine inventories now stored in the CSSF at the ICPP. The Settlement Agreement calls for calcination of current ICPP liquid waste inventories to be completed by the end of 2012. Various treatments for the calcine inventory are being considered. However, the treatment method for this study is to HIP the calcine.

\subsection{Objective and Scope of Work}

The objective of this study is to provide information, including the costs for the HWO, for input to an Environmental Impact Statement (EIS) that will be used to select the method of HLW treatment.

The scope of the HWO includes (a) the Calcine Retrieval and Transportation System (CRTS) for transferring calcine from the CSSF to the HIP facility, (b) the HIP facility, (c) utilities and infrastructure and (d) the ISF for the HIPed product. The processes and equipment for the CRTS and ISF are common to all of the options studied. Their details are given separately in Engineering Design File (EDF)-WTS002 (See Appendix A) and the Interim Storage Facility Report, ${ }^{4}$ respectively. 
ICPP site plan HWO-C-1 shows the location of the CSSF, the HIP facility, and the ISF at ICPP (see Appendix B). The overall HWO process is shown on block flow diagrams HWO-00 through 06 (see Appendix B). The HWO process includes (a) transporting calcine from the CSSF to the HIP facility, (b) mixing the calcine with the appropriate type and quantity of ámorphous silica and titanium powder,

(c) devolatilizing the calcine/additives mixture, (d) HIPing the cans, (e) loading the HIPed cans into canisters, and (e) transporting the canisters to the ISF.

In order to perform this study, it was necessary to make assumptions about the HIPed waste form (composition, dimensions, and total volume), the HIP facility, CRTS, ISF, and requirements and regulations that will apply. Failure modes were noted, project risks were identified and evaluated, and environmental impacts were estimated and summarized.

\section{PROJECT DESCRIPTION}

\subsection{Design Bases}

\subsubsection{HIP Cans and SRS HLW Canisters}

The HIP process has been developed at the INEEL on small-scale 1- to 6-in. diameter cans and those results have been extrapolated to full-scale cans (an approximately 23 -in. diameter and 34 in. length after HIPing). Three HIPed cans fit inside a SRS canister. To optimize the loading, each HIPed can must be in the form of a right circular cylinder after HIPing. A volume reduction of approximately $50 \%$ is expected.

To accomplish this, a corrugated HIP can is used in this study, although there are other styles of HIP cans that can also achieve this goal. A corrugated can contracts in length with no apparent change in diameter. Full-scale development of the HIP process is needed to optimize the pre-HIP can dimensions. For detailed information on the HIP cans and SRS canister loading, see EDF-HWO-002 in Appendix A.

Although this study is based on a 10-ft long SRS canister, the DOE Hanford Facility has adopted a 4.5 meter (15- $\mathrm{ft})$ long canister for containing immobilized HLW. This longer canister is apparently acceptable for co-disposal at the repository, and therefore should be considered before finalizing the HWO canister size.

Consideration of the 15- $\mathrm{ft}$ canister has been addressed by adding a corresponding future study in Subsection 9.2. Although adopting the 15 -ft canister would increase the capitol cost of the HIIP facility due to the increased head height of the hot cells, depth of excavation, equipment capacities, height of the ISF transport tunnel, size and capacity of the SRS canister handling machine, and ceiling height etc., it would reduce the total number of canisters ( 5,700 10-ft canisters) by about one-third; thus, greatly reducing the handling, shipping, and final disposal operations costs.

\subsubsection{Calcine Retrieval and Transportation System}

The design basis for the CRTS is given in the Fluor Daniel Waste Treatment Facilities Feasibility Study $90 \%$ review package. 1 EDF-WTS-002 in Appendix A documents the work done on the CRTS for alternatives including the HWO. The CRTS is generic to most of the waste treatment options studied. EDF-WTS-002 provides all CRTS components and their costs but the HIP facility building contains the following final CRTS equipment: calcine separation cyclones, sintered metal filters, HEPA filters, calcine transport blowers, and transport-air coolers. 
Calcine will be removed from a bin in the CSSF and transported to the HIP facility using a closedloop pneumatic transport system. The transport system provides the ability to retrieve calcine from one or two bins at a maximum rate of $5,400 \mathrm{~kg} / \mathrm{hr}$. Being able to retrieve calcine from two bins allows the flexibility of blending different calcines to achieve a specific recipe. The system will be remotely operated to reduce radiation exposure. Calcine will be transferred at a rate commensurate with processing demands.

\subsubsection{Interim Storage Facility}

The Interim Storage Study Report, ${ }^{4}$ presents the study for the HWO ISF (as well as storage facilities for the other applicable waste treatment options). The design baseline for the ISF is given in the Fluor Daniel Inc., Waste Treatment Facilities Feasibility Study. ${ }^{13}$ The ISF design will be a basic unit (holding about 900 SRS canisters) that will be repeated; as necessary, to accommodate the canisters produced by a particular waste treatment option. In the case of the HWO, the number of ISF units was increased until they could accommodate a minimum of 5,700 SRS canisters. HIPed cans are packaged in SRS canisters, and will be transferred to the ISF. The ISF will provide storage and monitoring up to year $2075 .^{4}$

\subsubsection{HIP Facility}

The HIP facility will provide the facility and equipment to process all the calcine over a 20 -year period from 2013 through 2032 . The facility will have enough shielded hot cells and remote controlled equipment to process a total of 5,700 canisters in 20 years. The facility design and equipment sizing is based on a two $10 \mathrm{hr} / \mathrm{day}$, Monday-Thursday operating schedule.

\subsection{Key Assumptions}

The following assumptions were identified during the study and used to establish a basis for design and cost (additional assumptions are listed in Appendix C):

- The SRS canisters containing the HIPed product will meet the repository Waste Acceptance Product Specifications (WAPS) for co-disposal with SNF.

- The SRS canisters will be acceptable for storage and transportation under 10 CFR 72, 10 CFR 71, and U.S. Department of Transportation (DOT) 49 CFR 173.

- This option will not process any waste generated after 2012. All SBW will be calcined by this date.

- The maximum weight of a filled SRS canister is $5,500 \mathrm{lb}$.

- A HIP can vendor will be capable of supplying the required quantities to meet the waste production rate and schedule.

- The HIPed HLW will be excluded from RCRA hazardous waste management requirements at the INEEL due to successful delisting and immobilization efforts that provide best demonstrated accepted technology equivalency.

- No part of the HIP facility will be regulated as an incinerator. 


\subsection{Requirements}

\subsubsection{Regulatory Compliance}

The following is a very brief summary of the regulatory issues regarding the processing and storing of mixed HLW using the HWO. Lists of design criteria documents, regulations pertaining to waste treatment and disposal, and explanations of the regulations may be found in EDF-WTS-003 and EDFHWO-001 (see Appendix A).

The wastes to be processed are considered mixed HLW because they include RCRA-hazardous wastes (both listed and characteristic) and high-level radioactive wastes. The hazardous components of the mixed HLW are regulated by the EPA under the Resource Conservation and Recovery Act and the radioactive contaminants are regulated by the Nuclear Regulatory Commission (NRC) under the Atomic Energy Act. The specific standards for HLW management, administered through the DOE and the NRC regulations, require disposal of HLW in a geologic repository. The transportation and disposal of that waste must comply with requirements established by the EPA, DOE, DOT, NRC, and other state and local agencies.

RCRA has established treatment standards for hazardous waste under the LDRs. The HIP process is not an LDR-specified technology for the treatment of hazardous waste. Therefore, the HWO will need to be approved by the EPA Administrator under the procedures set forth in 40 CFR 268.42(b), "Determination of Equivalent Treatment." HLW must be disposed in an approved HLW repository. Since the potential repository at Yucca Mountain currently does not accept any untreated hazardous wastes, any listed, hazardous wastes contained in HIPed waste must be delisted prior to disposal in the repository. The EPA has the authority to delist listed wastes after evaluating the method of treatment, based on available information like successful bench-scale or pilot-plant test results. The delisting must be approved by the state that ships the waste (Idaho), and by the state receiving the waste (Nevada), as well as other states through which the waste is transported. The listed hazardous waste could be delisted prior to or after calcination, if their concentrations are below the LDR regulatory levels. This study assumes that all these requirements will be met by the HWO and waste form. However, delisting petitions are seldom granted: between 1982 and 1995 only $13 \%$ of the 809 petitions were granted.

Prior to construction and operation of the HIP facility, various permits must be obtained. These include a RCRA permit, an air-emissions permit issued by the State of Idaho EPA, and an upgrade for the existing waste-water discharge permit. The HIP facility's design is governed by the DOE-ID Architectural Engineering Standards and DOE Order 6430.1A. If the interim storage facility is licensed by NRC, that facility's design will be governed by 10 CFR 72 and the DOE. This study assumes that all processing and storage facilities will be granted the necessary permits and will meet all design requirements.

\subsubsection{Applicable Codes and Standards}

The CRTS, HIP facility, and ISF covered in this study will be designed and constructed under DOE Orders, while complying with other regulatory and oversight agencies such as the EPA, State of Idaho, and the Defense Nuclear Facilities Safety Board. These facilities will be built in accordance with the requirements established in DOE Orders, including DOE 6430.1A, "General Design Criteria," DOE-ID Architectural Engineering Standards, and additional standard building codes. These requirements are presented in detail in EDF-WTS-003 (see Appendix A). There are currently no NRC regulations for the licensing of waste processing facilities such as the HIP facility. 
The cranes in the HIP facility will be designed in accordance with the DOE Hoisting and Rigging Manual, with careful consideration given to the following sections of the manual:

- $\quad$ Section 3.0, "Lifting Equipment," Paragraphs 2.3.9

- Design Standards-Cranes, which are to handle High-Consequence or Special-High Consequence loads shall meet the Type 2 requirements of ANSI/ASME NOG-1. Where nuclear or radioactive materials are involved, the cranes shall meet Type 1 requirements of ANSI/ASME NOG-1.

- Quality Assurance-Quality Assurance Programs for cranes which are to handle High Consequence and Special-High-Consequence Lift shall meet the requirements of ANSI/ASME NQA-1.

- DOE-ID Architectural Engineering Standards-CMAA (Crane Manufacturer's Association of America, Inc.) "Specifications for Electric Overhead Traveling Cranes," Specification No. 70 ANSI B30.2, OSHA 1910 Subpart N, "Material Handling and Storage," CMAA 74 "Specification for Top Running and Under Running Single Girder Electric Overhead Traveling Cranes," ANSI/ASME NOG-I "Rules for Construction of Overhead and Gantry Cranes Top Running Bridge Multiple Guides," and DOE 6430.1 A, "General Design Criteria."

Additional codes and standards that may apply to the proposed facility are discussed in detail in EDF-WTS-004 and EDF-HWO-006 (see Appendix A).

\subsubsection{Performance Requirements}

Section C.3 of the Settlement Agreement between DOE and the State of Idaho states that "DOE shall treat all high-level waste currently at INEEL so that it is ready to be moved out of Idaho for disposal by a target date of 2035." The HIP facility will start HIPing in 2013; this allows a 20-year period to complete the waste processing and packaging. The total number of SRS canisters is estimated to be 5,700 , which requires an average production rate of three SRS canisters per operating day. This is based on an 80 hour per week operations schedule.

The function of the HIP facility is to receive calcine from the CSSF, HIP it, package it into canisters, and transport it to the storage facility via a transfer tunnel.

\subsubsection{Cell Entry Requirements}

Hot cell entry is anticipated in order to perform maintenance that is beyond the capability of the remote-handling equipment. This may occur as often as twice a year for the first 5 years and more frequently beyond 5 years. Hot cell manned entry may be required in order to perform decontamination in the event of an unplanned incident. This maintenance philosophy is based on ALARA (as low as reasonably achievable) and is intended to keep personnel radiation exposure ALARA. Remotely maintained equipment in-cell will significantly reduce exposure. The hot cell entry requirements are specified in EDF-HW0-006 (see Appendix A). 


\subsubsection{Design Criteria}

The design requirements for the nonseparations and TRU-only separations options are documented in EDF-WTS-004 (see Appendix A). This EDF identifies the applicable DOE orders, regulations and guidance documents that would be used in the design of the facilities. There are currently no NRC regulations in place for the licensing of waste processing facilities such as those discussed in the EDF. The waste products are in many cases destined for NRC-licensed storage facilities. Where specific design criteria are provided under NRC regulations and guidance documents, whether directly applicable or for similar facilities, they will be referenced. This will be useful in determining the cost differential between DOE regulatory/oversight and NRC licensing requirements.

The criteria contained in EDF-WTS-004 are based only on the rudimentary descriptions of the processes presented in its Subsection 1.1. The purpose, as stated in the EDF, is to provide a set of highlevel requirements to guide the development of the conceptual designs of the facilities and provide a reasonable basis for cost estimating purposes. In general, the EDF does not attempt to cover criteria outside of the design and construction of the facilities.

\subsubsection{National HLW Geological Repository}

The waste acceptance criteria (WAC) related to vitrified HLW are found in the Waste Acceptance Product Specifications for Vitrified High-Level Waste Forms. ${ }^{6}$. The WAPS are derived from the requirements listed in the Waste Acceptance System Requirements Document. ${ }^{7}$ A summary of the WAC is documented in the Final Disposal Options Feasibility Study. ${ }^{8}$

The standard waste form is borosilicate glass, although provisions exist for qualifying other waste forms. Untreated RCRA-hazardous wastes are not allowed in the waste form. In addition to waste form requirements, the WAPS provide physical requirements and limitations associated with the standard 0.6-meter (24-in.) diameter by 3-meter (10-ft) long stainless-steel canister described in the WAPS.

The HIPed waste form is not an LDR-specified treatment process, and a determination of equivalent treatment petition must be submitted to and approved by the EPA in accordance with 40 CFR 268.42(b) ${ }^{3}$ for the HIPed waste form to be acceptable.

\subsection{Process Description}

The HWO is based on ten years of research, development, and testing of surrogate wastes at ICPP. The process was invented by researchers at Battelle Columbus Laboratories in 1955, and involves heating and pressurizing a siliceous mixture until a phase transformation occurs, resulting in the formation of a glass-ceramic having $40-60 \%$ higher density than the starting mixture. The product has wasteimmobilization properties similar to those of vitrified-borosilicate glass, which is an approved treatment process for hazardous wastes and the only waste form currently acceptable at the HLW repository. For more detailed information on the process see EDF-HWO-012 in Appendix A.

The HWO process design is based on the following processing steps:

1. High-level radioactive waste calcine is pneumatically transported to a temporary storage cell in the HIP facility where it is sized in a ball mill prior to being fed into a temporary storage/blending vessel and homogenized. 
2. Calcine is sampled, analyzed, and characterized. Based on the characterization, a HIPing "recipe" is selected from a set of recipes developed prior to the start of processing based on the expected range of calcine composition in the CSSF.

3. Calcine is mixed with pre-sized amorphous silica and titanium (or aluminum) powder in proportions specified by the selected recipe.

4. The mixture is gravimetrically metered into a stainless-steel HIP can.

5. A lid (with a suitable venting tube) is welded to the can.

6. The outside surface of the can is checked for contamination and decontaminated if needed.

7. The filled can is devolatilized at elevated temperature (approximately $650^{\circ} \mathrm{C}$ ), with the offgases vented through a manifold to an off-gas treatment facility.

8. The can is evacuated to 0.5 torr and the evacuation port is welded shut, and then placed in a HIPing vessel, which is pressurized with argon gas (approximately $20,000 \mathrm{psi}$ ) and heated to $1,050^{\circ} \mathrm{C}$.

9. The can is removed from the HIPing vessel, cooled, and non-destructively tested to determine whether HIPing was successful

10. HIPed cans determined to be unsatisfactory are recycled (after grinding) and re-HIPed. HIPed cans determined to be satisfactory are placed in $2 \times 10 \mathrm{ft}$ SRS canisters (three HIP cans to a canister), and the canister is welded closed and transported to Interim Storage Facility.

The intended final disposal site for the waste is a HLW repository. However, the waste must be stored in an ISF until that repository is ready to receive HLW from the INEEL, probably some time after 2065.

\subsection{Facility Description}

\subsubsection{Site Description}

The HIP facility will be located in the northeast corner of the ICPP between the east perimeter fence and Hemlock Street to the west because of its close proximity to the CSSF (see Drawing HWO-C-1 in Appendix B).

Existing site soils consist of poorly graded, gravely and sandy alluvial deposits ranging from $\mathbf{3 5}$ to $40 \mathrm{ft}$ deep, overlaying an 8-ft-thick clay layer which rests on top of a massive basalt bedrock formation. There is no groundwater table located above the basalt elevation.

The floor elevation at grade will be higher than the $100-y r$ flood elevation in accordance with RCRA requirements or the ICPP probable maximum flood elevation. The lowest floor-level elevation was chosen to minimize excavation of existing bedrock.

The facility was sited for delivery, service and emergency vehicle accessibility. Site roads connect to existing streets and have adequate maneuvering area for delivery trucks. 


\subsubsection{Utilities and Infrastructure}

The utilities and infrastructure associated with siting the HWO facilities at ICPP are detailed in a Utilities and Infrastructure Report. ${ }^{9}$

\subsubsection{Facility Layout}

The HIP facility is designed to house the equipment and operations for processing waste and provide essential features for safe and efficient operation and maintenance of the facility. Its layout is based on centrally-located process cells with heavy concrete walls for shielding, and with limited personnel access (see drawings HWO-A-1 through HWO-A-6, Appendix B). The cells are intended to house equipment that presents a high radiation hazard but requires minimal maintenance. The perimeter

of the facility contains office space, support facilities and non-radioactive operation areas. The building occupies an area measuring $302 \times 320 \mathrm{ft}$.

Below Grade Features. The HIP facility consists of a below grade, centrally-positioned group of six process cells, configured in four rows to accommodate four process lines. Three operating corridors 15- $\mathrm{ft}$ wide are located adjacent to the process cells. Two $30-\mathrm{ft}$ wide HVAC canyon cells are located between the two sets of process cells in each pair of cells. The HVAC canyon cells provide a secondary function as access into the process cells. Each cell wall and roof is constructed of 3-ft-thick reinforced concrete for shielding.

Stairways and freight elevators are located at the northwest and northeast corners of the building. A personnel corridor is located on the south end of the facility for egress.

Empty Can Load Cell-This $600 \mathrm{ft}^{2}$ cell contains a coiling overhead door for receiving pallets of empty HIP cans. The cell contains a $1 / 2$ ton jib crane used to transfer cans to the hot fill cell through a shielding door.

Fill Cell-Filling of the HIP cans with the calcine/silica/titanium mixture occurs in this $600 \mathrm{ft}^{2}$ cell. This hot cell contains stainless-steel-lined walls, floors, and ceilings; a shielded door for installation of equipment; and one leaded glass, oil filled, $3.5 \times 2.5 \times 3$-ft-thick shielding window aligned with the remote handling equipment. Personnel access is provided through a door to the HVAC canyon located between process lines. Any equipment requiring maintenance outside of the cell will be disassembled and removed through the DECON cell.

Weld Cell-After the filling process, the cans proceed to a welding station. The welding equipment is located above the hot welding cell. A shielding window and personnel door are provided.

DECON Cel/-Decontamination of the cans prior to devolatilization occurs in the DECON cell. Access to the DECON cell from the size/grind cell is also provided for decontamination of sizing/grinding equipment for maintenance and replacement. A shielding window is provided between the cell and operating corridor.

Size/Grind Ce/l-Off-specification cans may enter the $1,200 \mathrm{ft}^{2}$ size/grind cell from the Devol cell above or the HIPing cell to the south. A large shielding door is provided for equipment installation and a personnel door is provided for access. A shielding window provides visual line-of-sight for remote operations. 
HIP Cell-The 1,500 $\mathrm{ft}^{2}$, two-story HIP cell contains three HIP pressure vessels and furnaces, shielding windows, and a personnel access door.

Loading Cell-The final HIP cans are loaded into the 2-ft diameter by $10-\mathrm{ft}$ long SRS canisters (three HIP cans per canister) and placed on a transport cart. The carts proceed to the ISF through a transfer tunnel connected to the two-story loading cell.

HVAC Canyon-A 30-ft wide cell is provided for HEPA filter location for the process cell ventilation systems. This centrally located HEPA canyon allows for the installation of air filtration units close to the source of contaminants, and eliminates the potential for contamination of a large ventilation ductwork system.

Above Grade Features. Level 0 contains four rows of eleven process cells with 3-ft-thick reinforced concrete walls for shielding. Three 15 -ft operating corridors surround the cells. The eleven cells include blending equipment, DECON chemical tank storage, fill tank, weld equipment, DECON, devol/heat/weld, HIP, QA /assay, canister loading, loadout, remote maintenance, and crane maintenance cells. The HIPing and final loading cells are continued from a level of 20-ft. Administrative space including office, control room and restroom/change room space is located on the south side of the facility. An HVAC equipment room is located on the east side of the facility on level $0-\mathrm{ft}$. Seven stairwells provide egress and two freight elevators and a truck loading bay provide maneuverability for equipment and raw materials throughout the facility. Airlocks are provided at the interface between the office and operating corridor and directly between the operating corridor and the change rooms. The freight elevator acts as an airlock for equipment entering through the truck loading bay.

Blender Equipment Cell-This clean cell contains the equipment necessary for the ribbon blender located in the adjacent fill tank cell. An overhead coiling door provides equipment installation access.

DECON Chemical Tank Storage-This clean cell contains two 200-gallon DECON chemical tanks required for DECON capabilities throughout the hot process cells.

Fill Tank Cell-This cell, located directly above the fill cell, houses the ribbon blender and blended mixture calcine tank which feeds the HIP cans. This cell has 5-ft thick walls, floor, and ceiling for shielding.

Weld Equipment Cell-This is a clean cell located directly above the weld cell and contains the contact handled and maintained welding equipment.

DECON Cell-Decontamination of the cans prior to devolatilization occurs in the DECON cell. A shielding window is provided between the cell and operating corridor.

Devol, Heat, Weld Cell-This cell contains three heaters in which the HIP cans will be devolatilized. A final weld is performed prior to the can entering the HIP furnace in the HIP Cell. furnaces.

HIP Cell-The upper level of the HIP cell contains a cooling station for the cans exiting the HIP

QAAssay Cell-The QA assay cell will contain equipment necessary to perform a final assay on the HIP can prior to loading it into the SRS canisters. 
Recycle Sizing Cell-It has been assumed that $0.1 \%$ of all the HIPed cans will require destructive testing in order to qualify the HIP glass ceramic for disposal. Qualification will most likely be required by the repository to assure that the WAC is being satisfied. It is possible for HIP cans to rupture during the HIPing process. These cans and their contents will be recycled back into the process line for re-HIPing. A recycle sizing cell containing various pieces of equipment will accomplish the recycling of the HIPed materials. For a complete description of the equipment in this cell see EDF-HWO-011 in Appendix A of this report.

Remote and Crane Maintenance Cel/s-Remote maintenance and crane maintenance cells are provided for maintenance activities.

At 24-ft above grade, two groups of six cells are located above the process cells to hold clean equipment necessary for the HIP machines and the devolatilization and heating of the cans. The off-gas cell contains the equipment and filters necessary for the off-gas process. The cell containing the reclaimed argon and the off-gas cell will be shielded with 3-ft-thick reinforced concrete walls. Located above the fill cell are the calcine receiving tanks; cyclone; calcine removal equipment; and soil and titanium bins. These cells have 5 - $\mathrm{ft}$ thick reinforced concrete walls for calcine shielding. The equipment cells are centered on the process cells, leaving room for roof hatches into the process cells for equipment installation and removal. Located on the north side of the facility is loadout room for transferring large equipment from the laydown area to trucks.

At 45-ft above grade, two large shielded bridge crane areas provide hatch access to the six cells below and are open to the roof hatches on the 24- $\mathrm{ft}$ level. Two 75-ton bridge cranes span the two crane areas with hook access to all hatch covers. When cell access is required, the crane can move hatch covers and transfer components to and from the decontamination cell. A bridge crane maintenance area is located on the south end of each crane area.

\subsubsection{Structural Design}

Design loads for the new HIP facility shall be in accordance with DOE Standard $10200^{10}$ The process area and HVAC areas shall be designed to the Performance Category 3 level and the administrative areas to Performance Category I requirements. For the PC-3 category areas, seismic design will be performed according to the procedures and provisions of DOE 1020. The PC-I areas will be designed in accordance with the UBC, using seismic zone $2 \mathrm{~B}$ and an importance factor of 1.0, a basic wind speed of $70 \mathrm{mph}$, and an exposure category of " $\mathrm{C}$." Roof loadings will consider a minimum snow load of $30 \mathrm{lb} / \mathrm{ft}^{2}$, including any additional loading due to drifting, as applicable. Special loadings considered for this facility include floor wheel loads from a 2-ton forklift in the operating corridors.

The foundation system will extend to rock. All walls and floors will be sized and reinforced according to load-bearing (including crane) or shielding requirements and seismic criteria. Process cells will have stainless-steel floors and liner plates. In areas where only partial lining is required, the floor is will be covered and wall liner will extend $4 \mathrm{ft}$ above the floor level. Floor liner plates will be $1 / 4$-in. thick and wall liner plates will be 3/16-in thick. The roof over the crane bay is cast-in-place concrete and the walls are 3-ft thick concrete for shielding purposes. The HVAC exhaust equipment room will have reinforced concrete walls sized to meet shielding requirements. The remainder of the building superstructure is conventional structural steel frame construction with column footings and grade beam foundations at 5 - $\mathrm{ft}$ below grade. 


\subsubsection{Instrumentation and Control}

An evaluation of the required instrumentation and controls has been conducted for the HIP facility. Systems included radiological monitoring, closed circuit television (CCTV), plant control, data management, life safety, and electronic and pneumatic instruments. A complete listing of the required systems is contained in EDF-HWO-013 (see Appendix A).

\subsection{System Descriptions}

\subsubsection{HVAC System}

Up to three air handling units will supply 167,000 CFM of conditioned air to the operating corridor at levels $+24 \mathrm{ft}, 0 \mathrm{ft}$, and $-20 \mathrm{ft}$. Air from the operating corridors will be cascaded into the hot Cells via air-handling units each consisting of supply blower and a one stage testable HEPA filter. The cascade air supply units will have $100 \%$ redundancy for filter sections with less that 6,900 CFM and $50 \%$ redundancy for filters sections with air flow greater than or equal to 6,900 CFM. Air from the hot cells will be exhausted to the ambient via two-stage testable HEPA filter units and exhaust fans. HEPA filters and exhaust fans will have $100 \%$ redundancy for filter sections with less than 6,900 CFM air flow and $50 \%$ redundancy for filters sections with air flow of greater than or equal 6,900 CFM. The HVAC system for the HIP facility is described in more detail in EDF-HWO-014 (see Appendix A).

\subsubsection{Off-Gas System}

The process off-gas consists of (a) contaminated air from pneumatic transport of calcine to the HIP Facility, (b) ventilation air from temporary storage vessels for radioactive waste calcine and HIPing additives, (c) decontamination off-gas, (d) exhaust gases from devolatilization of pre-HIP and can sealing operations, (e) exhaust air from evacuation of HIP machines prior to pressurization with argon gas, and (f) non-recyclable argon. All off-gas streams will be double HEPA filtered prior to stack discharge. In addition to the final filtration, devolatilization off-gas will undergo an initial HEPA filtration through small HEPA filters attached to each HIP can, and will undergo mercury extraction via condensation and adsorption on sulfur-impregnated carbon. The initial HEPA filtration of devolatilization off-gas minimizes the spread of contamination. Two banks of final HEPA filters are provided, one for operation and one for backup.

\subsubsection{Calcine Retrieval and Transportation System}

EDF-WTS-002, in Appendix A, contains the detailed description of the CRTS portion of the HWO (it also contains CRTS descriptions for other waste treatment options). This section is a summary description of the CRTS.

The CRTS retrieves calcine from CSSF bins and places it directly in one of two transportation systems. Each transportation system consists of two closed-loop stages of pneumatic calcine transfer. The first stage pneumatically transfers calcine from the CSSF area to an Intermediate Transport Station (ITS); the second pneumatically transfers calcine from the ITS to the fluidized bed calcine blending vessels inside the HIP facility. The seven CSSF bins are covered by confinement enclosures that have an associated ventilation, instrumentation, and control building. The calcine retrieval system will remove the calcine from a bin and place it directly in the closed loop pneumatic transport system.

Calcine retrieval will be accomplished pneumatically with a suction nozzle and an air jet. The air jet will fluidize the calcine inside the bin and the suction nozzle will lift it out of the bin. Calcine enters 
the transport system through a shielded jumper from the retrieval line. A vertical deployment apparatus will keep the retrieval lines near the surface of the bulk calcine. The calcine will be retrieved at 2,700 $\mathrm{kg} / \mathrm{hr}$ from each bin. When both transport systems are operating, calcine will be delivered to the ITS at $5,400 \mathrm{~kg} / \mathrm{hr}$. The ITS delivers calcine to the HIP facility at the same rate.

Throughout calcine processing, retrieval can be switched from one CSSF bin to another as they are emptied or as different calcine mixes are required. For example, the frequent switching between CSSF bins could be used to adjust the mix of calcine types being delivered. The closed-loop pneumatic transfer systems operate at a vacuum and minimize the amount of released transport air by recycling it. Each system consists of the transfer line, a cyclone separator for removing the calcine from the air stream, a sintered metal filter and a HEPA filter to remove solid particulate, a blower for air circulation; and an air chiller to cool the air heated by blower compression. Each transport system will have a duplicate calcine transport line, in case the original line becomes plugged. Each transport system will be accompanied by a return airline, and all lines will be located above grade and bermed to provide shielding. Diverter valves will ensure that calcine can be transported from the CSSF bins to the ITS or to the HIP facility in either line of the transport system. The CRTS cyclone separators, sintered metal filters, HEPA filters, transport blowers, and air chillers for the ITS are located in the HIP facility. The costs for these components are included in the total costs for the CRTS given in EDF-WTS-002. The total CRTS costs are also presented in Section 3 of this report.

\subsection{Equipment Descriptions}

\subsubsection{Radiological Monitoring Equipment}

The HIP facility is designed with appropriate radiological monitoring equipment. This equipment will assure safe operation of the facility. The specifications for this equipment along with the quantities and general location within the facility are contained in EDF-HWO-006 (see Appendix A).

\subsubsection{Can Filling}

Several can filling options were looked at for filling HIP cans with the calcine additive mixture. The primary concern was to minimize the spread of radioactive contamination. The HIP can is conveyed remotely until it is positioned on a load cell located under the calcine and additives storage hopper. The can is vibrated while calcine is dispensed until a pre-determined weight is reached. To minimize contamination, each HIP can uses an internal plastic liner that is heat-sealed remotely with a hot wire after filling is completed. The liner material is selected to be chemically compatible with the HIP can and waste material, and to decompose and volatilize fully during the devolatilization process. An apron is provided below the can to catch any excess calcine if the can were to be accidentally overfilled. For a complete description of the can filling system see EDF-HWO-004 (Appendix A).

\subsubsection{HIP Equipment}

The HIPing process has been developed at the INEEL on small-scale (1-to .6-in.) cans and those results have been extrapolated to full-scale cans (approximately 23 -in. diameter by 34 -in.-long after HIPing). Three processed HIPed cans fit inside a 10-ft SRS canister. To optimize the loading, each HIPed can must be in the form of a right circular cylinder after the HIPing process has been performed. A volume reduction of $50-60 \%$ is expected after HIPing. To accomplish this, a corrugated HIP can is used in this study, although there are other styles of HIP cans that can also achieve this goal. A corrugated can contracts in length with no apparent contraction in diameter. Full-scale development of the HIPing process is needed to optimize the HIP can dimensions. 
The production facility in this study is designed to produce approximately 5,700 SRS canisters, each containing three HIPed cans, in a 20-year period. To accomplish this requires three production lines with each line using three HIP machines (nine total). A fourth full production line is used when one of the other three is non-operational. The production facility will operate four days a week with two shifts of ten hours per day to yield $36 \mathrm{HIPed}$ cans per week ( 12 SRS canisters) with $50 \%$ down time. This study further assumes that each HIP machines will have their own complement of necessary support equipment like vacuum pumps, compressors, heat exchangers, argon tanks, and coolers, so that an equipment failure in one line will have no impact on the other production lines. For the same reason, each HIP machine will require its own transformer, contractors and silicon-controlled rectifiers.

The heart of the HIP equipment is the pressure vessel, in which the HIP can and its contents are subjected to temperatures of $1,050-1,100^{\circ} \mathrm{C}$ and pressures up to $20,000 \mathrm{psi}$. For this study, a properly designed, one-piece vessel must withstand 15,000 thousand operating cycles without failure and with minimum routine maintenance and must be fully automated. Each pressure vessel will have an inside diameter of $38 \mathrm{in}$. and a usable height of $66 \mathrm{in}$. and will be cooled by a coolant pumped through an integral cooling jacket. Each pressure vessel will be heated internally by its own electrically-powered furnace. The heating elements have been selected for long life and low maintenance.

Vacuum pumps must be employed to evacuate the air and moisture from the pressure vessel prior to operation. Argon gas is used as the pressure medium and is introduced to the evacuated vessel. A pressure of 0.5 torr is needed during evacuation and is achieved by means of rotary-piston pumps backed by blower pumps. Three pressure vessels can be evacuated to 0.5 torr in one hour using one vacuum system.

Argon gas will be supplied from a tank of liquid argon located outside the building to storage tanks inside at a pressure of 5,000 psi using a heat exchanger and pump. To supply all four production lines, approximately 100,000 scf of argon gas compressed to 5,000 psi in 18 storage tanks (16-in. OD $\times 21-\mathrm{ft}$ long) will be needed. Argon gas will be reclaimed for reuse. This will require 24 tanks (24-in. OD $\times$ 21 -ft long) operating at 2,000 psi. HEPA filters will be needed between the pressure vessel and the reclamation tanks to remove particulate.

Each production line will require its own compressor in order to achieve the 20,000 psi in each pressure vessel. Each compressor (four total) will be rated to $100 \mathrm{hp}$. High-pressure liquid pumps are also needed. These compressor systems will also be used to pump argon gas from the pressure vessel to the reclamation tanks.

Each pressure vessel will require its own cooling system, which will consist of a cooling jacket, coolant, heat exchanger, and a pump for circulation. The heat will be removed from the coolant in a cooling tower located outside the building. A source of emergency cooling water will also be provided. The cooling requirement per HIP machine is $1,400,000 \mathrm{Btu} / \mathrm{hr}$.

Production line equipment would be operated from a centrally-located control room and would include continuous remote monitoring of each process. A computer-controlled system with manual backup is envisioned. The operation of the HIP machines would be completely automated, but a remotehandled overhead crane would be required for loading and unloading the cans.

\subsubsection{Can Sealing Systems}

A friction welding machine will be used to effectively and quickly attach and seal HIP can lids after filling. The basic machine is located in the weld equipment cell and is accessible for hands-on 
maintenance. A spindle extends through the cell ceiling to the weld cell station directly below. A cart is used to position the HIP can directly under the spindle. A special fixture attaches to the HIP can body and prevents it from rotating during the welding process. A manipulator loads a HIP can head onto the spindle and the spindle rotates and makes friction contact with the can. The spindle lowers the head into position and the weld is completed. Quality assurance of the weld will be determined using nondestructive measures. Inspection equipment may include magnetic particle or liquid penetrate examination equipment.

HIP can lids incorporate a small riser tube to be used for evacuation of the can volatiles after the head is welded in place. A tube crimper and sealer mechanism crimps and seals the tube following devolatilization. More detailed information on the can sealing systems is contained in EDF-HWO-005 (see Appendix A).

\subsubsection{Devolatilization Equipment}

Devolatilization and evacuation of the HIP cans prior to HIPing provides the maximum compaction of the HIP can and its contents is realized when the can is evacuated and sealed prior to HIPing. Any volatile compounds present in the HIP mixture during the actual HIPing process could vaporize and prohibit maximum compression of the HIPed can which would result in a failed can.

The devolatilization process requires heating the filled HIP cans to $625^{\circ} \mathrm{C}$ for approximately 24 hours. During this time, a vacuum pump is connected to the HIP can's vent tube. The vacuum pump maintains a partial vacuum on the HIP cans to remove any volatiles that are released from the HIP mixture (primarily residual $\mathrm{H}_{2} \mathrm{O}, \mathrm{CO}_{2}, \mathrm{Hg}$, and $\mathrm{NO}_{\mathrm{x}}$ ). Any radionuclides (including $\mathrm{Cs}-137$ ) that are present remain bound in the HIP mixture. At the end of the devolatilization cycle, the HIP can is evacuated to 0.5 torr $(0.01 \mathrm{psi})$ or less, and the vent tube is crimped and welded using master-slave manipulators. More detailed information on the devolatilization system is contained in EDF-HWO-008 (see Appendix A).

Furnaces. There are three devolatilization furnaces in each devolatilization cell. The furnaces incorporate a square split-tube design that allows greater accessibility for servicing activities and reduces the lifting height required for loading and unloading of cans.

One half of the furnace includes one side, a bottom, and a hinged half-lid. This part of the furnace is stationary and is attached to the floor. The other half of the furnace consists of three sides and a halflid. This part of the furnace is mounted on wheels and driven by screw gear to make closing simple and repeatable. The furnace walls are made of ceramic fiber. Heating elements are embedded in the ceramic fiber on two sides of the furnace. The elements are an iron-chrome type with a maximum temperature of $2,550^{\circ} \mathrm{F}$.

Each furnace requires $480 \mathrm{~V}$ 3-phase poiver, and generates $40 \mathrm{~kW}$ with a loading of 12.66 watts per square in. The surface temperature of the outer shell will be approximately $145^{\circ} \mathrm{F}$.

Vacuum Pumps. There is a total of 4 vacuum pumps, one per devolatilization cell. The vacuum pumps are located in separate cells directly above the devolatilization cells. This allows easier access for servicing and permits the pumps to be non-radiation hardened. The vacuum pumps are used to pull a continuous vacuum on the HIP cans during devolatilization. Three cans per devolatilization cell are manifolded together and connected to one vacuum pump. A condenser/heat exchanger is located in-line between the HIP cans and each vacuum pump for removal of elemental $\mathrm{Hg}$ from the off-gas. The vacuum 
is increased to 0.5 torr just prior to can closure and sealing. $\mathrm{NO}_{\mathrm{x}}$ and $\mathrm{Hg}$ will be present in the devolatilized off-gas. The presence of $\mathrm{NO}_{\mathrm{x}}$ requires the selection of a corrosion resistant vacuum pump.

\subsubsection{Dry Decontamination Equipment}

Vacuum hoses held by manipulators will be used where possible to cleanup contamination. High priority will be given to maintaining cells as clean as possible to assist in manned entry. The vacuum hoses will be equipped with HEPA filters and will be connected to the off-gas system. In addition, carbon dioxide pellet blasting will be used to remove clinging or encrusted contamination from cans and equipment. More detailed information on the decontamination equipment is contained in EDF-HWO-005 (see Appendix A).

\subsubsection{Quality Control/Recycle System}

In the HIPing process there will be a small portion of the HIPed cans that will be recycled into the process due to quality assurance destructive examination of a representative portion of the cans or failure of the cans to meet output specification or can failure during the HIPing process. The HIPed material in these cans will need to be reduced to a granular size and placed back into the HIP process stream. Specialized pieces of equipment required for this system are; 36-in. diameter concrete saw, 250-ton screw press, and jaw crusher. Specific information on the recycling system is contained in EDF-HWO-011 (see Appendix A)

\subsubsection{Remote Handling Equipment}

Because of the highly radioactive nature of the materials being processed, the processing plant must rely almost exclusively on automatic and remotely-controlled equipment. Such equipment is installed so that routine maintenance or complete removal and replacement can be accomplished remotely. Shielded windows allow personnel to perform certain tasks by means of remote controls, and to monitor the automated processes. To assist the production line operators, special tool-insertion ports, manipulators, and windows are installed in strategic locations, and television cameras and special lighting are provided throughout the plant. These lights are installed in such a way that they can be replaced without entering the radiation zone. Each production line will have 13 shielded windows, 13 tool ports, 20 master-slave manipulators, 3 electro-mechanical manipulators, 10 lights, and 10 cameras.

The following is a brief description of one of the four production lines requiring remotely-operated equipment. An empty HIP can is placed via a jib crane on a track-mounted, remote-controlled cart in the filling cell where a mixture of waste and additives is contained in a hopper. The cart is moved under the hopper and a plastic sleeve is pulled down from around the fill tube and inserted into the can, which is then filled. After the plastic sleeve is heat-sealed and tucked into the can, the cart is moved to the weld station, where a lid is welded in place via an inertial (friction) welder. This lid has a short, vent tube jutting up from the lid's center that will be used in a later operation. The cart is then moved to the lower part of the decontamination cell. Here, a bridge crane lifts the can from the cart for decontamination and then transports it to the next cell and places it in the devolatilization chamber where it is heated under vacuum to release volatile agents. After a final vacuum is applied through the vent tube, the vent tube is pinched off and welded shut. The can is then placed inside an overpack container for the HIPing operation. The crane lifts the assembly and places it into the HIP pressure vessel, which, after an initial evacuation, is backfilled with argon gas, heated to $1,050^{\circ} \mathrm{C}$, and pressurized to $20,000 \mathrm{psi}$. After the assembly has soaked at temperature and pressure for a predetermined time, the assembly is removed from the HIP vessel to cool; and the overpack container is set aside for re-use. 
The crane moves the HIP can to the inspection cell where it is examined for defects. If the can is free of defects, it is moved to the loading cell. Empty SRS HLW canisters and the tops are delivered to a staging area outside the loading cell at elevation $0^{\prime}-0^{\prime \prime}$ by forklift and placed on a shuttle cart. A shielding door is opened. The cart is actuated to move through the shielding door into the loading cell and is stopped by a locating mechanism at the welding station. The shielding door is closed. Three HIP cans are loaded into the canister and the top is placed on the lower part of the canister by a positioning mechanism. The top is then welded to the lower part and inspected. Following a successful inspection, the canister is loaded through a hatch into the transport cart located beneath the loading cell. This cart can transport up to four canisters to the ISF.

Remote handling equipment is detailed in EDF-HWO-005 (see Appendix A).

\subsubsection{Interim Storage Facility Equipment} Report. $^{4}$

The ISF equipment to support the HWO is detailed in the Interim Storage Facility Scoping Study

\subsection{Utility and Infrastructure Requirements}

A utilities summary is provided in EDF-HWO-012 (see Appendix A). The summary covers process cooling water, potable water, fire protection water, steam, pressurized air, and electrical requirements for the HIP facility. Engineering Design File EDF-HWO-006 (see Appendix A) contains the breathing air requirements for the hot cells. A separate Utility and Infrastructure Study addresses support facilities to provide the required utilities and infrastructure to the HIP facility. 


\section{3. $\operatorname{COST}$}

Table 1 presents the summary of the cost estimates for the CRTS, the HWO, the ISF, and the Utilities Support. In addition, Table 1 includes a summation of the costs of all of these individual facilities, which represent the total costs of the HWO. Appendix D presents the HIP facility detailed costs estimates and cash flow curves.

EDF-WTS-002 in Appendix A is the source of the CRTS costs developed for the HWO and included in Table 1. The Interim Storage Study Report is the source of the costs of the IFS developed for the HWO and included in Table 1. The Utilities and Infrastructure Report is the source of the costs of the Utilities Support function developed for the HWO and included in Table 1.

The Total Project Cost (TPC) in Table 1 is the sum of the Total Estimated Cost (TEC) for design and construction plus Other Project Cost (OPC). The OPC includes development, pre-design, and postconstruction activities. 
Table 1. HWO cost estimating summary.

\begin{tabular}{|l|r|r|r|r|r|}
\hline \multicolumn{1}{|c|}{ Cost Item } & CRTS (K\$) & HWO (K\$) & ISF (K\$) & Utilities (K\$) & Total (K\$) \\
\hline OPC (unescalated) & 21,267 & 188,329 & 16,228 & 1,472 & 227,296 \\
\hline OPC Escalation & 9,358 & 15,160 & 4,310 & 287 & 29,115 \\
\hline OPC Mgmt Reserve & 0 & 0 & 0 & 0 & 0 \\
\hline OPC Contingency & 10,475 & 61,711 & 5,161 & 443 & 77,790 \\
\hline Total OPC & 41,100 & 265,200 & 25,699 & 2,202 & 334,201 \\
\hline & & & & & \\
\hline TEC (unescalated) & 127,031 & 355,098 & 224,756 & 13,299 & 720,184 \\
\hline TEC Escalation & 53,841 & 93,692 & 80,542 & 4,109 & 232,184 \\
\hline TEC Mgmt Reserve & 13,788 & 31,420 & 22,291 & 1,227 & 68,726 \\
\hline TEC Contingency & 51,611 & 163,789 & 41,012 & 3,666 & 260,078 \\
\hline Total TEC & 246,271 & 643,999 & 368,601 & 22,301 & $1,281,172$ \\
\hline & & & & & \\
\hline TPC (unescalated) & 148,298 & 543,427 & 240,984 & 14,771 & 947,480 \\
\hline TPC Escalation & 63,199 & 108,852 & 84,852 & 4,396 & 261,299 \\
\hline TPC Mgmt Reserve & 13,788 & 31,420 & 22,291 & 1,227 & 68,726 \\
\hline TPC Contingency & 62,086 & 225,500 & 46,173 & 4,109 & 337,868 \\
\hline Total TPC & 287,371 & 909,199 & 394,300 & 24,503 & $1,615,373$ \\
\hline & & & & & \\
\hline Operations (unescalated) & 72,781 & 813,532 & 95,689 & 58 & 982,060 \\
\hline Operations Escalation & 71,923 & 806,834 & 119,204 & 67 & 998,028 \\
\hline Operations Contingency & 43,411 & 486,110 & 64,468 & 38 & 594,027 \\
\hline Total Operations & 188,115 & $2,106,476$ & 279,361 & 163 & $2,574,115$ \\
\hline & & & & & \\
\hline Post Operations (unescalated) & 21,960 & 246,078 & 65,515 & 343 & 333,896 \\
\hline Post Operations Escalation & 37,071 & 435,061 & 411,201 & 746 & 884,079 \\
\hline Post Operations Contingency & 8,855 & 204,342 & 143,015 & 327 & 356,539 \\
\hline Total Post Operations & 67,886 & 885,481 & 619,731 & 1,416 & $1,574,514$ \\
\hline & & & & & \\
\hline Total Cost (unescalated) & 243,039 & $1,603,037$ & 402,188 & 15,171 & $2,263,435$ \\
\hline Total Cost (w/escalation, mgt & & & & & \\
reserve, \& contingency) & 543,371 & $3,901,157$ & $1,293,391$ & 26,079 & $5,763,998$ \\
\hline Discounted Cost (escalated) & 196,876 & $1,106,861$ & 255,814 & 12,489 & $1,572,040$ \\
\hline & & & & & \\
\hline & & & & & \\
\hline & & & & & \\
\hline
\end{tabular}




\section{SCHEDULE}

The design, construction, and operation project schedule is shown below in Figure 1 and in Appendix D. The entire schedule spans from start of conceptual design and project management in June 2001, until the end of D\&D in December 2038. The 4-year construction schedule spans from November 2007 until November 2011. Testing will last three years, from January 2010 until startup in January 2013. The operation period is from 2013 through 2032, and D\&D is from 2033 through 2038. 
HIP OPTION

\begin{tabular}{|c|c|c|c|c|c|c|c|c|c|c|c|c|c|c|c|c|c|c|c|c|}
\hline \multicolumn{21}{|c|}{ HIP OPTION } \\
\hline 10 & Tosk Neme & 1997 & 1990 & 1099 & 2000 & 2001 & 2002 & 2003 & 2004 & 2005 & 2000 & 2007 & 2008 & 2009 & 2010 & 2011 & 2012 & 2013 & 2014 & 2015 \\
\hline 1 & HIP & & & & & & & & & & & & & & & & & & & \\
\hline 2 & CONCEPTUAL DESIGN & & & & & spe & min & $h^{1128}$ & & & & & & & & & & & & \\
\hline 3 & ADVANCED CONCEPTUAL DESIGN & & & & & & & (1) & 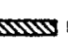 & & & & & & & & & & & \\
\hline 4 & PM FOA PAOUECT DEVELOPMENT. & & & & & shes & s & mII & 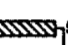 & & & & & & & & & & & \\
\hline 5 & PERMITTING & & & & & & 100 & : & 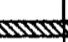 & 1227 & & & & & & & & & & \\
\hline 6 & PROJECT MANAGEMENT & & & & & & & & $5 / 31$ & & & & & & & $11 / 19$ & & & & \\
\hline 7 & TITLE DESIGN & & & & & & & & $5 / 31$ & & & $11 / 24$ & & & & & & & & \\
\hline 8 & CONSTRUCTION & & & & & & & & & & & & & & & $\operatorname{lng}$ & & & & \\
\hline 9 & SO TEST \& STARTUP & & & & 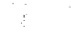 & & & & & & & & & & mas & 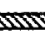 & 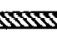 & & & \\
\hline 10 & START PAOCESSINO & & & & & & & $\therefore$ & & & & & & & & & & & . & \\
\hline 11 & OPERATIONS & & & & & & & & & & & & & & & & & & 0. & 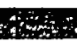 \\
\hline 12 & DSO & & & & & & & & & & & & & & & & & & & \\
\hline
\end{tabular}

\begin{tabular}{|ll}
\hline & HIP OPTION
\end{tabular}

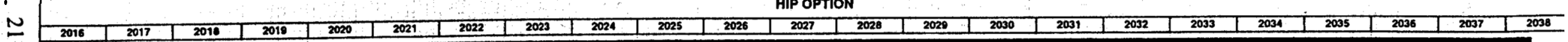

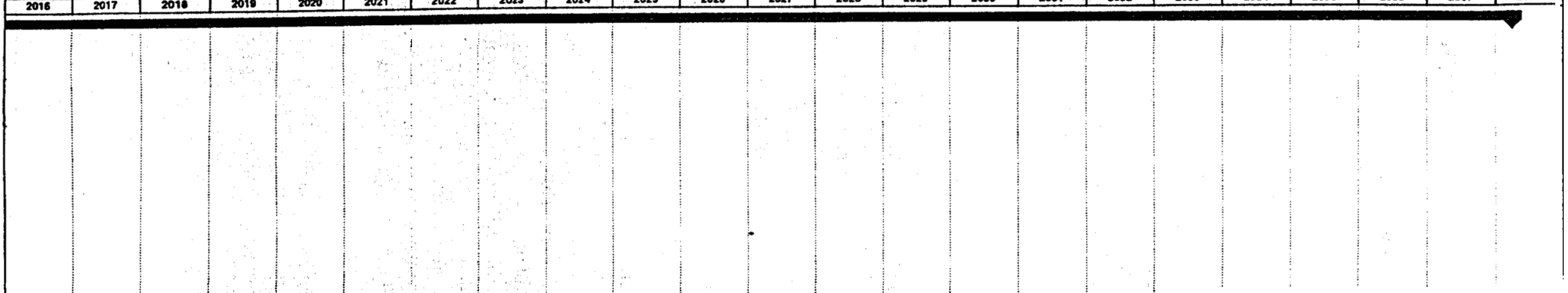

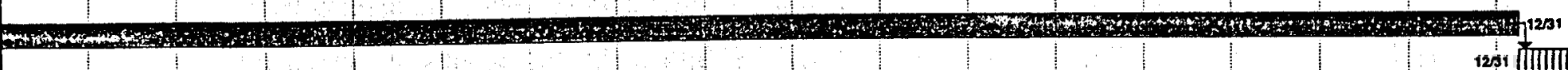

251 i d.

\begin{tabular}{|c|c|c|c|c|c|}
\hline $\begin{array}{l}\text { Project 2419.MPP } \\
\text { Date: Thu 1/29/98 }\end{array}$ & $\begin{array}{l}\text { Task } \\
\text { Progress }\end{array}$ & Bting & $\begin{array}{l}\text { Mitestono } \\
\text { Summany }\end{array}$ & $\begin{array}{l}\text { Rollod Up Task } \\
\text { Aollod Up Milestone } 0\end{array}$ & Rolled Up Progress \\
\hline
\end{tabular}

Figure 1. HWO project schedule. 


\section{RISK ASSESSMENT}

The overall risk for the HWO option has been broken down into three categories: project risk, technical risk, and environment safety and health (ES\&H) risk. An attempt has been made to quantify the risk in each category on a scale of 1 to 9,1 being low and 9 being high.

\subsection{Project Risk}

Project risk consists of completing the project within the designated bugdet and schedule. The HWO's budget is based on the historic DOE budget cycle as applied through the duration of the project and should be classified as a low risk. The principal risk to budget and schedule is directly related to the technical risk of the successful development of the full-scale production waste form by HIPing. To complete that development and to finish processing all of the HLW calcine by the end of 2035 should be considered a reasonable risk. The project risk is judged to be 2.5 .

\subsection{Technical Risk}

Technical risk consists of the project encountering technical difficulties during operation. These difficulties may arise in the form of consistently turning out acceptable product. The product will have to be eventually land disposed in a mined geologic disposal facility. Currently, vitrification is the EPA treatment standard to qualify the mixed waste calcine for land disposal. Research performed at the INEEL has shown that the HWO product is as good as or better than the vitrification product in connection with durability and leachability. However, the data would have to be presented to the EPA to qualify HIP as a treatment option for land disposal of mixed waste calcine. The risk of not obtaining EPA qualification for the product is estimated at 1.0 .

The other risk in consistently turning out acceptable product consists of reliably performing the HIP operation to obtain dimensionally reproducible shapes. Considerable research has been performed at the Chemical Processing Plant (CPP) on simulated waste. However, as mentioned in previous sections this research was performed on 1- to 6-in diameter 4-in long pre-HIP cans, and this data has been extrapolated to the 23.25-in diameter 34-in. long post-HIP forms. Additional research would need to be carried out to arrive at a suitable pre-HIP can shape to consistently obtain the desired shape within acceptable dimensional tolerances. The uniformity of packing the mixture in the HIP can effect the uprightness of the final HIPed form. The HIPed form will have a tendency to lean towards the less densely packed side if the mixture if not uniformly packed around the can central axis. To minimize the potential for this problem, the HIP can will be vibrated periodically during filling to ensure uniform packing density. Post-HIPed forms that do not meet dimensional and other tolerances will need to be and can be reworked. However, the rework, if greater than anticipated, will affect plant through put. The technical risk would ultimately depend on how well this additional research for the optimum pre-HIP can shape is carried out.

HIPing, though a more recently developed technology, is now well known and there is no reason to suspect that there will be any difficulty in obtaining the desired information from the research that needs to be carried out. The overall technical risk is rated to be 3.0 because of the additional research that needs to be carried out. 


\subsection{ES\&H Risk}

The ES\&H risk arises from various accidents and mishaps that may occur during processing. The process does not use hazardous chemicals. The mixed high-level waste calcine is the only hazardous chemical involved in the HWO process. High pressures $(20,000 \mathrm{psi})$ and high temperatures $1,050^{\circ} \mathrm{C}$ are involved. However, these occur inside thick walled and shielded process cells which will not be occupied when these conditions are present. Inert argon gas will be used in large quantities. Other than an asphyxiation hazard and the fact that it will be present under high pressure, argon poses little ES\&H risk. The other ES\&H risks are associated with the use of cranes and other remote equipment and these are similar to those that exist at any comparable facility remotely handling nuclear materials. There are some risks associated with the fire potential of the titanium powder that is used as an additive prior to HIIPing. It is recommended that a future study address this potential (see Section 9.2).

The main ES\&H risks unique to this facility are primarily associated with the spread of radioactive contamination due to unforeseen and accident conditions. The threats that may potentially occur and their consequences are presented below. Detailed evaluation and safety analysis is outside the scope of this study.

- Calcine retrieval system develops a leak-Most of the calcine retrieval system will be under a negative pressure with respect to the surrounding atmosphere. If a leak developed, the leakage would be into the calcine retrieval system and this would not result in any ES\&H hazards, but would cause operational difficulties.

- Calcine and additives hopper develops a leak-This is an accident condition that falls under the general category of contamination spread. The contamination spread would however be to nonoccupied areas of the plant and would be cleaned up by manned entry into the contaminated area. The ES\&H hazard would be radiation exposure to operating personnel. Unlike the calcine retrieval system where components are subjected to various abrasive forces, the potential for a leak to develop in the calcine and additives hopper is minimal.

- Calcine spill from a HIP can-This spill could occur when the can is filled or later by the can being tipped over before the lid has been sealed to the top of the can. The potential consequences would be similar to that of the earlier incident where the hopper developed a leak. A plastic sleeve concept will be used during can filling. This should limit the spread of contamination not only during can filling but also later until the lid is sealed to the top of the can, because the plastic sleeve will essentially form a bag around the calcine and keep it confined to the inside of the can. However, the hypothesized accident could occur if the plastic sleeve were accidentally punctured during the can filling operation.

- HIP can leak detected during devolatilization-If a vacuum cannot be applied to a HIP can during devolatilization, it would be an indication that the HIP can is leaking. There would be a potential for the calcine to be drawn from the can into the vacuum system. A HEPA filter will be included in this line to protect the vacuum system from contamination. The can would have to be reworked by emptying its contents and disposing of the failed can as radioactive waste.

- HIP can leak during HIPing - This incident would be detected by the radioactive contamination monitoring of the argon gas inside the pressure vessel during the HIPing operation. A leaking HIP can could cause this incident. The consequences would be contamination spread to the HIP machine components. The HIP can would have to be 
retrieved and recycled as in the previous incident, and the HIP machine decontaminated. This could result in some down time.

- The ES\&H risk is estimated at 2 for a handling accident that may impact schedule.

\subsection{Maturity of HIP Facility Technology}

Guidance for determining the maturity of HIP facility technology is found in the Interim GuidanceOffice of Science and Technology Technical Decision Process, DOE Standard Operating Procedure." The maturity is classified by stages 1 through 7 titled (1) Basic Research, (2) Applied Research, (3) Exploratory Development, (4) Advanced Development, (5) Engineering Development, (6) Demonstration, and (7) Implementation. Requirements for each stage dealing with minimum goals, objectives, measures of effectiveness, actions, and responsibilities to include requirements for entry into the next stage are detailed in the reference.

The basic technology used in the HIP facility is well developed for the manufacturer of turbine and other such components manufactured from powder aggregates. The HIPing of calcine waste has been shown to work in the laboratory and a HIPed product that satisfies leaching and durability criteria has been obtained. Additional testing however, would be required to determine pre-HIP can dimensions because the testing was done on much smaller cans than the production-scale can. Only small-scale testing has been completed using simulated calcine waste. Research performed at the INEEL has shown that the HWO product is as good as or better than the vitrification product in connection with durability and leachability. Hot isostatic pressing of materials in the commercial world has been on-going for many years. This technology is well developed. The risk of failure due to maturity of technology is perceived as low to medium.

The HWO technology is considered to be at the Engineering Development and Demonstration stages (5 and 6). Calcine blending, glass frit transport, calcine and frit metering, and mixing are not as developed; however, are estimated to be from the Exploratory Development to Demonstration stages ( 3 to 6). The off-gas system is estimated to be at the Engineering Development or Demonstration stage ( 5 or 6). The HIPing technology is not recognized as the best demonstrated available technology for treating HLW and, currently does not have regulatory acceptance.

Most of the other aspects of the HIP facility, such as remote decontamination, remote and hands on maintenance, remote handling, remote welding, remote leak checking, and swiping, remote canister handling, and HLW radiation protection, etc., are at the Implementation stage (7) in many existing DOE facilities. 


\section{FAILURE MODES}

The following possible failure scenarios were identified during this study. Their evaluation is outside the work scope of this study. Most of the activities involved in this study's proposed operations have to do with movement of HIP cans and SRS canisters containing calcine, amorphous silica, and titanium powder. The following is a list of possible failure modes:

- Calcine retrieval system develops a leak

- Calcine and additives hopper develops a leak

- Calcine spill in the can loading cell while loading a HIP can

- $\quad$ Loaded HIP can is dropped prior to sealing

- HIP can found to be out of spec after HIPing

- Crane failure-loaded HIP can

- $\quad$ Crane failure-loaded SRS canister

- Transfer cart failure-loaded SRS canister movement

- Friction welder inoperable

- HIP furnace door inoperable

- HIP can leak detected during devolatilization

- $\quad$ HIP can leak detected during HIPing

- HIP vessel failure and release of high pressure argon.

A drop accident involving a loaded HIP can or SRS canister will not inflict unacceptable physical damage to any of these items that would result in a safety concern to workers, the general population, or the environment. All handling of loaded HIP cans and SRS canisters takes place in a shielded, containment cell. Radioactive particulate resulting from an over-turned or dropped unsealed HIP can will be contained in side the cells. HEPA filtered ventilation will prevent contamination from leaving the cells.

An electrical power failure will have the effect of shutting down all by-life safety systems in the HIP facility. Crane activities are considered to be fail safe on loss of power and thus pose little risk to workers, the general public, or environment.

The major impact from a failure would be to the schedule. The level of impact will be determined by which items are involved; however, any accident will most likely halt all activities involving the production and storage of SRS canisters until the accident is resolved and any subsequent operating adjustments are made. For the HWO production rate assumed in this study, the overall schedule for completion by 2033 appears to have some slack to accommodate some slippage. 
If a catastrophe were to cause the release of all radioactive materials in the processing plant, approximately 700,000 curies would be released. That assumes that the released waste is from the most highly radioactive sources. 


\section{PROJECT DATA SHEETS-SUMMARY OF IMPACTS}

Table 2 contains the project data for the HWO project. Data are presented for the construction, operation, and decommissioning phases of the project. Estimates are included for the following parameters:

- Cost

- $\quad$ Schedule

- $\quad$ Air emissions

- $\quad$ Liquid effluents

- $\quad$ Solid wastes

- Utilities used

- Manpower requirements

- Regulatory requirements.

Because this project is at a very preliminary stage of design, much of the information presented in this project data sheet is based on representative literature values, exiting laboratory data, and engineering judgment. Appendix D includes the cost estimates from which the cost data in this table were taken. Appendix $\mathrm{E}$ provides the backup information for the remaining data in the table.

Project data sheets for the CRTS, ISF, and Utilities Support can be found in EDF-WTS-002 (see Appendix A), the Interim Storage Study Report, ${ }^{4}$ and the Utilities and Infrastructure Report, ${ }^{9}$ respectively. 
Table 2. Project data sheet for HWO.

Generic Information

Description/function

Hot isostatically press HLW calcine in preparation for roadready storage awaiting shipment to a permanent repository

EIS Alternatives (A, B, etc.)

Nonseparations - Direct HIPing Option

Project type or waste stream

HIPed HLW calcine.

Action type

New

Structure type

Size $\left(\mathrm{m}^{2}\right)$

$$
19,347 \mathrm{~m}^{2}
$$

Other features (e.g. pits, ponds, power/water/sewer None

lines)

Location

Inside/outside of fence

Inside ICPP fence

Inside/outside of building

Inside HIPing Facility

Candidate for privatization?

Yes

\section{Construction Information}

Cost (\$): Preconstruction

Conceptual Design

$\$ 139.793,860$

Management Costs

$\$ 17,906,490$

Project Development

$\$ 3,746,160$

Permitting and documentation

$\$ 42,042,780$

$\$ 61,710,710$

SO Test \& Start-Up

$\$ 265.200,000$

Total Preconstruction

$\$ 67,942,230$

$\$ 66,644,910$

$\$ 293,618,032$

$\$ 17,648,992$

G\&A/PIF

$\$ 198,145,836$

Procurement Fees, Mgmt Reserve, and Contingency

$\$ 644,000,000$

Schedule start/end: Preconstruction

January 2001 through December 2006

Schedule start/end: Construction

January 2007 through December 2010

Schedule start/end: SO Test \& Start-up

January 2010 through December 1012

Number of workers each year of construction (new/existing)

Nonradiation

100 New workers/yr

Number of radiation workers (construction)

None

Average annual worker radiation dose (rem/yr)

None 
Table 3. Continued.

\section{Heavy equipment}

Equipment used

Trips (construction materials delivery)

Hours of operation (including materials delivery vehicles)

\section{Acres disturbed and duration of disturbance}

New

Previous

Revegetated

Air emissions

Dust

Major gases $\left(\mathrm{CO}_{2}, \mathrm{H}_{2} \mathrm{O}, \mathrm{O}_{2}, \mathrm{~N}_{2}\right)$ from diesel exhaust

Contaminants (Particulates, $\mathrm{CO}, \mathrm{NO}_{\mathbf{x}}, \mathrm{SO}_{2}$,

hydrocarbons) from diesel exhaust.

SO testing air emissions (trace $\mathrm{SO}_{\mathrm{k}}, \mathrm{NO}_{2}$ )

Total air emissions

\section{Effluents}

SO testing process wastewater (non-radioactive)

Sanitary wastewater

Lube Oil

\section{Solid wastes}

Type - construction trash

Radioactive wastes

\section{Water usage:}

Dust control

SO testing process water (once through cooling)

Domestic water (construction and SO testing)

Hazardous/toxic chemicals and wastes

Storage/inventory

Pits/Ponds created $\left(\mathrm{m}^{2}\right)$

Hazardous waste (SO Testing... spent activated carbon)

Hazardous waste (construction)
Excavator, grader, crane, material delivery trucks

$$
1,982
$$

11,622 hours (total)

January 2001 through December 2037

None

3.7 acres

None

213 tons (total)

9,158 tons (total)

54 tons (total)

17 tons (total)

9,442 tons (total)

307,947,600 liters (total)

$12,774,375$ liters (total)

1,417 liters (total)

$$
4,742 \mathrm{~m}^{3} \text { (total) }
$$

None

$$
605,600 \text { liters (total) }
$$

$307,947,600$ liters (total)

$12,774,375$ liters (total)

$$
-\mathrm{m}^{3}
$$

None

$$
\begin{array}{r}
4.2 \mathrm{~m}^{3} \text { (total) } \\
217 \mathrm{~m}^{3} \text { (total) }
\end{array}
$$


Table 3. Continued.

Energy requirements

Electrical (MWh/yr)

Fossil fuel (liters)

Permits needed for construction

$$
\begin{gathered}
156 \mathrm{MWh} / \mathrm{yr} \\
357,807 \text { liters (total) }
\end{gathered}
$$

NEPA documentation (prior to start of Title II construction); New stationary sources/PTC/NOC/PSD for non-rad air emissions; HAPs and TAPs and RCRA (part $\mathrm{AA}, \mathrm{BB}$, and $\mathrm{CC}$ for air) for hazardous air emissions; air operating permit; NESHAPs, NPDES, NESHAPs subpart $\mathrm{H}$ for rad air emissions; approval of Engineering Plans; Cross Connection Control Plans; report and specifications for drinking water supply; RCRA Part A and Part B pernits.

\section{Operational Information}

Cost (\$): Operations

Faculty/Administration

$\$ 36,677,000$

Operations/Process Facility

$\$ 219,751,000$

Procurement, materials, utilities, maintenance

$\$ 557,106,000$

Total operations

$\$ 813,534,000$

Schedule start/end

January 2013 through December 2032

\section{Number of workers each year of operation (new/existing)}

Operations

Maintenance

Support

Total 78

Number of radiation workers

Average annual work radiation dose (rem/yr)

22 (included in above total)

$0.19 \mathrm{rem} / \mathrm{yr}$ per worker

\section{Heavy Equipment}

None

Air Emissions

Radioactive off-gas

0.1 tons/yr

Effluents

Sanitary Wastewater

Process water (once-through cooling water)

Decontamination Solution (nitric acid)

1,535, 196 liters/yr

$102,649,200$ liters/yr

37,850 liters/yr

Solid Wastes

Sanitary/Industrial Trash

$433 \mathrm{~m}^{3} / \mathrm{yr}$ 
Table 3. Continued.

Radioactive wastes (canisters, amalgam)

$167 \mathrm{~m}^{3} / \mathrm{yr}$

$1,152,000 \mathrm{Ci} / \mathrm{yr}$

Hazardous/toxic chemicals and wastes

Pits/Ponds used $\left(\mathrm{m}^{2}\right)$

Spent Carbon (mixed waste)

Misc. hazardous waste

None

$1 \mathrm{~m}^{3} / \mathrm{yr}$
$3 \mathrm{~m}^{3} / \mathrm{yr}$

Water usage:

Process water (once-through cooling water)

102,649,200 liters/yr

Domestic water

$1,535,196$ liters/yr

Energy Requirements:

Electrical

$$
8,472 \mathrm{MWh} / \mathrm{yr}
$$

Steam

$63,709,091 \mathrm{~kg} / \mathrm{yr}$

Fossil fuel (liters/yr)

Permits needed (for facility operations)

None

HAPs and TAPs and RCRA (part AA,BB, and CC for air) for hazardous air emissions; air operating permit; NPDES, NESHAPs subpart $H$ for rad air emissions; approval of Engineering Plans; Cross Connection Control Plans; report and specifications for drinking water supply; RCRA Part A and Part B permits.

Decontamination \& Decommissioning (D\&D) Information

\section{Cost (\$): D\&D}

Decommission

$\$ 34,142,000$

Decontamination

$\$ 81,514,000$

Demolition

$\$ 130,423,000$

Total D\&D

Schedule start/end: D\&D

$\$ 246,079,000$

Number of workers each year of D\&D (new/existing)

January 2034 through December 2036

Number of radiation workers (D\&D)

Average annual worker radiation dose (rem/yr)

593 New workers/yr

438 New workers/yr

$0.19 \mathrm{rem} / \mathrm{yr}$ per worker

Heavy equipment:

Equipment used

Trips Roll-off trucks

Mobile Cranes, Roll-off tnucks, Dozers, Loaders

Hours of operation (all heavy equipment)

15 per day

76,950 hours (total)

Acres disturbed and duration of disturbance

New

None 
Table 3. Continued.

Previous

Revegetated

Air emissions

Non-radioactive Fuel combustion gases $\left(\mathrm{CO}_{2}, \mathrm{H}_{2} \mathrm{O}, \mathrm{O}_{2}\right.$,

$\mathrm{N}_{2}$ )

Non-radioactive Fuel combustion contaminants ( $\mathrm{CO}$, particulates, $\mathrm{NO}_{x}, \mathrm{SO}_{2}$, hydrocarbons)

Radioactive HEPA filtered off-gas

Effluents

Radioactive spent decontamination solution

Non-radioactive sanitary wastewater

Non-radioactive lube oil

\section{Solid wastes:}

radioactive

Non-radioactive (industrial)

Hazardous

Hazardous/toxic chemicals and wastes (type)

Storage/inventory

Pits/Ponds created $\left(\mathrm{m}^{2}\right)$

radioactive (mixed waste)

Water usage:

Process water

Domestic water

Source of water

Energy requirements:

Electrical (MWh/yr)

Fossil fuel (liters)

Permits needed (e.g. for facility closures, physical characteristics and quantities of radioactive and hazardous materials remaining after closure)
3.7 acres

None

44,726 tons (total)

261 tons (total)

78,518 tons (total)

$5,109,750$ liters (total)

$5,110 \mathrm{Ci}$

$37.858,757$ liters (total)

14,563 liters (total)

$$
\begin{array}{r}
34,836 \mathrm{~m}^{3} \\
26,193 \mathrm{~m}^{3} \\
12 \mathrm{~m}^{3}
\end{array}
$$

$348 \mathrm{Ci}$

$$
205 \mathrm{~m}^{3} \text { (total) }
$$

None

$$
141 \mathrm{~m}^{3} \text { (total) }
$$

$1 \mathrm{Ci}$

$$
37,858,757 \text { liters (total) }
$$

ICPP site wells

$$
\begin{gathered}
156 \mathrm{MWh} / \mathrm{yr} \\
1,747,535 \text { liters (total) }
\end{gathered}
$$

Work will be done under closure provisions of existing permits. 


\section{POTENTIAL IMPACTS OF NRC LICENSING}

The HIP facility presented in this report is not NRC licensed and therefore, neither the HIP facility design nor the cost estimate included were modified to include NRC licensing. This section contains a brief discussion, gleaned from data contained in "The Regulatory Requirements and Criteria for ICPP Proposed Waste Processing Facilities," EDF-WTS-003 in Appendix A, and from the Waste Treatment Facilities Feasibility Study Report,' of the potential impacts of NRC licensing on the WTS. Existing NRC regulations are compiled in 10 CFRs, "Energy." These regulations follow a similar philosophy espoused by the DOE, the EPA, etc. The Commission has also issued regulatory guides (such as NUREGs) that provide acceptable methods to comply with the NRC regulations; they contain criteria for facility design, operations, and health and safety.

The only (WTS)-type activity that the NRC has routinely licensed is HLW waste storage. Currently NRC regulations do not exist to license WTS-type HLW separations or treatment facilities. The most applicable licensing process regulations to the WTS are as follows: for LLW or low-activity waste (LAW) facilities 10 CFR 2, 10 CFR 30, 10 CFR 51, and 10 CFR 61; and for HLW or high-activity waste (HAW) facilities 10 CFR 2, 10 CFR 50, 10 CFR 52, 10 CFR 70, and 10 CFR 72 . Licensing a nuclear facility requires preparing and submitting an application and supporting documents to the NRC, such as Safety Analysis Reports, Environmental Reports, quality assurance documents, training plans, monitoring plans, and safeguards and security plans. The NRC licensing process is divided into four stages: pre-application stage, application review stage, construction and operating license stage, and decontamination and site closure stage. The licensing duration from submitting the application to receiving of the license is expected to take three to five years, or longer. The Benefits of NRC licensing are enhanced operating safety, strengthened relationships with stakeholders, and license-holder participation in future regulation development.

According to data developed in the Fluor Daniel Inc., the Waste Treatment Facilities Feasibility Study Report, ${ }^{\prime}$ estimated capital cost percentage increases for NRC licensing of WTS facilities above current DOE requirements for those facilities are as follows:

$\begin{array}{lr}\text { Waste Separations } & 21 \% \\ \text { LAW Treatment } & 13 \% \\ \text { HAW Interim Storage } & 26 \% \\ \text { LAW Collection } & 8 \% \\ \text { Calcine Dissolution } & 15 \% \\ \text { Calcine Transfer } & 14 \% \\ \text { HAW Treatment } & 26 \% \\ \text { Infrastructure (Utilities) } & 9 \%\end{array}$

These estimates are hypothetical and highly speculative. The capitol costs here are equivalent to the unescalated, current dollar TEC in the cost estimate presented in Section 3 of this report. Reference 1 also estimated the operating schedule impact and dollar-value increase in annual operating costs for three groups of systems as follows:

- Group I-Negligible Schedule Impact $\$ 1.3 \mathrm{M}$

- Group II-Minimal Schedule Impact $\$ 2.7 \mathrm{M}$ 
- Group III-Significant Schedule Impact $\$ 4.7 \mathrm{M}$

Group I includes the LAW collection, infrastructure, and tank heel; Group II includes the waste separations, LAW treatment, condensate collection, and environmental analysis Laboratory; and Group III includes the HAW independent storage, calcine dissolution, calcine transfer, and HAW treatment. Additional costs resulting from operating schedule impacts experienced due to NRC involvement are based on a "best guess" reflecting perceived likelihood of NRC's difficulty in assimilating the Group into their new regulatory framework. "Negligible" could range from no costs, to tens of thousands of dollars. "Minimal" could range from a few thousand dollars to several hundred thousand dollars. "Significant" could range from a hundred thousand to several million dollars.

The HWO is best characterized by Group III except it does not have a calcine dissolution system so the portion of the increased cost associated with that facility must be subtracted from $\$ 4,700,000$ Group III cost to determine the HWO increase. Assuming the NRC licensing annual cost increase for the calcine dissolution system is $1 / 3$ this total, the annual cost increase for the HWO (the remainder of the Group III system) is approximately $\$ 3,100,300$.

In the event that the HWO is licensed by the NRC, the increases in capital cost (based on a $14 \%$ escalated TEC cost increase for the CRTS, a $26 \%$ escalated TEC cost increase for the ISF and the HIP facility, and a $9 \%$ escalated TEC cost increase for infrastructure) and the 20 -yr operating cost, will be $\$ 299,761,000$ and $\$ 62,000,000$ respectively, for a total of $\$ 361,761,000$.

Some of the potential major impacts associated with NRC licensing of waste treatment facilities, other than cost, are:

- Increased oversight, including more public involvement and input in all decision processes

- More restrictive physical limits on some parameters, including exposure limits, seismic, and tornado

- More strict radiation monitoring

- Restrictions on sharing utilities between facilities

- More stringent evaluations of the impact from off-site hazards.

- Full testing required for emergency utilities

- Physical changes to the plant and equipment

- $\quad$ More elapsed schedule time required

- The methods to comply with some other codes and standards may be complicated and require more time

- Although the NRC may license the WTS facilities, it may not automatically inherit or adopt the same agreements and obligations with the State of Idaho and EPA Region 10 that are in place for DOE and INEEL. 


\section{CONCLUSIONS AND RECOMMENDATIONS}

\subsection{HIP Facility}

The nonsepartions alternative HWO consists of CRTS, the HIP facility, ISF, and Utilities Support. Designs are based on existing feasibility and conceptual designs for the other facilities that have similar requirements. This report concentrates on the HIP facility portion of the HWO, which in this report will produce approximately 5,700 SRS canisters for the nonseparations alternative, in its 20-year operating life. This is equivalent to approximately $5,400 \mathrm{~m}^{3}$ of calcined HLW. The planned date for all SRS canisters to be in storage (in this case at the HWO ISF) is the end of 2032, which is ahead of the HLW treatment date of 2035 targeted by the DOE and State of Idaho. ${ }^{2}$ The HWO HIP facility will be designed to treat dry calcine from the ICPP CSSF only. This is because of the assumption that all SBW will be calcined and placed in the CSSF before the start of HIP facility operations.

The total costs for the HWO are summarized as follows and include costs for the CRTF, the ISF, and the Utility Service:

Total Cost (unescalated) is $\$ 2,263,435,000$

Total Cost (with escalation, management reserve, and contingency) is $\$ 5,763,998,000$

Discounted Cost (escalated) is $\$ 1,572,040,000$.

If the HWO is selected in the Record of Decision, then communication should be initiated as soon as possible with the NRC, State of Idaho, EPA, HLW Repository, and each state and EPA Region through which the waste will be transported for disposal.

\subsection{Future Studies}

During the course of this study, the following ideas for future studies have surfaced:

- Potential Fire Hazards Handling Titanium Powder-Handling, storing, transporting, and processing operations involving the titanium powder should be further studied to better understand and design for the fire characteristics of this metal.

- HIP Can Design and Testing-Minimal testing has been conducted at the INEEL using hot isostatic pressing technology; only small scale tests have been conducted. Further testing of HIP can design should be conducted to arrive at the final design HIP can dimensions.

- HIP Can Sealing - A separate study will develop the design concepts for remote ultrasonic examination equipment for checking weld integrity inside hot cells. The NRC requires $100 \%$ volumetric examination. In addition, the INEEL has done some preliminary work involving friction welding lids to cans. This procedure needs to be perfected and other methods for sealing the can need to be investigated.

- Devolatilization of HIP Can Contents-Further studies should look at complications with the heating and devolatilizing of the HIP can contents. Specifically investigate the temperatures and time required to complete the process. 
- HIP Can Filling Equipment-A lot of information and practical experience has been gained through the use of bagging systems at the INEEL. Remote bag sealing systems involving calcine have not been perfected. More work is need in this area to look at problems with the bagging system, remote handling, and sealing.

- HIP Furnace Design-The furnaces incorporated into this design are relatively large. Hot isostatic press technology is relatively new and only little experimentation has been conducted on systems as large as those specified herein. Further studies and testing need to be conducted on these issues. Full-scale development of the HIP process is needed to optimize the HIP can dimensions:

- Location of the HIP facility in Reference to the CSSF-The location of the HIP facility as depicted in this study should be re-evaluated. Close proximity of the HIP facility to the CSSF is very desirable due to transport problems of the calcine. In the current design the HIP facility is located due North of the CSSF. An evaluation of locating the HIP facility due East of the CSSF should be completed. Moving to this new location would make transfer piping much shorter. Also, the present North location may place the facility on contaminated soil.

- Determine if a standard 15-ft long "Hanford" HLW canister should be substituted for the 10ft SRS Defense Waste Processing Facility canister assumed in this study-Use of a $15-\mathrm{ft}$ canister would increase the HIP facility construction costs but would reduce the operation (SRS canister handling) costs, and greatly reduce off-site transpiration and disposal costs. A large net cost saving, primarily as a result of reduced transportation and disposal costs, could be realized by using the $15-\mathrm{ft}$ canister. 


\section{REFERENCES}

1. Fluor Daniel, Inc., Government Services Operating Company, Idaho Chemical Processing Plant Waste Treatment Facilities Feasibility Study Report, FDI Contract No. 04435336, December 19, 1997.

2. U.S. Department of Energy, Consent Order and Settlement Agreement Between DOE and the State of Idaho Regarding Spent Fuel and Nuclear Waste Issues, October 17, 1995.

3. 40 CFR 268, "Land Disposal Restrictions for Hazardous Waste,"

4. J. K. Rawlins, Interim Storage Study Report, INEEL/EXT-97-01393, February 1998.

5. J. Banaee, INEEL, K. Pechulis, EPA, Telephone conversation, January 21, 1998.

6. Environmental Management, "Waste Acceptance Product Specifications for Vitrified High-Level Waste Forms," EM-WAPS Rev. 01, May 1995.

7. Waste Acceptance System Requirements Document, December 1996 - DOE/RW-035.1P Revision 02.

8. N. E. Russell, Waste Disposal Options Report, INEEL/EXT-97-01145, February 1998.

9. R. S. Garcia, Utilities and Infrastructure Report, INEEL/EXT-98-01398, February 1998.

10. DOE Standard 1020,

11. Interim Guidance Office of Science and Technology Technical Decision Process, Standard Operating procedure.

12. D. A. Lopez, Vitrified Waste Option Study Report, INEEL/EXT-97-01389, February 1989.

13. Idaho Chemical Processing Plant, Waste Treatment Facilities Feasibility Study Report, Flour Daniel, Inc. Government Services Operating Company, FDI Contract No. 04435336, December 12, 1997.

The documents listed below are not cited in this report but are related to this work and may be mentioned in the appendices.

- Report of Advanced Conceptual Design Activities for the ICPP Spent Nuclear Fuel Dry Storage Project, LMITCO Report NEL-97/00177, February 1997.

- Idaho Chemical Processing Plant Feasibility Design Study for the Waste Immobilization Facility, Raytheon Engineers and Constructors, Inc. Western Operations, MS511.163, 9/27/94 
Appendix A

Referenced Engineering Design Files 


\section{Engineering Design Files}

The engineering design files (EDFs), prepared for this study are listed below.

\begin{tabular}{ll} 
EDF-HWO-001 & "Regulatory Analysis \& Planning Path for HWO Scoping Study" \\
EDF-HWO-002 & "HWO Can Design and SRS Canister Loading Information" \\
EDF-HWO-003 & "Hot Isostatic Pressing (HIP) Equipment" \\
EDF-HWO-004 & "HIP Can Filling" \\
EDF-HWO-005 & "Hot Isostatic Press Handling Equipment" \\
EDF-HWO-006 & "Radiological Evaluation for the Calcine HIP Feasibility Study" \\
EDF-HWO-007 & Deleted \\
EDF-HWO-008 & "Devolatilization Equipment" \\
EDF-HWO-009 & "HWO Electrical Requirements" \\
EDF-HWO-010 & "HWO Staffing “" \\
EDF-HWO-011 & "Recycle Sizing Cell" \\
EDF-HWO-012 & "HIP Waste Option (HWO) Design Basis" \\
EDF-HWO-013 & "HIP facility Instrument and Control Evaluation" \\
EDF-HWO-014 & "HIP Facility HVAC" \\
EDF-WTS-002 & "Calcine Retrieval and Transportation" \\
EDF-WTS-003 & "Regulatory Requirements and Criteria for ICPP Proposed Process Facilities" \\
EDF-WTS-004 & "Regulatory and Design Requirements for Waste Treatment Facilities" \\
\hline
\end{tabular}


Project File Number 02BG0

Project/Task

Waste Treatment Project Feasibility Studies

Subtask

HIP Waste Option (HWO) Scoping Study

Title: $\quad$ Regulatory Analysis \& Planning Path for HWO Scoping Study

Purpose:

The purpose of this EDF is to document the regulatory analysis and planning path forward for the Hot Isostatic Pressing (HIP) waste option scoping sudy. The HIPing process uses high pressure and high temperature to convert calcine or other solid wastes to a glass-œramic waste form. HIPed waste cans will be placed in Savannah River shipping canisters and, ulimately, sent to a geologic repository for permanent disposal.

\section{Summary:}

The HWO waste will be in a treated condition and meet applicable physical specifications so as to 1) permit ulimate disposal in a geobgic reposition outside the State of Idaho, and 2) permit the waste to be exchded from the Resource Conservation and Recovery Act (RCRA) hazardous waste management requirements.

The HIPed waste is chassified as mixed high-level waste (HLW) [ref: 1]. The hazardous components of the HIPed waste are subject to RCRA requirements and the radioactive contaminants are regulated under the Atomic Energy Act (AEA). RCRA has established treament sandards under the Land Disposal Restrictions (LDRs), 40 CFR 268 , for hazardous waste when the waste is land disposed. The HIP process is not a LDR specified technology. Therefore, the HWO will need to be approved by the Environmental Protection Agency (EPA) Administrator under the procedures set forth in 40 CFR 268.42(b), determination of equivalent treatment (DET). Approval should not be a problem sinœ the EPA has stated its belief that the glass-œramic prọcss is more efficient than the specified technology process (vitrification) for calcine waste forms [ref: 2]. EPA has also determined that the glass-œramic waste form that results from HIPing calcine is an acceptable technology to meet best demonstrated available technobgy (BDAT).

Since the potential repository at Yucca Mountain currently does not accept any hazardous wastes, the HIPed waste must be delisted prior to disposal at the repository. The delisting must be approved by both the waste shipping (Idaho) and the waste receiving state (Nevada), as well as all other states through which the waste is transported. The wastes can also be delisted prior to or after calcination if their concentrations at either point are below the LDR regulatory levels. Criteria for acceptance and disposal of wastes at the Yucca Mountain repository have not been finalized. However, it is anticipated that the waste acceptance procss will require demonstration of complianœ with the Environmental Management (EM) Waste Accetance Product Specifications (EM-WAPS) via four different documents, each prepared by the waste generator, reviewed and accepted by EM, and provided to the Office of Civilian Radioactive Waste Management (OCRWM). These four documents are: (1) the Waste Form Compliance Plan, (2) the Waste Form Qualification Report,(3) Production Records, and (4) Storage and Shipping Records

Distribution: N. E. Russell MS 3765, K. L. Williams MS 3765

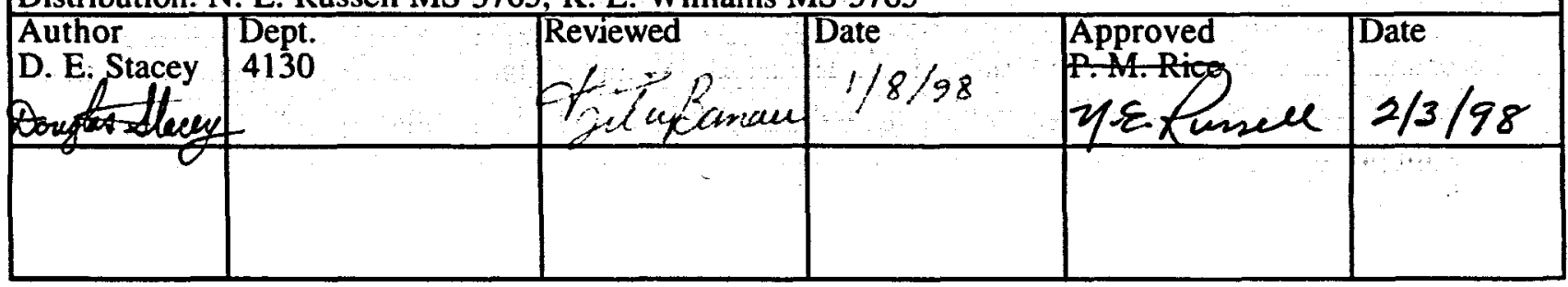


Introduction: The calcined waste will be HIPed without further processing (thus the term 'direct HIPing'), packaged and shipped to a geologic repository for permanent disposal. The calcined waste will be HIPed using the following process: All remaining high level liquid waste (HLLW), Sodiumbearing waste (SBW), and other radioactive waste currently stored in the Tank Farm at the Idaho Chemical Processing Plant (ICPP) is calcined. The calcine is temporarily stored in binsets until it can be HIPed. Calcine is taken from storage and blended with HIPing additives. This HIPing mixture is poured into thin-walled stainless steel HIPing cans designed to deform to a size and shape which will allow $+80 \%$ utilization of storage volume in a standard $2 \mathrm{ft}$ diameter $\times 10 \mathrm{ft}$ storage/disposal canister. A closure cap is welded to the tops of each can which incorporates a venting tube. The latter is capable of being sealed by a standard crimp-and-weld operation, and will incorporate a filter element comparable in performance to a HEPA filter. The cans are placed in a devolatilizing fixture in which the vent tubes are connected to a vacuum source and the centerline temperature of the can is raised to approximately $625^{\circ} \mathrm{C}$ for 16 to 24 hours. This step removes remaining undesired volatiles from the HIPing mixture (primarily residual $\mathrm{H}_{2} \mathrm{O}, \mathrm{CO}_{\mathrm{x}}, \mathrm{Hg}$, and $\mathrm{HO}_{\mathrm{x}}$ ), but leaves radionuclides [including Cs137] bound in the HIPing mixture. After devolatilization, the vent tube on the can is crimped and welded closed. The can is removed from the devolatilization fixture and placed in a HIPing machine. The HIPing machine is sealed shut, evacuated, and pressurized with argon gas. The internal heater of the HIPing machine is activated and the cans are heated and further pressurized (by heating only) to the required temperature and pressure. Processing temperatures for the HIP process are similar to vitrification, typically $1050-1100^{\circ} \mathrm{C}$. The typical HIP operating pressure is $20,000 \mathrm{psi}$.

HIPing is considered complete once the centerline temperatures of the cans have reached the required value and remained at that value for 4 hours. The cans are removed from the HIPing machine and moved to a cooling area. Following cooling to near-ambient temperature, the cans are moved to a decontamination area. The cans are decontaminated and non-destructively tested to verify solidification of all the mixture. Cans passing non-destructive testing are packaged in Savannah River shipping canisters and moved to interim storage. Cans not passing non-destructive testing are transported to a dissolution cell where they are sized, ground, and redissolved in concentrated nitric acid solution. The latter is recycled with other liquid tank farm wastes through the calciner and back to the HIPing facility.

This EDF is outlined to address the following areas (based on programmatic assumptions and Programmatic Regulatory Planning Path):

- Provide specific regulatory classification for the proposed HIPed waste form

- Determine the waste form requirements as specified in the repository waste acceptance criteria (WAC) and the regulating authority for the waste repository

- Determine the regulatory requirements for handling, packaging, storing, and transporting the HIPed waste

- Specify a regulatory planning path that will allow the HWO concept to be used for producing, storing, and eventual transportation of the HIPed HLW, including any exceptions/variations that must be addressed with the regulating authorities to make this approach viable including assumptions.

- Quality Assurance (QA) Program 
Programmatic Assumptions: (1) The HIPing operation is assumed to provide the BDAT to meet the Land Disposal Restriction (LDR) for all constituent wastes. (A waiver will be granted to allow the HIPing process to be used as BDAT for other hazardous constituents which currently require LDR technology specific treatment other than vitrification 40 CFR 261 Subpart C), (2) The key component of the INEEL waste management plan is the de-listing of "listed" hazardous wastes in the various waste streams such that RCRA requirements do not apply [ref: 3]. (3) The waste is packaged according to the specifications listed in the Repository WAPS, the waste form meets the required physical characteristics and is accompanied with the required documentation, and the HIPed form is qualified by the CRWMS.

Regulatory Classification of the HIPed Waste Form: HLW is defined by origin, not radionuclide concentration limit. Based on the NRC definition, HLW is highly radioactive material resulting from the reprocessing of spent nuclear fuel (SNF), including liquid waste produced directly in reprocessing and any solid material derived from such liquid waste that contains fission products in sufficient concentrations. Department of Energy (DOE) Order 5820.2A refers to HLW as waste in concentrations requiring permanent isolation. Thus, HLW definition relies on source term to define HLW and radionuclide concentration is implied within context but these limits are not specified or defined [ref: 1].

The calcine wastes to be HIPed were and will be produced from a variety of wastes including HLLW, SBW, and other radioactive wastes. These wastes have been stored in the Tank Farm at the ICPP. The Settlement Agreement between the State of Idaho and the DOE calls for the calcination of the remaining HLLW and the SBW wastes by June 30, 1998 and December 31, 2012, respectively. Direct HIPing of these calcines will result in a glass-ceramic HIP waste form. Under the Settlement Agreement between the State of Idaho and the DOE, the SBW calcine will be treated the same as HLW calcine. In addition, the waste at the ICPP has been determined to potentially contain RCRA listed wastes and characteristic hazardous constituents. Hence, all HIPed waste will be considered mixed HLW [ref: 1].

Estimates of the waste volumes and compositions for the different process methods being considered, including the HWO, are documented in a report authored by $C$. M. Barnes [ref: 4]. The developmental nature and process uncertainties present in all of the methods being considered contribute uncertainty to many of the estimates. The report clearly notes that very little analytical data are available for radionuclide, and RCRA-hazardous contaminants in the calcine. Data generated was based primarily on calcine compositions calculated from calcine feed compositions.

The proposed method of direct HIPing has been identified as candidate material for storage. A complete description of the waste form including volumes, density, hazardous constituents and concentrations, and estimated activity will be developed in the future [ref: 5 ].

Disposal Requirements: As previously discussed, the HIPed waste form will be considered as mixed HLW, and is subject to the requirements of both the AEA and the EPA RCRA. The State of Idaho adopted the Federal EPA RCRA regulations, and it has the authority to implement them in Idaho. The disposal of these wastes must be in accordance with the requirements established by the 
EPA, the DOE, the DOE Idaho Operations Office (DOE-ID), the Department of Transportation (DOT), the NRC, and other applicable state and local standards.

The hazardous components of the mixed HLW are subject to RCRA requirements and the radioactive contaminants are regulated under the AEA. The specific standards for radioactive materials management developed under AEA are administered through the DOE and the NRC regulations for disposal of HLW in a geologic repository.

The HIPed waste form will contain a number of radionuclides and RCRA hazardous chemicals [ref: 4,6]. RCRA hazardous constituents fall into two categories, characteristic hazardous wastes as identified in 40 CFR 261 subpart C, and the Lists of Hazardous Wastes as identified in 40 CFR 261 subpart D ("listed wastes"). The RCRA hazardous constituents include characteristic heavy metals, organic chemicals, and other inorganic. The majority of the hazardous chemicals are also RCRA "listed" wastes. In accordance with 40 CFR 268 Subpart C, characteristic hazardous wastes must be treated to a concentration based LDR standard which allows the treatment residues to be excluded from additional regulations as a hazardous waste.

RCRA has established treatment standards under the LDR, 40 CFR 268, for hazardous waste when the waste is land disposed. Hazardous waste codes and their treatment standards are identified in the table of "Treatment Standards for Hazardous Wastes" in 40 CFR 268.40. The treatment standards are expressed either as specified-technologies or as waste concentrations, and they are based on the performance of the BDAT for a waste code. For wastes covered by a technology standard, the wastes may be land disposed after being treated using the specified technology or an equivalent treatment technology approved by the EPA Administrator under the procedures set forth in 40 CRT 268.42(b), determination of equivalent treatment (DET). The HIP process is not an LDR specified technology. Therefore, a DET petition must be submitted to the EPA for using the alternative HIPing method in place of the EPA specified borosilicate glass technology (vitrification). The DET petition is also needed for the RCRA hazardous waste codes which require other LDR technology-specific treatments

It is anticipated that the EPA will approve a DET petition for using the HIP process in place of the EPA specified borosilicate glass technology. DOE believes that the glass-ceramic form meets the definition of high level vitrification (HLVIT) in 40 CFR 268.42 Table 1 [ref: 2]. DOE has also compared the definition and the waste acceptance criterion for the Defense Waste Processing Facility (DWPF) high level waste form to the data on glass-ceramic waste form. From the comparison, the glass-ceramic waste form meets the definition of borosilicate waste glass as well as the waste criterion applicable to such material [ref: 2]. Based on technical evaluations, and laboratory and pilot plant mockup tests, EPA has stated its belief that the glass-ceramic process is more efficient than the glass process for calcine waste forms. EPA has also determined that the glass-ceramic waste form that DOE is proposing to use is an acceptable technology to meet BDAT.

HLW Repository Waste Acceptance Criteria: The Nuclear Waste Policy Act (NWPA) of 1982 established a federal policy and the DOE responsibility for management and disposal of spent nuclear fuel and HLW of domestic origin in geologic repositories. It established the OCRWM to carry out the DOE responsibilities, subject to repository licensing by the NRC and the standards set by the EPA. The 1987 amendments to the Act. Nuclear Waste Policy Amendments Act (NWPAA) 
required, however, that the DOE characterizes only Yucca Mountain and terminate activities at other sites. Thus, the Yucca Mountain site in Nevada was designated for characterization as the candidate site for a HLW geologic repository. Criteria for acceptance and disposal of wastes at the repository have not been finalized.

Presently, the potential repository at the Yucca Mountain is not regulated under the RCRA as a hazardous waste, Subtitle $\mathrm{C}$ disposal facility. Therefore, it cannot accept any hazardous wastes [ref: 7]. Hence, the HIPed waste must be delisted prior to disposal at the repository. The delisting must be approved by both the waste shipping (Idaho) and waste receiving states (Nevada). ${ }_{\text {. }}$ The wastes can also be delisted prior to or after calcination if their concentrations at either point are below the LDR regulatory levels.

The DOE EM developed the EM-WAPS for the high level waste form generators as the basis for their waste acceptance programs. The specifications are based on the DOE criteria and EPA regulations. The EM-WAPS provide background information detailing the deliverables required by the waste acceptance process. They are the technical specifications the waste form generators are required to meet in order to ensure acceptance of their vitrified HLW into the Civilian Radioactive Waste Management System (CRWMS). The CRWMS is the composite of the sites, and all facilities, systems, equipment, materials, information, activities, and the personnel required to perform those activities, necessary to manage canistered waste form disposal.

The waste acceptance process requires demonstration of compliance with the EM-WAPS via four different documents, each prepared by the generators, reviewed and accepted by EM, and provided to OCRWM [ref: 1]. These four documents are: (1) the Waste Form Compliance Plan, (2) the Waste Form Qualification Report, (3) Production Records, and (4) Storage and Shipping Records.

Most of the WAPS information is useful by providing physical requirements and limitations associated with a glass log canister for storage. The same performance requirements will probably be required for the HIPed HLW. Based on review of the Repository WAPS, there is nothing that would prevent using the HWO system concept for waste processing, storage and shipping, provided:

- The waste is packaged according to the specifications listed in the WAPS

- The waste form meets the required physical characteristics and is accompanied with the required documentation

- The HIPed form is qualified by the CRWMS

A DOE comprehensive environmental assessment of several immobilization technologies for HLW led to the recommendation of borosilicate glass as the waste form that will be accepted into the repository [ref: 8]: However, provisions exist for qualifying other waste forms. This provision will have to be invoked to qualify the HIPed HLW form for repository disposal.

Regulatory Requirements for Handling, Packaging, Storing, and Transporting the HIPed HLW: Under DOE 0 460.1, Packaging and Transportation, - Each package and shipment of hazardous materials shall be prepared in compliance with Hazardous Materials Regulations of the DOT, Title 49 CFR Parts 106-199 and applicable tribal, State, and local regulations not otherwise 
preempted by DOT. Exclusions to DOE $\mathrm{O} 460.1$, include activities that are regulated through a license by the NRC or a State under an Agreement with the NRC, including activities certified by the NRC under section 1701 of the Atomic Energy Act.

At present, the NRC is not authorized by law to license DOE facilities for HLW processing and HLW short term storage. However, based on a recent DOE proposal, the NRC could take responsibilities for regulating the DOE nuclear facilities. If such were to happen, handling of HIPed HLW would be subject to NRC 10 CFR 72 licensing requirements during the receipt, packaging and storage as required for SNF, with the transportation cask subject to additional requirements of 10 CFR 71 for transportation. It is assumed that the Department of DOT Research and Special Programs Administration will approve shipment of special form HAW in NRC approved Type "B" shipping containers [ref: 9]. Overall the HAW would be controlled storage under 10 CFR 71, transported under 10 CFR 71, with packaging acceptable at the repository as defined in the EM-WAPS.

Currently, the NRC requires that canisters used to carry vitrified HLW to the potential Yucca Mountain repository with plutonium in excess of 20 Curies to be doubly contained (10 CFR 71.63). Recently, the NRC proposed to amend its regulations to remove the double containment requirements for canisters of vitrified HLW containing Plutonium [ref: 10]. The NRC believes solid forms of plutonium that are essentially nonrespirable should be exempted from the double containment requirement. It is reasonable to assume that the glass-ceramic HIP waste form would also be exempt from the double containment requirements. Even so, the HIP can in conjunction with the Savannah River shipping canister would in effect provide double containment

Note: All treatment processes will need to be permitted under Idaho's Hazardous Waste Management Act (HWMA) as well as DOE or NRC requirements.

Note: Delisting petitions are primarily granted by the state in which the waste is to be disposed. In addition, if the waste is to be shipped as a non-hazardous waste, then a delisting petition must be granted for each state and region through which the waste will travel on the way to disposal. This is an assumption that needs to be applied for transportation issues.

Regulatory Planning Path and Assumptions: The regulatory path forward should include early interactions with NRC, appropriate State of Idaho agencies, and DOE's OCRWM to obtain input on planned approaches and common issues being addressed for proposed repository RCRA materials, through development of detailed Licensing Plans and Strategies to facilitate licensing of storage and treatment facilities. This regulatory path forward is more clearly addressed in the Idaho Chemical Processing Plan High Activity Waste Treatment Project Regulatory Assessment Report, prepared by R. G. Morgan and S. E. Leroy, Duke Engineering Services, Inc. S. E. Leroy letter to V. L. Jacobson, dated April 25, 1997 [ref: 3].

QA Program: DOE-ID has directed the use of the applicable portions of DOE/RW-0333P, Quality Assurance Requirements and Description, as the baseline requirements document for developing and implementing SNF quality assurance programs. In addition, the EM-WAPS Rev. 01, Waste Acceptance Product Specifications for Vitrified High-Level Waste Forms, May 1995, also imposes a QA Program consistent with the QA requirements under the DOE/RW-0333P. This program requires 
the waste generator to establish, maintain, and execute a QA program that applies to the testing and analysis activities that demonstrate compliance with the EM-WAPS during waste form qualification, production, handling, storage, and preparation for shipment. The generator is also required to submit an action plan, signed by authorized personnel through EM to DOE-OCRWM for correction or disposition of nonconforming waste forms for verification and documented approval from the OCRWM. The action plan must identify and describe the nonconformance and any action to change and correct the existing nonconformance. 
References:

1. Banaee, J., Standard Criteria of Candidate Repositories and Environmental Regulations for the Treatment and Disposal of ICPP radioactive Mixed Wastes, INEEL/EXT-97-01147, December, 1997.

2. 57 Federal Register, No. 101, May 26, 1992, p. 22024.

3. Morgan, R. G., S. E. Leroy, Idaho Chemical Processing Plant High Activity Waste Treatment Project Regulatory Assessment Report, Duke Engineering Services, Inc., S. E. Leroy letter to B. L. Jacobson, dated April 25, 1997.

4. Barnes, C. M., Waste Characterization, EDF-01, August 21, 1997.

5. Banaee, J., Waste Form Classification for Fimal Disposal Options Feasibility Study, Draft, June, 1997.

6. Wichmann, T. L., N. Brooks, M. B. Heiser, Regulatory Analysis and Proposed Path Forward for the Idaho National Engineering Laboratory High-Level Waste Progam, Revision 0, DOE/ID10544,July, 1996.

7. Waste Acceptance System Requirements Document (WASRD), Rev. 2, Office of Civilian Radioactive Waste Management, DOE/RW-0351P, December 1996.

8. Environmental Assessment, Waste Form Selection for SRP High-Level Waste, DOE/EA0179,July 1982.

9. Regulatory Analysis and Proposed Path Forward for the Idaho National Engineering Laboratory High-Level Waste Program, DOE/ID-10544, October 1996.

10. 62 Federal Register, May 8, 1997. 
Project File Number 02BG0

Project/Task Waste Treatment Project Studies

Subtask $\quad$ HIP Waste Option (HWO) Study

\begin{tabular}{|c|c|}
\hline itle: & HWO Can Design and SRS Canister Loading Information \\
\hline irpose: & $\begin{array}{l}\text { The purpose of this Engineering Design File (EDF) is to propose a can design for th } \\
\text { The can is designed to meet weight and volume requirements that would allow three } \\
\text { cans to be loaded in a Savannah River canister and deposited in a geologic repositor }\end{array}$ \\
\hline
\end{tabular}

Summary: A corrugated-wall (also known as " bellows") can is the selected design for the HWO. The can will deform in the axial direction while resisting deformation in the radial direction. This will help ensure that the post-HIP cans fit into the Savannah River canister. Future experimentation will determine the number and size of corrugations in the can wall. The can's wall will be made of standard 15 gauge stainless steel. The ends of the HIP can will be made from $1 / 2$ inch stainless steel plate. The top will have a 5 inch diameter hole that will be used in conjunction with a bag system to fill the cans with calcine. A stainless steel plug will be friction welded to the top of each can after filling operations. The lid will incorporate lifting flanges and a vent tube. The vent tube will be used to devolatilize and evacuate the can prior to HIPing operations.

The weight of a Savannah River canister loaded with 3 HIPed cans could theoretically range from $2742.2 \mathrm{~kg}(6046.5 \mathrm{lb})$ for a $94 \%$ filled Savannah River canister to approximately $2461 \mathrm{~kg}$ (5426 lb) for an $80 \%$ filled Savannah River canister. The geologic repository Waste Acceptance Criteria (WAC) presently requires that canisters be at least $80 \%$ filled and weigh less than 2500 $\mathrm{kg}(5512 \mathrm{lb})$ for acceptance. A Savannah River canister filled with $2500 \mathrm{~kg}(5512.5 \mathrm{lb})$ of HIPed waste will fill approximately $82 \%$ of a Savannah River canister's volume

The $82 \%$ limit exceeds the $80 \%$ fill volume height by only approximately 2 inches. This leaves very little margin for error. One of two things should be considered: 1) the repository WAC should be reviewed and modified to accept a higher weight limit or reduce the volumetric fill requirement for this waste form, 2) the HIP waste product (HWP) density should be reduced from the $3.2 \mathrm{~g} / \mathrm{cm}^{3}$. Modifying the process design to slightly reduce the density of the final HWP would allow for an increase in the fill volume height while maintaining near maximum weight capacity. This modification would provide an increased margin that would avoid possible higher rejection rates. Neither of these recommendations should be implemented as part of this scoping study. The process data is far too preliminary to worry about changes at this point in time. This is merely a heads up for future work.

Distribution: N. E. Russell MS 3765, K. L. Williams MS 3765

\begin{tabular}{|c|c|c|c|c|c|}
\hline $\begin{array}{l}\text { Author } \\
\text { P. M. Rice } \\
\text { D. E. Stacey }\end{array}$ & $\begin{array}{l}\text { Dept. } \\
4130\end{array}$ & $\begin{array}{l}\text { Reviewed } \\
\text { N. E. Ryssell } \\
\text { U.E Kussel }\end{array}$ & $\begin{array}{l}\text { Date } \\
02 / 03 / 98\end{array}$ & 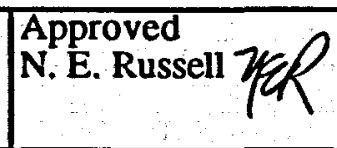 & $\begin{array}{l}\text { Date } \\
02 / 03 / 98\end{array}$ \\
\hline & & & & & \\
\hline
\end{tabular}


1. Introduction: This EDF addresses the HIP can that will be utilized as part of the HWO. The proposed HWO of calcined waste is a result of research that has been performed at the Idaho National Environmental Engineering Laboratory (INEEL), the ICPP, and Argonne National Laboratory-West (ANL-W) for a number of years. The process will convert high level nuclear calcined waste to an impervious, non-leaching, ceramic-glass waste form. The HIPed waste will then be loaded into Savannah River shipping canisters for final disposition at a geologic repository.

1.1 Description of HIPing Process: The HWO calls for HIPing calcined waste using the following process [ref 1]: All remaining high level liquid waste (HLLW), Sodium-bearing waste (SBW), and other radioactive waste currently stored in the Tank Farm at the Idaho Chemical Processing Plant (ICPP) is calcined. The calcine is temporarily stored in binsets until it can be HIPed. Calcine is taken from storage and blended with dry, organic-free, sized, soil and titanium powder. The blended HIPing mixture is placed into thin-walled stainless steel HIPing cans designed to deform down to a size and shape which will allow $+80 \%$ utilization of storage volume in a standard $2 \mathrm{ft}$ diameter x $10 \mathrm{ft}$ long storage/disposal canister. A closure cap is welded to the tops of each can which incorporates a venting tube. The latter is capable of being sealed by a standard crimp-and-weld operation. The cans are placed in a devolatilizing fixture in which the vent tubes are connected to a vacuum source and the centerline temperature of the can is raised to $625^{\circ} \mathrm{C}$ for approximately 24 hours. This step removes remaining undesired volatiles from the HIPing mixture (primarily residual $\mathrm{H}_{2} \mathrm{O}, \mathrm{CO}_{\mathrm{x}}, \mathrm{Hg}$, and $\mathrm{HO}_{\mathrm{x}}$ ), but leaves radionuclides [including $\mathrm{Cs}-137$ ] bound in the HIPing mixture.

After devolatilization, the vent tube on the can is crimped and welded closed. The can is removed from the devolatilization fixture and placed in a non-sealing outer can for potential contamination control prior to placement in the pressure vessel. The outer can and the HIPing can are placed together inside a HIPing machine. The HIPing machine is sealed shut, evacuated, and pressurized with argon gas. The internal heater of the HIPing machine is activated and the cans are heated to $1050^{\circ} \mathrm{C}$ and further pressurized (by heating only) to $20,000 \mathrm{psi}$. The high temperature causes the can wall and its contents to creep. The high pressure forces the can to collapse on itself yielding the desired impervious, dense, non-leaching, ceramic-glass waste form. The can volume is reduced approximately by one half of its pre-HIPed volume.

HIPing is considered complete once the centerline temperatures of the cans have reached $1050^{\circ} \mathrm{C}$ and remained at that value for 4 hours. The cans are removed from the HIPing machine and moved to a cooling area. Following cooling to near-ambient temperature, the cans are moved to a decontamination area. The cans are decontaminated and non-destructively tested to verify solidification of all the mixture. Cans passing non-destructive testing are packaged in Savannah River shipping canisters and moved to interim storage prior to being sent for final geologic disposal. Three HIP cans will be placed inside one Savannah River shipping canister. Cans not passing nondestructive testing are transported to a recycle cell where they are sized and ground. The sized material is returned to the calcine storage tanks and mixed with fresh calcine. The mixture is then loaded into HIP cans and processed.

2. Geologic Repository Canister Requirements: At present, the Yucca Mountain in Nevada is the only candidate site that has been designated for characterization as a HLW geologic repository. The repository's Waste Acceptance Criteria (WAC) requires that the waste form canister, the canister label, and any secondary canister must be fabricated from austenitic stainless steel. The overall length of the canister shall be $3.000 \mathrm{~m}(+0.005 \mathrm{~m},-0.020 \mathrm{~m})$, including the neck and lifting flange. The outer diameter of the unfilled canister shall be $61.0 \mathrm{~cm}(+1.5 \mathrm{~cm},-1.0 \mathrm{~cm})$. There are two containers that meet the geological repository's physical requirements: 1) the Savannah River 
Site HLW canister and 2) the West Valley Demonstration Project HLW canister. The Savanna River canister has been selected as the baseline for the design of the HWO.

The Yucca Mountain repository's Waste Acceptance Product Specification (WAPS) requires that the HLW canister be filled to a height equivalent to at least $80 \%$ of the volume of the empty canister. In addition, the weight of the canistered waste form shall not exceed $2,500 \mathrm{~kg}$ (5512.5 lb) [ref 2].

The NRC requires that canisters used to carry HLW to the potential Yucca Mountain repository with plutonium in excess of 20 Curies be doubly contained (10 CFR 71.63). Also, the WAPS refers to a "secondary canister" in materials discussion. The Waste Acceptance System Requirements Document (WASRD) states “ ... sealed inside austenitic stainless steel canister(s) ..." when discussing what the product is placed in. The use of a HIP'd drum/can placed inside a HLW canister appears to fit within the scope of the WAPS and WAS-RD text.

\section{HIP Can Design:}

3.1 Can Geometry: One of the challenges associated with HIPing calcine waste, is to design a pre-HIP can that will produce the desired post-HIP can configuration. The pre-HIP can undergoes significant deformation during the HIPing process. Studies indicate that HIPing of calcine waste will result in a volume reduction of 50-60 percent [ref 3]. The HWO calls for three HIPed calcine waste cans to be repackaged into one Savannah River canister. The HIPed cans are required to occupy a minimum of 80 percent of the canister's volume. The most effective way to meet this requirement is to use post-HIPed cans that have deformed to straight-walled cylinders. The post-HIPed cans will also need to consistently have a relatively small diametric tolerance (plus or minus 0.25 inch). This will allow the HIPed cans to utilize the maximum volume possible and still fit into the Savannah River canisters.

Different HIP can designs have been researched and tested in recent years at the INEEL, the ICPP, and ANL-W, in an effort to design a pre-HIP can that would result in a post-HIP straight-walled cylinder. In addition, ANL-W has jointly conducted experiments with the Australian Nuclear Science and Technology Organization (ANSTO) during the past two years under a Cooperative Research and Development Agreement (CRADA). The basic designs that have been tested are straight-walled cans, wine barrel shaped cans, bellows cans, and a double wine barrel shaped can designed by the ANSTO.

Experiments using straight-walled pre-HIPed cans have resulted in post-HIPed cans with concave walls and ends (see figure 1). This is not an optimal configuration for waste storage or ultimate disposition because of the wasted space. Wine barrel shaped pre-HIPed cans have been designed that resulted in nearly straight-walled post-HIPed cans (see figure 2). However, since some of the can's deformation is in the radial direction, the post-HIPed cans' diameters vary. The wine barrel can design is better than the straight-walled can, but may still produce more unacceptable post-HIPed cans than other designs. An unacceptable can is one that will not meet the physical requirements of the Savannah River canister. The corrugated-wall or bellows can has resulted in the most controllable post-HIP can configuration. Corrugations in the can wall allow the can to easily deform in the axial direction, while resisting deformation in the radial direction (see figure 3 ). For this reason, the bellows can has been selected for the HWO scoping study. The number and size of corrugations in the can wall will determine the actual configuration of the post-HIPed can. Various experiments will need to be conducted to determine these two parameters before selecting the final design of the HIP can. 
ANL-W and the ANSTO are currently conducting experiments to design the best HIP can design. A double wine barrel configuration is looking very promising. This design should be investigated further if the HWO progresses to the conceptual design stage.

3.2 Can Lid Design: The HIP can will be fabricated with a five inch diameter hole centered in its top. This hole will be used in conjunction with a bag fill system to fill the cans with calcine [ref 4]. A lid will be friction welded to the top of each can after filling operations. The lid will include a one inch vent tube and quick disconnect that will be used to devolatilize and evacuate the HIP can prior to actual HIPing operations. Previous work has been performed for the HIP can lid design [ref 5]. Figure 4 shows a conceptual design of the lid. The lid incorporates flanges that will allow the can to be lifted and transported by an overhead crane and a grappling device.

3.3 Caglculation of HIP Can Weight: The Savannah River canister has a total internal volume of $0.74 \mathrm{~m}^{3}$. However, the neck area of the canister is not usable for storage of HIPed cans. The volume of the the Savannah River canister that is usable for HIPed cans is $0.71 \mathrm{~m}^{3}\left(25.06 \mathrm{ft}^{3}\right)$ based on a right circular cylinder of $59.055 \mathrm{~cm}(23.25 \mathrm{in}$.) diameter and $259.08 \mathrm{~cm}(102 \mathrm{in}$.) length. The maximum usable volume of the Savannah River canister for HWP is therefore $96 \%$ of the total volume.

Three HIP cans will be loaded into one Savannah River canister. The option of placing three HIP cans per one Savannah River canister was selected, because it provides a larger margin for HIP cans to deform and still fit into the Savannah River canister than a single HIP can would. It also reduces the weight of each HIP canister by one third.

The post-HIP'd can is assumed to be a right circular cylinder $58.42 \mathrm{~cm}$ (23 in.) maximum outside diameter (for insertion clearance) by $86.36 \mathrm{~cm}$ ( 34 in.) maximum outside height. Accounting for the thickness of the material (nominally $0.0673 \mathrm{in}$.), the maximum inside diameter is $58.09 \mathrm{~cm}(22.87$ in.) with a maximum inside height of $86 \mathrm{~cm}(33.86 \mathrm{in}$.). The maximum postulated internal volume of a HWP drum is $0.228 \mathrm{~m}^{3}\left(8.05 \mathrm{ft}^{3}\right)$. The maximum postulated external volume of a HWP drum is $0.232 \mathrm{~m}^{3}\left(8.175 \mathrm{ft}^{3}\right)$. Three of these maximum volume cylinders can be placed into one Savannah River canister. The maximum postulated occupied volume of the Savannah River canister is therefore $0.695 \mathrm{~m}^{3}\left(24.53 \mathrm{ft}^{3}\right)$ or $94 \%$ of maximum capacity. In practice however the post-HIP'd can will in general be somewhat below its maximum postulated volume due to can deformation. A significant assumption is that all materials placed inside the $61 \mathrm{~cm}$ by $3 \mathrm{~m}$ (Savannah River) canister are considered when determining canister volume filled.

The pre-HIP'd waste can is assumed to be a right circular cylinder (the actual shape will depend on the number of corrugations in the can wall) approximately $73.66 \mathrm{~cm}(23 \mathrm{in}$.) maximum outside diameter by $162.56 \mathrm{~cm}$ (64 in.) maximum outside height. The HIP'ing can is assumed to be made of 15 gauge ( 0.0673 in. thick) SST-304L or similar material. The estimated pre-HIP'd weight of the waste drum is $33.3 \mathrm{~kg}\left(73.5 \mathrm{lb}\right.$ ) (based on a total of $0.1468 \mathrm{ft}^{3}$ of SST). The post-HIP'd weight of the waste drum will not change.

HWP density numbers were obtained from Barnes [ref 3]. Barnes estimates that the HIPed Waste Product (HWP) will have a density of aproximately $3.2 \mathrm{~g} / \mathrm{cm}^{3}$.

The total weight for a Savannah River canister loaded with three HIPed cans is calculated as follows:

Savannah River canister +3 (Empty HIP'ing can $)+3($ HWP waste $)=$ Total Weight 
So for the $94 \%$ fill volume case;

$$
453.5 \mathrm{~kg}+3(33.3 \mathrm{~kg})+3\left(0.228 \mathrm{~m}^{3} \times 3200 \mathrm{~kg} / \mathrm{m}^{3}\right)=2742.2 \mathrm{~kg}(6046.5 \mathrm{lb})
$$

The conclusion here is that the $94 \%$ fill volume case (maximum postulated) exceeds the maximum weight limits imposed by the repository acceptance criteria by $242.2 \mathrm{~kg}(534 \mathrm{lb})$. Obviously a lower fill volume must be used to reduce the weight while maintaining the $80 \%$ fill volume height.

Taylor [ref 1] has proposed an $82 \%$ fill volume and subsequently sized the post-HIP'd can to accommodate this reduction. His conclusion is that the loaded gross weight of the Savannah River canister is $2501.3 \mathrm{~kg}(5515.5 \mathrm{lb})$. At the $82 \%$ fill volume height this exceeds the maximum weight limit by $1.3 \mathrm{~kg}$ ( $3 \mathrm{lb}$ ); which for this exercise is close enough. However the $82 \%$ while at the maximum weight limit exceeds the $80 \%$ fill volume height by only approximately 2 inches. This leaves very little margin for error. However, these calculations do not take into account any void space that may occur due to can deformation. Additional voids will occur due to lifting flanges, lid configurations, and flanges on the bottom of the can. If these voids count as "filled volume", then there will be no problem in meeting the 80 percent fill volume requirement while remaining below the $2500 \mathrm{~kg}$ weight restriction. If the voids do not count as "filled volume", then a recommendation to modify the process design to slightly reduce the density of the final HWP would allow for an increase in the fill volume height while maintaining near maximum weight capacity. This would provide an increased margin that should avoid possible higher rejection rates.

The following calculations are to verify (corroborate) Taylor's $82 \%$ calculation:

The post-HIP'd waste drum is assumed to be a right circular cylinder $55.24 \mathrm{~cm}$ (21.75 in.) maximum outside diameter by $85.52 \mathrm{~cm}$ ( $33.67 \mathrm{in}$.) maximum outside height. Accounting for the thickness of the material (nominally $0.0673 \mathrm{in}$.), the maximum inside diameter is $54.91 \mathrm{~cm}(21.62 \mathrm{in}$.) with a maximum inside height of $85.17 \mathrm{~cm}$ (33.53 in.). (Taylor used 0.065 for the thickness. This calculation assumed a standard 15 gauge SST wall of 0.0673 in). The internal volume this HWP drum is $0.202 \mathrm{~m}^{3}\left(7.12 \mathrm{ft}^{3}\right)$. The $82 \%$ fill height occupied volume of the Savannah River canister is therefore $0.605 \mathrm{~m}^{3}\left(21.37 \mathrm{ft}^{3}\right)$.

So for the $82 \%$ fill volume case;

$453.5 \mathrm{~kg}+3(33.3 \mathrm{~kg})+3\left(0.202 \mathrm{~m}^{3} \times 3200 \mathrm{~kg} / \mathrm{m}^{3}\right)=2492.6 \mathrm{~kg}(5496.2 \mathrm{lb})$

The difference between the $2501.3 \mathrm{~kg}(5515.5 \mathrm{lb})$ Taylor calculation and $2492.6 \mathrm{~kg}(5496.2 \mathrm{lb})$ calculation herein is $8.7 \mathrm{~kg}(19.3 \mathrm{lb})$. Taylor used $37.4 \mathrm{~kg}(82.47 \mathrm{lb})$ as the initial mass of a HIP'ing can. These calculations used $33.3 \mathrm{~kg}(73.5 \mathrm{lb})$ as the initial mass of HIP'ing can. The rest is in the noise and mostly due to rounding errors. This confirms that the $82 \%$ fill level weight is at the maximum allowable limit. 
The following table summarizes the above calculations. The $82 \%$ weights shown are from Taylor.

\begin{tabular}{llllll}
\hline \% Fill & $\begin{array}{l}\text { Fill Volume } \\
\left(\mathrm{m}^{3}\right)\end{array}$ & $\begin{array}{l}\text { HWP Density } \\
\left(\mathrm{g} / \mathrm{cm}^{3}\right)\end{array}$ & $\begin{array}{l}\text { HWP Gross } \\
\text { Weight *(kg) }\end{array}$ & $\begin{array}{l}\text { Filled Canister } \\
\text { Weight }(\mathrm{kg})\end{array}$ & $\begin{array}{l}\text { Filled Canister } \\
\text { Weight (lb) }\end{array}$ \\
\hline $80 * * *$ & 0.590 & 3.2 & 2007 & 2461 & 5426 \\
82 & 0.605 & 3.2 & 2047.8 & 2501.3 & 5515.5 \\
94 & 0.695 & 3.2 & 2288.7 & $2742.2 * *$ & $6046.5 * *$ \\
\hline
\end{tabular}

* Includes weight of HIP'ing can

** Exceeds the maximum allowable weight limit of the repository

*** Extrapolated from the $82 \%$ and $94 \%$ calculations

4. Conclusions: A corrugated-wall HIP can design is the selected design for the HWO. The can will deform in the axial direction while resisting deformation in the radial direction. This will help ensure that the post-HIP cans fit into the Savannah River canister. Further experimentation will determine the number and size of corrugations in the can wall. The can's wall will be made of standard 15 gauge stainless steel. The top of the HIP can will have a five inch diameter hole that will be used in conjunction with a bag fill system to fill the cans with calcine. A lid will be friction welded to the top of each can after filling operations. The lid will incorporate lifting flanges and a vent tube. The vent tube will be used to devolatilize and evacuate the can.

Based on the data in this EDF, the weight of a filled canister could theoretically range from $\mathbf{2 7 4 2 . 2}$ $\mathrm{kg}(6046.5 \mathrm{lb})$ for a $94 \%$ filled Savannah River canister to approximately $2461 \mathrm{~kg}(5426 \mathrm{lb})$ for an 80\% filled Savannah River canister. The $82 \%$ filled Savannah River canister just meets the maximum weight limits at approximately $2500 \mathrm{~kg}(5512.5 \mathrm{lb})$. The maximum weight allowed in the repository WAC [ref 2] is $2500 \mathrm{~kg}(5512 \mathrm{lb})$.

For the HWP the maximum allowable weight limit is at the $82 \%$ fill volume. However the $82 \%$ limit exceeds the $80 \%$ fill volume height by only approximately 2 inches in the Savannah River canister. This leaves very little margin for error. One of two things should be considered: 1) the repository WAC should be reviewed and modified to accept a higher weight limit or reduce the volumetric fill requirement for this waste form, 2) the HWP density should be reduced from the $3.2 \mathrm{~g} / \mathrm{cm}^{3}$.

Modifying the process design to slightly reduce the density of the final HWP would allow for an increase in the fill volume height while maintaining near maximum weight capacity. This would provide an increased margin that should avoid possible higher rejection rates. Neither of these recommendations should be implemented as part of this scoping study. The process data is far too preliminary to worry about changes at this point in time. This is merely a heads up for future work on this process.

Future Work: The following is a list of work that will need done if the HWO proceeds to the design phase.

- A HIP can will need to be designed and fabricated for testing. The ANL-W should be consulted in the can's design. Their current experiments with a double barrel can design could be very helpful in selecting the best can design.

- Full scale experiments should be conducted to ensure that the HIP can deforms properly and is able to be loaded into a Savannah River canister. The can should also be tested to verify that the 
design will satisfy the geologic repository's WAC requirements regarding weight and volume limits.

- If it is not possible to design a can that will meet these requirements, then 1) the repository WAC should be reviewed and modified to accept a higher weight limit or reduce the volumetric fill requirement for this waste form, or 2) the HIP process should be modified to reduce the HWP density. Reducing the density of the final HWP slightly would allow for an increase in the fill volume height while maintaining near maximum weight capacity.

\section{References:}

1. Taylor, D., HWO Scoping Study, EDF-HWO-007, January. 1998

2. EM-WAPS Rev. 01, Waste Acceptance Product Specifications for Vitrified High-Level Waste Forms, May, 1995.

3. Barnes, C. M., D., Rev 1, Estimates of Feed and Waste Volumes, Compositions and Properties, EDF-FDO-001, October 29, 1997.

4. Pinto, A. P., HIP Can Filling, EDF-HWO-004, December, 1997.

5. S. M. Berry, T. R. Reed, R. C. Swainston, Friction Welding Method of Hot Isostatic Press Can Closure For The ICPP Calcine Immobilization Program, WINCO-1160, September, 1993. 


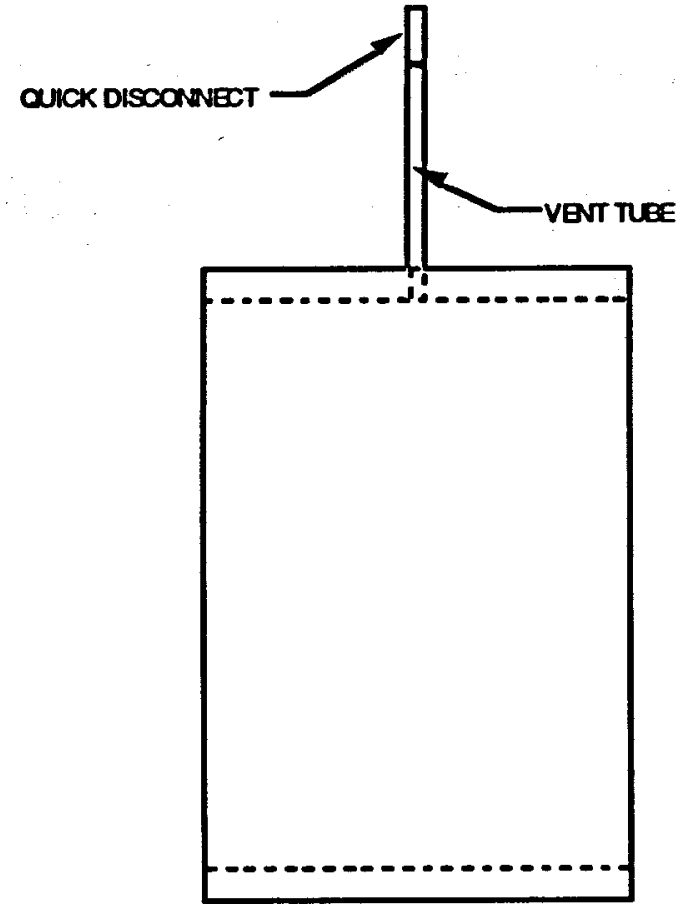

PRE-HIP CAN

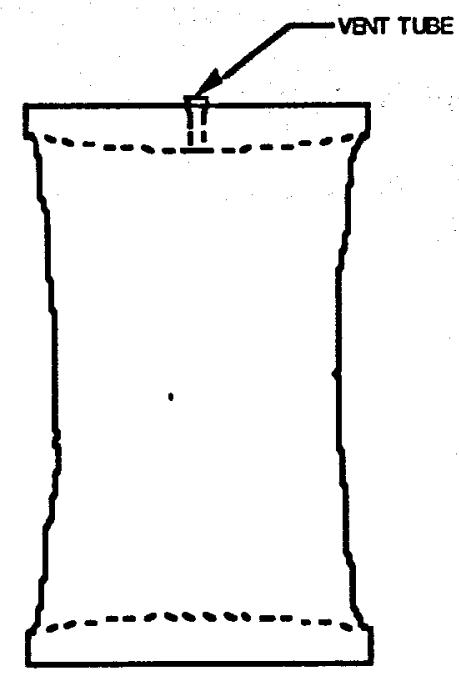

POST-HIP

Figure 1. Straight-Wall HIP Can Design 


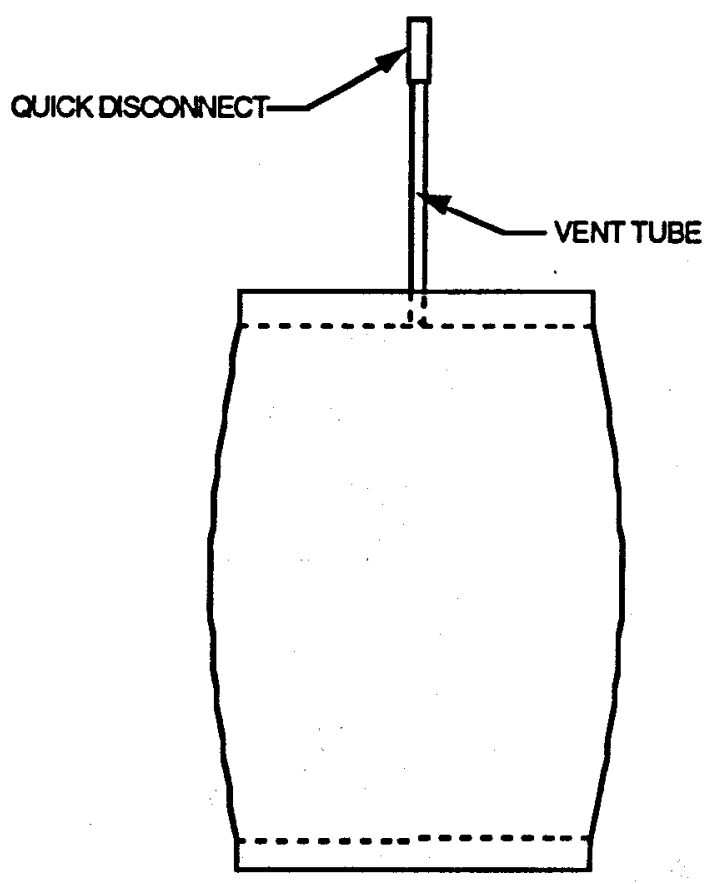

PRE-HIP CAN

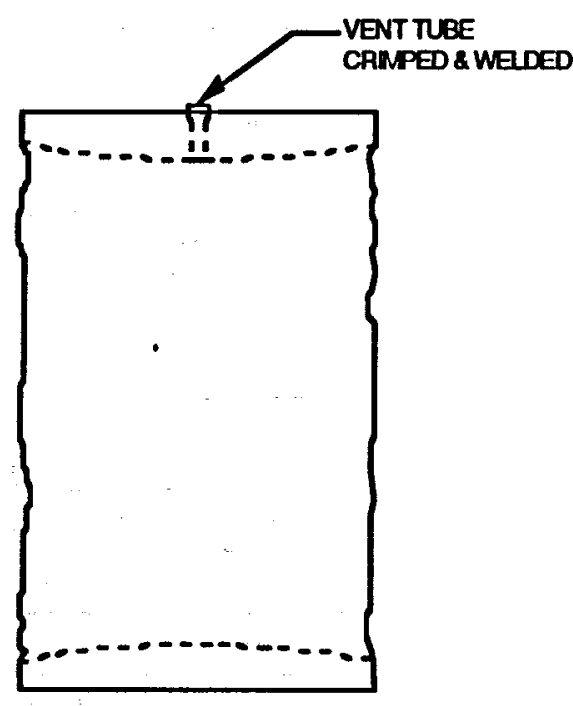

POST-HIP CAN

Figure 2. Wine Barrel Can Design 


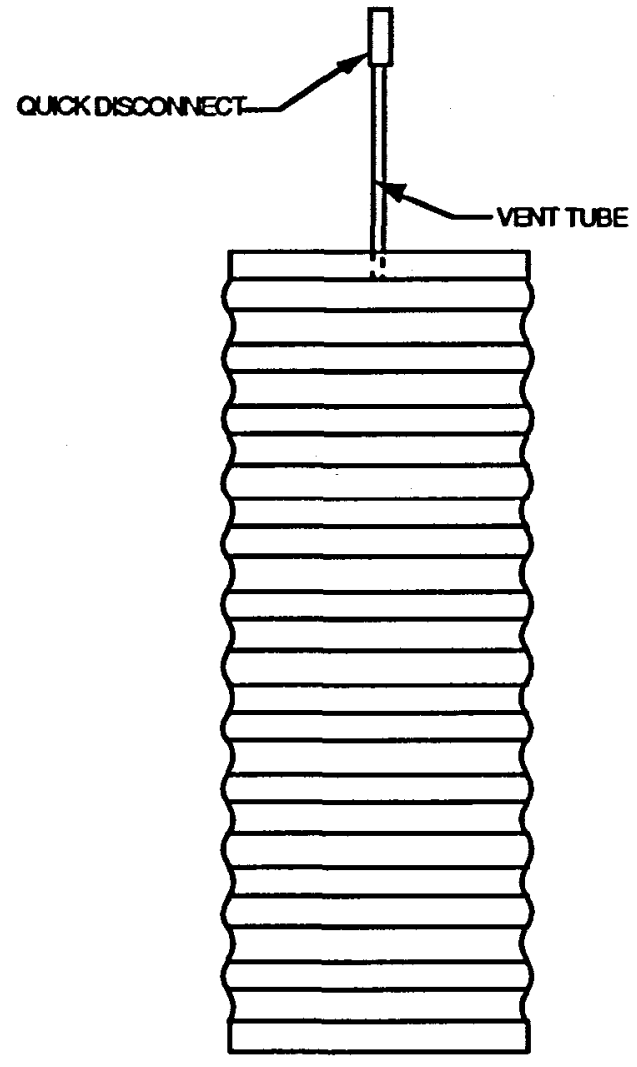

PREHIP CAN

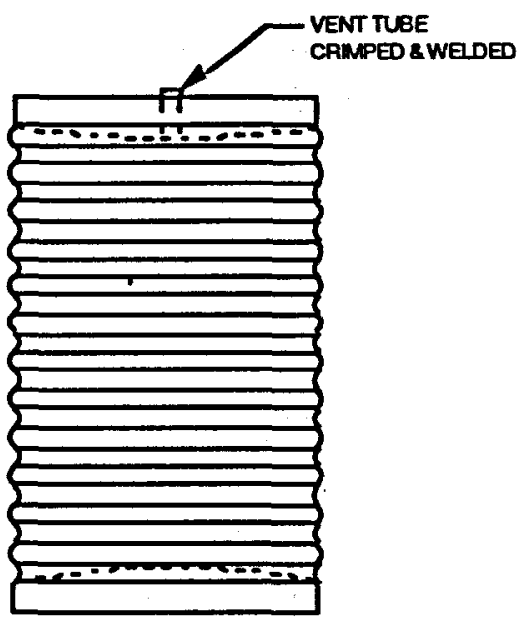

POST-HIP CAN

Figure 3. Bellows Can Design 

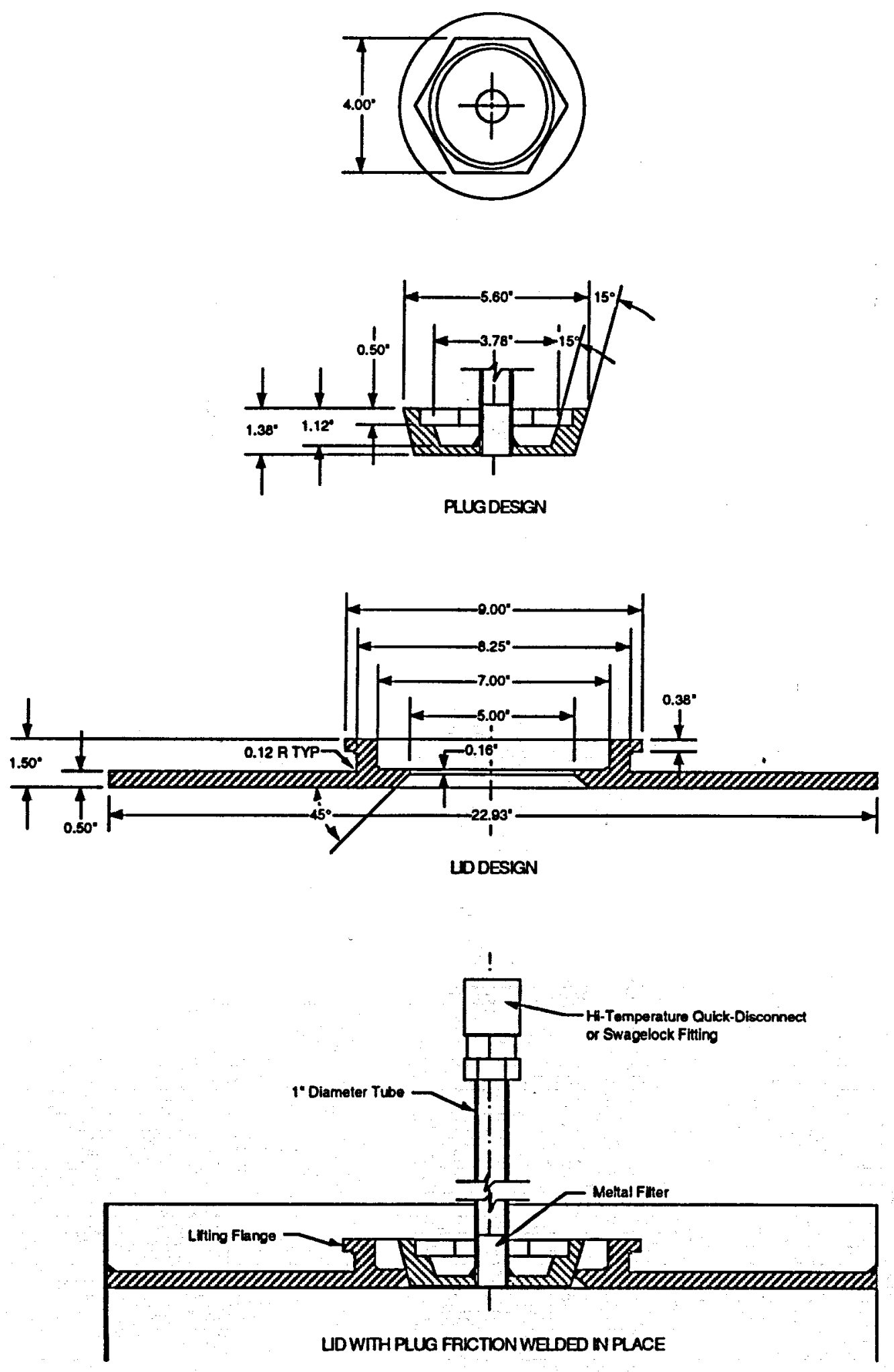

Figure 4. Proposed HIP Can Lid 
Project File Number 02BGO

Project/Task Waste Treatment Project Feasibility Studies

Subtask HWO Scoping Study

\section{Title: Hot Isostatic Pressing (HIP) Equipment}

Purpose: This study was conducted to identify the equipment items that would be required to perform the HIP operation in the HWO Scoping Study. The information obtained in this study will be used to design the portion of the facility where the HIP operation will be performed and HIP equipment located, and to obtain a cost estimate for the HIP portion of the HWO.

Summary: The HIP equipment needed to perform the HIP of ICPP high level nuclear waste calcine has been described. Approximate costs for each equipment item, power and foot print requirements have been provided. The assumptions upon which this study was based have been outlined.

Distribution (complete package): N.E. Russell MS-3765, K.L. Williams MS-3765

Distribution (summary package only): J.J. McCarthy MS-3625, B.R. Helm MS-3765

\begin{tabular}{|c|c|c|c|c|c|}
\hline $\begin{array}{l}\text { Author } \\
\text { A.P. Pinto }\end{array}$ & $\begin{array}{l}\text { Dept. } \\
4170\end{array}$ & $\begin{array}{l}\text { Reviewed } \\
\text { D.D. Taylor }\end{array}$ & $\begin{array}{l}\text { Date } \\
2 / 4 / 98\end{array}$ & $\begin{array}{l}\text { Approved } \\
\text { N.E. Russell }\end{array}$ & Date \\
\hline APPunc & & & & $\begin{array}{l}\text { LMITCO } \\
\text { Approval }\end{array}$ & Date \\
\hline
\end{tabular}




\section{Introduction}

Hot Isostatic Pressing (HIP) has been researched at the INEEL for the conversion of high level nuclear waste which is currently in the form of a dry granular powder (calcine) to an impervious, non-leaching glass ceramic waste form. The first step in the HIP process consists of blending the calcine with dry, organic free, sized, soil and titanium powder. The blended mixture will be placed in a suitable thin walled stainless steel can and heated to $650^{\circ} \mathrm{C}$ to drive off volatile components. The can will then be evacuated, to remove the air present inside the can, and sealed shut. The final step in the HIP process consists of heating the calcine and additive filled, air evacuated, and sealed can and its contents to $1050^{\circ} \mathrm{C}$ in a pressure vessel. The HIP can will be placed in a non-sealing outer can for contamination control in the event of a HIP can leak during the HIP process prior to being placed in the HIP machine pressure vessel. The pressure vessel will initially be evacuated to remove air and then pressurized by argon gas prior to being heated to $1050^{\circ} \mathrm{C}$. The final pressure of the argon after the final temperature is reached will be 20,000 psi. The high temperature causes the can wall and its contents to creep and the pressure forces the can to collapse on itself yielding the desired impervious, dense, nonleaching waste form. The can volume is reduced approximately by one half of its pre-HIP volume. The final waste form is expected to meet the RCRA land disposal requirements for the hazardous components present in the calcine. Three HIP cans will be placed inside a Savannah River shipping canister for interim storage on-site prior to being sent for final geologic disposal.

\section{Background Information and Assumptions}

\subsection{Background Information}

Research on HIP of nuclear waste has been performed at the INEEL at the ICPP and ANL-W. The research at the ICPP was performed on 4-inch diameter cans and the results have been extrapolated to the 23.5-in diameter 33.66-in long post HIP can. The research indicates that in order to achieve a post-HIP right circular cylinder, the pre-HIP shape would have to be in the form a whisky barrel with a bulged middle and tapered the ends. The shrinkage in the axial and radial dimensions is expected to be $15.27 \%$ and $19.12 \%$ respectively. Another approach is to use a corrugated can. The corrugations encourage the deformation to occur in the axial direction and resist dimensional change in the radial direction. Reductions in length of approximately $50 \%$ were noted at ANL-W and the ICPP. In the event the HIP waste option is selected, further research on full sized cans is recommended in order to determine the optimum pre-HIP can dimensions. This study has been baselined on a corrugated can with a linear dimensional contraction of $50 \%$ with essentially no radial dimension change. 


\subsection{Assumptions}

The facility will be designed for a production rate of 9 cans per day with ten hours of operation per day and four days of operation per week. Hence, the production rate per week will be 36 cans. Because 9 large cans per day is a fairly high processing rate for a HIP facility, the possibility of using a large HIP machine which could HIP several cans at a time was investigated. The maximum size HIP machine for use with a pressure of 20,000 psi that can be built with current state of the art technology and steel resources is 65 -inches in diameter and 145-inches high. A machine this large will be barely capable of processing four corrugated cans at a time (two cans side by side stacked two layers high). In the case of whisky barrel shaped cans that collapse in both the radial and axial directions, it is believed that 65 -inches may not be large enough to accommodate two cans placed side by side. With multiple cans placed at the same level, the vessel inside space efficiency will not be optimum. Also, the cost of the machine increases exponentially as the diameter is increased beyond a certain point.

In order to meet the aggressive schedule for completing this study, optimization with regard to HIP machine size and the number of cans processed at a time per machine, was abandoned and a HIP machine size capable of processing one corrugated can at a time was selected. In order to meet the processing rate of 9 cans per day with some allowance for downtime, 12 HIP machines in 4 trains with 3 machines per train was selected as the number of HIP machines for which the facility would be designed. Three trains would be in operation at any given time with one train on stand by. Additionally, with the 4 day per week 10 hours per day operation, it would be impossible to stagger the operation of the HIP machines and bring them into a state not requiring supervision prior to shutdown over the week end. Thus, each HIP machine would be performing the same operation as the other HIP machine at any given time. This would require the maximum number of each category of auxiliary equipment such as the power supplies, compressors, vacuum pumps, fresh argon gas tanks, reclaimed argon gas tanks, heat exchangers, and cooling pumps. The assumptions selected for the study will therefore result in a very conservative design and cost estimate.

\section{Equipment Description}

\subsection{Pressure Vessel}

The pressure vessel is the component of the HIP machine which contain the part to be HIP. This vessel contains a large amount of energy when the argon gas inside is at high pressure and temperature. Proper design with fatigue analysis and periodic inspections is a prerequisite. The pressure vessel is usually designed for several thousand cycles of operation. Depending upon the pressure, the cost of the vessel increases if the number of cycles specified is increased beyond a certain point. For 20,000 psi operation and $1050^{\circ} \mathrm{C}$, a pressure vessel life of 15,000 cycles would be 
normal and 20,000 cycles could be obtained with slightly additional cost. Using 15,000 cycles as a base number 12 pressure vessels would process 180,000 cans during their initial vessel life time.

Either full thread or 1/8 turn breach lock vessels could be manufactured to ASME code Division II or Division III. Government facilities are however exempt and would not require any ASME code. The cost difference between these two types of vessels is not very significant and operation with both types of vessels could be fully automated. Hence, the vessel selection is based largely on choice. The vessel could also be designed with a yoke and threadless closure. However, these vessels are generally more expensive, larger and heavier than the one piece unit and the cell would likewise require larger dimensions and weight capacity. For the purpose of this study, the design and costs have been based on a one piece unit. However, the costs have been estimated high as cost savings from buying multiple units and the various components as a system have generally been ignored.

A pressure vessel having inside dimensions of 38-inches in diameter and 66-inches high was selected for the HIP operation. The pressure vessel will have a cooling jacket in which a cooling medium will be circulated by a pump. There will be 12 pressure vessels installed one in each of the 12 HIP machines. One or two additional pressure vessels may be maintained as spares. The cost of the 38" diameter $66^{\prime \prime}$ high pressure vessel will be approximately $\$ 1.2$ million.

\subsection{Furnace}

Furnaces are electrically fired and have graphite, molybdenum, platinum, or Kanthal heating elements depending on the temperature range and application. A Kanthal furnace has been selected for the current application. The furnace is installed inside the pressure vessel and may be removed for maintenance, cleaning, or decontamination. Each furnace could have several heating zones to provide good thermal uniformity. Due to the $10 \mathrm{hr}$ per day 4 day per week operating schedule, power will not be capable of being shared by the furnaces. There will be 12 furnaces and each would be provided with $800 \mathrm{KW}$ of installed power. At $1050^{\circ} \mathrm{C}$ Kanthal should provide a very good life with low chance of failure. 2 to 4 spare furnaces may be kept on hand for replacement of burned out furnaces. The cost of a furnace that fits a $38^{\prime \prime}$ diameter vessel $66^{\prime \prime}$ high will be approximately $\$ 500,000$.

\subsection{Vacuum System}

The vacuum system is used to pump the pressure vessel down after the part to be HIP is placed inside. The air inside the pressure vessel is replaced with argon, an inert gas. An inert gas is used in order to prolong furnace and pressure vessel life. The vacuum system will consist of a Stokes rotary piston type vacuum pump assisted by a Roots blower to increase pumping speed. Each HIP train will be provided with two vacuum pumping systems, with one in operation and the other on standby. Each vacuum system will be sized such that 3 pressure vessels can be 
evacuated from atmospheric pressure down to 0.5 torr in $1 \frac{1 / 2}{2}$ hour. One Stokes rotary piston type vacuum pump and Roots blower are estimated to cost approximately $\$ 40,000$.

\subsection{Fresh Argon Tanks}

Argon supply is from a liquid argon storage tank located outside the facility. The liquid argon tank is usually leased. Liquid argon will be pumped into the fresh argon gas storage tanks at 5000 psi through a liquid to gas heat exchanger using one of two 5000 psi pumps. With staggered operation we would need capacity for only one train. However, since our operation is simultaneous, it is estimated that 100,000 scf of fresh argon gas at 5000 psi would be required. The fresh argon gas storage would be provided in 16" OD $\times 21$. ft long tanks. 18 tanks in 3 banks of 6 tanks per bank will be provided. The fresh argon storage tanks, the heat exchanger and the 5000 psi liquid pump will be located outside the facility. The cost of the fresh argon tanks is estimated to be approximately $\$ 50,000$. The cost of each 6000 psi rated liquid pump will be $\$ 35,000$.

\subsection{Reclaimed Argon Tanks}

Argon will be reclaimed for reuse. The reclaimed argon will be stored in 2000 psi tanks 24 -in OD $\times 21 \mathrm{ft}$ long. 24 tanks in 4 banks of 6 tanks per bank will be provided. One bank of 6 tanks will be located in each of the four trains along with the other HIP equipment inside each HIP cell. A HEPA filter will be provided in the line from the HIP machine pressure vessel to the argon reclaim tanks to filter out any particulate contamination that may be present in the used argon. The cost of the reclaim argon storage tanks is estimated to be approximately $\$ 75,000$.

\subsection{Compressors}

Eight electric $100 \mathrm{HP}$ each piston type compressors will be provided for the 20,000 psi system. There will be two compressors for each of the four trains. One compressor will be used while the second will be maintained as a spare. It is estimated that with an inlet pressure of 2000 psi, each compressor would be able to pump up three of the selected HIP machine pressure vessels in each train to pressure in approximately 2 hours. The compressors will be located inside the HIP cell. These compressors will also be used to pump the argon from the HIP machine to the argon reclamation tank after the cool down period following HIP. Each compressor is estimated to cost approximately $\$ 125,000$.

\subsection{Cooling System}

Each of the pressure vessels will be provided with a cooling jacked through which a cooling medium will be recirculated for the purpose of heat removal. The cooling medium will be recirculated by a pump. A total of eight pumps and four heat exchangers will be provided, two pumps and one heat exchanger for each of the four trains. Heat removal from the cooling medium will be accomplished by cooling water circulated by one of two pumps located outside the facility. The heat 
removal from the cooling water will be in a cooling tower also located outside the facility. Emergency cooling in the event of a cooling tower failure will be accomplished by connecting an unspecified source of water to the secondary loop pump inlet. The source for the emergency water will be specified later.

Assuming a steady state furnace heat load of $400 \mathrm{KW}$, dissipation of $1,400,000$ Btu/hr per HIP machine would be required. The heat exchangers for the removal of heat from the closed loop cooling system and the cooling tower would have to be designed for the above heat duty.

\subsection{Controls}

Controls would be located centrally in a control room. Each system would be controlled and monitored separately as each HIP machine would require continuous monitoring when in operation. A computer supervised PLC type system (AllenBradley) is envisioned. Manual back-up control capability would be provided. The operation of the HIP machine would be completely automated, and no remote handling systems would be required except for an overhead crane for loading and unloading the cans. Also, the overhead crane will be used to remove and install the furnace and pressure vessel when required.

\subsection{Power Supplies}

Separate transformers, contactors, and silicon controlled rectifiers need to be provided, even for the three HIP machines in each cell, because the operation of the HIP machines would be simultaneous rather than staggered. There would be 8 separate heating zones in each furnace and each zone would be 100 KVA capable.

\section{Foot Print Requirements}

\subsection{HIP Machine}

Each HIP machine requires a foot print $65^{\prime \prime} \times 140^{\prime \prime}$ and a overhead space of $360^{\prime \prime}$. This includes the can height while it is being loaded into the HIP machine, but does not include the additional overhead clearance required for the overhead crane that will be required to load the can into the HIP machine.

\subsection{Vacuum System}

Each vacuum system consists of a vacuum pump and a roots blower and will require a foot print $4 \mathrm{ft}$ square. A total of eight vacuum systems will be provided, two for each train.

\subsection{Argon Gas Tanks}

Each 6 pack of gas tanks will require a foot print $5 \mathrm{ft} \times 21 \mathrm{ft}$. 3 banks of fresh argon tanks will be needed. The banks of fresh argon gas storage tanks will be located outside the facility. 4 banks of reclaimed argon tanks will be provided. The 
reclaimed argon gas tank banks will be located within the facility.

\subsection{Compressors}

The foot print required for each compressor is $12 \mathrm{ft} \times 4 \mathrm{ft}$. A total of eight compressors, two for each train will be provided.

\subsection{Cooling System}

Four cooling skids one for each train will be located in the HIP room of each train. Each cooling skid will consist of two pumps, one heat exchanger, and valves and will require a foot print approximately $8 \mathrm{ft} \times 12 \mathrm{ft}$. A cooling tower and pumps will be located outside the facility.

\subsection{Power Supply}

Four power supplies located one in each HIP cell will be provided. Each power supply is estimated to require a foot print $12 \mathrm{ft} \times 6 \mathrm{ft}$.

\section{Process Description}

\subsection{HIP Can Preparation}

Cans to be HIP will be evacuated, sealed, and contain the devolatilized calcine/additive mixture. The vessel closure welds will be checked to the extent feasible. It is important that the can not have any leaks in its skin. The devolatilization and evacuation of the can help in HIP proces's. Additionally, the cans need to be maintained contamination free on the outside in order to keep the HIP machine from becoming contaminated. In order to protect the HIP machine from contamination during the HIP step, the can to be HIP will be placed in a breathable over-pack can prior to being placed inside the HIP can pressure vessel.

\subsection{HIP Process}

After the can to be HIP in its over-pack can is placed inside the pressure vessel, the pressure vessel is evacuated using the HIP system vacuum pumps. The evacuated air from the pressure vessel will be checked for the present of radioactive contamination. If contamination is detected, this would be an indication that the skin of the can to be HIP has leaks and the HIP process would be stopped and the can returned for rework. In the event no leaks are detected, the pressure vessel will be pressurized with argon from the argon reclamation tanks using the argon compressors, and additional argon will be used from the fresh argon tanks to bring the argon pressure in the pressure vessel to the desired pressure. The can to be HIP will be at approximately $650^{\circ} \mathrm{C}$ having just completed the devolatilization step. The furnace in the pressure vessel is turned on soon after the evacuation of the pressure vessel is complete and the vessel is pressurized with argon gas. The HIP can temperature will be raised to $1050^{\circ} \mathrm{C}$ with argon pressure will rise to approximately 20,000 psi due to the increase in temperature. 
The skin of the can to be HIP and the can contents will soften and creep due to the high temperature, and the external pressure will cause the can to gradually implode reducing its volume to approximately half that of its pre-HIP volume. During this process, if the skin of the HIP can has a leak, the argon pressure inside and outside the can will be the same, and the can will not implode on itself. Instead, when the pressure in the pressure vessel is reduced, the contents of the can would tend to migrate out of the can through the leak along with the argon, tending to contaminate the rest of the HIP machine.

\section{Additional Research}

HIP is a well known art that has been in existence for some time. Also extensive research has been performed at the INEEL on the calcine additive formulation. The area where additional research would be required is the pre-HIP can dimensions. The pre-HIP can dimensions on which this study is based is realistic, but will yield conservative HIP machine quantities, facility size, and cost estimates. In the event this option is selected, additional research is recommended to optimize the pre-HIP can size and the number of cans to be HIP at a time in a HIP machine.

\section{Acknowledgements}

Technical information and costs about the HIP machines were supplied by Cliff Orcutt, Vice President, American Isostatic Presses, Inc., 1278 S. Front Street, Columbus, $\mathrm{OH}$ 43206. Tel 614-445-9081 and Franz Zimmerman, Manager, Engineered Systems, ABB Autoclave Systems, Inc. 2820 W 23rd Street, Erie, PA 16506. Tel 814-838-5799 
Project File Number $02 B G 0$

Project/Task Waste Treatment Project Feasibility Studies

Subtask HIP Can Filling

\begin{tabular}{|l}
\hline Title: HIP Can Filling \\
\hline Summary: \\
This EDF describes the HIP can filling operation and the equipment that \\
is envisioned to be required. Prior work done with respect to filling the \\
HIP can with calcine/additive mixture was reviewed. A continuous \\
plastic sleeve is proposed to perform the can filling operation with \\
minimized potential for the spread of radioactive contamination to the \\
HIP can filling room and the outside of the HIP can.
\end{tabular}




\section{HIP Can Filling}

\section{Introduction}

This engineering design file (edf) documents the can filling options that were looked at for filling cans to be hot isostatically pressed (HIP) with the calcine addititive mixture while minimizing the spread of radioactive contamination. This work was performed in connection with defining the facility and costs for the Hipping Waste Option (HWO) for the final disposal of radioactive waste that was produced from the calcination of high level waste generated from the dissolution of spent nuclear fuel for the recovery of uranium.

\section{Prior Work}

Prior work on filling the HIP can was performed at the ICPP and two reports ${ }^{1,2}$ briefly reference the proposed method. The method uses a double door transfer system developed by Central Research Laboratory and used at the laboratory facilities at the ICPP. The referenced documents do not however provide any details about how the double door transfer system will be used in the present application of loading the calcine/additive mixture into the can to be HIP. The double door transfer system was evaluated for the purposes of this report. It was found that the double door transfer system will work very well for its intended purpose which is loading out sample bottles and other large mostly clean objects with very little loose contamination. It is believed that when large quantities of powdered material are to be transferred through the double doors, this system will have very little benefit. Also, the can to be HIP does not come with a lid that permits use of the double door transfer system. The lid has a hole and a tube through the center which complicates its use as one half of a double door transfer system.

ANL-W uses a flange-to-flange connection to load their HIP cans. Their HIP can have a 3-inch diameter fill tube which ends at the top in a flange. This flange is butted up against the flange at the bottom of a metered hopper and a valve is opened to let the contents of the metered hopped transfer to the HIP can. The valve at the bottom of the metered hopper is then closed and the can is then lowered. Any contamination if present on the exposed flange faces is then clean off. ANL-W is using pre-HIP cans which are approximately 6-inches in diameter and 8-inches tall. However, their cans are much smaller than ours and their processing rate is such that this system is sufficient to serve their needs. There are locations at ANL-W where the plastic sleeve loading technique selected for this option and described below are in use.

\section{Plastic Sleeve}

A continuous plastic sleeve is used to control contamination during the loading of a 
can to be HIP. The plastic material used for this purpose needs to be thin enough to be pliable and conform to the shape of the inside of the can when filled with the calcine/additive mixture, but strong enough to be puncture resistant. The can may be vibrated to cause the HIP mixture to settle and pack inside the can. A length of the plastic sleeve sufficient to load several cans is accordioned on to a spool of piping in sections as shown in the attached sketch. Each section when released or pulled down from the spool will provide a length of plastic sleeve sufficient for one can. The free end of the plastic sleeve is heat sealed closed. The spool is loaded into the can loading cell and bolted remotely on to the bottom flange on the calcine/additive storage hopper down stream of the calcine dispensing valve.

\subsection{Filling the can}

An empty open can is moved into an upright position below the using means designed by the remote handling engineers. The can will be positioned on a load cell and a mechanism for vibrating the can will be provided. An apron as shown in Figure 1 will then be placed on the can for catching any calcine/additive mixture that may tend to contaminate the outside of the can in the event the plastic sleeve was inadvertently ruptured. The apron designed to center itself around the can has a hole at the top which matches the HIP can opening. The appropriate length of the plastic sleeve is worked into the can through the opening in the apron and the top of the can. The appropriate amount of calcine/additive mixture is then added to the HIP can by opening the valve at the bottom of the hopper in which the calcine/additive mixture is stored. The mixture may tend to bridge at the opening of the can, depending on the size of the can opening. Bridging will be broken up by tapping the side of the plastic liner periodically using the master slave manipulators. The Hip can will also be periodically vibrated to ensure uniform packing of the mixture in the can. The load cell upon which the can is positioned will indicate when the desired quantity of HIP mixture has been transferred into the HIP can.

\subsection{Sealing the Plastic Sleeve}

The plastic sleeve may be marked with two lines running down along the length and diametrically opposed. When the desired quantity of HIP mixture has been loaded into the cans, the plastic sleeve will be stretched from two diametrically opposed points to remove creases using the manipulators and heat sealed in an approximately 1 -inch thick band using a thermal sealer and cut through the middle of the heat sealed band. Alternately, the plastic sleeve may be cinched together and heat sealed using a circular heat sealer that would have to be specially designed for this purpose. The end of the plastic bag enclosing the mixture will be worked into the HIP can using manipulators: The plastic bag will provide a barrier against the spread of contamination from the filled HIP can. The remaining portion of the plastic sleeve will already be sealed at the bottom and be ready for insertion into the next HIP can to be filled. The contamination control apron will likewise be transferred to the next HIP can to be filled. 


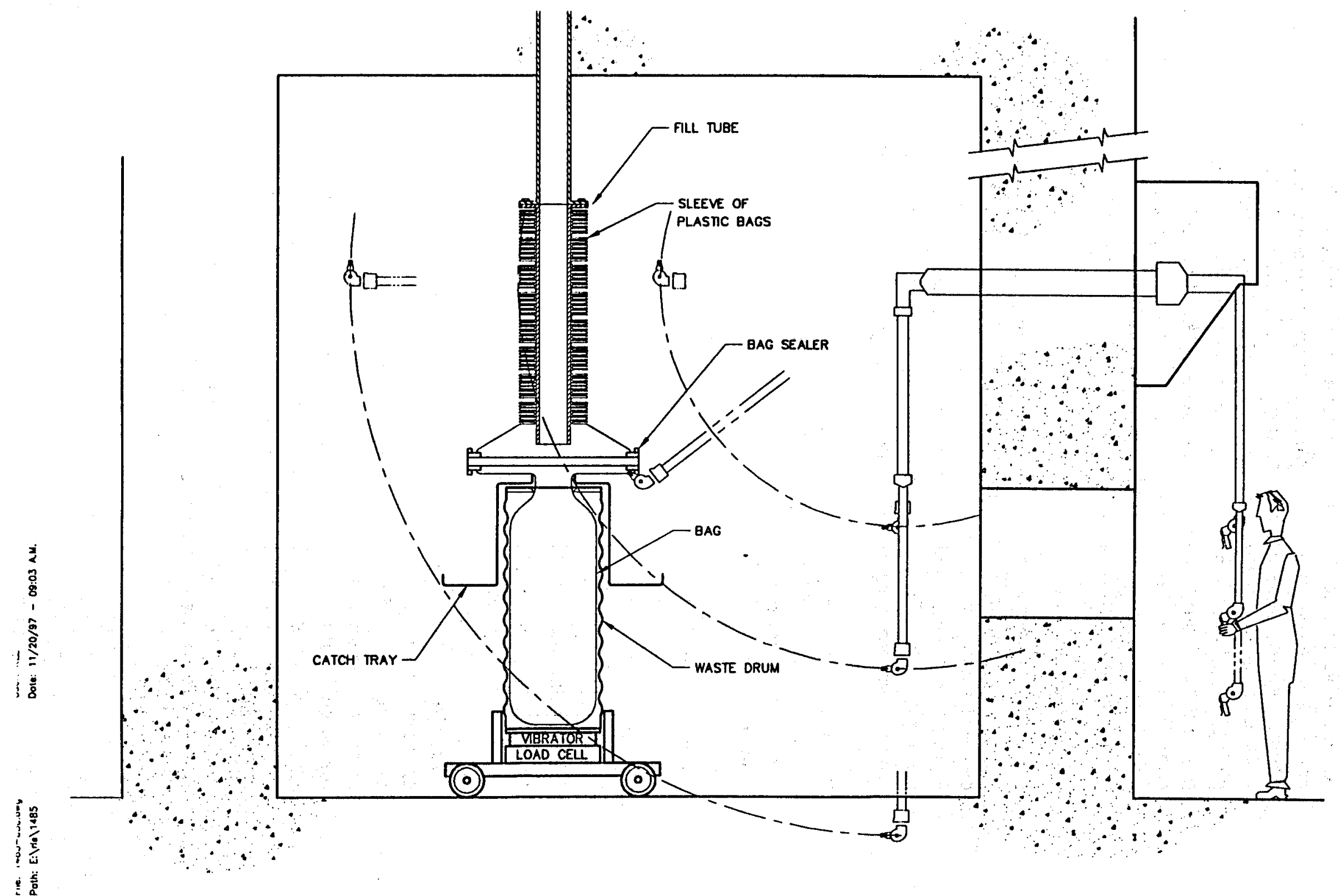




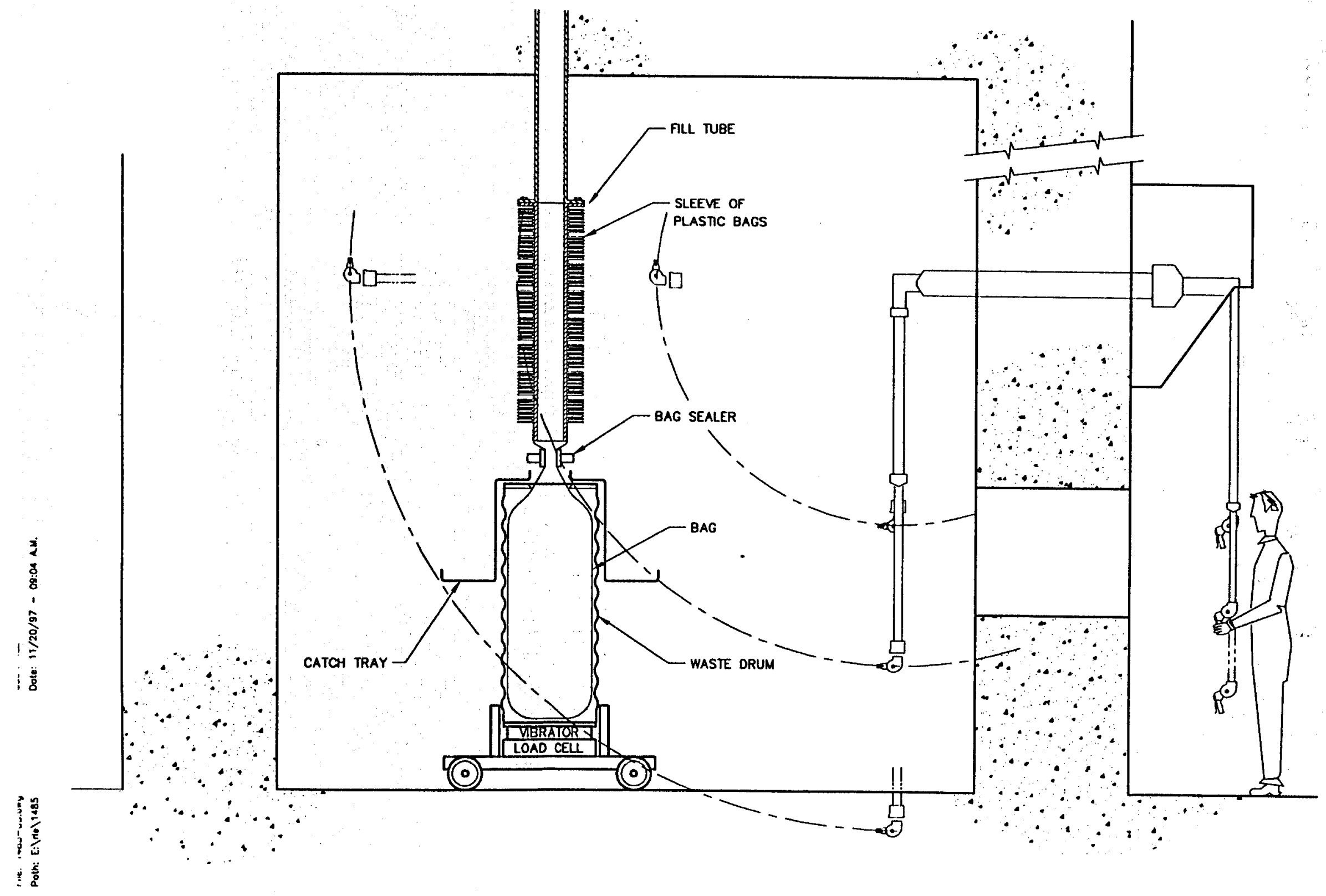




\subsection{Loading the Plastic Sleeve}

When the plastic sleeve runs out, a fresh spool with a fresh plastic sleeve accordioned on it is assembled and loaded into the can filling room. The old spool is unbolted remotely and the flange and contamination are cleaned off before the fresh spool is bolted on the flange, and the operation is continued as already explained. 
An assumption is made that the HIP can top flanges are designed for interfacing with a grappling mechanism that is attached to crane hooks or to end effectors on electro-mechanical manipulators. The HIP process cans as currently 'envisioned are cylindrical stainless steel, with annular corrugations, wall thickness of 0.065 in. and a top flange or head with a separate lid. The as-received cans are approximately 27 in. diameter by $40 \mathrm{in}$. high and weigh approximately 82 pounds. The can weight after filling with material is anticipated to be 1,505 pounds. After HIPing, the can is estimated to have final dimensions of about 21 in. diameter and between 29 and 33 in. high. Can handling should be done from the top because deformation of the corrugated can body occurs when heat is applied during the HIP process.

Another assumption is that the SRS HLW canisters will arrive with the tops (from the shoulder upwards) separate from the canister bodies. Canister nominal size is 2 $\mathrm{ft}$. outside diameter (OD) by $10 \mathrm{ft}$. high, with an empty weight of 1,000 pounds. Canisters have a usable internal diameter of 23.25 in. by 102 in. high, allowing stacking of three HIP cans inside. Gross loaded weight after installation of the canister top is estimated at 5,515 pounds.

\section{Equipment Description}

\subsection{Overview}

The highly radioactive nature of the materials processed in the HIP facility necessitates extensive use of remotely controlled equipment to comply with operational, maintenance, environmental and ALARA requirements. Equipment requiring frequent maintenance is designed so that normal maintenance activities or removal and replacement can be performed remotely. Other equipment is designed for removable modules with local preliminary decontamination, then removal to equipment maintenance areas. Shielding doors segregate equipment in high radiation areas that must be maintained "hands-on". The shielding doors are closed for remote decontamination, then personnel enter the area to perform maintenance.

Shielded viewing windows and remote equipment enable operating personnel to observe and perform the activities in the facility. In some cases, closed circuit television (CCTV) is needed to supplement the viewing windows. One particular case would be for identification of serial numbers of cans and canisters to enable accurate record keeping. Adequate lighting is required in virtually all areas.

Equipment must be designed for simplicity, robustness and reliability. Much of the equipment described in this EDF has been developed for, and been successfully used in, existing facilities with similar requirements. Equipment that has not had practical use in such a facility has been evaluated for the characteristics listed above and for potential remote controllability. While some development may be required, the practical applications could be realized within budgetary and time constraints. 


\subsection{Carts}

An effective and dependable method of moving the HIP cans (before they are filled) and the SRS HLW canisters (after they are loaded) is by four-wheeled cart. The cans or canisters would be placed on the cart in a cradle or rack. Support is from the bottom and/or sides. Loaded canisters and empty cans can easily be moved this way if appropriate consideration is given to placing on, and removing, them from the carts using external sources such as forklifts, cranes or other pick and place equipment. Carts are required in the following areas, with corresponding descriptions and quantities:

\section{Fill Cell Cart}

The purpose of this cart is to move HIP cans from the door of the staging room to the fill station, to the lid sealing station, and to the hoisting station underneath the decontamination cell. This cart will have an on-board cradle to rigidly hold one can at a time. It is approximately 30 in. wide $\times 36$ in. long $\times 18$ in. high with 4 wheels.

It is equipped with an electrically powered vibration mechanism to assist in compaction during filling of cans. On-board load cells enable measurement of empty and full can weight. All components are sized for a filled can weight of 1,505 pounds plus a safety factor. The cart is connected to a cable, reel at each end of the track with wire rope for emergency recovery and electrical cable for power and control. Propulsion is by an on-board $1 / 2$ HP motor through gearing to the wheels. Control consoles are placed in the operating corridor at the Fill, Weld and Lower Decontamination cells. Hardened metal pins, actuated by electric solenoids, are placed on the cart to mate with sockets at the Fill and the Weld stations to accurately position and hold the cart during those operations. The cart rides on rails with a bi-directional travel (track length) of $38 \mathrm{ft}$. Seismic restraints (devices to prevent the cart from jumping off the rails) are employed at each wheel.

Four carts are required to be designed and fabricated, one for each process line.

\section{Tunnel Cart}

The purpose for this cart is to move loaded SRS HLW canisters from the process area through a tunnel running under each Loading cell to the interim storage area. An overhead crane, with grapple, is used for loading and unloading canisters from the cart. This cart will have an on-board rack to hold up to 4 SRS HLW canisters at a time. It is approximately 60 in. wide $\times 72$ in. long $\times 24$ in. high with 4 wheels. All components are sized for holding and transporting 4 filled canisters, weighing 5,515 pounds each plus a safety factor. The cart is connected to a cable reel at each end of the tunnel with wire rope for emergency recovery and electrical cable for power and control. Propulsion is by an on-board 2 HP electric motor through gearing to the wheels. Control consoles are placed in the operating corridors at each Loading cell and at the Interim Storage building. Seismic restraints (devices to prevent the cart from jumping off the rails) are employed at each wheel. The cart 
rides on rails, with a bi-directional travel (track length) of approximately $400 \mathrm{ft}_{\text {, }}$ One cart is required for design and fabrication.

\subsection{Jib Crane}

A method of introducing clean HIP cans into the process area without spreading contamination can be obtained by use of a jib crane located in the Load (can staging) room. The shield door between this room and the Can Fill Cell will be closed while clean, empty cans are brought in by forklift. An operator rotates the jib crane, with a grapple attached, and picks up a HIP can. The shield door to the Fill cell is then opened and the operator rotates the crane, extends the boom, and lowers the can onto the cart in the Fill Cell. Requirements are for a commercially available 2 Ton capacity jib crane with a remotely controlled motorized boom swing, motorized boom extension of approximately 4-8 ft. from the column center, and a motorized hoist with a lift of approximately $10 \mathrm{ft}$. The operator controls the crane from a control station in the operating corridor. A grapple, requiring design and fabrication, is needed to interface with and lift the HIP cans. Power requirements are estimated at $1 \mathrm{HP}$. Four jib cranes are required, one for each process line.

\subsection{Overhead Bridge Cranes}

Moving the HIP cans from station to station after they are filled are more logically performed from above, supporting the cans by their flanges or heads. This method gives better interfacing with lifting devices because the can flanges are not as likely as the bodies to be deformed during the HIPing operation. Bridge cranes in the process cells should be supplied by festooned cabling. Bus bar power is not acceptable because of the potential for corrosion. Either overhead cranes or electro-mechanical manipulators have been used successfully to perform this function in similar facilities.

\section{High Bay Bridge Cranes}

These cranes will be used to install and remove heavy equipment, such as the HIP furnaces and tanks, through hatches in the cell roofs. They will span two process lines each. They should be overhead bridge, top running, meet requirements of ASME NOG-1, have true vertical lift, and be equipped with the slowest speeds commercially available. Seismic restraints (devices to prevent the trolley from jumping off the rails) are employed at each wheel. Hoist capacity should be at least 75 Tons, with the manufacturer's standard swivel hook and reach from the $-20 \mathrm{ft}$ to the $+40 \mathrm{ft}$ levels, for total hoist hook lift of $60 \mathrm{ft}$. The span is approximately $100 \mathrm{ft}$ with a runway length of $290 \mathrm{ft}$. The operator controls the crane from a traveling cab. Power requirements are estimated at $70 \mathrm{HP}$. Two cranes are required, one over each set of two process lines.

\section{Size/Grind Cell Bridge Cranes}


This crane will be used to move equipment and HIP cans around the Size/Grind Cell. It should be top running, meet requirements of ASME NOG-1, have true vertical lift, and be equipped with the slowest speeds commercially available. Seismic restraints (devices to prevent the trolley from jumping off the rails) are employed at each wheel. Hoist capacity should be 3 Tons with lift of $15 \mathrm{ft}$. A grapple, requiring design and fabrication, is needed to interface with and lift the HIP cans. Required span is approximately $24 \mathrm{ft}$ and runway length is $25 \mathrm{ft}$. Power requirements are estimated at $10 \mathrm{HP}$. Power and control are via festoon cable and a movable control console in the operating corridor. Four cranes are required, one for each process line.

\section{Main Process Line Bridge Cranes}

These cranes consist of two carriages on a common set of rails and are used to move HIP cans from the Decon cell into the Devol cell, into the HIP furnaces, to the cooling area, into the QA/Assay cell and into the Loading cell. They will also be used for handling the SRS HLW canisters. They will be able to move equipment into the Remote Maintenance cell or travel into the Crane Maintenance cell for maintenance. These should be commercial, overhead, top running bridge type cranes. They are to meet requirements of ASME NOG-1, have true vertical lift, and be equipped with the slowest speeds commercially available. Seismic restraints (devices to prevent the trolley from jumping off the rails) are employed at each wheel. Hoist capacity should be at least 7.5 Tons, and reach from the $-20 \mathrm{ft}$ to the $+20 \mathrm{ft}$ levels, for total hoist hook lift of $40 \mathrm{ft}$. A grapple, requiring design and fabrication, is needed to interface with and lift the HIP cans or the SRS HLW canisters. Crane span is approximately $32 \mathrm{ft}$ with a runway length of approximately $120 \mathrm{ft}$. Power requirements are estimated at $20 \mathrm{HP}$. Power and control are via festoon cable and movable control consoles in the operating corridor. Eight carriage assemblies are required, with two running on each set of rails. Four sets of rails are required, one for each process line.

\subsection{Viewing/Shielding Windows}

Viewing/shielding windows are required for normal effective operator vision of the process areas, especially when using manipulators and other items of equipment. Anticipated locations include the Fill, Lid Weld, Lower Decon, Upper Decon, Lower Devol, Upper Devol, Size/Grind, Cooling, QA/Assay, Canister Loading and Remote Maintenance cells. The windows should be of the commercial leaded glass type and oil filled. Nominal window size is 36 in. wide $\times 30$ in. high $\times 36$ in. thick (assumed cell wall thickness). Each process line will require 13 windows, for a total of 52 in the facility.

\subsection{Master-Slave Manipulators}

Master-slave (MS) manipulators are used for handling small objects and tools, manipulating levers and other similar actions. They are used in pairs in conjunction with shielding windows and are installed and removed from the operating corridor. 
Two each are located at the Fill, Weld, Size/Grind, Devol, Preheat, Can Cooling, QA/Assay, Loading, Remote Maintenance, and Upper Devol areas. Central Research Laboratories (CRL), the vendor for master-slave manipulators at the INEEL, offers a standard Model F or F-X that would function well in this application. Each process line will require $20 \mathrm{MS}$ manipulators, for a total of 80 in the facility.

\subsection{Electro-Mechanical Manipulators}

Electro-mechanical (EM) manipulators consist of telescoping tube assemblies hung under carriages and riding on rails. Several degrees of movement are available in the shoulder, arm, wrist, and hand assemblies attached to the telescoping tubes. The EM manipulators can be sized for handling cans, canisters and other equipment along the process line. One should be considered for use in the Size/Grind cell. Two EM manipulators, with reaches extending down to the lower level and riding on a single set of rails, should be considered for the Decon, Devol, HIP, Cooling, QA/Assay, Loading, Remote Maintenance, and Crane Maintenance areas. Either set of EM manipulators would be used instead of the bridge cranes identified in Section 3.3. They can be obtained with different end effectors, including grapples. These manipulators are commercially available from Programmed and Remote (PaR) Systems. Eight EM manipulators are required, with two running on each set of rails. Eight sets of rails are required, two for. Each process line will require 3 EM manipulators, for a total of 12; and two sets of rails for a total of 8 .

\subsection{HIP Can Lid Welding Equipment}

A friction (inertial) welding machine can be used to effectively and quickly attach and seal the HIP can lids to the cans after filling. Previous research has shown that a good seal is accomplished without the attendant heat and distortion produced by conventional welding techniques (see references). The basic machine is located in the Weld Equipment cell at EL $\mathrm{O}^{\prime}-\mathrm{O}^{\prime \prime}$ and is accessible for "hands-on" maintenance. A spindle protrudes through the floor to the Weld Cell station directly below. A cart is used to position a can directly under the spindle. A mechanism attached to the wall or floor fastens to the can head or flange and prevents it from rotating and translating. A lid is loaded onto the spindle with a manipulator, spindle rotation commences, and spindle extension forces the lid into the opening on the can flange. At a predetermined force and time, frictional heat welds the two surfaces together, and clutches allow the spindle to stop rotating. The spindle then retracts and the can is removed. The basic machinery is commercially available but the spindle, lid and can holding mechanisms require design and fabrication. Each process line will require one machine, with can holding mechanism, for a total of 4 .

\subsection{HIP Can Sealing Equipment}

It is assumed that the HIP can lid incorporates a small riser tube to be used for evacuation of can volatiles (devolatization) after the lid is welded in place. "This riser tube will be open to atmosphere until the sealing operation is completed after devolatilization. The can is introduced into a holding mechanism and the heating 
and evacuation equipment is attached. After heating and devolatilization, a mechanism closes or pinches off the tube and seals it. A seal weld is assumed. The holding and sealing mechanisms will require design and fabrication. Each process line will require one mechanism, for a total of 4 .

\subsection{Decontamination Equipment}

\section{Vacuum Hoses}

Vacuum hoses held by MS manipulators would be used for initial, partial removal of contaminated particles on cans, canisters and equipment. The Can Fill, Decon, Devolatization, Size/Grind and Loading stations would be equipped with vacuum

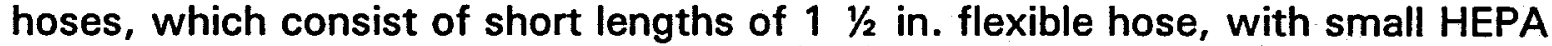
filters in-line, connected to the process off-gas system with remote quickdisconnects. They would be made up of commercially available components, with minor design and fabrication of nozzles and manipulator adapters. Each process line will require 5 hose hookups, for a total of 20 .

$\mathrm{CO}_{2}$ Pellet Blasting Equipment

$\mathrm{CO}_{2}$ Pellet Blasting Equipment is used for comprehensive removal of clinging or encrusted contamination from cans or equipment. The pellets are directed under pressure at the contamination with manipulators. After blasting, the pellets evaporate, leaving just the dry contamination residue or debris. Pellet forming equipment and pumps are located in a clean area with appropriate piping to the Decon cell. Pickup of the dry debris is by vacuum hoses as outlined above. Most of the equipment is commercially available, but manipulator adapters require design and fabrication. Each process line will require one unit, for a total of 4.

\section{Chemical Decontamination Equipment}

Prior to manned entry into the cells, it will be necessary to decontaminate them. A proven method used to decontaminate hot cells at CPP is to use a nitric acid wash supplied through piping from a holding tank with a spray wand and deployed by manipulator. Other chemicals or water are then sprayed to neutralize the acid. The residue is collected in a waste collection tank and processed in a waste processing facility. Tanks would be located in a service room, connected by piping to each other, and pumped through pipe to the Can Fill, Decon, Devol, Size/Grind and Loading stations. The equipment in the cells would consist of nozzles and short lengths of flexible hose connected to the piping with remote quick-disconnects. Most of the equipment is commercially available, but manipulator adapters require design and fabrication. Each process line will require 2-200 gal tanks, a $2 \mathrm{HP}$ electric motor and 5 local hoses for a total of 8-200 gal tanks, 4-2 HP motors and 20 local hoses.

\subsection{Closed Circuit Television (CCTV) Equipment}

Commercial CCTV equipment is used to supplement observation through windows. An assumption is made that radiation-hardened cameras are not needed because 
they will be mounted at a reasonable distance from radiation sources, usually on walls above the area of interest or on cranes or EM manipulators. The latter application has been proven useful in identification of container serial numbers and storage locations at the Idaho Chemical Processing Plant. Each remotely operated camera will have a zoom lens and variable auxiliary light mounted on a pan/tilt (P\&T) unit. Control will be via cabling from consoles that plug in to receptacles at each station in the operating corridor. A single commercial switcher will allow viewing of any area from any console at any receptacle for a given process line. Electrical power requirements are approximately 1,000 watts per camera with lights on full power. Assume 4 units per operating line will be active simultaneously for a total of 4,000 watts. The switcher, control consoles, recorders, etc. use up to 2,000 watts at any given time. Total power demand is 6,000 watts per process line. Minor design and fabrication is required for mounting and remote removal considerations. Each process line will require one switcher and 10 camera/P\&T units for a total of 4 switchers and 40 camera/P\&T units. Cost is $\$ 2,000$ per camera/P\&T unit with a switcher cost of $\$ 5,000$ per unit. 


\subsection{Removable Cell Lights}

Because of ALARA considerations, relamping of burned out commercial lights can only be accomplished after the areas are decontaminated and radiation sources are removed. Light assemblies replaceable from outside the cells are used to overcome this limitation. These lights also provide supplemental lighting above the operator at a viewing window because they are typically mounted in the cell walls directly above the viewing windows and between the MS manipulators. The light assemblies consist of high intensity halogen lamps housed in shielded enclosures that are installed and removed from the operating corridors. Electrical power required is 500 watts unit. Each process line will require 10 units for a total of 40. Cost is estimated at $\$ 6,000$ per unit.

\subsection{QA/Assay Equipment}

A method of remotely determining can or canister closure integrity is needed. Ultrasonic equipment is assumed to fulfill this need. Commercial equipment would be used where feasible, but will require adaptation for remote use. Additional can or canister handling and adaptive equipment will require somewhat extensive design and fabrication to meet requirements such as remote operability, decontaminability, modularity, replaceability and other related criteria. Units would be located at the Lid Weld, Can Seal, and Canister Lid Weld stations. Electrical power required is assumed to be $3 \mathrm{kw}$ per station. Each process line will require 3 units for a total of 12 units.

\subsection{Tool Ports}

A method to introduce tools, supplies and small equipment items into cells is required. A through-the-wall port fulfills this need. One would be required at each of the cells where viewing windows and manipulators are located. Design and fabrication are required. Each process line will require 13 ports for a total of 52 ports.

\section{References}

S. M. Berry, T. R. Reed and R. C. Swainston, Friction Welding Method of Hot Isostatic Press Can Closure for the ICPP Calcine Immobilization Program, WINCO1160, 22 pages (September 1993).

S. M. Berry, C. G. Cox and M. A. Hoover, Conceptual Design for Remote Handling Methods Using the HIP Process in the Calcine Immobilization Program, WINCO1213, 36 pages (March 1994). 


\section{Failure Modes}

The following is a sample of possible failure modes associated with HIP can or SRS

HLW canister filling and handling and the HIPing process:

- Empty can is dropped

- Empty can is dropped on operating hardware

- Full can is dropped after sealing

- Failure of lid seal weld on full can

- Any cell crane or electro-mechanical manipulator fails

- Maintenance crane fails

- Electro-mechanical manipulator fails

- Any transfer cart fails

- Any master-slave manipulator fails

- Welding station fails

- Decon station fails

- Any shielding door fails to open or close

- Failure of any grapple mechanism

- Failure of can filling equipment

- Failure of offgas system components

- Power failure

- Empty canister is dropped

- Empty canister is dropped on operating hardware

- Full canister is dropped

- Failure of weld between canister body and top 
EDF Serial Number CPP-97083

EDF-HWO-006

Functional File Number 4000-14

SPR-05

\title{
ENGINEERING DESIGN FILE
}

\author{
Radiological Evaluation \\ for the Calcine \\ Hot Isostatic Press (HIP) \\ Feasibility Study
}

\author{
By \\ B. J. Schrader \\ November 26, 1997
}


Project File Number N/A

Project/Task N/A

Subtask N/A

Title: Radiological Evaluation for the Calcine Hot Isostatic Press (HIP) Feasiblity Study

Summary: This summary briefly defines the problem or activity to be addressed in the $E D F$, gives a summary of the activities performed in addressing the problem and states the conclusions, recommendations, or results arrived at from this task.

This EDF evaluates and documents the radiological requirements for the feasibility of the Hot Isostatic Press (HIP) option for immobilization of the calcine. Areas of discussion in this evaluation are as follows:

1) Applicable codes and Standards

2) Radiological Monitoring Equipment

3) Hot Cell Manned Entry Requirements

4) Breathing Air Requirements

5) Radiological Risk Evaluation of Process

The discussion of each of the listed topics includes references to mandatory and nonmandatory requirements. The basis for this evaluation is the Department of Energy (DOE) would operate the facility under all currently applicable constraints and requirements. No attempt was made to evaluate the probability of changing requirements.

\section{Distribution (complete package): N.E. Russell MS-3765 G. W. Clarke MS-4145 B.J. Schrader MS-5209 File}

Distribution (summary package only):

\begin{tabular}{|c|c|c|c|c|c|}
\hline $\begin{array}{l}\text { Author } \\
\text { B.J. Schrader } \\
\text { BO X, Biadles }\end{array}$ & \begin{tabular}{|l} 
Dept. \\
Radiological \\
Support
\end{tabular} & $\begin{array}{l}\text { Reviewed } \\
\text { IfERusel }\end{array}$ & $\begin{array}{l}\text { Date } \\
1 / / 01 / 9 x\end{array}$ & Approved & $\mid \begin{array}{l}\text { Date } / 9 y \\
|2| 1 / 9\end{array}$ \\
\hline $4 f=5008$ & & $\begin{array}{l}\text { LMITCO } \\
\text { Review }\end{array}$ & Date & $\begin{array}{l}\text { LMITC } \varnothing \\
\text { Approval }\end{array}$ & Date \\
\hline
\end{tabular}

See Management Control Procedure (MCP) 6 for instructions on use of this form. 


\section{SUMMARY}

The Hot Isostatic Press (HIP) option of the Calcine Immobilization Program evaluates the feasibility of using the process to convert calcine into an acceptable glassceramic waste form suitable for terminal storage in a federal geologic repository. The fact that the calcine is highly radioactive requires that a radiological evaluation of the process and flow paths is performed to ensure that the process can be performed safely and maintain personnel exposure As Low As Reasonably Achievable (ALARA).

This EDF evaluates and documents the radiological requirements for the feasibility of the Hot Isostatic Press (HIP) option for immobilization of the calcine. Areas of discussion in this evaluation are as follows:

1) Applicable codes and Standards

2) Radiological Monitoring Equipment

3) Hot Cell Manned Entry Requirements

4) Breathing Air Requirements

5) Radiological Risk Evaluation of Process

The discussion of each of the listed topics includes references 'to mandatory and nonmandatory requirements. The basis for this evaluation is the Department of Energy (DOE) would operate the facility under all currently applicable constraints and requirements. No attempt was made to evaluate the probability of changing requirements.

The evaluation and recommendations of this EDF are based on existing technology and proven techniques and methods for handling highly radioactive material. The lessons learned from the NWCF Calciner, GSF canning station and the FSA fuel handling areas were evaluated for inclusion in this document.

This EDF does not include an evaluation of how the calcine will be removed from the Bin sets and moved into the facility. The process evaluation starts with the addition of the mixing agent with the calcine. 


\section{Key Assumptions}

The assumptions made during the development of this EDF are included below. These assumptions will require verification during follow-on design efforts. In some cases, the assumptions may have a strong bearing on the direction of the design; in other cases, the assumptions simply identify important issues that need to be addressed as the design progresses.

- The calcine will be processed in a facility that will be operated under the requirements and oversight of the Department of Energy. All applicable regulations and standards for the Department of Energy will be enforced.

- The mixing agent used in the process will be non-radiological or of such low level activity that shielding will not be required.

- Exposures to personnel both on and off-site will be maintained within the codified requirements of 10CFR20 and 10CFR835.

- The exhaust system will be monitored in accordance with ANSI-N42.17B-1989 to ensure and validate regulatory compliance with emission requirements.

- ANSI/ANS 57.8-1992 is the primary design document for configuring the HVAC systems and identifying contamination control zones. The DOE-ID ArchitectEngineer (A-E) Standard was used for guidance when specific direction was not provided in ANSIIANS 57.8 .

- Siting of the facility will ensure that adequate utilities and process systems are available. Siting will also include an evaluation on methods of movement of the calcine from the bin sets to the facility that maintains exposures ALARA. 


\section{CODES and STANDARDS}

\begin{tabular}{|l|l|}
\hline Code/Standard & \multicolumn{1}{|c|}{ TITLE } \\
\hline 10 CFR 20 & Standards for Protection Against Radiation \\
\hline 10 CFR 71 & Packaging and Transportation of Radioactive Material \\
\hline 10 CFR 830 & Nuclear Safety Management \\
\hline 10 CFR 835 & Occupational Radiation Protection \\
\hline 29 CFR 1910 & $\begin{array}{l}\text { Occupational Safety and Health Standards for } \\
\text { General Industry }\end{array}$ \\
\hline 29 CFR 1926 & $\begin{array}{l}\text { Occupational Safety and Health Standards for } \\
\text { Construction }\end{array}$ \\
\hline 40 CFR 53 & $\begin{array}{l}\text { Ambient Air Monitoring Reference and Equivalent } \\
\text { Methods }\end{array}$ \\
\hline 40 CFR 58 & Ambient Air Quality Surveillance \\
\hline $\begin{array}{l}\text { 49 CFR 173 } \\
\text { Sub Part I }\end{array}$ & $\begin{array}{l}\text { Shippers - General Requirements for Shipments and } \\
\text { Packages of Radioactive Materials }\end{array}$ \\
\hline $\begin{array}{l}\text { ANSI/ASME N510- } \\
\text { 1989 }\end{array}$ & Testing of Nuclear Air-Cleaning Systems \\
\hline $\begin{array}{l}\text { ANSI/ASME NQA- } \\
\text { 1-1989 }\end{array}$ & Quality Assurance Program \\
\hline $\begin{array}{l}\text { ANSI/NFPA 801- } \\
\text { 1995 }\end{array}$ & Facilities Handling Radioactive Materials \\
\hline ANSI N13.1-1969 & $\begin{array}{l}\text { Guide to Sampling Airborne Radioactive Materials in } \\
\text { Nuclear Facilities }\end{array}$ \\
\hline $\begin{array}{l}\text { ANSI N42.17B- } \\
1989\end{array}$ & $\begin{array}{l}\text { Performance Specifications for Health Physics } \\
\text { Instrumentation Occupational Airborne Radioactivity } \\
\text { Monitoring Instrumentation }\end{array}$ \\
\hline $\begin{array}{l}\text { ANSI/ANS 57.8- } \\
1992\end{array}$ & HEPA Systems \\
\hline $\begin{array}{l}\text { DOE-ID A-E } \\
\text { Manual }\end{array}$ & Architectural - Engineering Manual \\
\hline $\begin{array}{l}\text { INEL RadCon } \\
\text { Manual }\end{array}$ & Radiological Control Manual for the INEEL \\
\hline
\end{tabular}

The table listed above is a brief summary of the requirements and documents that are the basis for the design. It is also assumed that the applicable DOE orders will be implemented. Currently DOE is phasing out the order system in favor of codifying the requirements. Therefore no effort was made to determine the applicable orders and estimate if they will be changed over to CFR status. Let it be sufficient that at the time of title design a document search of the remaining DOE orders should be performed. 


\section{Radiological Monitoring Equipment}

The following is a list of the radiation monitoring equipment that would be required under the configuration as it exists on 11/20/97. Any deviation from this configuration would require evaluation/modification of this list. Most of the instruments listed must be capable of transmitting data to a microprocessor-based system for display, recording, alarm and trending. The instruments will also be connected to the Radiation, Environmental and Safety (RE\&S) computer system for remote monitoring. The RE\&S interface is available at several locations in the plant and is available in the utility tunnel.

\begin{tabular}{|c|c|c|c|c|c|}
\hline $\begin{array}{c}\text { Instrument } \\
\text { Type }\end{array}$ & $\begin{array}{l}\text { Radiation } \\
\text { Area } \\
\text { Monitor }\end{array}$ & $\begin{array}{l}\text { Constant } \\
\text { Air } \\
\text { Monitor }\end{array}$ & $\begin{array}{l}\text { Stack } \\
\text { Monitor }\end{array}$ & $\begin{array}{l}\text { Liquid } \\
\text { Effluent } \\
\text { Monitor }\end{array}$ & $\begin{array}{c}\text { Personnel } \\
\text { Contamination } \\
\text { Monitor }\end{array}$ \\
\hline \multicolumn{6}{|l|}{ Location } \\
\hline $\begin{array}{c}\text { Can } \\
\text { Loading } \\
\text { Bay }\end{array}$ & & $x$ & & & $x$ \\
\hline $\begin{array}{l}\text { Control } \\
\text { Room }\end{array}$ & $\bar{x}$ & $\bar{x}$ & & & $\bar{x}$ \\
\hline $\begin{array}{c}\text { Calcine } \\
\text { Storage } \\
\text { Room }\end{array}$ & $\bar{x}$ & & & & \\
\hline HVAC & $\begin{array}{c}\mathrm{X} \\
\text { On Filter } \\
\text { Banks }\end{array}$ & $x$ & $x$ & & $\bar{x}$ \\
\hline $\begin{array}{c}\text { Main } \\
\text { Floor } \\
\text { Control } \\
\text { Area }\end{array}$ & $\begin{array}{c}X \\
4 \text { for each } \\
\text { Train }\end{array}$ & $\begin{array}{c}x \\
4 \text { for each } \\
\text { Level }\end{array}$ & & $\begin{array}{c}X \\
\text { All drains }\end{array}$ & $\begin{array}{c}X \\
\text { At all exit points } \\
\text { from the facility. }\end{array}$ \\
\hline $\begin{array}{c}\text { Transfer } \\
\text { Tunnel }\end{array}$ & $\bar{x}$ & $\bar{x}$ & & $x$ & \\
\hline $\begin{array}{l}\text { Electrical } \\
\text { Room }\end{array}$ & & $\bar{x}$ & e & & $\bar{x}$ \\
\hline $\begin{array}{l}\text { Change } \\
\text { Rooms }\end{array}$ & & $\bar{x}$ & & & $\bar{x}$ \\
\hline $\begin{array}{l}\text { Outer } \\
\text { Offices }\end{array}$ & & & & & $\begin{array}{c}X \\
\text { Hand Held }\end{array}$ \\
\hline Elevator & & & & & $\begin{array}{c}\bar{X} \\
\text { At exit Points }\end{array}$ \\
\hline
\end{tabular}




\section{Hot Cell Manned Entry Requirements}

The Hot cell manned entry requirements will change if the methods of processing or the configuration changes.

Although the facility will be designed for the maximum remote operation and maintenance, the cells will require manned entry to perform non-periodic maintenance. The facility as referred to here is the process train area. The entry requirements for the facility are as follows:

- The facility shall be equipped with a breathing air system compliant with the applicable sections of 29CFR1910.

- The facility entrance will need to have a change out area that can isolate the operating area from the hot cells. This change out area should be air locked from the hot cells as a minimum with Zoned ventilation as defined in ANSI/ANS 57.81992.

- The cells shall be isolated from the access corridor by means of a door as a minimum. It is not necessary to airlock the cell entryways.

- The access corridor shall be wide enough to allow unencumbered access and egress. In addition, it is required that an outer pair of anti-contamination clothing be removed at the exit from the cell. The access corridor must be wide enough to allow an anti-c doffing station.

- An area large enough to store contaminated tools and equipment should be available inside of the contamination area.

- The access corridor will be maintained as a Contamination Area (CA) and Radiation Area (RA) in accordance with the requirements of 10CFR835. The cells will be controlled as High Contamination Areas (HCAs) and High Radiation Areas (HRAs) also in accordance with the requirements of 10CFR835.

- The cells must be capable of remote decon operations in addition to the requirements for manned entry decon. The cells shall have RCRA compliant drains and supporting systems.

- Fire suppression systems and alarms compliant with applicable codes and standards shall be available.

- The access corridor will need to be shielded from the cells. The shielding does not need to be as thick as the exterior walls. 


\section{Breathing Air Requirements}

Compressed air used for respiration shall comply with the quality requirements contained in 29CFR1910 Part 134(d). Breathing air shall meet at least the requirements of the specification for Grade D breathing air as described in the Compressed Gas Association Commodity Specification G-7.1-1966.

The Breathing Air supply that will provide air for airline respirators is contained in 29CFR1910 Part 134. The system should supply air to a minimum of two OSHA compliant manifolds capable of supporting 6 airlines. One system per frain would be required. The system will need to be provided with backup compressed gas cylinder air. The standby air shall comply with 29CFR1910(d)(2)(ii). Alarms to indicate compressor failure and overheating would be required.

The breathing air system will need to be capable of supporting personnel in an atmosphere as defined by OSHA - Immediately Dangerous to Life or Health (ILDH).

Although not all cells in the facility will need the requirement for ILDH supply air, some of them will.

\section{Radiological Risk Evaluation of Process}

The process has several parts that could increase the risk of radiological exposure and should be further evaluated in the design process.

- The ventilation system must be adequate to contain the radiological contaminants. The Hot cell area must be controlled as a process contamination area. Supply air ducting and exhaust ducting will be routed to and from the cells. These cell penetrations are a potential source of radiation streaming. The design must include a shielding evaluation.

- The utility support penetrations into the cells are a potential source of radiation exposure outside the cells and into the operating corridors.

- The Transfer tunnel could potentially be a source of very high exposure if maintenance is required while calcine is stuck in the tunnel. Consideration should be given to a method of remotely removing cans stuck in transit.

- The insertion of calcine into the process cell will be a weak point in the process. Calcine in notorious for solidifying in lines. Lessons learned in the process development of transferring the calcine to the bin sets from the calciner should be considered in further development of this option. 
- Containment of the contaminants within the cell will be difficult. Spread of radiological contamination must be minimized through the use of ventilation and air locks.

\section{Summary}

The evaluation and recommendations of this EDF are based on existing technology and proven techniques and methods for handling highly radioactive material. The lessons learned from the NWCF Calciner, GSF canning station and the FSA fuel handling areas were evaluated for inclusion in this document. The process and facilities as currently defined provide a strong measure of radiological control and will maintain personnel exposures ALARA. Further studies should consider the recommendations and concerns as defined in this EDF. 
Project File Number

02BG0

Project/Task Waste Treatment Project Feasibility Studies

Subtask HIP Waste Option (HWO) Scoping Study

Title: HWO Devolatilization Equipment

Purpose:

The purpose of this EDF is to document findings from a scoping study to identfy equipment that could be used to devolatilize and evacuate filled HIP cans prior to performing the HIP operation. The information provided in this report will be used as a basis to design that portion of the HIP facility where the HIP can devolatilization and evacuation will be performed. This report will also be used to prepare a cost estimate for the HWO.

Summary: The HWO will use a Hot Isostatic Press (HIP) process to prepare calcined waste from the Idaho Chemical Processing Plant (ICPP) for permanent disposal at a geological repository. An important step in the HIP process involves heating the calcine mixture to $650^{\circ} \mathrm{C}$ for 24 hours to drive off volatile components, and then evacuating and sealing the can prior to HIPing operations.

This report identifies the proposed process and equipment needed to perform the devolatilization and evacuation of the HIP cans. Brief descriptions of the equipment are included along with their associated costs, sizes, and power requirements.

This report proposes using a total of 12 furnaces for heating filled HIP cans during devolatilization. The furnaces have a square split tube design and have a screw gear to open and close the furnace during loading and unloading operations. The total cost for the 12 furnaces, their control systems, and installation is approximately $\$ 600 \mathrm{k}$.

In addition, 4 vacuum pumps will be required for devolatilization and evacuation. The vacuum pumps will be connected to the HIP cans while they are heated and remove any volitile compounds that may be released. The pumps will maintain a vacuum while the HIP cans are sealed. The total cost for the 4 vacuum pumps is approximately $\$ 8500$. This does not include a control system or installation.

Distribution: N. E. Russell MS 3765, K. L. Williams MS 3765

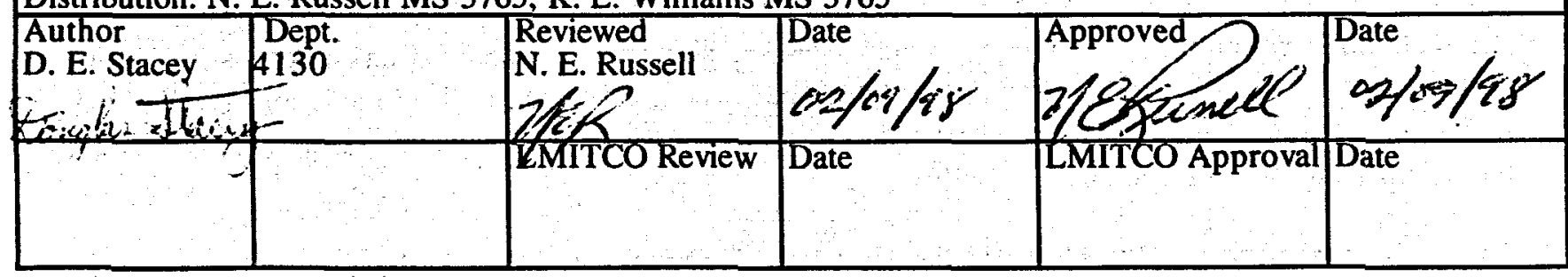




\section{Introduction}

1.1 Description of HIPing Process: The proposed HWO of calcined waste is a result of research that has been performed at the Idaho National Environmental Engineering Laboratory (INEEL), the ICPP, and Argonne National Laboratory-West (ANL-W) for a number of years. The process will convert high level nuclear calcined waste to an impervious, non-leaching glass-ceramic waste form. The HWO calls for HIPing calcined waste using the following process [ref. 1]: All remaining high level liquid waste (HLLW), Sodium-bearing waste (SBW), and other radioactive waste currently stored in the Tank Farm at the Idaho Chemical Processing Plant (ICPP) is calcined. The calcine is temporarily stored in binsets until it can be HIPed. Calcine is taken from storage and blended with dry, organic-free, sized, soil and titanium powder. The blended HIPing mixture is placed into thin-walled stainless steel HIPing cans designed to deform down to a size and shape which will allow $+80 \%$ utilization of storage volume in a standard $2 \mathrm{ft}$ diameter $\times 10 \mathrm{ft}$ storage/disposal canister. A closure cap is welded to the tops of each can which incorporates a venting tube. The latter is capable of being sealed by a standard crimp-and-weld operation. The cans are placed in a devolatilizing fixture in which the vent tubes are connected to a vacuum source and the centerline temperature of the can is raised to $625^{\circ} \mathrm{C}$ for approximately 24 hours. This step removes remaining undesired volatiles from the $\mathrm{HIPing}$ mixture (primarily residual $\mathrm{H}_{2} \mathrm{O}, \mathrm{CO}_{\mathrm{x}}, \mathrm{Hg}$, and $\mathrm{HO}_{\mathrm{x}}$ ), but leaves radionuclides [including $\mathrm{Cs}-137$ ] bound in the HIPing mixture.

After devolatilization, the vent tube on the can is crimped and welded closed. The can is removed from the devolatilization fixture and placed in a non-sealing outer can for potential contamination control prior to placement in the pressure vessel. The outer can and the HIPing can are placed together inside a HIPing machine. The HIPing machine is sealed shut, evacuated, and pressurized with argon gas. The internal heater of the HIPing machine is activated and the cans are heated to $1050^{\circ} \mathrm{C}$ and further pressurized (by heating only) to 20,000 psi. The high temperature causes the can wall and its contents to creep. The high pressure forces the can to collapse on itself yielding the desired impervious, dense, non-leaching, ceramic-glass waste form. The can volume is reduced approximately by one half of its pre-HIPed volume.

HIPing is considered complete once the centerline temperatures of the cans have reached $1050^{\circ} \mathrm{C}$ and remained at that value for 4 hours. The cans are removed from the HIPing machine and moved to a cooling area. Following cooling to near-ambient temperature, the cans are moved to a decontamination area. The cans are decontaminated and non-destructively tested to verify solidification of all the mixture. Cans passing non-destructive testing are packaged in Savannah River shipping canisters and moved to interim storage prior to being sent for final geologic disposal. Three HIP cans will be placed inside one Savannah River shipping canister. Cans not passing nondestructive testing are transported to a dissolution cell where they are sized, ground, and redissolved in concentrated nitric acid solution. The latter is recycled with other liquid tank farm wastes through the calciner and back to the HIPing facility.

1.2 Importance of Can Devolatilization and Evacuation. Devolatilization and evacuation of the HIPing cans prior to HIPing serves two purposes: 1) Maximum size reduction of the HIPing can is realized when the can is evacuated and sealed prior to HIPing. Any volatile compounds present in the HIPing mixture during the actual HIPing process could vaporize and prohibit 
3

maximum compression of the HIPing can, resulting in a "failed" can. 2) Devolatilization will drive off any RCRA "listed" wastes that might be present in the HIPing mixture. The presence of these hazardous wastes would prevent the acceptance of the HIPed waste forms into the designated geologic repository at Yucca Mountain, Nevada [ref. 2].

1.3 Assumptions: The following is a list of assumptions that were made while defining the devolatilizing/evacuation process and equipment:

- The HIPing facility will be designed for a production rate of nine cans per day with ten hours of operation per day and four days of operation per week. Hence, the production rate per week will be 36 cans.

- Equipment was sized to fit a pre-HIPed can 23 inches in diameter by 66 inches high.

- The lid of each HIP can will be fabricated with a vent tube and quick disconnect attached. Each vent tube will contain a small sintered metal filter designed to prevent the passage of calcine.

- The HIP facility's HVAC equipment will be able to keep the devolatilization cell adequately cooled.

- The devolatilization cell will be equipped with manipulators and cameras to facilitate remote operations such as connecting vacuum hoses.

- There will be an off-gas system to treat any gases released during devolatilization. The off-gas system and its related equipment will be covered in a separate Engineering Design File (EDF).

2. Devolatilization Equipment Description: Each filled HIP can will need to be devolatilized for approximately 24 hours. Twelve devolatilization stations in 4 process lines with three furnaces and one vacuum pump per line was selected for performing the devolatilization and evacuation operation. Three process lines will be in operation at any given time with one line maintained in stand-by status.

2.1 Devolatilization Furnaces: There will be a total of 12 furnaces, three per process line. The furnaces will incorporate a clam shell design. Other designs that were considered included: 1) a free-standing top-loaded furnace with lid and 2) a partially "buried" top-loaded furnace with lid. A free-standing top-loaded furnace would require the HIP cans to be lifted more than seven feet off the ground when being loaded and unloaded into the furnace. In addition, the design does not allow for easy replacement of heater elements. The partially "buried" furnace would require that approximately two-thirds ( five feet) of the furnace be embedded in the floor. This would require that the floor depth be increased significantly. This design also presents accessibility problems. The clamshell design allows greater accessibility for servicing activities, and it greatly reduces the lifting height required for loading and unloading of cans.

The devolatilization furnaces incorporate a square split tube design. One half of the furnace includes one side, a bottom, and a hinged half-lid. This part of the furnace is stationary and is attached to the floor. The other half of the furnace consists of three sides and a half-lid. This part of the furnace is mounted on wheels and driven by screw gear to make closing simple and repeatable (See Figure 1). The furnace walls will be made of ceramic fiber. Kanthal A-1 heating elements will be embedded in the ceramic fiber on two sides of the furnace. The sides, lid, and bottom of each furnace will be approximately six inches thick. An outer shell of 16 gauge stainless steel will protect the furnace from damage during can handling operations. The Kanthal A-1 elements are an iron-chrome type 
with a maximum temperature of $2550^{\circ} \mathrm{F}$. The elements will be modularized to facilitate replacement. There will be 3 elements embedded in two sides of each furnace for a total of six elements per furnace. Each devolatilization furnace requires a minimum foot print of approximately 37 inches by 94 inches, and an overhead space of approximately 90 inches.

Each furnace will require $480 \mathrm{~V} 3$ phase power, and will generate $40 \mathrm{~kW}$ with a loading of 12.66 watts per square inch. The surface temperature of the outer shell will be approximately $145^{\circ} \mathrm{F}$. One vender provided a quote of $\$ 50 \mathrm{k}$ per furnace installed. The price included a control system to operate the furnaces remotely. The total price for fabricating and installing 12 furnaces will be approximately $\$ 600 \mathrm{k}$. Individual elements will need to be replaced periodically. It is not known what effect the high radiation fields will have on the furnace materials. This will require further investigation if the HWO proceeds to the conceptual design phase. The wiring and electrical connections for the furnaces will need to be radiation-hardened.

2.2 Vacuum Pumps: There will be a total of 4 vacuum pumps, one per process line. The vacuum pumps will be located in separate cells directly above the devolatilization cells. This will allow easier access for servicing and permit the pumps to be non-radiation hardened. The vacuum pumps will be used to pull a continuous vacuum on the HIP cans during devolatilization. Three cans per devolatilization cell will be manifolded together and connected to one vacuum pump. A condenser/heat exchanger will be located in-line between the HIP cans and each vacuum pump. The condenser will remove $\mathrm{Hg}$ from the off-gas and is considered in a separate EDF [ref: 1]. The vacuum will be increased to 0.5 torr just prior to can closure and sealing. No and $\mathrm{Hg}$ will be present in the devolatilized off-gas. The presence of $\mathrm{No}_{\mathrm{x}}$ will require the selection of a corrosion resistant vacuum pump.

The pump that was chosen for this scoping study is designed to resist corrosion and handle corrosive gases to pressures below $1 \times 10-4$ torr. It features high contamination tolerance, low speed for low wear, and inert components. The pump requires $115 / 230 \mathrm{~V}, 60 \mathrm{~Hz}$ power. Each pump will cost $\$ 2110$. The total cost for the 4 pumps will be approximately $\$ 8440$. This does not include installation or a control system. Each vacuum pump requires a minimum foot print of approximately 49 inches by 36 inches, and stands approximately 40 inches high.

3. Description of Devolatilization Process: The HWO facility will contain four separate process lines. Each process line will consist of a number of separate process cells. In the first process cell, three HIP cans are filled with the calcine mixture and a closure cap welded to the top of each. Each closure cap incorporates a vent tube. The vent tube includes: 1) a small sintered metal filter designed to prevent passage of calcine particles and 2) a quick disconnect fitting for attaching vacuum lines. The cans are then transported by an overhead crane to the devolitilization cell. The crane is used to place each can in a separate devolatilization furnace. The furnaces' screw drives are activated and each furnace is closed. The hinged furnace lids are shut using a master-slave manipulator. Two of these manipulators are located at each devolatilization cell [ref: 3]. The masterslave manipulator connects the HIP cans' vent tubes to vacuum lines using quick disconnects. The vacuum lines are manifolded to the vacuum pump located in a separate cell directly above the devolatilization cell. 
The furnaces and the vacuum pump are turned on. The furnaces raise the centerline temperature of each can to $625^{\circ} \mathrm{C}$ for approximately 24 hours. During this time, the vacuum pump maintains a partial vacuum on the HIP cans to remove any volatiles that are released from the HIPing mixture (primarily residual $\mathrm{H}_{2} \mathrm{O}, \mathrm{CO}_{\mathrm{x}}, \mathrm{Hg}$, and $\mathrm{HO}_{\mathrm{x}}$ ). Any radionuclides [including $\mathrm{Cs}$-137] that are present remain bound in the HIPing mixture. Before passing through the vacuum pump, the off-gas passes through a condenser for recovery of elemental mercury. After passing through the vacuum pump, the off-gas is sent through the facility's off-gas system where it passes through a HEPA filter and a sulfur-impregnated activated carbon filter. The carbon filter removes any remaining $\mathrm{Hg}$ [ref: 1].

At the end of the devolatilization cycle, the HIP can is evacuated to 0.5 torr $(0.01 \mathrm{psi})$ or less, and the vent tube is crimped and welded using the master-slave manipulators. The weld is non-destructively inspected and the cans are transported by overhead crane to the HIPing cell.

4. Items to be Resolved: This report is based on a number of assumptions that may or may not prove to be valid. The following is a list of items involving the devolatilization and evacuation process that will need to be resolved if the HWO proceeds to the design phase:

- A final design for the HIP cans will need to be selected, and the devolatilization furnaces will need to be sized accordingly.

- The control system for the devolatilization furnaces will need to be integrated into the facility's control systems.

- Perform analytical analyses to determine if the facility's HVAC system can adequately cool the devolatilization cells. The rooms may require additional cooling. This could be accomplished by strategically placing cooling water pipes in the room. The water could be circulated through the HIP furnaces' cooling system.

- The manufacturer does not know what effect the high radiation fields will have on the furnace materials. This will require further investigation.

\section{References:}

1. Taylor, D., HWO Scoping Study, EDF-HWO-007, December, 1997.

2. Banaee, J., Environmental Regulations and Standard Repositories Criteria for the Disposal of Waste Forms from the INEEL Proposed High-Level Waste Processing Alternatives, Draft, INEEL/EXT-97-01147, October, 1997.

3. Cox, C. G., HWO Scoping Study, EDF-HWO-005, December, 1997. 


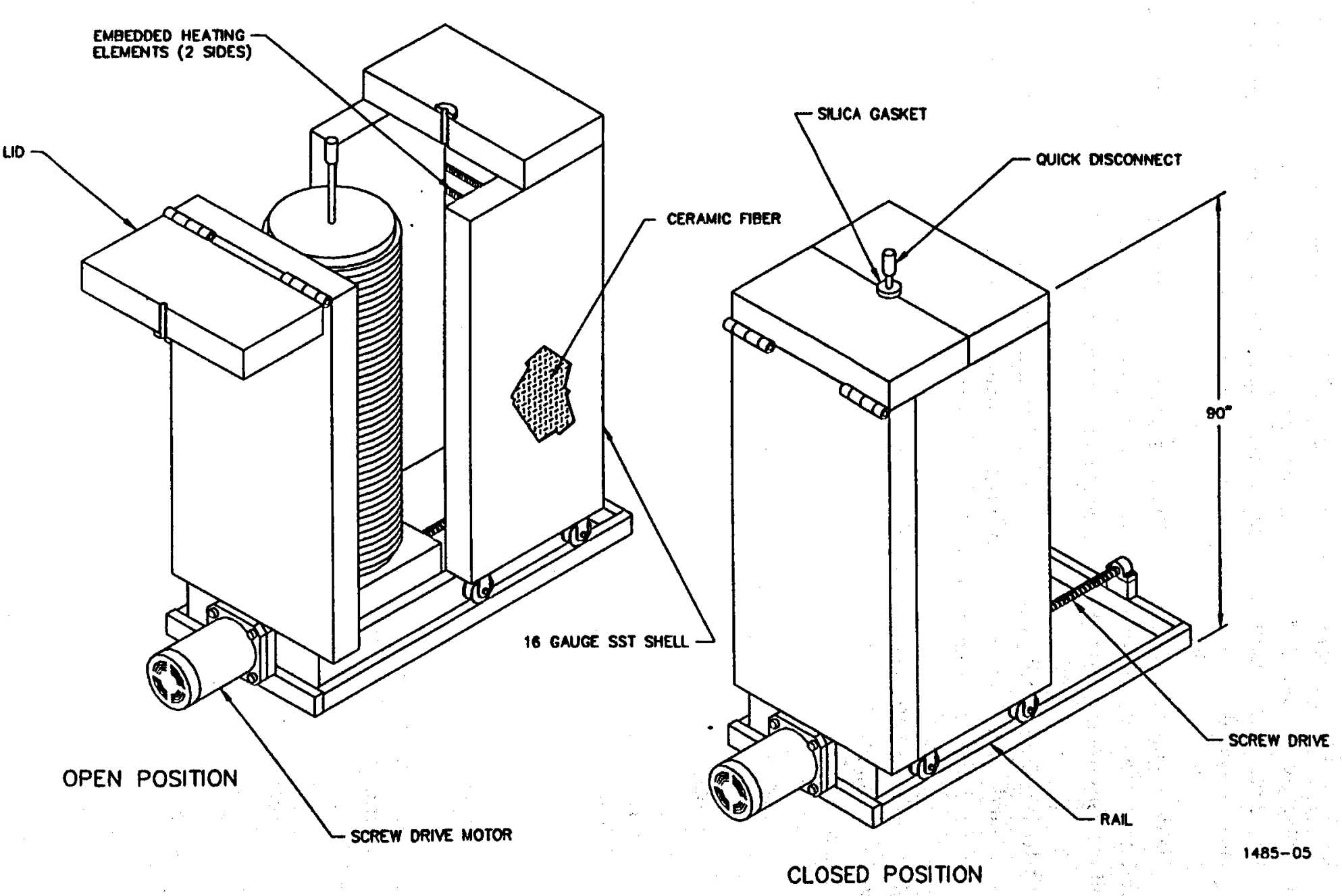

㲵

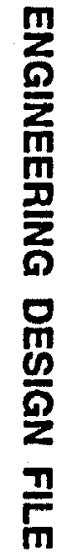

Figure 1

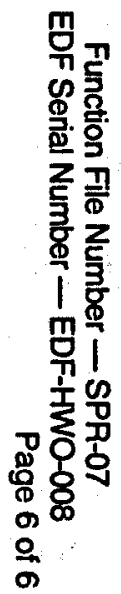


Project File Number $\quad$ 02BGO

Project/Task Waste Treatment Project

Subtask Hot Isostatic Pressing Facility

\begin{tabular}{|c|c|c|c|c|c|}
\hline \multicolumn{6}{|c|}{ Fitle: $\quad$ Electrical Requirements } \\
\hline ummary: & \multicolumn{5}{|c|}{$\begin{array}{l}\text { This EDF evaluated the electrical requirements for the Hot Isostatic } \\
\text { Pressing (HIP) Facility. The connected loads were estimated to be } 12.2 \\
\text { MVA, an evaluation of the usage indicated that the demand would be } \\
\text { approximately } 8.5 \text { MVA. The majority of the demand is from the } \\
\text { HIPing furnaces. These loads would be fed from a load center with a } \\
\text { secondary voltage of } 2,400 \text { Volts or } 4,160 \text { Volts. This load center } \\
\text { would be fed directly from Substation } 2 \text { and standby power would not } \\
\text { be available. Other process loads, facility loads and any standby loads } \\
\text { would be fed from a load center with a secondary voltage of } 480 \\
\text { Volts. This load center would be fed from Power Sectionalizing } \\
\text { Switches located in the northeast quadrant of the plant. These } \\
\text { switches are fed directly from Substation } 15 \text {. Standby power would } \\
\text { be supplied over the normal power distribution system from Substation } \\
60 \text { via Substation } 15 \text { and the Power Sectionalizing Switches. The } \\
\text { standby requirements for this facility are estimated to be } 282 \mathrm{kVA} \text {. }\end{array}$} \\
\hline \multicolumn{6}{|c|}{$\begin{array}{l}\text { Distribution (complete package): } \\
\text { Distribution (summary package only): }\end{array}$} \\
\hline $\begin{array}{l}\text { Author } \\
\text { John E. } \\
\text { Juggan }\end{array}$ & $\begin{array}{l}\text { Dept. } \\
\text { AEDL }\end{array}$ & Reviewed & $\begin{array}{l}\text { Date } \\
2-4-485\end{array}$ & $\begin{array}{l}\text { Approves } \\
\text { NEThuell }\end{array}$ & $\begin{array}{l}\text { Date } \\
02 / 04 / 98\end{array}$ \\
\hline & $2 / 4 / 93$ & $\begin{array}{l}\text { LMITCO } \\
\text { Review }\end{array}$ & Date & \begin{tabular}{|l} 
LMITCO \\
Approval
\end{tabular} & Date \\
\hline
\end{tabular}

See Management Control Procedure (MCP) 6 for instructions on use of this form. 


\section{HOT ISOSTATIC PRESSING}

\subsection{ELECTRICAL REQUIREMENTS}

\subsection{EXISTING AND PLANNED ELECTRICAL UTILTIIES AT ICPP}

The ICPP ties into the $138 \mathrm{kV}$ INEL loop at Substation 2 which is located outside the area fence to the south. Substation 2 transforms the $138 \mathrm{kV}$ to $13.8 \mathrm{kV}$ and provides power to Substation 10 which is located within the ICPP complex. Power at $13.8 \mathrm{kV}$ is than distributed from Substation 10 through the complex. The Electrical and Utility System Upgrade (EUSU) project is currently under construction. The EUSU project will install a new $13.8 \mathrm{kV}$ electrical distribution system throughout the complex. This new system will provide greater safety, additional capacity and greater reliability.

Currently, standby power is provided by each facility. Standby generators are located at various facilities and operate as an island of power during a normal power outage. The EUSU project will construct a standby power plant, install new standby generators and tie existing generators into the standby power system. Standby power will than be distributed through the complex by the new $13.8 \mathrm{kV}$ distribution system, The Utility Control System (UCS) will control the usage of standby power.

\subsection{POWER REQUIREMENTS}

\subsubsection{NORMAL POWER}

The electrical requirements of the Hot Isostatic Pressing (HIP) Facility were analyzed and determined to be $12,180 \mathrm{kVA}$ connected, with a demand projected to be $8,472 \mathrm{kVA}$. The results of the analysis are shown in Tables 1 and 2 . The major loads with the HIP Facility are the furnaces, air compressors, HVAC equipment, and lighting.

Normal power will be supplied to the HIIP Facility by $13.8 \mathrm{kV}$ feeders from Substation 15. A combination of new and existing duct banks will be used to route the feeders. 


\subsubsection{STANDBY POWER}

The requirements for standby power for the HIP Facility were analyzed and determined to be $212 \mathrm{kVA}$. The results of the analysis are shown in Table 3 . The standby loads for the HIP Facility will consist of the following:

- UPS Normal and Bypass feeders

- Selected lighting and miscellaneous loads

- Exhaust and supply fans

- Other loads as determined in later designs

Standby power to the HIP facility will be provided over the normal power distribution system from Substation 60, the Standby power plant substation via Substation 15. The standby power system is at or near capacity. Upon completion of the EUSU project, an evaluation of the spare capacity will be performed. If necessary, a $2000 \mathrm{kVA}$ diesel generator and associated equipment will be installed in the space available in the standby generator plant. Shedding of the non-essential loads will be performed by the UCS. The UCS will control the operation of circuit breakers and equipment to assure that only those loads requiring standby power remain in operation

\subsubsection{DISTRIBUTION SYSTEM}

Both normal and standby power will be provided by one set of redundant feeders. The EUSU project will install a redundant pair of sectionalizing switches in the north east quadrant of the complex. These switches, PSS-NCE-1507A and PSSNCE-1557A are supplied by one set of 500KCMIL cables each. These are switches are fed directly from Substation 15 and are very lightly loaded. New duct banks will be run from these switches to a new load center. The load center will be double ended and will provide a redundant source of power to the HIP facility.

\subsubsection{UNINTERRUBTABLE POWER SUPPLY (UPS)}

A solid state UPS with a static transfer switch will be provided. The UPS will be provided with a 20 minute battery backup. Both the normal feed and the bypass feed to the UPS will be on standby power. The UPS will feed a 208Y/120 Volt panel. The UPS and the panel will be located in the electrical room. The UPS will support the following loads: Voice paging/evacuation systems, environmental monitoring system and other critical loads. 


\subsection{LIGHTING}

\subsubsection{INTERIOR LIGHTING}

Lighting in office areas and other low ceiling areas will be supplied by recessed of pendant mounted fluorescent fixtures. These fixtures will be operated at 277 Volts and will be locally switched. Motion detectors will be utilized areas of low occupancy. Lighting in high bay areas will be will be supplied by metal halide fixtures operating at 277 volts. The metal halide fixtures will be switched at the lighting panel.

\subsubsection{CELL LIGHTING}

Lighting in the cells will be designed to allow for remote operation of the equipment via an in cell CCTV system or by operation through cell windows. Lighting of the cells will be indirect. Translucent panels will be provided on the top of the cells and on the side walls as required. Fixtures will be mounted so that maximum light is directed into the cell and so that the fixtures are easily accessible for maintenance. The light source will be metal halide. The lighting design will take into account light loss through the translucent panels as well as the light lost in viewing operations through the cell windows.

\subsubsection{EXTERIOR LIGHTING}

The exterior of the building will be illuminated with high pressure sodium wall pack fixtures mounted over each personnel door. Loading areas will be provided with high pressure sodium pall pack fixtures on each side of the doors. The need for area lighting in maneuvering areas will be evaluated during the conceptual and final designs.

\subsubsection{EMERGENCY AND EXIT LIGHTING}

Emergency egress lighting will be in accordance with NFPA 101, Life Safety Code. In areas where illumination is provided by fluorescent fixtures, selected fixtures will be provided with integral battery back up. In areas where illumination is provided by metal halide fixtures, selected fixtures will be provided with a quartz lamp which will be used for emergency lighting. The quartz lamp will be connected to the UPS system or will be provided with an integral battery. 


\subsection{DESIGN DESCRIPTION}

\subsubsection{SITE CONDITIONS}

Electrical equipment will be rated for continuous operation at an elevation of 5,000 feet above sea level.

\subsubsection{HAZARDOUS LOCATIONS}

Several areas within the facility will be used for storing or handling of hazardous materials. An evaluation will be performed during the conceptual design and the final design to determine the effects of these materials on the installation of electrical equipment. Flammable and Combustible Liquids Codes NFPA 30:

National Electrical Code, NFPA 70; and Recommended Practice for Classification of Class I Hazardous Locations for Electrical Installations in Chemical Process Areas, NFPA 497A will be used in making the determination.

\subsubsection{SERVICES}

\subsubsection{PRIMARY SERVICE}

Two $13.8 \mathrm{kV}$ feeders will provided the primary service to the site. The feeders will originate from Substation 2 located outside the fence. Power for the HIP Facility will be carried over existing feeders up to Substation 15. From Substation 15 , new feeders will be routed through new and existing duct banks.

\subsubsection{STANDBY POWER}

Standby power will be provided at $13.8 \mathrm{kV}$ over the existing primary distribution system. The existing UCS in conjunction with the Plant Control System which will be installed in the HIIP facility will control selected circuit breakers to limit the standby power distribution only to those loads deemed important.

\subsubsection{UTILIZATION VOLTAGES}

Three and possibly four utilization voltages will be provided for the HIP facility. Transformers and load centers located near the facility will transform the $13.8 \mathrm{kV}$ to $480 \mathrm{Y} / 277$ Volt, transformers down stream will transform the 480 Volts to $208 Y / 120$ Volts. The third and fourth utilization will be determined during the conceptual and title designs. $4160 \mathrm{Y} / 2400$ Volts is desired as the third utilization however, the ICPP currently utilizes 2400 Y/1386 Volts. Preferably, only one will be used. Equipment selection and operating personnel preference will determine the voltage to be utilized. 
Electrical loads will be assigned voltages as follows:

- Motors $100 \mathrm{HP}$ and larger $-4160 \mathrm{~V}, 3$ phase or $2400 \mathrm{~V}, 3$ phase

- Resistive loads $100 \mathrm{kVA}$ and larger $-4160 \mathrm{~V}, 3$ phase or $2400 \mathrm{~V}, 3$ phase

- Motors $1 / 2 \mathrm{HP}$ to less than $100 \mathrm{HP}-480 \mathrm{~V}, 3$ phase

- Resistive loads $1 \mathrm{kVA}$ to less than $100 \mathrm{kVA}-480 \mathrm{~V}, 3$ phase.

- Motors less than $1 / 2$ HP $120 \mathrm{~V}$, single phase

- Miscellaneous loads less than $1 \mathrm{kVA}-120 \mathrm{~V}$, single phase

- Lighting - 277V single phase.

In certain circumstances, $480 \mathrm{~V}, 3$ phase will be utilized for motors over $100 \mathrm{HP}$ and loads over $100 \mathrm{kVA}$. This will be determined on an individual basis after the effects have been evaluated.

\subsubsection{EQUIPMENT}

\subsubsection{LOAD CENTERS}

Two load centers will be provided. These load centers will be located outside the HIP Facility and will be a NEMA 3R Walk-in type similar the load centers currently in use at the ICPP. One load center will provide $480 \mathrm{Y} / 277$ Volts and the other will provide either $4160 \mathrm{~V}$ or 2400 Volts. The load centers will be double ended and each transformer will be sized to provide service to all loads on the load center. Load Centers will be provided with all equipment and wiring to insure that they are fully compatible with the existing UCS System.

\subsubsection{TRANSFORMERS}

Transformers 5,000 kVA and below will be cast coil, dry type transformers. Transformers over 5,000 kVA will be oil filled.

\subsubsection{LIGHTING}

Lighting levels will conform the Illuminating Engineer's Society (IES) handbook and standard practices at the ICPP. In general, the design will provide the following illumination levels:

- Work Stations 70 foot candles

- Work Areas 30 to 50 foot candles depending on activity

- Non-Work Areas 10 foot candles, 50 where data is obtained 


\subsubsection{GROUNDING}

Grounding at the ICPP is accomplished with bare copper conductors installed in all duct banks and ground rods installed in every manhole this in turn is solidly connected to the casing of the deep wells. Facilities and structures throughout the ICPP are connected to this ground system. As well, the HIP facility will be connected to the ground system. Grounding within the facility and at the outdoor load centers and other structures will be accomplished in accordance with the National Electrical Code and IEEE Standard 142-1991, IEEE Recommended Practice for Grounding of Industrial and Commercial Power Systems.

\subsubsection{LIGHTNING PROTECTION}

Lightning protection will be provided in accordance with NFPA 78, Lightning Protection Code. 
TABLE 1

\section{WASTE TREATMENT PROJECT FEASIBILITY STUDIES}

CONNECTED LOAD HOT ISOSTATIC PRESSING

\begin{tabular}{|c|c|}
\hline LOAD & kVA \\
\hline $\begin{array}{l}\text { General Building Lighting } \\
168,952 \text { sq. Ft @ 1.75 Watts per sq. Ft = 296,666 Watts }\end{array}$ & 296 \\
\hline $\begin{array}{l}\text { Miscellaneous Loads } \\
168,952 \text { sq. Ft. @ } 1.0 \text { Watts per sq. Ft =168,952 Watts }\end{array}$ & 169 \\
\hline $\begin{array}{l}\text { HVAC Loads: } \\
\text { Supply Fan Motors } \\
3 @ 50 \text { HP } \\
\text { Exhaust Fan Motors } \\
\text { 3@75 HP } \\
\text { Miscellaneous HVAC } \\
100 \text { HP Small Motors }\end{array}$ & $\begin{array}{l}150 \\
225 \\
100\end{array}$ \\
\hline $\begin{array}{l}\text { Process Equipment: } \\
\text { Heaters: } \\
\quad 12 \text { HIP Vessels @ 800KW } \\
\text { Devolatization equipment } 12 @ 40 \mathrm{KW} \\
\text { Compressors; } \\
\quad 8 @ 100 \mathrm{HP}\end{array}$ & $\begin{array}{r}9600 \\
480 \\
\\
800\end{array}$ \\
\hline $\begin{array}{l}\text { Welding Equipment } \\
4 @ 40 \mathrm{kVA}\end{array}$ & 160 \\
\hline $\begin{array}{l}\text { Miscellaneous Process } \\
\text { Size Grind } 4 @ 50 \mathrm{HP} \\
\text { Cranes } \quad 100 \mathrm{hp} \\
\end{array}$ & $\begin{array}{l}200 \\
100 \\
\end{array}$ \\
\hline Total Connected kVA & 12280 \\
\hline
\end{tabular}




\section{TABLE 2}

\section{WASTE TREATMENT PROJECT FEASIBILITY STUDIES}

\section{DEMAND}

HOT ISOSTATIC PRESSING

\begin{tabular}{|c|c|c|}
\hline LOAD & DEMAND & kVA \\
\hline $\begin{array}{l}\text { General Building Lighting } \\
168,952 \text { sq. Ft @ } 1.75 \text { Watts per sq. Ft }=296,666 \text { Watts }\end{array}$ & $296,666 @ 90 \%$ demand & 267 \\
\hline $\begin{array}{l}\text { Miscellaneous Loads } \\
168,952 \text { sq. Ft. @ } 1.0 \text { Watts per sq. Ft }=168,952 \text { Watts }\end{array}$ & $168,952 @ 50 \%$ demand & 85 \\
\hline $\begin{array}{l}\text { HVAC Loads: } \\
\text { Supply Fan Motors } \\
\text { 3@50 HP } \\
\text { Exhaust Fan Motors } \\
\text { 3@75 HP } \\
\text { Miscellaneous HVAC } \\
100 \text { HP @75\% } \\
\end{array}$ & $\begin{array}{l}2 @ 50 \mathrm{HP} \\
2 @ 75 \mathrm{HP} \\
\text { 100HP@75\% demand }\end{array}$ & $\begin{array}{r}100 \\
150 \\
50 \\
\end{array}$ \\
\hline $\begin{array}{l}\text { Process Equipment: } \\
\text { Heaters: } \\
12 \text { HIP Vessels @ } 800 \mathrm{KW} \\
\text { Devolatization equipment } 12 @ 40 \mathrm{KW}\end{array}$ & $\begin{array}{r}\text { 9600KW @ 75\% demand } \\
\text { 480KW @ 75\% demand }\end{array}$ & $\begin{array}{r}7200 \\
360\end{array}$ \\
\hline $\begin{array}{l}\text { Compressors; } \\
8 @ 100 \mathrm{HP}\end{array}$ & $1 @ 100 \mathrm{HP}$ & 100 \\
\hline $\begin{array}{l}\text { Welding Equipment } \\
4 \text { @ 40kVA }\end{array}$ & $1 @ 40$ kVA & 40 \\
\hline $\begin{array}{l}\text { Miscellaneous Process } \\
\text { Size Grind } 4 @ 50 \mathrm{HP} \\
\text { Cranes } \quad 100 \mathrm{HP} \\
\end{array}$ & $\begin{array}{l}1 @ 50 \mathrm{HP} \\
1 @ 70 \mathrm{HP} \\
\end{array}$ & $\begin{array}{l}50 \\
70 \\
\end{array}$ \\
\hline Total Demand kVA & & 8472 \\
\hline
\end{tabular}




\section{TABLE 3}

\section{WASTE TREATMENT PROJECT FEASIBILITY STUDIES}

\section{STANDBY POWER REQUIREMENTS HOT ISOSTATIC PRESSING}

\begin{tabular}{|l|l|r|}
\hline \multicolumn{1}{|c|}{ LOAD } & \multicolumn{1}{|c|}{ STANDBY POWER } & \multicolumn{1}{c|}{ kVA } \\
\hline General Building Lighting & $10 \%$ of $296,666=29,667$ & 30 \\
\hline Miscellaneous Loads & $10 \%$ of $168,952=16,895$ & 17 \\
\hline HVAC Loads & & 50 \\
Supply Fan Motors 3@50 HP & $1 @ 50 \mathrm{HP}$ & 75 \\
Exhaust Fan Motors 3@75 HP & $1 @ 75 \mathrm{HP}$ & 10 \\
Miscellaneous HVAC 100HP & $10 \%$ of 100HP & 70 \\
\hline Process Equipment & 1 @ $70 \mathrm{HP}$ & 282 \\
\hline Cranes & & \\
\hline Total Standby kVA & & \\
\hline
\end{tabular}


Project File Number 02BGO

Project/Task Non-Separation Alternatives

Subtask Hot Isostatic Press (HIP) Option

Title: Hipping Waste Option (HWO) Staffing Estimate

Summary:

This EDF addresses the estimate of the total staffing requirement for the Hot Isostatic Press (HIP) Waste Option (HWO). The estimate was made based upon the level of detail that was developed to perform this scoping study which includes general facility process flow description depicting each major process operation, a general facility layout description, and a worded description of the sequential operating steps. This staffing requirement was less labor intensive than some of the other alternatives due to the need to automate much of the process.

Essentially all of the actual Hot Isostatic Press operation is non-contact and will employ robotic manipulators and be remotely controlled. This process design is based on 4 operating days per week and 10 hours per operating day with a 50 percent downtime for scheduled and unscheduled maintenance. The required operating coverage for this process assumes the inclusion of a skeleton (reducedsize) crew of 4 operating personnel on a rotating 24 hour schedule for the 4 operating days per week. These 4 personnel work 10 hour shifts 4 days per week for monitoring of HIP canisters in processing and general follow-up of HIP Canisters in the cool-down cycle. Due to the high degree of automation equipment included in this process, there are specially trained maintenance personnel required. This maintenance function has been allocated to occur both on the 10 hour day shift and on a 10 hour night shift. During the night shift, the operations are essentially shutdown so the maintenance function can be carried out more effectively. The total estimated staffing requirement is 78 personnel which is broken down into 29 on-line operators, 15 on-line maintenance personnel and 34 support staff of varied disciplines.

Distribution (complete package): WTP EIS Studies Library, D.J.Harrell MS 3211, B.R.Helm MS 3765, V.L.Jacobson MS 3211, R.T.Jamison MS 4146, D.D.Taylor MS 3625, N.E.Russell MS 3765, K.L.Williams MS 3765, W.J.Prendergast MS 3710

Distribution (summary package only):

\begin{tabular}{|c|c|c|c|c|c|}
\hline $\begin{array}{l}\text { W. J. } \\
\text { Prendergast }\end{array}$ & 4170 & $\begin{array}{l}\text { R.T. Jamison } \\
\text { ก. Yyamison }\end{array}$ & Date & $\begin{array}{l}\text { Approved } \\
\text { N. E Russell } \\
\text { it }\end{array}$ & $\begin{array}{l}\text { Date } \\
0 / 67 / 98\end{array}$ \\
\hline wa & & $\begin{array}{l}\text { LMITCO } \\
\text { Review } \\
17-72,7\end{array}$ & Date & $\begin{array}{l}\text { LAITCO } \\
\text { Approval }\end{array}$ & Date \\
\hline
\end{tabular}

See Management Control Procedure (MCP) 6 for instructions on use of this form. 
Summary

This EDF identifies a total staffing requirement of 78 personnel made up of the following categories; on-line operations, on-line maintenance, administration, supervision, engineering, security, health and safety (Radcon), industrial safety, process development and facility maintenance. This estimate is based upon a review of all available engineering documentation. The total break-out of staffing is as follows:

Operations:

- Receiving Systems;

- Calcine Retrieval/Off-Spec Hnd'Ig 2 - HIP Can Filling (3 Oper'ng trains) 4

- Off-gas Systems

- $2^{\prime} \times 10^{\prime}$ Canister Loading

- Cool-down/decon/test/follow-up

\section{per day (unless noted otherwise)}

\section{2 3 2}

4/shift, 16 total

$\overline{29 \text { total }}$

Maintenance:

- Machinists (Spec. Trained)

- Boilermakers (Spec. Trained)

- Pipefitters

- Inst. \& Elec. Control

per day

5

3

4

3

$1 \overline{5 \text { total }}$

Support Staffing:

- Administration

- Administration Support 3

- Supervision 8

- Engineering Tech. Support 5

- Security 2

- Health and Safety (Radcon) 8

- Industrial Safety 2

- Process Development 2

- Facility Maintenance 2

Total Staffing Requirement: $\quad 7 \overline{8 \text { total }}$ 


\section{ENGINEERING DESIGN FILE}

Project/Task:

Subtask: HIP Waste Option

EDF page 1 of $\underline{4}$

Title: Recycle Sizing Cell

Abstract In the Hot Isostatic Press (HIP) waste processing there will be a small portion of the HIPed cans which will be recycled into the process due to Quality Assurance destructive examination of a representative portion of the cans or failure of the cans to meet output specifications. The HIPed material in these cans will need to be reduced to a granular size which can be placed back into the HIP process stream. This EDF documents a sizing operation which can be performed in a small cell. Included is a step by step process, an equipment list and a sketch of the equipment layout.

Distribution:

\begin{tabular}{|c|c|c|c|}
\hline $\begin{array}{l}\text { Author } \\
\text { Ted R. Reed }\end{array}$ & $\begin{array}{l}\text { Dept. } \\
4130\end{array}$ & 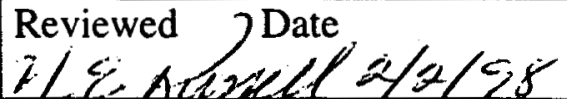 & $\begin{array}{l}\text { Approved } 7 \text { Date } \\
7 / / E_{2} / \text { Lenclle } 2 / 2 / 95\end{array}$ \\
\hline
\end{tabular}


This EDF discusses a method to reduce the HIPed monoliths of reject and QA cans to a granular form which can be fed back into the process and re-HIPed. The object of this method is to use equipment which is small and thus fit into the available space.

Step 1 Reject HIP can is received into the cell through a double door port. Transfer in the cell will be by means of an overhead crane.

Step 2 Wafers are sliced off the can using a large concrete saw. This saw assembly will have a 36 inch diameter concrete saw which is capable of two axis motion to properly position the blade on the HIP can. The can will be mounted on a rotary table which can be turned by an out-cell mounted manual turn wheel or electric motor. Dust and particle debris will be collected in a vacuum dust collection system connected to a lexan dust hood which will enclose the cutting operation.

Step 3 Wafers are lifted from the concrete saw to the screw press. An electromechanical manipulator using an 'ice tong' type of tool will lift the approximately 4 inch thick wafers from the saw to the screw press. The top of the press will swing out of the way to allow top placement of the wafer into the press.

Step 4 Wafers are crushed in the screw press. The 250 ton press will crush the wafers into approximately 4 inch chunks. The press uses a curved surface die to assure that the wafer sections will be placed in a bending mode which will allow the wafer sections to fail in tension, the weakest failure mode for these types of materials. The can material will be placed in a separate hopper for disposal. A $5 \mathrm{hp}$ motor will. power the press and can be mounted outside the cell. A screw press is used to preclude hydraulic fluid leaks in the cell.

Step 5 Wafer sections are moved from the screw press to the jaw crusher using master slave manipulators, electromechanical manipulators and the vacuum system.

Step 6 The jaw crusher will reduce the 4 inch pieces to approximately $1 / 16$ in granules. The 5 horsepower crusher has a rated capacity of $1800 \mathrm{lb} / \mathrm{hr}$. Discharge from the crusher will fall directly into a granule/dust hopper which will also receive dust from the dust collection system.

Step 7 The HIPed calcine dust and granules will be pneumatically transferred to the fill station for re-entry into the HIP process.

Step 8 The can material will be compacted in the screw press and bagged out of the cell. 


\section{Assumptions}

1) Maximum rate of handling will be 1 reject HIP can per week per recycle cell.

2) Alpha contamination will not be a big problem.

3) 1/16 inch granule size can be handled by the main HIP process system.

4) Stainless steel skin on cans can be broken away from the HIPed calcine.

5) Grinding the HIPed calcine will be inherently dusty. Manned entry into the cell will require considerable cell clean-up.

\section{Equipment List}

1) Overhead Crane, 2 Ton

2) Electromechanical Manipulator, $500 \mathrm{lb}$ lift capacity

3) Manipulator, master/slave, 2 each

4) Concrete saw, 36 in diameter, $10 \mathrm{hp}$, mounted on $x-y$ table, custom designed

5) 250 ton screw press, $5 \mathrm{hp}$, custom designed

6) Jaw crusher, $5 \mathrm{hp}$

7) Dust collection system, custom designed

8) Pneumatic transfer system, custom designed

9) Wafer handling tool

10) Rotating positioning table 


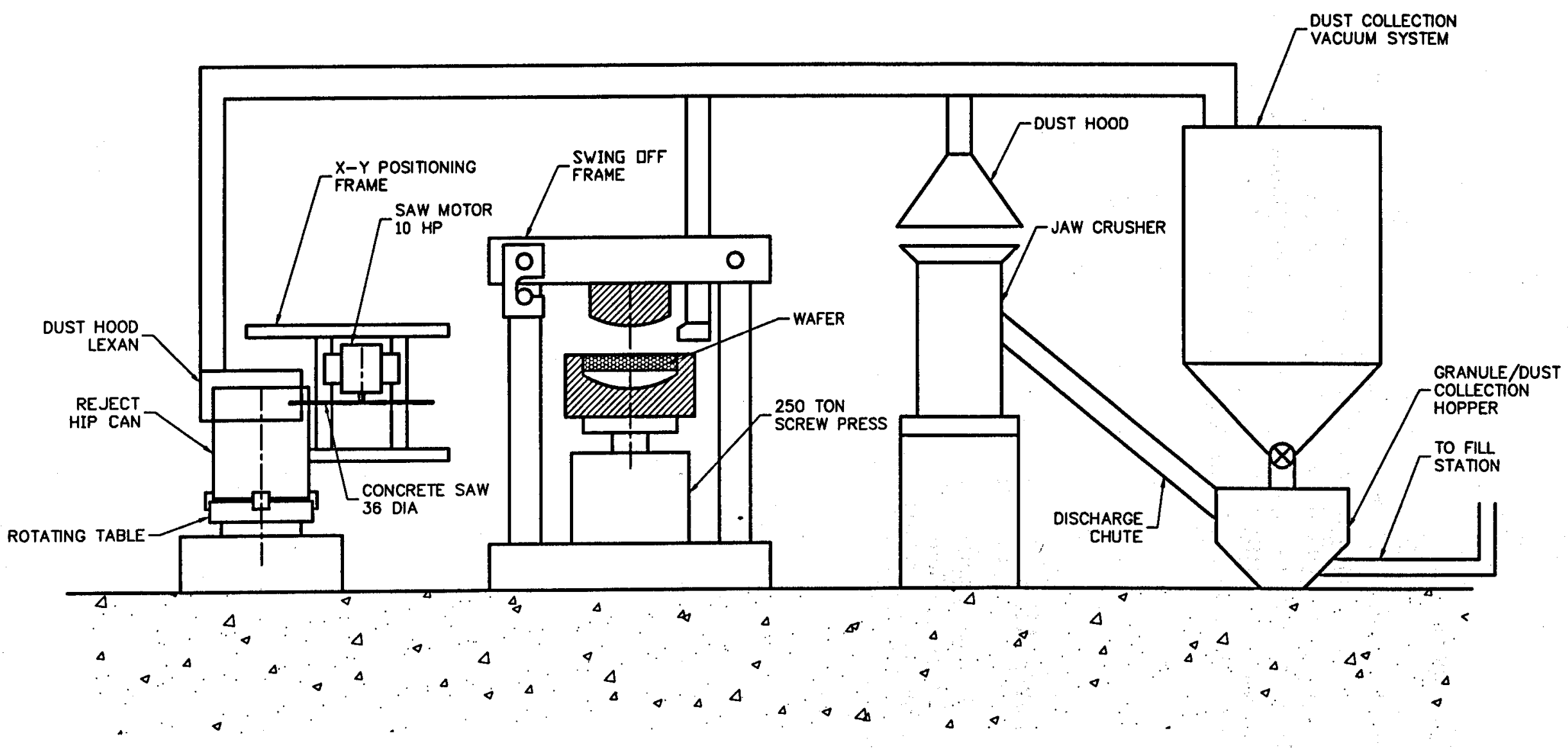

RECYCLE CELL EQUTPMENT SKETCH 
Project File Number

02BG0

Project/Task Waste Treatment Project Feasibility Studies

Subtask HWO Scoping Study

Title: HIP'ing Waste Option (HWO) Design Basis

Summary: This EDF describes the proposed process for the HIP'ing Waste Option (HWO) for treating high level radioactive waste calcine at the Idaho Chemical Processing Plant (ICPP) at the Idaho National Engineering and Environmental Laboratory (INEEL). The process consists of blending the calcine with suitable additives consisting of amorphous silica and titanium powder, devolatalizing the mixture, and hot isostatic pressing (HIP'ing) it at $1050^{\circ} \mathrm{C}$ and 20,000 psi to obtain a non-leaching, inert, durable waste form. The HWO process facility will be designed to operate 10 hours per day and four days per week. A process description, operational steps, processing rates, material balances, equipment lists, utility requirements and process flow sheets are provided.

Distribution (complete package): WTP EIS Studies Library, K. L. Williams M.S. 3765 , N.E. Russell M.S. 3765

Distribution (summary package only):

\begin{tabular}{|c|c|c|c|c|c|}
\hline $\begin{array}{l}\text { Author } \\
\text { D. D. Taylor }\end{array}$ & $\begin{array}{l}\text { Dept. } \\
4170\end{array}$ & $\begin{array}{l}\text { Reviewed } \\
\text { A. P. Pinto } \\
\text { R. R. Kimmitt }\end{array}$ & $\begin{array}{l}\text { Date } \\
12 / 4 / 97 \\
1 / 27 / 98\end{array}$ & Approved & $\begin{array}{l}\text { Date } \\
02 / 04 / 98\end{array}$ \\
\hline & & $\begin{array}{l}\text { LMITCO Review } \\
\text { APP jite } \\
\therefore \text { Lemmiz }\end{array}$ & $\begin{array}{l}\text { Date } \\
/ 2 / 4 / 6\end{array}$ & LMITCO Approval & Date \\
\hline
\end{tabular}




\section{REQUIREMENTS}

Process requirements are established by statutory laws, DOE orders, and the Batt agreement between DOE and the State of Idaho. These requirements are described in detail in Ref. 2.

\section{DESIGN BASIS AND ASSUMPTIONS}

\subsection{Background}

The process described below (the "HIP'ing Waste Option", hereafter referred to as the HWO - process) is based on a decade's collaborative research between the Idaho Chemical Processing Plant (ICPP) and the development and testing performed at the INEL $\mathrm{IS}^{3,4,5}$ on surrogate wastes. The process was invented by researchers at Battelle Columbus Laboratories in 1955, and involves heating and pressurizing a siliceous mixture until the point is reached at which phase transformation occurs, resulting in the formation of a glass-ceramic having 40-60\% higher density than the starting mixture, and possessing waste immobilization properties similar to those of borosilicate glass.

\subsection{Assumptions}

The following assumptions have been made in developing the HWO process:

1) All current liquid tank farm waste at ICPP will be calcined. Compositions and quantities of existing stored calcines, and of calcines that will yet be generated are as described in Ref. 1;

2) Calcine will be retrieved from binsets into short term storage/mixing hoppers. After the hopper is filled the contents are homogenized by mixing, and characterized sufficiently to select which one of a set of roughly ten pre-determined recipes is appropriate to use in HIP'ing the hopper contents;

3) HIP'ing additives will also be stored in short term storage hoppers. Each hopper homogenizes the bulk additive sufficiently that the contents may be considered to be completely uniform for purposes of HIP'ing per specification of any given recipe;

4) Calcine will be dry blended with HIP'ing additives in a suitable dry solids mixer;

5) HIP'ing will be done in stainless steel HIP'ing cans designed to deform to a size and shape that allows at least $80 \%$ utilization of the internal volume in a standard $2 \mathrm{ft}$ diameter $\times 10 \mathrm{ft}$ storage/disposal canister. The pre-HIP can dimensions will be determined by further research and development;

6) Vibration of the HIP'ing can during filling will be sufficient to achieved the required degree and uniformity of compaction prior to HIP'ing;

7) Mixing beyond the bulk mixing described in item 4 will not be required;

8) Sizing of calcine and cold additives [INEEL soil or equivalent and $\mathrm{Ti}$ (or $\mathrm{Al}$ ) metal] to 80 mesh $(180 \mu \mathrm{m})$ is required to achieved an acceptable HIP'ed waste form; 
9) A high-integrity seal can be achieved between the vent tube on each HIP'ing can and a vacuum manifold at temperatures typical of the devolatilization step $\left(650^{\circ} \mathrm{C}\right)$. A vacuum pressure of approximately 0.5 torr can be established, and a high-integrity crimp weld can be made (without cooling the can) which preserves the above level of vacuum within the can throughout the HIP'ing process;

10) Pressurization during the HIP'ing step will be achieved with argon gas;

11) All HIP'ed cans will be non-destructively tested to verify solidification of all the mixture. $1 \%$ of HIP'ed cans will be intrusively sampled to verify compliance with disposal facility waste acceptance criteria, and will require recycle;

12) $1 \%$ of HIP'ed cans will be offspec (unacceptable for disposal), and will be recycled by sizing, grinding, and rerouting to the temporary calcine storage bin;

13) Secondary solid and liquid waste streams generated by the HIP'ing process (e.g., decontamination wastes, liquid spills, filtered solids, etc.) must be accommodated by the HIP'ing process. Therefore, dissolution, evaporation, and calcination capabilities will be maintained throughout the HIP'ing program in order to able to recycle all wastes generated to the HIP'ing process.

14) No radioactive components of the waste will escape from the HIP'ing mixture during the devolatilization step. This assumption is based on the premise that alkali silicates will be formed on heating the mixture such that all alkali metals (including Cs-137) will be retained during devolatilization of filled HIP cans;

15) Calcination of existing tank farm wastes be complete by $12 / 31 / 2012$. Direct HIP'ing of calcine will begin on 01/01/13 and processing will be completed in 20 years.

16) Plant online factor is $50 \%$. This figure accounts for all scheduled down time, unscheduled downtime, and process inefficiency.

17) All waste operations (except calcination) will be performed in one $10-\mathrm{hr}$ shift per day.

18) The devolatilization and HIP'ing steps each require $24 \mathrm{hrs}$ to complete.

19) The average dry HIP'ing mixture consists of the following components (wt \%):

- Calcine: $70.0 \%$ (bulk density $=1.41 \mathrm{gm} / \mathrm{cm}^{3}$ )

- INEL soil: $25.0 \%$ (bulk density $=1.20 \mathrm{gm} / \mathrm{cm}^{3}$ )

- Titanium metal:5.0\% (bulk density $=2.25 \mathrm{gm} / \mathrm{cm}^{3}$ )

20) Dry titanium powder additive for HIP'ing will be trucked to ICPP and pneumatically offloaded to storage bins.

21) INEL soil used as a HIP'ing ingredient will be extracted from the subsurface and will require only heat treatment at $500^{\circ} \mathrm{C}$ (to eliminated organic matter) and sizing (sieving) prior to use in HIP'ing process. 
22) Radionuclide contamination during all waste processing operations is controlled by maintaining negative pressure inside all waste handling areas. Building air is double HEPA filtered to remove particulate radioactive contamination.

23) Mercury in the offgas from the devolatilization step will be extracted from the offgas by condensation and/or adsorption on suitable materials. Elemental mercury extracted by condensation will be amalgamated and disposed as low-level radioactive waste.

NOTE: This assumption presupposes that a delisting petition will be granted by EPA for ICPP calcines

\section{PROCESS DESCRIPTION}

\subsection{Process Steps}

The processing steps for the HIP'ing Waste Option (HWO) are shown schematically on the process flow diagrams for the HWO process (Section 10). These steps are described below.

\subsubsection{Main Process}

The conceptual process description below is applicable to a single processing line. The actual scoping design of the processing facility utilizes multiple such lines. Steps in the main process for HIP'ing waste are as follows:

1) High-level radioactive waste calcine stored at ICPP in the Calcine Solids Storage Facility (CSSF) binsets is remotely retrieved and pneumatically transported to a sizing operation (ball mill) where it is ground to pass an $\mathbf{8 0}$ mesh screen. After sizing, the calcine is deposited into a temporary mixing/storage bin (MB-201A in Dwg HIP-02);

2) Once MB-201A (or B, C, or D) is filled, its contents are thoroughly homogenized and then sampled, analyzed, and characterized. Based on the characterization, a HIP'ing "recipe" is selected from a set of roughly ten recipes developed prior to the start of processing waste, based on the expected range of calcine composition in the binsets;

3) Calcine is dry-blended with suitable cold ingredients (dry, organic-free, sized INEEL soil [or equivalent] and titanium powder) in proportions specified by the selected recipe in a suitable solids blender (RB-001 in Dwg HIP-00);

4) The blended mixture is gravimetrically metered into a stainless steel HIP'ing can. A load cell on the filling station is used to determine when the proper mass of mixture has been added (CV-001 in Dwg HIP-00). A polyethylene liner will be inserted in each can prior to filling, and will be sealed shut upon completion of the filling operation;

5) A closure cap (with a suitable venting tube and HEPA filter) is welded to the top of the can (WS-001 in Dwg HIP-00);

6) The can is dry decontaminated using $\mathrm{CO}_{2}$ blast decon to remove loose contamination that could be spread through the facility (V-301 in Dwg HIP-03); 
7) The filled can is moved to a devolatilizing fixture in which the vent tube is connected to a 2" W.C. vacuum source, and the centerline temperature of the can is raised to approximately $650^{\circ} \mathrm{C}$ for 24 hrs (EH-001 in Dwg HIP-00).

This step removes undesired volatiles from the HIP'ing mixture (primarily residual $\mathrm{H}_{2} \mathrm{O}, \mathrm{CO}_{2}, \mathrm{Hg}$, and nitrates), but leaves radionuclides [including Cs-137; see Section 2.2, item 14] bound in the HIP'ing mixture. Offgas from the devolatilization step is routed to an offgas system where mercury and particulates are extracted prior to release to the environment;

8) After devolatilization, the can is evacuated to 0.5 torr and the venting tube is crimped and weld sealed. These operations are performed without cooling (WS-002 in Dwg HIP-00);

9) The thermally hot can is overpacked in a second vented can for contamination control. This assembly is placed inside the pressure vessel of the HIP'ing machine, and pressurized to approximately $5,000-6,000 \mathrm{psi}$ using argon gas. It is subsequently heated to $1050^{\circ} \mathrm{C}$, during which time the pressure rises to approximately $20,000 \mathrm{psi}$. The HIP'ing step (including overpacking, placement in the HIP vessel, pressurization, heatup, and soak) is assumed to require approximately 24 hrs (HM-401 in Dwg HIP-04);

10) After the HIP'ing step is complete the argon gas is evacuated and analyzed for radioactivity to determine whether the HIP can has breached during HIP'ing. If breached, the can is unloaded from the HIP machine, cooled, and recycled (see item 13), and the HIP'ing vessel is deconned;

11) If analysis of the argon does not indicated that breaching has occurred, the can is unloaded from the HIP'ing machine and allowed to cool (Dwg HIP-00);

12) Once cooled, the HIP'ed can is evaluated (using non-destructive testing methods, together with surface radioactivity scans) to determine whether HIP'ing was successful (Dwg HIP-00);

13) HIP'ed cans determined to be unsatisfactory are pulled from the normal process stream and sent to sizing/grinding prior to recycle to the temperary calcine storage bins. HIP'ed cans determined to be satisfactory are placed into 2'x10' disposal canisters (CV-001 in Dwg HIP-00);

14) Once a disposal canister is filled with three properly HIP'ed cans the canister is welded closed and transported to interim storage (L-001 in Dwg HIP-00);

The intended final disposal site for the waste is an approved federal repository for high-level radioactive wastes. However, the waste must be stored in an interim storage facility pending the commencement of waste acceptance at such a repository.

\subsubsection{Auxilliary Processes}

Steps in the auxilliary processes to the main process are as follows:

1) HIP'ed cans which fail acceptance testing will be sized (broken down), ground, transported to a temporary storage bins (B-201 in Dwg HIP-02), and blended into the HIP'ing mixture with other HIP ingredients (RB-001 in Dwg HIP-00); 
2) INEEL pre-treated soil (or equivalent) is received in bulk shipments at a bulk receiving terminal and pneumatically transported to a cyclone (CY-602 in Dwg HIP-06) atop a soil storage bin (B-602 in Dwg HIP-06). Air used in transporting the soil to storage is routed through a baghouse (PB-601 in Dwg HIP-06) and recycled to the receiving terminal. Fines collected in the baghouse are also discharged to the B-602;

3) Titanium metal powder is received in bulk shipments at a bulk receiving terminal and transported to storage bin B-601 in Dwg HIP-06);

4) HIP'ing cans and 2'x10' disposal canisters are received on a "just in time" basis and temporarily stored in a "clean" storage facility (ST-601 in Dwg HIP-06);

5) Dry ice (solid $\mathrm{CO}_{2}$ ) is received in bulk and manually offloaded to cryogenic storage (CR-601 in Dwg HIP-06). The storage facility is in physical juxtaposition with the decontamination cell, and the dry ice is fed directly from storage into the shaving/blasting unit (DD-301 in Dwg HIP-03). Gaseous effluent from the dry decontamination operation goes to offgas system (Dwg HIP-05) for filtration, prior to release;

6) Air in the HIP'ing machine after the HIP'ing can is loaded is evacuated (P-401 in Dwg HIP-04) and pumped to the offgas system (Dwg HIP-05), prior to discharge to the atmosphere;

7) Virgin argon gas is received in bulk and a compressor (CP-404 in Dwg HIP-04) is used to pump it into storage (T-401 in Dwg HIP-04). Argon from T-401 is used to charge the HIP'ing machine following removal of air. After a can is HIP'ed the argon is evacuated (CP-402 in Dwg HIP-04) to interim argon storage (T-402 in Dwg HIP-04). Gas from T-402 is sampled to determine whether it can be recycled to virgin argon storage, or must be discarded due to contamination. Gas which is recycled is filtered (F-401 in Dwg HIP-04) and pumped/compressed (CP-403 in Dwg HIP-04) into T-401;

8) The HWO process offgas system treats gaseous effluents from:

- The HIP can devolatilization step

- Contaminated argon gas from the HIP'ing step (in the case of a HIP'ing can breach)

- Carbon dioxide gas from dry decontamination of HIP cans

- Air evacuation of HIP'ing machine

Offgas from devolatilization is cooled (E-501 in Dwg HIP-05) to condense out mercury volatilized from the HIP'ing mixture. Elemental mercury condensate is discharged to a filling station for 1-gal canisters ("paint cans"). When filled to the appropriate level, elemental sulfur is added (in excess) to each canister, and the canister is capped and placed in a jar mill and mixed until the mercury has been completely amalgamated. After amalgamation is complete, the canister is removed, surveyed, characterized, and sent either to low-level radioactive waste disposal at the Radioactive Waste Management Complex, or to mixed waste storage at the Waste Reduction Operations Complex (WROC).

Gaseous effluent from the offgas cooling operation, together with the other effluents from the above list (recycled argon gas, $\mathrm{CO}_{2}$ from dry decon, and air from evacuation of HIP'ing cans) are routed 
through a pre-filter (F-501 in Dwg HIP-05) to strip out high concentrations of particulates, and finally through a HEPA ${ }^{\prime}$ filter for polishing.

\subsection{Processing Rates} follows:

The principal processing rates and overall processing statistics for the HWO process are as

\section{TABLE 1: PROCESS RATES AND STATISTICS FOR HWO PROCESS}

\section{DESCRIPTION}

Operating time

Calcine processed

Ti metal consumed

Pre-treated soil consumed

HIP'ing cans filled

2'x10' disposal canisters filled

Total mass of HIP'ed waste (including cans)

Total mass of HIP'ed waste (excluding cans)

Total volume of HIP'ed waste (excluding cans)

\begin{tabular}{|c|c|c|c|}
\hline Hourly & $\underline{\text { Daily }}$ & $\underline{\text { Yearly }}$ & TOTAL \\
\hline & 10 & Irs & \\
\hline
\end{tabular}
$849 \mathrm{lbm} \quad 8,488 \mathrm{lbm} \quad 842,744 \mathrm{lbm} \quad 16,854,890 \mathrm{lbm}$ $61 \mathrm{lbm} \quad 606 \mathrm{lbm} \quad 60,196 \mathrm{lbm} \quad 1,203,921 \mathrm{lbm}$ $303 \mathrm{lbm} \quad 3,031 \mathrm{lbm} \quad 300,980 \mathrm{lbm} \quad 6,019,604 \mathrm{lbm}$ 0.87 units $\quad 8.70$ units $\quad 864$ units $\quad 17,280$ units

0.28 units $\quad 2.84$ units $\quad 282$ units $\quad 5,645$ units
$1,175 \mathrm{lbm} \quad 11,746 \mathrm{lbm} \quad 1,166,240 \mathrm{lbm} \quad 23,324,805 \mathrm{lbm}$
$0.17 \mathrm{~m}^{3}$
$1.67 \mathrm{~m}^{3}$
$165 \mathrm{~m}^{3}$
$3,309 \mathrm{~m}^{3}$

$1,257 \mathrm{lbm} \quad 12,571 \mathrm{lbm} \quad 1,248,123 \mathrm{lbm} \quad 24,962,457 \mathrm{lbm}$

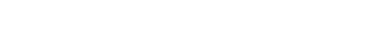

\section{MATERIAL BALANCES}

Material balances for process streams shown in the drawings in Section 10 are given in Table 2 below.

\footnotetext{
${ }^{1}$ High Efficiency PArticle filter.
} 
TABLE 2: MASS BALANCE FROM PROCESS FLOW DIAGRAMS

\begin{tabular}{|c|c|c|c|c|c|c|c|c|c|c|c|c|c|}
\hline & & & & 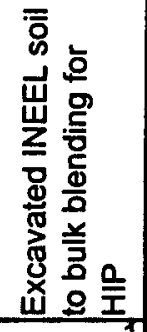 & 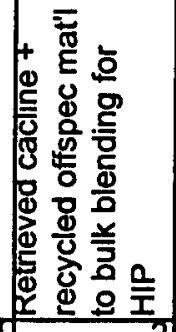 & 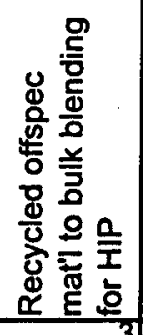 & 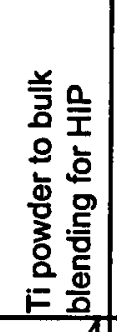 & 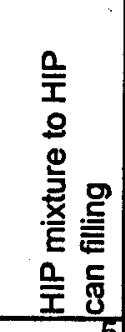 & 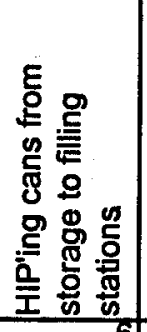 & 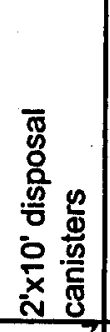 & 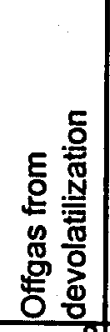 & 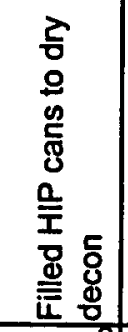 & 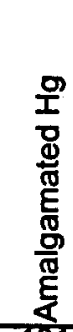 \\
\hline \multicolumn{3}{|c|}{ Materialstream io } & Units & 1 & 2 & 3 & 4 & 5 & 6 & 7 & 8 & 9 & 101 \\
\hline \multicolumn{2}{|c|}{ Pre-treated soil (or equivalent) } & ivalent) & $\mathrm{lom} / \mathrm{hr}$ & 30371 & & & & & & & & & \\
\hline Calcine & & & tbm/hr & & 848.8 & & & & & & & & \\
\hline \multirow{2}{*}{\multicolumn{2}{|c|}{$\begin{array}{l}\text { HIP'ed, offspec mat' } \\
\text { HIPmixture }\end{array}$}} & & Ibm/hr & & & 24.9 & & & & & & & \\
\hline & & & $\mathrm{Tbm} / \mathrm{hr}$ & & & & & $1,237.5$ & & & & $1,237.5$ & \\
\hline \multicolumn{2}{|c|}{\begin{tabular}{|l|l} 
Ti metal & \\
\end{tabular}} & & $16 \mathrm{~m} / \mathrm{hr}$ & & & & 60.6 & & & 18.0 & & & \\
\hline \multirow{2}{*}{\multicolumn{2}{|c|}{$\begin{array}{l}\text { Total gas flow } \\
\text { Total solids flow }\end{array}$}} & & scim & & & & & & & & 8.4 & & \\
\hline & & & lbm/hr & & & & & $1,237.5$ & & & & 1,320.0 & \\
\hline \multicolumn{3}{|l|}{ Air } & scm & & & & & & & & & & 4.0 \\
\hline \multirow{2}{*}{\multicolumn{3}{|c|}{\begin{tabular}{|l}
$\mathrm{Hg}$ \\
$\mathrm{HgSS}$
\end{tabular}}} & flom/hr & & & & & & & & & & 3.2 \\
\hline & & & $\mathrm{fbm} / \mathrm{hr}$ & & & & & & & & & & 4.0 \\
\hline \multicolumn{3}{|l|}{ s } & bom/hr & & & & & & & & & & 0.8 \\
\hline \multicolumn{3}{|c|}{ HIP'ing cans } & units/shift & & & & & & 8.7 & & & 8.7 & \\
\hline \multicolumn{3}{|c|}{$\begin{array}{l}2^{\prime} \times 10^{\prime} \text { disposal canisters } \\
\text { Paint cans }\end{array}$} & units/shift & & & & & & & 2.8 & & & \\
\hline \multicolumn{3}{|l|}{ Paint cans } & units/shift & & & & & & & & & & 0.7 \\
\hline $\mathrm{CO} 2$ & & & $1 \mathrm{bm} / \mathrm{hr}$ & & & & & & & & & & \\
\hline $\operatorname{Ar}$ (gas) & & & libm/shift & & & & & & & & & & \\
\hline
\end{tabular}




\begin{tabular}{|c|c|c|c|c|c|c|c|c|c|c|c|c|c|c|}
\hline Materialst & tream 10 & & Units & 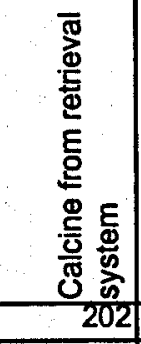 & 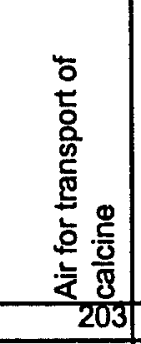 & 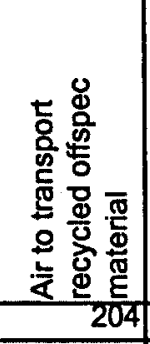 & 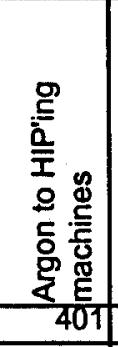 & 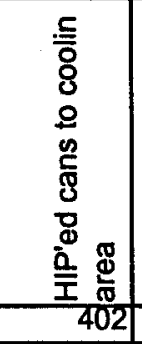 & 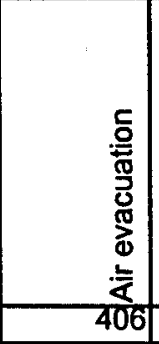 & 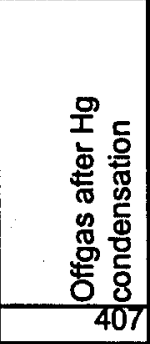 & 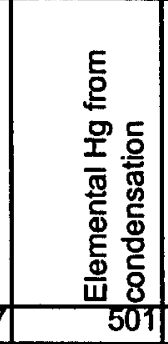 & 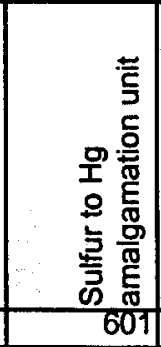 & 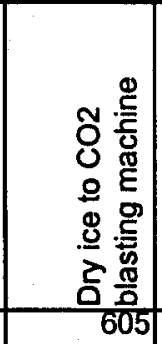 & 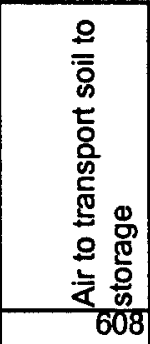 \\
\hline & & & & & & & & & & & & & & \\
\hline \multicolumn{3}{|c|}{ Pre-treated soll (or equivalent) } & $16 m / h r$ & & & & & & & & & & & \\
\hline Calcine & & & Ibm/hr & $5,940.0$ & & & & & & & & & & \\
\hline \multicolumn{2}{|c|}{ HIP'ed, oftspec mat' } & & $16 \mathrm{~m} / \mathrm{hr}$ & & & & & & & & & & & $i$ \\
\hline \multicolumn{2}{|l|}{ HIPmixture } & & tibm/hr & & & & & $1,174.6$ & & & & & & \\
\hline Timetal & & & Ibm/hr & & & & & & & & & & & widi \\
\hline \multicolumn{2}{|c|}{ Total gas flow } & & sctm & & & & & & & 70.2 & & & & 88.2 \\
\hline \multicolumn{2}{|c|}{ Total solids tlow } & & tbm/hr & & & & & $1,257.1$ & & & & & & $2:$ \\
\hline Air $\quad 1$ & & & sctm & $7,600.0$ & $1,600.0$ & 7.3 & & & 1.3 & & & & & s. \\
\hline $\mathrm{Hg}$ & & 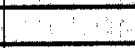 & $\mathrm{bm} / \mathrm{hr}$ & & & & & & & & 3.2 & & & 1 \\
\hline Hgs & & & Ibm/hr & & & & & & & & & & & \\
\hline 5 & & & tbm/hr & & & & & & & & & 0.8 & & \\
\hline \multicolumn{2}{|c|}{ HIP'ing cans } & & unitsishift & & & & & & & & & & & in \\
\hline \multicolumn{3}{|c|}{$2 \times 10^{\prime}$ disposal canisters } & units/shift & & & & & & & & & & & - \\
\hline Paint cans & & & unitsishift & & & & & & & & & & & \\
\hline $\mathrm{CO2}$ & & & $16 m / h r$ & & & & & & & & & & 4.4 & \\
\hline Ar (gas) & & & fibm/shift & & & & 2,672 & & & & & & & \\
\hline
\end{tabular}


Rev. $\$ 02$
Function File Number - SPR-10

EDF Serial Number - EDF-HWO-012

Page 10 of 18

\section{EQUIPMENT LIST}

\subsection{Equipment Labels}

Labels used to specify equipment in the process flow diagrams are described below in Table 3:

\section{TABLE 3: EQUIPMENT LABELS USED IN PROCESS FLOW DIAGRAMS}

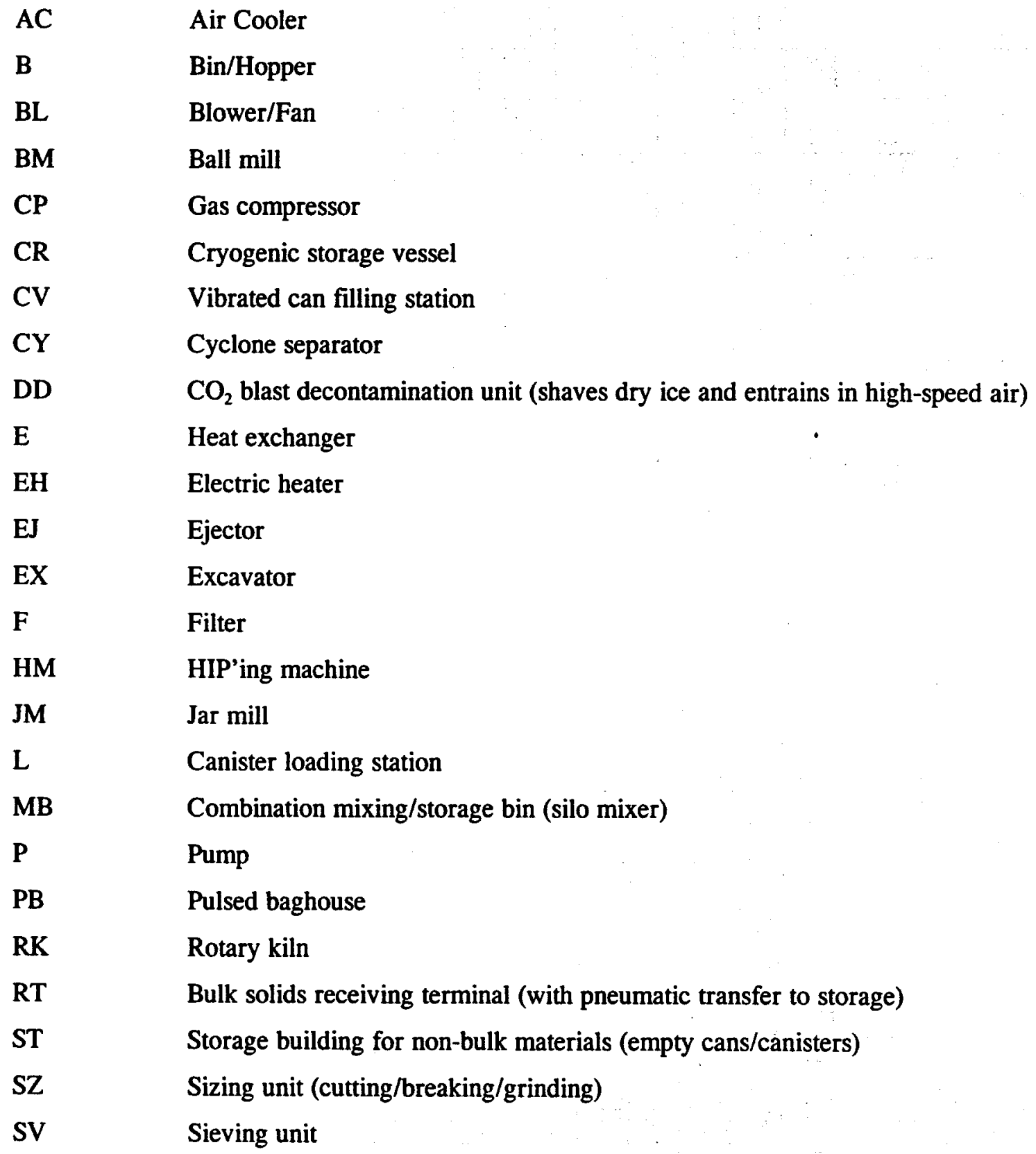

$\mathrm{AC}$

B

Air Cooler

BL

Bin/Hopper

Blower/Fan

BM

Ball mill

CP

Gas compressor

CR

Cryogenic storage vessel

CV

Vibrated can filling station

CY

Cyclone separator

DD

$\mathrm{CO}_{2}$ blast decontamination unit (shaves dry ice and entrains in high-speed air)

E

Heat exchanger

EH

Electric heater

EJ

Ejector

EX Excavator

F

Filter

HM

HIP'ing machine

JM

Jar mill

L

Canister loading station

MB

Combination mixing/storage bin (silo mixer)

$\mathbf{P}$

Pump

PB

Pulsed baghouse

RK

Rotary kiln

RT

Bulk solids receiving terminal (with pneumatic transfer to storage)

ST

Storage building for non-bulk materials (empty cans/canisters)

SZ

Sizing unit (cutting/breaking/grinding)

SV

Sieving unit 
$\mathrm{T}$

TK Truck for transporting cold, bulk solid material (soil)

V Vessel

WS Welding station

\subsection{Equipment Needed}

New equipment items required for the HWO process are described in Table 4, below:

TABLE 4: NEW EQUIPMENT LIST FOR HWO PROCESS

ID $\quad \frac{\text { DWG }}{\text { NO. }}$ DESCRIPTION

\section{OVERALL PROCESS:}

\begin{tabular}{l|l|l|l}
\hline RB-001 & HIP-00 & $\begin{array}{l}\text { Four (4) ribbon blenders to mix } \\
\text { HIP'ing mixture constituent }\end{array}$ & $309 \mathrm{lbm} / \mathrm{hr}$, each blender \\
\hline CV-001 & HIP-00 & Four (4) HIP can filling stations & $\begin{array}{l}309 \mathrm{lbm} / \mathrm{hr} \text {, each station } \\
\text { (see Ref. 8) }\end{array}$ \\
\hline WS-001 & HIP-00 & $\begin{array}{l}\text { Four (4) stations to weld partial } \\
\text { closures on filled HIP cans, } \\
\text { including of vent tubes and HEPA } \\
\text { filters }\end{array}$ & 0.22 cans/hr \\
\hline EH-001 & HIP-00 & $\begin{array}{l}\text { Four (4) stations for devolatilizing } \\
\text { HIP mixture in cans. Cans are } \\
\text { heated to 650'C for 24 hrs. }\end{array}$ & $\begin{array}{l}0.22 \text { cans/hr, each station } \\
\text { (see } \text { Ref. 9) }\end{array}$ \\
\hline P-401 & HIP-04 & $\begin{array}{l}\text { Four (4) vacuum systems to } \\
\text { evacuate cans following } \\
\text { devolatilization }\end{array}$ & (see Ref. 9) \\
\hline WS-002 & HIP-00 & $\begin{array}{l}\text { Four (4) stations to weld vent tube } \\
\text { and trim as necessary for loading } \\
\text { into HM-401, and for final loading } \\
\text { into 2'x10' disposal canisters }\end{array}$ & 0.22 cans/hr, each station \\
\hline L-001 & HIP-00 & $\begin{array}{l}\text { Four (4) stations to load HIP'ed } \\
\text { cans into 2'x10' disposal canisters, } \\
\text { and weld seal the canisters }\end{array}$ & $\begin{array}{l}0.0732 \text { 'x10' canisters/hr, each } \\
\text { station }\end{array}$ \\
\hline
\end{tabular}

CALCINE RETRIEVAL \& OFFSPEC PRODUCT RECYCLE:

\begin{tabular}{l|l|l|l}
\hline CY-201 & HIP-02 & $\begin{array}{l}\text { Two (2) cyclones to extract calcine } \\
\text { from pneumatic transport system }\end{array}$ & $\begin{array}{l}\text { (This item is called out in the design } \\
\text { of the calcine retrieval system. For }\end{array}$ \\
\hline
\end{tabular}




\begin{tabular}{|c|c|c|c|}
\hline$\underline{\text { ID }}$ & $\frac{\text { DWG }}{\text { NO. }}$ & DESCRIPTION & SIZING INFORMATION \\
\hline & & (one for each side of the facility) & $\begin{array}{l}\text { purposes of design of the HWO } \\
\text { process, only space must be allotted } \\
\text { for the equipment in the building.) }\end{array}$ \\
\hline CY-202 & HIP-02 & $\begin{array}{l}\text { Two (2) cyclones to extract sized, } \\
\text { ground offspec material from } \\
\text { pneumatic transport system between } \\
\text { sizing operation and calcine storage } \\
\text { bins, MB-201a,b }\end{array}$ & $\begin{array}{l}3.6 \mathrm{scfm} \text { per cyclone, } \\
12.5 \mathrm{lbm} / \mathrm{hr}\end{array}$ \\
\hline MB-201 & HIP-02 & $\begin{array}{l}\text { Four (4) Mixing/storage bins to } \\
\text { blend and store retrieved calcine } \\
\text { (also sized recycled offspec HIP'ed } \\
\text { material) prior to HIP'ing }\end{array}$ & $\begin{array}{l}100 \mathrm{ft}^{3} \text { for each bin } \\
\text { Bins must have capacity to } \\
\text { homogenized the bulk calcine } \\
\text { Total bin inventory is sufficient for } \\
4 \text { days' production }\end{array}$ \\
\hline BM-201 & HIP-02 & $\begin{array}{l}\text { Four (4) ball mills to size retrieved } \\
\text { calcine }\end{array}$ & $\begin{array}{l}\text { Each mill to grind } 250 \mathrm{lbm} / \mathrm{hr} \text { of } \\
1.0 \mathrm{~mm} \text { calcine to pass } 80 \text { mesh } \\
\text { screen }\end{array}$ \\
\hline B-202 & HIP-02 & $\begin{array}{l}\text { Four (4) storage bins for ground, } \\
\text { recycled offspec material }\end{array}$ & $20 \mathrm{ft}^{3}$ for each bin \\
\hline BL-202 & HIP-02 & $\begin{array}{l}\text { Four (4) blowers to provide motive } \\
\text { force for pneumatic transport of } \\
\text { recycled offspec material }\end{array}$ & $\begin{array}{l}3.6 \mathrm{scfm} \text { air @ } 1 \text { psi pressure drop, } \\
\text { each blower }\end{array}$ \\
\hline EJ-202 & & $\begin{array}{l}\text { Four (4) ejectors for pneumatic } \\
\text { transport of sized offspec HIP'ed } \\
\text { material between sizing operation } \\
\text { and temporary storage in MB-201a, } \\
\text { b }\end{array}$ & $\begin{array}{l}3.6 \mathrm{scfm} \text { air } \\
12.5 \mathrm{lbm} / \mathrm{hr} \text { solids }\end{array}$ \\
\hline
\end{tabular}

CAN DRY DECON:

\begin{tabular}{l|l|l|l}
\hline V-301 & HIP-03 & $\begin{array}{l}\text { Four (4) booths for } \mathrm{CO}_{2} \text { blast decon } \\
\text { of HIP cans }\end{array}$ & Decon capacity 0.22 cans/hr/booth \\
\hline DD-301 & HIP-03 & $\begin{array}{l}\text { Two (2) } \mathrm{CO}_{2} \text { shaving/blasting } \\
\text { machines for } \mathrm{CO}_{2} \text { blast } \\
\text { decontamination of HIP'ing cans }\end{array}$ & 2.2 lbm/hr per machine \\
\hline HIP: & HIP-04 & $\begin{array}{l}\text { Fourteen (14) HIP'ing machine } \\
\text { pressure vessels }\end{array}$ & (See Ref. 7) \\
\hline HM-401 & HIP-04 & $\begin{array}{l}\text { Sixteen (16) HIP'ing machine } \\
\text { furnaces }\end{array}$ & (See Ref. 7) \\
\hline HM-401 & &
\end{tabular}




\begin{tabular}{l|ll|l} 
ID & \multicolumn{2}{l}{ DWG } & \multicolumn{2}{l}{ DESCRIPTION } & SIZING INFORMATION \\
\hline P-404 & HIP-04 & $\begin{array}{l}\text { Eight (8) vacuum systems for } \\
\text { evacuation of HIP machines prior to } \\
\text { charging with argon gas }\end{array}$ & (See Ref. 7) \\
\cline { 3 - 4 } CP-401,402 & HIP-04 & $\begin{array}{l}\text { Eight (8) compressor systems for } \\
\text { charging HIP machines to high } \\
\text { pressure with argon gas }\end{array}$ & (See Ref. 7) \\
\hline T-402 & HIP-04 & $\begin{array}{l}\text { Twenty-four (24) storage tanks for } \\
\text { reclaimed argon }\end{array}$ & (See Ref. 7) \\
\hline T-401 & HIP-04 & $\begin{array}{l}\text { Eighteen (18) storage tanks for } \\
\text { uncontaminated argon gas }\end{array}$ & (See Ref. 7) \\
\hline E-401 & HIP-04 & $\begin{array}{l}\text { Heat exchanger to cool argon gas } \\
\text { exiting HIP'ing machines }\end{array}$ & 600,000 Btu/hr capacity \\
\hline
\end{tabular}

\section{RECEIVING:}

\begin{tabular}{|c|c|c|c|}
\hline RT-601 & HIP-06 & $\begin{array}{l}\text { Receiving terminal for bulk } \mathrm{Ti} \\
\text { powder }\end{array}$ & $34.6 \mathrm{ft}^{3} / 2$-wks \\
\hline CY-601 & HIP-06 & $\begin{array}{l}\text { Two (2) cyclones to extract } \mathrm{Ti} \\
\text { powder from pneumatic transport } \\
\text { system into storage bins B-601a,b }\end{array}$ & $\begin{array}{l}8.8 \mathrm{scfm} \text { per cyclone, } \\
61 \mathrm{lbm} / \mathrm{hr}\end{array}$ \\
\hline PB-602 & HIP-06 & $\begin{array}{l}\text { Two (2) pulsed baghouses to } \\
\text { remove fine Ti particles from } \\
\text { pneumatic transport air prior to } \\
\text { recycle to blowers }\end{array}$ & $\begin{array}{l}8.8 \mathrm{scfm} \text { per baghouse, } \\
3.0 \mathrm{lbm} / \mathrm{hr}\end{array}$ \\
\hline BL-601 & HIP-06 & $\begin{array}{l}\text { Two (2) blowers to provide motive } \\
\text { force for pneumatic transport of } \mathrm{Ti} \\
\text { powder }\end{array}$ & $8.8 \mathrm{scfm}$ per blower \\
\hline B-601 & HIP-06 & $\begin{array}{l}\text { Two (2) bins for storage of } \\
\text { powdered } \mathrm{Ti}\end{array}$ & $10 \mathrm{ft}^{3}$ capacity per bin \\
\hline CR-601 & HIP-06 & $\begin{array}{l}\text { Insulated storage pressure vessel for } \\
\mathrm{CO}_{2} \text { (dry ice) storage }\end{array}$ & $\begin{array}{l}7.2 \mathrm{ft}^{3} \text { capacity, } \\
100 \text { psig pressurization }\end{array}$ \\
\hline ST-601 & HIP-06 & $\begin{array}{l}\text { Storage bay for HIP'ing cans and } \\
2^{\prime} \times 10^{\prime} \text { canisters }\end{array}$ & $\begin{array}{l}3 \text { weeks' production requirements } \\
\text { (110-HIP cans, } 35-2 \text { 'x10' canisters) }\end{array}$ \\
\hline RT-602 & HIP-06 & $\begin{array}{l}\text { Receiving terminal for INEEL soil } \\
\text { (or equivalent) }\end{array}$ & $324 \mathrm{ft}^{3} / 2$-wks \\
\hline B-601 & HIP-06 & $\begin{array}{l}\text { Two (2) storage bins for INEEL soil } \\
\text { (or equivalent) }\end{array}$ & $100 \mathrm{ft}^{3}$ capacity, each bin \\
\hline
\end{tabular}




\begin{tabular}{|c|c|c|c|}
\hline$\underline{\text { ID }}$ & $\frac{\text { DWG }}{\underline{\text { NO. }}}$ & DESCRIPTION & SIZING INFORMATION \\
\hline EJ-603 & HIP-06 & $\begin{array}{l}\text { Two (2) ejectors for pneumatic } \\
\text { transport of INEEL soil between } \\
\text { receiving and temporary storage in } \\
\text { B-602a, b }\end{array}$ & $\begin{array}{l}44.1 \mathrm{scfm} \text { air } \\
303 \mathrm{lbm} / \mathrm{hr} \text { solids }\end{array}$ \\
\hline BL-603 & HIP-06 & $\begin{array}{l}\text { Two (2) blowers to provide motive } \\
\text { force for pneumatic transport } \\
\text { INEEL soil to } B-602 a, b\end{array}$ & $44.1 \mathrm{scfm}$ per blower \\
\hline PB-601 & HIP-06 & $\begin{array}{l}\text { Two (2) pulsed baghouses to } \\
\text { remove fine soil particles from } \\
\text { pneumatic transport air prior to } \\
\text { recycle to blowers }\end{array}$ & $\begin{array}{l}44.1 \mathrm{scfm} \text { gas flow per baghouse, } \\
15.2 \mathrm{lbm} / \mathrm{hr} \text { solids rate }\end{array}$ \\
\hline RT-603 & HIP-06 & $\begin{array}{l}\text { Receiving terminal for bulk } \\
\text { elemental sulfur }\end{array}$ & $0.49 \mathrm{ft} 3$ per 2-wk period \\
\hline
\end{tabular}

\section{OFFGAS SYSTEM:}

\begin{tabular}{l|l|l|l}
\hline E-501 & HIP-05 & $\begin{array}{l}\text { Heat exchanger/condensor to cool } \\
\text { offgas from devolatilization and } \\
\text { condense elemental mercury }\end{array}$ & $600,000 \mathrm{Btu} / \mathrm{hr}$ total capacity \\
\hline F-501 & HIP-05 & $\begin{array}{l}\text { Granular activated carbon column to } \\
\text { extract residual Hg from offgas, } \\
\text { after condensation }\end{array}$ & $10 \mathrm{ft}$ diameter $\times 10 \mathrm{ft}$ high \\
\hline F-502 & HIP-05 & HEPA filter bank & $10.2 \mathrm{scfm}$ \\
\hline
\end{tabular}

HG AMALGAMATION:

\begin{tabular}{l|l|l|l}
\hline L-101 & HIP-01 & $\begin{array}{l}\text { Filling station to decant elemental } \\
\text { Hg from condensor E-501 into 1-gal } \\
\text { paint cans }\end{array}$ & 0.71 paint cans/hr \\
\hline JM-101 & HIP-01 & $\begin{array}{l}\text { Jar mill to amalgamate elemental } \\
\text { mercury with sulfur }\end{array}$ & 0.71 paint cans/hr \\
\hline
\end{tabular}

\section{UTILITIES SUMMARY}

New utilities required to support the HWO process are summarized below in Table 5: 
Function File Number - SPR-10 EDF Serial Number - EDF-HWO-012

Page 15 of 18

TABLE 5: HWO PROCESS UTILITIES SUMMARY

EOUIPMENT ID DWG NO. DESCRIPTION

\section{PROCESS WATER (COOLING):}

\begin{tabular}{|c|c|c|c|}
\hline $\mathrm{HM}-401$ & HIP-04 & $\begin{array}{l}\text { Cooling jackets for HIP'ing } \\
\text { machines }\end{array}$ & $315 \mathrm{gpm}$ \\
\hline E-501 & HIP-05 & $\begin{array}{l}\text { Heat exchanger for cooling offgas } \\
\text { from devolatilization }\end{array}$ & $3.2 \mathrm{gpm}$ \\
\hline$E-401$ & HIP-04 & $\begin{array}{l}\text { Heat exchanger for cooling argon } \\
\text { gas from HIP'ing machines }\end{array}$ & $134 \mathrm{gpm}$ \\
\hline TOTAL & & r & $452 \mathrm{gpm}$ \\
\hline
\end{tabular}

\section{PRESSURIZED AIR:}

(No specific requirement was identified. The figure at right is an $50 \mathrm{scfm} @ 100 \mathrm{psig}$ estimate for total miscellaneous pressurized air requirements.)

\section{ELECTRICAL:}

Electrical requirements for the HIP'ing facility have been analyzed and documented in Ref. 10. New electrical equipment requirements and required modifications to the existing infrastructure at ICPP are described in detail in the above reference.

Figures at right include all identified electrical power requirements, including:

- building lighting

- miscellaneous building loads

- HVAC loads (supply fan motors, exhaust fan motors, miscellaneous HVAC loads)

- HIP'ing machines

- devolatilization equipment

- compressors

- welding equipment

- sizing (grinding) equipment

- cranes

\section{STEAM:}

Steam demand for HVAC heating load. (see Ref. 12)
$12,280 \mathrm{~kW}$ total connected load

$8,472 \mathrm{~kW}$ total demand load 
EOUIPMENT ID DWG NO. DESCRIPTION :

\section{POTABLE WATER:}

Total, all building services (see Ref. 11)
$35 \mathrm{gpm}$ maximum

7 gpm average

FIRE PROTECTION WATER:

Total, all building services see Ref. 11)

$1250 \mathrm{gpm}$

\section{CHEMICALS SUMMARY}

Required chemicals and additives for the HWO process are summarized below in Table 6:

TABLE 6: CHEMICALS SUMMARY FOR HWO PROCESS

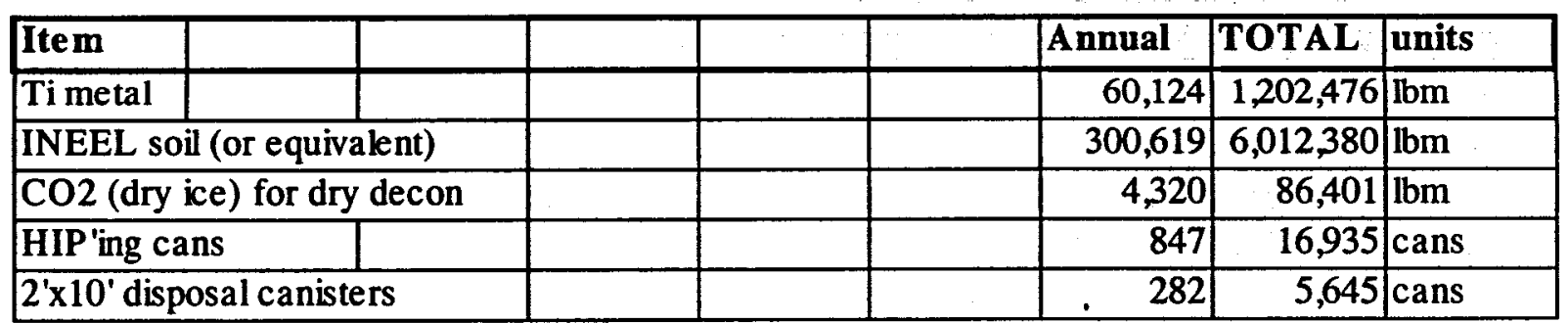

\section{CONCERNS}

The following concerns have been identified relative to the HWO process:

1) Significant quantities of argon gas must be used to pressurize each HIP'ing machine. Because of the cost of the gas, it is not feasible to discard it after use. However, each time a HIP machine is charged with argon during pressurization, some contamination of the gas will unavoidably occur. (At worst, breached HIP'ing cans inside the HIP'ing machine will result in contamination of the gas. At best, residual air left in the HIP'ing machine following air evacuation will be mixed with argon after HIP'ing is completed.)

In order to minimize the quantity of argon gas that is discarded due to contamination, it may be necessary to incorporate a system for separation of argon the gaseous mixture discharged from the HIP'ing machine. This could add considerable cost to the facility.

2) Entire recycled offspec HIP'ed cans are assumed to sized and ground, including the stainless steel can. The sizing operation is assumed to yield material that can

- be pneumatically transported upward from the sizing area back to the calcine temporary storage bins above the HIP can filling stations, and

- be re-HIP'ed along with the virgin HIP'ing mixture of calcine, soil, and Ti metal, with no effect on the HIP'ing recipe. In particular, the components of the stainless steel HIP'ing 
canister (i.e., steel, chromium, etc.) are presumed to HIP'able without affecting the normal HIP mixture.

The validity of the above assumptions has not been demonstrated.

\section{REFERENCES}

1. EDF-WTS-001 in the project file.

2. EDF-WTS-003 in the project file.

3. Krishna Vinjamuri, "Candidate Glass-Ceramic Waste Forms for Immobilization of the Calcines Stored at the Idaho Chemical Processing Plant", Ceramic Transactions, Vol 61, p. 439.

4. Krishna Vinjamuri, "Soil Based Glass-Ceramic Waste Forms for Immobilization of the Fluorinel/Sodium Calcined High-Level Waste Stored at the Idaho Chemical Processing Plant", Proceedings of the International Topical Meeting on Nuclear and Hazardous Waste Management, Spectrum '94, August 14-18, 1994, Atlanta, GA.

5. L. O. Nelson, K. Vinjamuri, "Results of Intermediate-Scale Hot Isostatic Press Can Experiments”, INEL-95/0145, May 1995.

6. S. Raman, "Hot Isostatically Pressed Aluminosilicate Glass-Ceramic With Natural Crystalline Analogs for Immobilizing Calcined HLW at the Idaho Chemical Processing Plant", WINCO-1173, UC-510, December 1993.

7. EDF-HWO-003 in the project file.

8. EDF-HWO-004 in the project file.

9. EDF-HWO-008 in the project file.

10. EDF-HWO-009 in the project file.

11. Estimated by Stephanie Austad.

12. EDF-HWO-014 in the project file.

\section{PROCESS FLOW DIAGRAMS}

Process flow diagrams (HWO-00 through HWO-08) are provided in Appendix B of the main (summary) document for the HWO process.

\section{MAXIMUM RADIOACTIVE INVENTORY}

The maximum potential activity inventory inside a facility used to house the HIP'ing process was estimated using the following assumptions:

- Maximum calcine activity (for alumina calcine) $=$

$14,500 \mathrm{Ci} / \mathrm{m}^{3}$

- Density of hottest calcine $=$

$1.09 \mathrm{gm} / \mathrm{cm}^{3}$ 
- The following equipment items in the facility are full of raw calcine:

- 4 calcine storage bins (100 $\mathrm{ft}^{3}$ in each)

- 4 ribbon blenders (10 $\mathrm{ft}^{3}$ in each)

- All the following equipment items in the facility contain one HIP'ing can:

- 4 can filling stations

- 4 can welding stations

- 4 can decontamination stations

- 12 devolatilization furnaces

- 12 HIP'ing machines

- 12 cooling stations

- $\quad 4$ offspec material recycle storage bins

- Maximum HIP cans in 2'x10' canisters awaiting transport to interim storage $=\quad 36$ canisters

- 3 canisters per processing line

- 4 processing lines

- 3 HIP'ing cans per canister

- Pre-HIP olume per HIP can =

$12.89 \mathrm{ft}^{3}$

- Pre-HIP ompacted mixture density =

$1.77 \mathrm{gm} / \mathrm{cm}^{3}$

- Waste loading in HIP mixture =

$0.7 \mathrm{lbm} / \mathrm{lbm}$

From the above assumptions the following results were obtained:

- Total raw calcine volume in HIP facility (outside HIP'ing cans) = $440 \mathrm{ft}^{3}$

- Total raw calcine volume in HIP facility (inside HIP'ing cans) =

- Total calcine activity in HIP facility = 
Project File Number

02BG4

Project/Task HIPing Facility Instrumentation and Control Evaluation

Subtask HWO Scoping Study

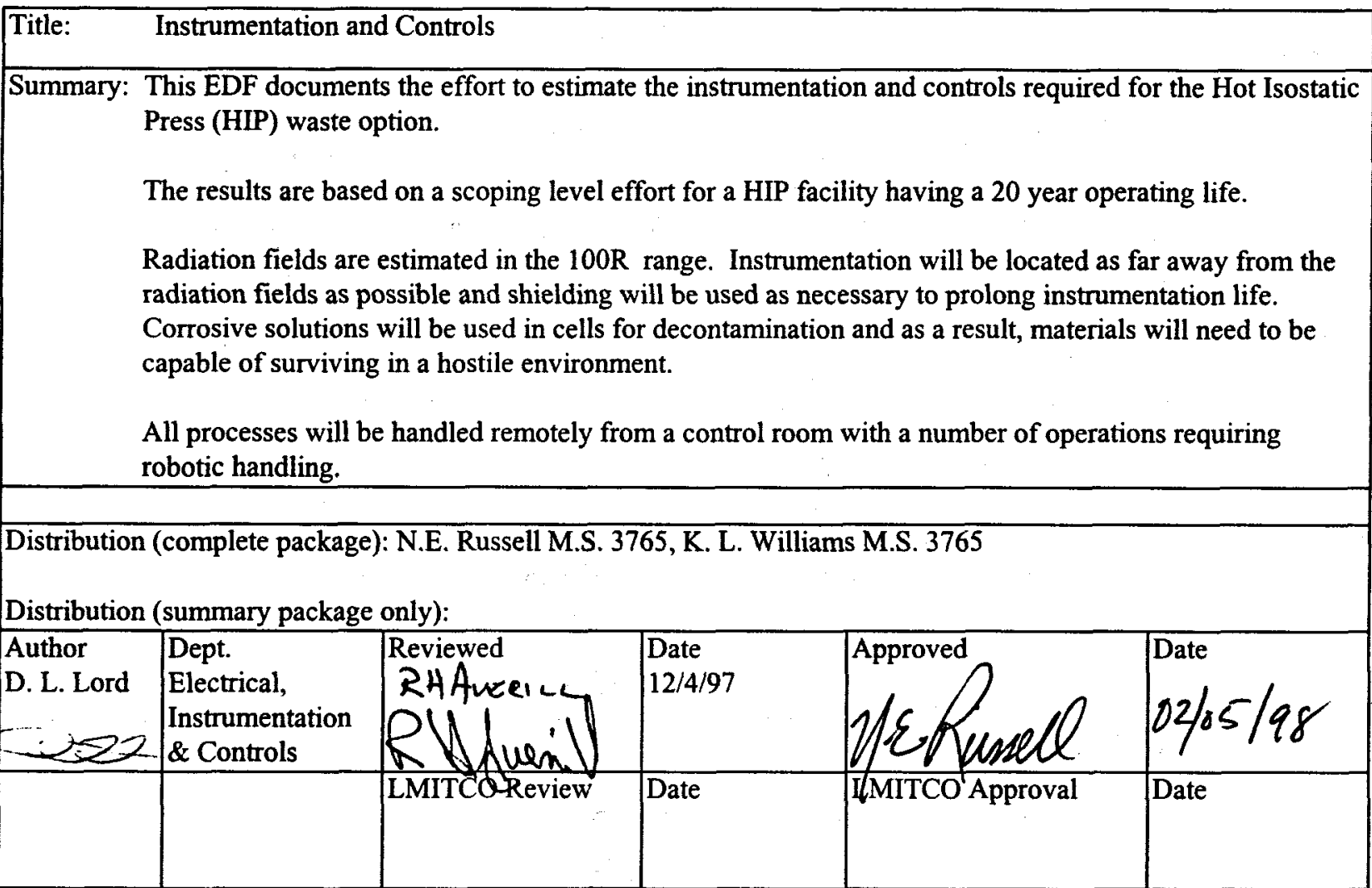

See Management Control Procedure (MCP) 6 for instructions on use of this form. 


\section{Introduction}

This report presents an outline of the instrumentation needed to support the operation of the Hot Isostatic Press (HIP) Facility. The Hipping Waste Option will be used in the disposal of calcined waste in an approved waste container suitable for disposal in a Mined Geologic Disposal System (MGDS). The process HIP can will be loaded with calcine waste and an additive, pressurized to 20,000 psi and heated to 1050 degrees $C$ for several hours then removed and allowed to cool.

\section{Process}

The process will contain 4 identical lines with typically 3 lines operation at any one time. Canisters will enter the facility, filled, blended with a glass additive, a lid welded on the canister, run through a decon operation, have a devolatilization operation performed, pressurized and heated. The can is removed from the HIPing machine and allowed to cool, assayed, loaded onto a cart and sent to a loading area. Evaluation of the instrumentation for the system is in listed in Table 1.

\section{Assumptions}

1. Devolatilization furnace will have a control system to operate the furnace remotely.

2. Devolatilization evacuation pump control system will be included in the general controls.

3. Radiological instrumentation for monitoring all aspects of the HIPing facility were extracted from the "Radiological Evaluation for the Calcine HIP Feasibility Study" (Reference - EDF-HWO-006)

4. HVAC I\&C is not included in this estimate.

5. Telephones, Facility Public Address System, Fire Alarm Systems and Lightning Protection Systems are included in the Electrical Estimate.

6. Remote controlled robotics will come with a control system for each unit.

7. Estimates of cost and labor were extracted from the Raytheon design. 


\section{Instrumentation and Controls List for the HIPing Facility}

TABLE 1

\begin{tabular}{|c|c|c|c|c|c|c|}
\hline Description & Qty & $\begin{array}{l}\text { Labor } \\
\text { Hours }\end{array}$ & $\begin{array}{l}\text { Total } \\
\text { Labor Hours }\end{array}$ & $\begin{array}{l}\text { Material } \\
\text { Cost/Unit }\end{array}$ & $\begin{array}{l}\text { Material } \\
\text { Cost Total }\end{array}$ & $\begin{array}{l}\text { Total } \\
\text { Cost }\end{array}$ \\
\hline Alpha Monitors & 24 & 31 & 744 & $5 \mathrm{~K}$ & $120 \mathrm{~K}$ & $147.1 \mathrm{~K}$ \\
\hline Beta Monitors & 24 & 31 & 744 & $3.8 \mathrm{~K}$ & $91.2 \mathrm{~K}$ & $117.2 \mathrm{~K}$ \\
\hline Gamma Monitors & 20 & 23 & 460 & $2.4 \mathrm{~K}$ & $48 \mathrm{~K}$ & $64.1 \mathrm{~K}$ \\
\hline Hand Frisker & 24 & 8 & 192 & $1.4 \mathrm{~K}$ & $33.6 \mathrm{~K}$ & $40.3 \mathrm{~K}$ \\
\hline $\begin{array}{l}\text { Personal } \\
\text { Contamination } \\
\text { Monitor }\end{array}$ & 12 & 24 & 288 & $19 \mathrm{~K}$ & $228 \mathrm{~K}$ & $238.1 \mathrm{~K}$ \\
\hline CCTV System & 1 & 400 & 400 & $200 \mathrm{~K}$ & $200 \mathrm{~K}$ & $214 \mathrm{~K}$ \\
\hline $\begin{array}{l}\text { Air sample probes } \\
\text { for HVAC system }\end{array}$ & 60 & 16 & 960 & 100 & $6 \mathrm{~K}$ & $39.6 \mathrm{~K}$ \\
\hline $\begin{array}{l}\text { Ventilating constant } \\
\text { air monitor }\end{array}$ & 10 & 8 & 80 & $5 \mathrm{~K}$ & $50 \mathrm{~K}$ & $52.8 \mathrm{~K}$ \\
\hline $\begin{array}{l}\text { Plant control } \\
\text { hardware }\end{array}$ & 8 & 100 & 800 & $50 \mathrm{~K}$ & $400 \mathrm{~K}$ & $428 \mathrm{~K}$ \\
\hline $\begin{array}{l}\text { Plant control } \\
\text { software }\end{array}$ & 8 & 100 & 800 & $50 \mathrm{~K}$ & $400 \mathrm{~K}$ & $428 \mathrm{~K}$ \\
\hline $\begin{array}{l}\text { Data management } \\
\text { system hardware }\end{array}$ & 8 & 99 & 792 & $50 \mathrm{~K}$ & $400 \mathrm{~K}$ & $427.7 \mathrm{~K}$ \\
\hline $\begin{array}{l}\text { Data management } \\
\text { system software }\end{array}$ & 8 & 99 & 792 & $50 \mathrm{~K}$ & $400 \mathrm{~K}$ & $427.7 \mathrm{~K}$ \\
\hline $\begin{array}{l}\text { Local area warning } \\
\text { system }\end{array}$ & 32 & 8 & 256 & $400 \mathrm{~K}$ & $12.8 \mathrm{~K}$ & $21.8 \mathrm{~K}$ \\
\hline $\begin{array}{l}\text { Instrumentation } \\
\text { bulk allowance }\end{array}$ & 345 & 4 & 1380 & 500 & $172.5 \mathrm{~K}$ & $221 \mathrm{~K}$ \\
\hline $\begin{array}{l}\text { Control and safety } \\
\text { valves }\end{array}$ & 345 & 8 & 2760 & $4 \mathrm{~K}$ & $1380 \mathrm{~K}$ & $96.6 \mathrm{~K}$ \\
\hline $\begin{array}{l}\text { Electronic } \\
\text { instruments }\end{array}$ & 345 & 8 & 2760 & $1.5 \mathrm{~K}$ & $517.5 \mathrm{~K}$ & $614 \mathrm{~K}$ \\
\hline $\begin{array}{l}\text { Pneumatic } \\
\text { instruments }\end{array}$ & 345 & 8 & 2760 & $1 \mathrm{~K}$ & $345 \mathrm{~K}$ & $441.6 \mathrm{~K}$ \\
\hline HIP control unit & 1 & 30 & 30 & $200 \mathrm{~K}$ & $200 \mathrm{~K}$ & $201 \mathrm{~K}$ \\
\hline Total & & & & & & $4,221 \mathrm{~K}$ \\
\hline
\end{tabular}

Notes:

1. NQA-1 requirements and labor due to site inefficiencies are not included in the estimate.

2. A cost of $\$ 35.00$ was used to calculate labor costs. 


\section{Project File Number 02BG0}

\section{Project/Task Waste Treatment Project Feasibility Studies}

\section{Subtask HIP HVAC}

\section{Title: HIPing Facility HVAC EDF}

\section{Summary: The HVAC design for the HIPing Facility was predicated on a floor plan of the facility} designed by S.L., Austad, and design requirements gleaned from similar facilities and DOE 6430.1A.

This EDF contains a list of design requirements for the HVAC system for the Direct HIPing Facility. From the design requirements and floor plan, a design is proposed. The design is based on the room volumes and ventilation rates given in the attached table. The design presented in this EDF has not been optimized for maximum performance nor economics. It is presented as a starting point for cost estimating, the review process and future studies.

In general, $167,000 \mathrm{cfm}$ of air is supplied to the building secondary confinement areas from the outside. $136,000 \mathrm{cfm}$ of the secondary confinement air is then supplied to the primary confinement areas (hot cells). From the primary confinement areas the air is exhausted up an exhaust stack.

Air to the main facility will be heated for personnel comfort, but will not be cooled (except for the office areas). All air supplied to the primary confinement areas will have single stage HEPA filtering. Air exhausted from the primary confinement areas will have two stage HEPA filtering. All air in the primary and secondary areas in the facility will be once-through air (no recirculation).

Additional water cooled air handlers may be required in order to remove excess process heat from the process cells. These air handlers will recirculate the air within the individual cells for cooling purposes only, and will not have any air filtering capabilities. A cold water chiller sized for the excess process heat will be provided to supply water to the air handlers.

Distribution (complete package): N.E. Russel MS 3765, K.L. Williams MS 3765 Distribution (summary package only):

\begin{tabular}{|c|c|c|c|c|c|}
\hline $\begin{array}{l}\text { Author } \\
\text { M. E. Vansigkle } \\
\text { PIJ }\end{array}$ & $\begin{array}{l}\text { Dept. } \\
4130\end{array}$ & $\begin{array}{l}\text { Reviewed } \\
\text { L.E. Guillé, } \text { f. E: }\end{array}$ & $\begin{array}{l}\text { Date } \\
2 / 5 / 2+2\end{array}$ & $\begin{array}{l}\text { Approved) } \\
\text { V/Eltersel }\end{array}$ & $\begin{array}{l}\text { Date } \\
2 / 5 / 58\end{array}$ \\
\hline & & LMITCO Review & Daté & $\begin{array}{l}\text { LMITCO } \\
\text { Approval }\end{array}$ & Date \\
\hline
\end{tabular}




\section{Direct HIPing Facility}

\subsection{HVAC}

The design requirements for the building HVAC System are:

Maintain office and operational areas at temperature recommended by the appropriate codes and standards specified to assure personnel comfort and safety and to protect instruments and equipment during normal and off-normal conditions.

Detect and monitor ventilation flows and pressure differentials throughout the facility as required to prevent the possible spread of potential hazards. All ventilation air flows and pressure differentials will be alarmed if out of compliance.

Assure facility airflows are from areas of less contamination potential to areas of greater contamination potential. Means should be provided to seal all containment boundaries in the event of loss of ventilation and/or pressure differentials.

Confine radioactive materials as close as practicable to the point of release.

Maintain ALARA release of the radioactivity to the environment as required by DOE Order 5400.5.

Provide redundant or backup equipment in all exhaust systems serving contaminated areas as needed to assure contamination control.

Provide sampling ports in the individual branches of supply and exhaust ducting for testing to verify system performance, operability, and in-place filter component leakage.

Provide air changes sufficient to remove heat, hazardous and particulate gases, and other contaminants. System will be designed to provide proper distribution of air flow throughout the facility during normal, off-normal and maintenance activities.

Provide an interlocked HVAC barrier system so that reversed airflow patterns cannot be established.

Provide stack for exhausting all contaminated or potentially contaminated air. The stack will be monitored using isokinetic sampling techniques, in accordance with ANSI-13.1, Guide to Sampling Airborne Radioactive Particles in Nuclear Facilities and, as a minimum monitor for Beta/Gamma particulate, Alpha particulate, and tritium. The monitoring equipment should allow for both local and remote readout and alarm annunciation.

General: 
Drawing SK-HVXXX depicts the air flow diagram of the HVAC system for the Direct HIIPing Facility:

Up to three Air Handling Units will supply 167,000 CFM of conditioned air to the Operating Corridor at Levels $+24^{\prime}, 0^{\prime}-0$, and $-20^{\prime}$. Air from the operating corridors will be cascaded into the hot Cells via air handling units each consisting of supply blower and a one stage testable HEPA filter. The cascade air supply units will have $100 \%$ redundancy for filter sections with less that 6900 CFM and $50 \%$ redundancy for filters sections with air flow greater than or equal to 6900 CFM. . Air from the hot cells will be exhausted to the ambient via a two stage testable HEPA filter units and exhaust fans. HEPA filters and exhaust fans will have $100 \%$ redundancy for filter sections with less than 6900 CFM air flow and 50\% redundancy for filters sections with air flow of greater than or equal 6900 CFM.

HEPA Filter Units for Zone II \& Zone III will be located in the four maintenance corridors between the hot cells.

The Control Room will be provided with an independent HVAC system. Air from the room will be recirculated. Supply air handler will have $100 \%$ redundancy.

The supply air handlers utilized for delivering air to various spaced in the facility, will be housed in HVAC equipment Rooms located at Levels $0^{\prime}-0^{n}$. This room will be provided with conditioned air via one single zone air handler to offset the internal heat gains. Air from the room will be recirculated.

Administrative offices will be provided with an independent HVAC system. Air from the rooms will be recirculated.

The facility will be provided with an independent chilled water system consisting of central chillers and pumps, delivering chilled water to various cooling coils. This cooling is to remove build up heat from process equipment and is not for personnel comfort. No cooling is required for personnel comfort in the operating corridor.

The facility will utilize steam from the ICPP Main steam plant for comfort heating.

The HVAC system for the facility will be controlled by a central electronic control system located within the facility.

Confinement Systems:

A ventilation confinement system is provided, which, in conjunction with the physical barriers, maintains a continuous airflow pattern from areas of low potential for contamination to areas of high potential for contamination. The objectives of the confinement systems are to prevent the spread of radioactive and other hazardous materials to occupied areas; and to minimize the release of radioactive and other 
hazardous materials in facility effluents.

This facility is required to have two confinement zones per DOE Order 6430.1A.

The primary confinement (Zone III) consists of the process hot cells. Primary confinement also includes primary exhaust system through the two stages of HEPA filtration.

The primary confinement boundary is comprised of hot cell walls, welded stainless steel ductwork and HVAC equipment designed to maintain its structural integrity during and after operational and natural phenomena DBAs.

The secondary confinement boundary (Zone II) consists of the operating corridors and other building structure which totally surround the primary confinement.

The secondary confinement boundary contains all of the ventilation system equipment such as HEPA filter units and exhaust fans.

The non-confinement boundary consists of offices, control rooms and support areas outside of the secondary confinement boundary. The non-confinement zones do not require unique ventilation systems. These areas will be maintained at a slight positive pressure with respect to ambient.

HEPA filters are included to remove contaminated particulates. Carbon absorber beds are not provided in the filter trains because semi-volatile fission products and iodine will be removed from gas streams in the hot cells before their release to the HVAC system.

Redundancy will be provided to ensure proper ventilation confinement during HEPA filter changeout or maintenance on the fans.

Exhaust ductwork will be located in areas that are not normally occupied.

HEPA filter housings will have the capability to be leak tested and tested for filter efficiency in place.

Single stage HEPA filtration will be provided at the hot cell intakes to prevent possible spread of contamination due to momentary back flow to the occupied areas.

Confinement boundaries are sealed to maintain isolation when pressure differentials fall below normal conditions.

Exhaust systems for Zone II and Zone III are round stainless steel welded joint ductwork designed and installed in accordance with applicable SMACNA and UMC standards, and the ACGIH Industrial Ventilation Manual.

Confinement zones are supplied by a once-through ventilation system. All the airflow 
from these zones is HEPA filtered and discharged out the stack, with no air recirculation.

Exhaust air HEPA filter units include a stainless steel housing, a prefilter, two stages of side bagout HEPA filters, DOP test ports, and an exhaust fan. The exhaust fan has manufacturer designed and installed adjustable flow control.

The supply and exhaust fans for the hot cells have the capability to be powered from the INEEL site standby power grid. This allows for the ventilation confinement to be maintained in the hot cells during a loss of off-site power condition.

The HVAC systems will be controlled automatically by local stand-alone controllers provided with the HVAC equipment. Graphic displays mimicking the HVAC system will be available in the central control room for monitoring and for remote manual override control. The HVAC system will be operated locally from local operator stations. However, the control room operator will have supervisory control capability to start and stop the HVAC system and to change setpoints. Alarms and out-or-tolerance conditions will be annunciated in the control room.

Stack: For the Direct HIPing Facility, there will be one exhaust stack provided for the discharge of ventilation system exhaust and offgas system effluents. The stack will be located so that the stack exhaust will not be entrained into the building ventilation intakes.

Stack Monitor: An isokinetic exhaust stack monitoring system will be provided at the ventilation exhaust stack to monitor plant emissions as required by RCRA. The system will be self-contained package units providing sample probes, transport tubing closed loop flow controllers and analyzers, all enclosed in industrial control cabinets. A dual radiation exhaust stack sampling system, consisting of an isokinetically controlled record sampler and an isokinetically controlled continuous sampling system will be provided. The stack monitoring system will keep local records of concentrations measured. Concentration levels will be indicated and recorded in the main control room. High concentration levels in emissions and/or analyzer trouble alarms will be annunciated in the main control room.

This facility is designed with the following ventilation requirements:

-Eight air changes per hour for secondary confinement zones (Zones II and III).

-Four air changes per hour for tertiary confinement zones (Zone I).

-1 CFM per square foot for administrative areas.

-2 CFM per square foot for the control room.

-One stage of testable HEPA filters for hot cell inlet

-Two stages of testable HEPA filters for hot cell exhaust.

-One stage of testable HEPA filters for tertiary confinement exhaust.

$-100 \%$ once through ventilation for secondary and tertiary confinement zones.

-Maintain room pressure in accordance with Table $\mathbf{X}$.

It is assumed that areas with large in-cell heat loads that are in excess of what the normal 
ventilation can readily cool will have additional fan coil cooling units installed in them. These units will recirculate the room air for cooling purposes only and will have no filtering capabilities. 


\section{HIPing Facility Ventilation Requirements}

\begin{tabular}{|l|l|l|l|l|l|}
\hline & & \multicolumn{1}{|c|}{$\begin{array}{l}\text { Volume } \\
\text { (Ft3) } \\
\text { X1000 }\end{array}$} & $\begin{array}{l}\text { Required } \\
\text { Air } \\
\text { Changes } \\
\text { per Hr. }\end{array}$ & $\begin{array}{l}\text { Static } \\
\text { Pressure } \\
\text { Required } \\
\text { (IWG) }\end{array}$ & $\begin{array}{l}\text { Ventilation } \\
\text { Required } \\
\text { (CFM) } \\
\text { X1000 }\end{array}$ \\
\hline 1 & Operating Corridor (24) & 1,700 & 4 & -0.25 & 113 \\
\hline 2 & Operating Corridor (0) & 530 & 4 & -0.25 & 35 \\
\hline 3 & Operating Corridor (-20) & 285 & 4 & -0.25 & 19 \\
\hline 4 & Cyclone Rm Train 1 & 6 & 8 & -0.75 & 1 \\
\hline 5 & Cyclone Rm Train 2 & 6 & 8 & -0.75 & 1 \\
\hline 6 & Cyclone Rm Train 3 & 6 & 8 & -0.75 & 1 \\
\hline 7 & Cyclone Rm Train 4 & 6 & 8 & -0.75 & 1 \\
\hline 8 & Calcine Retr Train 1\&2 & 15 & 8 & -0.75 & 2.3 \\
\hline 9 & Calcine Retr Train 3\&4 & 15 & 8 & -0.75 & 2.3 \\
\hline 10 & Devol Eqpt Train 1\&2 & 17 & 8 & -0.75 & 2.3 \\
\hline 11 & Devol Eqpt Train 3\&4 & 17 & 8 & -0.75 & 2.3 \\
\hline 12 & HIPing Eqpt Train 1\&2 & 41 & 8 & -0.75 & 5.5 \\
\hline 13 & HIPing Eqpt Train 3\&4 & 41 & 8 & -0.75 & 5.5 \\
\hline 14 & $\begin{array}{l}\text { Equiptment Corridor } \\
\text { Train 1\&2 }\end{array}$ & 29 & 8 & -0.75 & 3.8 \\
\hline 15 & $\begin{array}{l}\text { Equiptment Corridor } \\
\text { Train 3\&4 }\end{array}$ & 29 & 8 & -0.75 & 3.8 \\
\hline 16 & Blender Rm Train 1 & 12 & 8 & -0.75 & 1.6 \\
\hline 17 & Blender Rm Train 2 & 12 & 8 & -0.75 & 1.6 \\
\hline 18 & Blender Rm Train 3 & 12 & 8 & -0.75 & 1.6 \\
\hline 19 & Blender Rm Train 4 & 12 & 8 & -0.75 & 1.6 \\
\hline
\end{tabular}




\begin{tabular}{|l|l|l|l|l|l|}
\hline 20 & Fill Tank Rm Train 1 & 12 & 8 & -0.75 & \\
\hline 21 & Fill Tank Rm Train 2 & 12 & 8 & -0.75 & 1.6 \\
\hline 22 & Fill Tank Rm Train 3 & 12 & 8 & -0.75 & 1.6 \\
\hline 23 & Fill Tank Rm Train 4 & 12 & 8 & -0.75 & 1.6 \\
\hline 24 & Weld Eqpt Rm Train 1 & 5 & 8 & -0.75 & 0.7 \\
\hline 25 & Weld Eqpt Rm Train 2 & 5 & 8 & -0.75 & 0.7 \\
\hline 26 & Weld Eqpt Rm Train 3 & 5 & 8 & -0.75 & 0.7 \\
\hline 27 & Weld Eqpt Rm Train 4 & 5 & 8 & -0.75 & 0.7 \\
\hline 28 & Decon Rm Train 1 & 16 & 8 & -0.75 & 2.1 \\
\hline 29 & Decon Rm Train 2 & 16 & 8 & -0.75 & 2.1 \\
\hline 30 & Decon Rm Train 3 & 16 & 8 & -0.75 & 2.1 \\
\hline 31 & Decon Rm Train 4 & 16 & 8 & -0.75 & 2.1 \\
\hline 32 & Devol Weld Rm Train 1 & 13 & 8 & -0.75 & 1.8 \\
\hline 33 & Devol Weld Rm Train 2 & 13 & 8 & -0.75 & 1.8 \\
\hline 34 & Devol Weld Rm Train 3 & 13 & 8 & -0.75 & 1.8 \\
\hline 35 & Devol Weld Rm Train 4 & 13 & 8 & -0.75 & 1.8 \\
\hline 36 & HIP Furnace Train 1 & 52 & 8 & -0.75 & 7 \\
\hline 37 & HIP Furnace Train 2 & 52 & 8 & -0.75 & 7 \\
\hline 38 & HIP Furnace Train 3 & 52 & 8 & -0.75 & 7 \\
\hline 39 & HIP Furnace Train 4 & 52 & 8 & -0.75 & 7 \\
\hline 40 & QA Assay Rm Train 1 & 4 & 8 & -0.75 & 0.5 \\
\hline 41 & QA Assay Rm Train 2 & 4 & 8 & -0.75 & 0.5 \\
\hline 42 & QA Assay Rm Train 3 & 4 & 8 & -0.75 & 0.5 \\
\hline 43 & QA Assay Rm Train 4 & 4 & 8 & -0.75 & 0.5 \\
\hline 44 & Loading Rm Train 1 & 26 & 8 & -0.75 & 3.5 \\
\hline
\end{tabular}




\begin{tabular}{|l|l|l|l|l|l|}
\hline 45 & Loading Rm Train 2 & 26 & 8 & -0.75 & 3.5 \\
\hline 46 & Loading Rm Train 3 & 26 & 8 & -0.75 & 3.5 \\
\hline 47 & Loading Rm Train 4 & 26 & 8 & -0.75 & 3.5 \\
\hline 48 & $\begin{array}{l}\text { Remote Maintenance Rm } \\
\text { Train 1 }\end{array}$ & 5 & 8 & -0.75 & 0.7 \\
\hline 49 & $\begin{array}{l}\text { Remote Maintenance Rm } \\
\text { Train 2 }\end{array}$ & 5 & 8 & -0.75 & 0.7 \\
\hline 50 & $\begin{array}{l}\text { Remote Maintenance Rm } \\
\text { Train 3 }\end{array}$ & 5 & 8 & -0.75 & 0.7 \\
\hline 51 & $\begin{array}{l}\text { Remote Maintenance Rm } \\
\text { Train 4 }\end{array}$ & 5 & 8 & -0.75 & 0.7 \\
\hline 52 & $\begin{array}{l}\text { Crane Maintenance Rm } \\
\text { Train 1\&2 }\end{array}$ & 19 & 8 & -0.75 & 2.5 \\
\hline 53 & $\begin{array}{l}\text { Crane Maintenance Rm } \\
\text { Train 3\&4 }\end{array}$ & 19 & 8 & -0.75 & 2.5 \\
\hline 54 & Offices & 45 & 4 & +0.1 & 3 \\
\hline 55 & Incoming Load Rm Train 1 & 9 & 8 & -0.25 & 1.2 \\
\hline 56 & Incoming Load Rm Train 2 & 9 & 8 & -0.25 & 1.2 \\
\hline 57 & Incoming Load Rm Train 3 & 9 & 8 & -0.25 & 1.2 \\
\hline 58 & Incoming Load Rm Train 4 & 9 & 8 & -0.25 & 1.2 \\
\hline 59 & Can Fill Rm Train 1 & 9 & 8 & -0.75 & 1.2 \\
\hline 60 & Can Fill Rm Train 2 & 9 & 8 & -0.75 & 1.2 \\
\hline 61 & Can Fill Rm Train 3 & 9 & 8 & -0.75 & 1.2 \\
\hline 62 & Can Fill Rm Train 4 & 9 & 8 & -0.75 & 1.2 \\
\hline 63 & $\begin{array}{l}\text { Capping/Welding Rm } \\
\text { Train 1 }\end{array}$ & 5 & 8 & -0.75 & 0.7 \\
\hline 64 & $\begin{array}{l}\text { Capping/Welding Rm } \\
\text { Train 2 }\end{array}$ & 5 & 8 & -0.75 & 0.7 \\
\hline
\end{tabular}




\begin{tabular}{|l|l|l|l|l|l|}
\hline 65 & $\begin{array}{l}\text { Capping/ Welding Rm } \\
\text { Train 3 }\end{array}$ & 5 & 8 & -0.75 & 0.7 \\
\hline 66 & $\begin{array}{l}\text { Capping/ Welding Rm } \\
\text { Train 4 }\end{array}$ & 5 & 8 & -0.75 & 0.7 \\
\hline 67 & Size / Grind Rm Train 1 & 18 & 8 & -0.75 & 2.4 \\
\hline 68 & Size / Grind Rm Train 2 & 18 & 8 & -0.75 & 2.4 \\
\hline 69 & Size / Grind Rm Train 3 & 18 & 8 & -0.75 & 2.4 \\
\hline 70 & Size / Grind Rm Train 4 & 18 & 8 & -0.75 & 2.4 \\
\hline 71 & Transfer Tunnel Train 1\&2 & 27 & 8 & -0.75 & 3.6 \\
\hline 72 & Transfer Tunnel Train 3\&4 & 27 & 8 & -0.75 & 3.6 \\
\hline 73 & HVAC Supply Eqpt Rm & 148 & 4 & -0.25 & 10 \\
\hline 74 & HVAC Exhaust Eqpt Rm & 148 & 4 & -0.25 & 10 \\
\hline 75 & Can Loading Bay & 15 & 4 & -0.25 & 1 \\
\hline 76 & Electrical Rm & 13 & 4 & +0.1 & 0.9 \\
\hline 77 & Electrical Rm & 13 & 4 & +0.1 & 0.9 \\
\hline 78 & & & & & \\
\hline
\end{tabular}


Project File Number

02BD7

\section{Project/Task Waste Treatment Facility Study}

\section{Subtask Retrieve calcine from CSSFs and deliver it to the Waste Treatment Facility}

\section{Title: Calcine Retrieval and Transportation}

Summary:

A calcine retrieval and transportation system is presented to retrieve calcine from the CSSFs and transport it to the Waste Treatment Facility. The calcine retrieval and transportation system is designed to supply calcine to the treatment options currently understudy \{Cementitious Waste Option (CWO), Direct Cementitious Waste Option (DCWO), Hot Isostatic Press (HIP) Waste Option (HWO), Vitrification Waste Option (VWO), and TRU Separations options). The system is divided into three subsystems: CSSF access method, calcine retrieval system, and calcine transportation system. During CSSF access, the buildings, equipment, and piping are removed from the superstructure of each CSSF. Retrieval risers are installed and accessed. The CSSFs are prepared for calcine retrieval. The calcine retrieval system presents a viable method to retrieve calcine from the CSSFs. The system relies on an air jet and a suction nozzle. The calcine transportation system is a pneumatic system similar to one currently used at the ICPP for transportation of calcine. A process data sheet and cost estimate were developed for the calcine retrieval and transportation system.

Three cost estimates are presented to meet the needs of each waste treatment option. Each waste treatment option requires the same access activities for the seven CSSFs. The retrieval method is the same for each waste treatment option. The locations of the waste treatment facilities developed by each option necessitates variations in the transport system. The length of the transport system is the basic difference between the transport systems. The cost estimate includes costs associated with removing corrosion coupons prior to retrieving the calcine and installing D\&D risers after retrieval activities are complete.

The first cost estimate was developed to meet the 5-year operating schedule of the Cementitious Waste Option (CWO). This system delivers calcine from the CSSFs to an NWCF addition. A second estimate was developed to deliver calcine to the TRU Separations options' calcine dissolution facility. A third cost estimate for the calcine retrieval and transportation system is presented for the DCWO, HWO, and VWO options which require an intermediate transport station (ITS) to deliver the calcine to the Waste Treatment Facility.

The CWO option has a five year operating period that begins $1 / 1 / 2013$. The total unescalated cost for the calcine retrieval and transportation system is $\$ 176,566,000$. The total cost including escalation, management reserve, and contingency is $\$ 348,880,000$. The discounted annual cost is $\$ 166,409,000$.

The TRU-Separations Options have twenty year operating periods that begin $1 / 1 / 2013$. The total unescalated cost for the calcine retrieval and transportation system is $\$ 237,389,000$. The total 
Project File Number $\quad$ 02BD7

cost including escalation, management reserve, and contingency is $\$ 531,023,000$. The discounted annual cost is $\$ 192,309,000$.

The DCWO, HWO, and VWO options have twenty year operating periods that begin 1/1/2013. The total unescalated cost for the calcine retrieval and transportation system is $\$ 243,039,000$. The total cost including escalation, management reserve, and contingency is $\$ 543,371,000$. The discounted annual cost is $\$ 196,878,000$.

The scope of this study was limited to the Fluor-Daniels feasibility design. The purpose was to compare this system directly to the Fluor-Daniels system. However, two issues that warranted further review and inclusion in the cost estimate were identified. Separate cost estimates were developed for the removal of corrosion coupons from the bins and installation of D\&D risers.

Distribution (complete package): A complete copy of this EDF will be included in the following reports:

R. E. Dafoe, Direct Cementitious Waste Option Study Report, INEEL/EXT-97-01399, February 1998.

W. H. Landman, TRU Separations Options Study Report, INEEL/EXT-97-01428, February 1998.

A. E. Lee, Cementitious Waste Option Preliminary Study Report, INEEL/EXT-9701400 , February 1998.

D. A. Lopez, Vitrified Waste Option Study Report, INEEL/EXT-97-01389, February 1998.

N. E. Russell, Hot Isostatic Press (HIP) Waste Option Study Report, INEEL/EXT-9701392 , February 1998.

Distribution (summary package only):

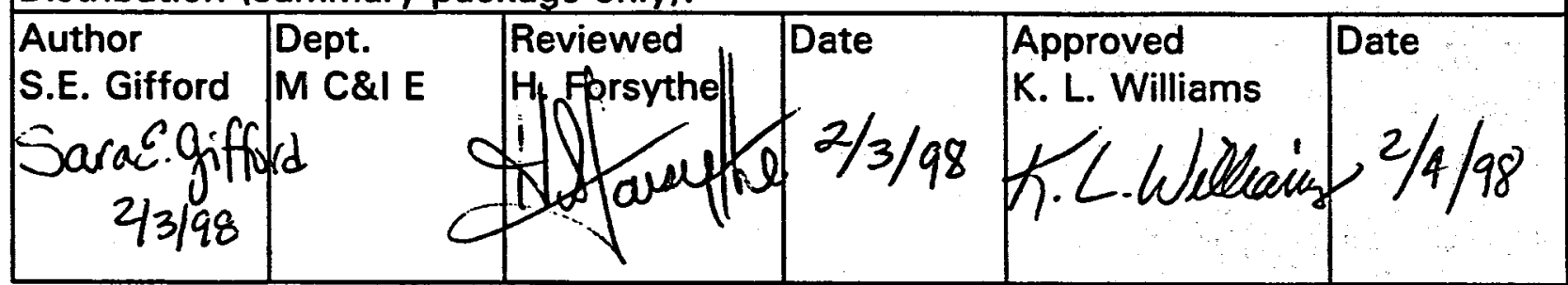

See Management Control Procedure (MCP) 6 for instructions on use of this form. 


\section{Outline}

1.0 Introduction

1.1 Background

1.2 Purpose and Scope

2.0 Design Basis

2.1 Design Criteria

2.2 Key Assumptions

2.3 Requirements

3.0 Process Design

3.1 CSSF Access

3.1.1 Process Basis

3.1.2 Process Description

3.1.3 Process Equipment Description

3.1.4 Process Issues

3.2 Calcine Retrieval

3.2.1 Process Basis

3.2.2 Process Description

3.2.3 Process Equipment Description

3.2.4 Process Issues

3.3 Calcine Transport

3.3.1 Process Basis

3.3.2 Process Description

3.3.3 Process Equipment Description

3.3.4 Process Issues

3.4 Implementation

4.0 Input to Project Data Sheet

5.0 Program Schedule

6.0 Costs

7.0 Recommendations for Further Study

8.0 Uncertainties

8.1 Maturity of Technology

8.2 Risk Assessment

8.2.1 Project Risk

8.2.2 Technical Risk

8.2.3 ES\&H Risk

8.3 Failure Modes

8.4 Cost Estimate Uncertainties

9.0 Potential Impacts of NRC Licensing

10.0 Summary and Conclusions

Appendices
A. Drawings
B. References
C. Equipment List 
D. Background Information for Project Data Sheet

E. Risk Assessment Data Sheets

F. Cost Estimate 
CSSF Calcined Solids Storage Facility

CWO Cementitious Waste Option

DCWO Direct Cementitious Waste Option

HAW High Activity Waste

HLW High Level Waste

HWO Hot Isostatic Pressing (HIP) Waste Option

ICPP Idaho Chemical Processing Plant

INEEL Idaho National Engineering and Environmental Laboratory

ITS Intermediate Transport Station

LAW Low Activity Waste

NRC Nuclear Regulatory Commission

NWCF New Waste Calcining Facility

SBW Sodium Bearing Waste

VDA Vertical Deployment Apparatus

VIC Ventilation Instrumentation and Control Building

VWO Vitrified Waste Option

WCF Waste Calcining Facility

WTF Waste Treatment Facility (generic facility name for the facility developed in each waste treatment option)

WTS Waste Treatment Study 


\subsection{Introduction}

At the ICPP, a fluidized bed calcination process changes the chemical composition of high-level radioactive mixed liquid waste generated from the reprocessing of spent nuclear fuel and sodium bearing waste (SBW) generated from decontamination activities. The calcination process converts the liquid waste to a solid waste and reduces the volume of the waste by a factor of 7 . After the calcination process, the resulting solid waste, called calcine, is pneumatically transported from the calciner to one of seven storage facilities, named calcined solids storage facilities (CSSF).

The settlement agreement between the Department of Energy and the State of Idaho mandates that high level waste be ready for removal from Idaho by a target date of 2035 for disposal. The calcine in the CSSFs must be retrieved from the CSSFs and treated. This EDF details a method to access and prepare the CSSFs for calcine retrieval, a calcine retrieval system, and a transport system to deliver the calcine to the Waste Treatment Facility. The information presented is applicable to the non-separations waste treatment options (DCWO, HWO, and VWO) and the TRU Separations waste treatment options.

\subsection{Background Information}

The calcine is stored in cylindrical steel bins within a CSSF. The number of separate, self contained bins in a CSSF varies from 3 to 7. The bins are either cylindrical or annular. The outside diameter of the bins is approximately $12 \mathrm{ft}$. The length of the bins range from $24 \mathrm{ft}$ to 61 $\mathrm{ft}$. A passive convection cooling system is used to cool the bins inside a large concrete vault. Above the bin vault are structures that house the necessary equipment to receive the calcine. These structures form the superstructure of each CSSF. Figure 1 shows a sketch of each CSSF.

Calcine production began in November $1963^{1}$. The first six CSSFs store several forms of calcine. Currently, CSSF 6 is being filled while CSSF 7 remains empty. As of 1996, the CSSFs housed approximately $134,500 \mathrm{ft}^{3}$ of calcine. There are three main calcine types: alumina calcine, zirconia calcine, and calcine blends. The amount of calcine stored in each CSSF is shown in Table 1. The information for this Table was taken from reference 1. 

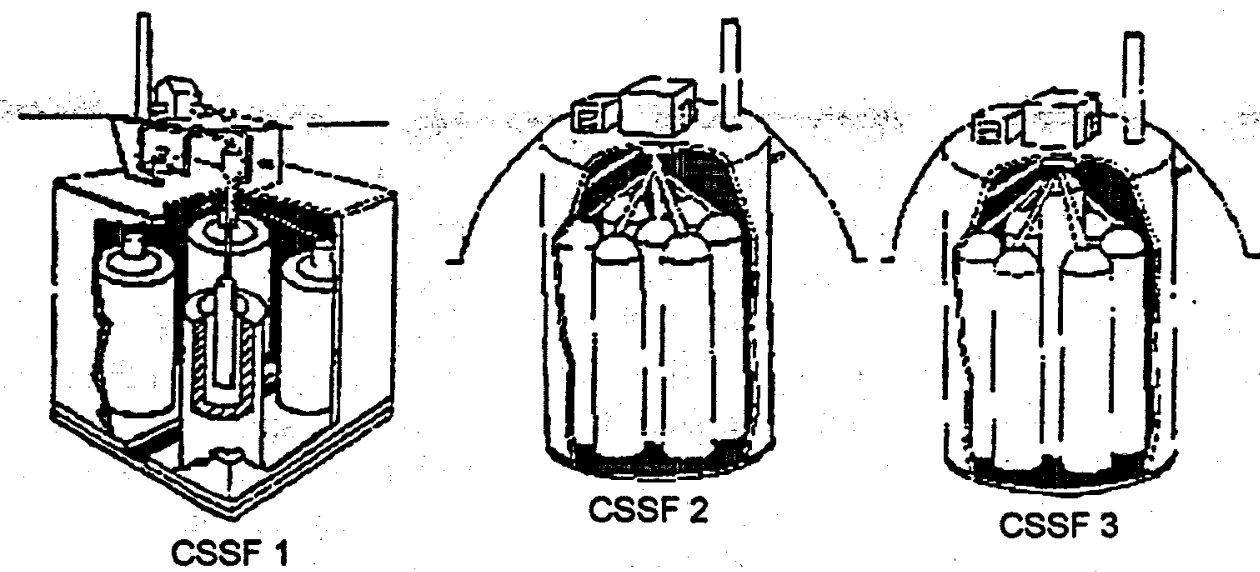

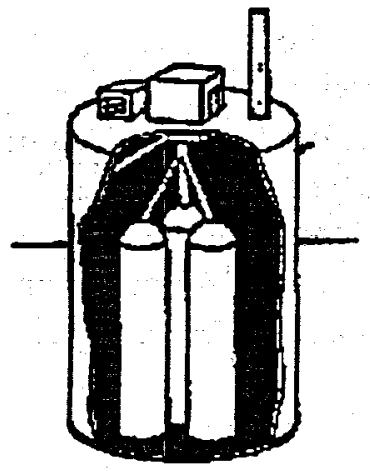

CSSF 4

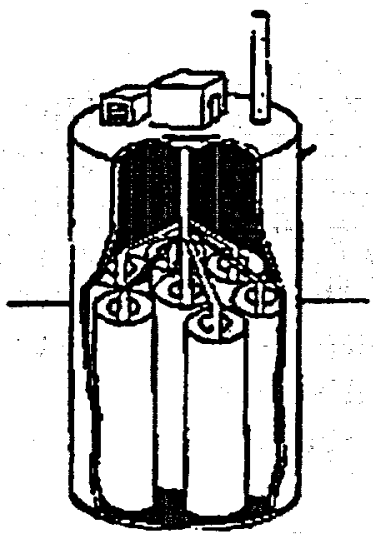

CSSF 5

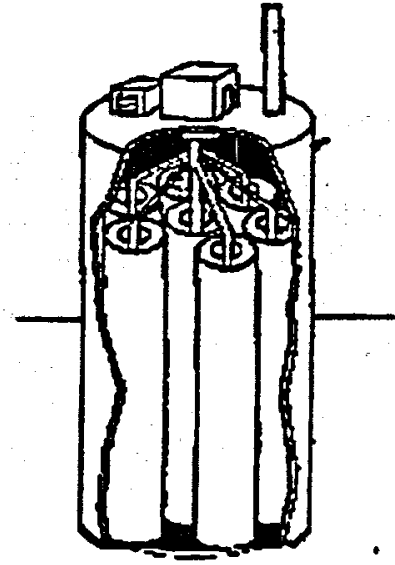

CSSF 6

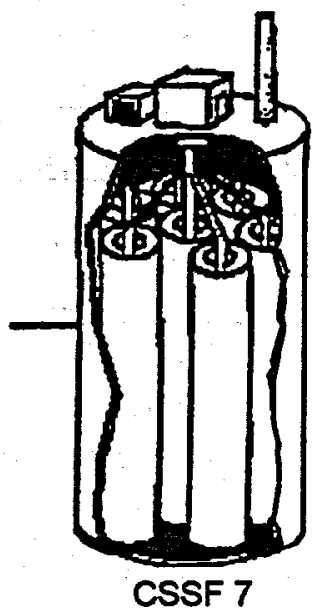

Figure 1. Calcined Solids Storage Facilities (CSSFs).

Table 1. Volume of Calcine Type in Each CSSF As of 1997.

\begin{tabular}{|c|c|c|c|c|c|c|}
\hline CSSF & $\begin{array}{c}\text { Alumina } \\
\text { Calcine } \\
\left(\mathrm{ft}^{3}\right)\end{array}$ & $\begin{array}{c}\text { Zirconia } \\
\text { Calcine } \\
\left(\mathrm{ft}^{3}\right)\end{array}$ & $\begin{array}{l}\text { Other } \\
\left(\mathrm{ft}^{3}\right)\end{array}$ & $\begin{array}{l}\text { Calcine } \\
\text { Blends } \\
\left(\mathrm{ft}^{3}\right) \\
\text { Description }\end{array}$ & $\begin{array}{c}\text { Cold/ } \\
\text { Dolomite } \\
\left(\mathrm{ft}^{3}\right)\end{array}$ & $\begin{array}{l}\text { Total } \\
\left(\mathrm{ft}^{3}\right)\end{array}$ \\
\hline 1 & 7292 & & & & 373 & 7665 \\
\hline 2 & 10,754 & 18,582 & & & 900 & 30,236 \\
\hline 3 & 2,250 & 24,844 & 50 & $\begin{array}{c}5,580 \\
\mathrm{Z}-\mathrm{SB} \overline{\mathrm{S}}\end{array}$ & 5,810 & 38,534 \\
\hline 4 & & 5,210 & & $\begin{array}{c}11,130 \\
1 \% \mathrm{Al}-\mathrm{Zr} \& \\
99 \% \mathrm{Zr}-\mathrm{SBW}\end{array}$ & 910 & 17,250 \\
\hline 5 & & & 50 & $\begin{array}{c}31,303 \\
A \mathrm{~A}-\mathrm{Z} \mathrm{r}-\mathrm{SB} W\end{array}$ & 3,670 & 35,023 \\
\hline 6 & & $\ldots$ & & $\begin{array}{c}5,010 \\
\mathrm{~A} \mathrm{l}-\mathrm{Z} \mathrm{r}-\mathrm{SBW}\end{array}$ & 730 & 5,740 \\
\hline 7 & & & & & & 0 \\
\hline
\end{tabular}




\subsection{Purpose and Scope}

The purpose of this study is to define a calcine retrieval and transportation plan that is compatible with the calcine processing options currently under study by the WTF program (namely the CWO, DCWO, HWO, VWO, and the TRU Separations Options). The plan will consist of accessing the calcine in each CSSF, removing the calcine from the bins, and transporting the calcine from each CSSF to the Waste Treatment Facility (the processing facility developed in each option study). Three versions of this plan were necessary to meet the needs of each waste treatment option. The equipment necessary for CSSF access, calcine retrieval and transportation will be approximately sized. A cost estimate for each option will be developed. The cost estimate will include capital equipment costs as well as operating and maintenance costs over the life of the project. As necessary, sketches will be included to clarify the systems and processes developed.

The scope of EDF is limited to the scope of the Fluor-Daniels ${ }^{2}$ design for the calcine retrieval and transportation system as presented in reference 2. The design presented in this EDF should not seek to define unique systems to accomplish the overall tasks. Modifications to the systems presented in the Fluor-Daniels ${ }^{2}$ design should only be made to accommodate the unique needs of the five processing options currently under study. The issues and recommendations for future study identified during this study will be documented. Additional activities, that are necessary to fully implement the calcine retrieval and transportation system but are beyond the scope of the Fluor-Daniels design, will be included in the cost estimate.

\subsection{Design Basis}

Although the overall design is based on the Fluor-Daniels ${ }^{2}$ design, design criteria and key assumptions were made. The requirements that must be met are explained in section 2.3. The criteria, assumptions, and requirements were independently developed and applied to the calcine retrieval and transportation system.

\subsection{Design Criteria}

The design criteria are listed below. All portions of the design must satisfy criteria in the general category. These criteria are essential to satisfy ES\&H goals.

\section{General:}

1. Minimize worker radiation exposure and spread of contamination.

2. The systems should be designed to withstand any credible fire or other applicable accidents and still serve as a confinement barrier.

3. The systems should be designed to withstand appropriate natural phenomena hazards.

4. Provide primary and secondary confinement at all times while minimizing the confinement volumes.

5. Adequately heat and cool occupied areas of enclosures.

6. Provide instrumentation and control for operation and data acquisition. 
7. Facility equipment and calcine retrieval and transport systems must be capable of being decontaminated and/or replaced safely and easily.

8. The systems should minimize the generation of hazardous wastes.

\section{$\underline{\text { Retrieval: }}$}

1. Minimize the amount of remote mechanical equipment placed in the bins. In effect, minimize the potential for equipment breakdown.

2. The bin pressure must remain slightly more negative than the surrounding vault space during retrieval. Controls are required to maintain the negative-pressure confinement.

3. Calcine will be retrieved from one bin in a CSSF a time. Although, calcine from more than one CSSF can be retrieved from at a given time.

4. Retrieval will be performed only if the transportation systems are operational.

5. Retrieve and deliver calcine to the Waste Treatment Facility according to the demand of the process.

\section{Transportation:}

1. Design the transportation system for a 30 year service life.

2. The transportation system should be readily maintainable.

3. Provide the appropriate amount of rod-out stations for the pneumatic transport system.

\subsection{Key Assumptions}

The scope of this study mandates the first and foremost assumption is that Fluor-Daniels ${ }^{2}$ has developed a viable and competitive option for calcine retrieval and transportation. The remaining assumptions are outlined below. They are divided into three categories: CSSF access, calcine retrieval, and transportation. A basis for each assumption is provided.

\begin{tabular}{|c|c|}
\hline Assumption & Basis \\
\hline \multicolumn{2}{|l|}{ CSSF Access: } \\
\hline $\begin{array}{l}\text { Installation of risers can be accomplished } \\
\text { with little modification to existing } \\
\text { technology. }\end{array}$ & $\begin{array}{l}\text { Similar risers were installed on hazardous } \\
\text { waste bins. The technology was developed } \\
\text { by West Valley Nuclear, Inc. and applied } \\
\text { to the CSSFs by Raytheon Engineers and } \\
\text { Constructors. } \\
\text { References: } 3 \text { and } 4\end{array}$ \\
\hline $\begin{array}{l}10 \% \text { of the ground fill removed for } \\
\text { construction and CSSF } 1 \text { access is } \\
\text { contaminated. }\end{array}$ & References: 2 and 3 \\
\hline $\begin{array}{l}\text { Transport piping from WCF and NWCF to } \\
\text { the CSSFs will be decontaminated as }\end{array}$ & $\begin{array}{l}\text { Closure plans of WCF and NWCF } \\
\text { Reference: } 5 \text { and } 6\end{array}$ \\
\hline
\end{tabular}




\begin{tabular}{|c|c|}
\hline $\begin{array}{l}\text { outlined in the WCF and NWCF closure } \\
\text { plans. This piping will remain accessible } \\
\text { for D\&D without endangering personnel. }\end{array}$ & \\
\hline $\begin{array}{l}\text { Access activities do not reduce CSSF } \\
\text { integrity. Additionally, superstructure } \\
\text { demolition reduces static stress on the } \\
\text { CSSF. }\end{array}$ & $\begin{array}{l}\text { Shoring activities will occur during fill } \\
\text { removal. The Raytheon study analyzed the } \\
\text { roof of CSSF } 1 \text { and found that these } \\
\text { activities would help to stabilize CSSF } 1 \text {. } \\
\text { Reference: } 3\end{array}$ \\
\hline $\begin{array}{l}\text { An adequate place for retrieval riser } \\
\text { attachment can be located on each bin. } \\
\text { Piping inside the bin vault will not interfere } \\
\text { with riser location. }\end{array}$ & $\begin{array}{l}\text { The exact location of retrieval risers was } \\
\text { not determined because it is highly } \\
\text { dependent on the requirements of the riser } \\
\text { welding method. This method is currently } \\
\text { being studied at the ICPP. However, } \\
\text { locations for } 40 \text { retrieval risers were found } \\
\text { for CSSF } 1 \text {. This number far exceeds the } \\
24 \text { retrieval risers required for CSSF1. The } \\
\text { remaining CSSFs at most require an } \\
\text { additional } 8 \text { retrieval risers to be installed. } \\
\text { Reference: } 3\end{array}$ \\
\hline $\begin{array}{l}\text { Bins will not be structurally weakened by } \\
\text { the attachment of retrieval risers. Measures } \\
\text { to avoid this (support retrieval riser weight } \\
\text { above bin and installation of a self- } \\
\text { supporting floor) can be taken but are not } \\
\text { documented. }\end{array}$ & Reference: 3 and 4 \\
\hline $\begin{array}{l}\text { Remote equipment can be sized } \\
\text { appropriately from equipment developed } \\
\text { for previous projects. }\end{array}$ & Reference: 4 \\
\hline \multicolumn{2}{|l|}{ Retrieval: } \\
\hline $\begin{array}{l}\text { All types of calcine in all the bins are } \\
\text { retrievable as a dilute phase using the } \\
\text { retrieval method provided. }\end{array}$ & Reference: 2 \\
\hline $\begin{array}{l}\text { The retrieval method is a viable option for } \\
\text { all bin shapes. This is pertinent to the } \\
\text { cylindrical bins. }\end{array}$ & $\begin{array}{l}\text { Reference: } 8 \text { and S. E. Gifford, telephone } \\
\text { conversation with Dan Griffith, INEEL. }\end{array}$ \\
\hline $\begin{array}{l}\text { Relocation of retrieval equipment (VDA } \\
\text { and jumper) from one CSSF to another will } \\
\text { take approximately } 1 \text { week. }\end{array}$ & $\begin{array}{l}\text { In the Fluor-Daniels }{ }^{2} \text { cost estimate } \\
\text { relocation of the confinement enclosure } \\
\text { and all associated equipment is } \\
\text { accomplished in two weeks. } \\
\text { Reference: } 2\end{array}$ \\
\hline $\begin{array}{l}\text { Calcine is assumed to have remained } \\
\text { unchanged. This mainly means that it has } \\
\text { not agglomerated in any of the CSSFs. }\end{array}$ & $\begin{array}{l}\text { This assumption allows the same retrieval } \\
\text { equipment design to be used in all the } \\
\text { CSSFs. Samples from CSSF } 2 \text { indicate } \\
\text { that the calcine can remain unchanged }\end{array}$ \\
\hline
\end{tabular}




\begin{tabular}{|c|c|}
\hline 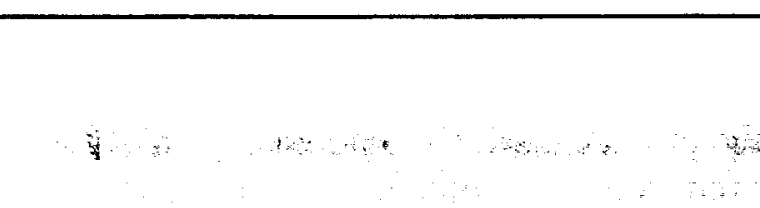 & $\begin{array}{l}\text { during storage. Samples from all CSSFs } \\
\text { are necessary to validate this assumption } \\
\text { for future studies. } \\
\text { Reference: } 7\end{array}$ \\
\hline $\begin{array}{l}\text { During calcine retrieval no less than } 95 \% \\
\text { of the calcine in a bin will be removed. } \\
\text { Beyond this level, as much of the calcine as } \\
\text { is reasonable will be retrieved. }\end{array}$ & $\begin{array}{l}\text { The } 95 \% \text { of the calcine in a bin has been } \\
\text { demonstrated to be retrievable at a high } \\
\text { rate. The next } 4.7 \% \text { of the calcine is } \\
\text { retrievable at a significantly lower rate. } \\
\text { Reference: } 8\end{array}$ \\
\hline $\begin{array}{l}\text { No internal obstructions (stiffening rods, } \\
\text { thermowells, etc.) will interfere with } \\
\text { extending the retrieval lines into the bins. }\end{array}$ & $\begin{array}{l}\text { The internal obstructions are well } \\
\text { documented. It is anticipated that the } \\
\text { retrieval risers can be located to avoid these } \\
\text { obstructions. The scope of this study does } \\
\text { not permit an in depth examination of this } \\
\text { issue. } \\
\text { Reference: INEEL drawings }\end{array}$ \\
\hline $\begin{array}{l}\text { No miscellaneous materials will enter the } \\
\text { suction nozzle. Where possible, such } \\
\text { material will be removed from the bins } \\
\text { prior to retrieval activities. }\end{array}$ & $\begin{array}{l}\text { The scope of this study does not permit an } \\
\text { in depth examination of this issue. } \\
\text { However, this is necessary that } \\
\text { miscellaneous materials present in the bins } \\
\text { do not enter the transportation system. } \\
\text { References: } 3 \text { and S. E. Gifford, separate } \\
\text { conversations with Dan Griffith and Dan } \\
\text { Staiger, INEEL. }\end{array}$ \\
\hline \multicolumn{2}{|l|}{ Transportation: } \\
\hline $\begin{array}{l}\text { All above ground piping must be shielded. } \\
\text { The concrete chase and earthen berm are } \\
\text { adequate to meet the radiological shielding } \\
\text { needs of dilute phase calcine. }\end{array}$ & Reference: 3 \\
\hline $\begin{array}{l}\text { All directional changes will utilize blinded } \\
\text { tees and laterals. All components, } \\
\text { including the cyclone, should be reinforced } \\
\text { with nitronic wear plates to prevent erosion } \\
\text { failures. }\end{array}$ & Reference: 11 \\
\hline
\end{tabular}

\subsection{Requirements}

Statutory law, DOE orders, and the Batt Agreement establish the requirements for the calcine retrieval and transportation system. These requirements are examined in reference 9. 


\subsection{Process Design}

The process design has been split into three sections to provide clarity to the description. CSSF access (section 3.1) will prepare each bin for calcine retrieval by decontaminating the CSSF superstructure and installing or accessing the retrieval risers. Calcine retrieval (section 3.2) will remove the calcine from each bin and place it directly in the transportation system. The transportation system (section 3.3) will deliver the calcine to the Waste Treatment Facility and provide the motive for $r$. A basis, process description, equipment description, and process issues are detailed for each section of the design.

\subsection{CSSF Access}

\subsubsection{Process Basis}

CSSF access prepares each bin for calcine retrieval by reducing radiation exposure, adding necessary retrieval risers, and accessing existing retrieval risers. The CSSFs will be prepared for calcine retrieval by erecting permanent confinement enclosures. The access method presented by Fluor-Daniels ${ }^{2}$ was originally developed in the Raytheon ${ }^{3}$ design for CSSF 1 . The specific details for each CSSF may vary but the overall the process is the same for all CSSFs.

\subsubsection{Process Description}

The primary goal of this phase of the retrieval and transport system is to prepare the CSSFs for retrieval. Bin vault ventilation systems will be replaced, confinement enclosures will be constructed, and retrieval lines will be installed and accessed. All modifications to the CSSFs and construction of new buildings will comply with the general design criteria outlined in reference 10. The CSSF access process is outlined in 9 steps. In order to protect the integrity of each CSSF some of these steps may overlap in the schedule.

1. Earthwork. Extensive excavation of CSSF 1 will expose the superstructure down to the bin vault roof. The excavation necessary to reach CSSF 1 will affect the earthen berms of CSSFs 2 and 3. Retaining walls must be installed to preserve these shielding berms. The uncontaminated portion of excavated fill, which must be covered, is estimated at $90 \%$. The contaminated fill must be disposed of appropriately. This work begins in an uncontaminated work area. Shoring of the CSSFs, construction of the retaining wall for CSSF 1, and removal of $10 \%$ contaminated fill require work in a radiation zone. Therefore, shielded or remote equipment should be used during this step.

An equipment ramp must be built to CSSF 1 . This ramp will be used during the installation of the bridge crane and the construction of the confinement buildings. For CSSF 2-7, a mobile crane will place the equipment on the CSSF roof. This work will primarily occur under a temporary decontamination tent. The cooling air stacks will interfere with locating the confinement enclosure on the bin vault roof. Relocation of the cooling air stacks will begin in this step. 
2. Construct ventilation, instrumentation, and control (VIC) building for each CSSF. The primary purpose of the VIC building is to house the ventilation, instrumentation, and control equipment. It will be a pre-manufactured steel building placed adjacent to each CSSF. During this step the HVAC, instrumentation, and control equipment will be installed. The HVAC equipment will regulate and decontaminate air from the bin vault, confinement enclosure, and this building. The interface between the VIC building and confinement enclosure for each CSSF is shown in sketch CRT-01. Temperature control will be maintained in the control room and operating areas with this system. Air flow will be monitored to minimize the risk of contamination spread by circulating air from low risk areas to high risk areas. Sampling ports will be provided to ensure the HVAC equipment is compliant with the applicable standards.

Installation of instrumentation will consist of relocating panels and rewiring because the instrumentation is functional in each CSSF. The control room will house the remote operations control and instrumentation. It will allow for internal viewing of the bins through the CCTV system as well as aide in installation of retrieval risers. Construction of this building includes floor, lights, windows, doors, $\mathrm{OH}$ doors, insulation, and fire protection. For all the CSSFs, this building will have the same layout and size. The VIC building for all CSSFs will require electricity, water, heating and/or cooling, breathing air, and plant air.

3. Construct confinement enclosure for each CSSF. The confinement enclosure is a nonreactor nuclear facility. It is pictured in figure 2 as it would appear on CSSF 5, 6, or 7 . For CSSFs 1, 2, 3, and 4 the confinement enclosure will be constructed on the roof of the bin vault. It acts as a confinement barrier during retrieval activities. This enclosure is a premanufactured steel building. This enclosure also includes ladder, guardrail, steel plate, and structural steel. It will be complete with fire protection equipment, lighting, equipment wiring and CCTV capabilities. The interior of the confinement enclosure will be coated with strippable coatings for decontamination purposes.

A negative pressure will be maintained inside the enclosure in order to reduce the risk of contamination spread. The confinement enclosure will house a bridge crane, core drilling platform, welding equipment, vertical deployment equipment, and shielded jumpers. The bridge crane will be installed for use during decontamination of the superstructure equipment and piping, core drilling procedures, and calcine retrieval.

This building will be decontaminated several times throughout the calcine retrieval process. The confinement enclosures for all the CSSFs will require electricity, water, breathing air, plant air, high pressure steam, service water, and instrument air. After construction of the confinement enclosure, the temporary confinement tent over the construction site may be removed.

4. Access vaults that require decontamination and decommissioning. In this step, equipment inside the vaults will not be disturbed. CSSFs $1,2,3$, and 4 require installation of access ways to the vaults. This will be accomplished by core drilling into the inaccessible rooms. Existing access ways to the vaults (CSSFs 5, 6, and 7) will be cleared. Necessary portable shielding should be placed at the vault entry locations. For all CSSFs, external 


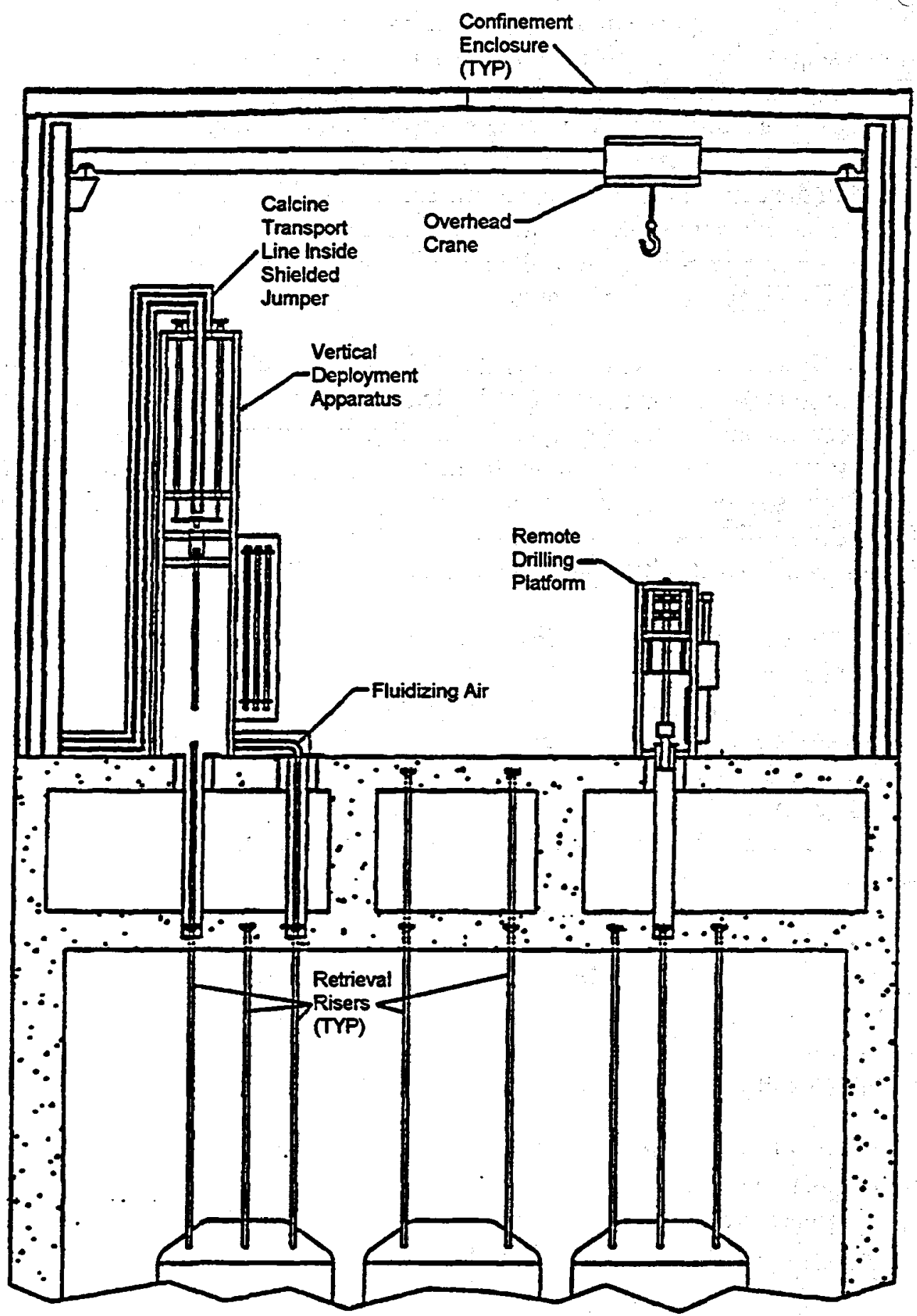

Figure 2. Confinement Enclosure and equipment pictured for CSSF 5,6 , or 7 . 
structures and equipment such as corrugated metal buildings, cooling stack ductwork, cooling air blowers, and their associated ductwork will be removed. As necessary, installation of plugs in ductwork penetrations will reduce worker exposure. Lead brick and conduit will be removed during this step. This work will be performed in a low radiation zone.

5. Decontaminate superstructure vaults and rooms. The vaults and rooms above the large concrete vault housing the bins comprise the superstructure of the CSSFs. The cyclone vault, equipment vault, instrument room, fan room, inlet plenum room, and exhaust plenum room will be decontaminated during this step. The vault that contains the calcine storage bins will not be decontaminated during CSSF access. Portable shielding should be placed in the vaults to reduce the exposure to acceptable limits. Remotely vacuum vault floors before entering with HEPA filtered vacuums. These vacuums have the ability to remove small debris and dust but not large objects. Strippable coating should be applied to the walls and floors of vaults that will be entered. Cut existing transport, probe, off-gas, rod out, monitoring and other nonessential piping that penetrate vault and room floors. The cut lines should then be plugged to prevent contamination spread during calcine retrieval. In CSSF 1, 2, 3, and 4 the pipes must be accessible after the new concrete floor is poured for closure activities. Access to the pipes should be provided in a similar manner to the accesses of existing retrieval lines in CSSFs 5, 6, and 7.

Once access to the vaults has been gained, decontamination activities begin. These activities require extensive shielding if it is to be accomplished manually. A better alternative is to employ remote equipment. This remote equipment must be designed and tested. The relative level of radiation in the superstructure vault is shown in Table 2. These relative levels of radiation are based on the function of the vault and if calcine was ever present in the vault. In the high radiation areas, shielding concrete floors should be poured before temporary shielding is installed. Furthermore, Table 2 notes vaults that may have solids accumulations ${ }^{2}$. These accumulations are a result of damage to transport piping during filling of several CSSFs. Efforts may have been made to clean and repair these vaults but a conservative approach is to assume these vaults are extremely contaminated.

During this step, piping, vessels, and conduit will be disassembled and packaged in appropriate containers. The bridge crane will be used to remove the packages from the CSSF. Wall penetrations should be plugged when the piping is removed. Contaminated lines that lead away from the CSSFs (such as transport lines from the WCF or the NWCF) should be decontaminated and flushed. Flushing activities are discussed in section 3.1.4. 
Table 2. Assumed Bin Vault Relative Radiation Levels

\begin{tabular}{|c|c|c|c|}
\hline CSSF & $\begin{array}{c}\text { Low } \\
\text { Radiation } \\
\text { Zone }\end{array}$ & $\begin{array}{c}\text { High } \\
\text { Radiation } \\
\text { Zone }\end{array}$ & $\begin{array}{c}\text { Known } \\
\text { Solids } \\
\text { Accumulations }\end{array}$ \\
\hline 1 & Ventilation Exhaust Room & Cyclone Vault & \\
\hline 2 & Instrument Building & Cyclone Vault & Cyclone Vault \\
\hline 3 & $\begin{array}{l}\text { Instrument Building } \\
\text { Equipment Vault }\end{array}$ & Cyclone Vault & Cyclone Vault \\
\hline 4 & Instrument Building & $\begin{array}{l}\text { Cyclone Vault } \\
\text { Ventilation } \\
\text { Equipment Room }\end{array}$ & \\
\hline 5 & $\begin{array}{l}\text { Instrument Room } \\
\text { Access Cell }\end{array}$ & Cyclone Vault & \\
\hline$\overline{6}$ & $\begin{array}{l}\text { Instrument Room } \\
\text { Fan Room } \\
\text { Inlet Plenum Room } \\
\text { Exhaust Plenum Room }\end{array}$ & $\begin{array}{l}\text { Cyclone Vault } \\
\text { Off-Gas Filter Room }\end{array}$ & \\
\hline 7 & $\begin{array}{l}\text { Instrument Room } \\
\text { Fan Room } \\
\text { Inlet Plenum Room } \\
\text { Exhaust Plenum Room }\end{array}$ & $\begin{array}{l}\text { Cyclone Vault } \\
\text { Off-Gas Filter Room }\end{array}$ & \\
\hline
\end{tabular}

6. Demolish CSSF superstructure. This step will only be conducted for CSSF 1 . The superstructures of CSSF 2, 3, and 4 will have been removed during step 1, as the superstructure enclosures are metal buildings and not concrete. During step 5 , the superstructure vaults of CSSF 5, 6, and 7 will be decontaminated. The superstructures of the last 3 CSSFs are much more robust than superstructures of previous CSSFs. The walls and roof of these will be left in place.

For CSSF 1, the temporary shielding and structural support steel will be removed from the vaults with the bridge crane. Demolish vault roof and walls. It is not necessary to demolish the CSSF superstructure for CSSFs 5, 6, and 7 because of the lower radiation levels in these CSSFs. The vault superstructure is a more permanent and integral part of the CSSF structure. At this point, the superstructure roof of CSSFs 5, 6, and 7 will be core drilled to allow access to the existing retrieval risers located in the superstructure floor.

7. Prepare confinement enclosure for bin access. This is accomplished by removing and replacing strippable coatings. Portable $\mathrm{CO}_{2}$ decontamination equipment will be used to remove any residue contamination on the walls and floors. After the confinement enclosure is decontaminated, the shielding concrete pad will be poured on the bin vault roof. Attention must be given to maintaining access to all piping exiting the bin vault through the floor and existing retrieval risers. The concrete pad will be 21 in. thick for CSSF 1 and 18 in. thick for 
CSSFs 2, 3, and 4. CSSFs 5,6, and 7 do not require shielding floors because the superstructure will provide shielding.

8. Access bins. The distinction between CSSFs is significant in this step. CSSF 1 requires all new access lines. Retrieval lines must be uncapped for CSSFs 4, 5, 6, and 7. In CSSFs 2 and 3 , the existing retrieval lines must be uncapped and new retrieval lines must be added. Table 3 details the location of existing risers by CSSFs and superstructure location. Retrieval lines in CSSFs 5, 6, and 7 have multiple lengths. The shorter lines rise from the bins to the floor - of the superstructure. The longer lines pass through the cyclone vault.

Table 3. Location of Existing Retrieval Risers

\begin{tabular}{|c|c|c|c|c|c|c|c|}
\hline CSSF & $\mathbf{1}$ & 2 & 3 & 4 & 5 & 6 & 7 \\
\hline Vault Roof & & 7 & 7 & $\overline{6}$ & & & \\
\hline $\begin{array}{c}\text { Instrument } \\
\text { Room }\end{array}$ & & & & & 13 & 7 & 7 \\
\hline $\begin{array}{c}\text { Cyclone } \\
\text { Room Floor }\end{array}$ & & & & & & 4 & 2 \\
\hline $\begin{array}{c}\text { Cyclone } \\
\text { Room Roof }\end{array}$ & & & & & $\overline{6}$ & 4 & 4 \\
\hline Fan Room & & & & & & 6 & $\overline{8}$ \\
\hline Access Cell & & & & & 9 & & \\
\hline $\begin{array}{l}\text { Exhaust } \\
\text { Plenum }\end{array}$ & & & & & $\cdot$ & 4 & 4 \\
\hline $\begin{array}{c}\text { Off-Gas } \\
\text { Filter Room }\end{array}$ & & & & & & 1 & 1 \\
\hline Inlet Plenum & & & & & & 2 & 2 \\
\hline $\begin{array}{c}\text { Total } \\
\text { Existing } \\
\text { Retrieval } \\
\text { Risers }\end{array}$ & $\overline{0}$ & $\begin{array}{c}7 \\
(1 / \text { bin })\end{array}$ & $\begin{array}{c}7 \\
(1 / \mathrm{bin})\end{array}$ & $\begin{array}{c}6 \\
(2 / \mathrm{bin})\end{array}$ & $\begin{array}{c}28 \\
(4 / \text { bin })\end{array}$ & $\begin{array}{c}28 \\
\text { (4/bin) }\end{array}$ & $\begin{array}{c}28 \\
\text { (4 / bin) }\end{array}$ \\
\hline $\begin{array}{l}\text { Additional } \\
\text { Lines } \\
\text { Required } \\
\text { (Length) }\end{array}$ & $\begin{array}{c}24 \\
(8 \text { are } 16 \mathrm{ft} \\
\& \\
16 \text { are } 23 \mathrm{ft})\end{array}$ & $8(26 \mathrm{ft})$ & $7(20 \mathrm{ft})$ & 0 & 0 & $\therefore \quad 0$ & 0 \\
\hline $\begin{array}{c}\text { Retrieval } \\
\text { Line } \\
\text { Required per } \\
\text { Bin }\end{array}$ & 2 & $\begin{array}{l}2 \text { in WC- } \\
136-1 \text { and } \\
1 \text { in the } \\
\text { remaining } \\
\text { bins }\end{array}$ & 1 & 0 & 0 & 0 & 0 \\
\hline $\begin{array}{l}\text { Current Rise } \\
\text { in Retrieval } \\
\text { Line from } \\
\text { Bin to End }\end{array}$ & 0 & $28 \mathrm{ft}$ & $18 \mathrm{ft}$ & $18 \mathrm{ft}$ & $\begin{array}{l}4 \text { are } 38 \mathrm{ft} \\
2 \text { are } 37 \mathrm{ft} \\
22 \text { are } 24 \mathrm{ft}\end{array}$ & $\begin{array}{l}4 \operatorname{are} 39 \mathrm{ft} \\
24 \text { are } 26 \mathrm{ft}\end{array}$ & $\begin{array}{l}4 \text { are } 39 \mathrm{ft} \\
24 \text { are } 26 \mathrm{ft}\end{array}$ \\
\hline $\begin{array}{c}\text { Total Length } \\
\text { of Retrieval }\end{array}$ & $1016 \mathrm{ft}$ & $959 \mathrm{ft}$ & $1038 \mathrm{ft}$ & $438 \mathrm{ft}$ & $1232 \mathrm{ft}$ & $1309 \mathrm{ft}$ & $1309 \mathrm{ft}$ \\
\hline
\end{tabular}




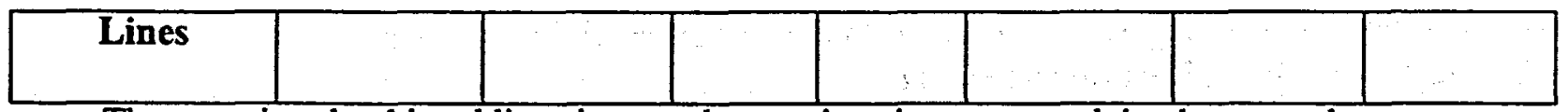

The steps involved in adding risers and accessing risers are explained separately.

Additional Retrieval Line Access: The core drilling equipment will be placed with the overhead crane. A 1 in. pilot hole will be drilled through the concrete floor to the bin vault. A 9 in. diameter hole will then be drilled through the concrete floor. Core capture equipment will prevent the core from falling into the bin vault and damaging the bins. The 8 in. retrieval lines will be extended and welded to the top of each bin. Inspection of the welds is necessary to ensure that calcine will not be released. Each bin requires two retrieval risers for calcine retrieval. The system used to install the risers will require further development and testing. It was used to access bins at the West Valley Demonstration Project ${ }^{4}$. In that project, the pipe diameter was half the size and the concrete floor was nearly twice as thick. A throughway between the riser and the bin will be made with remote equipment. A remotely operated hole saw could be used to cut a hole in the bin. Then a plug will be placed on the top end of the retrieval riser to minimize contamination of the confinement enclosure. CSSFs 1-3 and the bins will be inspected for safety hazards prior to welding and cutting operations. If hazards are identified (such as the presence of explosive gases) these hazards will be mitigated or a different welding or cutting method will be used.

Existing Retrieval Line Access: The flanged and welded terminations of the existing retrieval lines should have been located in the vault demolition step. These lines will be opened and capped until needed for calcine retrieval. It will be necessary to core drill through the confinement enclosure floor to access some of the retrieval lines in CSSF 5, 6 , and 7. The existing retrieval risers will be plugged with steel lined, concrete plugs. At the conclusion of each of these activities the radiation levels of the confinement enclosure should be inspected. If they are found to be excessive the enclosure should be decontaminated.

At the conclusion of step 9, the CSSF is prepared for calcine retrieval activities. The retrieval lines will remain in the bins. The retrieval risers will be plugged with the steel lined, concrete, stepped plugs. Step 10 occurs during CSSF closure.

9. CSSF D\&D preparation. The bins will be prepared for D\&D by adding 18 in. diameter risers. The method used to install retrieval risers will be used to install the D\&D risers. It is anticipated the same core drilling platform can be used to install the D\&D risers and the new retrieval risers. However, a larger drill bit will be required. The riser will be welded to the bin and extended to the floor of the confinement enclosure. A steel lined plug will be placed on top of the riser. As a safety precaution, the bin will not be opened into the D\&D risers until D\&D begins. Annular bins require two D\&D risers (CSSF 1, 5, 6, and 7). Cylindrical bins require one D\&D riser (CSSF 1 center bins, 2,3 , and 4). The riser will be used to insert a robot to aid in the retrieval of the final $5 \%$ of the calcine in the bins. The installation of the D\&D risers is essential to CSSF closure plan presented in reference 12 . The cost of installing the D\&D risers is included in the cost estimate (see section 6.0). 
The retrieval system will be available for $D \& D$. The positive displacement blower, vertical deployment apparatus (VDA), and shielded jumper will be available for D\&D. The retrieval lines will remain in each bin. The retrieval lines are basically too hot to do anything else. Some minor adjustment to the retrieval system may be necessary (such as relocating the shielded jumper and VDA within a CSSF). The installation of the D\&D risers are costed separately from the capital equipment. The operation of the retrieval system, once the CSSF is declared empty, is the responsibility of the CSSF closure team. These costs are documented in section 6.0.

\subsubsection{Process Equipment Description}

The equipment necessary for CSSF access mainly consists of ventilation and riser installation equipment. The ventilation equipment will satisfy the ventilation requirements of the bin vault and the confinement enclosure. This equipment is described in the equipment list in appendix A. The riser installation equipment consists of an overhead crane (used to remove packaged, contaminated equipment and place the remote drilling platform), remote drilling platform, and remote welding equipment.

The remote drilling platform will drill penetrations through the bin vault roof ( $2 \mathrm{ft}$ to $3 \mathrm{ft}$ of concrete) of each CSSF. Retrieval risers and D\&D risers will be inserted through these penetrations. The basic operation is as follows: drill a pilot hole (1 in. to 2 in.), insert a toggle type capture mechanism (to prevent the core from falling into the CSSF and damaging the bins), finally, drill a larger diameter hole (allowing installation of the risers). Secondary confinement will be provided during drilling operations by a tent confinement around the drilling platform. The tent confinement will reduce exposure to workers and contamination spread within the confinement enclosure. The remote drilling platform will be relocated from bin to bin within a CSSF. This will require coordinating the construction schedules. The platform will be secured to the confinement enclosure floor with anchor bolts. Safety barriers and warning signs will prevent exposure to shine radiation directly above the open penetration. A riser plug will be installed to provide a shielding barrier once the penetrations have been drilled.

The remote welding device will weld the new risers to the bins. Commercially, resistance welding is often used to join tubs to surfaces in a hands on manner. A test program is currently underway at the INEEL to better understand the parameters involved in converting this technique to remote operation. In general terms, flanged risers, approximately $4 \mathrm{ft}$ to $5 \mathrm{ft}$ long, will be welded to the top of each bin. The remaining length of the riser will be bolted to the flanged riser. It is anticipated that the welds will need to be inspected prior to opening the bins through the risers. At this stage, a remote weld inspection technique has not been identified. However, it should be a simple matter to convert a test method for remoter inspection of the welds. The best time to develop a remote weld inspection method is during the weld test program.

The remote hole drill will be used to provide a throughway into the bin from the new retrieval riser. It will cut a circular hole, inside a new retrieval riser, on the top of a bin. The retrieval lines will be inserted into the bins through these holes. Bins with existing retrieval risers will not require the use of this equipment. This equipment should be purchased off-the-shelf and then converted for remote operation. The core should be captured to prevent it from falling into the 
bins.

\subsubsection{Process Issues}

The CSSF access plan described above is not perfect, complete, or final. It is based on methods developed by Raytheon and Fluor-Daniels ${ }^{2}$ in previous and current studies. The details of the CSSF access plan are broad. They do not address the requirements of each CSSF individually. The specific points remain to be identified in a feasibility report. This section attempts to point out potential errors and concerns in the CSSF access method. They are not expected to impact the cost or schedule of the project but they warrant further examination and study.

\section{Radiation Levels in CSSF Superstructure:}

The radiation levels vary throughout the vault superstructure of each CSSF. The cost of demolishing the vault superstructure increases as the radiation level increases. At this stage in the design process, relative radiation levels were used to develop the cost estimate. The function of the room and evidence of operational anomalies determined the relative radiation level. Not all of the CSSFs contain all of these rooms. For future studies and cost estimates, a survey of each superstructure vault should be completed to quantify the level of radiation in the vaults.

The cyclone vault and the off-gas filter room were considered to be the highest radiation areas. These areas were exposed to the greatest levels of calcine solids. The cyclone vault houses the cyclone and the distribution piping. In CSSF 2 and 3, erosion failures are known to have occurred in this vault ${ }^{2}$. The accumulated calcine was cleaned up but higher levels should be expected in the cyclone vault for CSSF 2 and 3 . All equipment housed in this vault should be considered highly contaminated. During filling, the bins were vented through filters in the offgas filter room. The HEPA filters in this room are highly contaminated. After filling, this room was isolated to minimize contamination spread. Shielding is necessary for work in this room. The cyclone vaults and the off-gas filter rooms should be considered high radiation areas.

The instrument room, equipment room, and access cell are assumed to be low radiation zones. These rooms house the instrumentation and equipment used to monitor the CSSF. Calcine did not enter these rooms. The inlet and exhaust plenum rooms are used to passively cool the bin vault. It is unlikely these rooms have levels of contamination beyond that of a radiation area. The fan room contains HEPA filters used only if contamination is detected in the exhaust plenum room. This system has never permanently activated in any of the CSSFs. It is unlikely the HEPA filters in this room are contaminated but they should be treated as such for disposal purposes. The equipment and ductwork downstream from the HEPA filters should be considered uncontaminated. The remaining rooms in the superstructure are assumed to be radiation areas. Unless noted above, the piping or bins in the vault are assumed to be intact.

Existing Lines from the Calcining Facilities (WCF \& NWCF) to the CSSFs: The CSSF access plan calls for the original calcine transport lines to be cut and capped at the CSSFs. The cost of cutting and capping these lines is reflected in the cost estimate (section 6.0). However, the cost of decontaminating these lines is not included. The cost of decontaminating, cutting, and

\footnotetext{
"Staiger, D., "Review of High-Level Wastes Stored at the ICPP", draft, September 1997.
} 
capping the lines from the NWCF to the CSSFs is part of the NWCF closure cost. The WCF closure plan calls for the line from CSSF 1 to be used to flush the calcine transport line back to the WCF. The line will be flushed with a grout slurry. Eventually, the line will back up. The grout slurry will solidify just past the first wye. This makes it difficuit to flush the lines that run from CSSFs 2 and 3 to the WCF. It would be advantageous to develop detailed plans to flush and properly close these lines. Closure plans for other contaminated lines should be developed as they are identified.

Weight Loading of CSSFs: The weight loading on the CSSFs during access activities and retrieval operations is not expected to be a significant problem. The amount of equipment used during these activities has been minimized to reduce the weight loading on the CSSFs. The final design of the calcine retrieval and transportation system will incorporate the weight loading restrictions of the CSSFs. This issue will be resolved during the design stages of the calcine retrieval and transportation system.

\subsection{Calcine Retrieval}

\subsubsection{Process Basis}

The calcine retrieval system will remove the calcine from a bin and place it directly in the pneumatic transport system. The system minimizes the number of moving parts used to retrieve the calcine to reduce the risk of failure and downtime. The remote operation design of the calcine retrieval system reduces worker exposure.

The calcine retrieval system consists of the equipment necessary to remove calcine from a bin. Each CSSF is equipped with a complete set of retrieval equipment. The retrieval system relies on the transport system to provide the means for the calcine retrieval. There are two transport systems. The calcine retrieval system and the calcine transportation system are separate and distinct. Neither system can operate without the other. The interface between the calcine retrieval system and the calcine transportation system is shown in sketches CRT-02 and CRT-03.

Several modifications have been made to Fluor-Daniels ${ }^{2}$ design to satisfy the needs of the processing options. The basic design, equipment, and process are based on the Fluor-Daniels ${ }^{2}$ design for calcine retrieval. The Fluor-Daniels ${ }^{2}$ design specifies that alumina calcine and zirconia calcine are retrieved and transported using separate systems. The overall system will be more efficient if there are no restrictions placed on the type of calcine that can be retrieved and transported by a system. The alumina calcine system would be idle a large part of the time because the CSSFs contain more zirconia calcine. The duplicated systems allow two bins, in separate CSSFs, to be retrieved from at one time. Safety and efficiency issues require that one bin be completely emptied before another bin is retrieved from within a CSSF.

\subsubsection{Process Description}


Calcine retrieval will be accomplished pneumatically with a suction nozzle and an air jet. The air jet will fluidize the calcine inside the bin. The suction nozzle will lift the fluidized calcine out of the bin. Calcine will enter the transport system through a shielded jumper from the retrieval line. A retrieval system has been mocked up at the INEEL as a pilot plant facility. It is the only system to have successfully demonstrated solids retrieval from a full-scale bin model.

Two retrieval lines will be placed $180^{\circ}$ apart inside the bin. The retrieval lines will be composed of rigid, concentric pipes. The outer diameter of the retrieval lines will be $5 \mathrm{in}$.. The inner pipe will function as the suction line. It will be fitted with a nozzle designed to prevent clogging and uptake of miscellaneous items in the bins. The annulus will be an air jet. It will be fitted with an appropriate fluidizing nozzle. At a given time, a retrieval line will function as a suction line or an air jet. The suction nozzle and air jet will not be housed in the same retrieval line. The function of the retrieval lines will alternate, one line will act as the suction line while the other acts as the air jet. Calcine retrieval will be more efficient. Each line will have the capability to sweep a full circle but it will not be continuously rotating. This will aid in fluidizing agglomerated calcine.

The pressure inside a bin during retrieval should be slightly negative. The negative pressure reduces the risk of contamination spread while a vault is open for retrieval. The negative pressure will provide an additional safety if the confinement were to fail. The negative pressure must not maximum exceed the design pressure of the bins. The design pressure rating varies by CSSF.

A vertical deployment apparatus (VDA) will be used to keep the retrieval lines near the surface of the bulk calcine. This equipment is similar to well-drilling equipment. The retrieval lines will be sectioned. The length of each retrieval line can be extended as the calcine is retrieved. The retrieval system functions most effectively when the suction nozzle and air jet are near the calcine surface. However, it is necessary to adjust the level of each line independently. After the bin is emptied, the lines will be disconnected from the VDA and remain in the bin. The retrieval risers will be plugged, with steel-lined stepped plugs, before the VDA is decontaminated and moved to the next bin.

The calcine will be retrieved at a rate of $2700 \mathrm{~kg} / \mathrm{hr}$ from each bin. When both transport systems are operating, calcine will be delivered to the Waste Treatment Facility at a rate of $5400 \mathrm{~kg} / \mathrm{hr}$. The retrieval rate is set by Fluor-Daniels ${ }^{2}$. The mock-up tests ${ }^{8}$ reveal that retrieval rates above $2300 \mathrm{~kg} / \mathrm{hr}$ can be achieved with $3 \mathrm{in}$. retrieval lines and a maximum air flow rate of $300 \mathrm{scfm}$ at 12-15 psig. The higher retrieval rate could be reached by increasing the air flow rate and the blower capacity. More testing is necessary to show that this is a sustainable retrieval rate. The retrieval rate is dependent upon how agglomerated the calcine is. This issue is discussed further in section 3.2.3.

The retrieval system will retrieve at least $95 \%$ of the calcine each bin. This estimate is based on results from a pilot plant program (reference 8 ). The $1 / 4$ and full-scale mockup tests provide the best information about the amount of calcine that can be retrieved using this retrieval method. The details of the tests are not explained in this EDF. The target retrieval rate was not maintained after $95 \%$ of the solids were retrieved. In the $1 / 4$ scale test, less than $1 \%$ of the initial retrieval 
rate could be maintained during retrieval of the final $3 \%$ of solids. A significant amount of time is necessary to retrieve the final $3-4 \%$ of calcine at the bottom of the bin. For the full-scale tests, the retrieval rate dropped as the amount of solids in the bin decreased. The retrieval rate dropped below the target retrieval rate when $95.8 \%$ of the solids had been retrieved.

A conservative retrieval estimate is $95 \%$. A conservative approach is taken for several reasons. The calcine in the "nooks and crannies" created by thermowells, internal stiffening rods, and the bottom of the bins will be difficult to remove with this retrieval method. This system has not been tested on a caked material. It is highly possible that calcine in some of the bins may be caked. Such a material would have a greater tendency to stick to the walls, floors, and internal structure of the bins. It should be noted that in the actual operation of the retrieval system, retrieval should continue as long as a reasonable retrieval rate can be maintained. The schedule and other processing requirements must define that rate.

Throughout calcine processing, retrieval will switch from CSSF to CSSF as CSSFs are emptied or different calcine types are reached. For example, the CWO option requires frequent switching between CSSFs to achieve the correct calcine blend. The other processes need to switch CSSFs once a CSSF is emptied. Safety issues prevent switching from bin to bin within a CSSF before the first bin is emptied. Additionally, such a feature is not necessary to meet the process requirements. The process of switching the retrieval to another CSSF is outlined below: Let bin $A$ be the bin that is currently being retrieved and let bin $B$ be the bin that retrieval is being switched to.

1. Turn off retrieval system for bin A: This is accomplished by shutting off the transport air blower connected to the suction nozzle and air jet. Flush the shielded jumper and upper line with dolomite to remove any calcine deposited in the lines. Close the valve at the CSSF transport line connection. Disconnect the vertical deployment apparatus from the retrieval lines. The lines will rest on the bottom surface of the bin. Place the steel-lined, concrete plugs on the retrieval risers. Disconnect the shielded jumper from the VDA. Decontaminate and relocate the VDA to bin $B$.

2. Adjust Transport System: Diverter valves will be used to connect the CSSF leads to the main transport system. The diverter valves will be pneumatically controlled from the control room adjacent to each CSSF. The steam traced lines in the transportation system will condensation in the return air lines.

3. Turn on retrieval system for bin B: If necessary, the VDA must be transported to and correctly positioned at bin B. The correct set of retrieval line extensions must be placed in the extension tube carousel. The confinement tenting will be replaced around the VDA. The shielded jumper will connect the retrieval lines to the transport system. The plugs on the retrieval risers will be pulled. Retrieval lines will be extended to the top of the calcine in bin B. The power to the retrieval blower and suction jet will be turned on. Retrieval from bin B begins.

\subsubsection{Process Equipment Description}

The Vertical Deployment Apparatus (VDA) will extend the retrieval lines into the bins during calcine retrieval. The VDA will extend the retrieval lines independently. The equipment is 
similar to well drilling equipment. Temporary ventilation and confinement shielding is required. This will be accomplished with a confinement tent and a portable blower. A catch pan will collect radioactive dust and runoff water introduced in the VDA confinement area. The VDA is relocated with the bridge crane. It will be stabilized with anchor bolts attached to the confinement enclosure floor. The apparatus is $5 \mathrm{ft}$ to $6 \mathrm{ft}$ square and $25 \mathrm{ft}$ tall. External shielding panels, $21 / 2$ in. thick, reduce radiation fields inside the confinement enclosure during retrieval. An external ladder and gate provide maintenance access to the VDAs. When the plug is removed from the retrieval riser, the confinement area within the VDA has the same ventilation requirements as the calcine bin.

The VDA is equipped with a plug removal hoist, extension tube carousel, and extension tubes and couplings. A detailed description of their function appears in reference 3 . The plug removal hoist lifts the plug from the retrieval riser and stores it inside the VDA. The motor, brake, controls, and cable require periodic inspection. The load carrying capacity should also be regular checked. The extension tube carousel stores the extension tubes for the risers and retrieval lines.

The extension tubes with couplings form the retrieval line sections. As the retrieval lines are lowered into the bins, a section of tube is added. Each CSSF requires a particular set of extension tubes. These must be loaded into the VDA each time it is relocated.

The shielded jumper connects the discharge of the calcine retrieval line (top of the VDA) to the transport line. The jumper configuration will allow this connection to be made regardless of location of VDA. The shielded jumper is made of double walled, heavy pipe. The jumper is composed of $4 \mathrm{ft}$ to $5 \mathrm{ft}$ sections that are equipped with lifting lugs for easy handling. The jumper must be flushed with high velocity dolomite to reduce the amount of contamination in the line before it is moved.

The CCTV system contains a camera, light, boom, and control system. This system is installed to allow viewing inside the bins. It is not an essential component for the retrieval operation but it will be useful if unforeseen problems develop.

The retrieval equipment described in this section is located inside the confinement enclosure. This equipment must interface with the transport system in order for calcine to be retrieved.

\subsubsection{Process Issues}

The calcine retrieval system described has been tested at the INEEL. Even so, some unresolved issues exist regarding the system. Raytheon ${ }^{3}$ developed the equipment used in this system in a previous study. The purpose of this section is to ensure the feasibility of the calcine retrieval system by expressing concerns and issues that warrant further examination and study.

\section{Corrosion Coupons and Miscellaneous Items in CSSFs:}

Calcine retrieval will be hampered by internal obstructions inside the bins. At some point during the retrieval process, these obstructions should be removed from the bins. For example, the corrosion coupons should be retrieved from each CSSF prior to decontamination of the confinement enclosure during CSSF access. The corrosion coupons in each bin are hung from $1 / 4$ 
in. J hooks. In 1978, some of the corrosion coupon sets were retrieved from CSSF 2. A crane was used to pull the coupons from the bins. However, at least one of the coupon sets was dropped during this operation. In order to minimize the risk of dropping additional corrosion. coupon sets the CCTV system should oversee the corrosion coupon removal. The bridge crane can be used to retrieve the corrosion coupons sets. Upon removal of the corrosion coupons, they should be placed in a shielded cask. The coupons should be examined for evidence of corrosion. This information is valuable for retrieval and closure of the CSSFs. The analysis should take place at ICPP in a shielded cell. After the coupons have been analyzed they should be disposed of as radioactive waste. Table 4 describes the corrosion coupons in each CSSF.

\section{Table 4. Corrosion Coupon Description}

\begin{tabular}{|c|c|l|l|}
\hline CSSF & $\begin{array}{c}\text { Number Remaining } \\
\text { in Bin }\end{array}$ & \multicolumn{1}{|c|}{ Bin Location } & \multicolumn{1}{|c|}{ Description } \\
\hline 1 & 0 & & \\
\hline 2 & $3 /$ bin & $\begin{array}{l}\text { VES-WCS-136-1 and } \\
\text { VES-WCS-136-4 }\end{array}$ & Wall mounted \\
\hline 3 & 5 & VES-WC-140-1 & Inside riser \\
\hline 4 & $5 /$ bin & All bins & Wall mounted \\
\hline 5 & $5 /$ bin & $\begin{array}{l}\text { VES-WS5-149 and } \\
\text { VES-WS5-151 }\end{array}$ & $\begin{array}{l}\text { Corrosion coupon } \\
\text { retrieval through nozzle } \\
\text { J (6 in. Sch 40) }\end{array}$ \\
\hline 6 & $5 /$ bin & VES-WS5-156 and & $\begin{array}{l}\text { Corrosion coupon } \\
\text { retrieval through nozzle } \\
\text { J (8 in.) }\end{array}$ \\
\hline 7 & & VES-WS6-159 & $\begin{array}{l}\text { Corrosion coupons in } \\
\text { retrieval nozzle F }\end{array}$ \\
\hline
\end{tabular}

There are other miscellaneous items (such as rodout lines, weighted lines, lost samplers and penetrometer points) in the bins ${ }^{b}$. These items will not be as easy to retrieve as the corrosion coupons because their location is not known. Some of these items may be below the calcine surface while others may be on the surface of the calcine. Something must be done to reduce the risk of these items damaging the bins, the retrieval lines, and the transportation system. The air jet could pick up these items. The bin walls may not survive an impact. The bin could be breached. If these items enter the transportation system they could clog or puncture the system. The ideal solution is to detect and remove these items from the bins.

It is necessary to remove the corrosion coupons from the bins before retrieval begins. It is assumed that this activity will occur during the construction phase of the project for each CSSF. For purposes of developing a bounding cost estimate, the corrosion coupon removal activity was included in the cost estimate. A cost estimate was developed to remove the corrosion coupons. The escalated cost of planning and equipment to remove the corrosion coupons from all the

\footnotetext{
'Staiger, D. "Review of High-Level Wastes Stored at the ICPP”, draft, September 1997.
} 
CSSFs is $\$ 1,620,000$. This activity was also included in the operating and maintenance cost estimate (See section 6.0 for details).

Control of Retrieval Rate:

The retrieval rate cannot be rigidly controlled due to the nature of the system. The retrieval rate depends upon several factors. As the calcine supply in the bin diminishes the retrieval rate decreases. The retrieval rate also depends upon how free flowing the calcine is. This retrieval method has been extensively tested with free flowing solids. It is anticipated that agglomerated calcine can be broken up and placed in a dilute phase by the air jet. However, retrieval of agglomerated solids in this manner has not been tested. This issue has not been examined because of the difficulty of simulating agglomerated solids on a large scale. The bins should be sampled to determine if the calcine has agglomerated. If agglomerated calcine is found, a pilot plant study should be conducted to determine the ability of agglomerated calcine to be retrieved with this retrieval method.

\section{Location and Number of Retrieval Lines:}

Limited testing has been conducted to identify the optimum location and number of retrieval lines. The number, size and location of the air jet and suction nozzles will effect the efficiency of the calcine retrieval system. It is necessary to determine if the most efficient configuration has been selected. Reference 8 suggests that two suction nozzles located $\pm 90^{\circ}$ from the air jet may be more efficient. The costs associated with this activity are included in the cost estimate for the design of the retrieval system.

Additionally, the performance of the retrieval system in a cylindrical hin is not known. Tests ${ }^{3}$ have been conducted on an annular bin mock-up. Preliminary indications from the annular bin mock up tests suggest that the retrieval system will be even more effective for these bins. This is a source of concern because the optimal suction nozzle and air jet configuration may vary significantly from that of the annular bin.

\section{CSSF Retrieval Order:}

The order that the CSSFs will be retrieved is not identified in this EDF. Each CSSF will be ready for retrieval by $1 / 1 / 2013$. The order of retrieval is heavily dependent upon the operation of the Waste Treatment Facility. The operation of the Waste Treatment Facility determines when the calcine will be retrieved. The majority of the treatment options do not require a specific blend of calcine. Therefore, they do not have a preference for the CSSF retrieval order. However, it would be beneficial to the Waste Treatment Facility operating crews to retrieve and process the more homogeneous calcine in CSSF 1 and 2 first. The closure study ${ }^{12}$ for the CSSF facilities would prefer the placement of class $C$ grout in the better constructed CSSF 5, 6, and 7 . The order the CSSFs should be retrieved to accommodate the closure schedule is CSSF1, CSSF $5, \operatorname{CSSF} 6, \operatorname{CSSF} 7, \operatorname{CSSF} 2, \operatorname{CSSF} 3$, and finally CSSF 4 . This is an issue that must be coordinated between the waste treatment options and CSSF closure. Political input should be considered a major factor in determining the retrieval order. 


\subsection{Calcine Transport}

\subsubsection{Process Basis}

The calcine transportation system will deliver the retrieved calcine from the CSSFs to the calcine Waste Treatment Facility with a pneumatic transport system. It also provides the motivation for the suction nozzle and air jet necessary for calcine retrieval (see sketches CRT-02 and CRT-03). Pneumatic transport systems have been used to transport calcine from the calcining facility (NWCF or WCF) to the CSSFs for more than 30 years. Additionally, Raytheon ${ }^{3}$ studied the advantages and disadvantages of open-loop, closed-loop, and combined loop (combining a retrieval system with a closed-loop transport system) pneumatic transportation systems. The combined loop pneumatic transport system provides the best alternative for calcine transportation because recycling of the transport air minimizes the amount of air released.

The Fluor-Daniels ${ }^{2}$ design consists of two independent transportation systems. The independent transportation systems were specified to transport zirconia and alumina calcine separately. There appears to be no advantage, to the non-separations options and TRU Separations options, to keep the zirconia calcine separate from the alumina calcine. The two independent transportation systems, in this study, will allow retrieval and transportation of calcine from 2 CSSFs at one time.

\subsubsection{Process Design}

The calcine transport system will deliver calcine from the CSSFs to the Waste Treatment Facility. Each CSSF will be connected to one of the two pneumatic transport systems. The double transport systems will provide greater flexibility during calcine retrieval (allow more desirable calcine blends to be achieved) and CSSF closure (allow retrieval of the remaining $5 \%$ of calcine in the bins during off-peak hours).

The pneumatic transport system reduces the risk of calcine release by conveying the calcine under negative pressure. If a break develops in the transport line, air will flow in rather than out. This minimizes the risk of calcine release by reducing the potential for calcine to leave the transport line. The momentum of large particles may overcome the negative pressure and escape at an erosion failure (particularly those in bends or other direction changes). The risk of calcine release is lower for a vacuum system than for a pressure system. In a pressure system the calcine particles would be pushed out of the transport system at all erosion failures. Additionally, erosion failures in the transport piping can be minimized through proper layout of the transport system $^{11}$. The costs associated with properly designing the transport system are reflected in the cost estimate (section 6.0).

Each of the two transport systems will convey calcine in a $10 \mathrm{~mm}$ (4 in) $304 \mathrm{~L}$ stainless steel line encased in $15 \mathrm{~mm}(6 \mathrm{in}) 304 \mathrm{~L}$ stainless steel line. Each transport system will have a backup calcine transport line, to be used if the original line becomes permanently clogged or otherwise unusable. Rod out stations will be placed along straight runs to clear clogged transport lines. The transport lines will be accompanied by two return air lines, one for each transport system. 
The return air lines will be $20 \mathrm{~mm}$ ( $8 \mathrm{in}$ ) $304 \mathrm{~L}$ stainless steel. These lines will be steam-traced to prevent water from condensing.

The transport lines and the return air lines will be surrounded by a concrete pipe chase. The pipe chase will be designed to allow access to the diverter valves and rod out stations. The pipe chase will minimize "shine" radiation at accessible locations. An earthen berm will shield the pipe chase. Raytheon ${ }^{3}$ examined many routings and found a large number of obstructions from CSSF 1 to CSSF 6 that prevent burying the transport lines. For purposes of this study, it is assumed that it is more convenient and cost efficient to lay the transport lines above grade. Although, above ground placement does not preclude necessary relocation of some utility lines.

Diverter valves will be used to prevent back flow of calcine into CSSF connections. These valves will be manufactured out of stainless steel. Diverter valves are a typical component of pneumatic systems. Three diverter valves will be necessary to ensure that calcine can be transported from the CSSFs to the Waste Treatment Facility in either line of the transport system. These valves are ideal for use in the calcine transport system because they require little maintenance over their service life.

It is generally accepted in industry, that a vacuum transport system can transport fluidized solids up to $300 \mathrm{ft}$ efficiently. The CWO and TRU Separations options require calcine to be delivered to the NWCF and the Calcine Dissolution Facility, respectively. The site plan for the CWO option is shown in sketch CRT-05. The site plan for the TRU Separations options can be found in the TRU Separations options study report (sketches TRU-C-6 and TRU-C-12). Calcine can be transported from all the CSSFs to these facilities without exceeding the transport distance limitation. The Waste Treatment Facility in the DCWO, HWO, and VWO options are located in the north east corner of ICPP. The required transport distance from CSSF 3 to the Waste Treatment Facility is approximately $550 \mathrm{ft}$. An Intermediate Transport Station (ITS) and two separate transport system legs must be included in the transport system design to deliver calcine from the CSSFs to the Waste Treatment Facility for the DCWO, HWO, and VWO options. The relationship between the ITS and the transport system is shown in sketches CRT-03 and CRT-04.

For the DCWO, HWO, and VWO options, the calcine transport from the CSSFs to the Waste Treatment Facility is accomplished with two transport system legs (each leg contains piping and equipment for each transport system). The first leg transports calcine from the CSSFs to the ITS. At the ITS, the transport air is separated from the fluidized calcine with a cyclone and sintered metal filter. The calcine enters a storage hopper. As the calcine is metered out of the hopper it is fluidized by the second leg of the pneumatic transport system. The calcine is then transported from the ITS to the Waste Treatment Facility, as shown in CRT-04.

\subsubsection{Process Equipment Description}

For the CWO and TRU-Separations Options, there are two independent transportation systems. For the DCWO, HWO, and VWO options, there are four transportation systems (two from the CSSFs to the ITS and two from the ITS to the Waste Treatment Facility). Each transportation system has a backup calcine transport line installed. Two sets of transport equipment (transport air blower, cyclone, sintered metal filter, heat exchanger, and balancing air blower) are located 
inside the Waste Treatment Facility for all the waste treatment options. The DCWO, HWO, and VWO options have two additional sets of transport equipment located in the ITS. The shielding concrete chase is located between the CSSFs and the Waste Treatment Facility.

The transport air blower is a positive displacement blower. It functions as the transport air blower. For the CWO and TRU Separations options, it also serves as the retrieval blower. It has a capacity of $800 \mathrm{cfm}$ and $150 \mathrm{kPa}(10 \mathrm{psi})$. The blower sized in the Fluor-Daniels ${ }^{2}$ design was examined in reference 11. It was found that it is slightly oversized for the longest transport line length (CSSF 3 to the Calcine Dissolution Facility). The pressure drop and solids velocity are higher than optimum for a vacuum system. However, the blower is also used to retrieve the calcine from the bins. The extra capacity may be necessary to retrieve the calcine from the bottom of the bins.

The cyclone separates approximately $99 \%$ of the calcine solids from the transport air. It is sized at $2 \mathrm{ft}$ ID X $6 \mathrm{ft}$. This size is slightly higher than the one specified by Fluor-Daniels ${ }^{2}$. A larger cyclone is suggested by the Raytheon studies. It will be reinforced with nitronic plating to reduce the risk of erosion failures.

The sintered metal filter separates the entrained calcine particulates after the transport air leaves the cyclone. About $99.9 \%$ of these particles will be removed as the transport air passes through the sintered metal filter. Air will be back blown through the sintered metal filter to deliver calcine to the process batch bin.

The heat exchanger cools the air after it leaves the transport air blower. It is anticipated this will be water cooled heat exchanger. After the air leaves the heat exchanger it will be separated. Most of the air will be recycled but $10 \%$ of it will be exhausted through the process facility exhaust system.

The balancing air blower removes excess air from transport system. It is used to maintain a slightly negative pressure in the bin being retrieved. This is necessary to provide an additional contamination confinement.

The concrete shielding chase provides shielding to the transport lines that run from CSSFs to Waste Treatment Facility. The radiation fields are reduced to acceptable levels outside the chase. The design of the chase is similar to Raytheon design. The wall thickness is increased to account for the higher transport rate. It will protect the transport lines from weather damage.

\subsubsection{Process Issues}

Even though pneumatic transport systems have been used to transport calcine for over 30 years, some process issues remain for future study. Concerns and areas requiring further study that were identified during this study are detailed in this section.

Centrally Locate the Waste Treatment Facility:

Central location of the Waste Treatment Facility will serve to minimize the length of pipe runs. This will raise the efficiency of the transport equipment. Currently, the Waste Treatment Facility 
for the DCWO, HWO, and VWO options is located far from the CSSFs (as shown in sketch CRT-04). The location chosen by the TRU Separations Options (as shown in sketches TRU-C-6 and TRU-C-12.) is a better location considering the limitations of a vacuum transport system. However, even this location has its own unresolved issues. The requirements to move the ICPP fence must be identified. The Waste Treatment Facility will extend off the current ICPP site boundary marked by the fence. It is not known if the fence can simply be moved. The Waste Treatment Facility should be located as close to the CSSFs as possible.

\subsection{Implementation}

The calcine retrieval and transportation system could be implemented in several ways. Initially, two options were examined for the capital cost estimate. Alternative A was designed to meet the minimum need of the majority of the processing options (DCWO, HWO, VWO, and TRU Separations). Alternative B was designed to satisfy the requirements of CWO and CSSF closure activities. Both of these options differ from the implementation plan presented by FluorDaniels ${ }^{2}$. Alternative $B$ was selected as the best implementation plan. A cost estimate is included in section 6.0 based on alternative $B$.

Alternative $A$ was based on the requirements of the majority of the waste treatment options. The DCWO, HWO, VWO, and TRU Separations options require a well-blended and accurately categorized batch of calcine. These treatment options do not require a specific blend of calcine. In alternative A, the CSSFs were accessed (a confinement enclosure and VIC building were constructed for each CSSF) during the construction phase of the project. Two sets of retrieval equipment (consisting of a VDA and a shielded jumper) will be purchased. The retrieval equipment will be moved from CSSF to CSSF as the CSSFs are emptied. The retrieval equipment must be decontaminated before relocation. Moving the retrieval equipment between CSSFs is assumed to take less than one week.

The drawback to this implementation alternative is the impact it will have on D\&D work. CSSF closure requires that as much calcine as possible be removed from each bin. After, calcine retrieval as much as $5 \%$ of the calcine may remain in each bin. The CSSF closure study ${ }^{12}$ expects to use the retrieval equipment to remove as much as possible of the remaining calcine. The capital cost estimate for alternative A was not significantly lower that the estimate for alternative B (a copy of the preliminary capital cost estimate for alternative A is located in the project file). For these reasons, alternative A was not selected for further study.

Alternative B satisfies the requirements of the remaining waste treatment option, $\mathrm{CWO}$, and CSSF closure. CWO requires a specific blend of calcine for each processing batch. The calcine blend is achieved with calcine from up to four CSSFs (see reference 13 for details). Switching between CSSFs is required to maintain the blend as large layers of calcine are encountered in the bins. The large number of required moves between CSSFs make purchasing seven sets of retrieval equipment the most cost effective selection. It is not necessary, in this alternative to move the VDAs and shielded jumpers from CSSF to CSSF. The retrieval equipment will be moved between bins within a CSSF. It is expected that moving the retrieval equipment within a CSSF can be accomplished in less than a day. 
Alternative B does not adversely impact CSSF closures. Closure can begin on each CSSF when it is emptied. The calcine remaining in the bins will be retrieved when the high calcine retrieval rate is not necessary. Alternative B also satisfies the requirements of the DCWO, HWO, VWO, and TRU Separations options. Table 5 outlines the similarities and differences between the implementation alternatives.

\section{Table 5. Characteristics of Calcine Retrieval System Options}

\begin{tabular}{|c|c|c|}
\hline Characteristic & Option A & Option B \\
\hline $\begin{array}{l}\text { Retrieval Rate / Transport } \\
\text { System }\end{array}$ & $2700 \mathrm{~kg} / \mathrm{hr}$ & $2700 \mathrm{~kg} / \mathrm{hr}$ \\
\hline $\begin{array}{l}\text { Number of Independent } \\
\text { Transport Systems }\end{array}$ & 2 & 2 \\
\hline $\begin{array}{l}\text { Number of Confinement } \\
\text { Enclosure and VIC } \\
\text { Building Sets }\end{array}$ & 7 & 7 \\
\hline Number of VDAs Required & 2 & 7 \\
\hline $\begin{array}{l}\text { Relocation of VDAs } \\
\text { between CSSFs (Relocation } \\
\text { Time) }\end{array}$ & $\begin{array}{c}\text { Yes } \\
(<1 \text { week due to } \\
\text { decontamination activities })\end{array}$ & Not required \\
\hline $\begin{array}{l}\text { CSSFs Costed with New } \\
\text { VDAs }\end{array}$ & 1 and 2 & $1,2,3,4,5,6$, and 7 \\
\hline VDAs Relocated to CSSFs & $3,4,5,6$, and 7 & - \\
\hline Tasks to Utilize Alternative & $\begin{array}{l}\text { DCWO, HWO, VWO, } \\
\text { TRU Separations }\end{array}$ & $\begin{array}{l}\text { CWO (also DCWO, HWO, } \\
\text { VWO, TRU Separations) }\end{array}$ \\
\hline $\begin{array}{l}\text { Transport System Available } \\
\text { for Closure of CSSFs } \\
\text { during operations }\end{array}$ & No & Yes \\
\hline
\end{tabular}

Alternative B was selected as the best implementation option. It was used as the basis for the cost estimate.

\subsection{Input to Project Data Sheet}

A project data sheet was not completed for the calcine retrieval and transportation system. Instead the data was appended to the project data sheets for each waste treatment option. Table 6 shows the data that should be incorporated into the project data sheets of the each waste treatment option. It summarizes construction, operations, and some D\&D project data. Appendix D contains the calculations and justification for the data presented in Table 6.

The closure of the CSSFs is currently being studied, therefore, the D\&D project data for the CSSFs will be reported in reference 12. Reference 12 will cover closing of the CSSF structures, added confinement enclosures, VIC buildings, and the retrieval equipment. D\&D project data is included in Table 6 for closure of the transport lines, ITS (building and transport equipment), and 
transport equipment located in the WTF. The D\&D project data included in Table 6 is not comprehensive because a closure method for the transport lines, ITS, and transport equipment has not been developed. It was assumed that the D\&D portion of the project would have a 1year duration. The work may be more effectively accomplished over a longer period of time. A comprehensive examination of the $D \& D$ requirements of the transportation system, based on a closure method, should be completed.

\section{Table 6. Input to Project Data Sheets}

\section{Generic Information}

Structure Size $\left(\mathrm{m}^{2}\right)$

Location

\section{Construction Information}

Cost (\$): Preconstruction (escalation included)

Conceptual Design

Project Management

Permitting and Documentation

Start Up Activities

Contingency

Total Preconstruction

Cost (\$): Construction (escalation included)

Engineering, Design, and Inspection

Management Reserve (PM/CM)

Construction

Government Furnished Eqiupment

G\&A/PIF
Seven Confinement Enclosures which are each 40 $\mathrm{ft} X 40 \mathrm{ft}\left(978 \mathrm{~m}^{2}\right.$ total)

Seven VIC Buildings which are each $40 \mathrm{ft} X 60 \mathrm{ft}$ (1560 $\mathrm{m}^{2}$ total)

One ITS Building that is $600 \mathrm{ft}^{2}\left(55.7 \mathrm{~m}^{2}\right)$

A Confinement Enclosure will be built on the roof of each CSSF.

A VIC Building will be built adjacent to each CSSF.

An ITS Building will be built mid way between the CSSFs and the Waste Treatment Facility.

CWO, DCWO, HWO, VWO \& TRU Separations
Options
S $18,000,000$
S $2,700,000$
\$ $4,800,000$
S $5,100,000$
\$ $10,500,000$
\$ $41,100,000$

CWO \& TRU DCWO, HWO, \& VWO Separations Options
\$ $18,500,000$
$\$ 19,400,000$
$S 22,900,000$
S $23,500,000$
$\$ 104,200,000$
$\$ 106,500,000$
S $18,200,000$
\$ $19,300,000$
\$ $10,400,000$
\$ $10,700,000$ 
Procurement Fees, Management Reserve, and Contingency

Total Construction

Schedule start/end: Preconstruction

Schedule start/end: Construction

Number of workers each year of construction

Number of radiation workers (construction)

Average annual worker radiation dose (rem/yr)

Heavy equipment

Equipment used

Trips

Hours of operation

Acres disturbed and duration of disturbance

Air emissions

Major gases (CO2, $\mathrm{H} 2 \mathrm{O}, \mathrm{O} 2, \mathrm{~N} 2)$

Contaminants (Particulates, CO, NOx, $\mathrm{SO} 2$, hydrocarbons)

Radioactive wastes

Type

Energy requirements

Electrical (MWh/yr)

Fossil fuel (liters)

Permits needed for construction

\section{Operational Information}

Cost (\$): Operations (not escalated)

$$
\text { S } 64,600,000
$$

\$ $66,600,000$

$$
\$ 238,800,000
$$

$\$ 246,100,000$

$1 / 1 / 2004-12 / 31 / 2007$

$1 / 1 / 2008-12 / 32 / 2012$

100 workers per year

90 workers per year

$252 \mathrm{mrem} / \mathrm{yr}$ per worker

Mobile crane, roll off truck, loader, bulldozer, and cement truck

Cycle time/operation not applicable

$12,480 \mathrm{hr}$ (total)

0.5 acres for VIC Buildings, Transport Line Chase, ITS building and ramps

7,255 tons

42.5 tons

Contaminated fill $\left(1500 \mathrm{yd}^{3}\right)$

Steel/asbestos $(279,000 \mathrm{lb})$

Lead bricks/mixed wastes $(4,900 \mathrm{lb})$

$156 \mathrm{MWh} / \mathrm{yr}$

283,452 liters (total)

NEPA documentation (prior to start of Title II construction); New stationary sources/PTC/NOC/PSD for non-rad air emissions; HAP's and TAP's and RCRA (part AA, BB, and $C C$ for air) for hazardous air emissions; air operating permit; NESHAP's, NPDES, NESHAP's subpart $\mathrm{H}$ for rad air emissions; approval of Engineering Plans; Cross Connection Control Plans; reports and specifications for drinking water supply; RCRA Part A and Part B permits.

$$
\begin{array}{cc}
\text { CWO } & \begin{array}{c}
\text { TRU Separations } \\
\text { Options }
\end{array} \\
& \text { HWO, VWO }
\end{array}
$$


Facility Operations

Utilities

Maintenance of Equipment

Building Maintenance

Total Operations

Schedule start/end

Number of workers each year of operation

Managers

Engineers and other technicians

Supervisors and Administation/Support

Operators

Maintenance

Number of radiation workers

Average annual work radiation dose (rem/year)

Air Emissions

Type (radioactive/chemical)

Quantity (Ci/year, ton/year)

Energy Requirements

Electrical (MWh/yr)

Permits needed (for facility operations)
\$ $1,218,000$
\$ $4,661,000$
\$ $4,761,000$
$\$ 1,054,000$
$\$ 4,158,000$
$\$ 4,158,000$
S $7,866,000$
$\$ 28,840,000$
$\$ 28,840,000$
$\$ 9,255,000$
$\$ 33,933,00$
$\$ 35,120,000$
$\$ 19,393,000$
$\$ 71,594,000$
$\$ 72,781,000$

5-Year Operation: 1/1/2013 - 12/31/2017

20-Year Operation: 1/1/2013-12/31/2032

5-Year Operation 20-Year Operation

0.5

0.25

0.75

0.5

3

2

6

3

1

1

5-Year Operation: 10 workers

20-Year Operation: 6 workers

$192 \mathrm{mrem} /$ year per worker

Calcine

CWO Option: $5.6 \times 10^{-6}$ ton/year

TRU Separations Options: $1.4 \times 10^{-6}$ ton/year

DCWO, HWO, VWO Options: $2.8 \times 10^{-6}$ ton/year

Release of Ci/year dependent on the type and storage length of the calcine released.

CWO Option: 93.2 MWh/yr

TRU Separations Options: $74.1 \mathrm{MWh} / \mathrm{yr}$

DCWO, HWO, VWO Options: 88.7 MWh/yr

HAP's and TAP's and RCRA (part AA, BB, and $C C$ for air) for hazardous air emissions; air operating permit; NESHAP's, NPDES, NESHAP's subpart $H$ for rad air emissions; approval of Engineering Plans; Cross Connection Control Plans; report specifications for drinking water supply; RCRA Part A and Part B permits.

Decontamination \& Decommissioning (D\&D) Information 
Cost (\$): DD\&D (Unescalated)

Decommission

Decontamination

Demolition

Total DD\&D

Schedule start/end: D\&D

Number of workers each year of D\&D

(new/existing)

Number of radiation workers (D\&D)

Average annual worker radiation dose (rem/yr)

Heavy equipment

Equipment used

Hours of operation

Acres disturbed and duration of disturbance

Air emissions

Major gases (CO2, $\mathrm{H} 2 \mathrm{O}, \mathrm{O} 2, \mathrm{~N} 2)$
CWO

$\begin{array}{cc}\text { TRU- } & \text { DCWO, HWO, } \\ \text { Separations } & \& \text { VWO } \\ \text { Options } & \end{array}$

\$ $2,555,000$

$\$ 2,555,000$

\$ $2,681,000$

$\$ 7,223,000$

\$ $7,223,000$

S $4,935,000$

$\$ 11,557,000$

$\$ 14,713,000$

$\$ 21,335,000$

CWO: $1 / 1 / 2018-12 / 31 / 2018$

TRU-Separations Options: $1 / 1 / 2034-12 / 31 / 2034$

DCWO, HWO, \& VWO: $1 / 1 / 2034-12 / 31 / 2034$

CWO: 108

TRU-Separations Options: 155

DCWO, HWO, \& VWO: 160

CWO: 75

TRU-Separations Options: 104

DCWO, HWO, VWO: 102
Mobile Cranes, Roll-off Trucks, Dozers, Loaders, cement trucks, and other specialty equipment used during D\&D

CWO: $4,992 \mathrm{hr}$

TRU-Separations Options: $6,240 \mathrm{hr}$

DCWO, HWO, \& VWO: $7,488 \mathrm{hr}$

CWO \& TRU-Separations Options (transport lines only): 0.09 acre

DCWO, HWO, \& VWO (ITS \& transport lines):

0.11 acre

CWO: 2,902 tons (total)

TRU-Separations: 3,627 tons (total)

DCWO, HWO \& VWO: 4,353 tons (total)

Contaminants (Particulates, $\mathrm{CO}, \mathrm{NOx}, \mathrm{SO}$, hydrocarbons)

CWO: 17 tons (total)

TRU-Separations: 21 tons (total)

DCWO, HWO, \& VWO: 25 tons (total)

Solid wastes 


\author{
Type \\ Quantity (m³) \\ Radioactive wastes \\ Type and Quantity \\ Energy requirements \\ Electrical (MWh/yr) \\ Fossil fuel (liters)
}

Permits needed (e.g. for facility closures, physical characteristics and quantities of radioactive and hazardous materials remaining after closure)
Metal building and uncontaminated transport equipment

CWO \& TRU-Separations Options: $45 \mathrm{~m}^{3}$

DCWO, HWO, \& VWO options: $90 \mathrm{~m}^{3}$

Cyclones, metal filters, and hoppers from transport system

CWO \& TRU-Separations Options: $1.2 \mathrm{~m}^{3}$

DCWO, HWO, \& VWO options: $2.6 \mathrm{~m}^{3}$

$156 \mathrm{MWh} / \mathrm{yr}$ (based on John Duggan's estimate of $3000 \mathrm{kWh} / \mathrm{wk}, 52 \mathrm{wk} / \mathrm{yr}$ )

CWO: 113,380 liters

TRU-Separations Options: 141,725 liters

DCWO, HWO, \& VWO: 170,070 liters

Work will be done under closure provisions $f$ existing permits

Some differences are present between the input to project data sheets and the more formal project data sheet. The primary difference involves the waste streams generated by the system. Quantities for effluents, solid wastes, hazardous/toxic chemicals and wastes, and pits/ponds were not reported. These values are negligible, therefore, the categories have been eliminated from Table 6. The most significant waste stream is the radioactive waste removed from the CSSFs during construction activities.

\subsection{Program Schedule}

The calcine retrieval and transportation system will observe the same construction schedule for each waste treatment option (CWO, DCWO, HWO, VWO, and TRU Separations Options). The DCWO, HWO, VWO and TRU Separations options operate under a 20-year schedule. The CWO option has a 5-year operational schedule. The calcine retrieval system has the capacity to meet both of these schedules.

\author{
Conceptual Design \\ Title Design \\ Construction \\ Operations
}

\author{
$1 / 1 / 2004-12 / 31 / 2005$ \\ $1 / 1 / 2006-12 / 31 / 2007$ \\ $1 / 1 / 2008-12 / 31 / 2012$ \\ $1 / 1 / 2013-12 / 31 / 2032$ or $1 / 1 / 2013-12 / 31 / 2017$
}

At the end of construction all of the CSSFs should be ready for retrieval by $1 / 1 / 2013$. SO testing and operational readiness reviews will be conducted during the construction period. The waste treatment options require that calcine retrieval begin on 1/1/2013 to allow time for D\&D of the 
Waste Treatment Facility and the CSSFs by the target date of 2035 for storage of road ready HLW.

The calcine retrieval and transportation system described above has the capacity to retrieve the estimated total volume of calcine during the operations time period. The total estimated volume of calcine present in the CSSFs by 2013 is $5435 \mathrm{~m}^{3}$ (determined in reference 14). The average bulk density of calcine is $1400 \mathrm{~kg} / \mathrm{m}^{3}$ (according to reference 1). The calcine retrieval and transportation system has the capacity to retrieve calcine at a combined retrieval rate of 5400 $\mathrm{kg} / \mathrm{hr}$ (two independent systems with a retrieval rate of $2700 \mathrm{~kg} / \mathrm{hr}$ ). The calcine retrieval and transportation system will need to operate for $1409 \mathrm{hr}$ to retrieve the total estimated volume of calcine. The waste treatment facilities generally assume a downtime factor of $50 \%$ to allow for equipment maintenance. Accounting for the $50 \%$ downtime factor, the calcine retrieval and transportation system will need to operate for $10.8 \mathrm{hr} / \mathrm{wk}$ and $2.7 \mathrm{hr} / \mathrm{wk}$ for the 5 -year and 20year operation schedules, respectively. The short operating time suggests that the optimum retrieval rate could be reduced without adversely impacting the schedule. The calcine retrieval and transportation system has the capacity to retrieve the total estimated volume of calcine during the required operational periods.

A retrieval schedule for the CSSFs not presented in this EDF. There are too many unknown parameters to develop a complete and optimum calcine retrieval schedule. The retrieval schedule must be coordinated between the Waste Treatment Facility and the CSSF closure study $^{12}$. This section is merely intended to show that the proposed retrieval system has the capacity to retrieve the estimated volume of calcine in the time period outlined by the Consent Order. The Consent Order requires that all high level waste be placed in a road ready form by a target date of 2035. The above calculation shows the total estimated calcine volume can be retrieved and delivered to the Waste Treatment Facility in the necessary time frame.

\subsection{Costs}

The cost estimate for the calcine retrieval and transportation system was completed in modular sections to accommodate the differences in the waste treatment options. Each CSSF was independently evaluated. CSSFs 5, 6, and 7 are similar therefore one cost estimate, which may be applied to CSSF 5, 6, and 7, was developed. Two transport system costs were developed. Transport system A reflects the cost of transporting calcine from the CSSF to the necessary facilities for the CWO and TRU Separations options. Transport system B reflects the cost of transporting calcine from the CSSFs to the Waste Treatment Facility for the DCWO, HWO, and VWO options. Estimates to purchase and install D\&D risers and remove corrosion coupons are also included. The cost estimate from implementation alternative $B$ (see section 4.0 ) is presented below. A preliminary cost estimate for implementation of alternative A can be found in the project file.

Appendix F contains the Cost Estimate Support Data Recapitulation, summary sheets, and contingency analysis for each module of the capital cost estimate and the complete life cycle cost estimate. The detail sheets used to develop the capital cost estimate are not included in this EDF. They are located in the project file and are available upon request. 
Although the Fluor-Daniels study was the basis for this study, the total estimated cost (TEC) of the calcine retrieval and transportation system developed in this EDF is nearly twice the TEC for the Fluor-Daniels ${ }^{2}$ design. The higher cost estimate can be attributed to 4 factors. First, more demolition work during the CSSF access phase was estimated for this design than for the FluorDaniels design. The higher cost of demolition work is a result of higher estimated radiation levels in the superstructure and removal of more equipment (including the cyclone and its associated piping). Second, Fluor-Daniels specified that 2 sets of retrieval equipment (confinement enclosures, bridge cranes, VDAs, and shielded jumpers) were necessary. The sets of retrieval equipment would be moved from CSSF to CSSF. Seven sets of retrieval equipment were necessary for the design presented in this EDF because of the interfaces with the Waste Treatment Facility and the CSSF closure study. Third, the location of the Waste Treatment Facility for the DCWO, HWO, and VWO options requires an intermediate transport station to deliver the calcine to the Waste Treatment Facility. This resulted in 2 more sets of transport equipment (transport air blowers, balancing air blowers, HEPA filters, heat exchangers, cyclones, and sintered metal filters) as well as additional transport piping. This additional equipment resulted in a higher cost for the transport system. Fourth, the Fluor-Daniels study did not examine removal of corrosion coupons or installation of D\&D risers. During this study it was found to be necessary to remove the corrosion coupons prior to retrieval activities. The corrosion coupons present a significant risk to the safe and efficient operation of the calcine retrieval and transportation system. D\&D risers, installed after retrieval operations are complete, are necessary to interface with the CSSF closure project. The TEC of the calcine retrieval and transportation system developed in this EDF is nearly twice the TEC for Fluor-Daniels ${ }^{2}$ calcine retrieval and transportation system. 
Table 7. Cost Summary of the Calcine Retrieval and Transportation System (Costs Shown are x1000)

\begin{tabular}{|c|c|c|c|c|c|}
\hline Costrem & TCwO & JUCWO & jRWo & jowo & Thu separations \\
\hline $\begin{array}{l}\text { OPC (unescalated) } \\
\text { OPC Escalation } \\
\text { OPC Mgmt Reserve } \\
\text { OPC Contingency } \\
\text { Total OPC }\end{array}$ & $\begin{array}{r}27,267 \\
9,358 \\
0 \\
0 \\
10,475 \\
41,100\end{array}$ & $\begin{array}{r}21,267 \\
9,358 \\
0 \\
10,475 \\
41,100\end{array}$ & $\begin{array}{r}21,267 \\
9,358 \\
0 \\
10,475 \\
41,100\end{array}$ & $\begin{array}{r}21,267 \\
9,358 \\
0 \\
10,475 \\
41,100\end{array}$ & $\begin{array}{r}27,267 \\
9,358 \\
0 \\
10,475 \\
41,100\end{array}$ \\
\hline $\begin{array}{l}\text { TEC (unescalated) } \\
\text { TEC Escalation } \\
\text { TEC Mgmt Reserve } \\
\text { TEC Contingency } \\
\text { Total TEC }\end{array}$ & $\begin{array}{r}123,193 \\
52,330 \\
13,406 \\
49,992 \\
238,921\end{array}$ & $\begin{array}{r}127,031 \\
53,841 \\
13,788 \\
51,611 \\
246,271\end{array}$ & $\begin{array}{r}127,031 \\
53,841 \\
13,788 \\
51,611 \\
246,271\end{array}$ & $\begin{array}{r}127,031 \\
53,841 \\
13,788 \\
51,611 \\
246,271\end{array}$ & $\begin{array}{r}123,193 \\
52,330 \\
13,406 \\
49,992 \\
238,921\end{array}$ \\
\hline $\begin{array}{l}\text { TPC (unescalated) } \\
\text { TPC Escalation } \\
\text { TPC Mgmt Reserve } \\
\text { TPC Contingency } \\
\text { Total TPC }\end{array}$ & $\begin{array}{r}144,460 \\
61,688 \\
13,406 \\
60,467 \\
280,021\end{array}$ & $\begin{array}{r}148,298 \\
63,199 \\
13,788 \\
62,086 \\
287,371\end{array}$ & $\begin{array}{r}148,298 \\
63,199 \\
13,788 \\
62,086 \\
287,371\end{array}$ & $\begin{array}{r}148,298 \\
63,199 \\
13,788 \\
62,086 \\
287,371\end{array}$ & $\begin{array}{r}144,460 \\
61,688 \\
13,406 \\
60,467 \\
280,021\end{array}$ \\
\hline $\begin{array}{l}\text { Operations (unescalated) } \\
\text { Operations Escalation } \\
\text { Operations Contingency } \\
\text { Total Operations }\end{array}$ & $\begin{array}{r}19,393 \\
11,085 \\
9,143 \\
39,621\end{array}$ & $\begin{array}{r}72,781 \\
71,923 \\
43,41.1 \\
188,115\end{array}$ & $\begin{array}{r}72,781 \\
71,923 \\
43,411 \\
188,115\end{array}$ & $\begin{array}{r}72,781 \\
71,923 \\
43,411 \\
188,115\end{array}$ & $\begin{array}{r}71,594 \\
70,751 \\
42,704 \\
185,049\end{array}$ \\
\hline $\begin{array}{l}\text { Post Operations (unescalated) } \\
\text { Post Operations Escalation } \\
\text { Post Operations Contingency } \\
\text { Total Post Operations }\end{array}$ & $\begin{array}{r}14,713 \\
10,712 \\
3,814 \\
29,239\end{array}$ & $\begin{array}{r}21,960 \\
37,071 \\
8,855 \\
67,886\end{array}$ & $\begin{array}{r}21,960 \\
37,071 \\
8,855 \\
67,886\end{array}$ & $\begin{array}{r}21,960 \\
37,071 \\
8,855 \\
67,886\end{array}$ & $\begin{array}{r}21,335 \\
36,016 \\
8,603 \\
65,954\end{array}$ \\
\hline $\begin{array}{l}\text { Total Cost (unescalated) } \\
\text { Total Cost (w/escalation, mgt reserve, \& contingency) } \\
\text { Discounted Cost (escalated) }\end{array}$ & $\begin{array}{l}178,566 \\
348,880 \\
166,409\end{array}$ & $\begin{array}{l}243,039 \\
543,371 \\
196,876\end{array}$ & $\begin{array}{l}243,039 \\
543,371 \\
196,876\end{array}$ & $\begin{array}{l}243,039 \\
543,371 \\
196,876\end{array}$ & $\begin{array}{l}237,389 \\
531,023 \\
192,309\end{array}$ \\
\hline
\end{tabular}

\subsection{Recommendations for Further Study}

Issues that should be further studied are identified in sections 3.1.4, 3.2.4, and 3.3.4. The majority of these issues will be resolved as feasibility studies and title design are completed. Several have significantly more impact on whether or not the design is viable. Efforts should be made to characterize the state of calcine in the bins as well as the radiation levels in the CSSF superstructures. The limits on the transport length of a vacuum system should be identified. The feasibility of an intermediate transport station and its configuration should be examined. A closure method should be developed for the transportation system. There are several issues that require coordination with the Waste Treatment Facility and the CSSF closure study ${ }^{12}$. These issues must be resolved before title design can begin.

\subsection{Uncertainties}

Many issues and their associated uncertainties were discussed in sections 3.1.4, 3.2.4, and 3.3.4. These issues will not be repeated in this section. The major uncertainties, which apply to the overall project, will be discussed in this section. 


\subsection{Maturity of Technology}

Guidance for determining the maturity of technology is found in the U.S. Department of Energy Standard Operating Procedure, Interim Guidance, Office of Science and Technology,Technology Decision Process, May 8, 1997. The technological maturity is classified into stages 1 through 7. They are titled Basic Research, Applied Research, Exploratory Development, Advanced Development, Engineering Development, Demonstration, and Implementation. This reference details the minimum goals, objectives, measures of effectiveness, actions, and responsibilities to include requirements for entry into the next stage.

The basic technologies (brief descriptions of these basic technologies can be found in sections 3.1.2, 3.2.2, and 3.3.2) necessary to implement the calcine retrieval and transportation system are generally well developed. The classifications of the various technologies range from the "Exploratory Development" stage to the "Implementation" stage. Some of these technologies (particularly the remote welding device and VDA) have been proven in industry in hands on applications. They must be converted for remote use prior to implementation in the calcine retrieval and transportation system. The majority of the remote technologies necessary for decontamination have been demonstrated at the INEEL and other facilities. Applied research on INEEL surrogate calcine has shown that free flowing calcine is retrievable using this technology. These systems require development and testing to ensure their reliability and performance in this application. Some aspects of engineering development require considerably more work.

\subsection{Risk Assessment}

Schedule and cost risks are identified in this EDF. They are categorized below according to the source of the risk. The risks are the same for both implementation options and project schedules. Risk Assessment Forms for all identified risks are included in Appendix E along with an explanation of the Risk Rating calculation method.

The risk ratings can vary from " 1 " to " 9 ". The highest risk in each category is rated at " 4 ". The risks with the highest ratings will be discussed in this section.

\subsubsection{Project Risk}
P.1 Integrity of CSSF maintained
risk $=3$
P. 2 Location of retrieval risers
risk $=3$
P.3 Estimated retrieval percentage too high
risk $=2$
P.4 Internal obstructions prevent retrieval
risk $=2$
P.5 Waste Treatment Facility too slow
risk $=2$
P.6 Miscellaneous materials prevent retrieval

$$
\text { risk }=4
$$

This risk is discussed in some detail in section 3.2.4. However, it bears repeating here. During filling of the CSSFs, miscellaneous materials entered the bins. No attempt has been made to remove these materials from the bins. There is a high potential that the material is scattered throughout the bins. These materials may damage the bins or the calcine retrieval and transportation system if they were to be picked by the suction nozzle or air jet. Therefore, this 
risk was assigned a probability of " 2 ." There is some potential that the schedule will be disrupted, costs will increase, and the performance of the system may be degraded. The impact of this risk is rated at " 2 " because the calcine retrieval and transportation system minimizes the impact. The potential for schedule disruption and increased costs are reduced because each transport system has a back up transport line and retrieval could be switched to another bin or CSSF.

\subsubsection{Technical Risk}

T.1 Objective retrieval rate too high

risk $=3$

T.2 All calcines are not retrievable

$$
\text { risk }=4
$$

This risk is based on an assumption. It was necessary to assume at the onset that all types of calcine could be retrieved with one system. It is possible that some of the calcine in the CSSFs is agglomerated. If it is agglomerated the potential exists that it is not retrievable. Schedule disruptions and increased costs are possible if a significant amount of calcine is not retrievable using the calcine retrieval and transportation system. This risk was assigned a probability and impact of " 2 " because it is possible that it will occur and adversely affect the schedule and costs.

\subsubsection{ES\&H Risk}

ESH.1 Construction radiation dose rates incorrect risk $=4$

The radiation levels in the CSSF superstructures are not known. A comprehensive survey of these areas has not been conducted. The relative radiation levels used to develop the cost estimates were assumed. It is likely that these levels were incorrectly estimated. The radiation levels may be significantly higher in the CSSF superstructure. If the actual radiation levels are different from the estimated levels there is a potential to impact the schedule and costs. Therefore, the probability and impact were each assigned a value of " 2 ." The risk is given a value of " $4 . "$

\subsection{Failure Modes}

Possible failure scenarios are identified in this section. It is outside the work scope of this study to evaluate these scenarios. However, efforts have been made to ensure that double confinement of the calcine is maintained at all times. This reduces the risk of a source-term release due to a failure of the calcine retrieval and transportation system. The failure modes include:

- Loss of negative pressure in the confinement enclosure

- Leakage in the confinement enclosure

- Bin breach caused during installation of additional retrieval risers leading to a calcine release into the bin vault

- Loss of calcine confinement around the retrieval equipment during operation of retrieval equipment

- Erosion failure in the transport lines 
- Erosion failure in the cyclone

- Power failure during calcine retrieval

A failure would most significantly affect the schedule. The level of significance is dependent upon the failure. Any failure is expected to halt all activities involving calcine retrieval and transportation until the cause of the failure is resolved and necessary modifications are made. The current schedule for calcine retrieval allows $50 \%$ downtime for maintenance. This allows some slack time for unanticipated failures.

\subsection{Cost Estimate Uncertainties}

Competent cost estimators who are familiar with work conducted at the ICPP prepared the cost estimate. Efforts have been made to ensure the cost estimate for the calcine retrieval and transportation system is consistent with the cost estimates for the non-separations options and the TRU Separation option. Radiation zone work has been conservatively estimated based on known incidents during filling of the CSSFs (Dan Staiger's draft report "Review of High Level Wastes Stored at the ICPP"). The assumptions used to develop the cost estimate are outlined in the introductory letter. The cost estimate is well detailed.

\subsection{Potential Impacts of NRC Licensing}

Licensing a nuclear facility requires preparing and submitting an application and supporting documents to the NRC, such as Safety Analysis Reports, an Environmental Reports, quality assurance documents, training plans, monitoring plans, and safeguards and security plans. The $\mathrm{NRC}$ licensing process is divided into four stages: pre-application stage, application review stage, construction and operating license stage, and decontamination and site closure stage. The licensing duration from submitting the application to receiving the license is expected to require a minimum of an additional three to five years. The benefits of NRC licensing are enhanced operating safety, strengthened relationships with stakeholders, and license-holder participation in future regulation development.

According to data developed by Fluor-Daniels ${ }^{2}$, the estimated cost for NRC licensing is $14 \%$ of the escalated Total Estimated Cost to comply with the NRC requirements that exceed the current DOE requirements. A NRC licensed facility will experience greater costs during the operating period. These additional costs are discussed in the reports for the separate processing options (in the section titled "Potential Impacts of NRC Licensing").

Some of the potential major impacts associated with NRC licensing of Waste Treatment Facilities, other than cost, are:

- Increased oversight, including more public involvement and input in all decision processes

- More restrictive physical limits on some parameters, including exposure limits, seismic, and tornado 
- More strict radiation monitoring

- Restrictions on sharing utilities between facilities

- More stringent evaluations of the impact from off-site hazards.

- Full testing required for emergency utilities

- Physical changes to the plant and equipment

- More elapsed schedule time required

- The methods to comply with some other codes and standards may be complicated and require more time

- Although the NRC may license the WTS facilities, it may not automatically inherit or adopt the same agreements and obligations with the State of Idaho and EPA Region 10 that are in place for DOE and INEEL

\subsection{Summary and Conclusions}

The calcine retrieval and transportation system presented above combines the best elements of previous studies (references 2,3 , and 8 ), pilot plant tests, and experience. The system meets the requirements set forth in the Consent Order, statutory law, and DOE orders. The assumptions used to develop this system have strong bases.

The system was discussed in three sections: CSSF access, calcine retrieval system, and calcine transportation system. During CSSF access, the CSSFs will be prepared for calcine retrieval. Superstructure buildings, equipment, and piping will be decontaminated and removed from CSSFs 1-4. The concrete vaults of CSSFs 5-7 will be decontaminated but not removed. Existing retrieval lines will be accessed. New retrieval lines will be added to CSSFs 1, 2, and 3. The calcine retrieval and transportation systems will function simultaneously. Calcine will be retrieved from the CSSFs using a fluidizing air jet and a suction nozzle. Then the calcine will be directly placed in the pneumatic transport system for transport to the Waste Treatment Facility.

There are several issues that must be resolved before the calcine retrieval and transportation system can be termed feasible. A plan to deal with the corrosion coupons and other miscellaneous items in the bins should be developed. These items should be removed from the bins or prevented from entering the transport system. The transport system currently calls for longer transport distances than are accepted by industry. It was proposed that testing be done to verify that a vacuum system (with intermediate transport stations, if necessary) can be efficiently used over long distances. Resolving these issues will increase the feasibility of the calcine retrieval and transportation system. The remaining issues (sections 3.1.4, 3.2.4, and 3.3.4) should be resolved over the course of feasibility studies and title design. 
The cost estimate was developed in modules to allow an "apples to apples" comparison with the Fluor-Daniels retrieval and transportation system. Initially, two alternatives for implementation were examined. The first alternative was removed from consideration. It did not satisfy all the processing options and adversely impacted CSSF closure study ${ }^{12}$ because only 2 sets of retrieval equipment were specified. The second alternative represents a retrieval and transportation system that interfaces with the Waste Treatment Facility and the CSSF closure study ${ }^{12}$. A cost estimate based on the second alternative bounds the cost of the project. Separate capital cost estimates were developed for installation of D\&D risers and removal of corrosion coupons.

Life cycle costs for construction, operation, and closure of the calcine retrieval and transportation system were developed. Removal of corrosion coupons and installation of D\&D risers are included in the life cycle cost estimate for each waste treatment option.

The CWO option requires a 5-year operating period. This option uses transport system $A$ to deliver the calcine from the CSSFs to the NWCF. The total unescalated cost for the CWO option is $\$ 178,566,000$. The total cost with escalation, management reserve, and contingency is $\$ 348,880,000$. The discounted annual cost for the CWO option is $\$ 166,409,000$.

The TRU-Separations Options requires the calcine retrieval and transportation system to operate for 20 years. This option employs transport system A to deliver the calcine from the CSSFs to the Calcine Dissolution Facility. The total unescalated cost for the CWO option is $\$ 237,389,000$. The total cost with escalation, management reserve, and contingency is $\$ 531,023,000$. The discounted annual cost for the CWO option is $\$ 192,309,000$.

The DCWO, HWO, and VWO options have a 20 year operating period. These options require transport system B to deliver the calcine from the CSSFs to the Waste Treatment Facilities. The total unescalated cost for the CWO option is $\$ 243,039,000$. The total cost with escalation, management reserve, and contingency is $\$ 543,371,000$. The discounted annual cost for the CWO option is $\$ 196,876,000$. 
Appendix A

Drawing
CRT-01 HVAC Flow Diagram
CRT-02 Pneumatic Transport System
CRT-03 Intermediate Transport Station (ITS)
CRT-04 Site Plan for DCWO, HWO, and VWO
CRT-05 Site Plan for CWO 


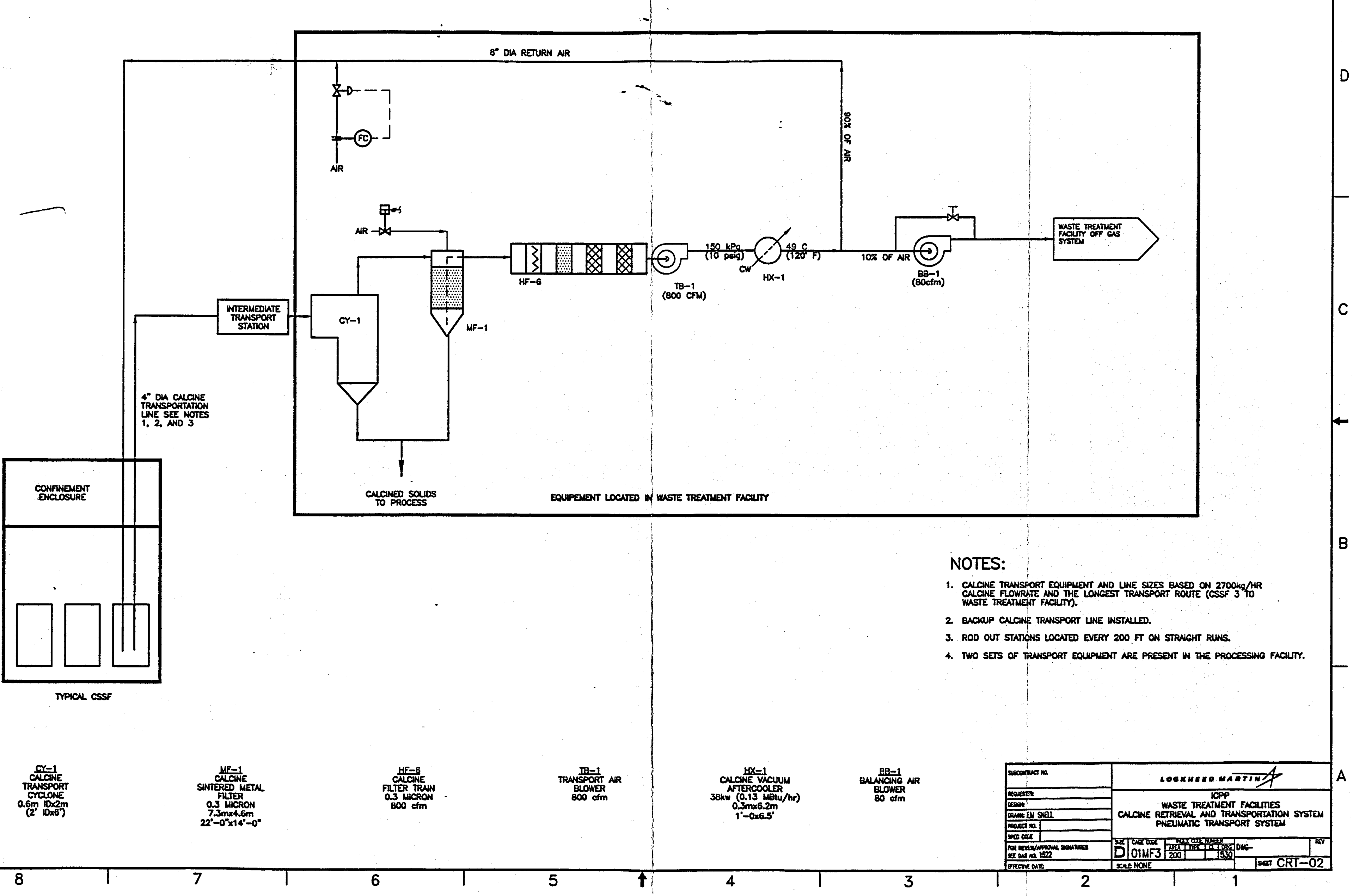




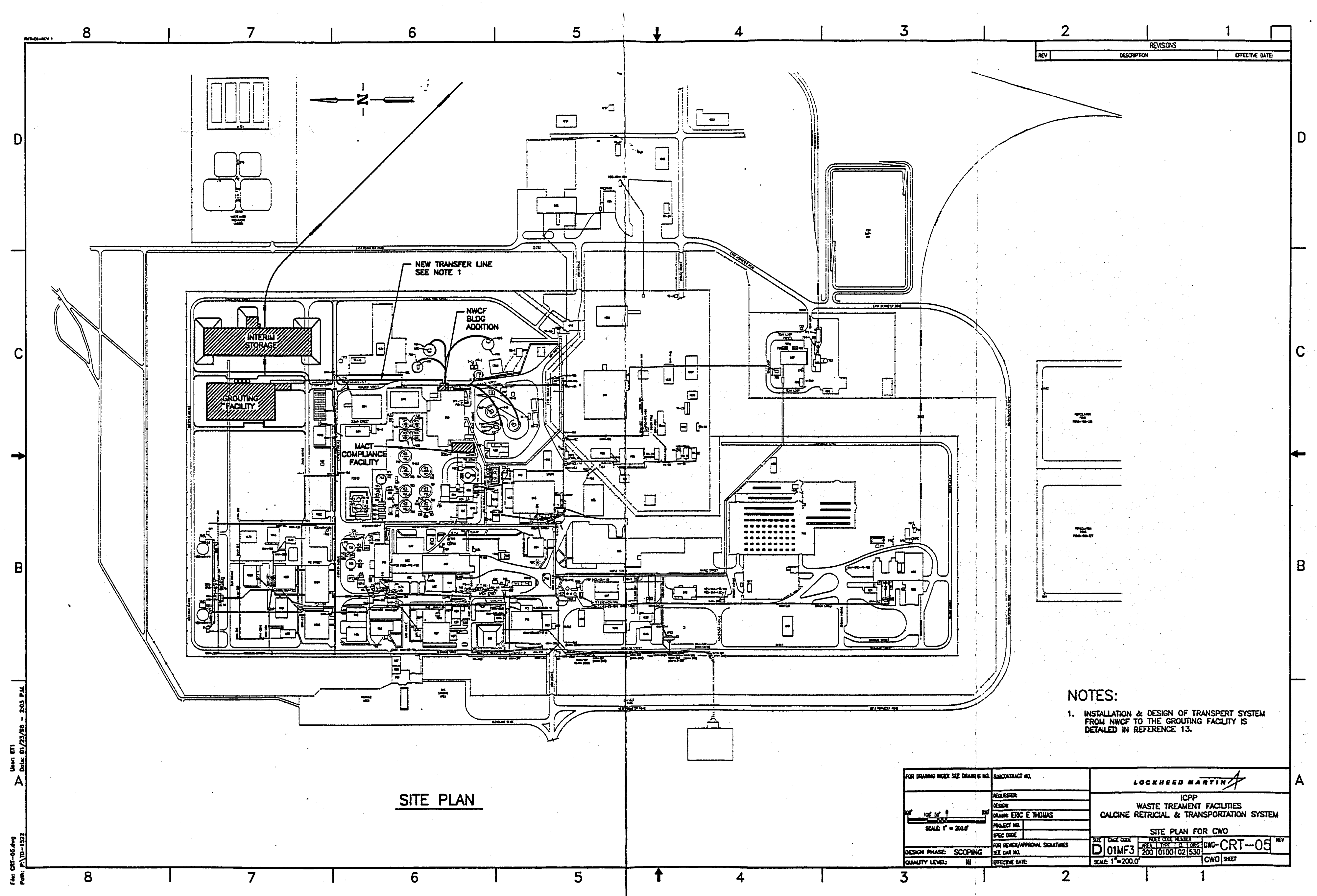




\section{Appendix B}

\section{References}

1. INEEL, Waste Inventories / Characterization Study, INEEL/EXT-97-00600, September 1997.

2. Fluor-Daniels, Inc. (Government Services Operating Company), Idaho Chemical Processing Plant Waste Treatment Facilities Feasibility Study, Delivery Order 94-36, 30\% Design Review Package, June 1997, 60\% Design Review Package, August 1997, and 90\% Design Review, October 1997.

3. Raytheon Engineers and Constructors, Inc., Idaho Chemical Processing Plant Bin Set 1 Calcine Recovery Project: Phase I and II Special Studies Report Volume I, DE-AC07-89ID12679, February 1995.

4. West Valley Nuclear Services Inc., West Valley Nuclear Services, Inc. Remote Installation of Risers on Underground Nuclear Waste Storage Tanks, DOE/NE/44139-45 (DE88010531), 1988.

5. INEEL, HWMA Closure Plan for the Waste Calcining Facility at the Idaho National Engineering and Environmental Laboratory rev 2, INEEL-96/0189, June 1997.

6. INEEL, New Waste Calcining Facility Deactivation Option for Low-level Waste Grout Disposal, INEEL/EXT-97/01076, December 1997.

7. Westra, A.G., J.S. Schofield, S.J. Horn, J.A. Hendricks, G.S. Pomiak, Sampling of Stored High-Level Radioactive Calcined Waste at ICPP, ICP-1186, May 1979

8. D. L. Griffith, Status of Calcine Retrieval Development Work-DLG-06-96, September 1996.

9. Regulatory Requirements and Standard Criteria for the ICPP Proposed Waste Processing Facilities, EDF-WTF-003.

10. Regulatory Design Requirements for Waste Treatment Facilities, EDF-WTS-004.

11. Calculations by Dan Griffith, December 1997 (included in this Appendix).

12. INEEL, Calcined Solids Storage Facility Closure Study, INEEL/EXT-97-01296, 1998.

13. INEEL, Cementitious Waste Option Study Report, INEEL/EXT-97-01400, 1998.

14.Estimates of Feed and Waste Volumes, Compositions, and Properties, EDF-FDO-011 rev. 1, 1998. 


\section{Memo of Conversation}

Name

Organization

Phone

Dan Griffith

LMITCO Chief Engineer

$6-3760$

Sara Gifford

MC\&I Engineering

6-5162

Date: $\quad 12$ November 1997

Subject: Nozzle design and retrieval system efficiency

Discussion:

In the mock up facility, the retrieval method appears to be just as efficient (if not more so) for cylindrical bins as it is for annular bins. This is evidenced by returning the solids to the outer bin.

Previous designs indicate that it is not too difficult to design a nozzle that will prevent uptake of extraneous materials. The nozzles used in the Rover project shown that it not be a significant design effort to develop a nozzle for the retrieval lines. 
Date: $\quad$ November 19, 1997

To: Sara Gifford

From: $\quad$ Dan Griffith

Subject: Pressure Drop in Proposed Pneumatic Transport System

As requested I have calculated pressure drop for four cases as shown below. All cases are vacuum systerns with a length of 315 feet. Inlet pressure to the transport line is $12.3 \mathrm{psia}$. I assumed the transfer line was steel pipe.

\begin{tabular}{|c|c|c|c|c|c|c|}
\hline $\begin{array}{l}\text { Diameter } \\
\text { Inchess }\end{array}$ & $\begin{array}{l}\text { Flow Rate } \\
\text { at Blower } \\
\text { cfim }\end{array}$ & $\begin{array}{l}\text { Solids } \\
\text { to Air Ratio } \\
\text { Ib } d \mathrm{~b}\end{array}$ & $\begin{array}{l}\text { Solids } \\
\text { Flow } \\
\text { kg/hr }\end{array}$ & $\begin{array}{l}\text { Inlat } \\
\text { Velocity } \\
\text { pm }\end{array}$ & $\begin{array}{l}\text { Out. } \\
\text { Vel. } \\
\text {. }\end{array}$ & $\begin{array}{l}\text { Pres. } \\
\text { Drop } \\
\text { psi }\end{array}$ \\
\hline 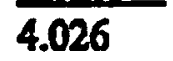 & 800 & 3.9 & 2700 & 4635 & 9049 & 6.0 \\
\hline 4. & 350 & 6.0 & 2700 & 2993 & 3959 & 3.0 \\
\hline 4.0 & 350 & 2.7 & 1360 & 3380 & 3959 & 1.8 \\
\hline 06 & 175 & 2.7 & 680 & 2896 & 3409 & 1.9 \\
\hline
\end{tabular}

These results do not include a return air line.

Note that for the first two cases the pressure at the blower will fall below 10 psia which is the pressure you specified. The first case may not be feasible for a vacuum system because of the high pressure drop. The second case may not be feasible for a vacunum system because the high solids to air ratio might result in transport line plugging. The other two cases also have a fairly high solids to air ratios, but I believe they aro feasible. If it is important to achieve such high transfer rates, we should mock this up. I could test anything but the first case in my existing pilot plant. All we would need is a feeder to meter solids in at the desired rate and 300 feet of pipe. We could consider using plastic pipe to save money. We probably bave components in the old pilot plant which we could use for the feeder. 
431.02\#

02/37/98

Rev. $\$ 00$

\section{ENGINEERING DESIGN FILE}

Equipment List

\section{Appedix C}

Function File Number - SPR-WTS-01

EDF Serial Number - EDF-WTS-002

Page 47 of 62 


\section{Appendix C}

\section{Equipment List}

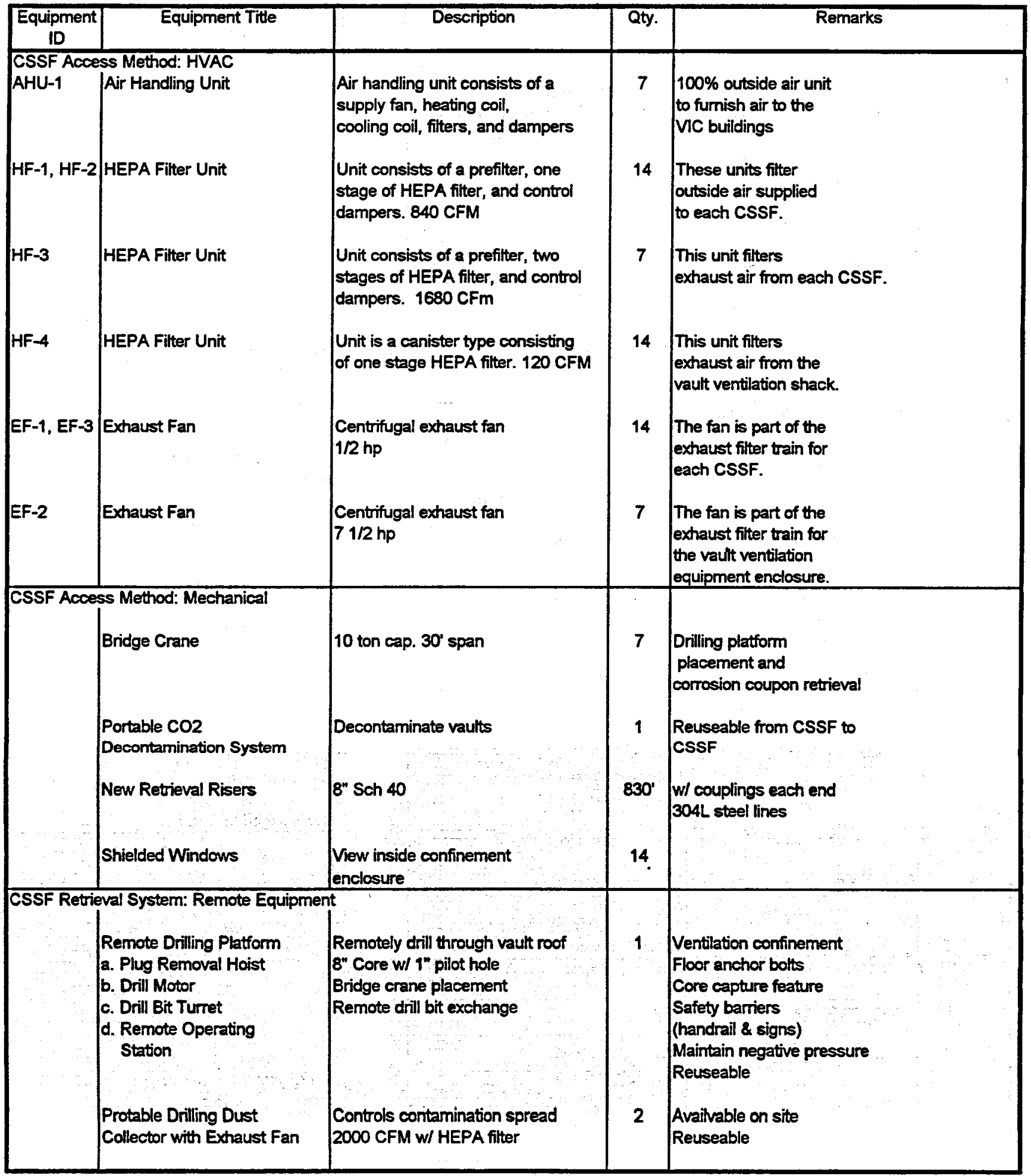




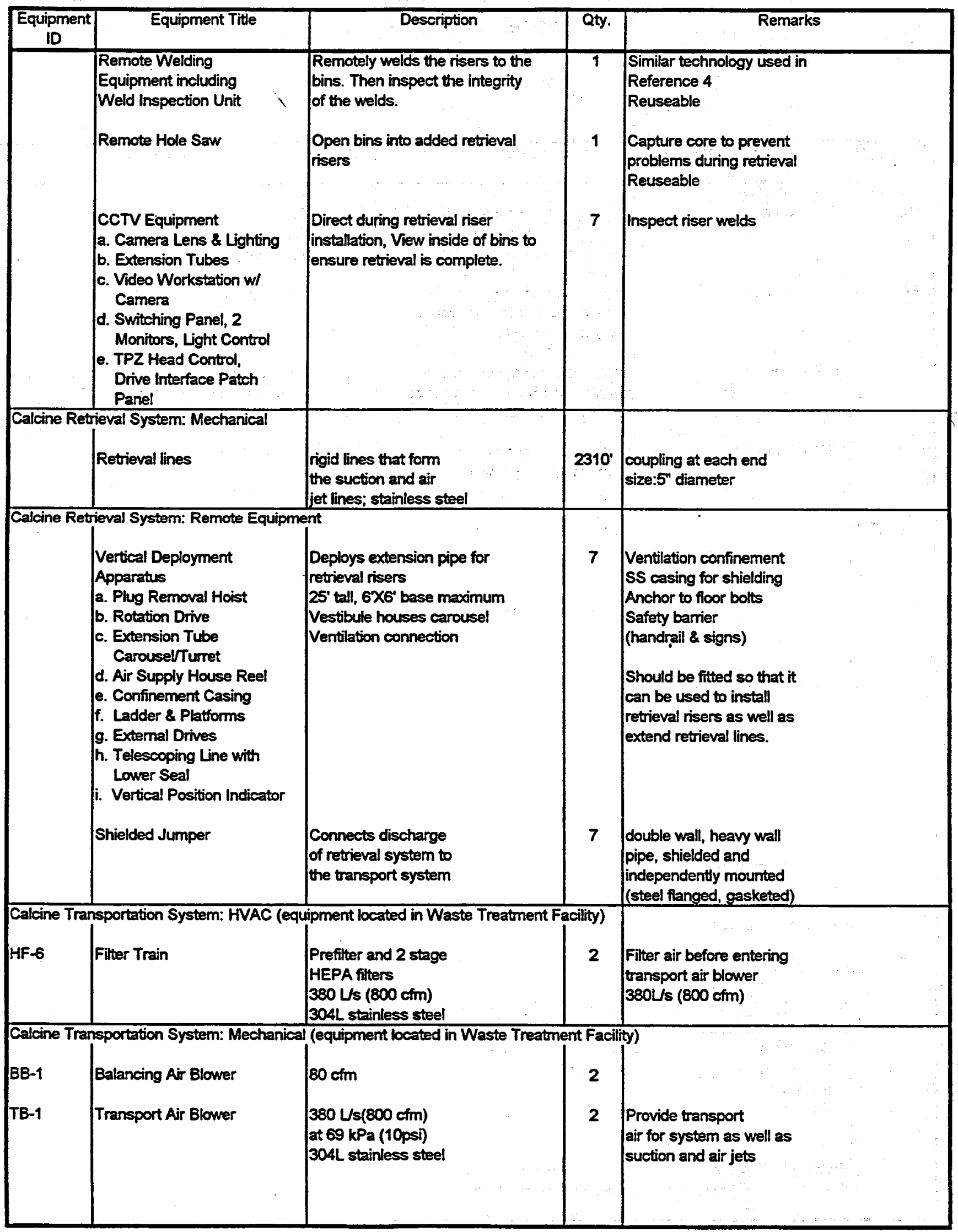




\section{$\ldots+\ldots, \ldots, \ldots+\ldots$}

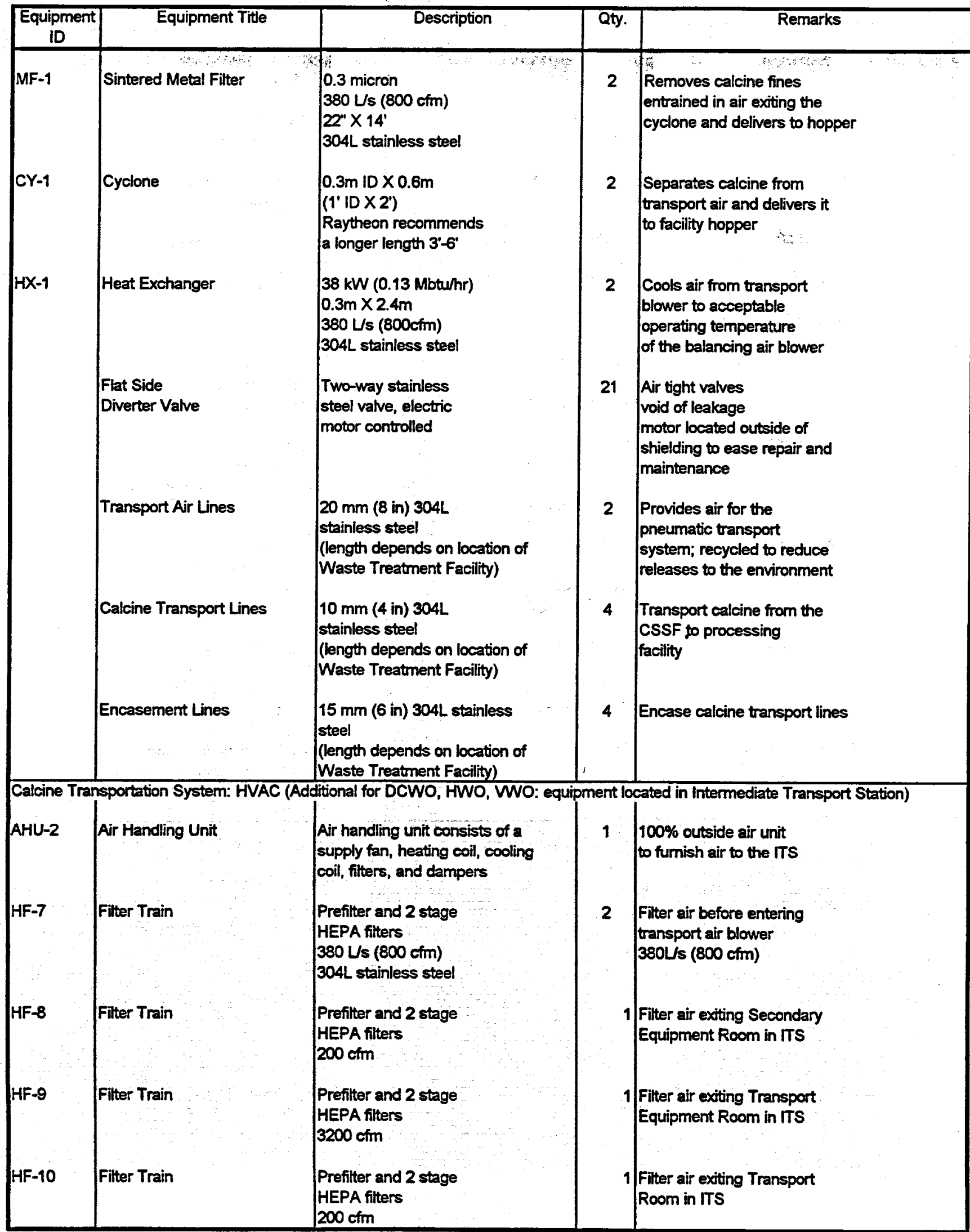




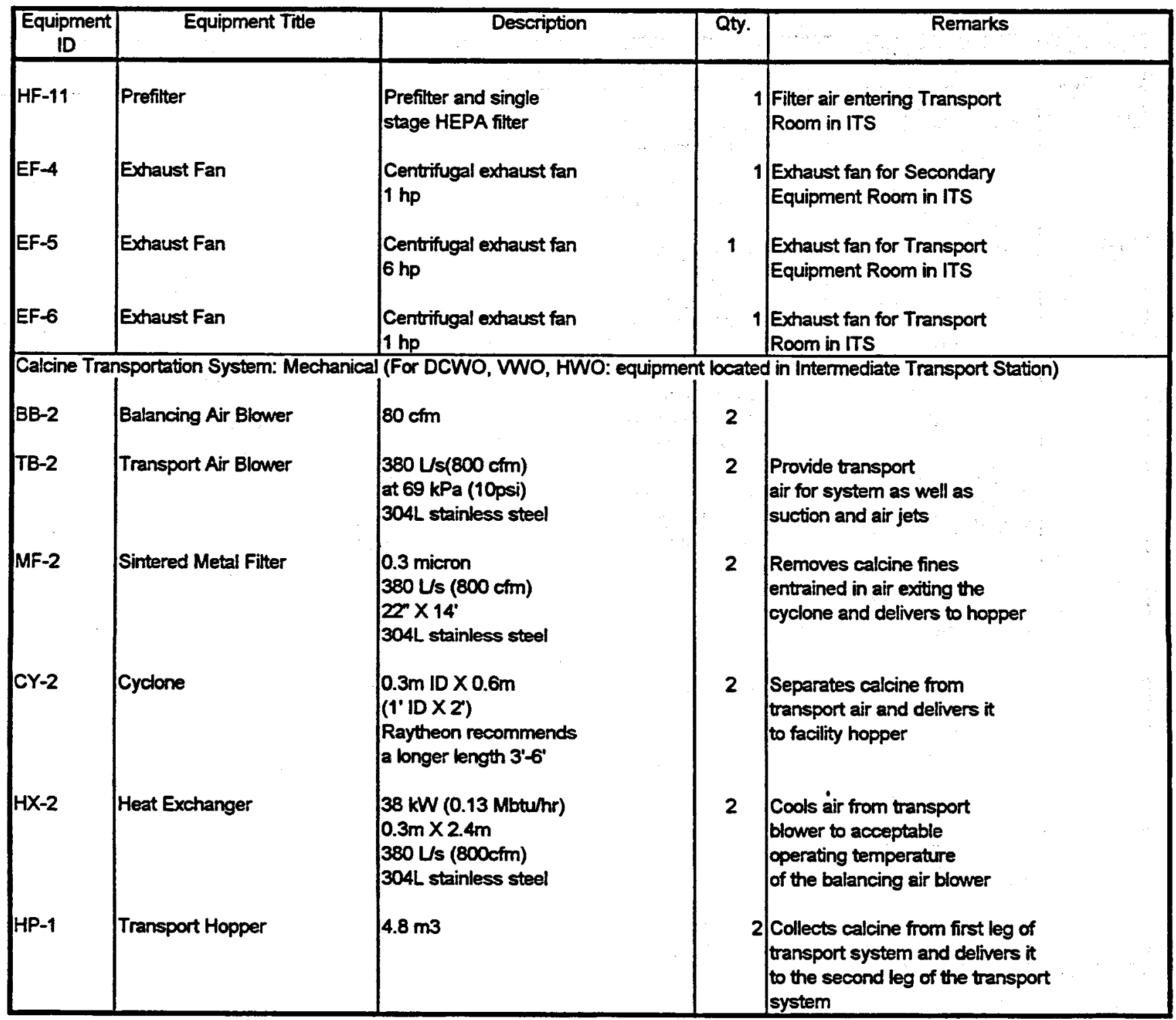




\title{
Appendix D \\ Background for Project Data Sheets
}

Table 6 is repeated here for convenience. The justifications for the data entered in this table are found below along with brief explanations. Reference letters coordinate the data.

\section{Table D-1. Input to Project Data Sheet}

\author{
Generic Information \\ Structure Size $\left(\mathrm{m}^{2}\right)$ \\ Seven Confinement Enclosures which are each $40 \mathrm{ft}$ X 40 \\ $\mathrm{ft}$ \\ ( $978 \mathrm{~m}^{2}$ total) \\ Seven VIC Buildings which are each $40 \mathrm{ft}$ X $60 \mathrm{ft}$ (1560 \\ $\mathrm{m}^{2}$ total) \\ One ITS Building that is $600 \mathrm{ft}^{2}\left(55.7 \mathrm{~m}^{2}\right)$ \\ Location \\ A Confinement Enclosure will be built on the roof of each \\ CSSF. \\ A VIC Building will be built adjacent to each CSSF. \\ An ITS Building will be built mid way between the CSSFs \\ and the Waste Treatment Facility.
}

\section{Construction Information}

Cost (\$): Preconstruction (escalated included)

CWO, DCWO, HWO, VWO \& TRU Separations Options

Conceptual Design

Project Management

Permitting and Documentation

Start Up Activities

Contingency

Total Preconstruction

Cost (\$): Construction (escalation included)

Engineering, Design, and Inspection

Management Reserve (PM/CM)

Construction

Government Furnished Eqiupment

G\&A/PIF
B

$\$ 18,000,000$

S $2,700,000$

S $4,800,000$

S $5,100,000$

\$ $10,500,000$

S $41,100,000$

CWO \& TRU Separations Options

DCWO, HWO, \& VWO

S $18,500,000$

\$ $19,400,000$

S $22,900,000$

S $23,500,000$

$\$ 104,200,000$

$\$ 106,500,000$

S $18,200,000$

S $19,300,000$

\$ $10,400,000$

\$ $10,700,000$ 
Procurement Fees, Management Reserve, and Contingency

Total Construction

Schedule start/end: Preconstruction

Schedule start/end: Construction

Number of workers each year of construction

Number of radiation workers (construction)

Average annual worker radiation dose (rem/yr)

Heavy equipment

Equipment used

Trips

Hours of operation

Acres disturbed and duration of disturbance

Air emissions

Major gases (CO2, H2O, O2, N2)

Contaminants (Particulates, $\mathrm{CO}, \mathrm{NOx}, \mathrm{SO}$, hydrocarbons)

Radioactive wastes

Type (Quantity)

Energy requirements

Electrical (MWh/yr)

Fossil fuel (liters)

Permits needed for construction
\$ $64,600,000$

$\$ 66,600,000$

$\$ 238,800,000$

$\$ 246,100,000$

$1 / 1 / 2004-12 / 31 / 2007$

$1 / 1 / 2008-12 / 31 / 2013$

100 workers per year

$\mathbf{D}$

90 workers per year

$252 \mathrm{mrem} / \mathrm{yr}$ per worker

E

F

Mobile crane, roll off truck, loader, bulldozer, and cement truck

Cycle time/operation not applicable

$12,480 \mathrm{hr}$ (total)

0.5 acres for VIC Buildings, Transport Line Chase, ITS building and ramps

\section{$\mathrm{G}$}

$\mathrm{H}$

7,255 tons (total)

42.5 tons (total)

I

Contaminated fill (1500 $\left.\mathrm{yd}^{3}\right)$

Steel/asbestos $(279,000 \mathrm{lb})$

Lead bricks/mixed wastes $(4,900 \mathrm{lb})$

$156 \mathrm{MWh} / \mathrm{yr}$

283,452 liters (total)

NEPA documentation (prior to start of Title II construction); New stationary sources/PTC/NOC/PSD for non-rad air emissions; HAP's and TAP's and RCRA (part $A A, B B$, and CC for air) for hazardous air emissions; air operating permit; NESHAP's, NPDES, NESHAP's subpart $\mathrm{H}$ for rad air emissions; approval of Engineering Plans; Cross Connection Control Plans; reports and specifications for drinking water supply; RCRA Part A and Part B permits.

\section{Operational Information}


Cost (\$): Operations (includes contingency but not escalation)

Facility Operations

Utilities

Maintenance of Equipment

Building Maintenance

Total Operations

Schedule start/end

Number of workers each year of operation (new/existing)

Managers
Engineers and other technicians
Supervisors and Administration/Support
Operators

Maintenance

Number of radiation workers

Average annual work radiation dose (rem/yr)

Air Emissions

Type (radioactive/chemical)

Quantity (Ci/year, tons/year)

Energy Requirements

Electrical (MWh/yr)

Permits needed (for facility operations)

CWO TRU Separations DCWO, HWO, VWO Options

K
$\$ 1,218,000$
\$ $4,661,000$
\$ $4,761,000$
S $1,054,000$
S $4,158,000$
\$ $4,158,000$
S $7,866,000$
$\$ 28,840,000$
$\$ 28,840,000$
\$ $9,255,000$
$\$ 33,933,00$
\$ $35,120,000$
S $19,393,000$
$\$ 71,594,000$
$\$ 72,781,000$

5-Year Operation: $1 / 1 / 13-1 / 1 / 18$

20-Year Operation: $1 / 1 / 13-1 / 1 / 33$

5-Year Operation

0.5

0.75

3

6

1

5-Year Operation: 10 workers 20-Year Operation: 6 workers

$192 \mathrm{mrem} / \mathrm{year}$ per worker

Calcine

CWO Option: $5.6 \times 10^{-6}$ ton/year

TRU Separations Options: $1.4 \times 10^{-6}$ ton/year.

DCWO, HWO, VWO Options: $2.8 \times 10^{-6}$ ton/year

Release of Ci/year dependent on the type and storage length of the calcine released.

CWO Option: $93.2 \mathrm{MWh} / \mathrm{yr}$

TRU Separations Options: $74.1 \mathrm{MWh} / \mathrm{yr}$

DCWO, HWO, VWO Options: $88.7 \mathrm{MWh} / \mathrm{yr}$

HAP's and TAP's and RCRA (part AA, BB, and CC for air) for hazardous air emissions; air operating permit; NESHAP's, NPDES, NESHAP's subpart H for rad air emissions; approval of Engineering Plans; Cross Connection Control Plans; report specifications for drinking water supply; RCRA Part A and Part $B$ permits. 


\section{Decontamination \& Decommissioning (D\&D) \\ Information \\ Cost (\$): DD\&D (Unescalated)}

CWO

TRU-Separations DCWO, HWO, \& Options vwo $\mathbf{P}$

\section{Decommission \\ Decontamination \\ Demolition}

Total DD\&D

Schedule start/end: D\&D

Number of workers each year of D\&D (new/existing)

Number of radiation workers (D\&D)

Average annual worker radiation dose (rem/yr)

Heavy equipment

Equipment used

Hours of operation

Acres disturbed and duration of disturbance

Air emissions

Major gases (CO2, $\mathrm{H} 2 \mathrm{O}, \mathrm{O} 2, \mathrm{~N} 2)$
\$ $2,555,000$

\$ $7,223,000$

\$ $2,555,000$

$\$ 7,223,000$

$\$ 11,557,000$

\$ $21,335,000$

$\$ 14,713,000$
CWO: $1 / 1 / 2018-12 / 31 / 2018$

TRU-Separations Options: 1/1/2034 - 12/31/2034

DCWO, HWO, \& VWO: 1/1/2034-12/31/2034

CWO: 108

TRU-Separations Options: 155

DCWO, HWO, \& VWO: 160

CWO: 75

TRU-Separations Options: 104

DCWO, HWO, VWO: 102

$252 \mathrm{mrem} / \mathrm{yr}$ for each worker

$\mathbf{R}$

S

Mobile Cranes, Roll-off Trucks, Dozers, Loaders, cement trucks, and other specialty equipment used during D\&D

CWO: $4,992 \mathrm{hr}$

TRU-Separations Options: $6,240 \mathrm{hr}$

DCWO, HWO, \& VWO: 7,488 hr

CWO \& TRU-Separations Options (transport lines only): 0.09 acre

DCWO, HWO, \& VWO (ITS \& transport lines): 0.11 acre

CWO: 2,902 tons (total)

TRU-Separations: 3,627 tons (total)

DCWO, HWO \& VWO: 4,353 tons (total)

Contaminants (Particulates, $\mathrm{CO}, \mathrm{NOx}, \mathrm{SO} 2$, hydrocarbons)

CWO: 17 tons (total)

TRU-Separations: 21 tons (total)

DCWO, HWO, \& VWO: 25 tons (total) 
Solid wastes

\section{V}

\section{Type \\ Quantity $\left(\mathrm{m}^{3}\right)$}

Radioactive wastes

Type and Quantity

Energy requirements

Electrical (MWh/yr)

Fossil fuel (liters)

Permits needed (e.g. for facility closures, physical characteristics and quantities of radioactive and hazardous materials remaining after closure)
Metal building and uncontaminated transport equipment CWO \& TRU-Separations Options: $45 \mathrm{~m}^{3}$ DCWO, HWO, \& VWO options: $90 \mathrm{~m}^{3}$

Cyclones, metal filters, and hoppers from transport system

CWO \& TRU-Separations Options: $1.2 \mathrm{~m}^{3}$

DCWO, HWO, \& VWO options: $2.6 \mathrm{~m}^{3}$

$156 \mathrm{MWh} / \mathrm{yr}$ (based on John Duggan's estimate of $3000 \mathrm{kWh} / \mathrm{wk}, 52 \mathrm{wk} / \mathrm{yr}$ )

CWO: 113,380 liters

TRU-Separations Options: 141,725 liters

DCWO, HWO, \& VWO: 170,070 liters

Work will be done under closure provisions f existing permits

A. Confinement Enclosures: $(30 \mathrm{ft} 6$ in. $\mathrm{X} 30 \mathrm{ft} 6 \mathrm{in})+.6(40 \mathrm{ft} \mathrm{X} 40 \mathrm{ft})=10530 \mathrm{ft}^{2}=978 \mathrm{~m}^{2}$ VIC Buildings: $7(40 \mathrm{ft} \mathrm{X} 60 \mathrm{ft})=16,800 \mathrm{ft}^{2}=1560 \mathrm{~m}^{2}$

ITS building: $600 \mathrm{ft}^{2}=55.7 \mathrm{~m}^{2}$

B. Preconstruction costs taken from the Cost Estimate prepared by Frosty Hanson (see escalated summary sheets in Appendix F). The reported costs reflect the cost associated with CSSFs 1-7, installation of D\&D risers, removal of corrosion coupons, and the appropriate transportation system. The values reported include escalation, contingency, and management and management reserve.

C. Construction costs taken from the Cost Estimate prepared by Frosty Hanson (see escalated summary sheets in Appendix F). The reported costs reflect the cost associated with CSSFs 1-7, installation of $\mathrm{D} \& \mathrm{D}$ risers, removal of corrosion coupons, and the appropriate transportation system. The values reported include escalaton.

D. The number of construction workers per year was developed from information provided by F. P. Hanson in the capital cost estimate. A spreadsheet details how the number of construction workers was developed. The number of rad workers was taken as a high percentage ( $90 \%$ ) of the total number of workers due to the nature of the construction work. Typically, the number of rad workers is closer to $80 \%$ of the total work force. In this case, the electricians, welders, and other finishing personnel should receive rad worker training. 
E. Entry into and demolition work will occur in highly contaminated areas throughout the construction phase of the project. The historical dose rates at ICPP were examined to develop a reasonable estimate of the worker dose. The average annual worker dose rates at ICPP were examined for the period 1994-1996. The dose rates were highest in 1995 when a significant amount of work was completed on the tank farm. It was assumed that the 1995 dose would be representative of the average annual worker dose rate during construction. The average annual worker dose rates for 1994-1996 at ICPP are reported in a memo "Average Worker Dose Rate at ICPP" dated 11/24/97.

F. The most prominent pieces of heavy equipment used during the construction phase of this project include a mobile crane, roll off truck, loader, bulldozer, and cement truck. It is estimated that at any given time an average of 4 vehicles will be in operation during the 5year construction period. Each vehicle was assumed to operate for $624 \mathrm{hr} / \mathrm{yr}$ (which is approximately $1 / 3$ of a man-year). The hours of operation are ( 4 vehicles)( 624 $\mathrm{hr} /$ vehicle* $\mathrm{yr})(5 \mathrm{yr})=12,480 \mathrm{hr}$.

G. For CWO and TRU-Separations Options:

VIC Buildings: $1560 \mathrm{~m}^{2}=0.39$ acre (approximately the VIC building footprint) Transport Lines: $(800 \mathrm{ft})(5 \mathrm{ft})=4000 \mathrm{ft}^{2}=0.09$ acre (approximately the footprint of the shielding chase)

Total $=0.48$ acre which is approximately 0.5 acre

For DCWO, HWO, and VWO options:

VIC Buildings: $1560 \mathrm{~m}^{2}=0.39$ acre (approximately the VIC building footprint) Transport Lines: $(925 \mathrm{ft})(5 \mathrm{ft})=4625 \mathrm{ft}^{2}=0.1$ acre (approximately the footprint of the shielding chase)

ITS building: $600 \mathrm{ft}^{2}=0.01$ acre

Total $=0.5$ acre

H. The construction air emissions are primarily derived from emissions of heavy equipment. A spreadsheet was developed by Rod Kimmitt to analyze the air emissions produced by heavy equipment. A copy of the spreadsheet is attached for the calcine retrieval and transportation system.

I. An estimate of the radioactive wastes removed from CSSF 1 is made in reference 3. This estimate includes removal of equipment and concrete vaults. The removed contaminated fill is estimated to be $1,500 \mathrm{yd}^{3}$. The removed steel and suspected asbestos material is estimated to weigh $5,300 \mathrm{lb}$. The lead bricks are estimated to weigh $300 \mathrm{lb}$. These estimates were used as the basis for the radiactive wastes removed from CSSF 2 -7.

CSSF 2 and 3 are estimated to be similar to CSSF 1 because similar construction will occur on these CSSFs. However, the amount of contaminated fill is assumed to be negligible. There is no need to (except no contaminated fill is removed).

CSSF 4, 5, 6, and 7 are expected to have less concrete and steel removed because the superstructure vaults will not be demolished. There is no fill removal for these CSSFs. 
Equipment (steel) that is removed is estimated to weigh about 3,000 lb. The lead bricks are assumed to weigh $1,000 \mathrm{lb}$.

Contaminated fill:

Steel and suspected asbestos material:

Lead bricks and mixed waste:

$$
\begin{aligned}
& 1,500 \mathrm{yd}^{3} \\
& 3(5,300 \mathrm{lb})+4(3,000 \mathrm{lb})=279,000 \mathrm{lb} \\
& 3(300 \mathrm{lb})+4(1,000 \mathrm{lb})=4,900 \mathrm{lb}
\end{aligned}
$$

J. The electrical energy requirement is derived from John Duggan's suggestion that construction requires $3000 \mathrm{kWh} / \mathrm{wk}$. $(3000 \mathrm{kWh} / \mathrm{wk})(52 \mathrm{wk} / \mathrm{yr})=156 \mathrm{MWh} / \mathrm{yr}$. The estimated fossil fuel consumed during the construction phase of this project was determined from an average value for fuel consumption of heavy equipment. The John Deere Construction equipment web page (www.deere.com) indicates an average fuel consumption of heavy equipment to be $6 \mathrm{gal} / \mathrm{hr}$. $(6 \mathrm{gal} / \mathrm{hr})(12,480 \mathrm{hr})=74,880 \mathrm{gal}=283,452$ liters.

K. Operational costs are derived from the Cost Estimate prepared by Bob Turk. The operational costs associated with retrieving calcine from CSSF 1-7 and transport system, installation of D\&D risers, and removal of corrosion coupons are included. These values are not escalated.

L. Operational crew requirements were developed with the assistance of Jack Prendergast for the 5-year and 20-year operations options. The number of radiation workers was derived from the number of operators, maintenance workers, and other technicians.

M. The average value of the average annual dose rates at ICPP for 1994-1996 was used to determine the average annual work radiation does rate during operations. The average over the 3 year period is more representative of work that would occur during the operations phase of the calcine retrieval and transportation system. (180 mrem/yr $+252 \mathrm{mrem} / \mathrm{yr}+143$ $\mathrm{mrem} / \mathrm{yr}$ ) $/ 3$ = $192 \mathrm{mrem} / \mathrm{yr}$. See attached memo (also referenced in E).

N. During normal operations and idle time for each CSSF, air emissions are assumed to be negligible due to the multiple layers of confinement. These layers include several stages of HEPA filters. Air emissions were estimated for the exhausted transport air. This estimate is developed for the transport air after it has been through a two stage HEPA filter. The air emissions are primarily composed of calcine particles. The radioactivity of the calcine emitted to the environment varies depending upon the type of calcine and its length of storage.

Assuming the cyclone will have $99 \%$ efficiency, the sintered metal filter will have $99.9 \%$ efficiency, and the HEPA filter will have $99.97 \%$ efficiency. Rod Kimmitt provided these efficiencies.

Calcine remaining in the transport air after HEPA filters: $(0.01)(0.001)(0.0003)(2700 \mathrm{~kg} / \mathrm{hr})=0.009 \mathrm{~g} / \mathrm{hr}$

Total hours each transport system must operate: $\left(5435 \mathrm{~m}^{3}\right)\left(1400 \mathrm{~kg} / \mathrm{m}^{3}\right)(1 \mathrm{hr} / 5400 \mathrm{~kg})=1409 \mathrm{hr}$ 
For CWO (5-Year Operations):

Assuming all the transport air is exhausted through the Waste Treatment Facility off-gas system.

The transportation system will release:

$$
2(0.009 \mathrm{~g} / \mathrm{hr})(1409 \mathrm{hr})=25 \mathrm{~g}=2.8 \times 10^{-5} \text { ton }
$$

The total air emissions from both transportation systems are $2.8 \times 10^{-5}$ ton for 5-years (5.6 $\times 10^{-6}$ ton/yr).

For TRU Separations Options (20-Year Operation):

Assuming all the transport air is exhausted through the Waste Treatment Facility off-gas system.

The transportation system will release:

$$
2(0.009 \mathrm{~g} / \mathrm{hr})(1409 \mathrm{hr})=25 \mathrm{~g}=2.8 \times 10^{-5} \text { ton }
$$

The total air emissions from both transportation systems are $2.8 \times 10^{-5}$ ton for 20-years $\left(1.4 \times 10^{-6}\right.$ ton/yr).

For DCWO, HWO, and VWO (20-Year Operation):

Assuming all the transport air is exhausted through the Waste Treatment Facility off-gas system.

The transportation system will release:

$$
4(0.009 \mathrm{~g} / \mathrm{hr})(1409 \mathrm{hr})=50 \mathrm{~g}=5.6 \times 10^{-5} \text { ton }
$$

The total air emissions from the 4 transportation system legs are $5.6 \times 10^{-5}$ ton for 20 -years $\left(2.8 \times 10^{-6}\right.$ ton $\left./ \mathrm{yr}\right)$.

For actual operations the air emissions would be much lower because $90 \%$ of the air is recycled in the transportation system. These calculations assume that all of the transport air is released through the facility off-gas system.

O. The power requirement is determined by the power needs of the transportation equipment, ventilation equipment, and VDA. The transport air blower and balancing air blower require $37.8 \mathrm{~kW}$ and $4 \mathrm{~kW}$ of power, respectively. The exhaust fans (EF-1 and EF-3) require $50 \mathrm{~W}$ of power. The remaining exhaust fan (EF-2) requires $1 \mathrm{~kW}$. The VDA is estimated to require $15 \mathrm{~kW}$. These power consumption values used to compute the power requirement are estimates based on manufacturer specifications.

For CWO (5-Year Operation):

The transportation system operates $10.8 \mathrm{hr} / \mathrm{wk}$ for $26 \mathrm{wk} / \mathrm{yr}$. The ventilation blowers in each VIC building operated $24 \mathrm{hr} /$ day everyday. The VDA is estimated to be in operation approximately $3 \mathrm{hr} / \mathrm{wk}$ during calcine retrieval. 


$$
\begin{aligned}
& \text { Power }=2\left(10.8 \frac{h r}{w k}\right)\left(26 \frac{w k}{y r}\right)(37.8 k W+4 k W) \\
& +7\left(24 \frac{h r}{d a y}\right)\left(365 \frac{d a y}{y r}\right)(2(0.05 k W)+1 k W) \\
& +2\left(3 \frac{h r}{w k}\right)\left(26 \frac{w k}{y r}\right)(15 k W)=93.2 \frac{M W \cdot h r}{y r}
\end{aligned}
$$

For TRU Separations Options (20-Year Operation):

The transportation system operates $2.7 \mathrm{hr} / \mathrm{wk}$ for $26 \mathrm{wk} / \mathrm{yr}$ in this alternative. The ventilation blowers in each VIC building operate $24 \mathrm{hr} /$ day every day. The VDA is estimated to be in operation approximately $1 \mathrm{hr} / \mathrm{wk}$ during calcine retrieval.

$$
\begin{aligned}
& \text { Power }=2\left(2.7 \frac{h r}{w k}\right)\left(26 \frac{w k}{y r}\right)(37.8 k W+4 k W) \\
& +7\left(24 \frac{h r}{d a y}\right)\left(365 \frac{d a y}{y r}\right)(2(0.05 k W)+1 k W) \\
& +2\left(1 \frac{h r}{w k}\right)\left(26 \frac{w k}{y r}\right)(15 k W)=74.1 \frac{M W \cdot h r}{y r}
\end{aligned}
$$

For DCWO, HWO, VWO (20-Year Operation):

There are 4 transportation system legs operating $2.7 \mathrm{hr} / \mathrm{wk}$ for $26 \mathrm{wk} / \mathrm{yr}$ in these alternatives. Therefore, there are 4 transport air blowers and 4 balancing air blowers. The ventilation blowers in each VIC building operate $24 \mathrm{hr} /$ day every day. The VDA is estimated to be in operation approximately $1 \mathrm{hr} / \mathrm{wk}$ during calcine retrieval. Additionally, the ventilation blowers in the ITS run $24 \mathrm{hr} /$ day every day. The power requirement for EF-4 and EF-6 is estimated to be $100 \mathrm{~W}$ each. The power requirement for EF-5 is estimated to $800 \mathrm{~W}$ based on the estimate for EF-2.

$$
\begin{aligned}
& \text { Power }=4\left(2.7 \frac{h r}{w k}\right)\left(26 \frac{w k}{y r}\right)(37.8 k W+4 k W) \\
& +7\left(24 \frac{h r}{d a y}\right)\left(365 \frac{d a y}{y r}\right)(2(0.05 k W)+1 k W) \\
& +2\left(1 \frac{h r}{w k}\right)\left(26 \frac{w k}{y r}\right)(15 k W)+\left(24 \frac{h r}{d a y}\right)\left(365 \frac{d a y}{y r}\right)(2(0.1 k W)+0.8 k W) \\
& =88.7 \frac{M W \cdot h r}{y r}
\end{aligned}
$$


P. D\&D costs taken from life cycle cost estimate developed by Bob Turk. See Appendix F. The numbers presented are not escalated.

Q. The number of workers needed during D\&D was developed from the unescalated D\&D costs (See Appendix F). The unescalated costs for each option was inputed into a spreadsheet developed by Rod Kimmitt. The spreadsheets are attached.

R. D\&D work will occur in highly contaminated areas of the transportation system. The historical dose rates at ICPP were examined to develop a reasonable estimate of the worker dose. The average annual worker dose rates at ICPP were examined for the period 19941996. The dose rates were highest in 1995 when a significant amount of work was completed on the tank farm. It was assumed that the 1995 dose would be representative of the average annual worker dose rate during construction. The average annual worker dose rates for 1994-1996 at ICPP are reported in a memo "Average Worker Dose Rate at ICPP" dated 11/24/97. The dose during the D\&D phase was assumed to be the same as during the construction phase of the project.

S. The most prominent pieces of heavy equipment used during the D\&D phase of this project include a mobile crane, roll off truck, loader, bulldozer, cement trucks, and other specialized demolition equipment.

For the CWO options, it is estimated that at any given time an average of 8 vehicles will be in operation during the 1-year construction period. Each vehicle was assumed to operate for $624 \mathrm{hr} / \mathrm{yr}$ (which is approximately $1 / 3$ of a man-year). The hours, of operation are (8 vehicles $)\left(624 \mathrm{hr} /\right.$ vehicle $\left.^{*} \mathrm{yr}\right)(1 \mathrm{yr})=4,992 \mathrm{hr}$.

For the TRU-Separations Options, it is estimated that at any given time an average of 10 vehicles will be in operation during the 1-year construction period. Each vehicle was assumed to operate for $624 \mathrm{hr} / \mathrm{yr}$ (which is approximately $1 / 3$ of a man-year). The hours of operation are $(10$ vehicles $)(624 \mathrm{hr} /$ vehicle $* \mathrm{yr})(1 \mathrm{yr})=6,240 \mathrm{hr}$.

For the DCWO, HWO, and VWO options, it is estimated that at any given time an average of 12 vehicles will be in operation during the 1-year construction period. Each vehicle was assumed to operate for $624 \mathrm{hr} / \mathrm{yr}$ (which is approximately 1/3 of a man-year). The hours of operation are $(12$ vehicles $)\left(624 \mathrm{hr} /\right.$ vehicle $\left.^{*} \mathrm{yr}\right)(1 \mathrm{yr})=7,488 \mathrm{hr}$.

T. For the CWO and TRU-Separations Options, only the transport lines are D\&D.

Transport Lines: $(800 \mathrm{ft})(5 \mathrm{ft})=4000 \mathrm{ft}^{2}=0.09$ acre (approximately the footprint of the shielding chase)

Total $=0.09$ acre which is approximately 0.5 acre

For DCWO, HWO, and VWO options:

Transport Lines: $(925 \mathrm{ft})(5 \mathrm{ft})=4625 \mathrm{ft}^{2}=0.1$ acre (approximately the footprint of the shielding chase)

ITS building: $600 \mathrm{ft}^{2}=0.01$ acre 
Total $=0.11$ acre

T. The D\&D air emissions are primarily derived from emissions of heavy equipment. A spreadsheet was developed by Rod Kimmitt to analyze the air emissions produced by heavy equipment. A copy of the spreadsheet is attached for D\&D work on the calcine transportation system.

U. For the CWO and TRU-Separations Options:

The solid wastes disposed of during the D\&D of the transport system include the 2 transport system blowers, 2 heat exchangers, and the associated piping and duct work. The transport equipment for a single transport system is located in a $10 \mathrm{ft} \mathrm{X} 20 \mathrm{ft}$ area. The equipment is assumed to be no greater than $5 \mathrm{ft}$ tall. The transport equipment is assumed to occupy $60 \%$ of the area. The associated piping is assumed to occupy $20 \%$ of the transport equipment area.

$$
\begin{aligned}
& \text { Volume }=2(0.6)(10 f t \times 20 f t \times 5 f t)+2(0.2)(10 f t \times 20 f t \times 5 f t) \\
& =1200 f^{3}+400 f^{3}=1600 f^{3}=45 m^{3}
\end{aligned}
$$

For the DCWO, HWO, and VWO options:

The solid wastes include metal from the metal building in the ITS, 4 transport system blowers, 4 heat exchangers, and the associated piping and duct work. The upper level of the ITS is $20 \mathrm{ft} \mathrm{X} 30 \mathrm{ft} \mathrm{X} 14 \mathrm{ft}$. It is assumed that the metal can be compacted into no more than $5 \mathrm{~m}^{3}$.

$$
\begin{aligned}
& \text { Volume }=4(0.6)(10 f t \times 20 f t \times 5 f t)+4(0.2)(10 f t \times 20 f t \times 5 f t)+5 m^{3} \\
& =2400 \mathrm{ft}^{3}+800 \mathrm{ft}^{3}+5 \mathrm{~m}^{3}=95 \mathrm{~m}^{3}
\end{aligned}
$$

W. For the CWO and TRU-Separations Options:

The radioactive wastes include the 2 cyclones and 2 sintered metal filters. The cyclone has a $2 \mathrm{ft}$ diameter and is $6 \mathrm{ft}$ long. The sintered metal filter has a volume of $3.1 \mathrm{ft}^{3}$. This equipment is located in the Waste Treatment Facility.

$$
\text { Volume }=(2)\left[\pi\left(\frac{2 f t}{2}\right)^{2}(6 f t)\right]+(2)\left(3.1 f^{3}\right)=44 f^{3}=1.2 m^{3}
$$

For the DCWO, HWO, and VWO options:

The radioactive wastes include 4 cyclones, 2 sintered metal filters, and hoppers. The additional equipment is located in the ITS. The hoppers hold $4.8 \mathrm{~m}^{3}$ it is assumed that it may be compacted $50 \%$.

$$
\text { Volume }=(4)\left[\pi\left(\frac{2 f t}{2}\right)^{2}(6 f t)\right]+(4)\left(3.1 f^{3}\right)+(0.5)(2)\left(4.8 m^{3}\right)=92.8 f t^{3}=2.6 m^{3}
$$


$\mathrm{X}$. The electrical energy requirement is derived from John Duggan's suggestion that construction requires $3000 \mathrm{kWh} / \mathrm{wk}$. $(3000 \mathrm{kWh} / \mathrm{wk})(52 \mathrm{wk} / \mathrm{yr})(1 \mathrm{yr})=156 \mathrm{MWh}$

The estimated fossil fuel consumed during the construction phase of this project was determined from an average value for fuel consumption of heavy equipment. The John Deere Construction equipment web page (www.deere.com) indicates an average fuel consumption of heavy equipment to be $6 \mathrm{gal} / \mathrm{hr}$.

For CWO: $(6 \mathrm{gal} / \mathrm{hr})(4,992 \mathrm{hr})=29,952 \mathrm{gal}=113,380$ liters

For TRU-Separations Options: $(6 \mathrm{gal} / \mathrm{hr})(6,240 \mathrm{hr})=37,440 \mathrm{gal}=141,725$ liters

For DCWO, HWO, and VWO options: $(6 \mathrm{gal} / \mathrm{hr})(7,488 \mathrm{hr})=44,928 \mathrm{gal}=170,070$ liters 
Backup to

$E, M, \Psi R$

\section{Memo of Telephone Conversation}

$\begin{array}{lll}\text { Name } & \text { Organization } & \text { Phone } \\ \text { Steve Aitken } & \begin{array}{l}\text { LMITCO S\&H } \\ \text { ICPP ALARA Coordinator }\end{array} & 6-3174\end{array}$

Bill Landman Chemical and Environmental Eng'g - 6-5279

Date: - November 24,1997 $\quad-\quad \cdots \quad$ Time: 4:15 pm

Subject: Average Worker Dose Rate at ICPP.

Discussion:

Steve was contacted for information to support development of the Project Data

Sheet for the Separations Options. He provided the following information for the ICPP site:

Average dose (per worker) for $1996 \quad 180 \mathrm{mR} / \mathrm{hr}$

Average dose (per worker) for 1995 .. $252 \mathrm{mR} / \mathrm{hr}$

Average dose (per worker) for 1994 , $143 \mathrm{mR} / \mathrm{hr}$

The 1995 year average was. higher due to extensive work on the tank farm. 
Back up to $\#$

Construction

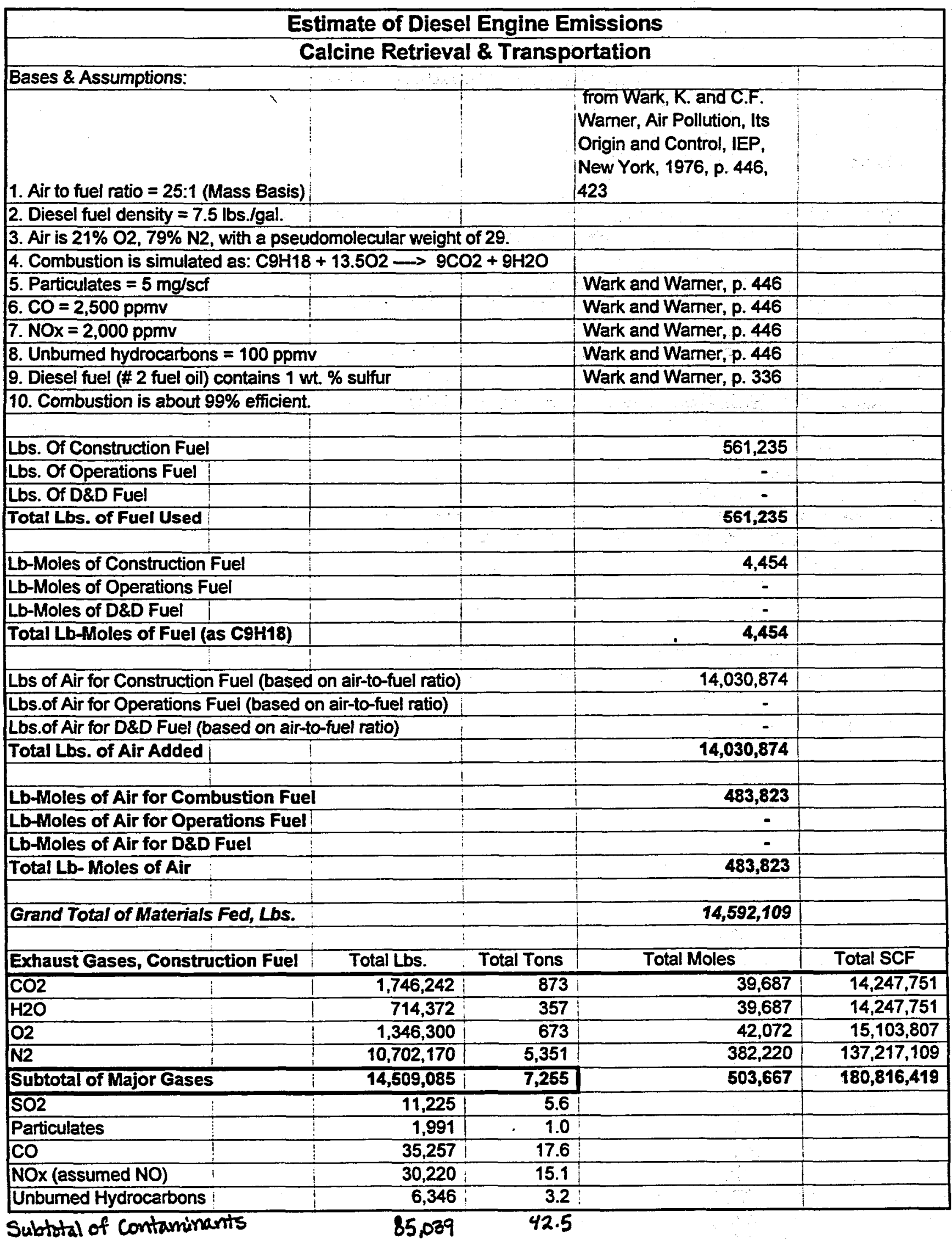




\begin{tabular}{|c|c|c|c|c|c|}
\hline \multicolumn{6}{|c|}{ Project Data Sheet for Calcine Retrieval - CWO } \\
\hline \multicolumn{2}{|c|}{ Decontamination \& Decommissioning (D\&D) Information } & & & 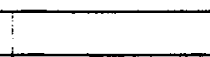 & \\
\hline \multicolumn{2}{|c|}{ Cost (\$): D\&D (Undiscounted dollars) } & & & $s:$ & $\operatorname{tg} t x$ \\
\hline \multicolumn{2}{|c|}{ Decommission } & $\$ 2,555,000$ & & 1 & \\
\hline \multicolumn{2}{|l|}{ Decontamination } & $\$ 7,223,000$ & & & \\
\hline Demolition & $i$ & $\$ 4,935,000$ & & & \\
\hline Total D\&D & & $\$ 14,713,000$ & & & \\
\hline \multicolumn{2}{|c|}{ Schedule start/end: D\&D } & \multicolumn{3}{|c|}{ January 2033 through December 2037} & \\
\hline \multicolumn{2}{|c|}{ Number of workers each year of D\&D (new/existing) } & \multicolumn{3}{|c|}{108 |New workers/yr } & \\
\hline \multicolumn{2}{|c|}{ Number of radiation workers (D\&D) } & 75 & \multicolumn{2}{|c|}{ New workers/yr } & \\
\hline \multicolumn{2}{|c|}{ Average annual worker radiation dose (rem/yr) } & 0.19 & rem/yr & per worker & \\
\hline & & & & & \\
\hline \multicolumn{2}{|c|}{ Heavy equipment: } & & & & \\
\hline \multicolumn{2}{|l|}{ Equipment used } & \multicolumn{4}{|c|}{ Mobile Cranes, Roll-off trucks, Dozers, Loaders } \\
\hline Trips & Roll-off trucks & 15 & per day & & \\
\hline \multicolumn{2}{|c|}{ Hours of operation (all heavy equipment) } & 27,990 & Hours & & \\
\hline \multicolumn{2}{|c|}{ Acres disturbed and duration of disturbance } & \multicolumn{3}{|c|}{ January 2033 through December 2037} & \\
\hline New & & None & & & \\
\hline Previous & & 2.7 & acres & & \\
\hline \multirow[t]{2}{*}{ Revegetated } & & None & & & \\
\hline & & & & & \\
\hline \multicolumn{6}{|l|}{ Air emissions } \\
\hline non-radioactive & Fuel combustion gases $\left(\mathrm{CO}_{2}, \mathrm{H}_{2} \mathrm{O}, \mathrm{O}_{2}, \mathrm{~N}_{2}\right)$ & 16,269 & tons (total) & & \\
\hline non-radioactive & $\begin{array}{l}\text { Fuel combustion contaminants (CO, } \\
\text { particulates, } \mathrm{NO}_{x}, \mathrm{SO}_{2} \text {, hydrocarbons) }\end{array}$ & 95 & țons (total) & & \\
\hline \multirow[t]{2}{*}{ radioactive } & HEPA filtered off-gas & 26,173 & tons (total) & & \\
\hline & & & & & \\
\hline Effluents & & & & & \\
\hline radioactive & Spent decontamination solution & $1,703,250$ & liters (total) & 1,703 & $\mathrm{Ci}$ \\
\hline non-radioactive & Sanitary wastewater & $2,295,160$ & liters (total) & & \\
\hline non-radioactive & Lube oil & 5,297 & liters (total) & & \\
\hline Solid wastes: & & & & & \\
\hline radioactive & & 29,421 & $\mathrm{~m}^{3}$ & 294 & $\mathbf{C i}$ \\
\hline Non-radioactive & (industrial) & 22,122 & $m^{3}$ & & \\
\hline Hazardous & & 10 & $m^{3}$ & & \\
\hline & $+\ldots$ & & & & \\
\hline Hazardous/toxic & chemicals and wastes (type) & & & & \\
\hline Storage/invento & & 205 & $m^{3}$ (total) & & \\
\hline Pits/Ponds crea & ated $\left(m^{2}\right)$ & None & & & \\
\hline radioactive & (mixed waste) & 47 & $m^{3}$ (total) & 0 & $\mathrm{Ci}$ \\
\hline & 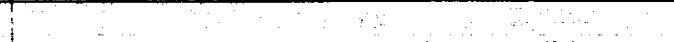 & 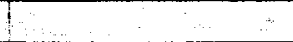 & 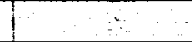 & & \\
\hline Water usage: & $m$ & i & & & \\
\hline Process water & & $2,284,875$ & liters (total) & 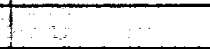 & \\
\hline Domestic water & & $2,295,160$ & liters (total) & & \\
\hline Source of water & & ICPP site wells & & 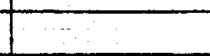 & \\
\hline & 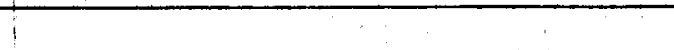 & T & & & \\
\hline Energy requiren & ments: & i & & & \\
\hline
\end{tabular}


D\&D Labor

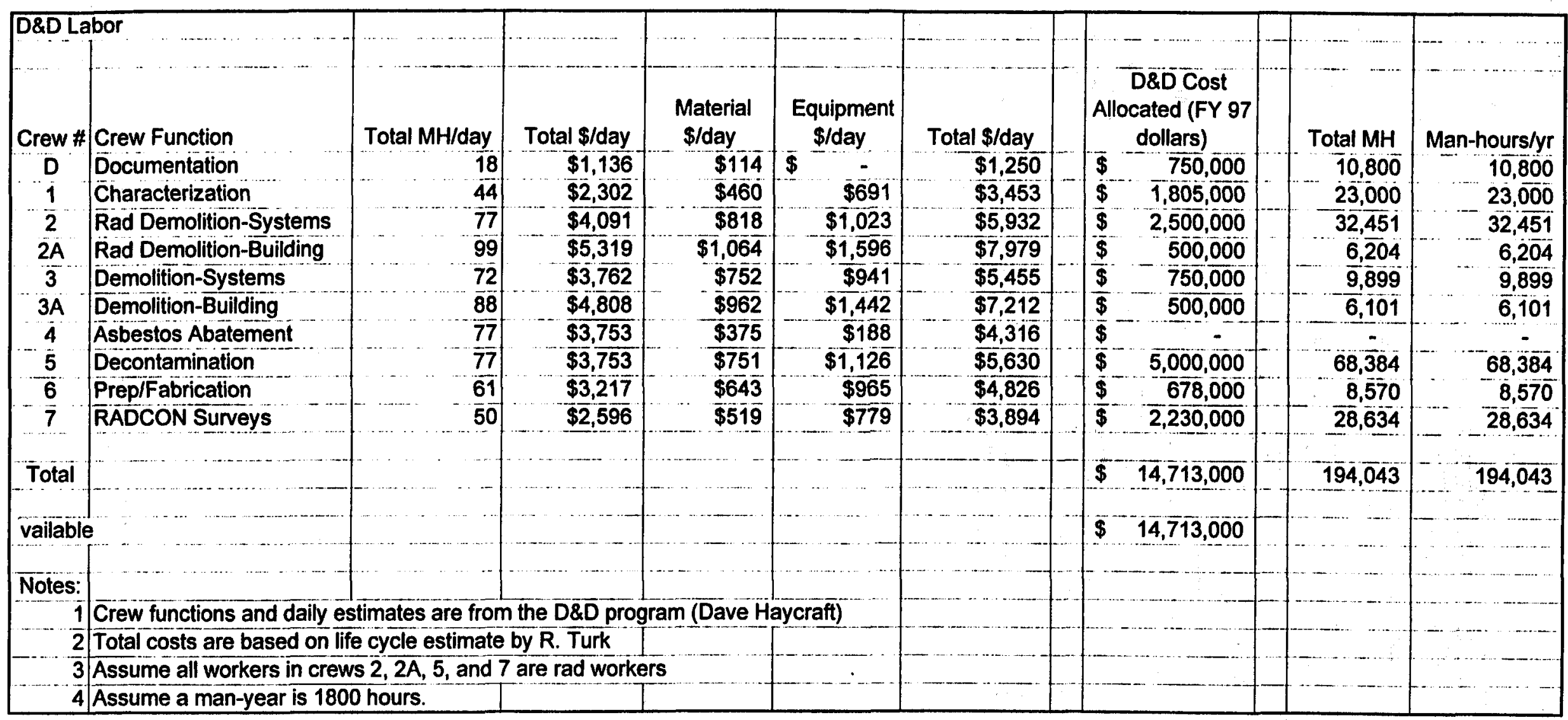




\begin{tabular}{|c|c|c|c|c|c|c|c|}
\hline Duration of $D \& D=$ & & years & & & & & \\
\hline & i & 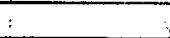 & is & & 95 & & \\
\hline Heavy Equipment & & \# Used & Hours/day & Days/wk & Wks/yr & Hours/yr & \\
\hline & Mobile Crane & $\therefore$ & 3 & 4 & 45 & 540 & \\
\hline & Roll-Off Truck & 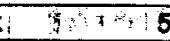 & 8 & 5 & 45 & 9,000 & \\
\hline & Dozer & 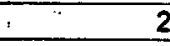 & 5 & 5 & 45 & 2,250 & \\
\hline & Loader & $\vdots$ & 8. & 5 & 45 & 9,000 & \\
\hline & $\begin{array}{l}\text { Scabbler (w/ } \\
\text { Vacuum } \\
\text { System) }\end{array}$ & 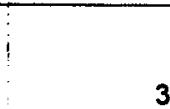 & 8 & 5 & 45 & 5,400 & \\
\hline & $\begin{array}{l}\text { IPneumatic } \\
\text { !Ram }\end{array}$ & 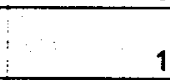 & $4 !$ & 4 & 45 & 720 & \\
\hline & \begin{tabular}{l|} 
Demolition \\
Machine \\
(Remote \\
(Control)
\end{tabular} & 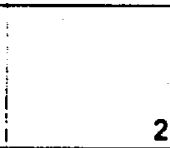 & $4 \mid$ & 3 & 45 & 1,080 & $\cdots$ \\
\hline & & $i$ & & & & & \\
\hline Total hourslyr & 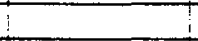 & 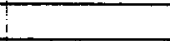 & & & & 27,990 & \\
\hline & & i & $\frac{1}{3}$ & 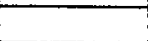 & & 4 & \\
\hline Total heavy equipment $h$ & ours $=$ & + & 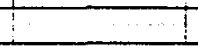 & & & 27,990 & \\
\hline $\begin{array}{l}\text { Assume each piece of } \\
\text { Web Site (Construction }\end{array}$ & $\begin{array}{l}\text { quipment uses } 6 \\
\text { Equipment - http: }\end{array}$ & $\begin{array}{l}6 \text { gallon of die } \\
0: / / \text { mw.deere }\end{array}$ & $\begin{array}{l}\text { esel fuel per hou } \\
. . c 0 \mathrm{~m} / \text { ind/produc }\end{array}$ & $\begin{array}{l}\text { ur. Consump } \\
\text { ct/product.ht }\end{array}$ & $\begin{array}{l}\text { ption rate from } J \\
\text { tmi) }\end{array}$ & hn Deere & \\
\hline No. of gallons of fuel use & during $0 \& D$ & & 167,940 & $\mathrm{gal}=$ & 635,653 & liters (total) & \\
\hline & & 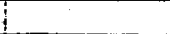 & & & & & \\
\hline Acreage disturbed is the & same as for con & instruction = & 2.7 & acres & & F & \\
\hline & & & & & & & \\
\hline D \& D labor requirements & $s$ are taken from & n D \& D labor & and equipment : & spreadshee & & & \\
\hline & & & 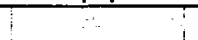 & & $i$ & & \\
\hline$D \& D$ costs come from th & he life cycle cost & st estimate. & & & & 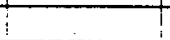 & \\
\hline & & & & & & & \\
\hline Assume each roll-off truc & k makes 3 trips & 5 per day to $\mathrm{R}$ & WMC & & & & \\
\hline No. of trips $=$ & & & 15 & & & $\cdot$ & \\
\hline Miles traveled @ 12 mile & s/round trip= & & 180 & miles/day & & & \\
\hline & & & 7 & & & 1 & \\
\hline Decontamination solution & stored= & & 2,000 & gallons & 205 & $\mathrm{~m}^{3}$ & \\
\hline & & & & & & 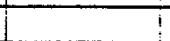 & \\
\hline Daily process water usag & & & 3000 & galday $=$ & $2,284,875$ & liters (total) & \\
\hline (washing, decon, etc.; ba & sed on 225 days & $y s / y r)$ & & & & & \\
\hline & 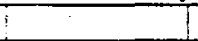 & & $T$ & & & 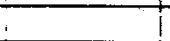 & \\
\hline Domestic water usage $=$ & & $2,295,160$ & liters (total) & & & $i$ & \\
\hline & & & 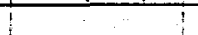 & & & & \\
\hline Sanitary wastewater $=$ sa & me as domestic & ic water usage & $\frac{1}{e}$ & & & & \\
\hline & & & $\cdots$ & & & $1 \cdots$ & \\
\hline Assume portable HEPA : & systems off-gas & rate $=$ & 2000 & $\operatorname{sefm}=$ & 26,173 & Tons (total) & \\
\hline (assumes 225 days/yr) & 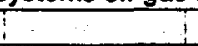 & & 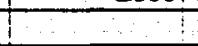 & & & 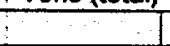 & \\
\hline 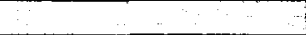 & 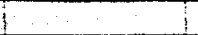 & 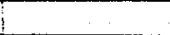 & $\ldots$ & & & & \\
\hline Assume daily spent deco & in. solution = & 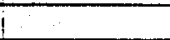 & 2000 & galvday & $1,703,250$ & liters (total) & \\
\hline (assumes 225 days/yr to & & 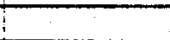 & 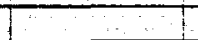 & & & & \\
\hline & $i$ & 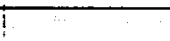 & 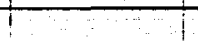 & & & & \\
\hline Solid Waste Generation & (factors from D & Jave Kenoyer & - D\&D Program & & 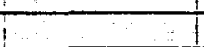 & & \\
\hline Waste Type & $\begin{array}{c}\text { Factor } \\
\text { (cu.ft./sq.ft.) }\end{array}$ & $\begin{array}{l}\text { Sq.Ft. in } \\
\text { Facility }\end{array}$ & $\begin{array}{l}\text { Cu.Ft. of } \\
\text { Waste }\end{array}$ & Cu. Meters & & & \\
\hline & $i$ & $\vdots$ & $\therefore$ & $2 \ldots$ & $\bar{\vdots}$ & $\therefore$ & $\therefore$ \\
\hline $\begin{array}{l}\text { WERF-LLW } \\
\text { Combustible PPEs }\end{array}$ & 0.167 & 175,878 & 29,372 & 832 & & & \\
\hline $\begin{array}{l}\text { WERF-LWW } \\
\text { Combustible Building } \\
\text { Debris }\end{array}$ & 0.128 & 175,878 & 22,512 & 638 & & & \\
\hline
\end{tabular}




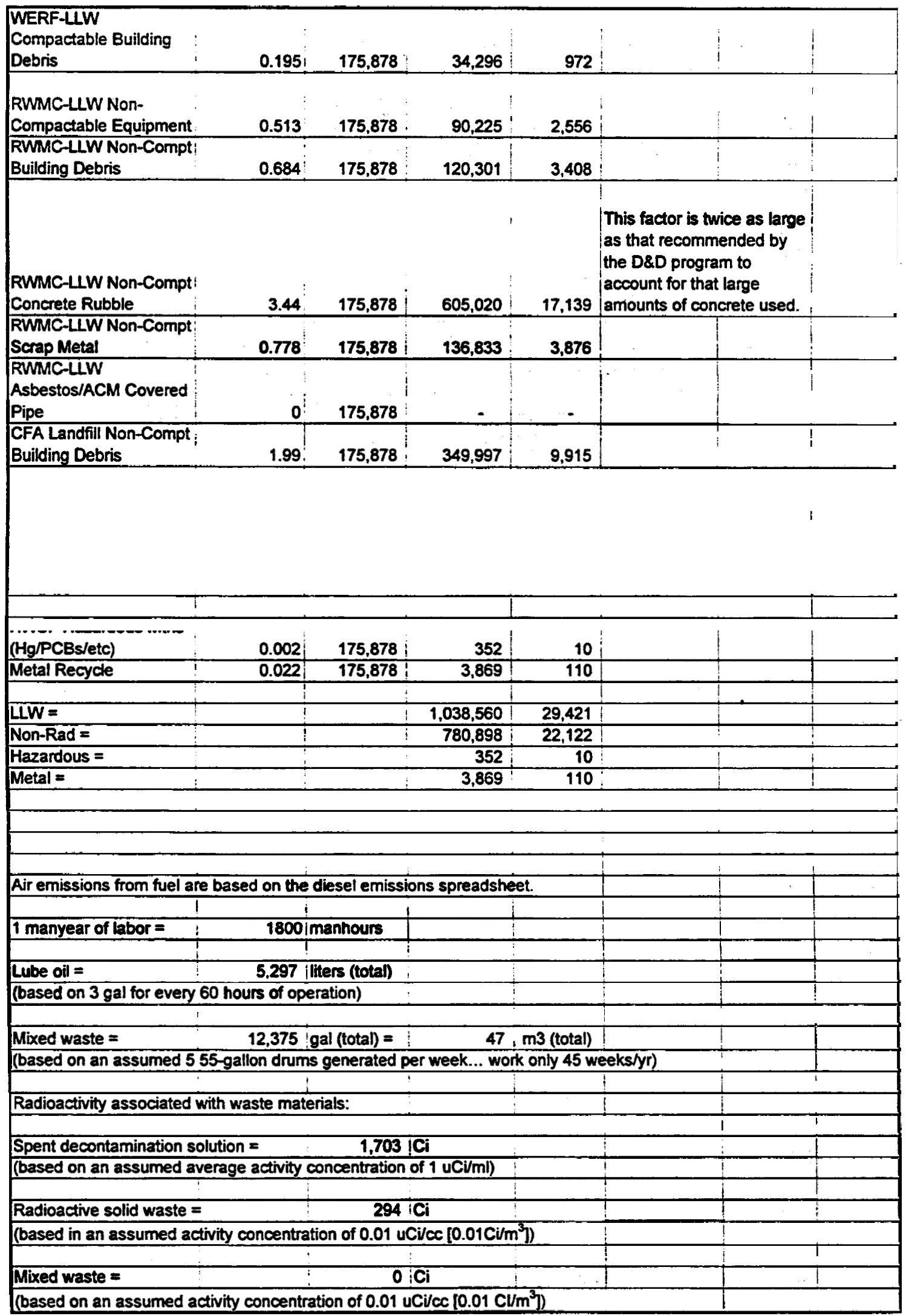




\begin{tabular}{|c|c|c|c|c|c|}
\hline & Project Data Sheet for $C$ & cine Feed - TF & RU-Sep & & \\
\hline Decontaminati & on \& Decommissioning (D\&D) Information & 8 & & & \\
\hline Cost(\$):D\&D (1) & Unescalated dollars) & & & & \\
\hline Decommission & & $\$ 2,555,000$ & & & \\
\hline Decontaminatio & & $\$ 7,223,000$ & & & \\
\hline Demolition & & $\$ 11,557,000$ & $\cdot$ & & \\
\hline Total D\&D & & $\$ 21,335,000$ & & & \\
\hline Schedule start/t & end: D\&D & January 2033 throt & ugh Decemb & er 2037 & \\
\hline Number of work & ers each year of D\&D (new/existing) & 155 & New worker & & \\
\hline Number of radia & tion workers (D\&D) & 104 & New worker & ss/yr & \\
\hline Average annual & worker radiation dose (rem/yr) & 0.19 & $\mathrm{rem} / \mathrm{yr}$ & per worker & \\
\hline Heavy equiome & & & & & \\
\hline Equipment used & & Mobile Cranes, Ro & & Dozers Loade & \\
\hline Trips & Roll-off trucks & 15 & per day & & \\
\hline Hours of operati & ion (all heavy equipment) & 27,990 & Hours & & \\
\hline & & & & & \\
\hline Acres disturbed & and duration of disturbance & January 2033 throl & ugh Decembe & er 2037 & \\
\hline New & & None & & & \\
\hline Previous & & 2.7 & acres & & \\
\hline Revegetated & & None & & & \\
\hline & & & & & \\
\hline Air emissions & & & & & \\
\hline non-radioactive & Fuel combustion gases $\left(\mathrm{CO}_{2}, \mathrm{H}_{2} \mathrm{O}, \mathrm{O}_{2}, \mathrm{~N}_{2}\right)$ & 16,269 & tons (total) & & \\
\hline non-radioactive & $\begin{array}{l}\begin{array}{l}\text { Fuel combustion contaminants (CO, } \\
\text { particulates, } \mathrm{NO}_{2}, \mathrm{SO}_{2}, \text { hydrocarbons) }\end{array} \\
\end{array}$ & 95 & tons (total) & & \\
\hline radioactive & HEPA filtered off-gas & 26,173 & tons (total) & & \\
\hline & & & & & \\
\hline Effluents & & & & & \\
\hline radioactive & Spent decontamination solution & $1,703,250$ & liters (total) & 1,703 & $\mathrm{Ci}$ \\
\hline non-radioactive & Sanitary wastewater & $3,301,896$ & liters (total) & & \\
\hline non-radioactive & Lube oil & 5,297 & liters (total) & & \\
\hline Solid wastes: & & & & & \\
\hline radioactive & & 29,421 & $\mathrm{~m}^{3}$ & 294 & $\mathrm{Ci}$ \\
\hline Non-radioactive & (industrial) & 22,122 & $\mathrm{~m}^{3}$ & & \\
\hline Hazardous & & 10 & $\mathrm{~m}^{3}$ & & \\
\hline & & & & & \\
\hline Hazardous/toxic & chemicals and wastes (type) & & & & \\
\hline Storage/inventor & & 205 & $\mathrm{~m}^{3}$ (total) & & \\
\hline Pits/Ponds creat & $\operatorname{ted}\left(m^{2}\right)$ & None & & & \\
\hline radioactive & (mixed waste) & 47 & $\mathrm{~m}^{3}$ (total) & 0 & $\mathrm{Ci}$ \\
\hline Water usage: & & & & & \\
\hline Process water & & $2,284,875$ & liters (total) & & \\
\hline Domestic water & & $3,301,896$ & liters (total) & & \\
\hline Source of water & & ICPP site wells & & & \\
\hline & & & & & \\
\hline Energy requiren & nents: & & & & \\
\hline
\end{tabular}


D\&D Labor

\begin{tabular}{|c|c|c|c|c|c|c|c|c|c|c|c|}
\hline \multicolumn{12}{|c|}{ J\&D Labor } \\
\hline Crew \# & Crew Function & Total MH/day & Total \$/day & $\begin{array}{l}\text { Material } \\
\$ / \text { day }\end{array}$ & $\begin{array}{l}\text { Equipment } \\
\text { \$/day }\end{array}$ & \multicolumn{2}{|l|}{ Total \$/day } & $\begin{array}{c}\text { D\&D Cost } \\
\text { Allocated (FY 9; } \\
\text { dollars) }\end{array}$ & & Total MH & Man-hours/vi \\
\hline $\bar{D}$ & Documentation & 18 & $\$ 1,136$ & $\$ 114$ & $\$$ & $\$ 1,250$ & & $\$ 750,000$ & & 10,800 & Man-hours/yı \\
\hline 1 & C̄haracterization & 44 & $\$ 2,302$ & $\overline{\$ 460}$ & $\$ 691$ & $\$ 3,45 \overline{3}$ & & $1, \overline{755,000}$ & & 22,363 & 22.363 \\
\hline 2 & Rad Demolition-Systems & 77 & $\$ 4,091$ & $\$ 818$ & $\$ 1,023$ & $\$ 5,932$ & & $6,000,000$ & & $77,8 \overline{83}$ & 77,883 \\
\hline $2 A$ & Rad Demolition-Building & $\overline{9} \overline{9}$ & $\$ 5,319$ & $\$ 1,064$ & $\$ 1,596$ & $\$ 7,979$ & & $1,0 \overline{00}, 000$ & & $\overline{12,408}$ & $-\overline{12,40 \overline{8}}$ \\
\hline 3 & Demolition-Systems & 72 & $\overline{\$ 3.762}$ & $\$ 752$ & $\$ 941$ & $\$ 5,455$ & & $2,100,000$ & & 27,718 & 27,718 \\
\hline $3 A$ & Demolition-Building & & $\$ 4,808$ & $\$ 962$ & $\$ 1,442$ & $\$ 7,212$ & & $\$ 1,442,760$ & & $17, \overline{604}$ & $\overline{17,604}$ \\
\hline 4 & Asbestos Abatement & 77 & $\$ 3,753$ & $\$ 375$ & $\$ 188$ & $\$ 4,316$ & & $\$$ & & - & - \\
\hline 5 & Decontamination & & $\$ 3,753$ & $\$ 751$ & $\$ 1,126$ & $\$ 5,630$ & & $\overline{5,000,000}$ & & $6 \overline{8,384}$ & $-68,384$ \\
\hline$\overline{6}$ & Prep/Fabrication & 61 & $\$ 3,21 \overline{7}$ & $\overline{\$} 643$ & $\$ 965$ & $\$ 4,826$ & & $\overline{1,057,240}$ & & $13, \overline{363}$ & $1 \overline{3,363}$ \\
\hline 7 & RADCON Surveys & 50 & $\$ \overline{2}, \overline{596}$ & $\$ \overline{519}$ & $\$ 779$ & $\$ 3,894$ & & $2,230,000$ & & 28,634 & 28,634 \\
\hline Total & & & & & & & - & $21,335,000$ & & 279,156 & 279,156 \\
\hline & $\ldots \ldots \ldots$ & - & & & & & & & & & $\ldots$ \\
\hline vailable & $\ldots$ & -. & & & & & & $\$ 21,335,000$ & & & $\ldots$ \\
\hline otes: - - l & & & & & & & & $\ldots$ & & & $\cdots-\ldots$ \\
\hline & Crew functions and daily $e$ & timates are from & the D\&D pros & ram (Dave H & aycraft) & & & & & $\cdots$ & \\
\hline 2 & Total costs are based on 1 & e cycle estimate & by R. Turk & & & & & & & & \\
\hline & Assume all workers in crev & is $2,2 \bar{A}, 5$, and 7 & are rad work & & & & & & & & \\
\hline 4 & Assume a man-year is 180 & o hours. & & & & & & & & & \\
\hline
\end{tabular}




\begin{tabular}{|c|c|c|c|c|c|c|}
\hline $\begin{array}{l}\text { WERF-LLW } \\
\text { Compactable Building } \\
\text { Debris }\end{array}$ & 0.195 & 175,878 & 34,296 & 972 & 198 & \\
\hline $\begin{array}{l}\text { RWMC-LLW Non- } \\
\text { Compactable Equipment: }\end{array}$ & 0.513 & $\begin{array}{r}175,878 \\
178\end{array}$ & 90,225 & 2,556 & $a_{1}^{2}$ & 1 \\
\hline $\begin{array}{l}\text { RWMC-LLW Non-Compt: } \\
\text { Building Debris }\end{array}$ & 0.684 & 175,878 & 120,301 & 3,408 & 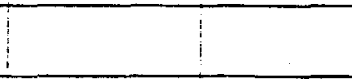 & \\
\hline $\begin{array}{l}\text { RWMC-LLW Non-Compt } \\
\text { Concrete Rubble }\end{array}$ & 3.44 & 175,878 & 605,020 & 17,139 & $\begin{array}{l}\text { This factor is twice as large } \\
\text { as that recommended by } \\
\text { the D\&D program to } \\
\text { laccount for that large } \\
\text { lamounts of concrete used. }\end{array}$ & $\sqrt{20}$ \\
\hline $\begin{array}{l}\text { RWMC-LLW Non-Compt! } \\
\text { Scrap Metal }\end{array}$ & 0.778 & 175,878 & 136,833 & 3,876 & & \\
\hline $\begin{array}{l}\text { RWMC-LLW } \\
\text { Asbestos/ACM Covered } \\
\text { Pipe }\end{array}$ & 0 & 175,878 & 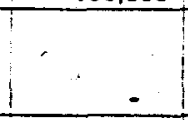 & - & 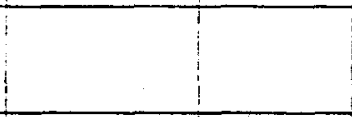 & \\
\hline $\begin{array}{l}\text { CFA Landfill Non-Compt } \\
\text { Building Debris }\end{array}$ & 1.99 & 175,878 & 349,997 & 9,915 & & \\
\hline $\begin{array}{l}\text { CFA Landfill Non-Compt } \\
\text { Concrete Rubble }\end{array}$ & 2.45 & 175,878 & 430,901 & 12,207 & $\begin{array}{l}\text { This factor is twice as large } \\
\text { as that recommended by } \\
\text { the D\&D program to } \\
\text { account for that large } \\
\text { amounts of concrete used. }\end{array}$ & \\
\hline CFA Landfill Asbestos & 0 & 175,878 & - & - & & \\
\hline $\begin{array}{l}\text { HWSF Hazardous Mitrls } \\
\text { (Hg/PCBs/etc) }\end{array}$ & 0.002 & 175,878 & 352 & 10 & & 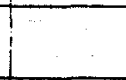 \\
\hline Metal Recycle & 0.022 & 175,878 & 3,869 & 110 & & \\
\hline & & & & & & \\
\hline LLW $=$ & & & $1,038,560$ & 29,421 & & \\
\hline Non-Rad $=$ & & & 780,898 & 22,122 & & \\
\hline Hazardous $=$ & & & 352 & 10 & & \\
\hline Metal $=$ & & & 3,869 & 110 & & $!$ \\
\hline & & & & & i & 1 \\
\hline Electric power usage $=$ & 156,000 & kWh/yr & 156 & MWh/yr & & \\
\hline (based on $3,000 \mathrm{kWh} / \mathrm{wk}$ - & hn Duggan & & & & & \\
\hline & & $i$ & i & $\ldots$ & & \\
\hline Air emissions from fuel are & sed on the & diesel emissi & ions spreadshe & & & \\
\hline : & & & 7 & & & \\
\hline 1 manyear of labor $=$ & 1800 & manhours & & & & \\
\hline & & & $\ldots$ & & & \\
\hline Lube oil = & 5,297 & titers (total) & & & & \\
\hline (based on 3 gal for every 6 & Mours of op & eration) & & & & \\
\hline & & & 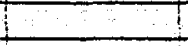 & & & 1 \\
\hline Mixed waste $=$ & 12,375 & gal (total) $=$ & 47 & $\mathrm{~m} 3$ (total) & & $i$ \\
\hline (based on an assumed 5 & jallon drum & is generated p & Der week... wor & k only 45 we & eeks/yr) & 1 \\
\hline & $=$ & & & & & $i$ \\
\hline Radioactivity associated w & waste mat & terials: & & & 1 & \\
\hline$\cdots$ & & & 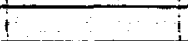 & & 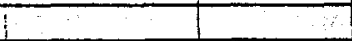 & \\
\hline Spent decontamination so & $o n=$ & 1,703 & $\mathbf{C i}$ & & 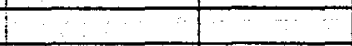 & \\
\hline (based on an assumed av & ge activity & concentration & of $1 \mathrm{uCi} / \mathrm{ml})$ & & & \\
\hline 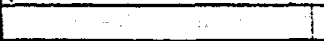 & & & & & $i$ & \\
\hline Radioactive solid waste $=$ & & 294 & $\mathbf{C i}$ & & & \\
\hline (based in an assumed act & concentra & ation of $0.01 \mathrm{uC}$ & $\mathrm{Ci} / \mathrm{cc}[0.01 \mathrm{Ci} / \mathrm{m}$ & & & \\
\hline & & 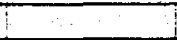 & & & $i$ & \\
\hline Mixed waste $=$ & & 0 & $\mathrm{Ci}$ & & & \\
\hline (based on an assumed ac & concentr & ration of $0.01 \mathrm{u}$ & uCice $10.01 \mathrm{Cl} / \mathrm{r}$ & & & \\
\hline
\end{tabular}


Cost (\$): D\&D (Undiscounted dollars)

Decontamination

Demolition

Total D\&D

Schedule startend: D\&D

Number of workers each year of D\&D (new/existing)

Number of radiation workers (D\&D)

Heavy equipment:

Equipment used

\begin{tabular}{l|l}
\hline Trips & Roll-off trucks \\
\hline
\end{tabular}

Hours of operation (all heaw equioment)

Acres disturbed and duration of disturbance

New

Previous

Revegetated

Air emissions

non-radioactive Fuel combustion gases $\left(\mathrm{CO}_{2}, \mathrm{H}_{2} \mathrm{O}, \mathrm{O}_{2}, \mathrm{~N}_{2}\right)$

Fuel combustion contaminants (CO,

non-radioactive particulates, $\mathrm{NO}_{x}, \mathrm{SO}_{2}$, hydrocarbons)

radioactive iHEPA filtered off-gas

Effluents

radioactive Spent decontamination solution

non-radioactive ISanitary wastewater

non-radioactive | Lube oil

Solid wastes:

radioactive

Non-radioactive (industrial)

Hazardous

Hazardous/toxic chemicals and wastes (type)

Storage/inventory

Pits/Ponds created $\left(\mathrm{m}^{2}\right)$

radioactive (mixed waste)

Water usage:

Process water

Domestic water.

Source of water

Energy requirements:
I

$\$ 7,415,000$

$\$ 11,864,000$

$\$ 21,960,000$

January 2033 through December 2037

160 New workers/yr

102 New workers/vr

IMobile Cranes. Roll-off trucks. Dozers. Loaders

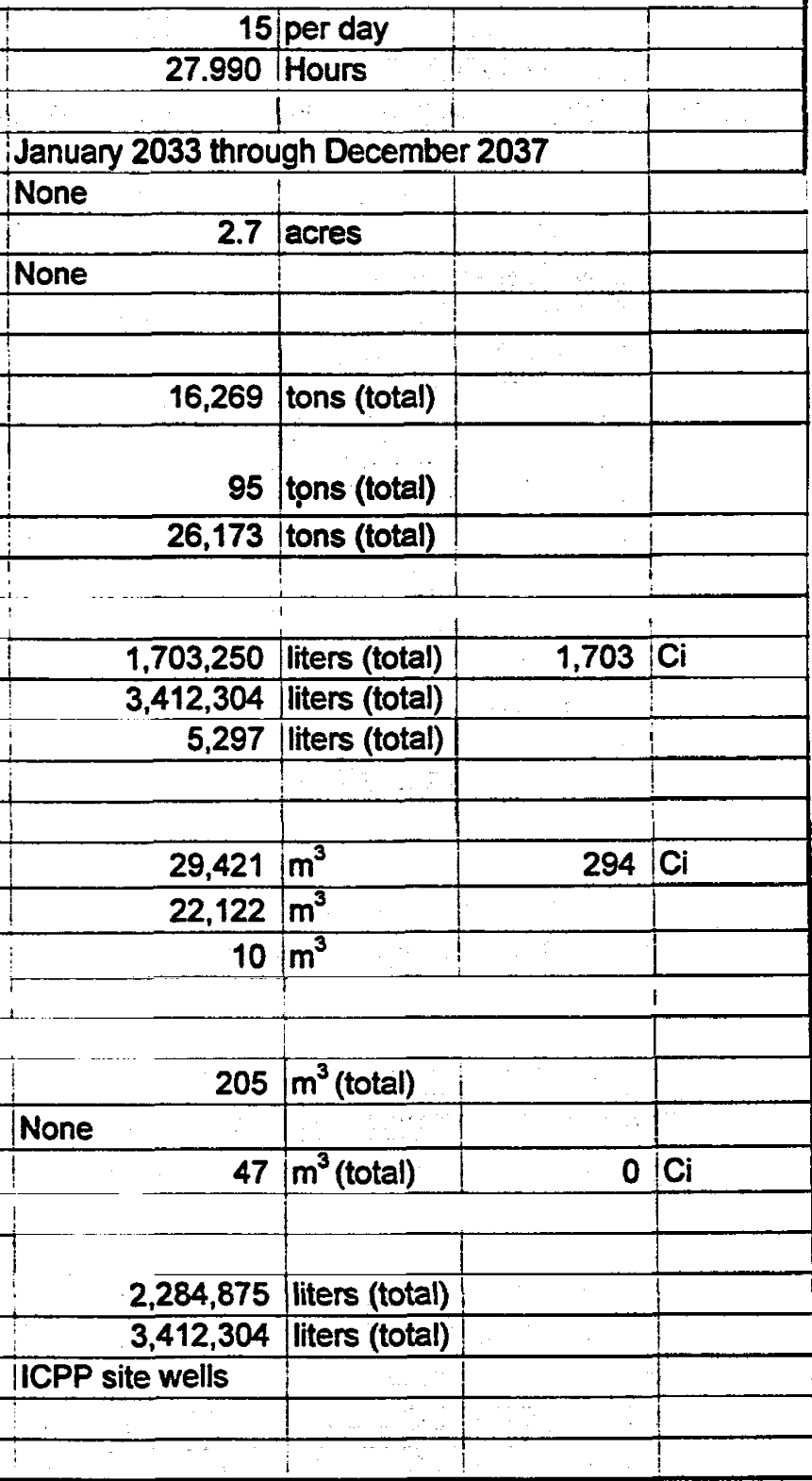


D\&D Labor

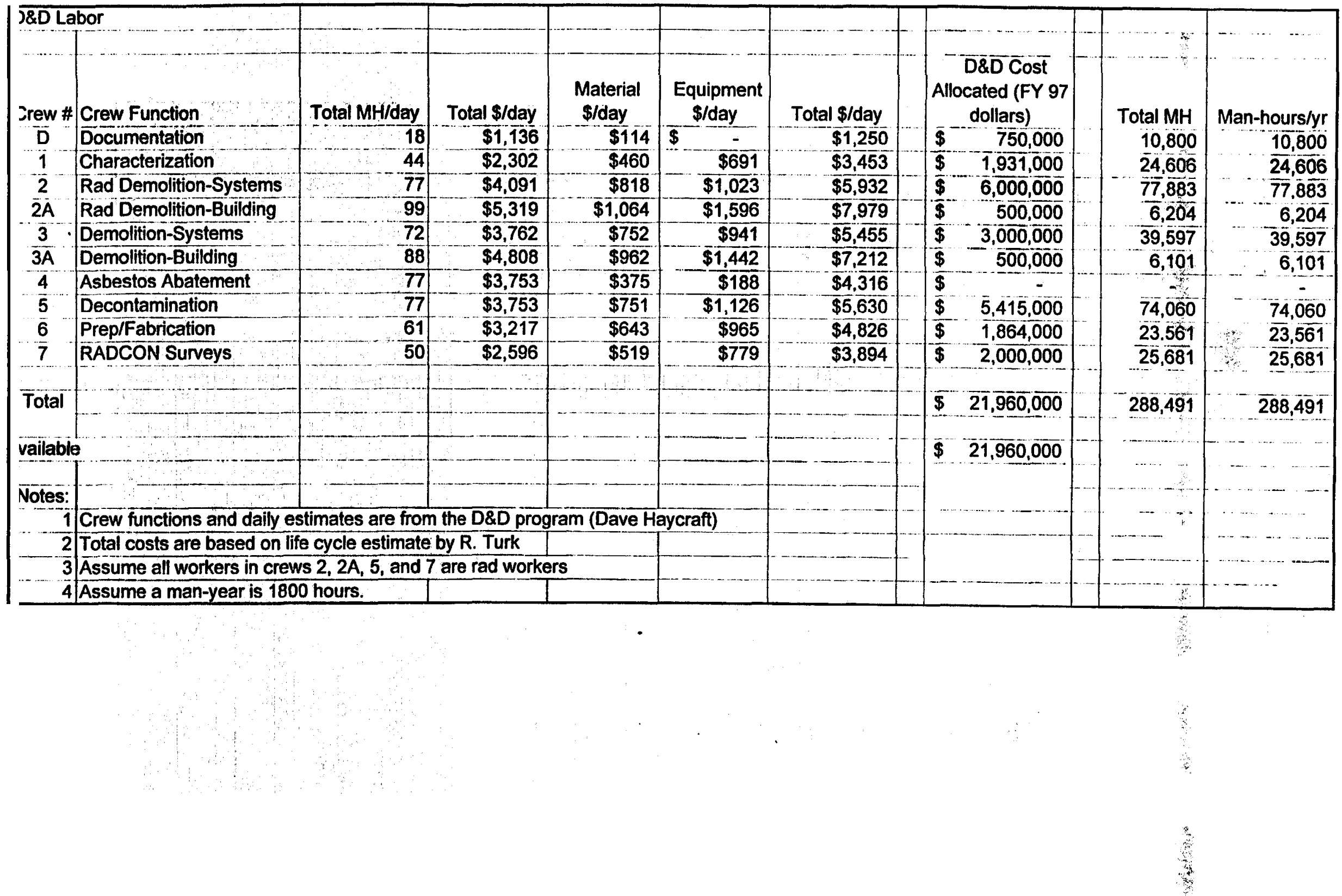


D D Assumptions

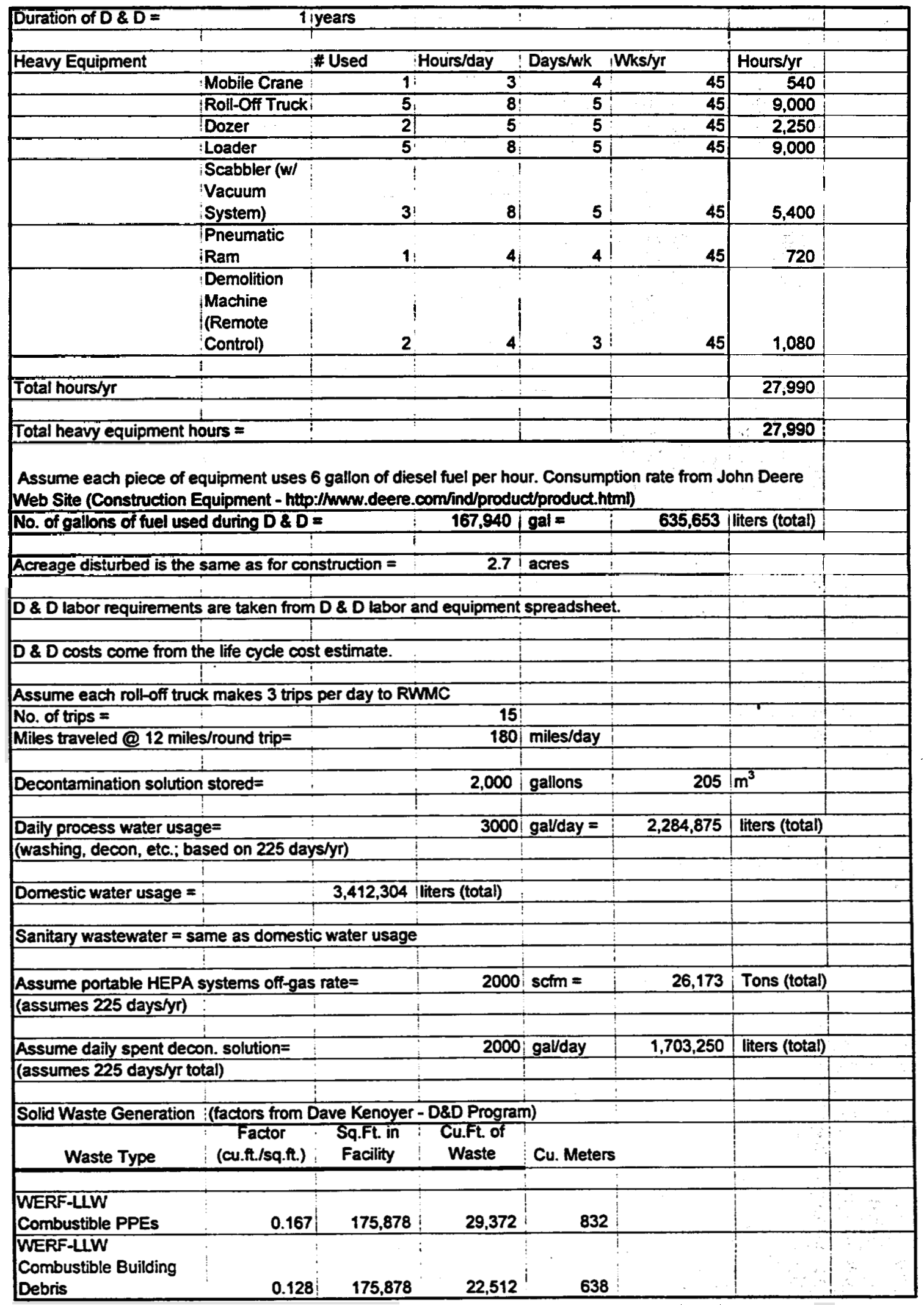




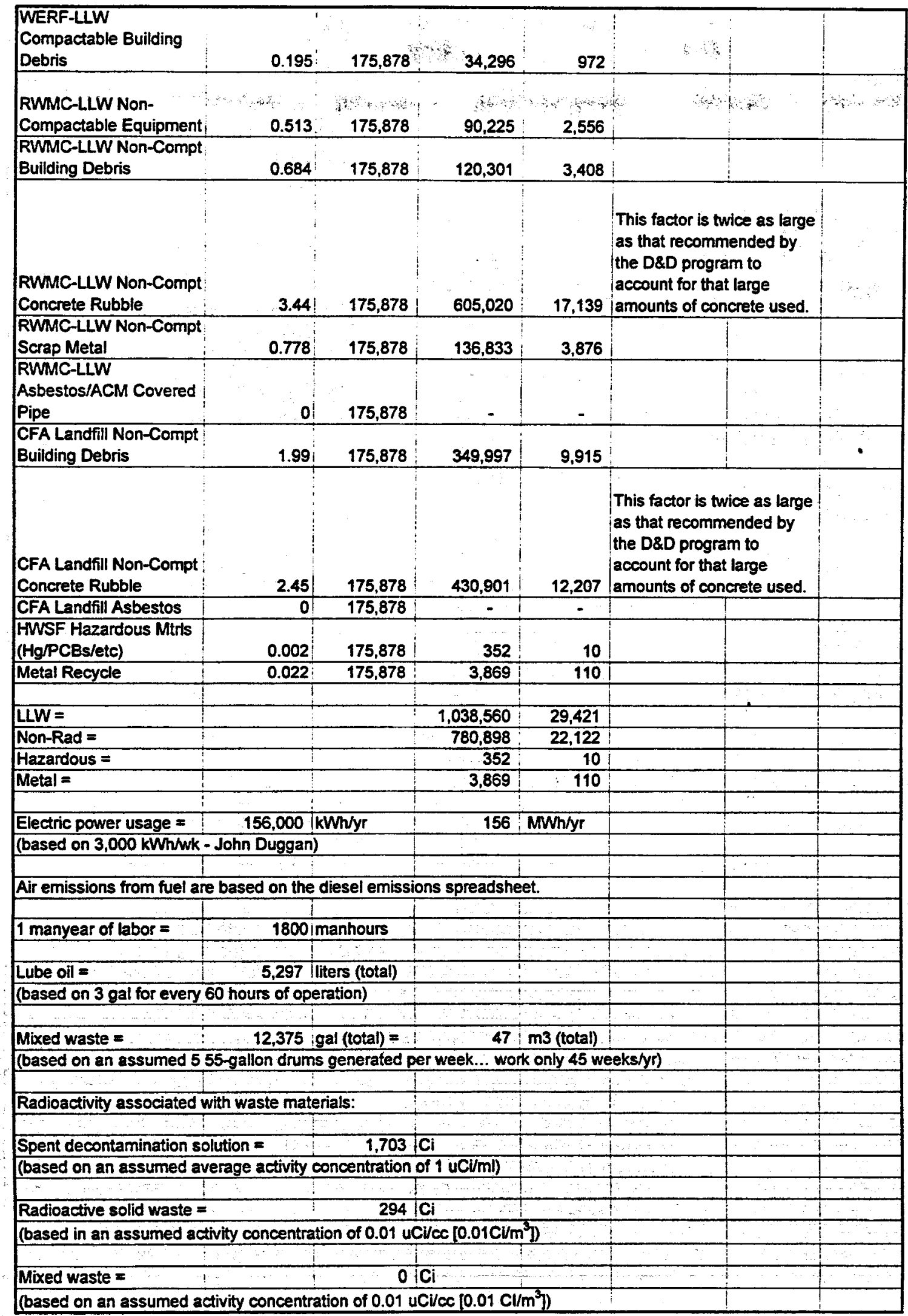


Back up to 4

\section{Estimate of Diesel Engine Emissions Calcine Retrieval for CWO}

Bases \& Assumptions:

1. Air to fuel ratio $=25: 1$ (Mass Basis)

from Wark, K. and C.F.

Warner, Air Pollution, its

Origin and Control, IEP,

New York, 1976, p. 446,

2. Diesel fuel density $=7.5 \mathrm{lbs} . / \mathrm{gal}$.

3. Air is $21 \%$ O2, 79\% N2, with a pseudomolecular weight of 29 .

4. Combustion is simulated as: $\mathrm{C9H} 18+13.5 \mathrm{O} 2 \longrightarrow 9 \mathrm{CO} 2+9 \mathrm{H} 2 \mathrm{O}$

5. Particulates $=5 \mathrm{mg} / \mathrm{scf}$

6. $\mathrm{CO}=2,500 \mathrm{ppmv}$

7. $\mathrm{NOx}=2,000 \mathrm{ppmv}$

8. Unbumed hydrocarbons $=100$ ppmv

9. Diesel fuel (\# 2 fuel oil) contains 1 wt. \% sulfur

423

10. Combustion is about $99 \%$ efficient.

Lbs. Of Construction Fuel

Lbs. Of Operations Fuel

Lbs. Of D\&D Fuel

Total Lbs. of Fuel Used !

Lb-Moles of Construction Fuel

Lb-Moles of Operations Fuel

Lb-Moles of D\&D Fuel

Total Lb-Moles of Fuel (as C9H18)

Lbs of Air for Construction Fuel (based on air-to-fuel ratio)

Lbs.of Air for Operations Fuel (based on air-to-fuel ratio)

Lbs.of Air for D\&D Fuel (based on air-to-fuel ratio)

Total Lbs. of Air Added

Lb-Moles of Air for Combustion Fue

Lb-Moles of Air for Operations Fuel

Lb-Moles of Air for D\&D Fuel

Total Lb-Moles of Air

Grand Total of Materials Fed, Lbs.

Exhaust Gases, Construction Fuel | Total Lbs.

$\mathrm{CO} 2$

$\mathrm{H} 2 \mathrm{O}$

$\mathrm{O} 2$

N2

Subtotal of Major Gases

$\mathrm{SO} 2$

Particulates

CO

NOx (assumed NO)

Unbumed Hydrocarbons

:

Wark and Warner, p. 446

Wark and Wamer, p. 446

Wark and Wamer, p. 446

Wark and Warner, p. 446

Wark and Warner, p. 336

10




\begin{tabular}{|c|c|c|c|c|}
\hline Subtotal of Contaminants & - & - & & \\
\hline & & & $\therefore$ & \\
\hline 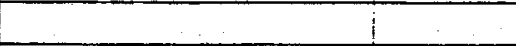 & 2 & & & \\
\hline Exhaust Gases, Operations Fuel & $a y$ Total Lbs & Total Tons & STotal Moles $\mathrm{s}$ & Total SCF \\
\hline $\mathrm{CO} 2$ & - & - & -1 & - \\
\hline $\mathrm{H} 2 \mathrm{O}$ & - & - & - & - \\
\hline$\overline{O 2}$ & - & - & - & - \\
\hline N2 & $=$ & - & - & - \\
\hline Subtotal of Major Gases & - & - & - & - \\
\hline $\mathrm{SO} 2$ & - & - & & \\
\hline Particulates & - & - & 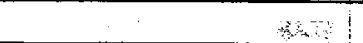 & \\
\hline Co & - & - & T & \\
\hline NOx (assumed NO) & - & - & & \\
\hline Unbumed Hydrocarbons & - & - & $T$ & \\
\hline Subtotal of Contaminants & - & - & & \\
\hline & & & & \\
\hline & & & & \\
\hline Exhaust Gases, D\&D Fuel & Total Lbs. & Total Tons & Total Moles & Total SCF \\
\hline $\mathrm{CO2}$ & 698,492 & 349 & 15,875 & $5,699,060$ \\
\hline $\mathrm{H} 2 \mathrm{O}$ & 285,747 & 143 & 15,875 & $5,699,060$ \\
\hline$\overline{\mathrm{O} 2}$ & 538,516 & 269 & 16,829 & $6,041,480$ \\
\hline N2 & $4,280,837.83$ & 2,140 & 152,887 & $54,886,457$ \\
\hline Subtotal of Major Gases & $5,803,593$ & 2,902 & 201,465 & $72,326,057$ \\
\hline SO2 & 4,350 & 2.2 & & \\
\hline Particulates & 797 & 0.4 & & \\
\hline$\overline{C O}$ & 14,103 & 7.1 & & \\
\hline NOx (assumed NO) & 12,088 & 6.0 & . & \\
\hline Unbumed Hydrocarbons ! & 2,538 & 1.3 & & \\
\hline Subtotal of Contaminants & 33,875 & 17 & & \\
\hline
\end{tabular}


Back up tou

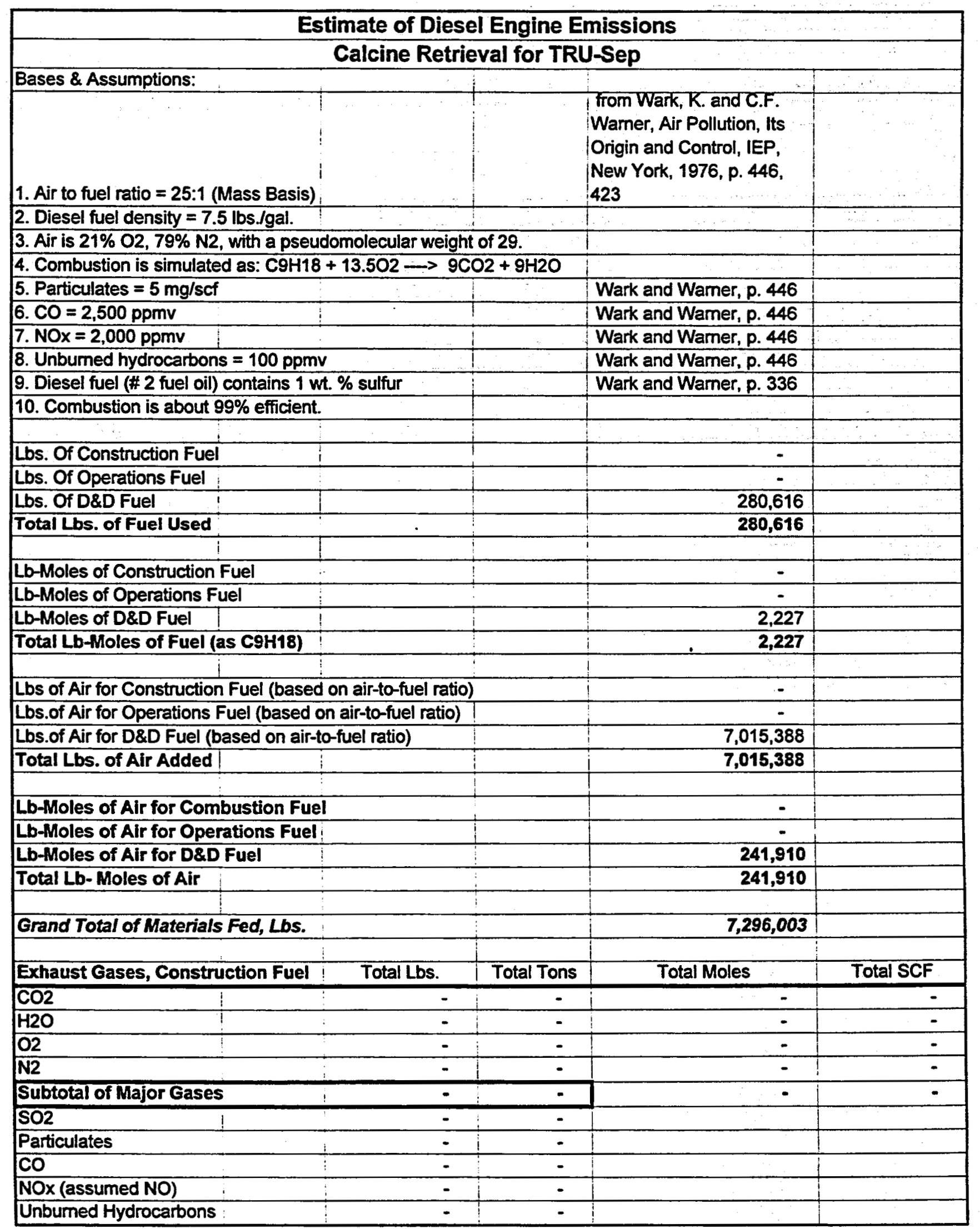




\begin{tabular}{|c|c|c|c|c|c|}
\hline Subtotal of Contaminants & & - & - & 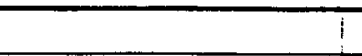 & \\
\hline$t$ & $T$ & $\therefore$ & - & & \\
\hline & & & & 1 & \\
\hline Exhaust Gases, Operations Fuel & $\bar{i} ; x_{i}$ & Total Los & Total Tons & Total Moles & Total SCF \\
\hline $\mathrm{CO} 2$ & $i$ & - & - & - & - \\
\hline $\mathrm{H} 2 \mathrm{O}$ & 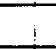 & - & - & - & - \\
\hline 02 & 1 & - & - & - & - \\
\hline N2 & 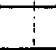 & $=$ & - & - & - \\
\hline Subtotal of Major Gases & - & - & - & - & - \\
\hline $\mathrm{SO} 2$ & $T$ & - & - & & \\
\hline Particulates & 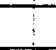 & - & - & $\ldots$ & \\
\hline $\mathrm{CO}$ & $i$ & - & - & 4 & \\
\hline NOx (assumed NO) & $!$ & - & - & & \\
\hline Unburned Hydrocarbons & 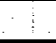 & - & - & & \\
\hline Subtotal of Contaminants & $!$ & - & - & & \\
\hline 1 & 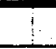 & & & & \\
\hline$i$ & 1 & & & : & \\
\hline Exhaust Gases, D\&D Fuel & & Total Lbs. & Total Tons & Total Moles & Total SCF \\
\hline $\mathrm{CO} 2$ & & 873,115 & 437 & 19,844 & $7,123,825$ \\
\hline $\mathrm{H} 2 \mathrm{O}$ & $\vdots$ & 357,183 & 179 & 19,844 & $7,123,825$ \\
\hline 02 & 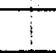 & 673,145 & 337 & 21,036 & $7,551,850$ \\
\hline N2 & $!$ & $5,351,047.29$ & 2,676 & 191,109 & $68,608,071$ \\
\hline Subtotal of Major Gases & & $7,254,491$ & 3,627 & 251,832 & $90,407,572$ \\
\hline SO2 & $T$ & 5,437 & 2.7 & & \\
\hline Particulates & 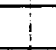 & 996 & 0.5 & & \\
\hline $\mathrm{CO}$ & 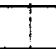 & 17,628 & 8.8 & & \\
\hline NOx (assumed NO) & & 15,110 & 7.6 & & \\
\hline Unbumed Hydrocarbons & 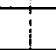 & 3,173 & 1.6 & & \\
\hline Subtotal of Contaminants & & $42,344 i$ & $\overline{21}$ & & \\
\hline
\end{tabular}




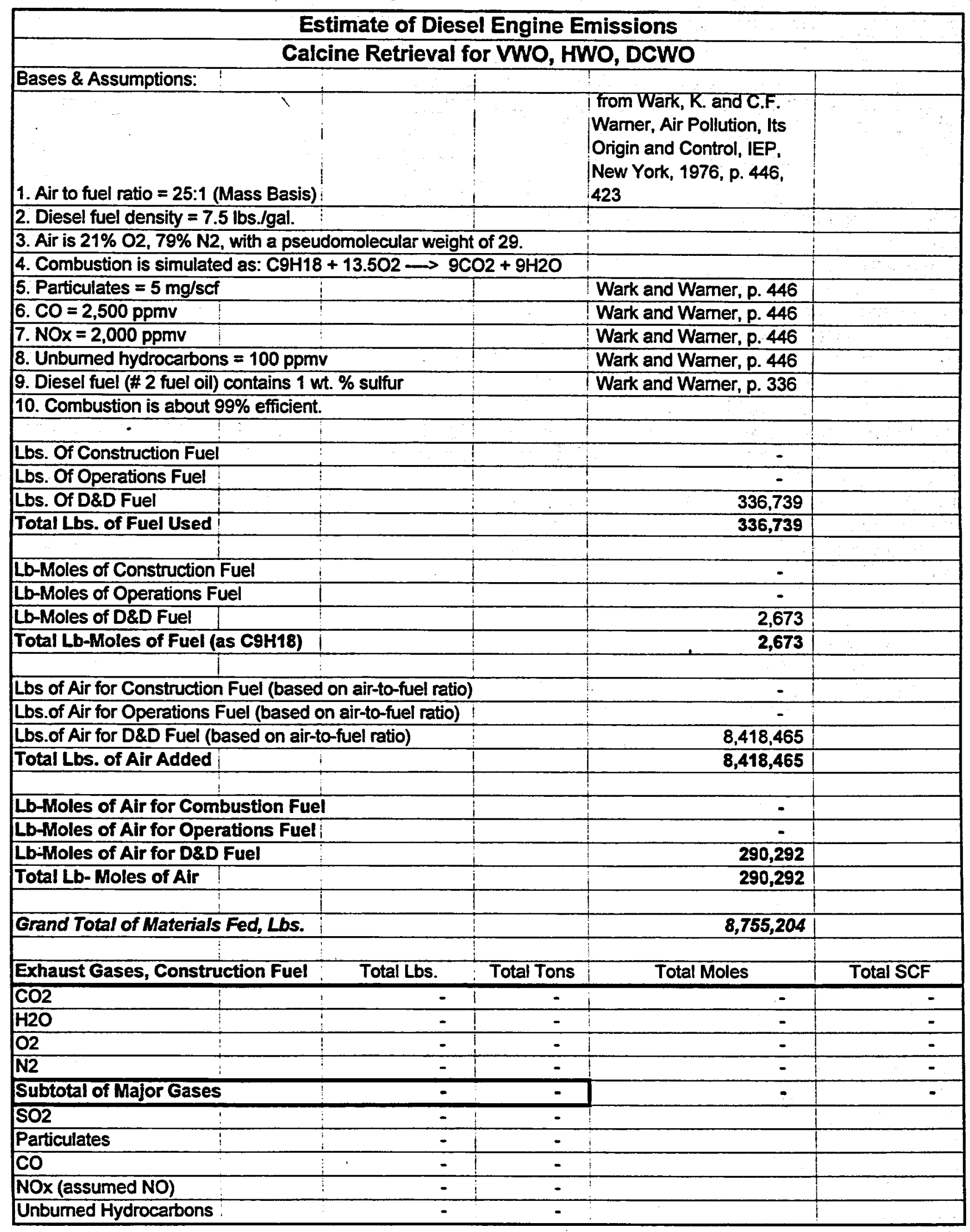




\begin{tabular}{|c|c|c|c|c|c|}
\hline Subtotal of Contaminants & 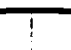 & - & - & 1 & \\
\hline 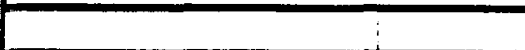 & $\bar{\vdots}$ & & & - & \\
\hline & 7 & & & & \\
\hline Exhaust Gases, Operations Fuel & by & Total Lbs. & Total Tons & STotal Moles & Total SCF : \\
\hline $\mathrm{CO} 2$ & $i$ & - & - & - & - \\
\hline $\mathrm{H} 12 \mathrm{O}$ & 4 & - & - & - & - \\
\hline 02 & $!$ & - & - & - & - \\
\hline $\bar{N} 2$ & 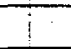 & - & - & - & - \\
\hline Subtotal of Major Gases & 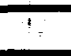 & - & - & 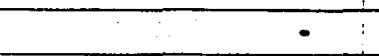 & - \\
\hline SO2 & 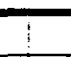 & 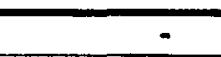 & - & 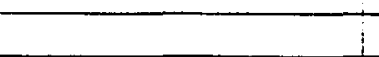 & \\
\hline Particulates & 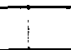 & - & - & 1. & \\
\hline $\mathrm{CO}$ & 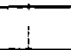 & - & - & $!$ & \\
\hline NOx (assumed NO) & + & $\cdots$ & - & & \\
\hline Unbumed Hydrocarbons & T & - & - & 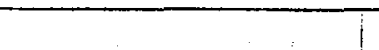 & \\
\hline Subtotal of Contaminants & & - & - & & \\
\hline & & & & & \\
\hline & & & 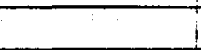 & & \\
\hline Exhaust Gases, D\&D Fuel & & Total Lbs. & Total Tons & Total Moles & Total SCF \\
\hline $\mathrm{CO} 2$ & & $1,047,738$ & 524 & 23,812 & $8,548,590$ \\
\hline $\mathrm{H} 2 \mathrm{O}$ & & 428,620 & 214 & 23,812 & $8,548,590$ \\
\hline $\mathrm{O} 2$ & & 807,775 & 404 & 25,243 & $9,062,220$ \\
\hline N2 & & $6,421,256.75$ & 3,211 & 229,331 & $82,329,685$ \\
\hline Subtotal of Major Gases & & $8,705,390$ & 4,353 & 302,198 & $108,489,086$ \\
\hline SO2 & & 6,524 & 3.3 & 1 & \\
\hline Particulates & & 1,195 & 0.6 & & \\
\hline CO & & 21,154 & 10.6 & & \\
\hline NOx (assumed NO) & & 18,132 & 9.1 & . & \\
\hline Unburned Hydrocarbons & & 3,808 & 1.9 & & \\
\hline Subtotal of Contaminants & & 50,813 & 25 & & \\
\hline
\end{tabular}




\section{Appendix E}

\section{Risk Assessment Data Sheets}

This appendix contains a Risk Assessment Form for each significant risk identified in the calcine retrieval and transportation system. The risks have been assigned to one of three categories:

Project, Technical, and ES\&H (Environmental, Health, and Safety).

Project Risk (cost or schedule):

P.1 Integrity of CSSF maintained

P.2 Location of retrieval risers

P.3 Estimated retrieval percentage too high

P.4 Internal obstructions prevent retrieval

P.5 Waste Treatment Facility too slow

P.6 Miscellaneous materials prevent retrieval

$$
\begin{aligned}
& \text { Risk }=3 \\
& \text { Risk }=3 \\
& \text { Risk }=2 \\
& \text { Risk }=2 \\
& \text { Risk }=2 \\
& \text { Risk }=4
\end{aligned}
$$

Technical Risk:

T.1 Objective retrieval rate too high

Risk $=3$

T.2 All calcines are not retrievable

Risk $=4$

ES\&H Risk (environment, safety, or health):

ESH.1 Construction radiation dose rates incorrect Risk $=4$

As risks were evaluated, the probability of occurrence and the impact if the risk is realized were rated. The probability and impact were assigned numerical values of " 3 " for high, " 2 " for medium, and " 1 " for low. The equation for risk calculation is Risk = Probability X Impact. The maximum risk rating is "9." 
The risk matrix, Table E-1, shows what action to take as a function of risk rating. These actions are defined in table E-2.

\author{
Table E-1. Risk Matrix \\ Risk $=$ Probability X Impact
}

Probability

Impact

Low (1) Medium (2)

High (3)

High (3)

Medium (2)

Low (1)

\begin{tabular}{|c|c|c|}
\hline Evaluate (3) & Contingency Plan (6) & Eliminate Risk (9) \\
\hline Monitor (2) & Contingency Plan (6) & Contingency Plan (6) \\
\hline Forget (1) & Monitor (2) & Evaluate (3) \\
\hline
\end{tabular}

\title{
Table E-2. Risk Action Definition
}

\begin{tabular}{|c|l|}
\hline Risk Rating & \multicolumn{1}{c|}{ Action } \\
\hline 9 & $\begin{array}{l}\text { Any risk determined to be in this category will be mitigated through } \\
\text { additional design or analysis until the risk is not longer in this category. }\end{array}$ \\
\hline 6 and 4 & $\begin{array}{l}\text { Risks in these categories will be mitigated to the extent feasible within } \\
\text { the cost and schedule guidelines. For those risks that cannot be } \\
\text { mitigated, contingency plans have been made to deal with the risk if it } \\
\text { occurs. }\end{array}$ \\
\hline 3 & $\begin{array}{l}\text { Risks in this category will be evaluated during the project to identify if } \\
\text { they are becoming problems. }\end{array}$ \\
\hline 2 & These risks will be monitored with no specific action identified. \\
\hline 1 & These risks are noted for interest only. \\
\hline
\end{tabular}


Risk Assessment - Data Sheet

Risk Trpe O Project O Technical OESH

\section{RISK: Integrity of CSSFs maintained}

Significant construction activities will occur on the roof of each CSSF. For nearly all CSSFs, $8^{\prime \prime}$ holes must be drilled through the concrete roof. There is a possibility that the structural integrity of the CSSFs will be reduced.

\section{PREVENTIVE PLANS}

As part of locating the retrieval risers, a structural analysis of th CSSF roofs will be conducted.

\section{PROBABLE CAUSE(S):}

Structural integrity of the CSSF roofs will b compromised during access activities.

\section{CONSEQUENCES IF RISK NOT RESOLVED}

The schedule and cost would be effected by this risk. The CSS roof would need to be shored up. This would slow down the . construction schedule and increase the cost.

\section{PROBABILITY}

High (3)

Medium (2)

(-) Low (1)

\section{IMPACT}

$\begin{array}{ll}\text { ○ } & \text { High (3) } \\ \bigcirc & \text { Medium (2) } \\ \bigcirc & \text { Low (1) }\end{array}$

\section{CONTINGENCY PLAN(S) IF RISK IS REALZED:}

The CSSF storage vault roof should be shored up.

\section{Risk $=3$}

Risk $=$ Probability $\times$ Impact

Probability Definition

High - Likely to occur during the project.

Medium - Has the potential to occur during the project.

Low - Has little potential to occur during the project.

Impact Definition

High - Likely to cause significant disuption of sheduke, increase in cost, or degradation of performance.

Medium - Has the potential to cause some disrutpion to schedule, increase in cost, or degradation of performance.

Low - Has little potential to cause disuption to schedule, increase in cost, or degradation of pertormance.

\section{TRIGGER POINT(S) FOR EARLY RISK} DENTIFICATION:

During feasibility studies, a structural analysis of the CSSF roofs should be conducted. 


\section{Risk Assessment - Data Sheet}

\section{Risk Type OProject OTechnical OESH}

\section{RISK: Location of retrieval risers}

Locations for installation of retrieval risers must be identified. Enough locations may not exist on each bin to install the necessary retrieval risers.

\section{PREVENTIVE PLANS}

This risk has been significantly minimized by decreasing the number of retrieval lines need for calcine retrieval.

\section{PROBABLE CAUSE(S):}

The requirements for installing retrieval risers are not currently known. However, pipes in the bin vault may prevent the installation of the retrieval risers. There may not be adequate space on the bins to install the retrieval risers.

\section{CONSEQUENCES IF RISK NOT RESOLVED}

Calcine retrieval using the proposed calcine retrieval and transportation system would be prevented if the retrieval risers could not be installed. This would significantly impact the schedule and costs.

\section{PROBABILITY}

\begin{tabular}{ll}
\hline & High (3) \\
$O$ & Medium (2) \\
C Low (1)
\end{tabular}

\section{Risk $=3$}

Risk $=$ Probability $\times$ Impact

\section{CONTINGENCY PLAN(S) IF RISK IS REALIZED:}

Develop a less restrictive method for installing the retrieval lines.

\section{Probability Definition}

High - Likely to occur during the project.

Medium - Has the potential to occur during the project.

Low - Has little potential to occur during the project.

Impact Definition

High - Likely to cause significant disruption of schedule, increase in cost, or degradation of performance.

Medium - Has the potential to cause some disutpion to schedule, increase in cost, or degradation of performance.

Low - Has ittle potential to cause disruption to schedule, increase in cost, or degradation of performance.

\section{TRIGGER POINT(S) FOR EARLY RISK}

\section{IDENTIFICATION:}

The requirements of the riser installation process must be know prior to the earty identification of this risk. 


\section{Risk Assessment - Data Sheet}

\section{Risk Type OProject OTechnical OESH}

\section{RISK: Estimated retrieval percentage too high}

It is estimated that $95 \%$ of the calcine in each bin can be retrieved. This estimate is based on the best available data fro pilot plant tests (ref. 9)

\section{PREVENTIVE PLANS}

The optimum configuration of suction nozzies and air jets shou be identified through pilot plant study. The optimum configurati should minimize the number of retrieval lines while maximizing the retrieval rate.

\section{PROBABLE CAUSE(S):}

Calcine may stick to the walls of the bin. It may get wedged in the "nooks and crannies" created by thermowells and internal stiffening rings and rods. The more agglomerated the calcine is the harder it is to retrieve.

\section{CONSEQUENCES IF RISK NOT RESOLVED}

This risk will effect the closure of the CSSFs the most. The mo calcine left in each bin will increase closure costs and lengthen the closure schedule. Pilot plant tests show that $97 \%$ of the calcine (ref. 9) is retrievable at a high retrieval rate.

\section{PROBABILITY}

High (3)

O Medium (2)

(-) Low (1)

\section{IMPACT}

- Medium (2)

Low (1)

\section{Risk $=2$}

Risk $=$ Probability $\times$ Impact

Probability Definition

High - Likely to occur during the project.

Medium - Has the potential to occur turing the project.

Low - Has little potential to occur during the project.

Impact Definition

High - Likely to cause significant disruption of schedule, increase in cost, or degradation of performance.

Medium - Has the polential to cause some disrutpion to schedule, increase in cost, or degradation of performance.

Low - Has Ittle potential to cause disnuption to schedule, increase in cost, or degradation of pertormance.

\section{IRIGGER POINT(S) FOR EARLY RISK} IDENTIFICATION:

During operation of the calcine retrieval and transportation system. 
Risk Assessment - Data Sheet

Risk Type OProject OTechnical OESH

\section{RISK: Intemal obstructions prevent retrieval}

Intemal obstructions may interfere with extension of the rigid retrieval lines into the bins.

\section{PREVENTIVE PLANS}

Examine the available CSSF drawings to determine retrieval ris locations that will not interfere with existing, internal obstructions

\section{PROBABLE CAUSE(S):}

Each bin has its own set of stiffening rods and thermowells. II retrieval lines may run into these internal obstructions.

\section{CONSEQUENCES IF RISK NOT RESOLVED}

Calcine retrieval may be completely stopped from a bin. This would adversely impact the schedule and drive costs up.
PROBABILITY

High (3)

Medium (2)

() Low (1)

\section{IMPACT}

$\bigcirc$ High (3)
$\bigcirc$ Medium (2)
$\bigcirc$ Low (1)

Risk $=2$

Risk $=$ Probability $x$ Impact

Probability Definition

High ... Likely to occur during the project.

Medium - Has the potential to occur during the project.

Low - Has ittie potential to occur during the project.

\section{Impact Definition}

High - Likely to cause significant disruption of schedule, increase in cost, or degradation of perfommance.

Medium - Has the potential to cause some disntpion to schedule. increase in cost, or degradation of performance.

Low - Has little potential to cause disnuption to schedule, increase in cost, or degradation of performance.

\section{TRIGGER POINT(S) FOR EARLY RISK} IDENTIFICATION:

During operation of the calcine retrieval and transportation system.

\section{CONTNGENCY PLAN(S) IF RISK IS REALIZED:}

None. 


\title{
Risk Assessment - Data Sheet
}

\author{
Risk Trpe OProject OTechnical OESH
}

\section{RISK: Waste Treatment Facility too slow}

The waste treatment facility cannot process calcine fast enougl It falls behind the retrieval rate of calcine.

\section{PREVENTIVE PLANS}

The processing capacity of the Waste Treatment Facility shoul be defined during the conceptual design phase. The operation the Waste Treatment Facility and the calcine retrieval and transportation system must be coordinated.

\section{PROBABLE CAUSE(S):}

The waste treatment facility may be slowed down by an equipment failure. The processing rate may be over estimated the adjoining scoping studies.

\section{CONSEQUENCES IF RISK NOT RESOLVED}

The calcine retrieval and transportation system should not operate unless the WTF requires additional calcine. The 50\% time estimate provides for some operational lapses. The risk is that the calcine batch bins will overflow with calcine. This will further contaminate the shielded cell when calcine is delivered the Waste Treatment Facility.

\section{PROBABIUTY}

High (3)

O Medium (2)

- Low (1)

\section{IMPACT}

\begin{tabular}{|ll|}
\hline O & High (3) \\
0 & Medium (2) \\
$O$ & Low (1) \\
\hline
\end{tabular}

\section{CONTINGENCY PLAN(S) IF RISK IS REALIZED:}

The amount of calcine retrieved should be adjusted to match tt amount of calcine processed in each batch.

\section{Risk $=2$}

Risk $=$ Probability $\times$ Impact

Probability Definition

High - Libety to occur during the project.

Medium - Has the potential to occur during the project.

Low - Has ittle potential to occur during the project.

Inpact Definition

High - Likely to cause significant disruption of schedule, increase in cost, or degradation of performance.

Medium - Has the potential to cause some disrutpion to schedule. increase in cost, or degradation of perfomance.

Low - Has nttle potential to cause disuption to schectule, increase in cost, or degradation of performance.

\section{TRIGGER POINT(S) FOR EARLY RISK}

\section{IDENTIFICATION:}

Changes in operations of the Waste Treatment Facility would identify the need to adjust the calcine retrieval rate. 


\title{
Risk Assessment - Data Sheet
}

\author{
Risk Type OProject OTechnical OESH
}

\section{RISK: Miscellaneous material prevents retrieval}

The miscellaneous material may damage or plug the calcine retrieval and transportation system. Damage tot he calcine retrieval and transportation system or the bins may occur wher this material is picked up by the air jet. Clogging can occur if a item enters the transportation system

\section{PREVENTIVE PLANS}

As much of this miscellaneous materias should be removed a: possible.

\section{PROBABLE CAUSE(S):}

Over the years, non-calcine materials have entered the CSSFs 2, and 3. Rod out lines have been lost. Weighted lines have purposefully fallen into the bins. And other foreign materials ha entered the bins. This material is scattered throughout the calcine. It is at different levels. It is not known exactly what material entered the CSSFs 1,2 , and 3.

\section{CONSEQUENCES IF RISK NOT RESOLVED}

The schedule can tolerate a fair amount of down time (currenth operated $50 \%$ of the time). The backup transportation lines should minimize delays in the schedule. This will impact the $a$ if the damage is extensive.

\section{PROBABILITY}

\begin{tabular}{ll}
$O$ & High (3) \\
O & Medium (2) \\
$O$ & Low (1) \\
\hline
\end{tabular}

Risk $=4$

\section{IMPACT}

\begin{tabular}{ll|}
$O$ & High (3) \\
$O$ & Medium (2) \\
$O$ & Low (1) \\
\hline
\end{tabular}

\section{CONTINGENCY PLAN(S) IF RISK IS REALZED:}

Implement a method to remove these items before they enter $t$ | transport system.

Risk $=$ Probability $\times$ Impact

\section{Probability Definition}

High : Ukely to occur during the projed.

Medium - Has the potential to occur during the project.

Low - Has tittle potential to occur during the project.

\section{Inpact Definition}

High - Lkely to cause significant disruption of schedule, increase in cost, or degradation of performance.

Medium - Has the potential to cause some disntpion to schedule. increase in cost, or degradation of performance.

Low - Has little potential to cause disruption to schedule, increase in cost, or degradation of pertomance.

\section{TRIGGER POINT(S) FOR EARLY RISK} IDENTIFICATION:

During operation of the calcine retrieval and transport system. 


\section{Risk Assessment - Data Sheet}

Risk Type OProject OTechnical OESH

\section{RISK: Objective retrieval rate too high}

The objective retrieval rate is $2700 \mathrm{~kg} / \mathrm{hr}$. It is expected that calcine can be retrieved near this rate. This rate is based on th Fluor-Daniels design retrieval rate. Retrieval tests (ref. 9) show that it is difficult to maintain any given retrieval rate.

\section{PREVENTIVE PLANS}

A minimum and maximum retrieval rate should be defined. The operator should be able to control, to some extent, the retrieval rate by changing the heights of the suction and air jet nozzles.

\section{PROBABLE CAUSE(S):}

The retrieval rate appears to be directly related to the amount o calcine in the bin. The less calcine there is to retrieve the less calcine can be retrieved. Agglomerated calcine is more difficult to retrieve than free flowing calcine. The transport air blower, which provides the air jet and suction nozzles, may be undersized to retrieve such a large volume of calcine near the bottom of the bins.

\section{CONSEQUENCES IF RISK NOT RESOLVED}

The schedule should not be adversely impacted as long as the calcine can be retrieved at a rate greater than approximately 50 $\mathrm{kg} / \mathrm{hr}$. However, the cost will increase for operations if the calcine retrieval and transportation system must be operated fol more than two $10 \mathrm{hr}$ days/week.

\section{PROBABILITY}

\begin{tabular}{|ll|}
\hline & High (3) \\
$\bigcirc$ & Medium (2) \\
$\odot$ & Low (1) \\
\hline
\end{tabular}

\section{IMPACT}

\begin{tabular}{|ll|}
\hline$\bigcirc$ & High (3) \\
$\bigcirc$ & Medium (2) \\
$\bigcirc$ & Low (1) \\
\hline
\end{tabular}

\section{CONTINGENCY PLAN(S) IF RISK IS REALIZED:}

Calcine retrieval will be conducted using extra shitts if the calcir can be retrieved at a reasonable rate. The reasonable rate will be determined by the needs of the waste treatment process. A good general number would be on the order of $500 \mathrm{lb} / \mathrm{hr}$.

\section{Risk $=3$}

Risk $=$ Probability $\times$ Impact

Probability Definition

Migh - Likely to occur during the project.

Medium - Has the potential to occur during the project.

Low - Has fittle potential to occur during the project.

\section{Impact Definition}

High - Likely to cause significant disruption of schedule, increase in cost, or degradation of performance.

Medium - Has the potential to cause some disutpion to schedule, increase in cost, or degradation of performance.

Low - Has ittle potential to cause disruption to schedule, increase in cost, or degradation of performance.

\section{TRIGGER POINT(S) FOR EARLYRISK} IDENTIFICATION:

Operation of the calcine retrieval and transportation system 


\section{Risk Assessment - Data Sheet}

Risk Type OProject OTechnical OESH

\section{RISK: All calcines are not retrievable}

All types of calcine are retrievable as a dilute phase using this calcine retrieval and transportation system.

\section{PREVENTIVE PLANS}

Pilot plant tests should be conducted on agglomerated calcine Also samples of the calcine in the CSSFs should be taken and analyzed to determine if the calcine has agglomerated.

\section{CONSEQUENCES IF RISK NOT RESOLVED}

\section{PROBABLE CAUSE(S):}

The calcine may be agglomerated. It is anticipated that agglomerated calcine will not fuidize as readily as free fowing calcine

The retrieval rate could be significantly lower than expected. T operating costs will increase. The schedule may fall behind.

\section{CONTINGENCY PLAN(S) IF RISK IS REALZED:}

\section{PROBABIUTY}

High (3)

(C) Medium (2)

Low (1)

\section{Risk $=4$}

Risk $=$ Probability $\times$ Impact

Probability Definition

High - Likely to occur during the project

Medium - Has the potential to occur during the project.

Low - Has little potential to occur during the project.

Impact Definition

High - Likely to cause eignificant disnuption of schedule, increase in cost, or degradation of pertomance.

Medium - Has the potential to cause come disrutpion to schedule, increase in cost, or degradation of performance.

Low - Has fittle potential to cause disruption to schedule, increase in cost, or degradation of performance.
The agglomerated calcine must be broken up before it retrievec If the potential for agglomerated calcine is high for a particular bin, a vibrator should be added to the end of the retrieval line before it is inserted into the bin. If agglomerated calcine is not suspected, then the air jet should be increased.

\section{TRIGGER POINTIS) FOR EARLY RISK} IDENTIFICATION:

Operation of the calcine retrieval and transportation system on actual calcine. 


\section{Risk Assessment - Data Sheet}

Risk Type OProject OTechnical OESH

RISK: Construction radiation dose rates incorrect

The radiation dose rates are estimated from the best available data. The big unknown is the radiation levels in the CSSF superstructures.

\section{PREVENTIVE PLANS}

Proposed radiological surveys of each CSSF superstructure.

\section{PROBABLE CAUSE(S):}

A comprehensive radiological survey of the CSSF superstructures has not been conducted. The radiation levels in the superstructures are not known. They may be significantly higher than estimated.

\section{CONSEQUENCES IF RISK NOT RESOLVED}

More workers will be needed during the construction phase of th project. This will negatively impact the schedule and costs during construction. There is a high confidence that the radiatio levels can be maintained at lower levels during the operations phase of the project.

\section{PROBABILITY}

High (3)

(-) Medium (2)

O Low (1)
IMPACT

High (3)

(-) Medium (2)

Low (1)

\section{Risk $=4$}

Risk $=$ Probability $\times$ Impact

Probability Definition

Migh - Likely to occur during the project.

Medium - Has the potential to occur during the project.

Low - Has fitle potential to occur during the project.

Impact Definition

High - Likely to cause significant disruption of schedule, increase in cost, or degradation of perfomance.

Medium - Has the polential to cause some disutpion to schedule. increase in cost, or degradation of performance.

Low - Has little potential to cause disnuption to schedule, increase in cost, or degradation of performance.

\section{CONTINGENCY PLAN(S) IF RISK IS REALZED:}

More workers and time will be necessary during the constructio phase of the project.

\section{TRIGGER POINT(S) FOR EARLY RISK}

\section{DENTIFICATION:}

This risk should be addressed during the conceptual design phase. If not, it well become evident during construction. 
Function File Number - SPR-WTS-01

Rev. $\$ 00$

EDF Serial Number - EDF-WTS-002

Page 62 of 62

\section{Appendix F}

Cost Estimates

4
$y$

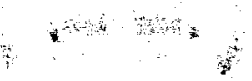


CSSF RETRIEVAL \& TRANSPORT SYSTEM
CWO 5-YEAROOPTION

\begin{tabular}{c|l}
\hline ID & Task Name \\
\hline 1 & CALCINE TRANSPORT SYSTEM
\end{tabular}

\begin{tabular}{l|l}
1 & CONCEPTUAL DESIGN \\
\hline 2
\end{tabular}

ADVANCED CONCEPTUAL DESIGN

PM FOR PROUECT DEVELOPMENT

PERMITTING

PROJECT MANAGEMENT

TIILE DESIGN

CORROSION COUPON REMOVAL

D\&D RISER INSTALLATION

CALCINE REMOVAL OPERATIONS

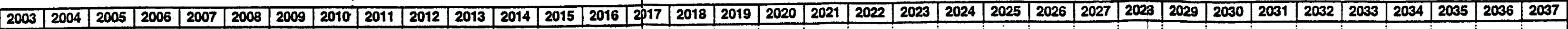

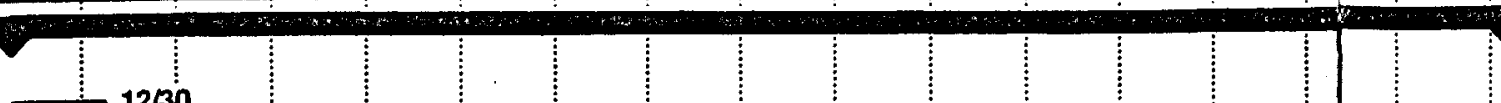

$\square^{1230}$

$12 / 31 \quad 12 / 13$

$\square_{1}^{12 / 27}$

$6 / 2+\square$

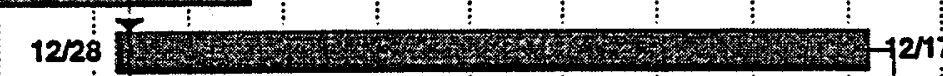

$1228{ }_{1225}^{1225}$

${ }_{1226}^{1225}$ :

1222

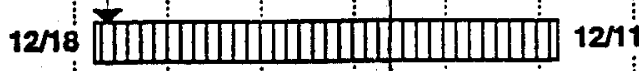

11 稀 
Date: January 24, 1998

To:

S. E. Gifford

MS 3765

$6-5162$

From:

F. P. Hanson

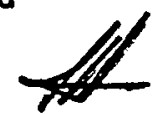

MS 3655

6-0548

Subject: HLW EIS WASTE TREATMENT SCOPING STUDIES - FPH-01-98

Reference: F. P. Hanson letter to S. E. Gifford, FPH-33-97, Same Subject, December 9, 1997

Cost Estimating has reviewed the referenced draft cost estimates and prepared the attached final Planning Cost Estimates for the subject project. Nine estimates have been prepared for the activities shown below; the work scope for each activity is described in the respective estimate.

1. Other Project Costs (OPC) including conceptual design, proof of process, permitting and documentation, start-up activities, and related project management costs.

2. One estimate each for Option B for Calcined Solids Storage Facilities (CSSFs) 1 through 4, and one estimate for CSSFs 5 through 7. Since the scope and nature of work for CSSFs 5 through 7 are nearly identical, one estimate has been prepared showing costs which may be applied to each of those CSSFs.

3. Installation of D\&D risers

4. Removal of corrosion coupons

5. One estimate each for Option A and Option B for the Calcine Transport System. Option B incorporates an Intermediate Transport Station with associated equipment.

The general scope of work covered by the estimates includes necessary modification of the CSSF vaults and CSSFs; construction of a new Containment Enclosure and a new Ventilation, Instrumentation, and Control (VIC) Building at each CSSF; construction of a new calcine transport system; and removal of corrosion coupons from the CSSFs.

The estimates incorporate all comments received to date, including your review of the draft estimates dated December 9, 1997 and intermediate draft estimates for the Calcine Transport System, as well as appropriate internal reviews. In addition, G\&A and Performance Incentive Factor (PIF) fees, not previously applied, have been added to the estimates as appropriate. 
S. E. Gifford

January 24, 1998

FPH-01-98

Page 2

Option A for modification of the CSSFs incorporated relocation and reuse of certain operational equipment. An examination of this option showed that it did not fully meet the needs of the system and was not sufficiently cost effective to warrant further consideration; therefore, in accordance with your directive, estimates are provided for Option B only.

Assumptions which form the bases of the estimates and any concerns that may affect the costs are shown in the attached Support Data Recapitulation Sheets. Cost Estimate Summary Sheets, Detail Sheets, and Contingency Analysis Sheets for each estimate are also attached for your information. These describe in detail the scope of work and unit costs upon which the estimates are based. In addition, a Summary of Cost Estimates has been prepared showing the Total Project Cost for each estimate. If you have further comments or questions regarding the estimates, please feel free to call.

fph

Attachment

cc: Estimate File \#2414-1

F. P. Hanson File

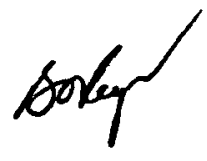


Lockheed Martin Idaho Technologies Co.

(Rev. 06/96)

\section{COST ESTIMATE SUPPORT DATA RECAPITULATION}

Project Title: HLW EIS Waste Treatment

Scoping Studies

Calcine Retrieval and Transport
Estimator: F. P. Hanson

Date: $1-24-98$

Type of Estimate: Planning File No: $2414-1$

Approved By:

I. SCOPE OF WORK:- Brief description of the proposed project.

This project will prepare Calcined Solids Storage Facilities (CSSFs) \#1 through $\# 7$ for retrieval and transport of calcined waste to a processing facility. Each CSSF vault and CSSF will be modified as required, a new Containment Enclosure, and a new Ventilation, Instrumentation, and Control (VIC) Building will be constructed at each CSSF, and a new caicine transport system will be constructed. Construction of treatment and process facilities are not in the scope of the attached estimates.

\section{BASIS OF THE ESTIMATE: Drawings, Design Report, Engineers notes, and/or other documentation upon which the estimate is originated.}

a. Cost Estimate for Alternative 3, Phase I \& II Special Studies, Bin Set 1. Bin Set 1 Calcine Retrieval System, Raytheon Engineers and Constructors, Inc:, 11-8-94.

b. Feasibility Study Cost Estimate, Waste Treatment Facilities, Fluor Daniel Northwest, 10-22-97.

c. Oraft Bin Set Access PIan with accompanying tables, provided by S. E. Gifford, cognizant technical lead.

d. Drawings, sketches, and miscellaneous supporting information provided by $S$. E. Gifford.

e. Title II Cost Estimate, Waste Characterization Facility, Lockheed Idaho Technologies Co., 11-22-94. This estimate provides the basis for costs for the Calcine Transport System Intermediate Transport Station. Costs are updated to current costs. 
Lockheed Martin Idaho Technologies Co.

\section{COST ESTIMATE SUPPORT DATA RECAPITULATION (CONTINUATION)}

File No: $2414-1$

Page 2 of 6

III. ASSUMPTIONS: Condition statements accepted or supposed true without proof or demonstration. An assumption has a direct impact on total estimated cost.

1. The Raytheon estimate provides a comprehensive breakdown of work tasks and associated costs for work required to prepare CSSF \#1. The Fluor Daniel estimate addresses CSSFs $\# 2$ and $\# 3$, and closely reflects the Raytheon estimate, with no further scope or significant cost development. Because the Raytheon estimate represents the primary scope and cost development, it has been used as the basis of costs and scope of work addressed by the attached estimates. Hork scopes and associated labor and material costs have been adjusted as deemed appropriate for subsequent CSSFs.

2. It has been assumed that the Raytheon estimate was developed from a reasonably well developed description of work scope, therefore, quantities, unit costs, and labor effort have been incorporated as presented in the Raytheon estimate, except as otherwise determined by factors specific to this estimate effort. The costs provided in the attached estimates are dependent upon the underlying assumptions, inclusions, exclusions, and basis of quantity development and pricing for the Raytheon estimate.

3. Design, Title III Inspection, and Management costs were applied in the Raytheon estimate as a percentage of construction costs. Those rates have been modified for the attached estimates as follow: Title Design at $20 \%$ of construction and GFE; Title III at 5\% of construction and GFE; and PM and $C M$ each at $10 \%$ of construction and GFE. Title design modifications for CSSFs \#2 through \#7 have been assumed at $20 \%$ of Titie design costs for CSSF $\# 1$, assuming only relatively minor design modifications would be required.

4. Conceptual design and process development costs have been assumed at $30 \%$ of Title design costs for CSSF $\# 1$. It is assumed that conceptual design costs would not be impacted by subsequent Title design modifications for the remaining CSSFs. See Section IV for further comments.

6. It has been assumed that removal of corrosion coupons will be accomplished by LMITCO operating personnel.

(Continued) 
Lockheed Martin Idaho Technologies Co.

$x \rightarrow 3$

COST ESTIMATE SUPPORT DATA RECAPITULATION

(CONTINUATION)

File No: $2414-1$

Page 3 of 6

III. ASSUMPTIONS: (Continued)

5. It is assumed that all demolition and new construction work will be competitively bid and performed by a general contractor as the prime subcontractor, with specialty lower tier subcontractors as appropriate. One tier of subcontractor markups has been applied, at $40 \%$ for overhead and profit, plus $1 \%$ for bonding, in accordance with the Raytheon estimate.

7. The Raytheon estimate does not specifically identify costs for subcontractor supervision. It has been assumed that the labor figures incorporated include allowances for subcontractor project coordination and supervision. Costs for personnel $O S \& H$ and site specific training have been included at $2 \%$ of project labor, per the Raytheon estimate, for CSSF $\# 1$, and at $1 \%$ of 1 abor for the remaining CSSFs, assuming primarily refresher and update training for subsequent CSSFs. Construction of the Calcine Transport System and installation of the D\&D risers are assumed to require additional personnel, therefor, the $2 \%$ allowance for training has been applied to those estimates.

8. Unit costs are assumed to include all costs necessary to accomplish the work including, but not necessarily limited to, site preparation; installation and removal of waste products, decontamination and cleanup, mobilization and demobilization, and cost of supporting organizations.

9. The labor hours shown in the Raytheon estimate have been incorporated; however, current INEEL Site Stabilization Agreement rates have been used, which may differ from the rates shown in the reference.

10. Allowances for undefined costs and for NQA-1 have been applied as shown in the Raytheon estimate, and are assumed to be appropriate for the project.

11. Material costs have been applied as shown in the Raytheon estimate, as appropriate, and further escalated at approximately $1.5 \%$ per year from the date of the estimate to the current date.

12. The Raytheon estimate does not include costs for the Containment Enclosure or the VIC Building. The attached estimates assume both the structures to be pre-engineered metal buildings, complete with appropriate services nd equipment. The Containment Enclosure is assumed to be $30^{\prime} \times 30^{\prime}$ or $40^{\prime} x$ $40^{\prime}$, depending upon the vault dimension, with a $60^{\prime}$ eave height. The VIC building is assumed to be $40^{\prime} \times 60^{\prime} \times 14^{\prime}$ eave height in all cases. Costs are based on historical data and estimating judgement. 
Lockheed Martin Idaho Technologies Co.

\section{COST ESTIMATE SUPPORT DATA RECAPITULATION (CONTINUATION)}

File No: $2414-1$

Page 4 of 6

III. ASSUMPTIONS: (Continued)

13. It is assumed that minimal site preparation will be required. Costs have not been included for additional service and access roads.

14. The following equipment is associated with the Calcine Transport System and is to be located in the processing facility; costs are assumed to be addressed in the appropriate facility cost estimate and have not been included herein. Equipment numbers are identified in appropriate drawings and equipment lists.

- Air Handling Unit, 2,130 CFM

- Exhaust Fan, 830 CFM

- Exhaust Fan, 230 CFM

- HEPA Filter w/Prefilter, 530 CFM

- HEPA Canisters w/Prefilters, 230 CFM

15. The cost estimate for Other Project Costs (OPC) - is intended to show all permitting costs associated with the entire CSSF modification and construction of the transport system. Costs for permitting and documentation are assumed to encompass all activities required.

16. The estimates identify certain activities related to demolition, earthwork, and construction which are to be accomplished during the overall time frame shown, rather than showing labor hours for the specific activities. It is assumed that the time frames and labor loading shown are adequate to accomplish the activities.

17. The proposed schedule shown in the Raytheon estimate calls for engineering from 10/1997 to 10/1999, with a mid-pint of 10/1998, and all other activities from $12 / 2000$ to $5 / 2005$, with a mid-point of $11 / 2002$. Using the schedule of operations provided, the following activity mid-points have been established for purposes of calculating escalation:

- Conceptual design: 2003 - 2005, mid-point 2004.

- Title design: 2005 - 2007, mid-point 2006.

- Construction: 2008 - 2013, mid-point 2011.

(Continued) 
Lockheed Martin Idaho Technologies Co.

COST ESTIMATE SUPPORT DATA RECAPITULATION

(CONTINUATION)

File No: $2414-1$

Page 5 of 6

III. ASSUMPTIONS: (Continued)

- Installation of D\&D risers: Mid-point of operations (2014 - 2033), 2023

- Removal of corrosion coupons: Mid-point of construction, 2011

19. It is assumed that the Calcine Transport System will consist of two separate systems. The quantities shown in the estimate reflect total quantities for the two systems.

21. It is assumed that the Intermediate Transport Station for Option B will be of reinforced concrete construction housing process equipment, with a preengineered metal building portion housing utilities and support equipment, and that the facility will require normal features for equipment shielding and accessibility, personnel protection, and normal utilities, HVAC, and electrical services.

20. Information available to the cognizant technical lead indicates that, due to corrosion failure of piping in CSSFs 2 and 3 , radiological conditions arising from contamination are similar to CSSF \#1. The estimates for CSSFs 2 and 3 have been prepared with that factor in mind, and labor allowances incorporated accordingly.

22. LMITCO G\&A has been applied at $23 \%$ of construction and GFE, with a $\$ 500,000$ ceiling applied, and the Performance Incentive Fee (PIF) has been applied at $5.5 \%$. Procurement fees have been assumed at $1 \%$, as procurement support to DOE, rather than the normal $3 \%$ fee. Adders are applied to each estimate based on the assumption the work addressed therein will be accomplished in one year. 
Lockheed Martin Idaho Technologies Co.

\section{COST ESTIMATE SUPPORT DATA RECAPITULATION} (CONTINUATION)

File No: $2414-1$

IV. CONTINGENCY GUIDELINE IMPLEMENTATION: The percentage used for contingency as determined by the contingency allowance guidelines can be altered to reflect the type of construction and conditions that may impact the total estimated cost.

Time constraints and lack of definitive design and project requirements have been taken into consideration in generating the costs and attendant rates of contingency shown in the estimate. Very little is known at this time regarding specific facility and process requirements, and there is a very real potential for encountering radiological conditions beyond those anticipated, resulting in increased labor and equipment costs. This, together with the unknowns associated with subsurface work and radiological. conditions, with the inherent possibility of encountering differing conditions as existing work is operied up, create a high potential for increased costs. Some equipment may not be standard and may require development, and the schedule extends over many years. For these reasons, the rate of contingency typically exceeds the guidelines for a planining estimate and extends into the range for special conditions, as defined by DOE/FM 50, Cost Estimating Guide, Vol. 6, and the INEEL Cost Estimating Guide.

Overall contingency rates for escalated estimates are slightly higher than unescalated estimates, due to the assumed higher degree of associated risk as activities and costs are extended into the out years.

\section{OTHER COMMENTS/CONCERNS SPECIFIC TO THE ESTIMATE:}

Individual estimates have been prepared for Other Project costs (OPC); two options for the Calcine Transport System; and each of CSSFs 1 through 4. Since the scope and nature of work for CSSFs 5 through 7 are nearly identical, one estimate has been prepared showing costs which may be applied to each of those CSSFs. After analyzing draft cost estimates for Option A and Option B, for CSSF modifications, it was determined by the cognizant technical lead that Option A did not sufficiently meet system requirements and would not be further pursued; therefore, complete estimates are provided only for Option B for each case, and Summary Sheets are provided for both escalated and unescalated costs for each estimate. Separate estimates have also been prepared for installing D\&D risers and for removing corrosion coupons.

The allowance of $30 \%$ of construction for Title Design included in the Raytheon estimate appears excessive for this magnitude of work. It was determined by the cognizant technical lead that this allowance was based on the total lack of a.proven retrieval method at the time the Raytheon estimate was prepared. Because of subsequent design development, the allowance is reduced to $20 \%$ in the attached estimates. 
Lockheed Martin Idaho Technologies Co.

\section{SUMMARY OF COST ESTIMATES}

HLW EIS WASTE TREATMENT

SCOPING STUDIES

CALCINE RETRIEVAL AND TRANSPORT

LOCATION: INEEL-ICPP

REQUESTOR: $K$ L. WILLIAMS
PLANNING ESTIMATE

ESTIMATE NO. 2414-1

PREPARED BY: F. P. HANSON
DATE: 24 JAN 1998

CHECKED

APFROVED

\section{OPTION B}

ACTIVITY

OTHER PROJECT COSTS (OPC)
CSSF \#1
CSSF \#2
CSSF \#3
CSSF \#4
CSSF \#5
CSSF \#6
CSSF \#7
INSTALL D\&D RISERS
REMOVE CORROSION COUPONS
HWO, WWO, DCWO OPTIONS (B)
TOTAL PROJECT COST
(LESS TRANSPORT SYSTEM)
CALCINE TRANSPORT SYSTEM OPTIONS
CWO \& TRU SEPARATION OPTIONS (A)

\begin{tabular}{|l|l}
\hline UNESCALATED & .
\end{tabular}

COSTS

$\$ 28,300,000$

$\$ 37,100,000$

$\$ 24,000,000$

$\$ 23,400,000$

$\$ 16,000,000$

$\$ 14,700,000$

$\$ 14,700,000$

$\$ 14,700,000$

$\$ 5,100,000$

$\$ 1,125,000$

$\$ 179,125,000$

$\$ 258,370,000$

$\$ 41,100,000$

$\$ 52,750,000$

$\$ 34,000,000$

$\$ 33,100,000$

$\$ 22,500,000$

$\$ 21,000,000$

$\$ 21,000,000$

$\$ 21,000,000$

$\$ 10,300,000$

$\$ 1,620,000$

$\$ 15,300,000$

$\$ 21,650,000$

$\$ 20,400,000$

$\$ 29,000,000$ 
Lockheed Martin Idaho Technologies Co. COST ESTIMATE SUMMARY Rev. 699 PRQUECT NAME: HLW EIS -WASTE TREATMENT SCOPING STUDIES TMPE OF ESTIMATE: PLANNING
CALCINE RETRIEVAL AND TRANSPORT LOCATION 7: INEEL-ICPP REQUESTOA: K. L WILLAMS PAEPARED BY: F.P.HANSON AEPORT NAME: Cost Estimate Summary

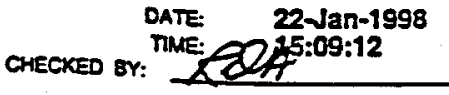

APPRO BY:

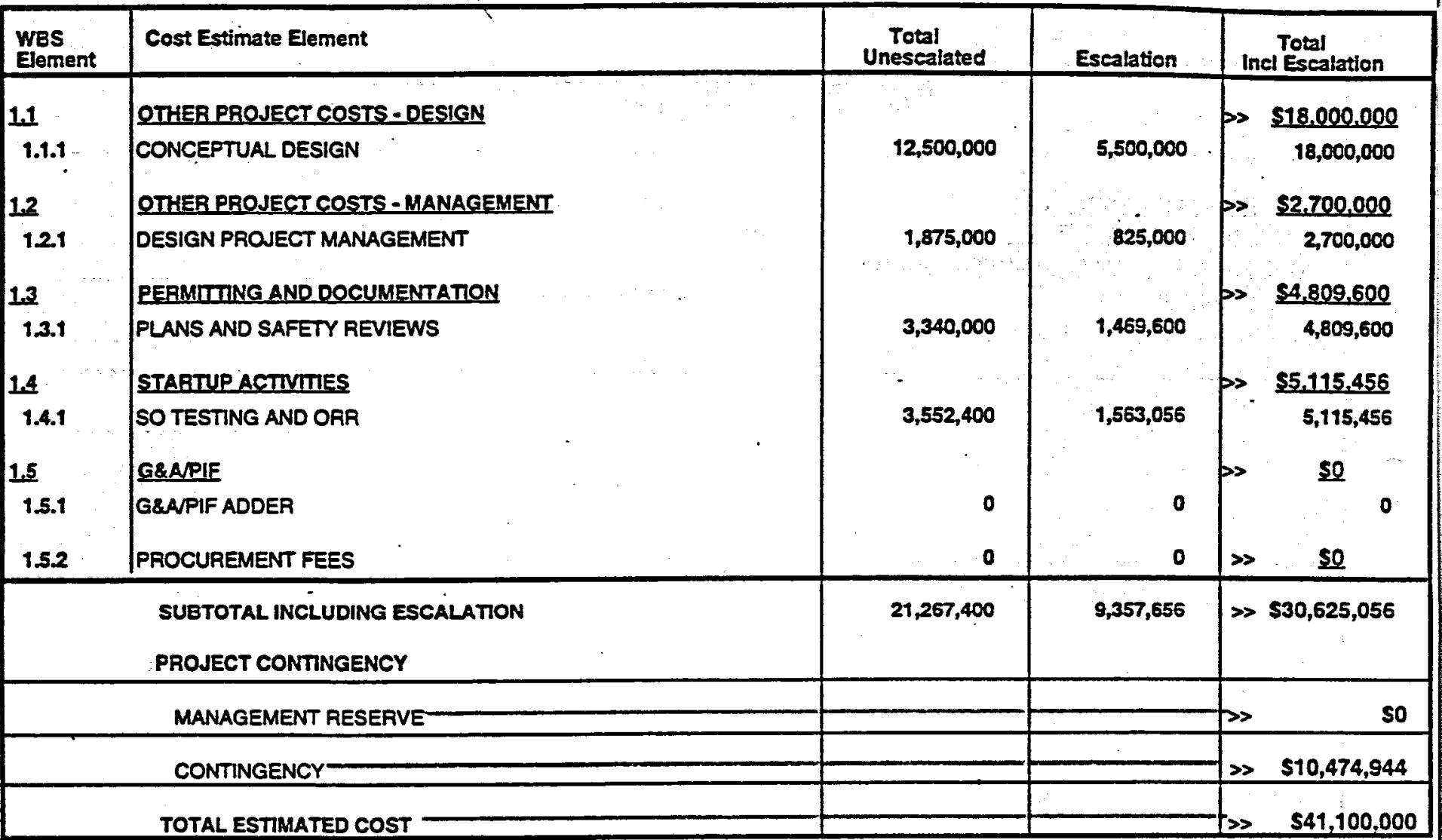

\section{PROJECT COST PARAMETERS}

EDI AS A \% OF CONST. + GFE= 
Lockheed Martin Idaho Technologies Co.

COST ESTIMATE SUMMARY

PROJECT NAME: HLW EIS -WASTE TREATMENT SCOPING STUDIES TPE OF ESTMATE: PLANNING

CALCINE RETRIEVAL AND TRANSPORT

PAOAECT NO: 2414-1 (OPC)

REOUESTOR:

K. L. WILLAAMS

PAONECT NO: 2414-1 (OPC)
PREPAREO BY: F.P. HANSON

AEPORT NAME: Cost Estimate Summary

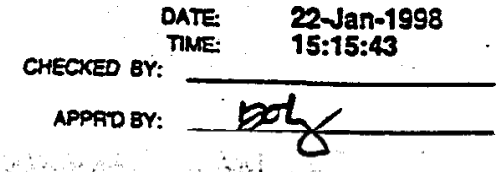

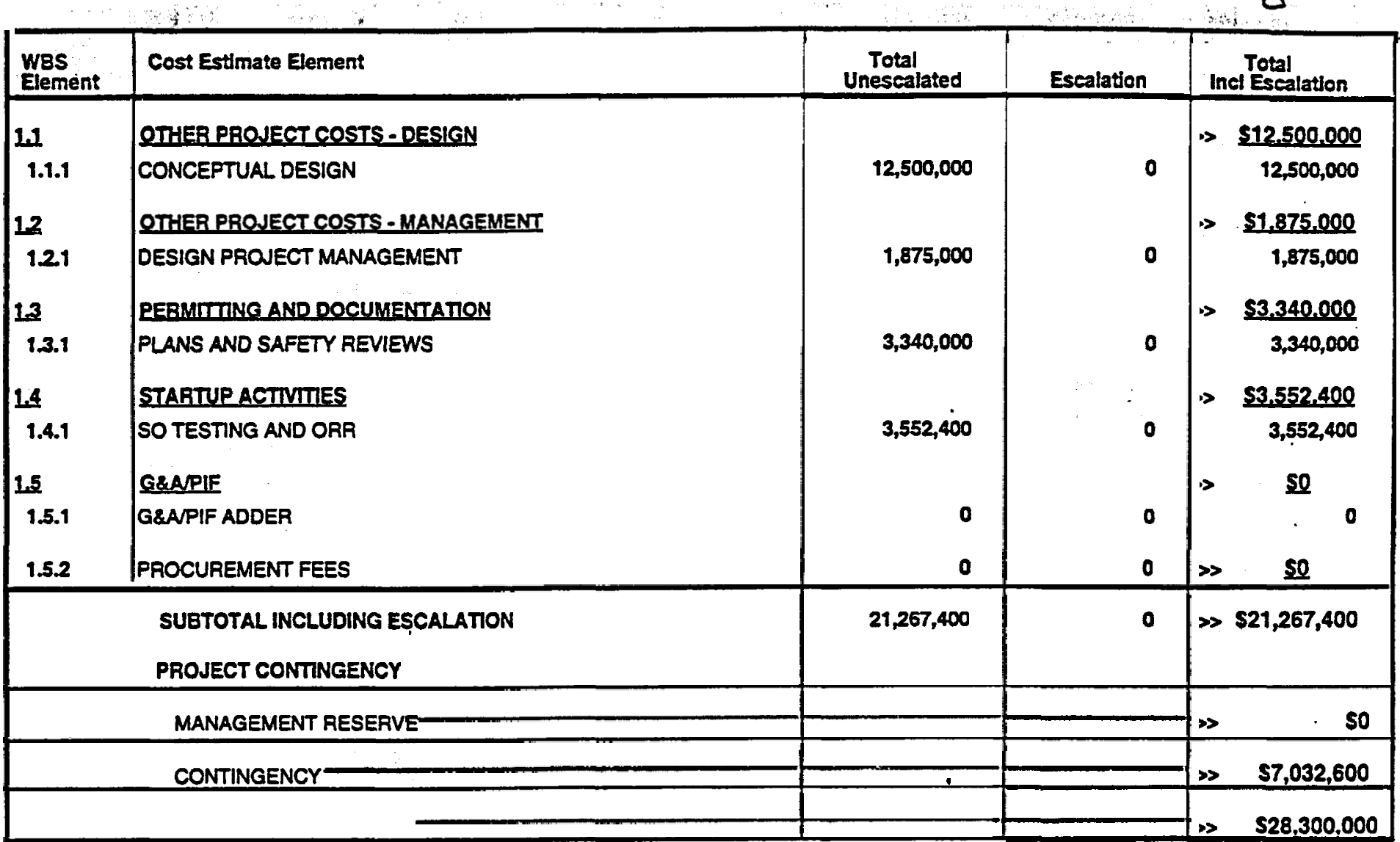

PROJECT COST PARAMETERS

EDI AS A \% OF CONST. + GFE= . .

CONTINGENCY $=33.07 \%$ 
Lockheed Martin Idaho Technologies Co.

HLW EIS -WASTE TREATMENT SCOPING STUDIES TPE OF ESTIMATE:
CALCINE RETIEIEVAL AND TRANSPORT - OPTION B PROECT NO:

PLANNING

- ICPP

AEPORT NAME: Cost Estimate Summary

2414-1-1 (CSSF 1)

F.P. HANSON

$K$. WIUAMS

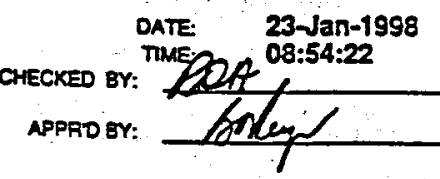

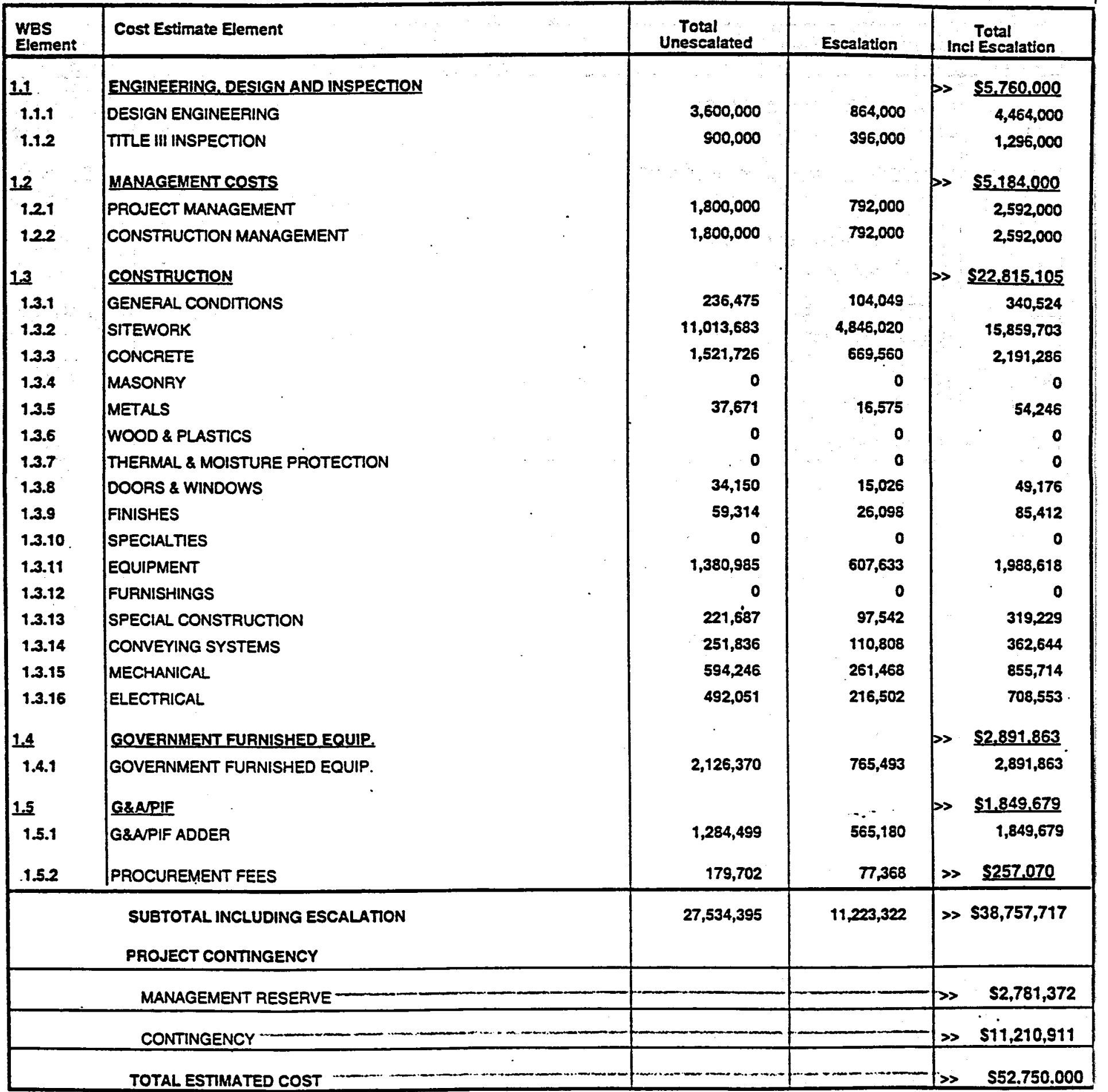

\section{PROJECT COST PARAMETERS}

EDI AS A $\%$ OF CONST. + GFE $=22.00 \%$

CONTINGENCY $=36.10 \%$ 
Lockheed Martin Idaho Technologies Co.

COST ESTIMATE SUMMARY

PRQSECT NMVE

HLW EIS -WASTE TREATMENT SCOP
CALCINE RETRIEVAL AND TRANSP

STUDIES TYPE OF ESTIMATE PLANNING

AEOUESTOR:

INEEL - ICPP

K. L. WILLIAMS

PLANNING
2414-1-1 (CSSF 1)
F. P. HANSON

PROUECT NO:

REPCAT NAME: Cost Estimate Summary

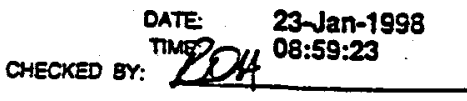

APPRO BY:

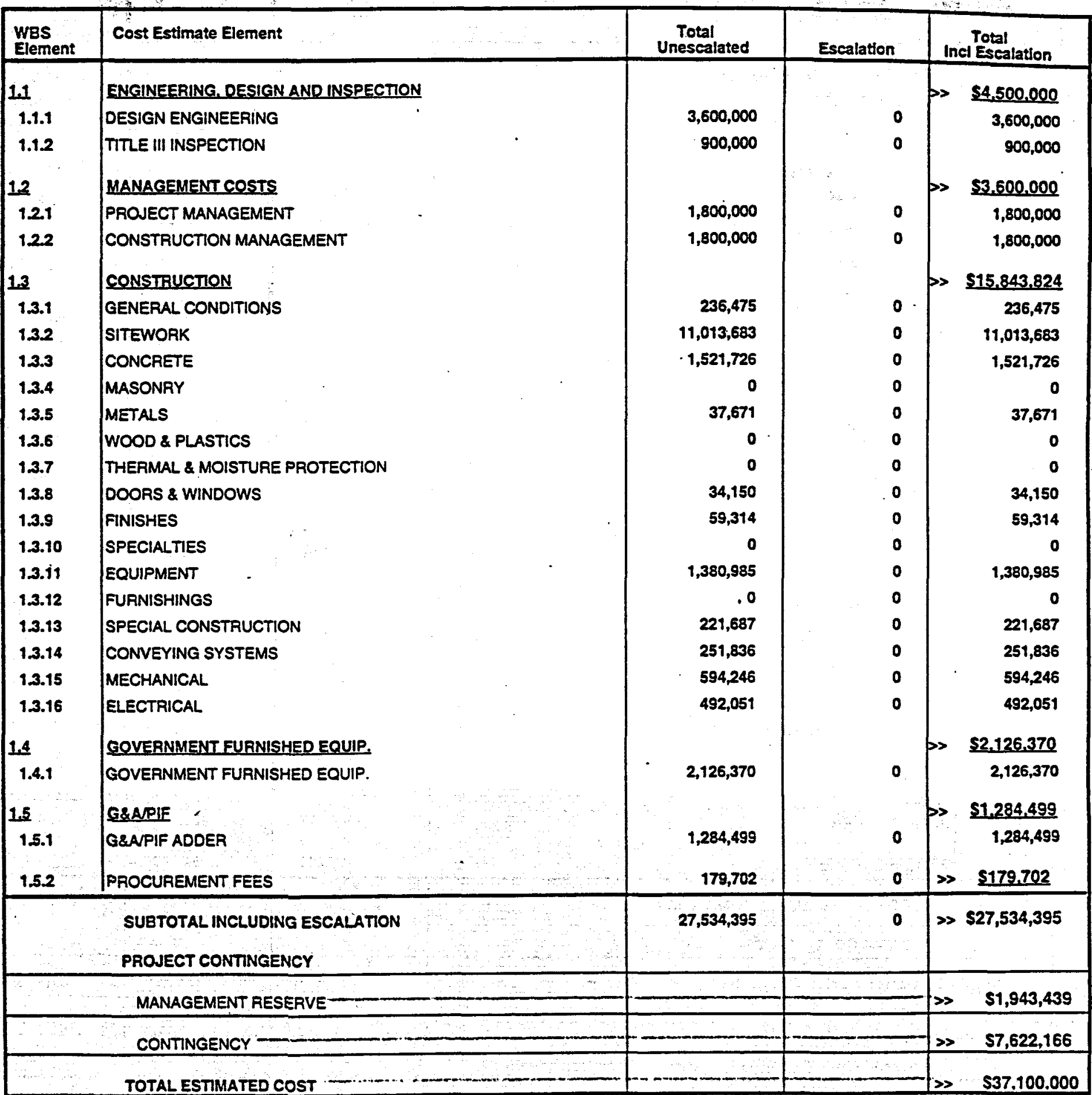

PROJECT COST PARAMETERS

EDI AS A \% OF CONST. + GFE $=25.00 \%$

CONTINGENCY $=34.74 \%$ 
Lockheed Martin Idaho Technologies Co.

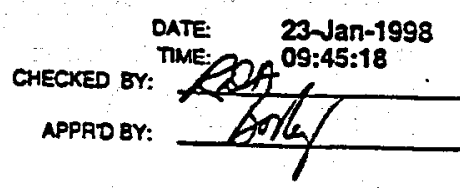

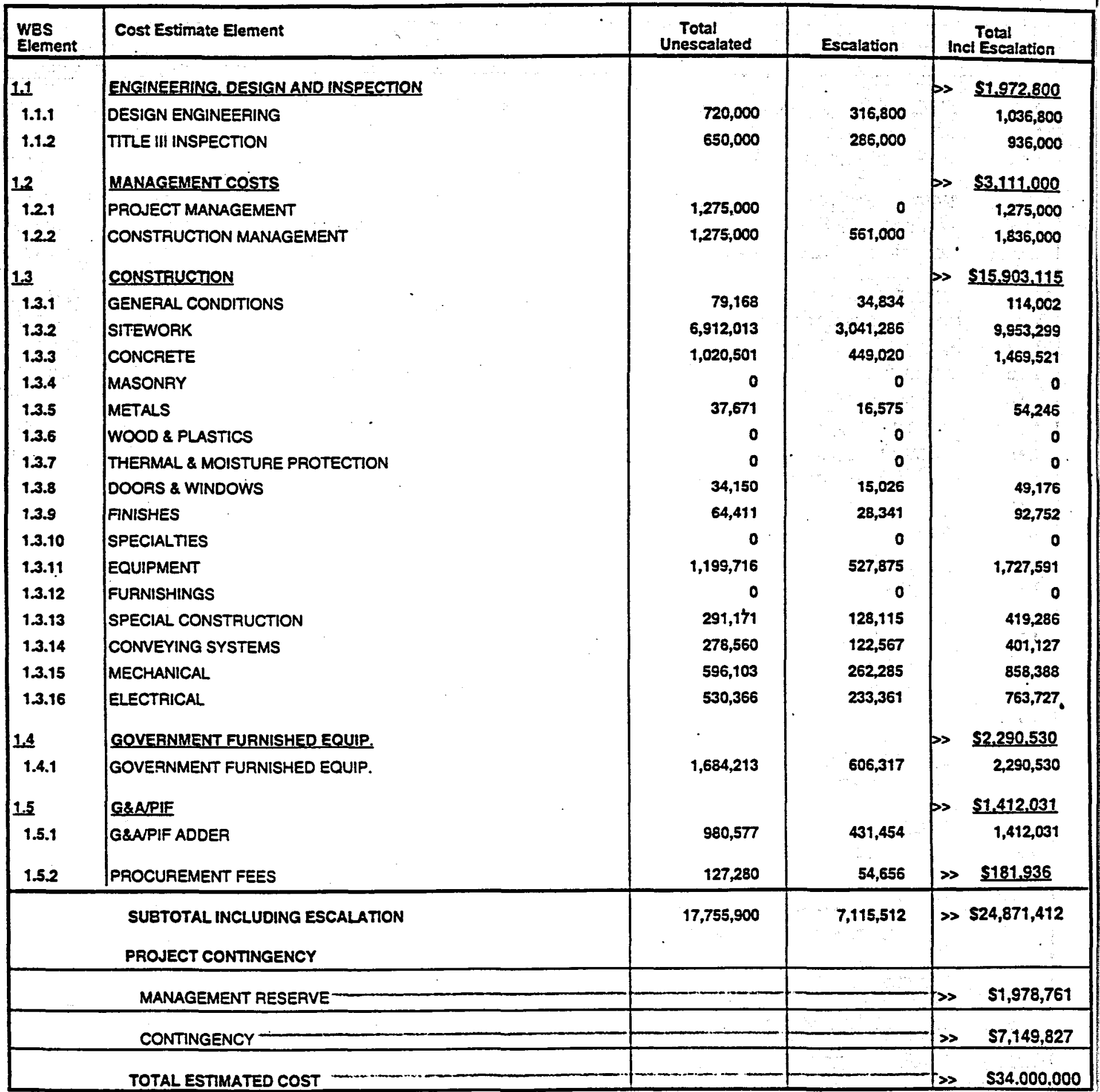

\section{PROJECT COST PARAMETERS}

EDI AS A \% OF CONST. + GFE $=11.00 \%$ 
Lockheed Martin Idaho Technologies Co.

PROUECT NAME: HLW EIS -WASTE TREATMENT SCOPING STUDIES TYPE OFESTIMATE: PLANNING

LOCATON 1: CALCINE RETRIEVAL AND TRANSPORT - OPTIONB

INEEL - ICPP

PAEPACTNO: 2414-1-2 (CSSF 2)

REOUESTOR:

K. L. WILLIAMS

REPORT NAME: Cost Estimate Summary

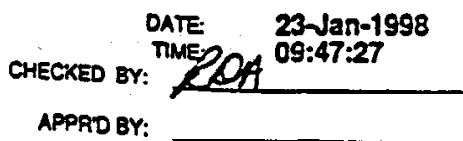

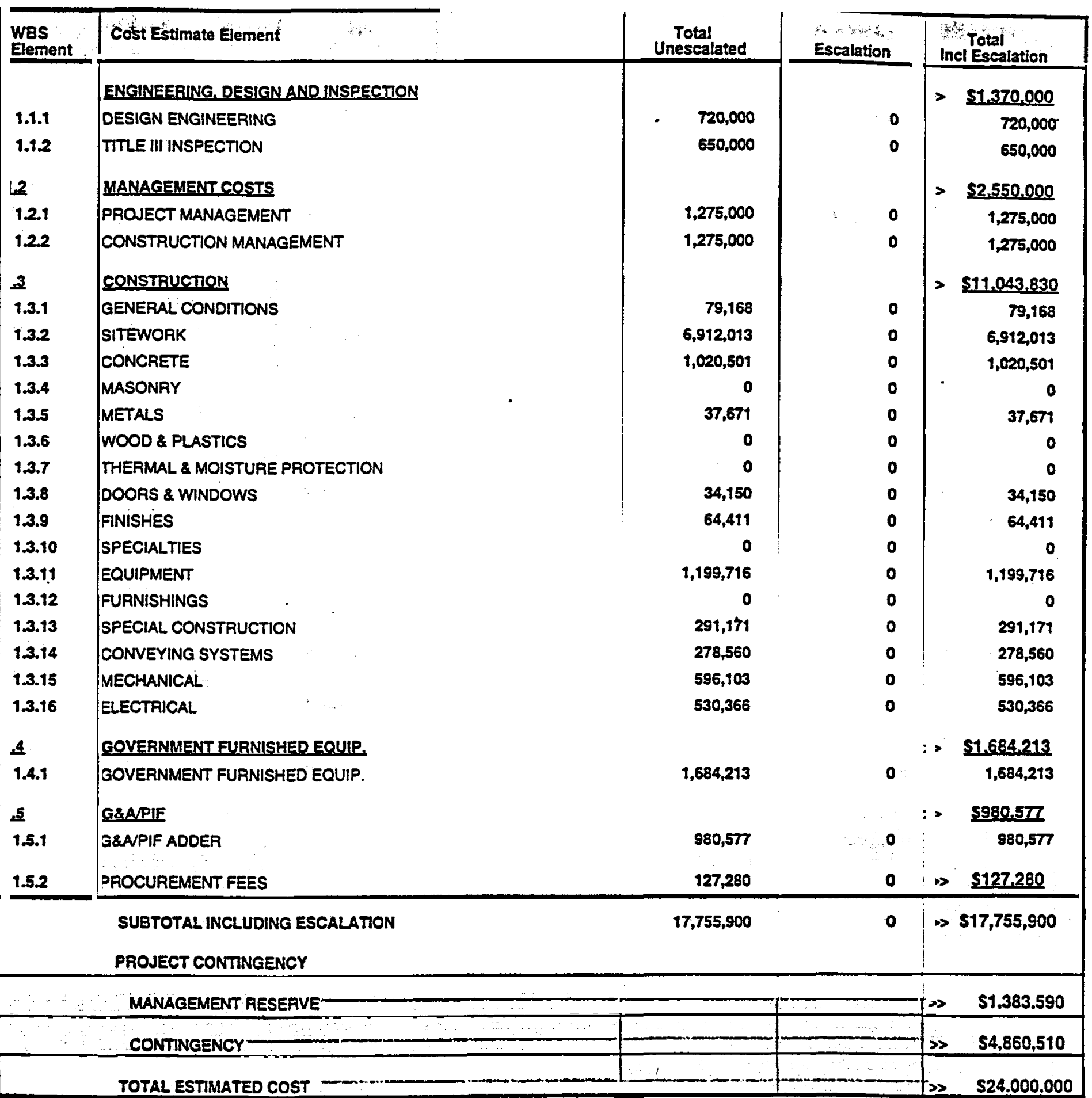

\section{PROJECT COST PARAMETERS}

EDI AS A $\%$ OF CONST. + GFE $=11.00 \%$ 
Lockheed Martin Idaho Technologies Co. PROAECT NaME

LOCATION I: REOUESTOA HLW EIS -WASTE TREATMENT SCOPING STUDIES TYPE OF ESTIMATE: PLANNING CALCINE RETRIEYAL AND TRANSPORT - OPTION B PACIECT NO:

INEEL-ICPP

K.LWILLAMS
2414-13 (CSSF 3)

F. P. HANSON

REPORT MAME: Cost Estimate SUmmary

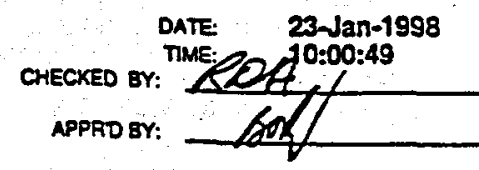

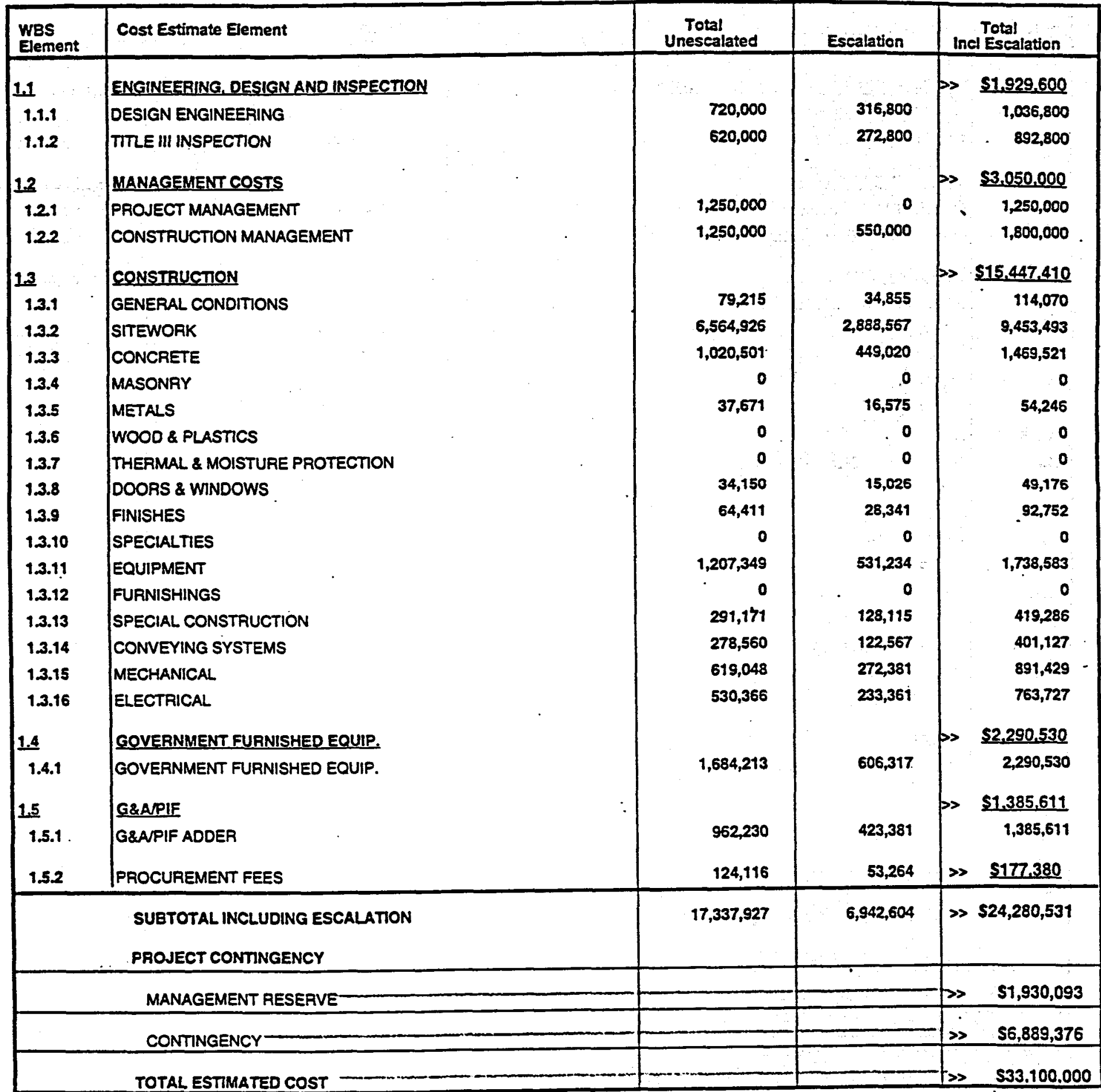

\section{PROJECT COST PARAMETERS}

EDI AS A \% OF CONST. + GFE $=11.00 \%$ 
Lockheed Martin ldaho Technologies Co.

COST ESTIMATE SUMMARY

PROSECT NAME: HLW EIS -WASTE TREATMENT SCOPING STUDIES TPE OF ESTIMATE: PLANNING

LOCATION : CALCINE RETRIEVAL AND TRANSPORT - OPTIONB

$2414-13$ (CSSF 3)

INEEL - ICPP

PREPAAED BY:

F. P. HANSON

REPORT NAME: Cost Estimate Summary

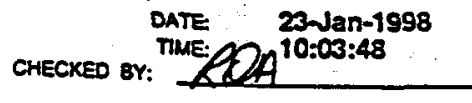

APPROEY:

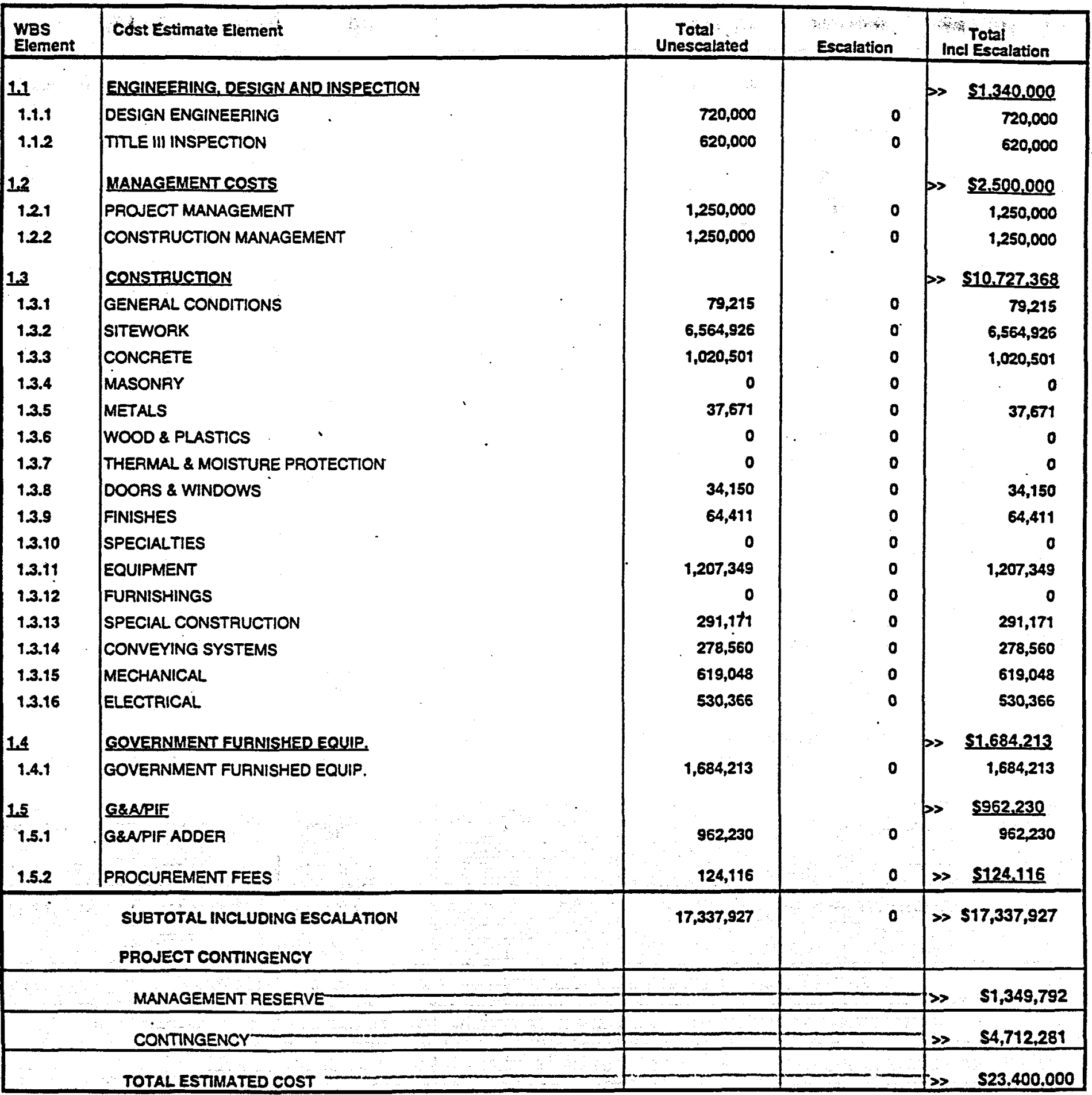

\section{PRONECT COST PARAMETERS}

EDI AS A $\%$ OF CONST. + GFE $=11.00 \%$ 
Lockheed Martin Idaho Technologies Co.

COST ESTIMATE SUMMARY

PROAECT NUE: HLW ES -WASTE TREATMENT SCOPING STUDIES TMPE OF ESTIMATE: PLANNING

LOCATON t:

INEEL - ICPP

PROLECT NO:

2414-14 (CSSF 4 )

REOUESTOR:

KL MLLLAMS

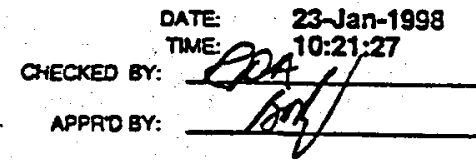

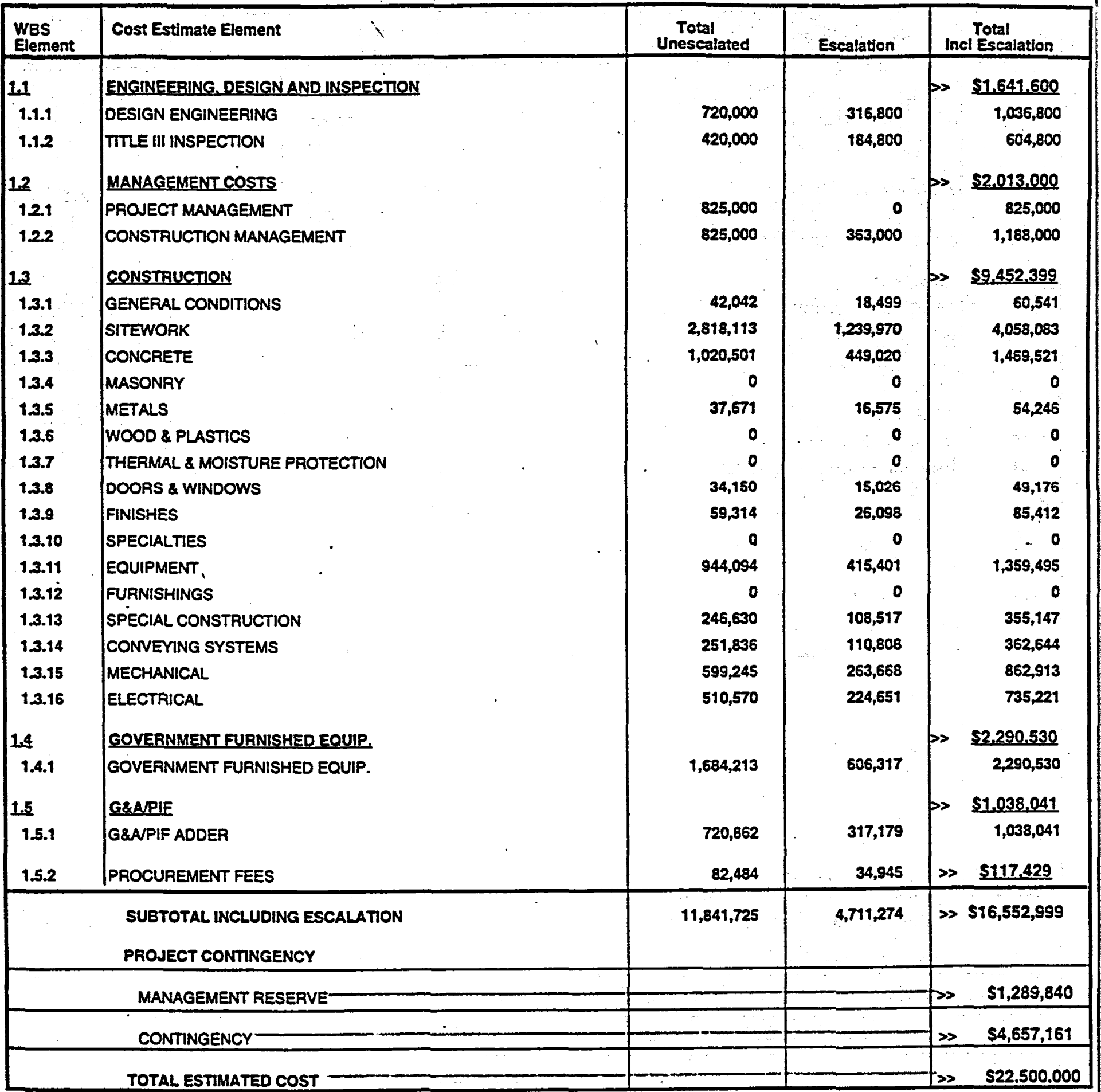

\section{PROJECT COST PARAMETERS}

EDI AS A \% OF CONST. + GFE= $14.00 \%$ 
Lockheed Martin Idaho Technologies Co.

COST ESTIMATE SUMMARY

PAOAECT NMME: HLW EIS -WASTE TREATMENT SCOPING STUDIES TYPE OF ESTIMATE: PLANNING CALCINE RETRIEVAL AND TRANSPORT-OPTION B PROJECT NO: $2414-14$ (CSSF 4) LOCATION 1: INEEL - ICPP

REQUESTOR: K. L. WLLIAMS PAEPARED BY: F.P. HANSON REPORT NUME: Cost Estimate Summary

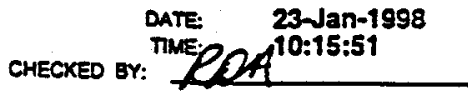

APPRO BY:

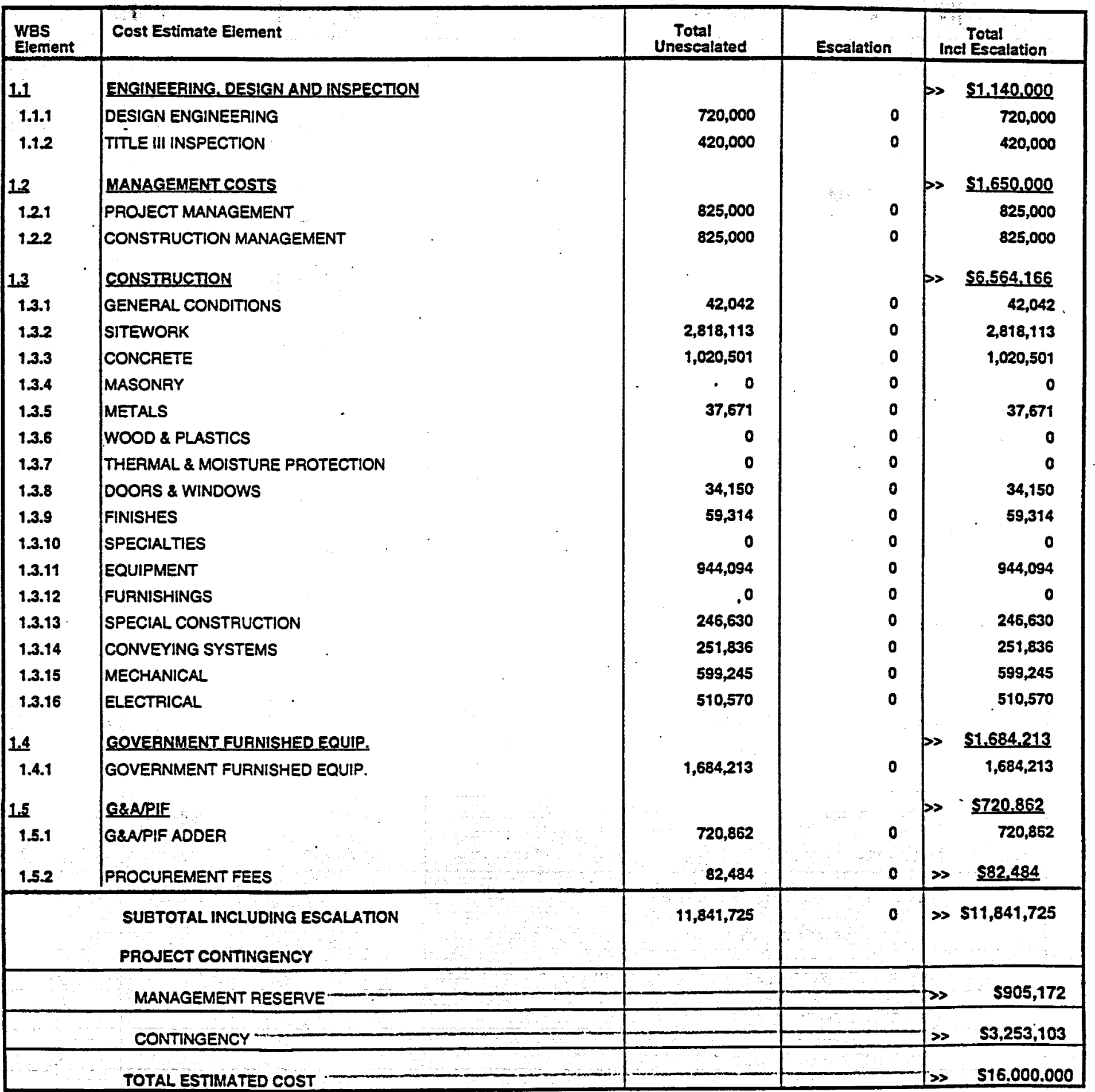

PROJECT COST PARAMETERS

EDI AS A $\%$ OF CONST. + GFE $=14.00 \%$

CONTINGENCY $=35.12 \%$ 
Lockheed Martin Idaho Technologies Co. PROJECT Nare REQUESTOA:
COST ESTIMATE SUMMARY

PLANNING

2414-1-5 (CSSFs 5 - 7)

PREPARED BY: F.P. HANSON
AEPORT NMUE: Cosi Estimate Summary
LOCATION :

\section{CAL}

K.LWILUAMS CALCINE AET

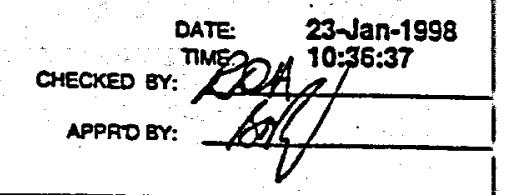

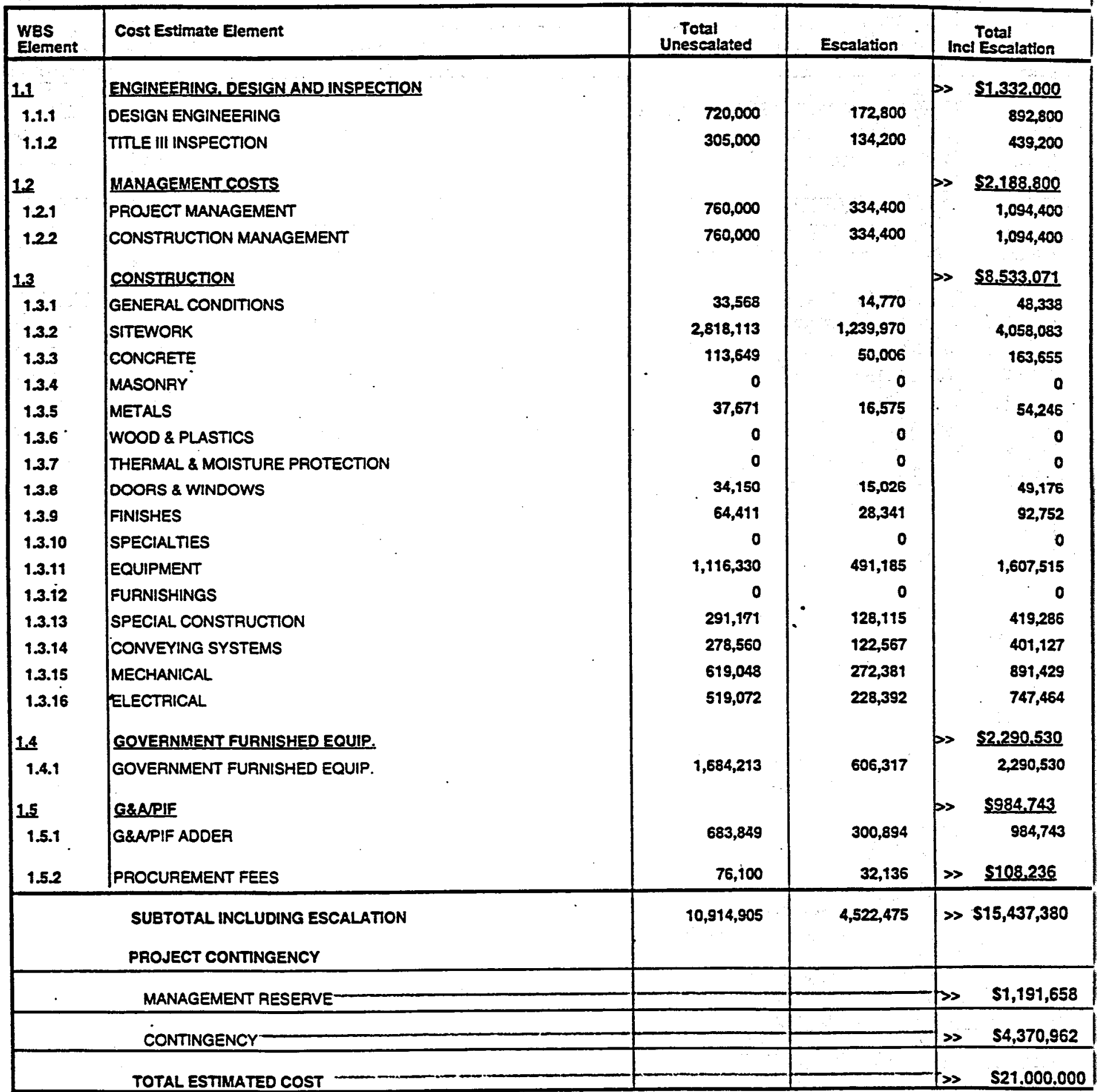

PROJECT COST PARAMETERS

EDI AS A \% OF CONST. + GFE $=12.00 \%$ CONTINGENCY $=36.03 \%$ 
Lockheed Martin Idaho Technologies Co.

PROJECT NAME: HLW EIS -WASTE TREATMENT SCOPING S TUDIES TYPE OF ESTIMATE: PLANNING

LOCATON 1: CALCINE RETRIEVAL AND TRANSPORT - OPTION B INEEL - ICPP

2414-1-5 (CSSFs 5 - 7 )

RECUESTOR:

K.L. WLLIAMS

$\begin{array}{ll}\text { PROJECT NO: } & 2414-1-5 \text { (CSS } \\ \text { PREPARED BY: } & \text { F.P. HANSON }\end{array}$

Cost Estimate Summary

CHECKED 8Y: ${ }^{\text {OATE: }}$ ROA $^{\text {23-Jan-1998 }}$

APPRD BY:

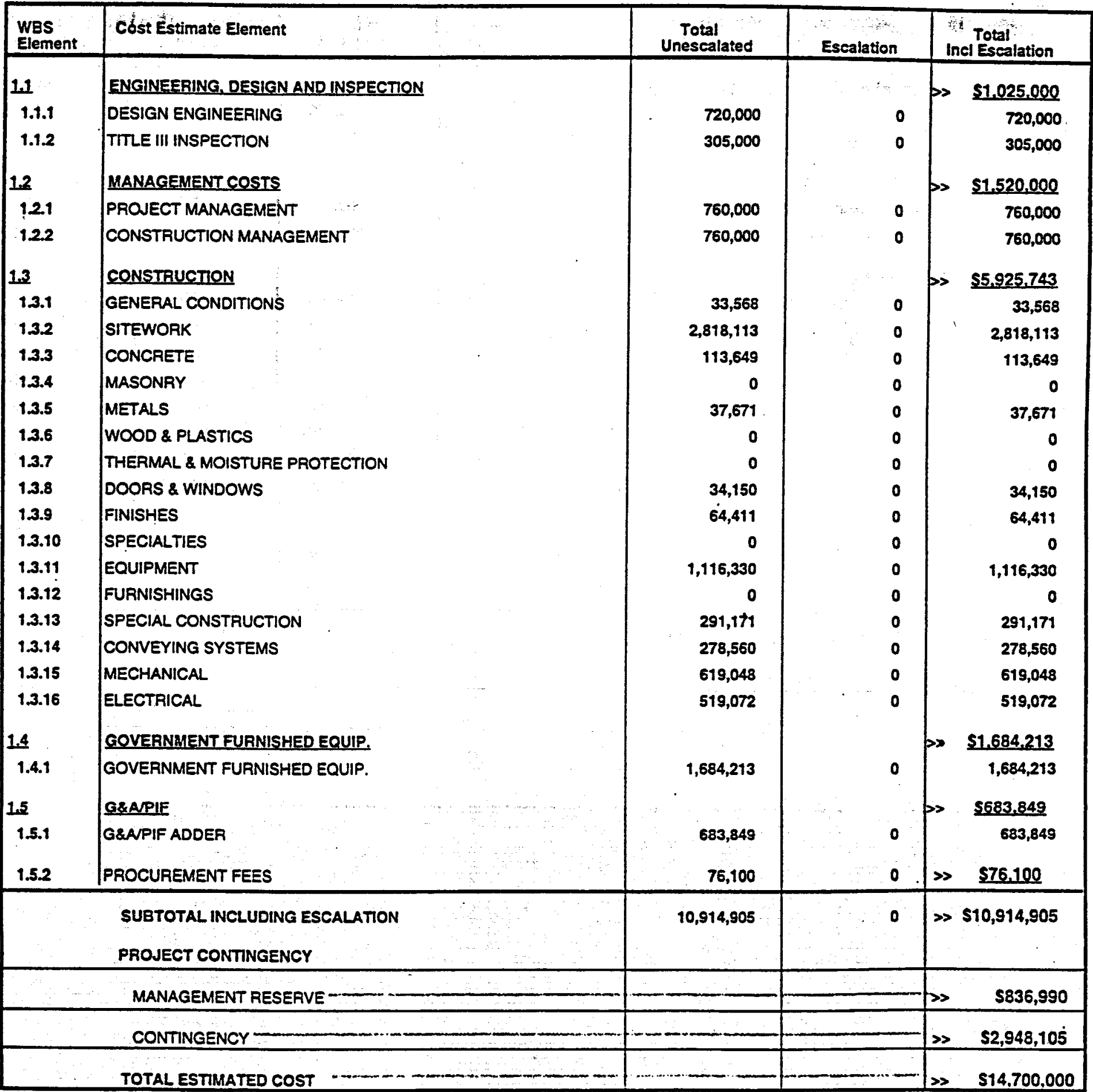

PROJECT COST PARAMETERS

EDI AS A $\%$ OF CONST. + GFE $=13.00 \%$

CONTINGENCY $=34.68 \%$ 
Lockheed Martin Idaho Technologies Co.

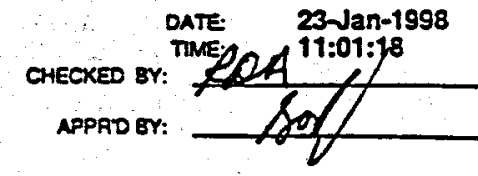

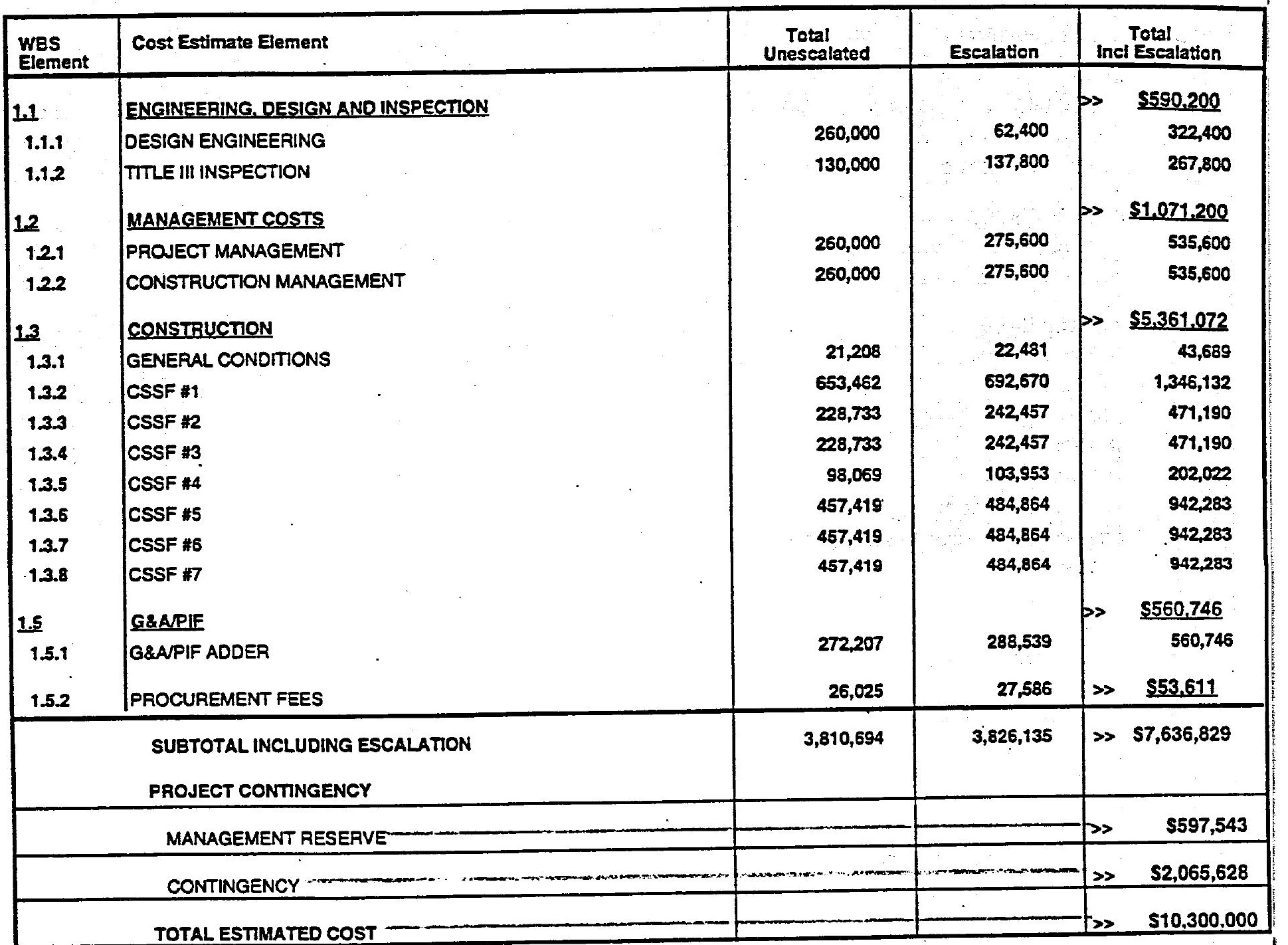

PROJECT COST PARAMETERS

EDI AS A \% OF CONST. + GFE $=11.00 \%$ 
Lockheed Martin Idaho Technologies Co.

COST ESTIMATE SUMMARY

PROUECT NAME: HLW EIS -WASTE TREATMENT SCOPING STUDIES MPE OF ESTIMATE: PLANNING $\begin{array}{lll} & \text { CALCINE RETRIEVAL AND TRANSPORT } & \text { PROECT NO: 2414-1 (DED FISERS) } \\ \text { LOCATON : } & \text { PREPARED QY: F.P.HANSON }\end{array}$

AEOUESTOR: KL MILLIAMS PREPARED 8Y: F.P. HANSON
REPORT NAME: Cost Estimate Summary

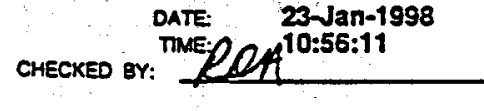

APPRD BY:

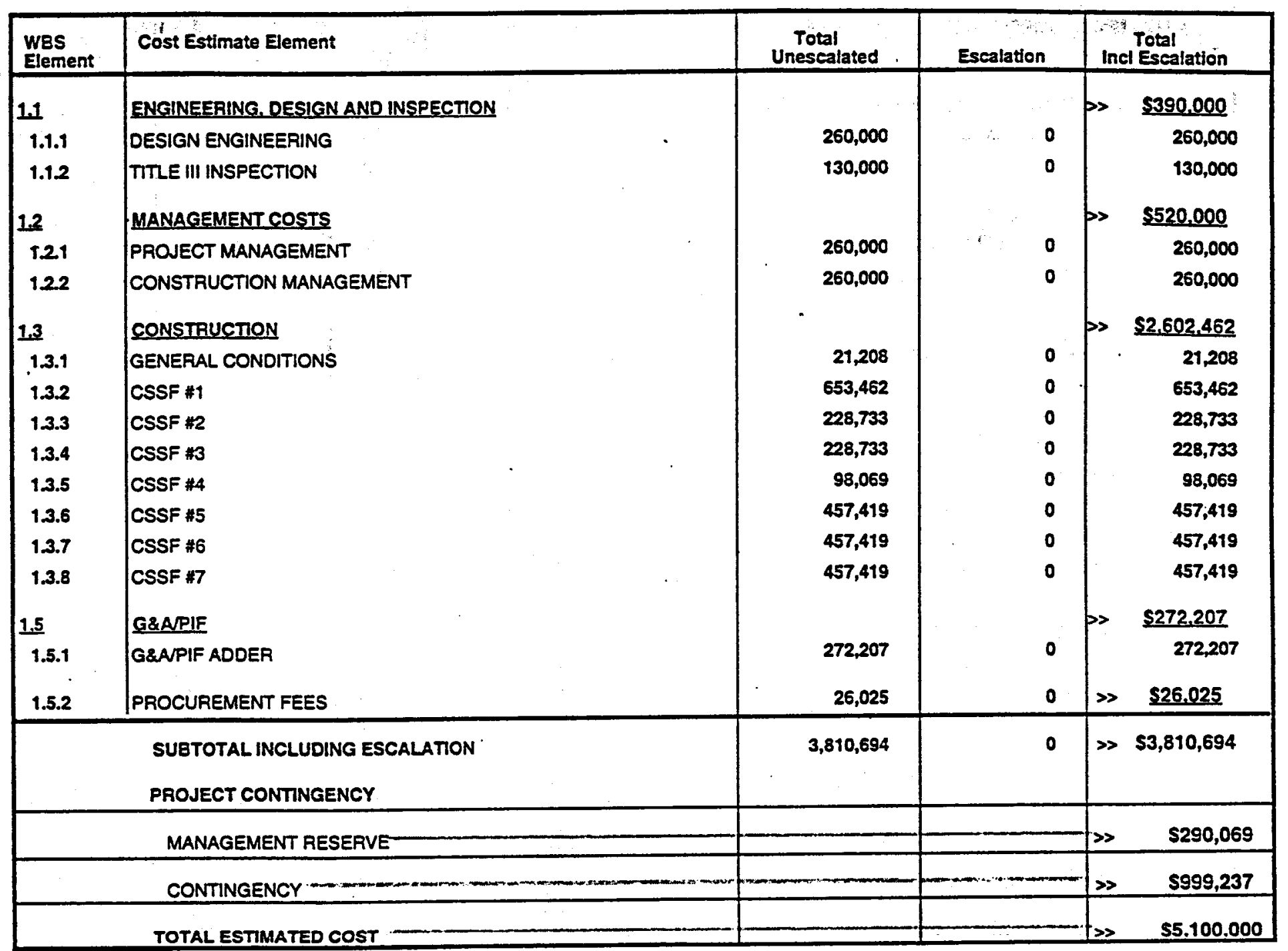

\section{PROJECT COST PARAMETERS}

EDI AS A \% OF CONST. + GFE $=15.00 \%$

CONTINGENCY $=33.83 \%$ 
Lockheed Martin Idaho Technologies Co.

Pauect

LOCATION i: HLW EIS -WASTE TREATMENT SCOPING
CALCINE RETRIEVAL AND TRANSPORT CALCINE RE
INEEL - ICPP

REQUESTOA:

INEEL-ICPP
COST ESTIMATE SUMMARY
PLANNING

2414-1 (CORR CPNS) PROAECT NO PREPAAED BY: REPORT NAME: Cost Estimate SUmmary

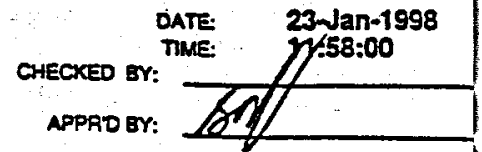

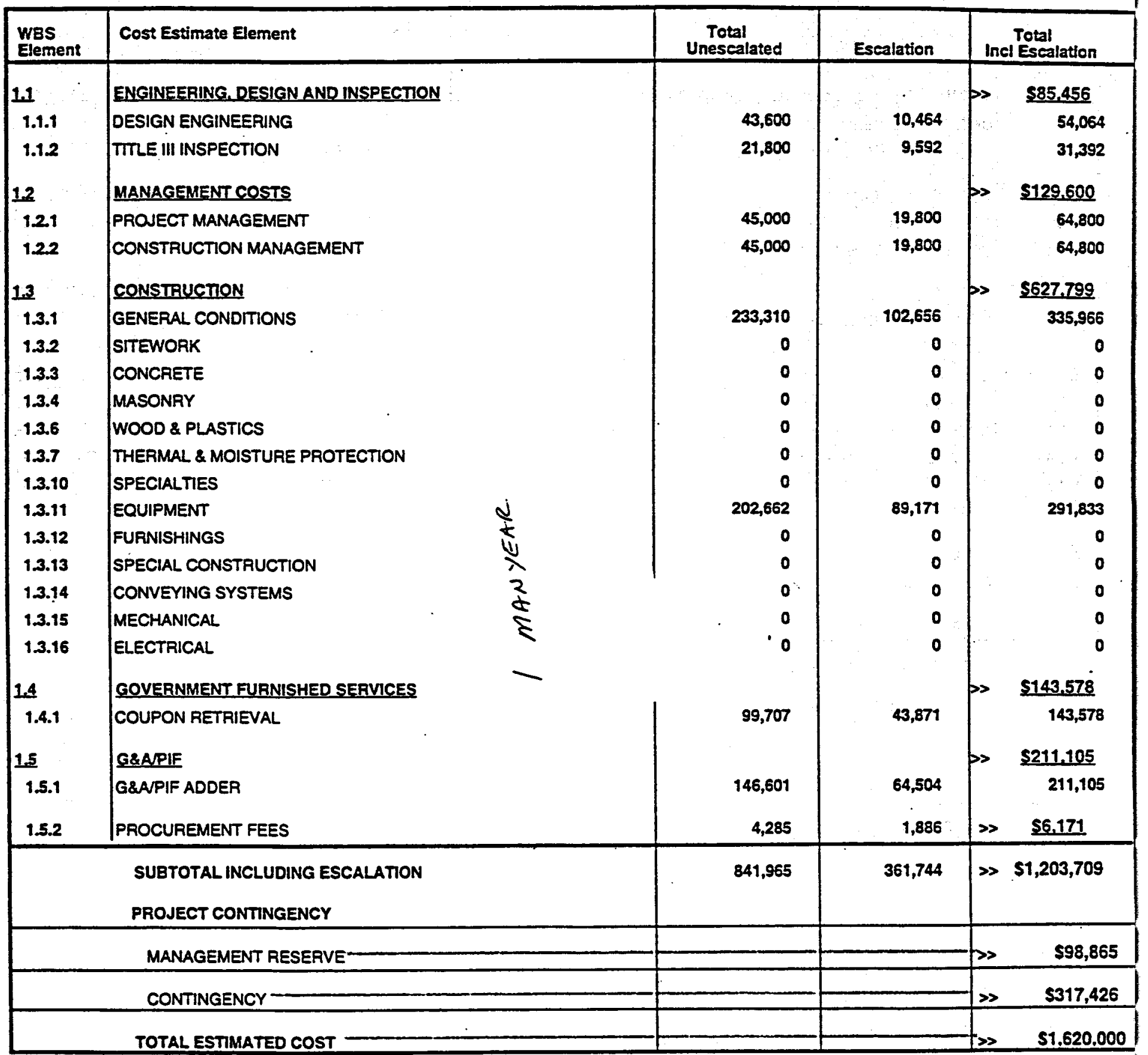

PROJECT COST PARAMETERS

EDI AS A \% OF CONST. + GFE= $11.00 \%$ 
Lockheed Martin Idaho Technologies Co.

COST ESTIMATE SUMMARY

PROSECT NUME: HLW EIS -WASTE TREATMENT SCOPING STUDIES TPE OF ESTIMATE: PLANNING

LOCATION 1:

CALCINE RETRIEVAL AND TRANSPORT

REOUESTOR:

INEEL - ICPP

PAOAECT NO:

PAEPARED BY:

2414-1 (CORR CPNS)

REPORT NAME:

F. P. HANSON

K.L WILLIAMS

ost Estimate Summary

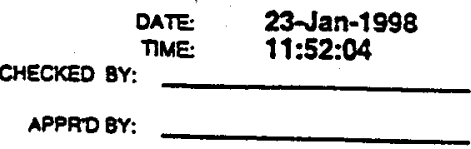

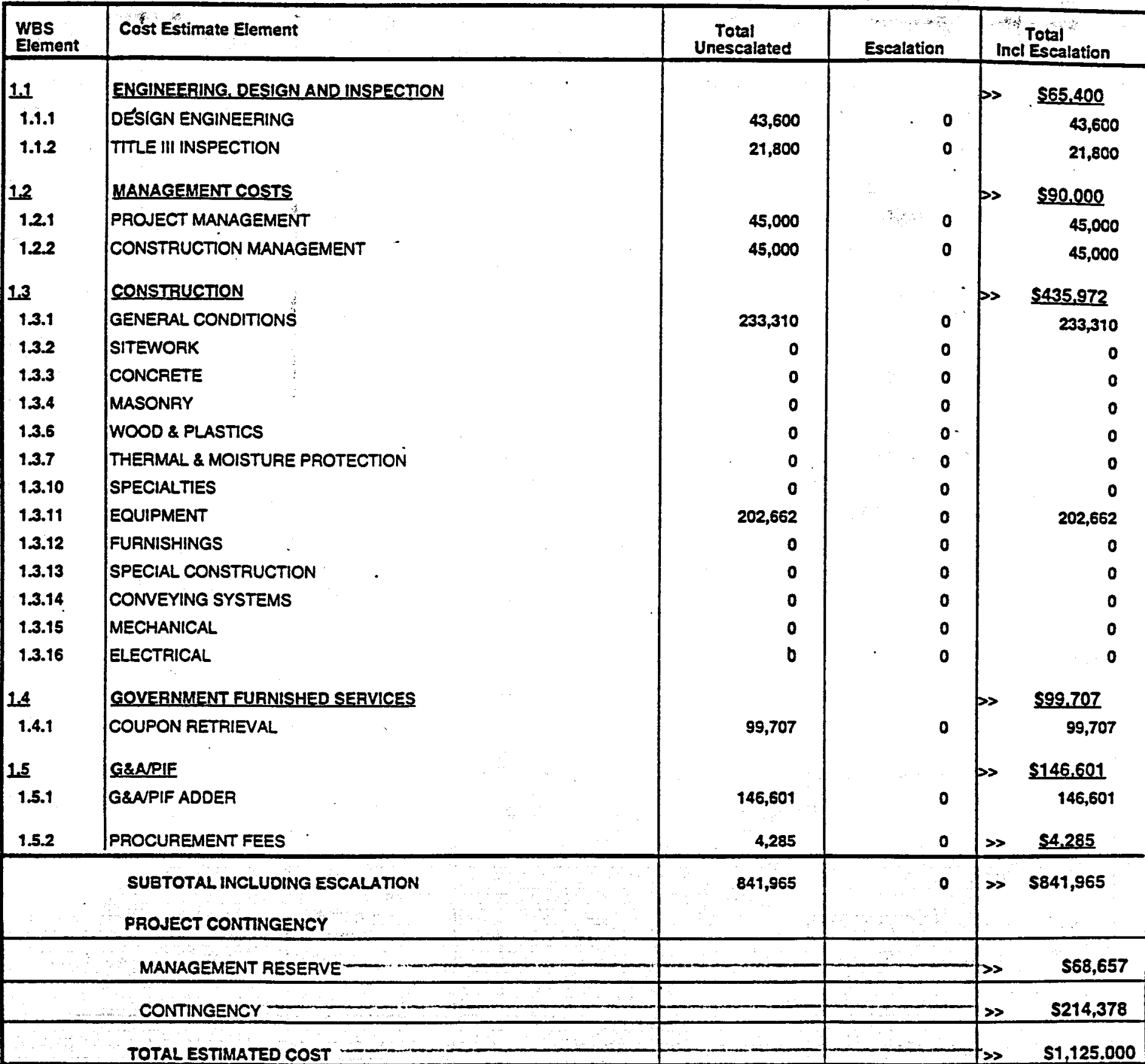

PROJECT COST PARAMETERS

EDI AS A $\%$ OF CONST. + GFE $=12.00 \%$

CONTINGENCY $=33.62 \%$ 
Lockheed Martin Idaho Technologies Co.

Provect vaus

LOCATON 1:

REOUESTOR:

CALCINE RETRIEVAL AND TRANSPORT - OPTION B INEEL - ICPP

K. L WILLIAMS
COST ESTIMATE SUMMARY

PE OF ESTIMATE: PLANNING

PAOLECT NO: $\quad 2414-1$ (TRANS SYS A)

PREPARED BY: F. P. HANSON

REPORT NAME: Cost Estimate Summary

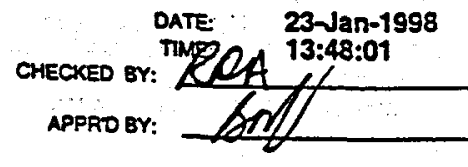

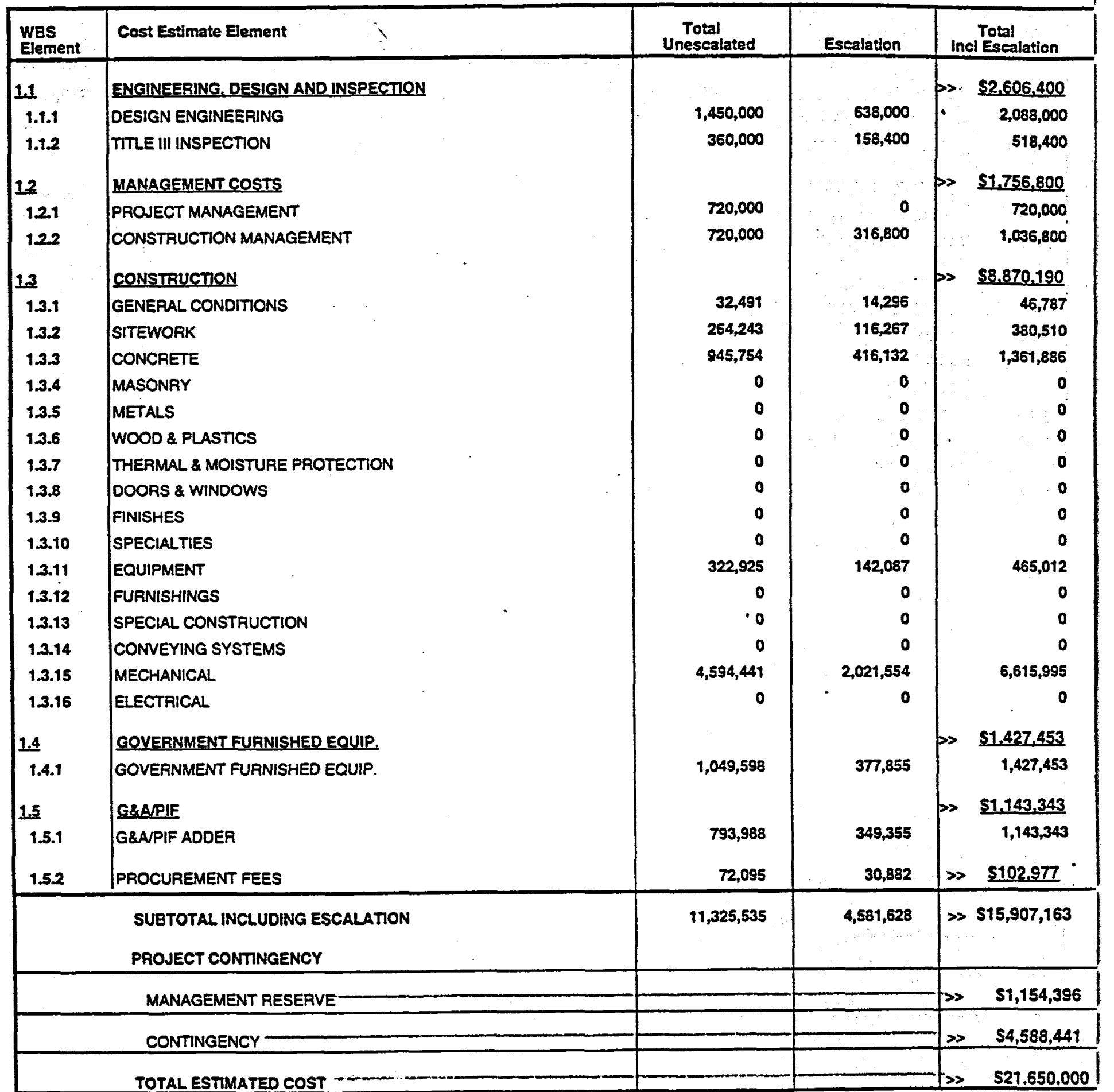

PROJECT COST PARAMETERS

EDI AS A \% OF CONST. + GFE $=25.00 \%$

CONTINGENCY $=36.10 \%$ 
Lockheed Martin Idaho Technologies Co. COST ESTIMATE SUMMARY

PROIECT NAME: HLW EIS -WASTE TREATMENT SCOPING STUDIES TYPE OF ESTIMATE: PLANNING CALCINE RETRIEVAL AND TRANSPORT - OPTION B PROAECT NO: 2414-1 (TRANS SYS A)
LOCATON 1: INEEL - ICPP REOUESTOR: KL WLLLAMS REPOAT NAME: Cost Estimate Summary

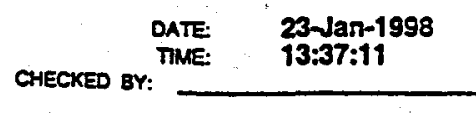

APPAD BY:

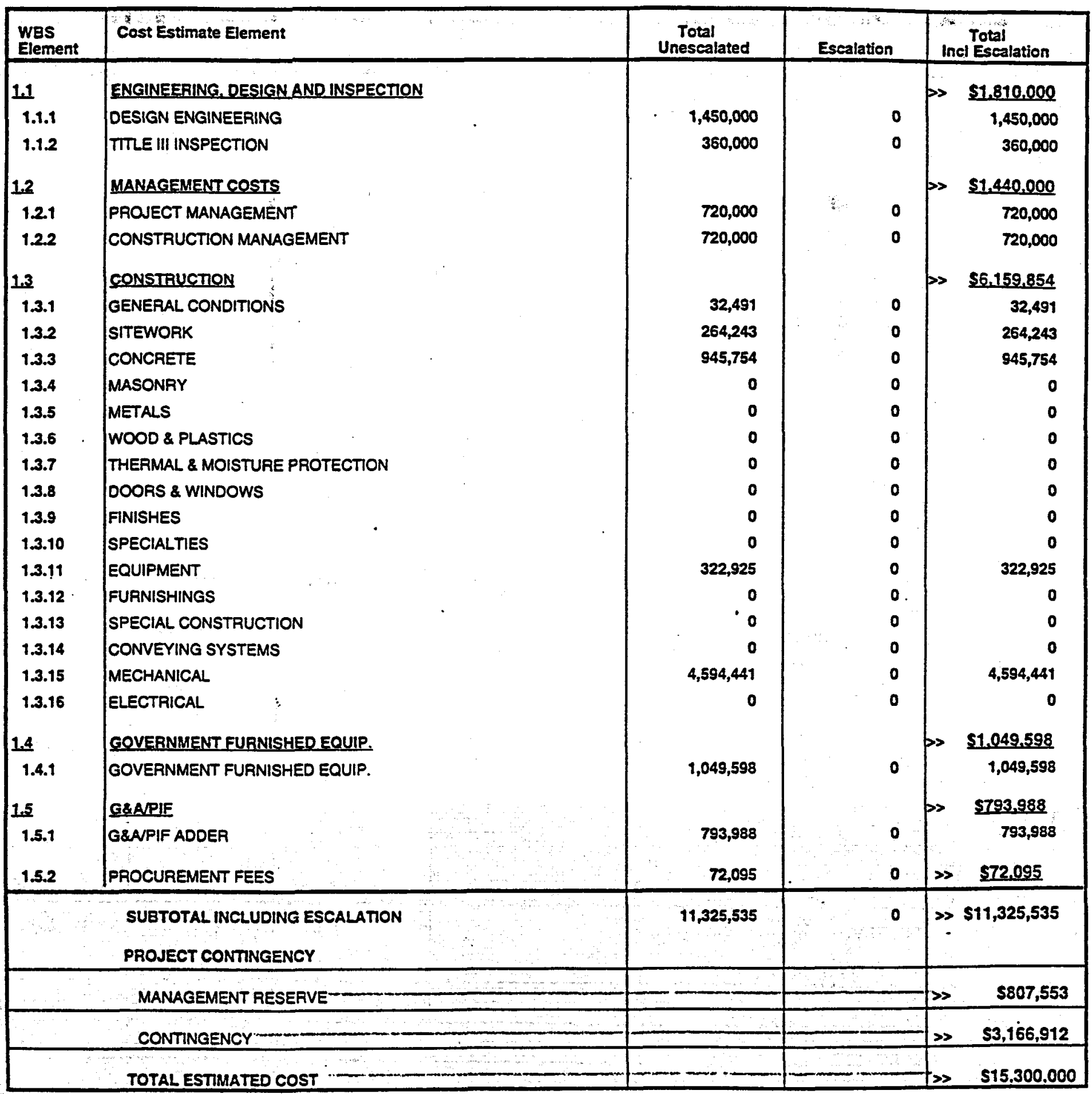

\section{PROJECT COST PARAMETERS}

EDI AS A \% OF CONST. + GFE $=25.00 \%$ 
Lockheed Martin Idaho Technologies Co. PROAECT VWME: HLW EIS -WASTE TREATMENT SCOPING STUDIES TYPEOFESTIMATE PLANNING LOCATION I: AECUESTCR: CAL CINE RETRIEVAL AND TRANSPORT - OPTION B PRONET NO. INEEL - ICPP K. L WILLIAMS
2414-1 (TRANS SYS B)

F.P. HANSON REPORT NAME: Cost Estimate Summary
OATE:
CHECKEO BY:
AME:
APPRD BY:

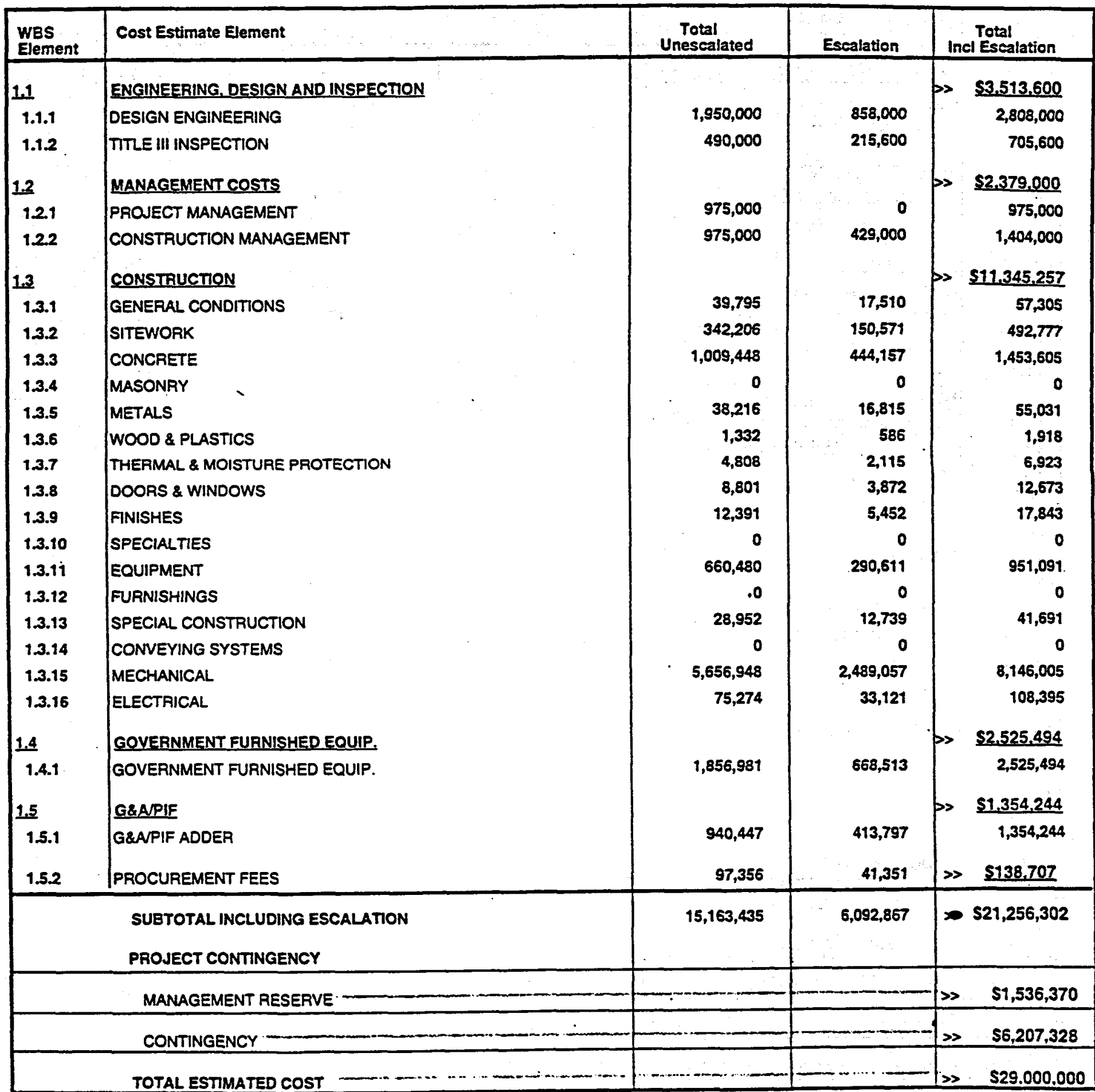

\section{PROJECT COST PARAMETERS}

EDI AS A \% OF CONST. + GFE $=25.00 \%$ 
Lockheed Martin Idaho Technologies Co. PROJECT NAME: HLW EIS -WASTE TREATMENT SCOP

LOCATION T:

REOUESTOR:

INEEL - ICPP

K. L WILLAMS
CALCINE RETIE TREATMENT SCOPING STUDIES TYPE OF ESTIMATE:
COST ESTIMATE SUMMARY

PLANNING

2414-1 (TRANS SYS B)

F. P. HANSON

PREPARED 8Y: Cost Estimate Summary

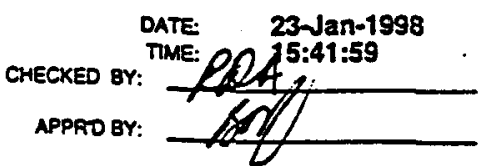

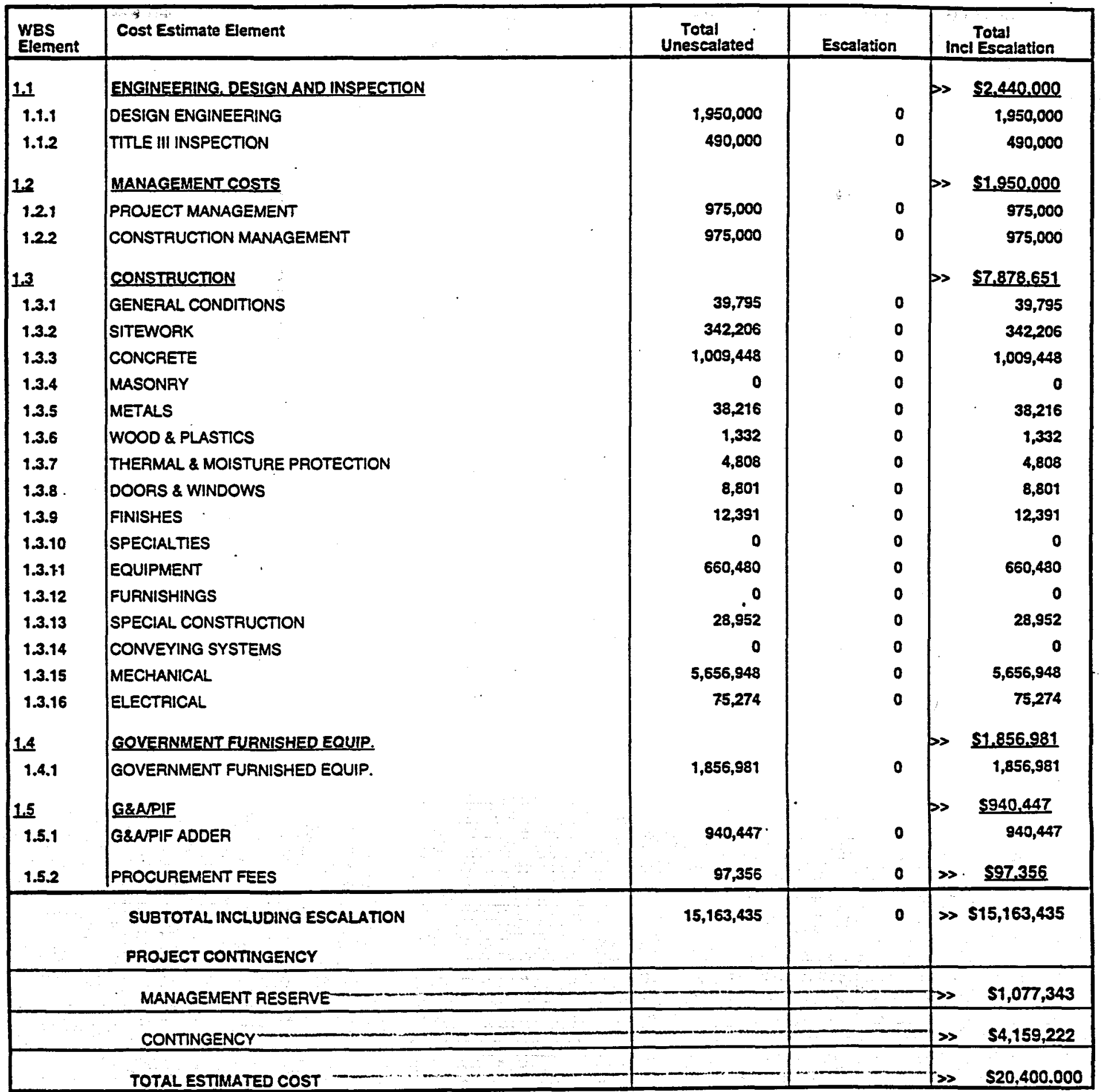

PROJECT COST PARAMETERS

EDI AS A \% OF CONST. + GFE $=25.00 \%$ 
Date: January 28, 1998

To:

S. E. Gifford

MS 3765

6-5162

From:

R. J. Turk Pflach

MS 3875

$6-3611$

Subject: ECONOMIC AND LIFE CYCLE ANALYSIS CONDUCTED FOR CALCINE RETRIEVAL SYSTEM -RJT-08-98

Purpose:

As requested an Economic and Life-Cycle Cost (LCC) has been conducted to evaluate the CALCINE RETRIEVAL SYSTEM. This process is proposed to retrieve calcine from the Calcine Solids Storage Facilities (CSSF) and transport it to the waste treatment facility. The calcine retrieval and transportation system is designed to supply calcine to the treatment options of Vitrification, Direct Cementitious, Cementitious, Hot Isostatic Pressing and TRU currently understudy. A five and a twenty-year option utilizing a transport system "A or B" per your direction was conducted to coincide with various waste treatment activities.

This economic analysis is based on information provided by Karen Williams, Sara Gifford, A. E. Lee, Ron DaFoe, Dan Griffith, D. Lopez, N. Russell, B. Landman, R. Kimmett and other team members.

F. P. Hanson provided cost estimates. Jack Prendergast provided process personnel modeling.

\section{Methodology:}

The Economic Evaluation assumed a five-year and a 20-year operations period since this is the estimated time required to supply the calcine to the waste treatment options currently being evaluated. The LCC identifies and evaluates the initial development, construction, operation and post-operating costs over the life-cycle. A discounted LCC assumes a current 1998-dollar basis, discounted at $6.30 \%$ annually per the Office of Management and Budget (OMB) Circular A-94. All costs are conservatively discounted assuming the end-of-year convention. 
S. E. Gifford

January 28, 1998

RTT 08-98

Page 2

\section{Assumptions:}

The scope of work and requirements of all related activities are vague at this time. Facility and processing costs were developed from historical experience associated with DD\&D work at the INEEL. The LCC analysis was generated to match cost estimating cost structure. These costs include Permitting, Direct and Indirect Construction, G\&A, Procurement Fee, Engineering, Inspection, Project Management, Construction Management, Escalation and Contingency costs. The design period was assumed to be accomplished in five years with construction completed in six years, complete with eighteen months of start-up and testing. Labor rates were assumed as follows: Managers, \$125/hr; Engineers, \$108 \$/hr; Other Technicians \$ 85/hr; Administration/Support staff $\$ 65 / \mathrm{hr}$; Operators and Maintenance personnel $\$ 65 / \mathrm{hr}$. The operational period for these facilities was modeled for five and twenty years, followed by one year of post-operations activities. Utilities were assumed to cost $\$ 3.00 / \mathrm{sf}$ for the facility. Due to this projects lack of complexity and relative cleanliness this analysis assumed a decommissioning cost equal to $20 \%$ of the unescalated engineering design cost, decontamination costs equal to $5 \%$ of total unescalated pre-operation cost, and demolition costs equal to $8 \%$ of total unescalated pre-operation cost.

Results:

The Five-year operation of the CALCINE RETRIEVAL SYSTEM "A"Option has a Discounted LCC of \$167 million.

The Twenty-year operation of CALCINE RETRIEVAL SYSTEM "A" Option has a Discounted LCC of $\$ 192$ million.

The Twenty-year operation of CALCINE RETRIEVAL SYSTEM "B" Option has a Discounted LCC of \$ 197 million.

Attachments:

cc: R. J. Turk File 


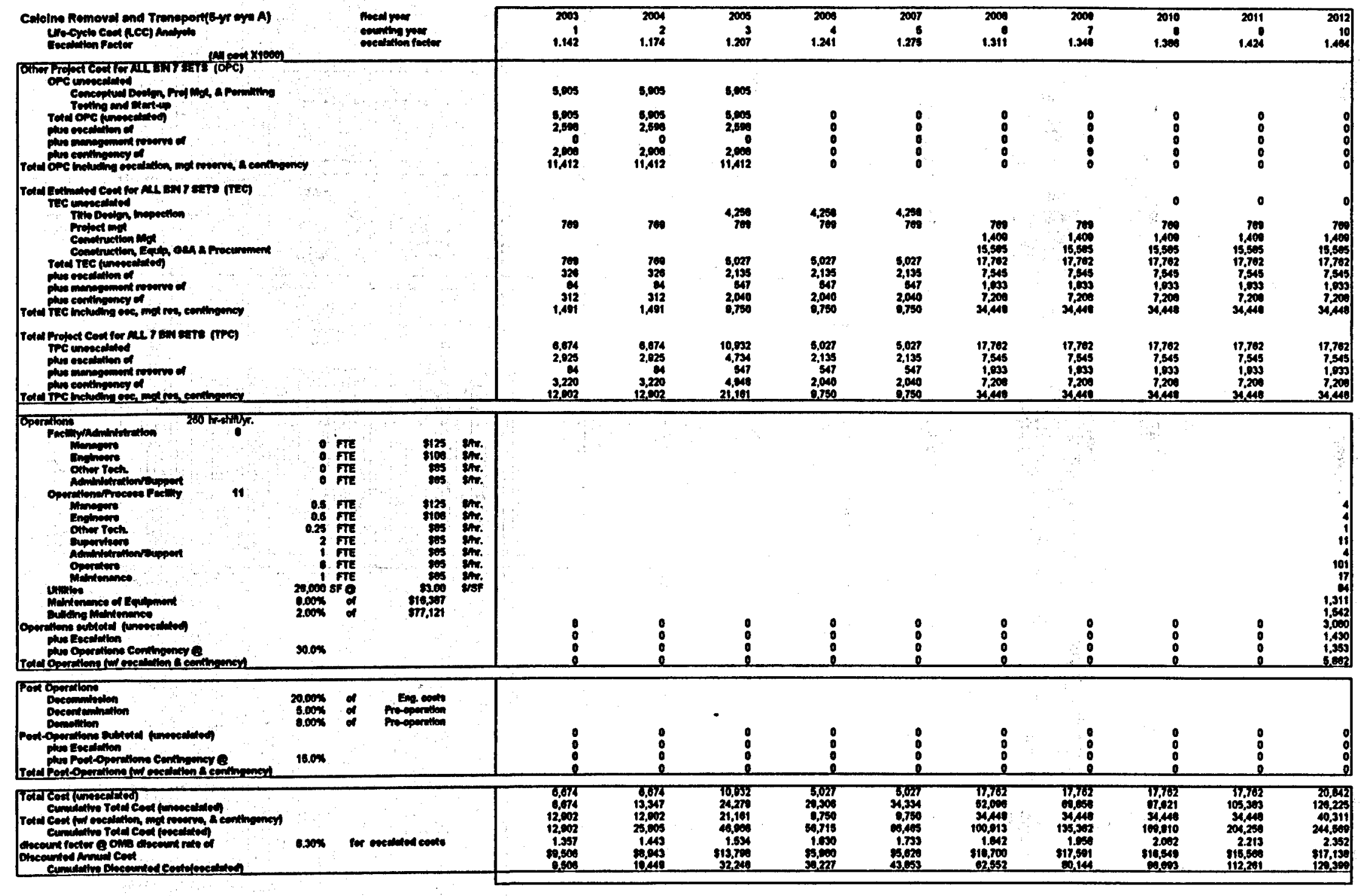




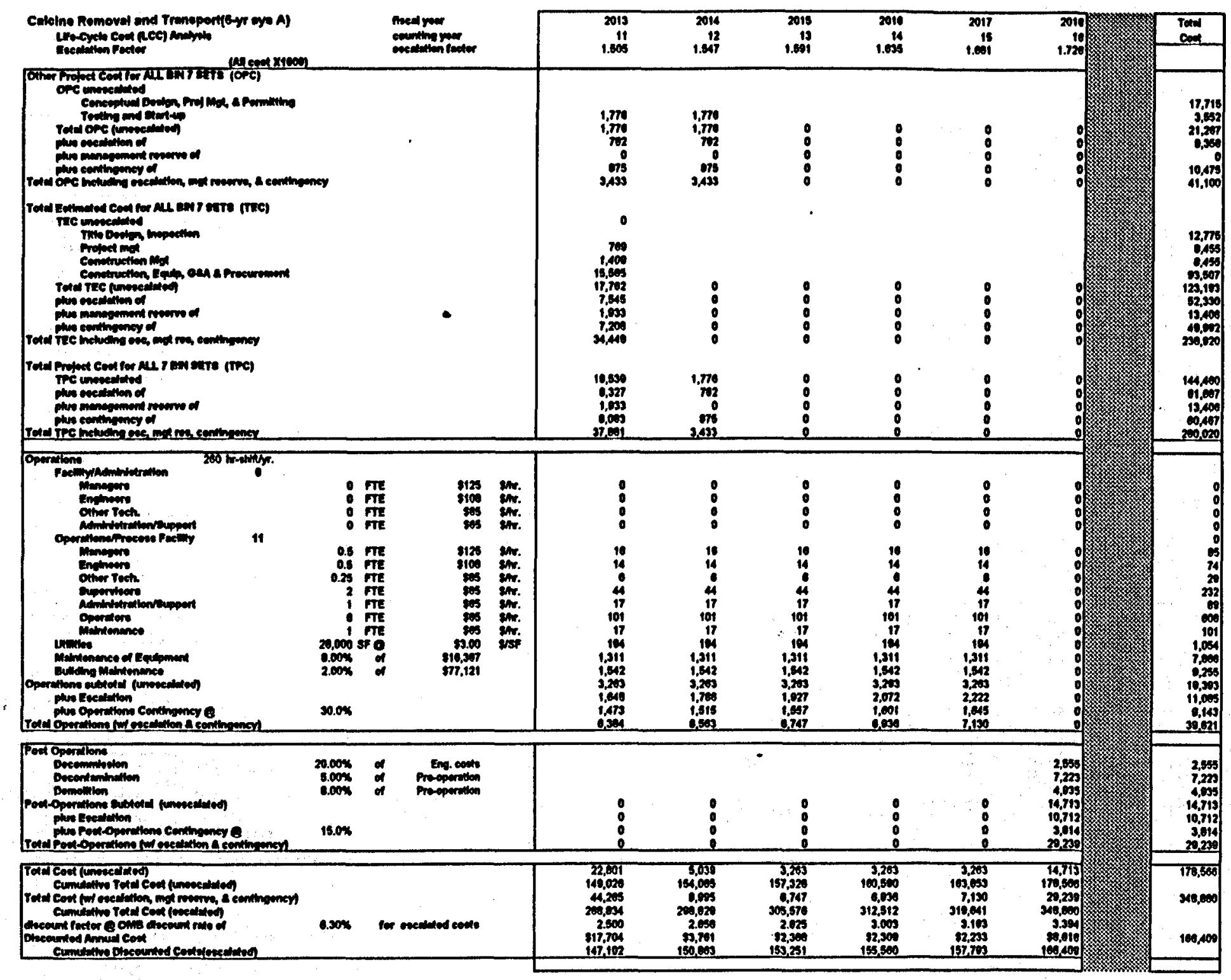




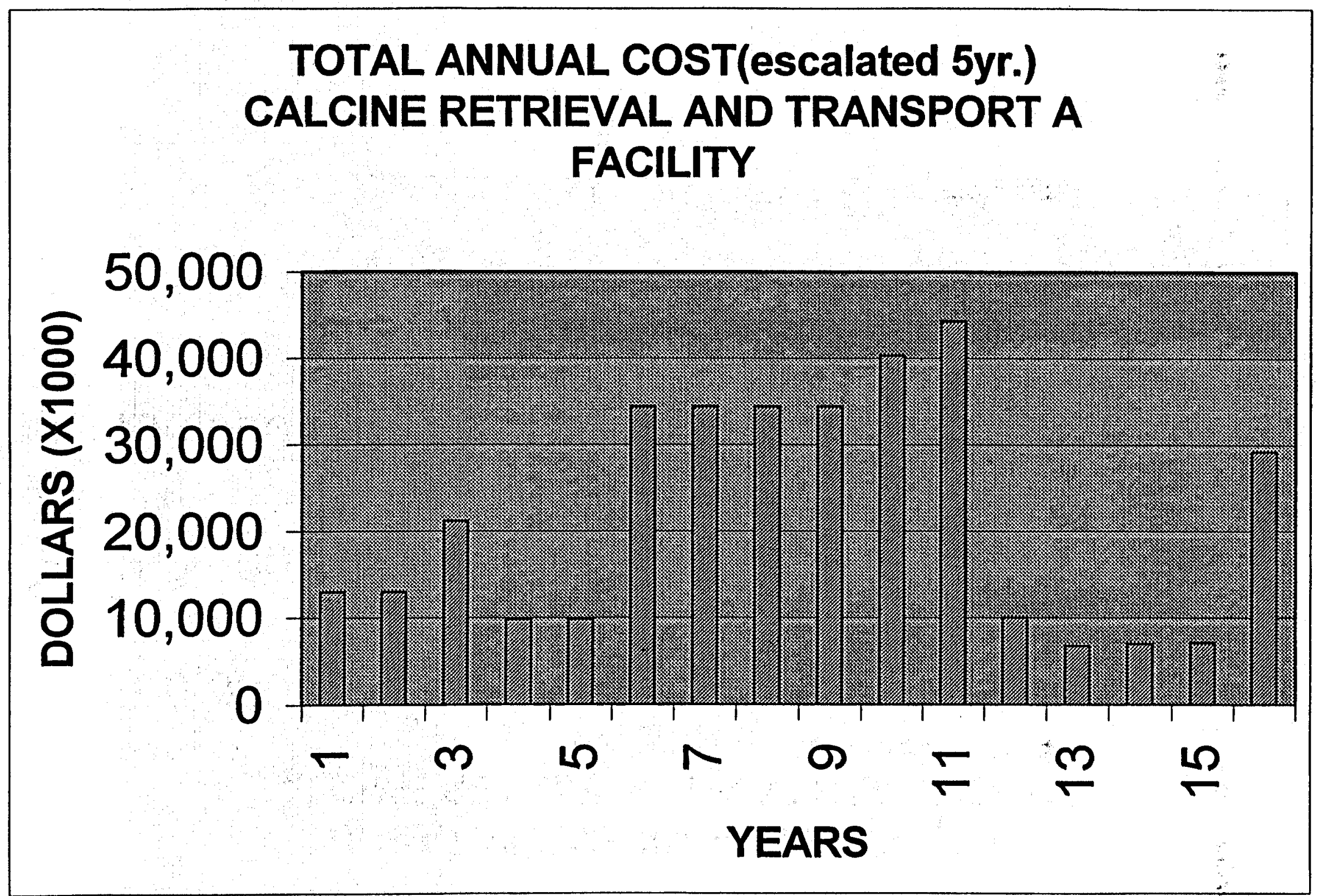




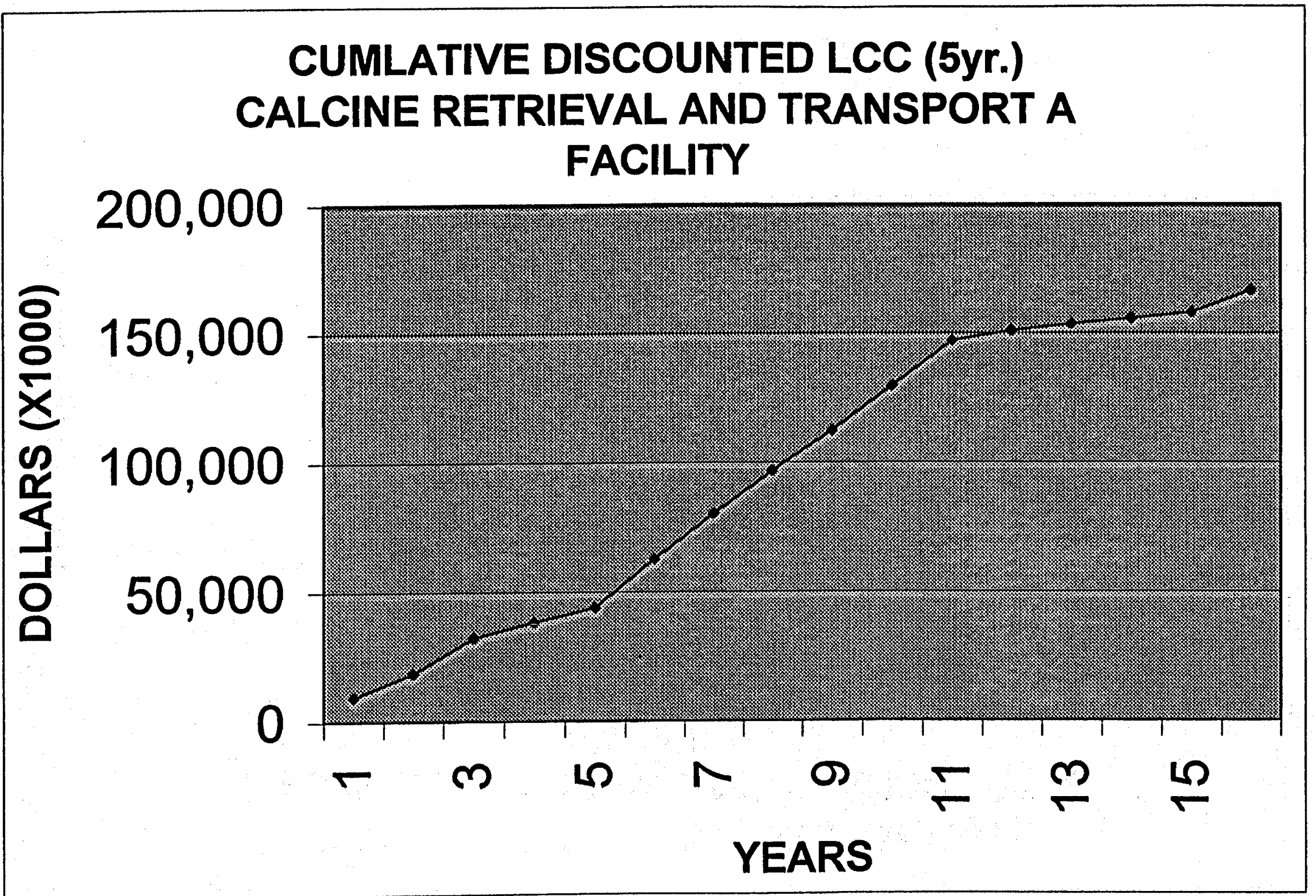




\begin{tabular}{|c|c|c|c|c|c|c|c|c|c|c|c|}
\hline 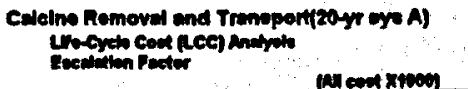 & mecidnom & $\begin{array}{l}2000 \\
1 \\
1.102\end{array}$ & $\begin{array}{r}2004 \\
1.174\end{array}$ & $\begin{array}{r}2005 \\
1.207\end{array}$ & 1.291 & $\begin{array}{l}2007 \\
1.275\end{array}$ & 1.311 & $\begin{array}{l}2009 \\
1.306\end{array}$ & 1.2010 & $\begin{array}{c}2011 \\
1.428\end{array}$ & $\begin{array}{r}2012 \\
10 \\
1.494\end{array}$ \\
\hline 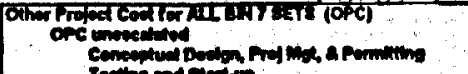 & & 8.005 & 8,005 & s,ms & & & & & & & \\
\hline 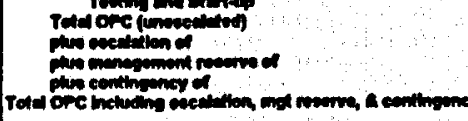 & & $\begin{array}{r}3,000 \\
2,000 \\
2,000 \\
11,12\end{array}$ & $\begin{array}{r}5,009 \\
2,600 \\
2,000 \\
11,412\end{array}$ & $\begin{array}{l}8,005 \\
2,000 \\
2,000 \\
11,112\end{array}$ & $:$ & $\begin{array}{l}: \\
: \\
:\end{array}$ & $:$ & $:$ & $:$ & $:$ & $:$ \\
\hline 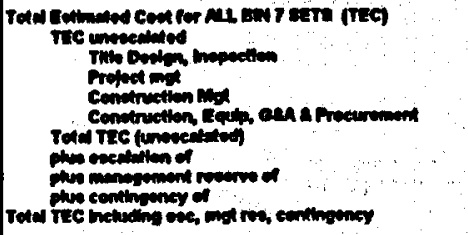 & & $\begin{array}{l}700 \\
700 \\
320 \\
94 \\
312 \\
1,010\end{array}$ & 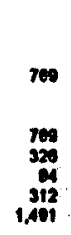 & 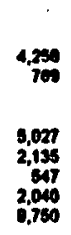 & 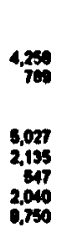 & 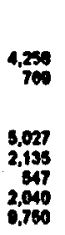 & 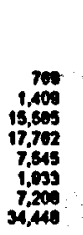 & 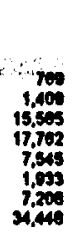 & 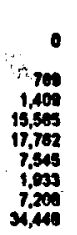 & 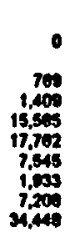 & 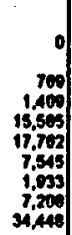 \\
\hline 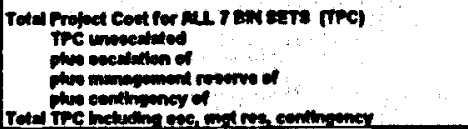 & & $\begin{array}{r}0.074 \\
2,025 \\
3,220 \\
12,2002\end{array}$ & $\begin{array}{r}0.074 \\
2,025 \\
3,2020 \\
12,002\end{array}$ & $\begin{array}{l}10,032 \\
4,734 \\
6,7 \\
1.40 \\
21,101\end{array}$ & $\begin{array}{l}5,027 \\
2,1,15 \\
640 \\
2,0,00 \\
0.730\end{array}$ & $\begin{array}{l}5.027 \\
2,15 \\
547 \\
2.040 \\
0.750\end{array}$ & 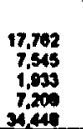 & 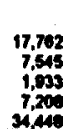 & 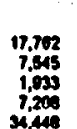 & $\begin{array}{r}17,702 \\
7,345 \\
1,030 \\
7,200 \\
1,40\end{array}$ & 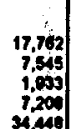 \\
\hline
\end{tabular}
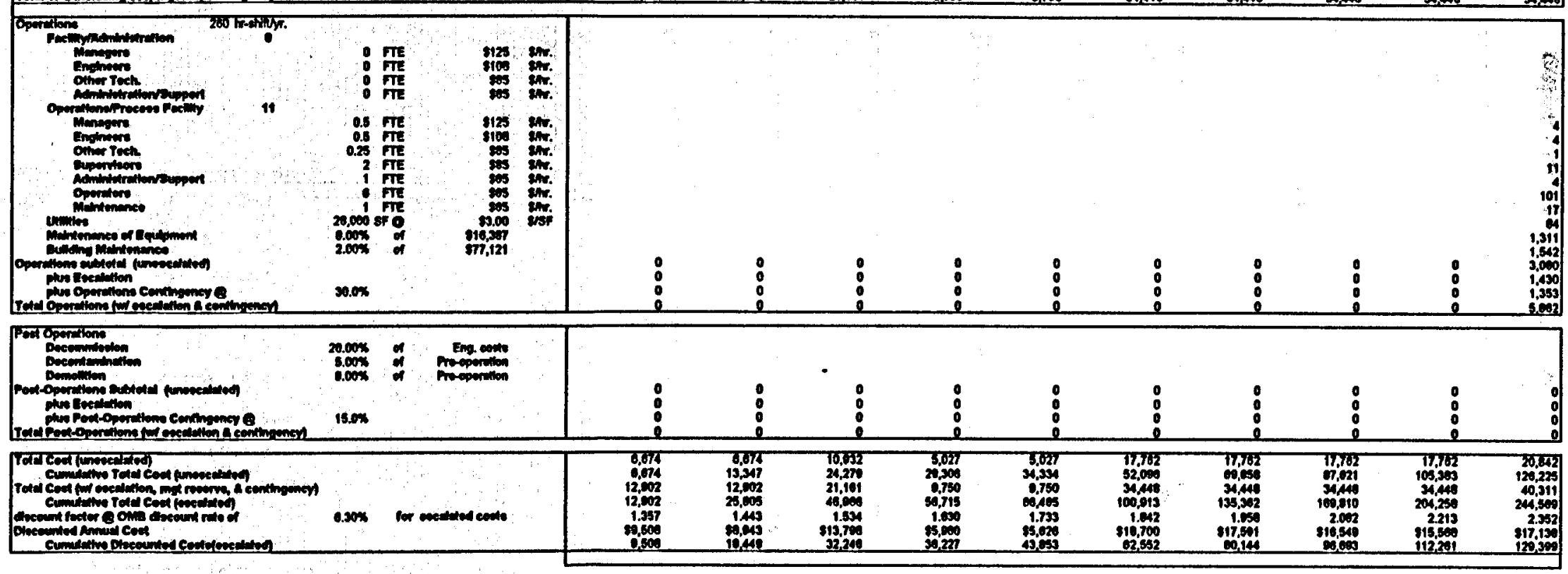


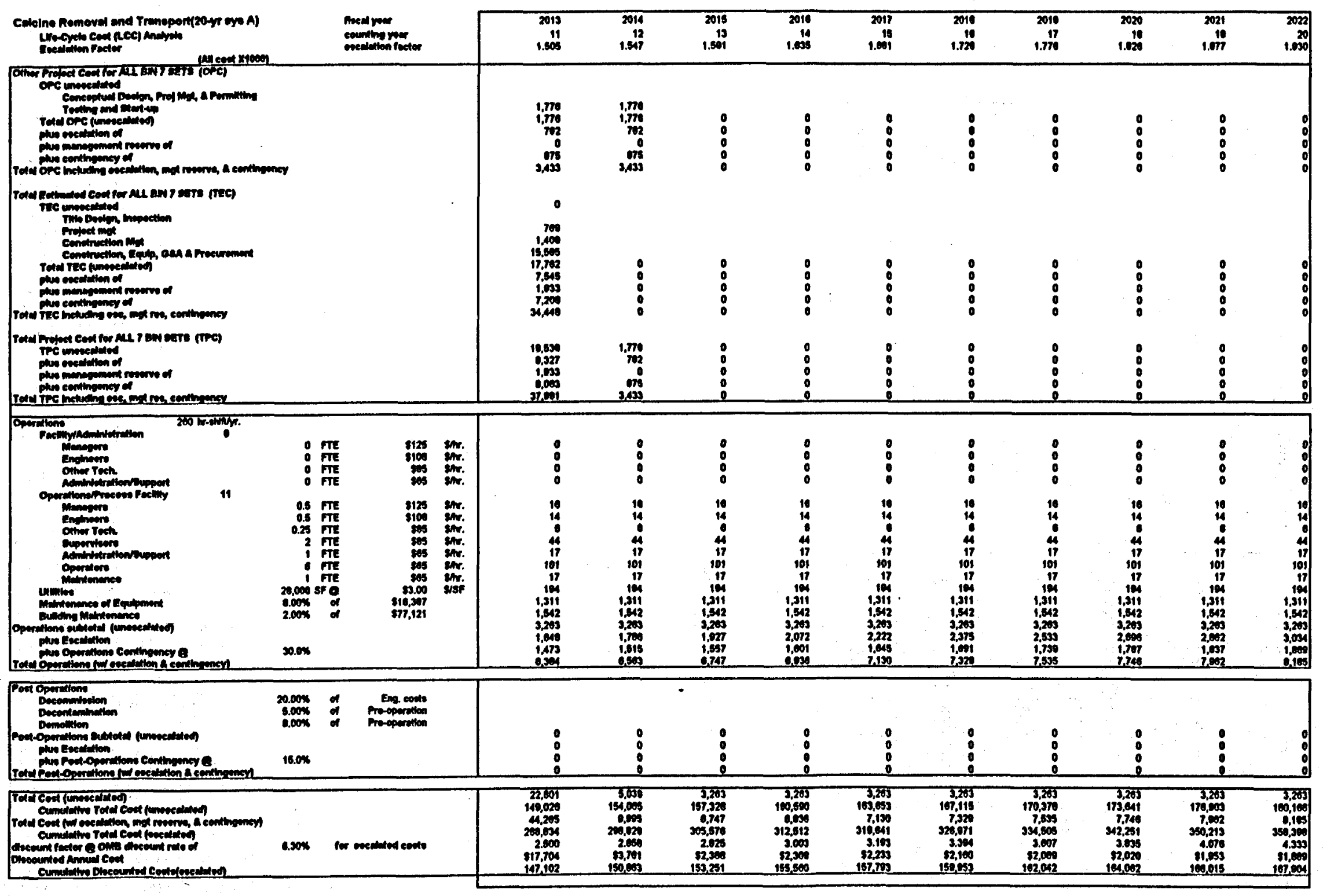




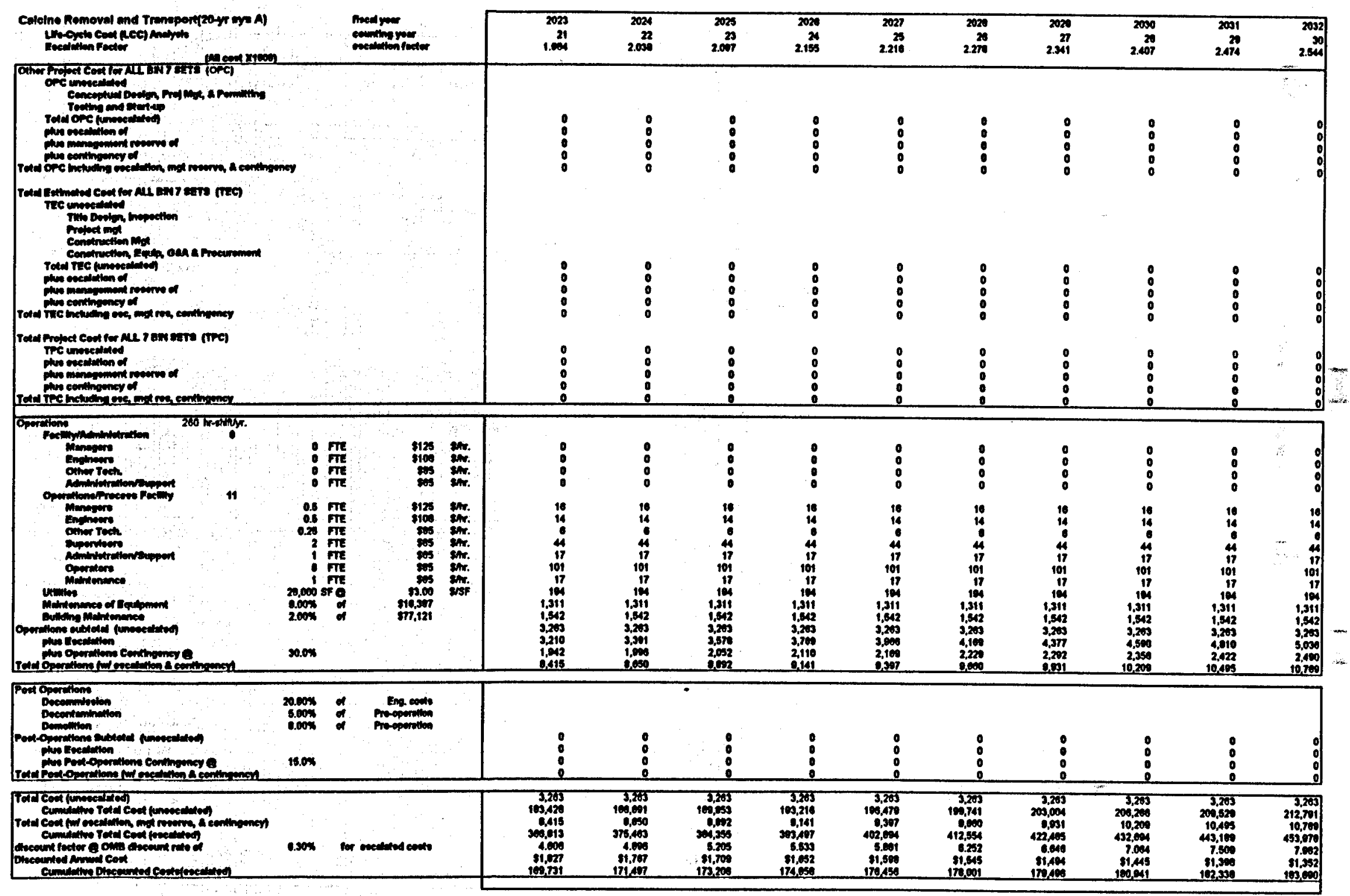




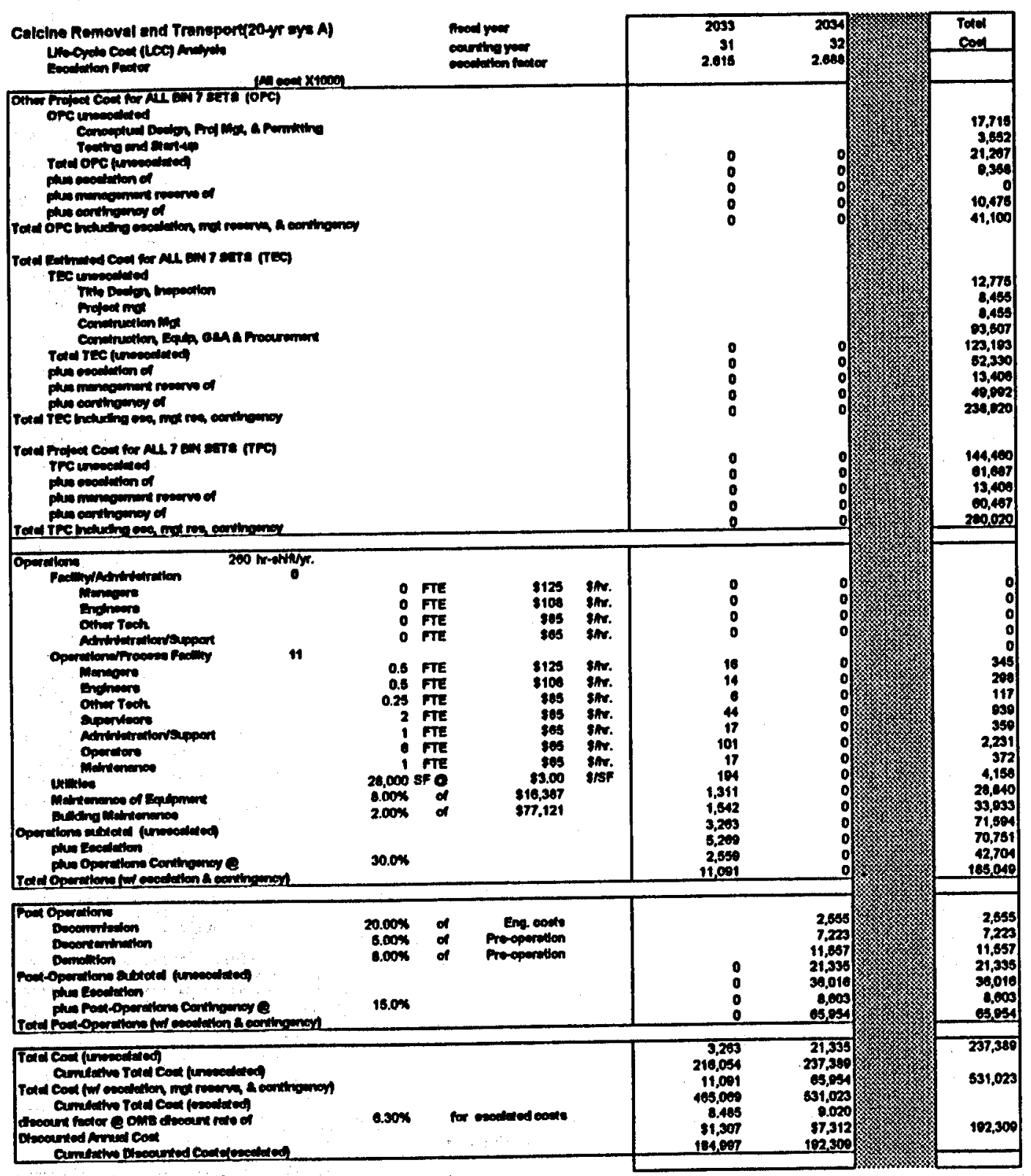




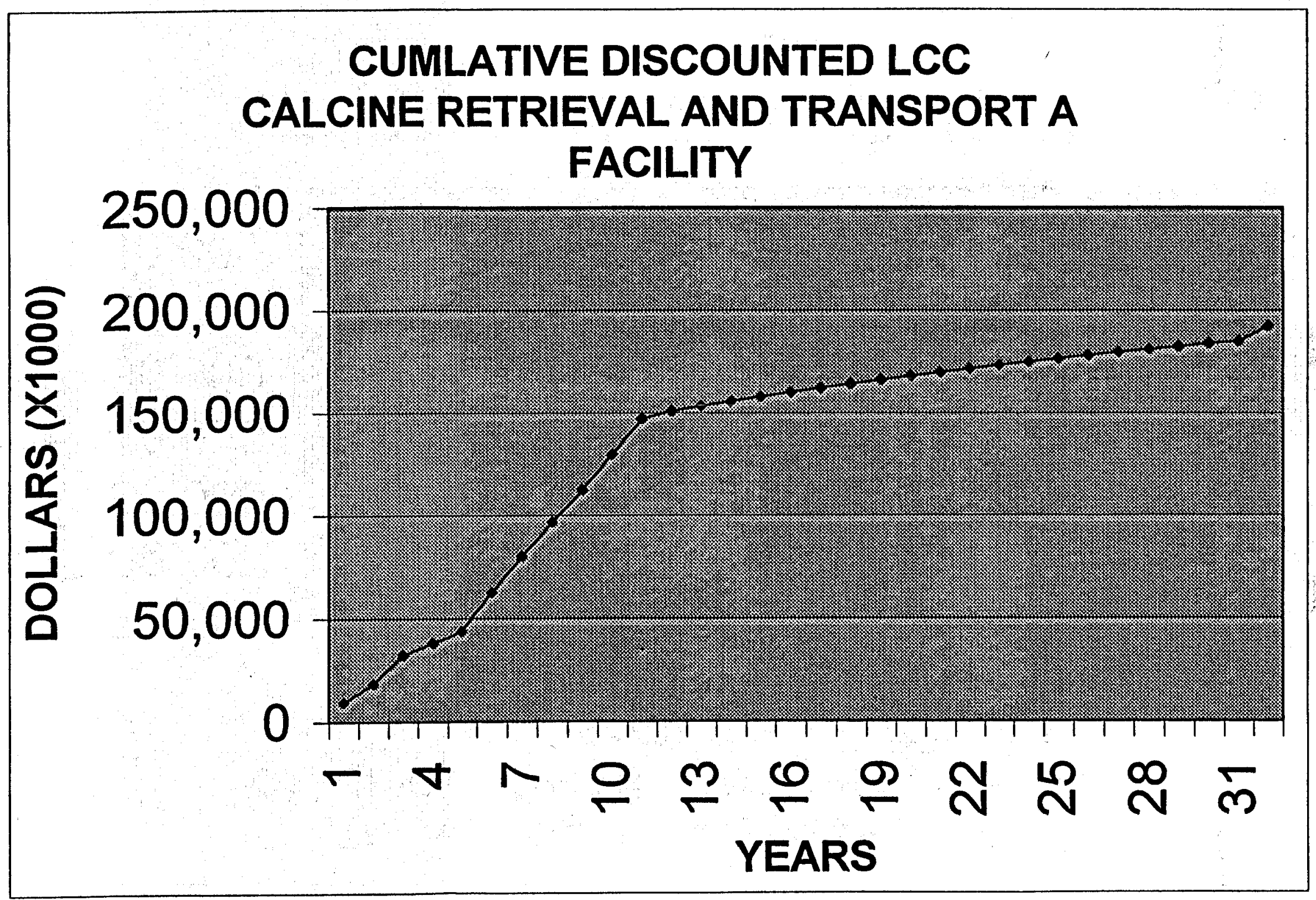




\section{TOTAL ANNUAL COST(escalated) CALCINE RETRIEVAL AND TRANSPORT A FACILITY}

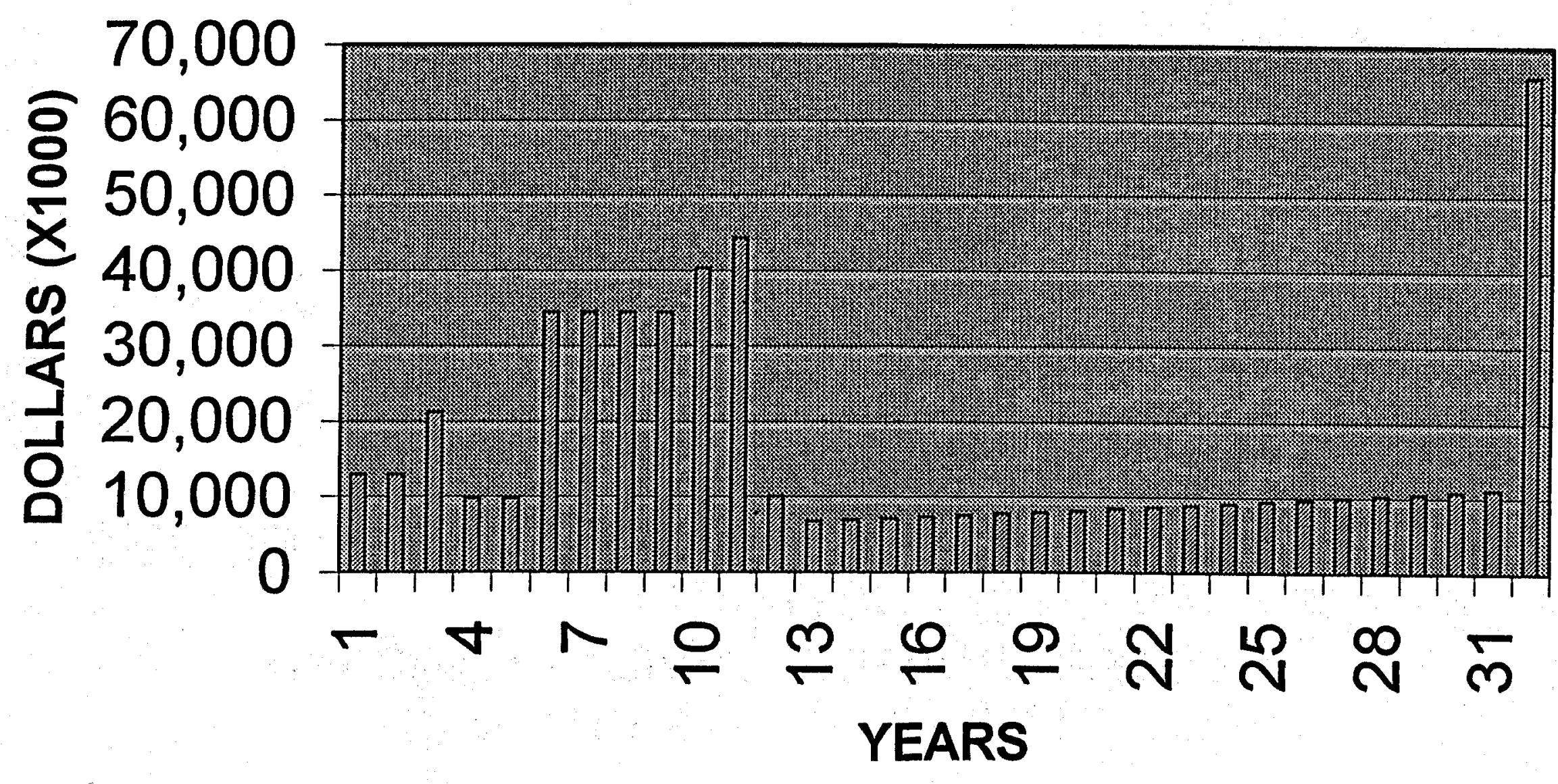




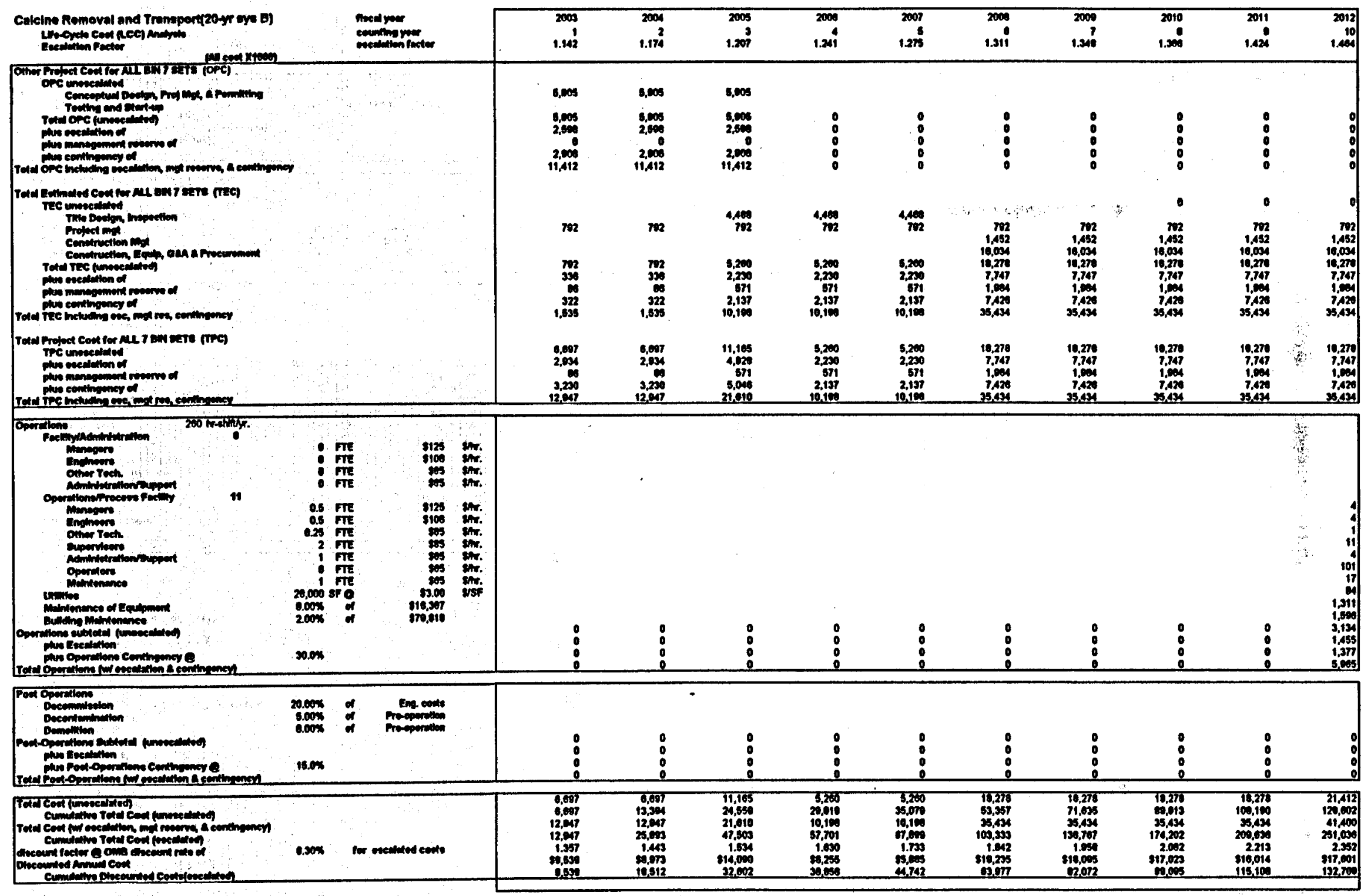




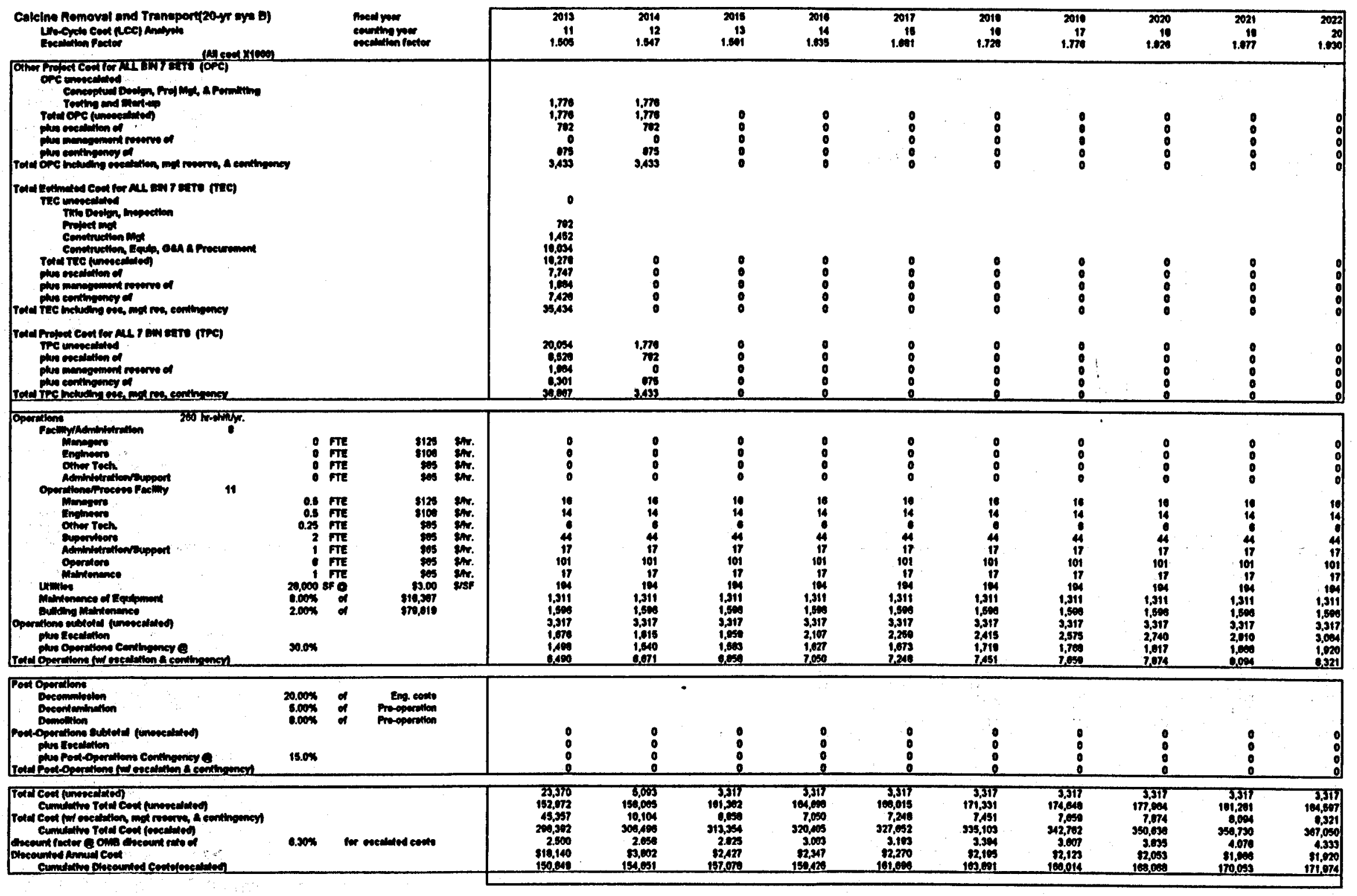




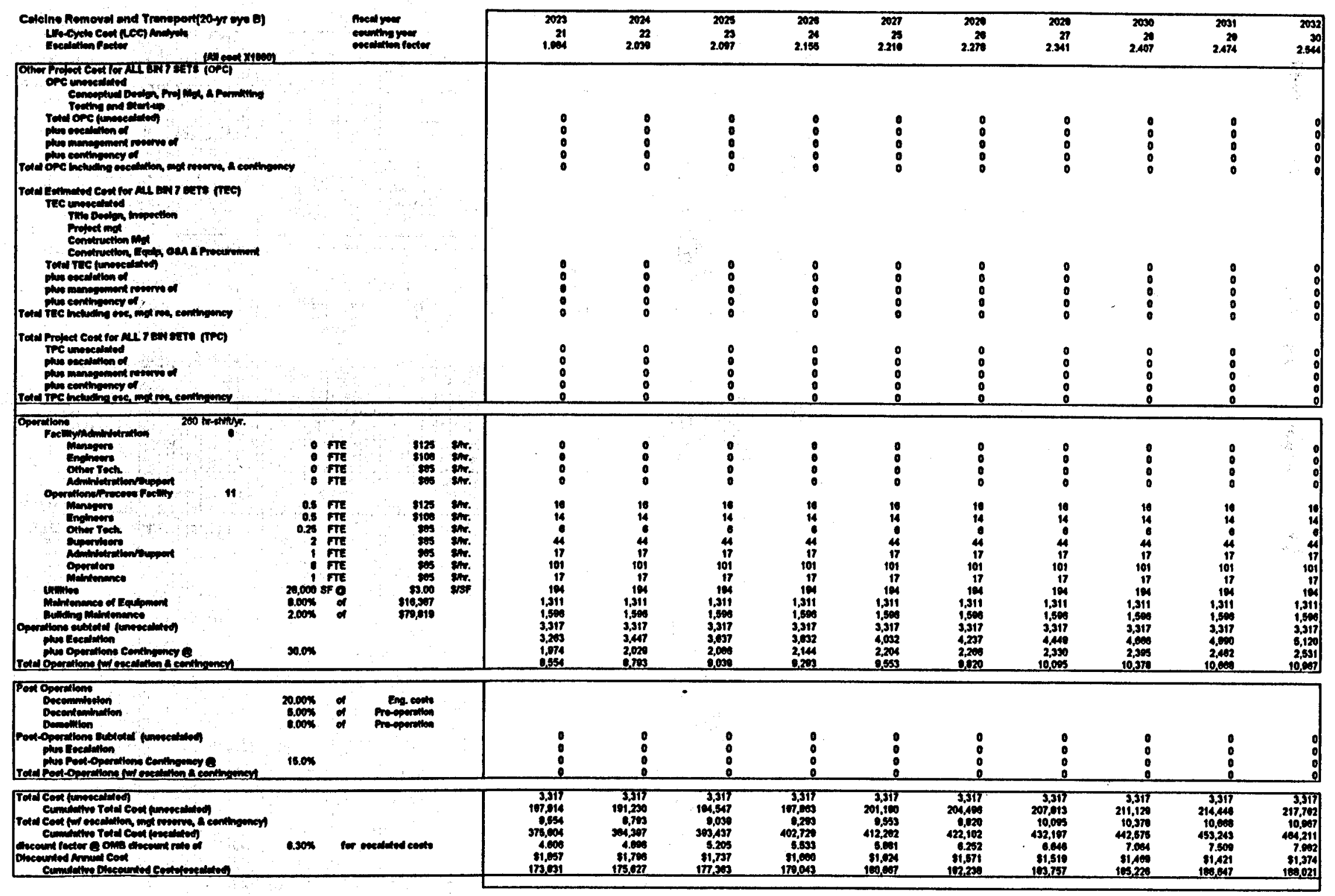




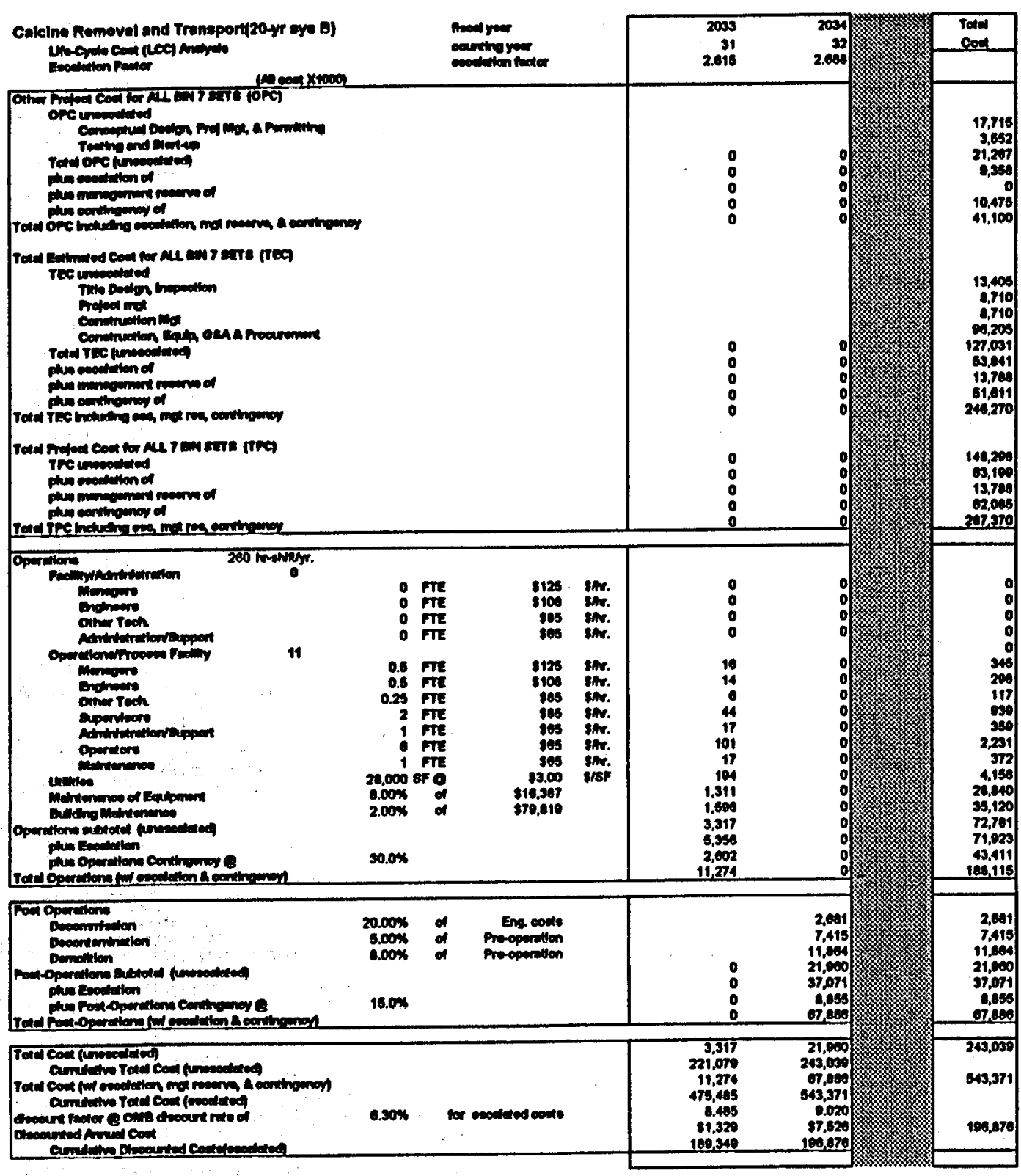




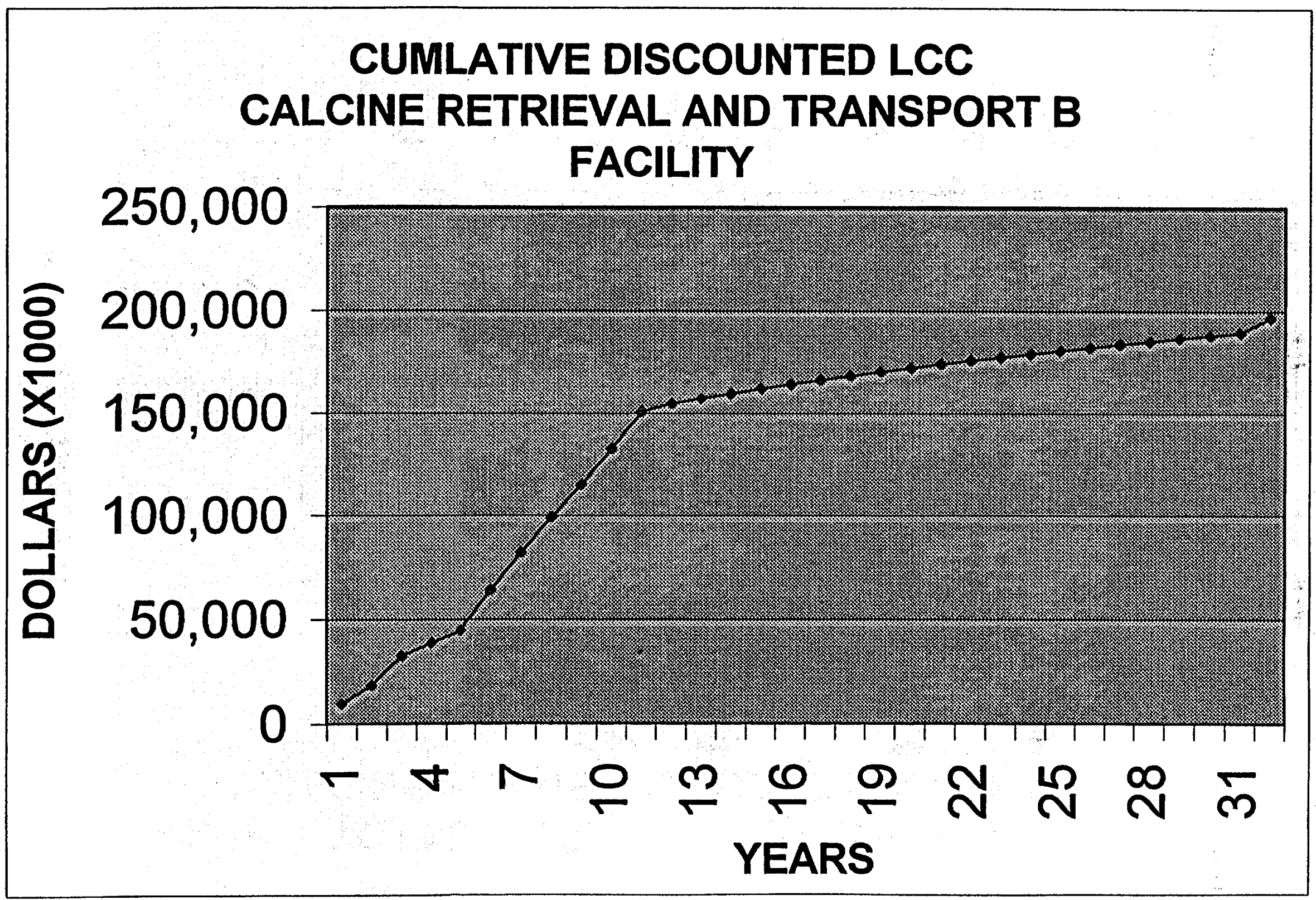




\section{TOTAL ANNUAL COST(escalated) CALCINE RETRIEVAL AND TRANSPORT B FACILITY}

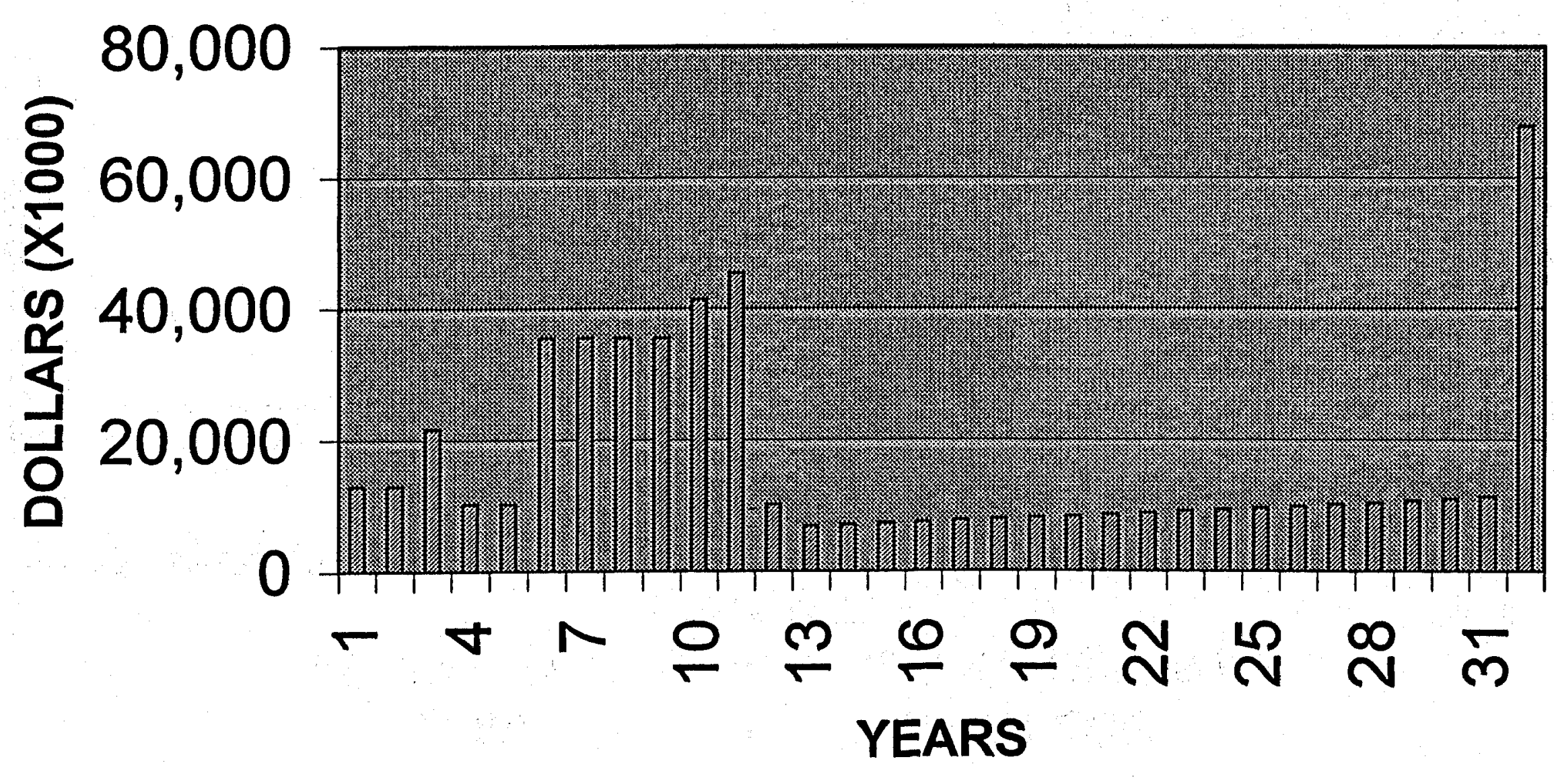


431.02:

$06 / 17 / 97$

Rov. $\$ 04$
ENGINEERING DESIGN FILE

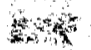

Function File Number - SRP.WTS-02

EDF Serial Number - EDF-WTS-003

Project File Number

02BD7

Page 1 of 44

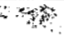

$b$

Project/Task HLW EIS Supporting Studies

Subtask

Title: Regulatory Requirements for the Design, Construction, and Operations of the ICPP Proposed Waste Processing Facilities

Summary: This EDF identifies and provides the existing environmental regulations and codes pertaining to the design, construction, operations, and performance of the proposed waste treatment and storage facilities at the Idaho Chemical Processing Plant (ICPP). This study also presents an assessment of the current NRC regulations and their potential applicability to the proposed facilities if the facilities were to be licensed by the NRC in the future. The NRC requirements for regulating DOE facilities or activities have not been defined yet. The NRC requirements to be applied will need to be determined by the appropriate NRC and DOE Task Forces.

The principal sources of requirements for the design, construction, and operations presented here are the Department of Energy (DOE), the DOE Idaho Operations Office (DOE-ID), the Environmental Protection Agency (EPA), the Idaho laws and regulations, the National . Environmental Policy Act (NEPA), and other local codes and standards. The proposed facilities under consideration in this study will provide waste retrieval, treatment, and interim storage capabilities. They will process various wastes that are considered mixed wastes. These are wastes that contain both radioactive and RCRA hazardous constituents. The RCRA constituents include characteristic heavy metals and "listed" hazardous constituents, as defined in 40 CFR 261, subparts $C$ and $D$. The management of the wastes, as well as the facilities, is subject to the requirements of both the EPA and the Atomic Energy Act (AEA). The specific requirements for radioactive waste management developed under the AEA are administered through the DOE. The proposed treatment facilities are expected to process several types of waste and to convert them to distinct waste forms that are suitable for disposal. The regulatory requirements for the disposal of the various waste forms resulting from the proposed treatment options and the criteria of the potential target repositories are described in detail in INEEL/EXT-97-01147. It is assumed that the wastes resulting from the treatment options will be delisted and will no longer be considered RCRA hazardous waste prior to being sent to interim storage facilities.

Existing NRC requirements apply to commercial, non-DOE, facilities. The degree of applicability of these requirements to the proposed facilities should be determined by the NRC and the DOE, with input from the DOE contractor. Of the existing NRC regulations, it has been determined in this study that 10 CFR 61 will apply to the proposed near-surface disposal facility for the grouted Low-Activity Waste (LAW) or grouted LLW, and 10 CFR 72 will be applicable to the proposed interim storage facilities for the vitrified, Hot Isostatic Pressed (HIPed), or grouted High-Level Waste (HLW), and for the liquid High-Activity Waste (HAW) and vitrified HAW storage facilities. Independently, it was determined by Leroy and Morgan in "Nuclear Regulatory Commission (NRC) Licensing Assessment for the Idaho National Engineering and Environmental Laboratory (INEEL) High-Level Waste program," April 23, 1997, that 10 CFR 30 and 10 CFR 70 
will apply to the following facilities:

- 10 CFR 30 for the LAW collection and grouting facilities and for the collection and treatment of the LLW from the INEEL ongoing operations.

- 10 CFR 70 for the separations facility, for the interim storage of liquid HAW resulting from the separation processes; and for the HAW vitrification facility.

- 10 CFR 70 for the HLW vitrification, HIPing, or grouting facilities.

- 10 CFR 70 for the calcine retrieval and dissolution facilities.

Additional NRC regulations applicable to the proposed facilities are in 10 CFR 2, 10 CFR 19, 10 CFR 20,10 CFR 21, 10 CFR 50,10 CFR 51, 10 CFR 52, and 10 CFR 73. 10 CFR 71 and 49 CFR 173 (Department of Transportation) contain requirements for the packaging and transportation of waste. These requirements could have impact on the design and operations of the storage facilities. The existing facilities that will be modified to be used for storage of treated HLW or HAW are anticipated to be exempted by DOE from any further jurisdiction of NRC. Such a jurisdiction would be excessively difficult, costly, and complex to apply. All the work requirements for the modification of the existing facilities are expected to be performed in accordance with the DOE/RW/0333P, "Quality Assurance Requirements and Description"

If DOE facilities become regulated by NRC, the jurisdiction of other currently government applicable authorities will not automatically or necessarily cease. In particular, it is expected that local, State, Federal EPA, and some DOE regulatory requirements would still apply.

In addition to all the regulatory requirements established by the various government authorities discussed above, the schectule of the construction and operations of the proposed facilities must meet the terms and the dates of the commitments as stated in the Settlement Agreement between the State of Idaho and the DOE.

Distribution (complete package): HLW EIS Library, also contained in INEEL-EXT-01389 (VWO), INEELEXT-97-01392 (HWO), INEEL-EXT-97-01400 (CWO), INEEL-EXT-97-01399 (DCWO), and INEEL-EXT97-01428 (TRU Separations), S. L. Austad MS 3650, J. B. Bosley MS 3428, R. E. Dafoe MS 3765, W. H. Landman MS 3625, A. E. Lee MS 3765, D. A. Lopez MS 3765, B. R. Helm MS 3765, J. J. McCarthy MS 3625, T. A. Solle MS 3428, N. E. Russell MS 3765, D. S. Vandel MS 3625.

Distribution (summary package only): D. J. Harrell MS 3211, K. L. Williams MS 3765.

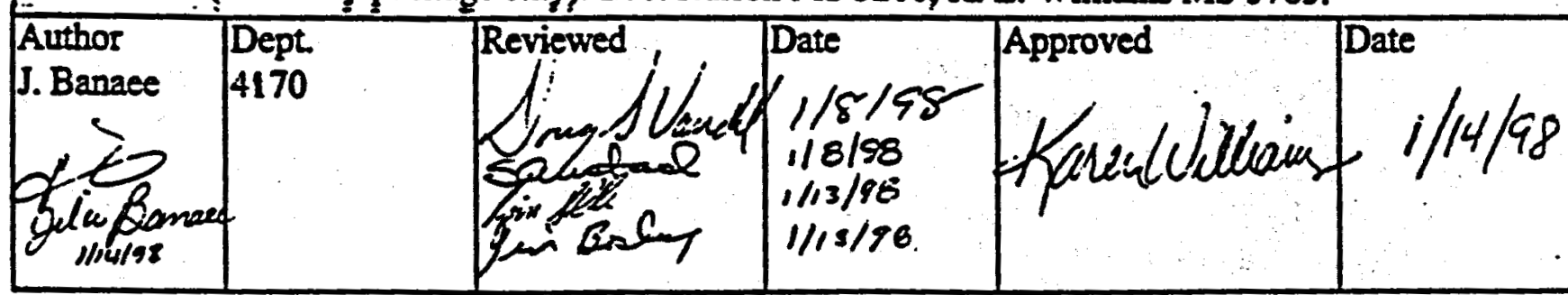




\section{INTRODUCTION}

This study identifies and presents the existing environmental regulations and standard codes for the design, construction, operations, and performance of the proposed waste treatment and storage facilities at the Idaho Chemical Processing Plant (ICPP). Also, it provides the applicable existing Nuclear Regulatory Commission (NRC) regulations and guidance documents to the proposed facilities if they were to be licensed by the NRC in the future. The existing licensing process and related licensing issues applicable to the proposed facilities are also discussed.

The environmental regulations are primarily based on safety and health considerations. The standards define the requirements that protect human health and the environment. The principal sources for the standard regulations and codes presented here are:

- Environmental Protection Agency

- Idaho Laws and regulations

- National Environmental Policy Act (NEPA)

- Deparment of Energy

- DOE Idaho Operations Office (DOE-ID)

- Other applicable standards and codes

In addition to the current regulations, the governing stardards for the facility design and performance considerations of the future (i.e., DOE Orders 435.1) drafted at the time of preparation of this report are also presented.

The facilities under consideration in this study will provide waste retrieval, treatment, and interim storage capabilities. They will process various wastes that are considered mixed wastes. These are wastes that contain both radioactive and Resource Conservation and Recovery Act (RCRA) hazardous constituents. The RCRA constituents include characteristic heavy metals and "listed" hazardous constituents, as defined in 40 CFR 261, subparts C and D. The management of the wastes, as well as the facilities, is subject to the requirements of both the EPA and the Atomic Energy Act (AEA). The specific standards for radioactive waste management developed under AEA are administered through the DOE.

The proposed treatment facilities are expected to process several types of waste to convert them to distinct waste forms that are suitable for disposal. The wastes resulting from the proposed treatment options are assumed to be delisted prior to being transported to the proposed interim storage facilities. The waste forms are produced starting from a variety of mixed wastes including high-level liquid waste (HLLW), Sodium-bearing liquid waste (SBW), and other radioactive wastes form ongoing operations (1996-2012), known as the newly generated wastes (NGW). These wastes have been stored in the Tank Farm at the ICPP. Most of the HLLW have been calcined and stored at the Calcined Solids Storage Facility (CSSF).

The EPA has established treatment standards under the RCRA Land Disposal Restrictions (LDRs), in 40 CFR 268, for hazardous waste constituents prior to land disposal. The regulatory 
requirements for the disposal of the various waste forms resulting from the proposed options and the criteria of the potential target repositories are described in detail in INEEL/EXT-97-01147.

\section{PROPOSED WASTE TREATMENT OPTIONS}

Several treatment options are being proposed including four non-separations and two separation processes. In addition, a no-action alternative will likely be considered, defined as the continuation of the current practice of calcination and storage in stainless steel bins at ICPP. The non-separation options include: (a) vitrified waste option (VWO), (b) Hot Isostatic Pressed (HII) waste option (HWO), (c) direct cementitious waste option (DCWO), and (d) cementitious waste option (CWO). The separation processes are expected to generate up to three different waste streams; designated as high activity waste (HAW), low activity waste (LAW), and transuranic (TRU) waste. These options are summarized below:

\section{Vitrified Waste Option}

This option involves the following steps: 1) calcination of HLLW, SBW, and the NGW, 2) vitrification of all the celcine wastes (existing and future) and placing in canisters (2' $\times 10^{\prime}$ or other canisters approved by the repository/NRC), and 3) interim storage prior to shipment to a HIL repository.

Process duration: 20 year Schedule

\section{HIP Waste Option (HWO)}

As in the VWO, the wastes will be calcined but instead of being vitrified, they will be directly HIP processed and placed in canisters (2' $x 10^{\prime}$ or other canisters approved by the repository/NRC), and 3) will be sent to an interim storage facility prior to shipment to and disposal at a HLW repository.

Process duration: 20 year schedule

\section{Cementitious Waste Option (CWO)}

This option includes calcining the HLLW, retrieving the calcine wastes, and recalcining with the SBW in the modified New Waste Calcining Facility (NWCF), grouting in canisters ( $2^{\prime} \times 10^{\prime}$ canisters), and sending to an interim storage facility for transport to and ultimate disposal at an off-site HLW disposal facility. It is proposed that the cementitious waste would be suitable for disposal at the Nevada Test Site (NTS) using Greater Confinement Disposal (GCD) facility. 
Currently, the GCD facility has not been approved for disposal of HLW and waste acceptance requirements for the GCD facility have not been defined. Pursuant to the 1987 Nuclear Waste Policy Amendments Act (NWPAA), the Yucca Mountain in Nevada is designated for characterization as the only candidate site for a HLW geologic repository. However, projections of future wastes suggests a need for a second repository at some time in the future, or expansion of the first potential repository. Criteria for acceptance and disposal of waste at the potential HLW repository at the Yucca Mountain have not been finalized. The current waste acceptance criteria are preliminary at the present time. These criteria are covered in detail in INEEL/EXT97-01147.

Process duration: 5 year schedule

\section{Direct Cementitious Waste Option}

The DCWO consists of step 1 of the VWO, then direct grouting of all the calcined wastes and packaging in canisters ( $2^{\prime} \times 10^{\prime}$ or other canisters approved by the repository/NRC), and interim storage prior to shipment to an off-site HIW repository such as the NTS-GCD, if approved for the HLW disposal, or possibly to a potential HLW geologic repository at the Yucca Mountain. This option is planned to have the same processing time as the CWO with the difference in starting date.

\section{Separations Options}

Two waste separation options have been proposed: HAW/LAW, known as full separations, and TRU separations. The full separations option involves calcining the HLW and SBW, retrieving and dissolving the calcine, and feeding the dissolved calcine and the remaining liquid SBW and the NGW to a waste separations facility to separate them into the HAW and LAW streams. The NGW, if classified as LLW, would bypass the separations facility and would ultimately be combined with the LAW.

In the TRU separations, as in the HAW/LAW separation option, the dissolved calcine and the remaining liquid SBW, and the NGW will be fed to a waste separations system. Two separation alternatives are being considered under this option, designated as (1) TRU/LAW Class C and (2) TRU/LAW Class A/HAW. In the first alternative, the wastes would be separated into TRU waste and LAW. The TRU waste fraction is expected to contain alpha-emitting TRU radionuclides with half-lives greater than twenty years. The remaining waste stream, designated as LAW Class C, would contain Cesium (Cs) and strontium (Sr) isotopes, and low activity waste portion. It is anticipated that the LAW in this alternative would meet the definition of NRC LLW Class $C$. In the second alternative, $C s$ and $S r$ will be separated as HAW, and the remaining waste from separations will be designated as TRU and LAW. The LAW is expected to meet the definition of NRC LLW Class A. 
The HAW is planned to be vitrified using the same process described in the VWO and be shipped to a HLW geological repository for permanent disposal. The HAW containing isolated $\mathrm{Cs}$ and $\mathrm{Sr}$ would be stored at the INEEL awaiting disposal in a HLW geologic repository or an alternate approved disposal facility. The TRU waste stream would be converted to a solid form to be send to the Waste Isolation Pilot Plant (WIPP) for disposal. The LAW would be grouted and shipped to a LLW disposal facility. The disposal options being considered for the grouted LAW are the CSSF, the tanks at ICPP, or a LLW near-surface disposal facility. The requirements for the design and operations of a near-surface LLW disposal facility are covered in detail in EDF-FDO-008. This reference is contained in INEEL/EXT-98-00051.

Based on the NRC source term definition of HLW (10 CFR 60.2), the HAW, LAW and the TRU waste streams are actually considered $H L W$. These wastes do not conform to the existing classification for radioactive waste. Although, the separations alternatives and the resultant waste streams may be technically and economically feasible and attractive, they will need to receive evaluation, redefinition of types of waste, and the concurrence of applicable government authorities. It is assumed that a determination will be made by the appropriate authorities (e.g., the DOE and the NRC) that the TRU waste and the LAW streams meet the TRU waste and the NRC LLW-Class A or Class C definition, respectively. The LAW also meets the definition of incidental waste in the NRC evaluation of HLW separation processes at Hanford Site ( 58 FR, "State of Washington and Oregon, Denial for Petition for Rulemaking," U.S. Nuclear Regulatory Commission, "March 4, 1993, p. 12342.). The HAW would be considered HLW and can be classified as HLW.

\section{ASSUMPTIONS}

1) All of the wastes produced from the treatment and storage facilities will meet the requirements enforeed by the EPA, the DOE, the DOT, the NRC, and other potential target repositories for the disposal.

2) Under EPA 40 CFR 268.42(b), an equivalency petition for using alternative waste treatment technologies including CWO and DCWO to borosilicate glassa will be granted by the EPA.

3) All of the wastes resulting from the various treatment options will be delisted prior to being transported to the interim storage facilities. The EPA Upfront Exclusions for the petitioned wastes will be granted to delist the RCRA listed hazardous waste codes. The EPA delisting

\footnotetext{
Vitrification using borosilicate glass technology is considered by the EPA a best demonstrated available technology (BDAT) for treatment of mixed HILW (55 Federal Register (FR), June 1, 1990, p.22627). DOE's studies of glass-ceramic process and comparison of glass-ceramic process and waste form with borosilicate glass waste have shown that glass-ceramic waste form meets the definition of EPA vitrification and borosilicate glass. EPA has concurred with the DOE conclusion and has determined that the glass-ceramic process is an acceptable technology to meet BDAT (see 57 FR, May 26, 1992, p. 22024).
} 
criteria and processes for preparing a delisting petition are contained in "Petitions to Delist Hazardous Wastes: A Guidance Manual," Second Edition, PB93-169365, March 1993. The Upfront Exclusions may be granted for wastes and/or waste residues that have not been generated, but will be generated in the future. The EPA will evaluate the petitioned wastes based on available information such as the characteristics of the untreated wastes, process description, and bench-scale or pilot scale treatment data.

4) An off-site facility would need to be approved for the disposal of HLW resulting from the CWO, DCWO, and HWO.

\section{ENVIRONMENTAL REGULATIONS, DOE CRITERIA, AND OTHER STANDARD CODES}

\subsection{FEDERAL AND STATE LAWS AND REGULATIONS}

\section{Resource Conservation and Recovery Act}

The RCRA has established minimum national standard requirements which apply to owners or operators of all facilities that treat, store, or dispose of hazardous waste. The State of Idaho has the authority to implement the RCRA requirements through the Idaho Department of Health and Welfare (IDHW). The State of Idaho adopted the Federal RCRA regulations, pursuant to the Idaho Hazardous Waste Management Act of 1983 . The regulations are incorporated by reference as provided in the Federal requirements under 40 CFR into the "Idaho Rules and Standards for Hazardous Waste", under administrative code known as Idaho Administrative Procedures Act (IDAPA) 16.01.05.

The RCRA requirements applicable to the hazardous waste facilities are defined in 40 CFR 264 (IDAPA 16.01.05.008), "Standards for Owners and Operators of Hazardous Waste Treatment, Storage, and Disposal Facilities" and in 40 CFR 270 (IDAPA 16.01.05.012), "EPA Administered Permit Programs: the Hazardous Waste Permit Program."

40 CFR 264 sets regulatory requirements for the design, construction, and operation of the facility, quality assurance program, testing and maintenance of the equipment, air emission standards, groundwater protection standards, security, inspection, personnel training, preparedness and prevention, contingency plan and emergency procedures, manifest system and record keeping, closure and post-closure, financial requirements, and use and management of containers.

The existing hazardous waste facilities used for any future hazardous waste management activities can continue operations while meeting the requirements in 40 CFR 265 (16.01.05.009), 
"Interim Status Standards for Owners and Operators of Hazardous Waste Treatment, Storage, and Disposal Facilities". This will allow the existing facilities to continue operations while meeting minimum operational requirements defined in 40 CFR 265 . To be qualified for interim status, the existing facility must have been in operation or under construction on November 19, 1980 or have been in operation when the facility became subject to the RCRA requirements.

40 CFR 262.34 (subpart of 40 CFR 262 - IDAPA 16.01.05.006), "Accumulation Time". and 40 CFR 268.50 (subpart of 40 CFR 268 - IDAPA 16.01.05.011), "Prohibitions on Storage of Restricted Wastes" contain requirements, conditions, and time limits for storage of hazardous wastes. Based on 40 CFR 262.34, a generator may accumulate hazardous waste on-site for 90 days or less without a permit or an interim status, provided that the generator meet the conditions specified in 40 CFR 262.34. A generator who accumulates hazardous waste for more than 90 days is an operator of a storage facility and is subject to the requirements of 40 CFR 264 and 40 CFR 265, and the permit requirements of 40 CFR 270 unless the generator has been granted an extension to the 90-day period by the EPA. A 30-day extension may be granted at the discretion of the EPA on a case-by-case basis. A generator who accumulates hazardous waste greater than 100 kilograms but less than 1000 kilograms in a calendar month may accumulate hazardous waste on-site for 180 days or less without a permit or without an interim status provided the generator meets the requirements stated in 40 CFR 262.34.

Under 40 CFR 268.50, the storage of hazardous wastes such as those present in the Tank Farm is prohibited, unless the following conditions are met:

(1) A generator stores such wastes in tanks, containers, or containment buildings on-site solely to facilitate proper recovery, treatment, or disposal and the generator complies with the requirements in 40 CFR 262.34, 40 CFR 264, and 40 CFR 265.

(2) An owner/operator of a hazardous waste treatment, storage, or disposal facility stores such wastes in tanks, containers, or containment buildings to facilitate proper recovery, treatment, or disposal, and an owner/operator must comply with the operating record requirements specified in 40 CFR 264.73 and 40 CFR 265.73.

An owner/operator of a treatment, storage, or disposal facility may store hazardous waste restricted from land disposal beyond one year provided that the owner/operator proves to the EPA that such storage was solely for the purpose of facilitating proper recovery, treatment, or disposal.

The prohibition in storage does not apply to hazardous wastes that meet the LDR treatment standards and treatment equivalency as defined in 268.42(b). However, if the waste is still listed, the generator must comply with the RCRA requirements for hazardous waste storage. 


\section{Permit Requirements}

Various permits are required prior to the construction and operations, and during the operations of the proposed facilities. These include RCRA permit, air emissions permit, wastewater discharges permit, etc. In addition, separate permits may be needed once the processes or activities are better known, as individual pilot plant operations or modifications to the existing facilities/systems may require separate permits. The applicable permit requirements are described below. A summary of the permit requirements and regulatory drivers is presented Section 5.

\section{RCRAPermit}

All facilities that treat, store, or dispose of hazardous wastes are required to obtain a RCRA permit during the active life (including the closure period). 40 CFR 270 establishes the requirements for obtaining a Permit. A RCRA Permit application consists of two parts, Part A and Part B. Part A of the permit application is a short standard form that collects general information about the treatment, storage, or disposal facility. Part B of the permit application includes a much more detailed technical description of the facility. The permit application covers all aspects of the design, construction, operation, monitoring, and maintenance of the facility. The requirements for Part A permit application are in 40 CFR 270.13, and for Part B Permit application are in 40 CFR 270.14 through 29.

Once the owner or operator of a facility has submitted a permit application, the regulator conducts an in-depth evaluation to determine if the application satisfies the RCRA requirements. For the new hazardous waste facilities, Parts A and Part B of the permit application must be submitted a least 180 days prior to physical construction is expected to commence. For the existing hazardous waste facilities, the requirements to submit an application is satisfied by submitting only Part $A$ application to operate under interim status until the permitting agency sets a date for submitting Part $B$ of the application.

\section{Air Permit}

Air permits will be required from the State of Idaho and/or EPA Region X prior to construction and operations of each of the treatment, storage, and disposal facilities with radioactive and nonradioactive emissions sources. The existing facilities that will be used for the proposed waste processing activities may require permit modification if the existing permit does not satisfy the permit requirements for the proposed use.

The Clean Air Act (CAA) sets permit requirements and emission standard limits. The CAA requirements are implemented by the IDHW under Idaho codes (see Idaho Codes and regulations below) or by EPA Region X. The CAA implementing regulations are in 40 CFR 50, 52, 60, 61, $62,63,70,77$, and 124 . The air permit requirements are briefly described below. 
For nonrad emissions a Permit to Construct (PTC) will be required from the IDHW for each of the new emission points prior to the construction or modifications of a facility. Individual pilot plant systems may require separate PTCs once the processes are known. Hazardous Air Pollutants (HAPs) and the Toxic Air Pollutants (TAPs) will need to be quantified prior to permitting.

The National Emission Standards for Hazardous Air Pollutants (NESHAPs), Subpart H sets the standards for the radioactive air emissions. The proposed facilities will qualify as radiological sources if they emit any radiological emissions. They are regulated by the EPA under the NESHAPs and the State of Idaho for radioactive air emissions. The state of Idaho treats the INEEL as one large facility. Currently, the maximum off-site limits for the total INEEL radiological emissions is $10 \mathrm{mrem} / \mathrm{yr}$.

The National Ambient Air Quality Pollutants Standards (NAAQS) has established requirements for particulate matter, sulfur dioxide, ozone, nitrogen dioxide, carbon monoxide, fluoride, and lead. If their emissions are significant as defined in IDAPA 16.01.01.88, they must comply with the requirements of the Prevention to Significant Deterioration (PSD). The Best Available Control Technology (BACT) mist be used to control pollutants if compliance with the PSD is required.

The air emissions must be calculated for each of the new facilities to determine the permit -requirements and compliance with the regulatory standards, and to identify how they impact the sitewide total emissions at the INEEL because the State of Idaho treats the INEEL as one large facility. The determination of the expected air emissions is usually done during the Title II design.

Appendix D to 40 CFR 61 should be used for estimating the radionuclide emissions from the new sources to determine if a NESHAPs approval to construct is needed. If the estimated dose is greater than $0.1 \mathrm{mrem} / \mathrm{year}$, the NESHAPs application will be required. In such case, a PSD evaluation will required by the State of Idaho.

Some of the process vents associated with the hazardous waste treatment units must meet the RCRA air emission standards in 40 CFR 264/265 Subparts AA. A process vent is any openended stack or pipe that is vented to the atmosphere. 40 CFR 264/265 Subparts BB and CC contain air emissions standards which are applicable only to certain types of processes such as equipment leaks, tanks, and containers.

The EPA proposed MACT Rule which enforces limits on air pollutants applies to hazardous waste incinerators or other comparable facilities which burn hazardous waste and/or are qualified as an incinerator by the EPA. This study assumes that the MACT Rule will be applicable to the vitrification and HIPing facilities. The MACT Rule sets emission limits for dioxin/furan, hydrocarbons, chlorine, carbon monoxide, lead, cadmium, mercury, antimony, arsenic, beryllium, chromium, and particulate matter. 


\section{Wastewater Effluent Discharges and Drinking Water Permit}

The EPA has established requirements for stormwater and nonstormwater discharges into the environment under the National Pollution Discharge Elimination System (NPDES). The NPDES contains the requirements that control the discharge of pollutants to waters of the U.S. (e.g., Big Lost River) as defined in the Clean Water Act (CWA) in 40 CFR 122. These sources can include sanitary, industrial processes, and storm water runoff from industrial and construction areas.

A permit under the NPDES is required for storm and nonstorm waters (e.g., service water, sewer discharges). The INEEL has a general NPDES permit. Therefore, the existing INEEL NPDES permit should be evaluated to determine if there is a need for modifications of the INEEL permit or addendum to the permit to satisfy the permit requirements for the proposed facilities.

Wastewater Land Application Permits are required for construction, modifications, and operation of facilities that dispose of municipal and industrial wastewater to the land surface. The requirements are defined in 40 CFR 122 (CWA).

Pursuant to the CWA, the facilities that engage in storing, transferring, and consuming oil and oil products which could reasonably be expected to discharge oil in the Big Lost River or other waters of the U.S. must have Spill Control Prevention and Countermeasures Plans. The Plans are required if the oil discharges are in harmful quantities that violate the applicable water quality standards and cause harm to the human health and environment.

\section{Idaho Laws and Regulations}

This section lists the Idaho codes and standards for air and water pollution control and for releases into the environment. The standards are based on the Federal requirements established by the CAA, the CWA, and the RCRA.

Idaho Code 39-44, "Hazardous Waste Management Act"

IDAPA 16.01.05, "Rules and Standards for Hazardous Waste"

IDAPA 16.01.01, "Rules for the Control of Air Pollution in Idaho"

IDAPA.16.01.01.161, "Toxic Substances"

IDAPA 16.01.01.210, "Demonstration of Reconstruction Compliance with Toxic Standards"

IDAPA 16.01.01.575, "Air Quality Standards and Area Classification"

IDAPA 16.01.01.650, "Rules for Control of Fugitive Dust"

IDAPA 16.01.09, "Idaho Radiation Control Rules"

Idaho Code 39-36, "Water Quality Act"

IDAPA 16.01.02, "Water Quality Standards and Wastewater Treatment"

IDAPA 16.01.08.500, "Design Standards for Public Drinking water Systems"

IDAPA 16.01.08.551, "Construction Requirement for Public Water Systems" 
IDAPA 16.01.08, "Idaho Rules for Public Drinking Water Systems"

IDAPA 16.01.17, "Wastewater Land Application Permit Regulations"

40 CFR 191, "Environmental Radiation Protection Standards for Management and Disposal of Spent Nuclear Fuel, High-Level Waste and Transuranic Waste"

The EPA has set radiation protection requirements for management of radioactive waste in 40 CFR 19i. The radiation protection standards for management and storage of radioactive wastes apply to:

(a) Radiation doses received by members of the public as a result of the management (except for transportation) and storage of spent nuclear fuel or HIW or TRU waste at any facility regulated by the NRC or by Agreement States, to the extent that such management and storage operations are not subject to the provisions of 40 CFR 190, "Environmental Radiation Protection Standards for Nuclear Power Operations"; and

(b) Radiation doses received by members of the public as a result of the management and storage of spent nuclear fuel or HLW or TRU waste at any disposal facility that is operated by the DOE and that is not regulated by the NRC or by Agreement States.

\section{CFR 257, “Criteria for Classification of Solid Waste Disposal Facilities and Practices”}

The proposed LLW land disposal facility at the INEEL will be comparable to the LLW disposal facility of the Radioactive Waste Management Complex (RWMC). The Idaho Department of Environmental Quality (DEQ) evaluated the applicability of federal and state regulations to the RWMC LLW disposal facility. The $\mathrm{DEQ}^{\mathrm{b}}$ has concluded that, in addition to other requirements, disposal of waste at RWMC is subject to Subtitle D landfill standards, 40 CFR 257. The environmental standards required by 40 CFR 257 are based on safety and health considerations which protect human health, wildlife, and the environment. The DOE or the NRC requirements for design and performance of a LLW disposal facility are much more stringent than those in $\mathbf{4 0}$ CFR 257 and supersede the subtitle $D$ landfill standards.

40 CFR 257 requires that disposal facilities or practices in floodplains not restrict the flow of the base flood, reduce the temporary water storage capacity of the floodplain, or result in washout of solid wastes which pose a hazard to human life, wildlife, land or water resources. The disposal facilities shall not cause a discharge of pollutants into waters of the United States. Such a discharge would be a violation of the NPDES. Also, the facilities must not contaminate any underground drinking water source beyond solid waste facility boundary or beyond an alternative specified boundary.

'DEQ letter to Jay Mitchell, Manager of LMITCO NEPA/Permitting, July 23, 1996. 


\subsection{DEPARTMENT OF ENERGY}

The AEA of 1954 authorizes the DOE to establish standard criteria to ensure safe operations of its facilities, and to protect human health and to minimize dangers to life and property. The DOE has developed a series of Orders and Directives. They contain standards that require the planning, design, and construction of DOE facilities be performed in a manner that will satisfy all applicable Federal, State, and local environmental, safety and health laws and regulations, and the DOE criteria. The DOE and DOE-ID standards applicable to this study include the following:

\section{DOE Order 6430.1A, "General Design Criteria”}

Compliance with DOE Order $6430.1 \mathrm{~A}$ is mandatory under the current LMITCO contract. DOEID Notice 430.1A, "Life Cycle Asset Management- ID expectations," requires that for facilities under the purview of the Defensec Nuclear Facilities Safety Board (DNFSB), the DOE Order 6430.1A remains effective until 10 CFR 830.340, "Maintenance Management", and DOE Order 420.1, "Facility Safety", are finalized and incorporated into the LMITCO contract.

DOE-ID Notice 430.1A establishes the DOE-ID expectations of the contractor in areas covered by DOE Order 430.1, "Life Cycle Asset Management", in managing the INEEL. This order incorporates private industry standards safety design criteria, and requires additional nuclear safety criteria for nuclear facilities.

DOE Order 6430.1A provides general and specific design standards, guidance, and practices for use in the DOE facilities. The standards are to provide levels of design for occupant life safety, reduction in loss of government property, functioning essential operations and confinement of radioactive and hazardous material. Division 13, Section 1300, General Requirements, and Section 1324, Radioactive Solid Waste Facilities, address general and specific design criteria. Also, Section 0900-99.0, Nonreactor Nuclear Facilities, contains additional criteria relevant to

\footnotetext{
"The term "defense" nuelear facility has not been defined anywhere in the regulations or by the DOE yet. I have spoken with a number of people in the LMITCO Mechanical, Civil, and Industrial Engineering Department and the DOE-ID (David Crandall, Scott. Jensen, Lee Williams, and others) to learn what might constitute a "defense" nuclear facility and to find out the difference between a defense nuclear facility and a nuclear facility. They were not sure about the definition of a "defense" nuclear facility. However, they all believe that the facilities under consideration in this study could be considered "defense" nuclear facilities because they will be used for management of the DOE defense related wastes. According to Scott Jensen, the RWMC LLW disposal facility is considered a "defense" nuclear facility.
}

The definition of a nuclear facility is in MCP-2446. Based on this document, a "nuclear facility" is a facility with operations that involve radioactive and/or fissionable material in such form and quantity that a nuclear hazard potentially exits to the employees or the general public. A nuclear facility includes nonreactor and reactor facilities. 
facility design. All of these criteria provide minimally acceptable requirements for the facility design. It should be noted that the applicable local building codes and models always take precedence on the issues covered in the DOE order and provide additional design requirements not covered in the DOE order.

\section{DOE-W, “Architectural Engineering Standards” (AE)}

The $A E$ contains general design requirements such as those defined in DOE Order $6430.1 \mathrm{~A}$, and additional specific construction codes. The following is a list of some of the applicable standards and codes included in the AE documents:

ICBO UBC, "Uniform Building Code, latest edition"

ICBO UFC, "Uniform Fire Code, latest edition"

29 CFR 1910, "Occupational Safety and Health Standards"

29 CFR 1926, "Safety and Health Regulations for Construction"

ADAAG, "Americans with Disabilities Act (ADA) - Accessibility Guidelines"

ASCE-4-86, "Seismic Analysis of Safety-Related Nuclear Structures"

ASCE-7-93, "Minimum Design Loads for Buildings and Structures"

DOE-STD-93, "Natural Phenomena Hazard Performance categorization"

DOE-STD-1020-94, "Natural Phenomena Hazard Design and Evaluation Criteria for Department of Energy Facilities"

DOE-STD-1021-93, "Natural Phenomena Hazards Performance Categorization Guidelines for Structures, Systems, and Components"

\section{DOE Order 5820.2A, “Radioactive Waste Management"}

DOE Order 5820.2A established policies and criteria for management of HLW, TRU, and LLW. The Order requires that radioactive and mixed waste be managed in a manner that is in compliance with all applicable Federal, State, and local environmental, safety, and health regulations and laws and DOE criteria.

Design objectives for facilities shall assure protection of the public and operating personnel from hazards associated with normal HLW operations, accident conditions, and the effects of natural phenomena. Other objectives are compliance with the DOE policies regarding nuclear safety, quality assurance, contingency plans, training, fire protection, pollution control, and safeguards and security protection for waste and protection of essential operations from the effects of potential accidents.

The development of large scale waste treatment facilities shall be supported by the appropriate documentation such as NEPA documentation, construction design report including projected 
waste throughputs, and treatment methods, construction and operating cost estimates, and Safety Analysis Report (SAR).

All new HLW handling, transfer, and storage facilities shall be doubly contained. Where required, ventilation and filtration systems shall be provided to maintain radionuclide releases within the guidelines specified in DOE Order 5481.1B, "Safety Analysis and Review System", DOE Order 5480.23, "Nuclear Safety Analysis Report,"and other applicable orders discussed in this EDF. Ventilation systems shall be provided where the possibility exists for generating flammable and explosive mixtures of gases (e.g., hydrogen or organic).

Nuclear criticality safety considerations and controls shall be evaluated for normal operations and, before any significant operational changes are made, to protect against an uncontrolled nuclear criticality incident. Each facility shall utilize remote maintenance features and other appropriate techniques to minimize personnel radiation exposure in accordance with DOE . 5481.1B, "Environment, Safety, and Health Program for Department of Energy Operations," DOE Order 5480.23, and DOE Order 5480.24, "Nuclear Criticality Safety."

Monitoring, surveillance, and leak detection capability shall be incorporated in the engineering systems (e.g., liquid level sensing devices and alarms for high-level waste liquid systems) to provide rapid identification of failed containment, and measurement of abnormal temperatures. The following, at a minimum, shall be monitored: temperature; pressure: radioactivity in ventilation exhaust, and liquid effluent streams associated with HLW facilities. Where the possibility exists for the generation of flammable and explosive mixtures of gases, monitoring shall be conducted.

Training and qualification standards shall be developed and an up-to-date record of training status shall be maintained. Worker safety training must comply with the requirements of DOE 5480.1B and applicable Orders. Quality Assurance consistent with DOE Order 5700.6C, "Quality Assurance", shall be conducted in accordance with applicable requirements of the American National Standards Institute and other applicable codes.

As in HLW facilities, the TRU and LLW treatment and storage facilities must be equipped with monitoring, surveillance, and leak detection capabilities. The DOE Order 5820.2A requires that the IRU temporary storage area at the generator site, prior to shipment to the WIPP, be designed, constructed, operated, and monitored to minimize the possibility of fire, explosion, or accidental release of waste to the environment. The activities to assure the self storage of TRU waste shall also be consistent with the RCRA requirements and 40 CFR 191. In this study, no interim storage area is planned for the TRU waste because it expected that the TRU waste will be roadready for shipment to the WIPP. A temporary staging or package transfer area may be required for the waste container handling prior to the TRU waste transfer to the WIPP.

LLW disposal performance must be in a manner that assures external exposure to the waste and concentrations of radioactive material which may be released into surface water, ground, water, soil, plants and animals results in and effective dose equivalent that does not exceed $25 \mathrm{mrem} / \mathrm{yr}$ 
to any member of the public. Releases to the atmosphere shall meet the requirements of 40 CFR 61. Reasonable effort should be made to maintain releases of radioactivity in effluents to the general environment as low as is reasonably achievable.

\section{DOE Order 435.1 (Draft), "Radioactive Waste Management"}

Currently, a draft DOE Order 435.1 has been issued by the DOE for review. This order will replace the current DOE Order 5820.2A, Radioactive Waste Management. The cancellation of this order does not, by itself modify or otherwise affect contractual obligation with the order. Therefore, the provisions of the $5820.2 \mathrm{~A}$ will remain in effect until the LMITCO contract is modified to delete the reference to the requirements in the canceled order.

DOE Order 435.1 requires that facility siting and design be in compliance with all federal, state, and local laws and regulations, and be performed in accordance with the requirements in DOE Manual 435.1, Radioactive Waste Management Manual, and with other applicable DOE Orders.

DOE Manual 435.1 further describes and establishes the requirements of DOE Order 435.1 for management of DOE FLW, TRU, and LLW. Based on the DOE Manual 435.1, waste storage, pre-treatment, and treatment facilities design and operation are required to comply with the following applicable Orders and regulations.

DOE $O$ 151.1, "Comprehensive Emergency Management System"

DOE 0 420.1", "Facility Safety"

DOE 0 430.1, "Life-Cycle Asset Management"

DOE 0440.1 , "Worker Protection Management for DOE Federal and Contractor Employees"

DOE O 460.1A, "Packaging and Transportation Safety"

DOE O 4330.4B, "Maintenance Management Program"

DOE 0 5400.1, "General Environmental Protection Requirements"

DOE O 5400.5, "Radiation Protection of the Public and the Environment

DOE 0 5480.19, "Conduct of Operations Requirements for DOE Facilities"

DOE O 5480.20A, "Personnel Selection, Qualification, and Training Requirements for DOE Nuclear Facilities"

DOE O 5480.21, "Unreviewed Safety Questions"

DOE 05480.22 , "Technical Safety Requirements"

DOE O 5480.23, "Nuclear Safety Analysis Reports"

DOE $06430.1 A$, General Design Ćriteria"

10 CFR 820, "Procedural Rules for DOE Nuclear Activities"

10 CFR 830.120, "Quality Assurance Requirements 10 CFR 835, Occupational Radiation

Protection"

10 CFR 1021, "National Environmental Policy Act Implementing Procedures"

29 CFR 1910, "Occupational Safety and Health Standards"

"DOE Order 420.1 will replace DOE Order 5480.24, "Nuclear Criticality Safety." 
40 CFR 61, National Emission Standards for Hazardous Air Pollutants"

40 CFR 264, "Standards for Owners and Operators of Hazardous Waste Storage, Treatment, and Disposal Facilities"

40 CFR 265, "Interim Status Standards for Owners and Operators of Hazardous Waste Storage, Treatment, and Disposal Facilities"

49 CFR 106 - 110 Subchapter A, "Hazardous Materials Transportation"

49 CFR 171-180 Subchapter C, "Hazardous Materials Regulations"

\section{DOE Order 5400.5, "Radiation Protection of the Public and the Environment"}

DOE Order 5400.5 establishes standards and requirements for operations of the DOE and contractors to protect the public and environment against undue risk from radiation

Chapter II, Requirements for Radiation Protection of the Public and the Environment, specifies that exposure of members of the public to radiation sources as a consequence of all routine DOE activities shall not cause, in a year, an effective dose equivalent greater than 100 mrem. The 100 mrem limit is the sum of the effective dose equivalent from exposure to radiation sources external to the body during the year plus the committed effective dose equivalent from radionuclides taken into the body (radioactive decay inside the body) during the year. Exposure of members of the public to radioactive materials reileased to the atmosphere as a consequence of routine DOE activities shall not cause members of the public to receive an effective dose equivalent greater than 10 mrem annually.

Chapter IV, Residual Radioactive Material, presents radiological protection requirements and guidelines for cleanup of residual radioactive material and management of the resulting residues and release of property. Basic dose limits, guidelines and authorized limits for allowable levels of residual radioactive material, and control of the radioactive wastes and residues are provided.

\section{DOE Order 5480.23, "Nuclear Safety Analysis Reports"}

This Order establishes requirements for DOE-owned nuclear facilities and operations, and for contractors responsible for the design, construction, operation, decontamination, or decommissioning of nuclear facilities to develop safety analyses that establish and evaluate the adequacy of the safety bases of the facilities. The SAR required by this Order documents the results of the safety analysis. 


\section{DOE Order 5480.28, “Natural Phenomena Hazard Mitigation”}

The requirements provided in this order shall be used in conjunction with the general design criteria in DOE 6430.1A and other departmental design criteria as applicable. DOE Order 5480.28 requires that facilities structures, systems, and components (SSCs) be designed and constructed to withstand the effects of natural phenomena hazards. An objective for all SSCs is to prevent loss of structural integrity endangering life safety. An additional objective for selected SSCs or site activities is to prevent loss of capability to perform functions consistent with: (1) importance to safety for workers and the public; (2) impact on the environment; (3) repair/replacement costs; or (4) programmatic mission.

\section{DOE Order 5700.6C, “Quality Assurance”}

The provisions of this Order apply to the work performed by all Departmental Elements and management and operating (M\&O) contractors as provided by law and/or contract and as implemented by the Department's Contracting Officer. If conflicts between this and other Departmental Orders exist, the quality assurance requirements of DOE 5700.6C take precedent. Work licensed by the NRC or an NRC Agreement State and subject to the quality assurance requirements of that agency are excluded from this Order.

\subsection{NATIONAL ENVIRONMENTAL POLICY ACT}

Under 10 CFR 1021, the NEPA establishes national policy procedures promoting awareness of the environmental impacts of major federal activities during the planning and decisionmaking stages of a project. The NEPA requires all agencies of the federal government prepare a detailed EIS describing potential effects of the proposed major federal actions that may be significantly affect the quality of the human environment.

All federal facilities under the NEPA are encouraged, to the extent practicable, to incorporate Pollution Prevention/Waste Minimization (P2/WMin) criteria and recycling in the planning stages and in the design of the new facilities or modifications to the existing facilities. The P2NWMin and recycling activities will make facilities more efficient and compatible with future environmental regulations and increase energy efficiency and conservation.

\subsection{OTHER STANDARDS AND CODES}

In addition to the requirements discussed above, this section provides a list of other applicable standard codes pertinent to health and safety. 
1) General design of structures, systems, and components

$\rightarrow+\infty$,

Uniform Building Code, International Conference of Building Officials

American Institute of Steel Construction

American Welding Society Standards

American Concrete Institute

DOE-ID Welding Procedure Specification Manual

DOE-STD-1027-92, "Hazard Categorization and Accident Analysis Techniques" for Compliance with DOE Order 5480.23; "Nuclear Safety Analysis Reports"

The hazard categorization is based on a simple approach which is intended to meet DOE Order 5480.23 requirements for a preliminary assessment and hazard categorization. DOE Order 5480.23, states that a hazard categorization of the DOE facilities is to be performed on processes, operations, or activities and not necessarily whole facilities.

DOE-STD-3007-93, "Guidelines for Preparing Criticality Safety Evaluations at Department of Energy Non-Reactor Nuclear Facilities"

DOE-STD-3009-94, "Preparation Guide for U.S. DOE Nonreactor Nuclear Facility Safety Analysis Reports"

\section{2) Radiological control design features}

INEL Radiological Control Manual

10 CFR 835e, "Occupational Radiation Protection"

\section{3) Fire design features}

Uniform Fire Code, Western Fire Chiefs Association and International conference of Building Officials

National Fire Protection Association (NFPA)

Uniform Building Code, Section 505 (e)

DOE Order 5480.7A, "Fire Protection"

\section{4) Seismic design feature, Flood design features, and Wind design features}

DOE-STD-1020-94(CH-1) Natural Phenomena Hazards Design and Evaluation Criteria for Department of Energy Facilities

40 CFR 264.18

40 CFR 270.14

-DOE Order 5480.11 has been canceled and replaced by 10 CFR 835. 


\section{SUMMARY OF REGULATORY DRIVERS AND PERMIT REQUIREMENTS}

The following table presents a summary of the Federal and State regulatory requirements applicable to the construction and operations of the proposed facilities.

\begin{tabular}{|c|c|c|c|c|}
\hline $\begin{array}{l}\text { Media or type } \\
\text { of stream }\end{array}$ & $\begin{array}{c}\text { Requirements prior } \\
\text { to: }\end{array}$ & $\begin{array}{l}\text { Permit, approval, } \\
\text { or requirements }\end{array}$ & $\begin{array}{c}\text { Regulatory } \\
\text { Agency }\end{array}$ & Regulatory citation \\
\hline NEPA & $\begin{array}{l}\text { Title II Design and } \\
\text { procurement }\end{array}$ & NEPA documentation & DOE & 10 CFR 1021 \\
\hline $\begin{array}{l}\text { Nonrad air } \\
\text { emissions }\end{array}$ & Construction and operation & $\begin{array}{l}\text { PTC for new emission } \\
\text { sources }\end{array}$ & IDHW, EPA & $\begin{array}{l}40 \text { CFR } 50 \\
40 \text { CFR } 60 \\
40 \text { CFR } 62 \\
40 \text { CFR } 63 \\
40 \text { CFR } 70 \\
40 \text { CFR } 77 \\
40 \text { CFR } 124\end{array}$ \\
\hline $\begin{array}{l}\text { Nonrad air } \\
\text { emișsiọns }\end{array}$ & Construction and operation & $\begin{array}{l}\text { NAAQS, PSD (if } \\
\text { significant emissions) }\end{array}$ & IDHW, EPA & 40 CFR 52 \\
\hline $\begin{array}{l}\text { Nonrad air } \\
\text { emissions }\end{array}$ & Construction and operation & HAPs and TAPs & IDHW, EPA & $\begin{array}{l}40 \text { CFR } 61 \\
40 \text { CFR } 63 \\
\text { IDAPA 16.01.01 }\end{array}$ \\
\hline $\begin{array}{l}\text { Hazardous waste air } \\
\text { emissions }\end{array}$ & Construction and operation & $\begin{array}{l}\text { Treatment, storage, and } \\
\text { disposal facilities }\end{array}$ & IDHW, EPA & $\begin{array}{l}40 \text { CFR } 264,40 \text { CFR } 265 \\
\text { (Subparts AA, BB, and CC), } \\
\text { IDAPA 16.01.01 } \\
\text { IDAPA } 16.01 .05\end{array}$ \\
\hline $\begin{array}{l}\text { Radioactive air } \\
\text { emissions }\end{array}$ & Construction and operation & NESHAPS & IDHW, EPA & $\begin{array}{l}40 \text { CFR 61, Subpart H } \\
\text { IDAPA } 16.01 .01\end{array}$ \\
\hline All air emissions & Operations & Air Operating Permit & IDHW, EPA & $\begin{array}{l}40 \text { CFR } 70 \\
\text { IDAPA } 16.01 .01\end{array}$ \\
\hline Asbestos & Renovation and demolition & $\begin{array}{l}\text { Notification prior to } \\
\text { renovation or demolition }\end{array}$ & DHW, EPA & 40 CFR 61, Subpart M \\
\hline $\begin{array}{l}\text { Ozone depleting } \\
\text { substances }\end{array}$ & $\begin{array}{l}\text { Operation, reporting, } \\
\text { training }\end{array}$ & $\begin{array}{l}\text { Release prevention, } \\
\text { recovery/recycle, } \\
\text { Certificate labeling }\end{array}$ & IDHW, EPA & 40 CFR 82 \\
\hline $\begin{array}{l}\text { Sanitary wastewater } \\
\text { discharges }\end{array}$ & Discharges & NPDES Permit & EPA, IDHW & $\begin{array}{l}40 \text { CFR } 122 \text {, and } 125 \\
\text { IDAPA } 16.01 .02\end{array}$ \\
\hline Land surface & Construction and & NPDES Permit & EPA, IDHW & 40 CFR 122 \\
\hline
\end{tabular}


431.02:

$06 / 17 / 97$

Rev. 104
Function File Number - SRP-WTS-02

EDF Serial Number - EDF-WTS-003

\begin{tabular}{|c|c|c|c|c|}
\hline $\begin{array}{l}\text { wastewater } \\
\text { discharges }\end{array}$ & Operations & a & $\cdots$ & IDAPA 16.01 .02 \\
\hline $\begin{array}{l}\text { Storm wastewater } \\
\text { and nonstorm } \\
\text { wastewater } \\
\text { discharges }\end{array}$ & $\begin{array}{l}\text { Construction and } \\
\text { Operations }\end{array}$ & $\begin{array}{l}\text { NPDES Permit or } \\
\text { compliance with Idaho } \\
\text { Water Quality Standards }\end{array}$ & EPA & 40 CFR 122 \\
\hline $\begin{array}{l}\text { Drinking water } \\
\text { supply }\end{array}$ & $\begin{array}{l}\text { Construction and } \\
\text { operations } \\
\ddots\end{array}$ & $\begin{array}{l}\text { Approval of Engineering } \\
\text { Plans, Cross Connection } \\
\text { Control Plans, Report, } \\
\text { and Spec. }\end{array}$ & IDHW, EPA & $\begin{array}{l}40 \text { CFR 141, } \\
40 \text { CFR 143, } \\
\text { IDAPA 16.01.08 }\end{array}$ \\
\hline $\begin{array}{l}\text { Hazardous waste } \\
\text { treatment, storage, } \\
\text { Disposal }\end{array}$ & $\begin{array}{l}\text { Construction, operation, } \\
\text { and maintenance of new } \\
\text { facilities or modifications } \\
\text { of existing facilities }\end{array}$ & $\begin{array}{l}\text { Hazardous Waste Permit } \\
\text { (Part A and B) }\end{array}$ & IDHW, EPA & $\begin{array}{l}40 \text { CFR } 270 \\
40 \text { CFR } 264 \\
40 \text { CFR } 265\end{array}$ \\
\hline $\begin{array}{l}\text { Underground } \\
\text { storage Tanks } \\
\text { (UTSs) }\end{array}$ & $\begin{array}{l}\text { Construction and } \\
\text { operations }\end{array}$ & Technical standards & IDHW, EPA & 40 CFR 280 \\
\hline $\begin{array}{l}\text { Land disposal of } \\
\text { waste }\end{array}$ & $\begin{array}{l}\text { Construction, operations, } \\
\text { disposal }\end{array}$ & LDRs & IDHW, EPA & $\begin{array}{l}40 \text { CFR } 268,40 \text { CFR } 257 \text {, } \\
\text { IDAPA } 16.01 .05,10 \text { CFR } 61\end{array}$ \\
\hline
\end{tabular}

\section{SETTLEMENT AGREEMENT}

The State of Idaho and the DOE signed an agreement on October 16, 1995. The Agreement contains several commitments for the treatment of the HLW and SBW and their transfer out of Idaho. Based on the Agreement, all remaining liquid $H L W$ must be calcined by June 30, 1998, and calcination of all SBW must be completed by December 31, 2012. The Agreement requires that all HLW be treated and be road-ready to be moved out of Idaho for disposal by the year 2035. The calcination and the proposed treatment shall provide for completion of treatment of all calcine wastes by December 31, 2035.

It is stated in the Agreement that the DOE, as soon as practicable, commence the procurement of a treatment facility at INEEL for the treatment of mixed waste. The DOE shall execute a procurement contract for the Facility by June 1, 1997, complete construction of the Facility by December 31, 2002 , and commence operation of the Facility by March 31, 2003.

Commencement of construction is contingent upon Idaho approving necessary permits.

Based on the Agreement, the DOE shall accelerate efforts to evaluate alternatives for the treatment of calcined waste so as to put it into a form suitable for transport to a permanent repository or an interim storage facility outside Idaho. To support this effort, the DOE shall solicit proposals for feasibility studies by July 1, 1997, and shall commence negotiating a plan and schedule with the State of Idaho for calcine treatment by December 31, 1999. The plan and schedule shall provide for completion of the treatment of all calcined waste located at the INEEL 
by a date established by the Record of Decision (ROD) for the EIS that analyzes the alternatives for treatment of such waste. The State of Idaho expressly reserves its right to seek appropriate relief from the Court in the event that the date established in the ROD for the EIS that analyzes the alternatives for treatment of such waste is significantly later than the DOE's target date.

\section{NUCLEAR REGULATORY COMMISSION}

The purpose of this study is to provide an assessment of the current NRC regulations and their potential applicability to the proposed facilities if the facilities were to be licensed by the NRC in the future. The NRC requirement for regulating the DOE facilities or activities have not been defined yet. The requirements will need to be determined by the NRC and DOE Task Forces. Existing NRC regulations apply to commercial, non-DOE, facilities. The degree of applicability of the NRC requirements to the proposed facilities should be determined by the NRC and DOE, with input from the DOE contractor. If DOE facilities become regulated by NRC, the jurisdiction of other currently government applicable authorities will not automatically or necessarily cease. In particular, it is expected that local, State, Federal EPA, and some DOE regulatory requirements would still apply.

- Currently, the NRC is not authorized by law to license DOE facilities for:

- HLW processing such as those for vitrification, solidification, Cs and Sr extraction,

- short term storage of HLW, for TRU waste storage and disposal from DOE activities, and

- DOE LLW processing, storage, and disposal.

However, based on the recent DOE proposal, the NRC could take responsibilities for regulating the DOE nuclear facilities. Existing NRC regulations are compiled in 10 CFR, titled "Energy". These regulations follow a similar philosophy as the DOE, the EPA, and other codes and standards previously discussed above. The Commission has also issued a number of regulatory guides (e.g., NUREG) and other guidance documents which provide acceptable methods for complying with the NRC regulations. They contain criteria for facility design, operations, and for safety and bealth.

Of the existing NRC regulations, it has been determined in this study that 10 CFR 61 will apply to the proposed LAW or the LLW disposal facility, and 10 CFR 72 will be applicable to the proposed interim storage facilities for the vitrified, HIPed, or grouted HLW, and for the liquid HAW and vitrified HAW storage facilities. Independently, it was determined by Leroy and Morgan in "Nuclear Regulatory Commission (NRC) Licensing Assessment for the Idaho National Engineering and Environmental Laboratory (INEEL) High-Level Waste program," April 23, 1997, that 10 CFR 30 and 10 CFR 70 will apply to the following facilities: 
- 10 CFR 30 for the LAW collection and grouting facilities and for the collection and treatment of the LLW from the INEEL ongoing operations.

- 10 CFR 70 for the separations facility, for the interim storage of liquid HAW from the separation processes, and for the HAW vitrification facility.

- 10 CFR 70 for the HLW vitrification, HIPing, or grouting facilities.

- 10 CFR 70 for the calcine retrieval and dissolution facilities.

10 CFR 30, "Rules of General Applicability to Domestic Licensing of Byproduct Material", and 10 CFR 70, "Domestic Licensing of Special Nuclear Material", are not specifically or directly applicable to the facilities listed above. According to Steve LeRoy (personal communication, 12/03/97), they are the only ones which came close to being applicable to the proposed treatment, separations, and retrieval facilities. It is believed that certain elements of 10 CFR 30 and 10 CFR 70 could potentially be applicable to licensing of the proposed facilities. The fact remains that NRC will most likely have to promulgate new regulations specifically for the DOE HLW, LLW, and calcine retrieval and treatment facilities or to revise the requirements of 10 CFR 30 and 10 CFR 70 if they were to apply them to the proposed facilities.

Additional NRC regulations that are applicable to all of the proposed facilities are in 10 CFR 2, 10 CFR 19, 10 CFR 20, 10 CFR 21, 10 CFR 50, 10 CFR 51, 10 CFR 52, and 10 CFR 73. 10 CFR 71 and 49 CFR 173 (Department of Transportation) contain requirements for the packaging and transportation of radioactive wastes. These requirements would have impact on the design and operations of the storage facilities.

Appendix A provides a detailed source list of the regulations used by the NRC in commercial, non-reactor, nuclear facilities. The regulations are primarily based on the health and safety considerations. The list includes applicable parts and subparts of 10 CFR 20,21,30,50,51,61, 70 , and 72 as well as related guidance documents. The requirements and guidance documents are listed under the following categories: 1) radioactive waste management ,2) design of structures, components, equipment, and systems, 3) electric power, utility services, and fire protection, 4) radiation protection, 5) conduct of operation, 6) safety analysis report criteria, 7) quality assurance, and 8) decommissioning.

The existing facilities that will be modified to be used for storage of HLW are expected to be exempted by DOE from any further jurisdiction of NRC. Such a jurisdiction would be excessively difficult, costly, and complex to apply. All the work requirements for the modification of the existing facilities are expected to be performed in accordance with the DOE/RW/0333P, "Quality Assurance Requirements and Deseription" The requirements in DOE/RW/0333P are endorsed by the Office of Civilian Radioactive Waste Management

\footnotetext{
Byproduct material means any radioactive material (except special nuclear material) yielded in or made radioactive by exposure to the radiation incident to the process of producing or utilizing special nuclear material. Special nuclear material means (1) plutonium, uranium 233, uranium enriched in the isotope 233 or in the isotope 235, and any other material which the Commission determines to be special nuclear material, but does not include source material; or (2) any material artificially enriched by any of the foregoing but does not include source material.
} 
(OCRWM) which carries out the DOE mission for safe design and operation of a HIW geologic repository and a HIW storage facility.

\section{Current Licensing Process}

Most of the discussion in this section is based on the information contained in the DOE-STD101-92, "Compilation of Nuclear Safety Criteria Potential Application to the DOE Nonreactor Facilities" and in the report by Morgan and LeRoy, "Nuclear Regulatory Commission (NRC) Licensing Assessment for the Idaho National Engineering and Environmental Laboratory (INEEL) High-Level Waste program," April 23, 1997.

The applicable NRC regulations that define licensing processes are in 10 CFR 2, 10 CFR 30, 10 CFR 51, and 10 CFR 61 for LLW facilities and in 10 CFR 2, 10 CFR 50, 10 CFR 52, 10 CFR 70, and 10 CFR 72 for HLW or HAW facilities. The licensing of a nuclear facility requires preparation and submittal of an application and a number of supporting documents to the NRC such as SAR, environmental report (ER), quality assurance document, training plan, monitoring plan, and safeguards and security plan. The following is a generic description of the various documents that will be applicable to the proposed facilities.

The ER must meet the NRC requirements in 10 CFR 51. Appendix A, Section 7 provides regulatory sources containing quality assirance procedures for the facility design, construction, and operations. The quality assurance requirements in DOE/RW-0333P are expected to be used for the existing facilities that will be modified to be used for storage of $H L W$ or HAW. The SAR documents the adequacy of safety analysis for a nuclear facility to ensure that the facility can be designed, constructed, operated, maintained, shut down, and decommissioned safely and in compliance with applicable laws and regulations. The SAR criteria must meet the regulations listed in Appendix A, Section 6. The training, monitoring, and safeguards and security plans used by the license applicant to protect health and minimize danger to life or property must be developed in accordance with the applicable regulations. The training program should include an analysis of the job, leaming objectives and performance criteria, procedures for personnel monitoring, procedures to avoid accidents, etc. It is assumed that the DOE will retain the responsibility for safeguard and security for its facilities.

The NRC licensing process is divided into four stages: pre-application stage, application review stage, construction and operating license stage, and decontamination and site closure stage. The licensing duration from submittal of the application to receipt of the license is expected to take three to five years or longer.

Pre-application stage is prior to filing a license application with the NRC. It entails the development of the license application and the pre-submittal communications with the NRC. This includes the NRC and DOE interactions to clearly define the NRC acceptance criteria against which the ICPP proposed facilities license application will be reviewed. 
The application review stage describes the activities after submittal of the license application to the NRC. A notification will be published in the Federal Register for public hearing when the NRC receives the application. This application review stage begins with a review process referred to as a "Docketing Review" which is usually performed within 1 to 3 months. This review is to ensure that the application is complete and contains the necessary information. The Docketing Review process is followed by a detailed safety review of the application by the NRC staff. The NRC will ensure that the regulatory requirements are met as established in the regulations. The NRC usually requests additional information during this review which can be extensive and delay the review. Submittal of high quality, complete, and detailed SAR will reduce the request for additional information, hence the review time.

The construction and operating license stage follows the receipt of the license. The NRC will have the regulatory oversight during construction and operations.

NRC issues a license for certain time period. Before a facility license expires, a decommissioning plan will be developed by the DOE for review by the NRC. It is expected that the EPA will regulate the decontamination and decommissioning activities. Before the final closure, the DOE must submit a closure plan to the NRC for review. The closure plan must describe how the owner/operator will conduct clean-up, what clean-up levels will be attained, and how clean-up will be verified. The plan also includes a post-closure, and long term monitoring and maintenance. Upon review and acceptance, the NRC will aithorize closure. Monitoring will be performed during the post-closure plan in accordance with the applicable requirements. When all the monitoring and control requirements are met, the license will be terminated.

\section{LLW Near-Surface Disposal}

\section{CFR 61, Licensing Requirements for Land Disposal of Radioactive Waste}

10 CFR 61 contains specific technical requirements and performance objectives applicable to near-surface disposal of radioactive wastes. It contains requirements for design, operation, closure and post-closure, and monitoring. Near-surface disposal involves disposal of waste in the uppermost portion of the earth, approximately 30 meters or 100 feet of natural grade. The NRC maintains that the use of shallow land disposal is adequate for protection of individuals and the public, when properly sited, designed, and operated, as required by 10 CFR 61 .

Design, operation, and closure of the land disposal facility must ensure protection of any individual inadvertently intruding into the disposal site and occupying the site or contacting the waste at any time after active institutional controls over the disposal site are removed. Operations at the land disposal facility must be conducted in compliance with the standards for radiation protection set in 10 CFR 20, except for releases of radioactivity in effluents from the land disposal facility, which shall be governed by 10 CFR 61.41. At the time a license application is submitted, the applicant shall have conducted a preoperational monitoring program to provide basic environmental data on the disposal site characteristics. The applicant shall 
obtain information about the ecology, meteorology, climate, hydrology, geology, geochemistry, and seismology of the disposal site. For those characteristics that are subject to seasonal variation, data must cover at least a twelve month period.

The regulations for near surface disposal of radioactive wastes include a waste classification system which divides the wastes into three classes: Class A, B, and C. The classification system is based on the overall disposal hazards of the wastes. Certain minimum requirements must be met for all waste Classes as provided in 10 CFR 61.56 (a). In addition; Class B and C wastes are required to have structural stability as discussed in 10 CFR 61.56(b). The detailed information regarding the NRC requirements for a LLW disposal facility can be found in EDF-FDO-008.

\section{HLW Storage}

10 CFR 72, "Licensing Requirements for the Independent Storage of Spent Nuclear Fuel and High-Level Radioactive Waste"

10 CFR 72 contains regulations and procedures that are applicable to HLW or HAW interim storage facilities. The regulations in this part establish requirements for the issuance of licenses to the DOE to receive, transfer, package, and possess HLW, spent fuel, and other radioactive materials associatiu with spent fuel and HLW storage, in a monitored retrievable storage facility (MRS)g. This part also defines requirements for the safety design features of the facility structure and equipment. It requires that structures, systems, and components be designed, fabricated, erected, and tested to provide protection against environmental conditions and natural phenomena such as earthquakes, tornadoes, lighting, hurricanes, and floods. The facilities should also be designed to prevent massive collapse of building structures or the dropping of heavy objects as a result of building structural failure on the spent fuel or high-level radioactive waste or on to structures, systems, and components important to safety. If the facilities are located over an aquifer which is a major water resource, measures must be taken to preclude the transport of radioactive materials to the environment through this potential pathway.

Structures, systems, and components against fires and explosions must be designed and located so that they can continue to perform their safety functions effectively under credible fire and explosion exposure conditions. Noncombustible and heat-resistant materials must be used wherever practical, particularly in locations vital to the control of radioactive materials and to the maintenance of safety control functions. Explosion and fire detection, alarm, and suppression systems shall be designed and provided with sufficient capacity and capability to minimize the adverse effects of fires and explosions on structures, systems, and components important to safety.

\footnotetext{
Pursuant to the Nuclear Waste Policy Act, a MRS is an option for providing safe and reliable long-term storage of HLW or spent nuclear fuel. However, disposal of HLW and spent fuel in a repository should proceed regardless of any construction of a MRS pursuant to the Act.
} 
Other features that are important to safety must be designed to permit inspection, maintenance, and testing. Emergency capability must be designed to provide for accessibility to the equipment of onsite and available offsite emergency facilities and services such as hospitals, fire and police departments, ambulance service, and other emergency agencies.

Ventilation systems and off-gas systems must be provided where necessary to ensure the confinement of airborne radioactive particulate materials during normal or off-normal conditions. Storage confinement systems must have the capability for continuous monitoring in a manner such that the licensee will be able to determine when corrective action needs to be taken to maintain safe storage conditions. Instrumentation and control systems must be provided to monitor systems that are important to safety over anticipated ranges for normal operation and off-normal operation. Those instruments and control systems that must remain operational under accident conditions must be identified in the SAR.

Control room or control area must be designed to permit occupancy and actions to be taken to monitor the facilities under normal conditions, and to provide safe control of the facilities under off-normal or accident conditions. Utility or other services must be designed to meet emergency conditions.

It is required that $H \mathrm{~W} W$ be packaged in a manner that allows handling and retrievability without the release of radioactive materials to the environment or radiation exposures in excess of 10 CFR 20, "Standards for Protection Against Radiation", limits. The package must be designed to confine the high-level radioactive waste for the duration of the license. During normal operations and anticipated occurrences, the annual dose equivalent to any real individual who is located beyond the controlled area must not exceed 25 mrem to the whole body, 75 mrem to the thyroid and 25 mrem to any other organ as a result of exposure to planned discharges of radioactive materials and decay products excepted, to the general environment, and direct radiation from operations. Operational restrictions must be established to meet as low as is reasonably achievable (ALARA) objectives for radioactive materials in effluents and direct radiation levels associated with storage operations. Operational limits must be established for radioactive materials in effluents and direct radiation levels associated operations to meet the limits given above.

\section{CFR 72.124, "Criteria for nuclear criticality safety"}

The design of handling, packaging, transfer, and storage systems must include margins of safety for the nuclear criticality parameters that are commensurate with the uncertainties in the data and methods used in calculations. It must demonstrate safety for the handling, packaging, transfer and storage conditions and in the nature of the immediate environment under accident conditions.

When practicable the design of an MRS must be based on favorable geometry, permanently fixed neutron absorbing materials (poisons), or both. Where solid neutron absorbing materials are used, the design shall provide for positive means to verify their continued efficacy. 
A criticality monitoring system shall be maintained in each area where special nuclear material is handled, used, or stored which will energize clearly audible alarm signals if accidental criticality occurs. Monitoring of dry storage areas where special nuclear material is packaged in its stored configuration under a license issued under this subpart is not required.

10 CFR 72.128, "Criteria for spent fuel, high-level radioactive waste, and other radioactive waste storage and handling".

The regulations of this subpart require that HLW storage and other systems that might contain or handle radioactive materials be designed to ensure adequate safety under normal and accident conditions. These systems must be designed with: (1) a capability to test and monitor components important to safety, and suitable shielding for radioactive protection under normal and accident conditions, (2) confinement systems, (3) a heat-removal capability having testability and reliability consistent with its importance to safety, and (4) means to minimize the quantity of radioactive wastes generated. Provisions must be made for the packing of site-generated lowlevel wastes in a form suitable for storage onsite awaiting transfer to disposal sites. 


\section{APPENDIX A}

The following lists the current NRC requirements and guides applied to the areas of safety addressed in the SAR. The requirements are listed under the following categories: 1) radioactive waste management , 2) design of structures, components, equipment, and systems, 3) electric power, utility services, and fire protection, 4) radiation protection, 5) conduct of operation, 6) safety analysis report criteria, 7) quality assurance, and 8) decommissioning.

\section{1) Radioactive waste management}

This section identifies criteria for the control, collection, handling, processing, storage, and disposal of liquid, gaseous, and solid wastes that may contain radioactive materials, and the instrumentation used to monitor the release of radioactive materials. Also, as previously discussed, all RCRA hazardous and radioactive waste (mixed waste) management facilities are also subject to EPA RCRA regulations.

10 CFR 30, "Rules of General Applicability to Domestic Licensing of Byproduct Material" 10 CFR 61, “Licensing Requirements for Land Disposal of Radioactive Waste" 10 CFR 70.59, "Effluent Monitoring Reporting Requirements".

10 CFR 72.104, "Criteria in Effluents and Direct Radiation in Effluents and Direct Radiation from an ISFSI or MRS"

D. 10 CFR 72.128, “Criteria for Spent Fuel, High-Level Radioactive Waste, and Other Radioactive Waste Storage and Handling"

Regulatory Guide 1.21, "Measuring, Evaluating, and Reporting Radioactivity in Solid Wastes and Releases of Radioactive Materials in Liquid and Gaseous Effluents from Light-WaterCooled Nuclear Power Plants."

Regulatory Guide 1.143, "Design Guidance for Radioactive Waste Management Systems, Structures, and Components Installed in Light-Water-Cooled Nuclear Power Plants."

Regulatory Guide 3.10, "Liquid Waste Treatment Design Guide for Plutonium Processing and Fuel Fabrication Plants."

Regulatory Guide 3.13, "Guide for Acceptable Waste Storage Methods at UF6 Production Plants." 
Regulatory Guide 3.20, “Process Off-gas Systems for Fuel Reprocessing Plants.”

Regulatory Guide 3.49, "Design of an Independent Spent Fuel Storage Installation (Water-Basin Type)."

Regulatory Guide 3.60, “Design of an Independent Spent Fuel Storage Installation (Dry Storage)."

Regulatory Guide 4.18, "Standard Format and Contents of Environmental Reports for Nearsurface Disposal of Radioactive Waste."

NUREG-1199, "Standard Format and Content of a License Application for a Low-level Radioactive Waste Disposal Facility."

NUREG-1200, "Standard Review Plan for the Review of a License Application for a Radioactive Low-level Waste Disposal Facility."

NUREG-1300, "Standard Review Plan for the Review of a License Application for a Radioactive Low-level Waste Disposal Facility."

NUREG-0800, Section 11.2, "Liquid Waste Management .Systems."

NUREG-0800, Section 11.3, "Gaseous Waste Management Systems."

NUREG-0800, Section 11.4, "Solid Waste Management Systems."

NUREG-0800, Section 11.5, "Process and Effluents radiological Monitoring."

NUREG-1567, "Offgas Treatment and Ventilation."

2) Design of structures, components, equipment and systems

10 CFR 21, "Reporting of Defects and Noncompliance"

10 CFR 50.34, "Contents of Applications: Technical Information"

10 CFR 50, Appendix F, "Policy Relating to the Siting of Fuel Reprocessing Plants and Related Waste Management Facilities"

10 CFR 61.51, "Disposal Site Design for Land Disposal"

10 CFR 61.52, "Land Disposal Facility Operation and Disposal Site Closure" 
10 CFR 61.54, "Altemative Requirements for Design and Operations"

10 CFR 70, "Domestic Licensing of Special Nuclear material"

10 CFR 72, "Licensing Requirements for the Independent Storage of Spent Nuclear Fuel and High-Level Radioactive Waste"

10 CFR 72.120, "General Considerations"

10 CFR 72.122, "Overall Requirements"

10 CFR 72.124, "Criteria for Nuclear Criticality Safety"

10 CFR 72.126, "Criteria for Radiological Protection"

10 CFR 72.128, "Criteria for Spent Fuel, High-Level Radioactive Waste, and Other Radioactive Waste Storage and Hand-ling"

10 CFR 72.130, "Criteria for Decommissioning"

Regulatory Guide, 3.10, "Liquid Waste Treatment System Design Guide for Plutonium Processing and Fuel Fabrication Plants."

Regulatory Guide 3.12, "General Design Guide for Ventilation Systems of Plutonium Processing and Fuel Fabrication Plants."

Regulatory Guide 3.20, "Process Off-gas Systems for Fuel Reprocessing Plants"

Regulatory Guide 3.32, "General Design Guide for Ventilation Systems for Fuel Reprocessing Plants."

Regulatory Guide 3.38, "General Fire Protection Guide for Fuel Reprocessing Plants."

Regulatory Guide 3.56, "General Guidance for Designing, Testing, Operating, and Maintaining Emission Control Devices at Uranium Mills."

Regulatory Guide 5.25, "Design Considerations for Minimizing Residual Holdups of Special Nuclear Material in Equipment for Wet process Operations."

\section{Seismic systems criteria}

10 CFR 61.12, "Specific Technical Information" 
10 CFR 72.120, "General Considerations"

Regulatory Guide 1.29, "Seismic Design Classification."

Regulatory. Guide 3.14, "Seismic Design Classification for Plutonium Processing and Fuel Fabrication Plants.

\section{Wind and Tornado Loading criteria}

10 CFR 61.12; "Specific Technical Information"

10 CFR 72.40, "Issuance of License"

10 CFR 72.90, "General Considerations"

10 CFR 72.92, "Design Basis External Natural Events"

10 CFR 72.98, "Identifying Regions Around an ISFSI or MRS Site"

10 CFR 72.122, "Overall Requirements"

Regulatory Guide 1.76, "Design Basis Tornado for Nuclear Power Plants.”

Regulatory Guide 3.10, "Liquid Waste Treatment Design Guide for Plutonium Processing and Fuel Fabrication Plants."

Regulatory Guide 3.12, “General Design Guide for Ventilation Systems of Plutonium Processing and Fuel Fabrication Plants."

Regulatory Guide 3.16, “General Fire Protection Guide for Plutonium Processing and Fuel Fabrication Plants."

Regulatory Guide 3.18, “Confinement Barriers and Systems for Fuel Reprocessing Plants.

Regulatory Guide 3.20, "Process Offgas Systems for Fuel Reprocessing Plants."

Regulatory Guide 3.31, "Emergency Water Supply Systems for Fuel Reprocessing Plants."

Regulatory Guide 3.32, "General Design Guide for Ventilation Systems for Fuel Reprocessing Plants."

Regulatory Guide 3.38, "General Fire Protection Guide for Fuel Reprocessing Plants." 
Regulatory Guide 3.49, "Design of an Independent Spent Fuel Storage Installation, (Water Basin Type)."

Regulatory Guide 3.53, “Applicability of Existing Regulatory Guides to the Design and Operation of an Independent Spent Fuel Storage Installation."

Regulatory Guide 3.60, "Design of an Independent Spent Fuel Storage Installation (Dry Storage)."

NUREG/CR-3874, "Near-Ground Tornado Wind Fields," McDonald, J.R., Texas Tech. University, July 1984.

NUREG/CR-3848, "Experimental Investigation of Unsteady Tornadic Wind Loads on Structures," Jischke, M.C., Oklahoma Teaching Hospitals, June 1984.

NUREG/CR-3058, “A Methodology for Tomado Hazard Probability Assessment,” McDonald, J.R., Texas Tech. University, October 1983.

NUREG/CR-2944, "Tomado Damage Risk Assessment," Reinhold, T.A. and Ellingwood, B., National Bureau of Standards, February 1983.

NUREG/CR-2565, "Structural Performance of HEPA Filters Under Simulated Tomado Conditions," Horak, H.L. and Smith, P.R., Los Alamos National Laboratory, May 1982.

NUREG/CR-2014, "Kinematics of Translating Tornado Wind Fields," Peterson, R.E., Texas Tech. University, April 1981.

NUREG/CR-1585, "Modeling Tornado Dynamics," Aeronautical Research Association, September 1980.

\section{Water level (flood) design}

10 CFR 61.12, "Specific Technical Information".

10 CFR 61.50, "Disposal Site Suitability Requirements for Land Disposal"

10 CFR 72.40, "Issuance of License"

10 CFR 72.90, "General Considerations"

10 CFR 72.92, "Design Basis External Natural Events"

10 CFR 72.94, "Design Basis External Man-Induced Events" 
10 CFR 72.98, "Identifying regions Around and ISFSI or MRS Site"

10 CFR 72.122, "Overall Requirements"

Regulatory Guide 3.10, "Liquid Waste Treatment Design Guide for Plutonium Processing and Fuel Fabrication Plants."

Regulatory Guide 3.11, "Design, Construction, and Inspection of Embankment Retention Systems for Uranium Mills."

Regulatory Guide 3.18, "Confinement Barriers and Systems for Fuel Reprocessing Plants. Regulatory Guide 3.31, "Emergency Water Supply Systems for Fuel Reprocessing Plants."

Regulatory Guide 3.40, "Design Basis Floods for Fuel Reprocessing Plants and for Plutonium Processing and Fuel Fabrication Plants."

Regulatory Guide 3.49, "Design of an Independent Spent Fuel Storage Installation, (Water Basin Type)."

Regulatory Guide 3.53, "Applicability of Existing Regulatory Guides to the Design and Operation of an Independent Spent Fuel Storage Installation."

Regulatory Guide 3.60, "Design of an Independent Spent Fuel Storage Installation (Dry Storage)."

NUREG/CR-2678, "Flood Risk Analysis Methodology Development Project - Final Report" Wagner, D.P. et al., Oak Ridge National Laboratory, July 1982.

\section{Missile protection}

10 CFR 61.12, "Specific Technical Information"

10 CFR 72.40, "Issuance of License"

10 CFR 72.90, “General Considerations"

10 CFR 72.92, "Design Basis External Natural Events”

10 CFR 72.94, "Design Basis External Man-Induced Events"

10 CFR 72.98, "Identifying Regions Around an ISFSI or MRS Site" 
10 CFR 72.122, “Overall Requirements"

Regulatory Guide 3.10, "Liquid Waste Treatment Design Guide for Plutonium Processing and Fuel Fabrication Plants."

Regulatory Guide 3.12, “General Design Guide for Ventilation Systems of Plutonium Processing and Fuel Fabrication Plants."

Regulatory Guide 3.16, "General Fire Protection Guide for Plutonium Processing and Fuel Fabrication Plants."

Regulatory Gujde 3.18, "Confinement Barriers and Systems for Fuel Reprocessing Plants."

Regulatory Guide 3.20, "Process Off-gas Systems for Fuel Reprocessing Plants."

Regulatory Guide 3.31, "Emergency Water Supply Systems for Fuel Reprocessing Plants."

Regulatory Guide 3.32, "General Design Guide for Ventilation Systems for Fuel Reprocessing Plants."

Regulatory Guide 3.38, "General Fire Protection Guide for Fuel Reprocessing Plants.".

Regulatory Guide 3.49, "Design of an Independent Spent Fuel Storage Installation, (Water Basin Type)."

Regulatory Guide 3.53, "Applicability of Existing Regulatory Guides to the Design and Operation of an Independent Spent Fuel Storage Installation."

Regulatory Guide 3.60, "Design of an Independent Spent Fuel Storage Installation (Dry Storage).

NUREG-0533, "Aircraft Impact risk Assessment, Data Base for Assessment of Air Carrier Impact Risk in the Vicinity of Airports," USNRC, July 1979.

NUREG/CR-2462, "Capacity of Nuclear Power Plant Structures to Resist Blast Loading," Kennedy, R.P. et al., Sandia National Laboratories, September 1983.

NUREG/CR-2859, "Evaluation of Aircraft Crash Hazards for Nuclear Power Plants," Kot, C.A. et al., Argonne National Laboratory, September 1982. 
Seismic design

10 CFR 61.12, "Specific Technical Information"

10 CFR 70.22, "Contents of Applications"

10 CFR 70.23, "Requirements for the Approval of Applications"

10 CFR 72.40, "Issuance of License"

10 CFR 72.90, “General Considerations"

10 CFR 72.92, "Design Basis External Natural Events"

10 CFR 72.98, "Identifying Regions Around an ISFSI or MRS Site"

10 CFR 72.102 "Geological and Seismological Characteristics"

10 CFR 72.122, "Overall Requirements".

Regulatory Guide 3.10, "Liquid Waste Treatment Design Guide for Plutonium Processing and Fuel Fabrication Plants."

Regulatory Guide 3.12, "General Design Guide for Ventilation Systems of Plutonium Processing and Fuel Fabrication Plants."

Regulatory Guide 3.14, "Seismic Design Classification for Plutonium Processing and Fuel Fabrication Plants."

Regulatory Guide 3.16, "General Fire Protection Guide for Plutonium Processing and Fuel Fabrication Plants."

Regulatory Guide 3.17, "Earthquake Instrumentation for Fuel Reprocessing Plants.”

Regulatory Guide 3.18, "Confinement Barriers and Systems for Fuel Reprocessing Plants.

Regulatory Guide 3.20, "Process Off-gas Systems for Fuel Reprocessing Plants."

Regulatory Guide 3.31, "Emergency Water Supply Systems for Fuel Reprocessing Plants."

Regulatory Guide 3.32, "General Design Guide for Ventilation Systems for Fuel Reprocessing Plants."

Regulatory Guide 3.38, "General Fire Protection Guide for Fuel Reprocessing Plants.” 
Regulatory Guide 3.49, "Design of an Independent Spent Fuel Storage Installation, (Water Basin Type)."

Regulatory Guide 3.53, "Applicability of Existing Regulatory Guides to the Design and Operation of an Independent Spent Fuel Storage Installation."

Regulatory Guide 3.60, "Design of an Independent Spent Fuel Storage Installation (Dry Storage)."

NUREG/CR-1069, "Effects of Earthquakes on Underground Facilities: Literature Review and Discussion," Carpenter, D.W. and Chung, D.C., Lawrence Livermore National Laboratory, June 1986.

\section{Ventilation and process off-gas systems}

10 CFR 72.132, “Overall Requirements"

Regulatory Guide 1.140, "Design, Testing, and Maintenance for Normal Ventilation Systems."

Regulatory Guide 1.52, "Design, Testing, and Maintenance aCriteria for Post-accident engineered Safety Feature Ventilation Systems."

Regulatory Guide 3.12, "General Design Guide for Ventilation Systems of Plutonium Processing and Fuel Fabrication Plants."

Regulatory Guide 3.20, "Process Off-gas Systems for Fuel Reprocessing Plants."

Regulatory Guide 3.32, "General Design Givide for Ventilation Systems for Fuel Reprocessing Plants."

Regulatory Guide 3.49, "Design of an Independent Spent Fuel Storage Installation (Water Basin Type)."

Regulatory Guide 3.60, "Design of an Independent Spent Fuel Storage Installation (Dry Storage)."

NUREG-1567, Section 11.4.1.3 (DRAFT), "Ventilation offgas System Design Feature." 
3) Electrical power, utility services, and fire protection

10 CFR 50.55(a), “Codes and Standards"

10 CFR 72.122, "Overall Requirements"

Regulatory Guide 1.108, "Periodic Testing of Diesel Generator Units Used as Onsite Electric Power Systems at Nuclear Power Plants."

Regulatory Guide 3.14, "Seismic Design Classification for Plutonium Processing and Fuel Fabrication Plants."

Regulatory Guide 3.16, "General Fire Protection Guide for Plutonium Processing and Fuel Fabrication Plants."

Regulatory Guide 3.38, "General Fire Protection Guide for Fuel Reprocessing Plants."

\section{4) Radiation protection}

The criteria identified in this chapter are for the radiation protection of operating, construction, and maintenance personnel during normal and anticipated operational occurrences. The compilation includes criteria for facility equipment design and programs to minimize and monitor radiation exposure to meet the standards for protection against radiation of 10 CFR 20 .

10 CFR 19.12, "Instructions to Workers"

10 CFR 20, "Standards for Protection Against Radiation"

10 CFR 61.41, "Protection of the General Population From Releases of Radioactivity"

10 CFR 61.43, "Protection of Individuals During Operations"

10 CFR 72.44, "License Conditions"

10 CFR 72:104, "Criteria for Radioactive Materials in Effluents and Direct Radiation from an ISFSI or MRS"

10 CFR 72.126, "Criteria for Radiological Protection"

Regulatory Guide 3.6, "Content of Technical Specifications for Fuel Reprocessing Plants."

Regulatory Guide 8.1, "Radiation Symbol." 
Regulatory Guide 8.2, “Administrative Practices in Radiation Monitoring.”

Regulatory Guide 8.10, “Operating Philosophy for Maintaining Occupational Radiation Exposures as Low as is Reasonably Achievable."

Regulatory Guide 8.24, "Health Physics Surveys During Enriched Uranium Processing and Fuel Fabrication."

\section{5) Conduct of operations}

The criteria identified in this chapter address training, emergency planning, plant procedures, and the maintenance of records and reporting.

10 CFR 61, "Licensing Requirements for Land Disposal of Radioactive Waste"

10 CFRR 51, "Environmental Protection Regulations for Domestic Licensing and Related Regulatory Functions"

10 CFR 70, "Domestic Licensing of Special Nuclear Material"

10 CFR 72.190, "Operator Requirements"

10 CFR 72.192, “Operator Training and Certification Program"

10 CFR 72.194, "Physical Requirements."

Regulatory Guide 3.28, "Welder Qualification for Welding in Areas of Limited Accessibility in Fuel Reprocessing Plants and in Plutonium Processing and Fuel Fabrication Plants."

Regulatory Guide 3.42, "Emergency Planning for Fuel Cycle Facilities and Plants Licensed Under 10 CFR Parts 50 and 70.

6) Safety analysis report criteria

10 CFR 20, "Standards for Protection Against Radiation"

10 CFR 30, "Rules of General Applicability to Domestic Licensing of Byproduct Material"

10 CFR 50.33, "Contents of Application, General Information"

10 CFR 50.36(b), "Environmental Conditions" 
10 CFR 50.55, "Conditions of Construction Permits"

10 CFR 50.71, "Maintenance of Records, making Reports"

10 CFR 61, "Licensing Requirements for Land Disposal of Radioactive Waste"

10 CFR 61.10, "Contents of Application"

10 CFR 70, "Domestic Licensing of Special Nuclear Material”

10 CFR 70.22, "Contents of Application"

10 CFR 70.23, "Requirements for the Approval of Applications"

10 CFR 72, "Licensing Requirements for the Independent Storage of Spent Nuclear Fuel and High-Level Radioactive Waste"

10 CFR 72.22, "Contents of Application: General and Financial Information"

10 CFR 72.24, "Contents of Application: Technical Information"

10 CFR 72.30, "Decommissioning Planning, Including Financing and Record Keeping"

10 CFR 72.48, "Changes, Tests, and Experiments"

Regulatory Guide 3.15, "Standard Format and Content of License Application for Storage Only of Unirradiated Power Reactor Fuel and Associated Radioactive Material."

Regulatory Guide 3.25, "Standard Format and Content of Safety Analysis Reports for Uranium Enrichment Facilities."

Regulatory Guide 3.26, "Standard Format and Content of Safety Analysis Reports for Fuel Reprocessing Plants."

Regulatory Guide 3.39, "Standard Format and Content of License Applications for Plutonium Processing and Fuel Fabrication Plants."

Regulatory Guide 3.44, "Standard Format and Content for the Safety Analysis Report for an Independent Spent Fuel Storage Installation (Water-Basin Type)."

Regulatory Guide 3.48, "Standard Format and Content for the Safety Analysis Report for an Independent Spent Fuel Storage Installation or Monitored Retrievable Storage Installation (Dry Storage)." 
Regulatory Guide 3.50, "Standard Format and Content for a License Application to Store Spent Fuel and High-Level Radioactive Waste."

Regulatory Guide 3.52, "Standard Format and Content for the Health and Safety Sections of License Renewal Applications for Uranium Processing and Fuel Fabrication."

Regulatory Guide 3.55, "Standard Format and Content for the Health and Safety Sections of License Renewal Applications for Uranium Hexafluoride Production.”

Regulatory Guide 3.61, "Standard Format and Content for a Topical Safety Analysis Report for a Spent Fuel Dry Storage Cask."

Regulatory Guide 3.62, "Standard Format and Content for the Safety Analysis Report for Onsite Storage of Spent Fuel Storage Casks."

\section{Accident analysis}

The criteria in this chapter are for initiating events that result in a criticality accident.

10 CFR 50.34, "Contents of Applications: Technical Information"

10 CFR 61.13, "Technical Analyses"

10 CFR 70.22, "Content of Applications"

10 CFR 70.23, "Requirements for the Approval of Applications"

10 CFR 72.24, "Contents of Application: Technical Information"

10 CFR 100.11, "Determination of Exclusion Area, Low Population Zone, and Population Center Distance"

Regulatory Guide 1.25, “Assumptions Used for Evaluating the Potential Radiological Consequences of a Fuel-Handling Accident in the Fuel-Handling and Storage Facility for Boiling and Pressurized Water Reactors."

Regulatory Guide 1.91, "Evaluations of Explosions Postulated to Occur on Transportation Routes Near Nuclear Power Plants."

Regulatory Guide 1.113, "Estimating Aquatic Dispersion of Effluents from Accidental and Routine Releases." 
Regulatory Guide 1.145, “Atmospheric Dispersion Models for Potential Accident Consequence Assessments at Nuclear Power Plants."

NUREG-1320, "Nuclear Fuel Cycle Facility Accident Analysis Handbook," USNRC, May 1988.

NUREG-1179, "Rupture of Model 48Y UF6 Cylinder and Release of Uranium Hexafluoride," USNRC, February 1986.

NUREG-0772, "The Effects of Natural Phenomena on the Exxon Nuclear Company MixedOxide Fabrication Plant at Richland Washington," USNRC, September 1980.

NUREG/CR-4303, "High-Level Waste Preclosure Systems Safety Analysis," GA Technologies, Inc., September 1985.

NUREG/CR-3682, "Nuclear Fuel Cycle Risk Assessment-Review and Evaluation of Existing Methods," Pelto, P.J. et al., Battelle Pacific Northwest Laboratories, May 1984.

NUREG/CR-3210, "Low-Level Waste Risk Methodology Development," Cox, N.D. et al., EG\&G Inc., May 1983.

NUREG/CR-3139, "Scenarios and Analytical Methods for UF6 Releases at NRC-Licensed Fuel Cycle Facilities," Simantov, M. et al., Oak Ridge National Laboratory, July 1984.

7) Quality assurance during design, construction, and operation

10 CFR 50.4, "Written Communications"

10 CFR 50.55, "Conditions of Construction Permits"

10 CFR 50, Appendix B, "Quality Assurance Criteria for Nuclear Power Plants and Fuel Reprocessing Plants"

10 CFR 61.12, "Specific Technical Information"

10 CFR 72.40, "Issuance of License"

10 CFR 72 Subpart G, "Quality Assurance"

Regulatory Guide 1.30, "Quality Assurance Requirements for the Installation, Inspection, and Testing of Instrumentation and Electric Equipment."

Regulatory Guide 2.3, “Quality Verification for Plate-Type Uranium-Aluminum Fuel Elements for Use in Research Reactors." 
Regulatory Guide 3.3, "Quality Assurance Program Requirements for Fuel Reprocessing Plants and for Plutonium Processing and Fuel Fabrication Plants."

Regulatory Guide 3.10, "Liquid Waste Treatment System Design Guide for Plutonium Processing and Fuel Fabrication Plants.

Regulatory Guide 3.12, "General Design Guide for Ventilation Systems or Plutonium Processing and Fuel Fabrication Plants."

\section{8) Decommissioning}

10 CFR 50, Appendix F, "Policy Relating to the Siting of Fuel Reprocessing Plants and Related Waste Management Facilities."

10 CFR 50.75, "Reporting and Record Keeping for Decommissioning Planning"

10 CFR 50.82, "Application for Termination of Licenses"

10 CFR 61.12, "Specific Technical Information"

10 CFR 61.14, "Institutional Information"

10 CFR 61.23, "Standards for Issuance of a License"

10 CFR 61.24, "Conditions of Licenses"

10 CFR 61.28, "Contents of Application for Closure"

10 CFR 61.29, "Post Closure Observation and Maintenance"

10 CFR 61.30, "Transfer of License"

10 CFR 61.31, "Termination of License"

10 CFR 61.40, "General Requirement"

10 CFR 61.42, "Protection of Individuals From Inadvertent Intrusion"

10 CFR 61.44, "Stability of the Disposal Site After Closure"

10 CFR 61.52, "Land Disposal Facility Operation and Disposal Site Closure" 
10 CFR 61.53, "Environmental Monitoring"

10 CFR 61.62, "Funding for Disposal Site Closure and Stabilization"

10 CFR 70.25, "Financial Assurance and Record Keeping for Decommissioning"

10 CFR 70.38, "Expiration and Termination of Licenses"

10 CFR 72.30, "Decommissioning Planning Including Financing and Record Keeping"

10 CFR 72.40, "Issuance of License"

10 CFR 72.54, “Application for Termination of License”

10 CFR 72.130, "Criteria for Decommissioning"

Regulatory Guide 3.65, "Standard Format and Content of Decommissioning Plans for Licensees Under 10 CFR Parts 30, 40, and 70."

NUREG-0436, Rev. 1 and Supplements 1 and 2, "Plan for Reevaluation of NRC Policy on Decommissioning of Nuclear Facilities," USNRC, December 1978.

NUREG-0278, Vol. 1 \& Vol. 2, "Technology, Safety, and Costs of Decommissioning a Reference Nuclear Fuel Reprocessing Plant," Schneider, K.J. et al., Battelle Pacific Northwest Laboratory, October 1977.

NUREG/CR-1754, Addendum 1, "Technology, Safety, and Costs of Decommissioning Reference Non-Fuel-Cycle Nuclear Facilities," Short, S.M., Pacific Northwest Laboratory, October 1989. 
Project File Number $\quad 02 B D 7$

Project/Task Waste Treatment Project Feasibility Studies

Subtask WTF Design Requirements

Title: $\quad$ Regulatory and Design Requirements for Waste Treatment Facilities

SUMMARY: The purpose of this document is to delineate the design requirements for the nonseparations and TRU only separations options for the Waste Treatment Facilities (WTF) feasibility studies. The facilities will be designed and constructed under one of three possible regulatory scenarios: 1) performance against US Department of Energy (DOE) Orders with maintenance of status-quo interfaces with other regulatory and oversight agencies such as the EPA (State of Idaho)

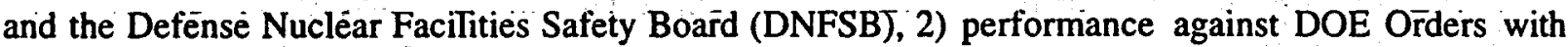
all current regulatory/oversight relationships maintained and or Nuclear Regulatory Commission (NRC) oversight to achieve "NRC Equivalency" or, 3) NRC licensing though replacement of DOE Orders with NRC Regulations and replacement of DNFSB oversight with NRC licensing process. For the purposes of this study and at the direction of the high level waste alternatives feasibility studies project manager, the base case for this study is performance against DOE Orders (scenario 1, above). This is consistent with the approach taken by Fluor Daniel, Inc., at the direction of the HLW Program in the preparation of the planning alternative and will provide an apples-to-apples comparison of the alternatives.

\section{TABLE OF CONTENTS:}

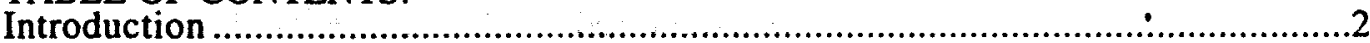

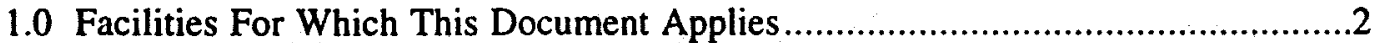

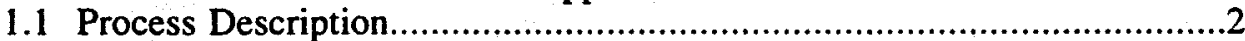

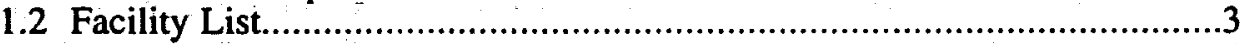

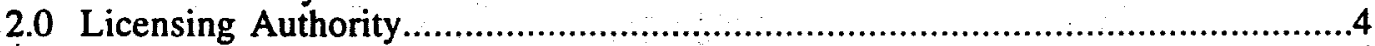

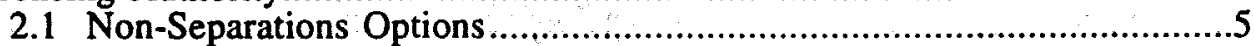

2.2 TRU-Only Separations Options.......................................................5

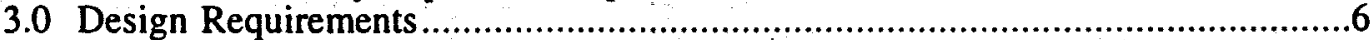

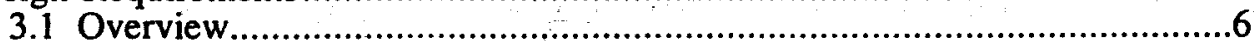

3.2 Non-Separations Options Waste Stabilization Facility ...............................

4.0 References.

Distribution (complete package):

Distribution (summary package only):

\begin{tabular}{|c|c|c|c|c|c|}
\hline $\begin{array}{l}\text { Author } \\
\text { P.M. Rice } \\
\text { S.L. Austad, P.E } \\
\text { L.E, Guillen, P.E }\end{array}$ & $\begin{array}{l}\text { Dept. } \\
4130\end{array}$ & 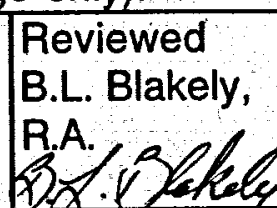 & \begin{tabular}{|l} 
Date \\
$1 / 27 / 98$
\end{tabular} & Approved & $\begin{array}{l}\text { Date } \\
2 / 2 / 98\end{array}$ \\
\hline scumets & & $\begin{array}{l}\text { LMITCO } \\
\text { Review }\end{array}$ & Date & $\begin{array}{l}\text { LMITCO } \\
\text { Approval }\end{array}$ & Date \\
\hline
\end{tabular}




\section{Introduction}

The purpose of this document is to delineate the design requirements for the non-separations and TRU only separations options for the Waste Treatment Facilities (WTF) feasibility studies. The facilities will be designed and constructed under one of three possible regulatory scenarios: 1) performance against US Department of Energy (DOE) Orders with maintenance of status-quo interfaces with other regulatory and oversight agencies such as the EPA (State of Idaho) and the Defense Nuclear Facilities Safety Board (DNFSB), 2) performance against DOE Orders with all current regulatory/oversight relationships maintained and or Nuclear Regulatory Commission (NRC) oversight to achieve "NRC Equivalency" or, 3) NRC licensing though replacement of DOE Orders with NRC Regulations and replacement of DNFSB oversight with NRC licensing process. For the purposes of this study and at the direction of the high level waste alternatives feasibility studies project manager, the base case for this study is performance against DOE Orders (scenario 1, above). This is consistent with the approach taken by Fluor Daniel, Inc., at the direction of the HLW Program in the preparation of the planning alternative and will provide an apples-to-apples comparison of the alternatives.

With the ground rules clearly established above, the following is a discussion of how they will be selectively applied/ignored.

This EDF will identify the applicable DOE orders, regulations and guidance documents that would be used in the design of the facilities. There are currently no NRC regulations in place for the licensing of waste processing facilities such as those discussed herein. The only WTF activities for which the NRC has been routinely involved is the licensing of waste storage and disposal facilities. Never-the-less, NRC requirements are looming on the horizon. In addition, the waste products to be produced are in many cases destined for NRC licensed storage facilities. Therefore, there are some NRC requirements that just cannot be ignored. Thus, where appropriate, NRC regulations are explicitly specified in the design requirements. Where specific design criteria is provided under NRC regulations and guidance documents whether directly applicable or for similar facilities, it will be referenced. This will be useful in helping to determine the cost differential between DOE regulatory/oversite and NRC licensing requirements.

\subsection{Facilities For Which This Document Applies}

\subsection{Process Description}

The following is a very brief description of each of the processes that this document will consider:

Direct Vitrification Direct vitrification is a process for converting calcine into a glass waste. In the direct vitrification process, calcine is mixed with "frit" materials and fed to a melter, which would operate at a temperature of around $1100^{\prime \prime} \mathrm{C}$. Numerous small-scale tests have been performed to determine frit formulations and glass properties, primarily leachability. No pilot data or design data is available for direct vitrification of calcine. 
Direct Grout Grouting is an ambient temperature process for solidifying or stabilizing a waste material. Grouting utilizes hydraulic cement that hardens by chemical interactions with water, and various additives which may aid dispersion, control hardening, control pumping characteristics or enhance retention of certain contaminants in the waste.

Cementitious Waste Process Darryl Siemer has proposed a direct grouting process ${ }^{33}$ with differences from that described above. Siemer suggests mixing existing calcine with existing $\mathrm{SBW}$, and recalcining the resulting slurry in the existing calciner, using sugar as additive to permit calcination of high-sodium waste. This recalcined waste would then be mixed with a combination of cementitious agents and water, and transferred to a stainless steel can. After setting at ambient temperature, the can is transferred to an autoclave and cured with steam. If further processed by HIPing, the can would be vented and placed in a furnace to remove volatiles. Then the can would be transferred to the HIP chamber, an inert gas added to pressurize to $30-125 \mathrm{MPa}(4350-18,100$ psi), and the can heated at $850-1050^{\circ} \mathrm{C}$ for the required "soak" time.

Hot Isostatic Press (HIP) The HIP process uses high pressure and high temperature to convert calcine or other solid wastes to a glass-ceramic waste form. In a conceptual flowsheet proposed for processing calcine, calcine from storage is mixed with frit or other additives, fed to a HIP can, the can sealed and decontaminated, and then isostatically pressed in a furnace. Processing temperatures for the HIP process are similar to vitrification, typically $1050-1100^{\circ} \mathrm{C}$. The typical HIP operating pressure is 20,000 psi.

TRU Waste Alternative In this alternative, calcine is dissolved and actinides removed from the resulting solution by the TRUEX process. TRUEX wash effluents and raffinate along with other ICPP low level wastes, are evaporated, denitrated and grouted. The TRUEX strip effluent is evaporated, denitrated and then packaged for shipment to WIPP. An alternative to denitration would be to neutralize and evaporate the effluents from separation.

\subsection{Facility List}

Below is a list of the primary, main ancillary, and common support facilities that will be required for each of the options discussed herein:

1. Non-Separations Direct Vitrification Option:

- Vitrification Facility

2. Non-Separations Direct Grout Option:

- Grouting Facility

3. Non-Separations Calcine Hot Isostatic Press (HIP) Option:

- Calcine HIP Facility 
4. Non-Separations Cementitious Waste Option:

- Calcine Slurry and Grouting Facility

5. TRU-Only Separations:

- TRU Separations Facility

- TRU Product Handing, Packaging and Lag Storage Facility (TRU-only Separations Option):

- Class C Grouted Waste Interim Storage Facility:

In addition, a number of common support facilities/systems will be required to support the above facilities which include:

- Calcine Retrieval System (may vary depending on the process design for each option)

- Temporary Calcine (surge or staging) Storage

- Interim HLW Storage Facility

Note: For all of these alternatives, the study ends with interim storage of the waste product prior to shipment. Thus none of the studies includes facilities for receiving and internment of the final waste product at a repository.

\subsection{Licensing Authority}

As previously stated, for the purposes of this effort, the base case for this study is performance against DOE Orders. The following discussion is presented to defined under what NRC regulations each of the above referenced facilities would be licensed if NRC licensing were the preferred approach. This information is provided for reference only.

In early 1997 the INEEL Spent Nuclear Fuel, High-Level Waste and Related Programs prepared a licensing assessment report for proposed INEEL ICPP High Activity Waste Treatment Facilities (Idaho Chemical Processing Plant High Activity Waste Treatment Project Regulatory Assessment Report, prepared by R. G. Morgan and S. E. Leroy, Duke Engineering Services, Inc. S. E. Leroy letter to V. L. Jacobson, dated April 25, 1997) (1). The report provided an assessment of how the proposed ICPP Waste Treatment Facilities could be licensed under existing NRC regulations and processes. The report identifies the applicable NRC regulations and guidance documents that would be used in the licensing process. It also identifies those areas where additional NRC guidance documents, regulations, or rulemaking may be necessary.

The above referenced report specifically addresses the facilities defined in the "preferred alternative', whereas this EDF is examining other methods of processing and disposing of the 
calcined wastes at ICPP. For the purpose of defining the licensing criteria for the options discussed in this EDF, the above referenced report will be used. Licensing criteria will be based on similarities between the preferred alternative facilities and the facilities described here.

\subsection{Non-Separations Options (Primary and Ancillary Facilities)}

The non-separations options include: 1) direct vitrification, 2) direct grouting, 3) calcine HIPing, and 4) the Cementitious Waste options. Each option will include a facility to perform the appropriate operations to produce the end product (e.g., vitrification facility, direct grouting facility, HIPing facility, and a calcine slurry and grouting facility for the Cementitious Waste option).

The non-separations options are similar in scope to the High Activity Waste Treatment (HAWT) Facilities described in reference 1. The HAWT facilities include a calcine retrieval, transport, and receiving system; a calcine dissolution process; a high activity waste vitrification process; and vitrified product storage. The non-separations options include a calcine retrieval, transport, and receiving system; a waste stabilization process (vitrification, grouting, HIPing); and product storage.

The facilities which will be licensed are the Waste Stabilization (WS) Facilities (e.g., the vitrification, grouting, HIPing facilities), the temporary calcine (surge or staging) storage tanks associated with the receipt of the feed stock, the calcine retrieval system, and the interim HLW storage facility.

Based on the existing NRC regulations and rulemaking activities, it is expected that the following licenses would be required to support the non-separations option plan:

- Waste Stabilization (WS) Facilities (e.g., the vitrification, grouting, HIPing facilities) would require a 10 CFR Part 70 license

- Temporary calcine (surge or staging) storage tanks associated with the receipt of the feed stock would require a 10 CFR Part 70 license.

- Calcine retrieval system would require a 10 CFR Part 70 license.

- Interim (temporary) HLW storage facility would require a 10 CFR Part 72 license.

Other NRC regulations that are applicable to the design, licensing, and operations of the facilities will be addressed later in this EDF.

\subsection{TRU-Only Separations Options (Primary and Ancillary Facilities)}

As with the non-separations options, the TRU-only separations options licensing requirements were derived by similarity to the preferred option HAWT facilities.

The facilities which will be licensed are the TRU Separations (TS) facility, TRU product handing, packaging and lag storage facility, class $C$ grouted waste interim storage facility, the 
temporary calcine (surge or staging) storage tanks associated with the receipt of the feed stock, and the calcine retrieval system.

Based on the existing NRC regulations and rulemaking activities, it is expected that the following licenses would be required to support the non-separations option plan:

- TRU Separations (TS) facilities, including product handling, packaging, and lag storage would require a $10 \mathrm{CFR}$ Part 70 license

- Temporary calcine (surge or staging) storage tanks associated with the receipt of the feed stock would require a 10 CFR Part 70 license.

- Calcine retrieval system would require a 10 CFR Part 70 license.

Other NRC regulations that are applicable to the design, licensing, and operations of the facilities will be addressed later in this EDF.

\subsection{Design Requirements}

\subsection{Overview}

The criteria contained in this document are based only on the rudimentary descriptions of the processes presented in section 1.1. As the design is developed further, some of the criteria may become nonapplicable, and others will be identified. The purpose here is to provide a set of highlevel requirements to guide the development of the conceptual designs of the facilities and provide a reasonable basis for cost estimating purposes. In general this document will not attempt to cover criteria outside of the design and construction of the facilities. Process criteria such as the waste form acceptance criteria, treatment standards and so forth will be addressed by others.

\subsubsection{A Note on NRC Regulations}

NRC regulations are contained in Title 10, Energy of the Code of Federal Regulations. CFR's have the authority of legal mandates, and require compliance, under penalty of law, by all affected parties. NRC generates guidance documents as needed to provide clarification and elaboration of the regulations, describe information to be included in the reports, and give acceptance criteria. These publications truly are guidance documents which are not required to be followed but provide suggested methods for achieving successful licensing. Guidance documents include:

\section{$\underline{\text { NRC Regulatory Guides }}$}

Regulatory Guides delineate acceptable methods of meeting NRC requirements. Different methods for meeting these requirements may be used if justified but the licensees usually attempt to use the Regulatory Guide methods because alternate approaches require extensive justification and additional NRC review. The use of the guides simplifies and shortens the licensing process. 
There are over 480 Regulatory Guides that have been issued to support the licensing of commercial nuclear facilities. While many of the guides apply to nuclear reactors, others, such as those describing waste storage may be viewed as applicable to the WTF. However, no definitive guidance is available for the type of facilities discussed below.

\section{$\underline{\text { NRC Reports }}$}

NRC Reports (NUREGs) and other NRC reports developed by contractors are published on a variety of technical and regulatory issues. They may pertain to specific proceedings such as Safety Evaluation reports or Environmental Impact statements.

\section{NRC Technical Positions}

Technical Position and Staff Position Papers are also prepared by the NRC as a means of providing guidance on requirements for specific facilities regulated by the agency.

\section{Generic Communications}

NRC Generic communications include NRC Information Notes, Generic Letters and NRC Bulletins. These documents provide the licensees with specific information on problems or matters of interest to the licensee.

\section{National Standards}

NRC regulations and documents often incorporate or refer to national codes such as the ASME boiler and pressure vessel codes. These codes then become a requirement and are used in developing design criteria. If the licensee wishes an exception, the exception must be identified and basis for the exception agreed to during the licensing process.

\subsection{Non-Separations Options Waste Stabilization Facility}

The non-separations options include: 1) direct vitrification, 2) direct grouting, 3) calcine HIPing, and 4) the Cementitious Waste options. Each option will include a facility to perform the appropriate operations to produce the end product (e.g., vitrification facility, direct grouting facility, HIPing facility, and a calcine slurry and grouting facility for the Cementitious Waste option). The requirements for supporting (ancillary) facilities will be discussed under separate headings.

\subsubsection{Civil Requirements}

\subsubsection{Site Development}

A suitable site shall be located for the Waste Stabilization Facility at the INEEL in the vicinity of the Idaho Chemical Processing Plant (ICPP) with the proximity to waste sources, utilities, other facilities, vehicular access, shipping and storage capability, and future growth. A study of the impact of this facility on site utilities and infrastructure shall be performed. Information regarding 
topography, soil conditions, subsurface rock formations, road and structure locations shall be included in the final site decision process.

\subsubsection{Flood Design}

Flood design shall be in accordance with DOE-STD-1020. Additionally, if the facility is a RCRA facility, design shall be in accordance with 40 CFR 270.14. This standard requires the facility to be located above the 100-yr flood elevation or for engineered barriers against flooding of the site to be constructed. If the facility is a TSCA facility, 40 CFR 761.65 requires the facility to be located above the 100 -yr flood elevation with no allowance for engineered barriers against flooding.

\subsubsection{Surface Drainage}

Design for surface drainage from local precipitation shall be in accordance with DOE-STD1020 and should be consistent with the ICPP site drainage plan. The INEEL site specific local precipitation standard for a 25 -year, 6 -hour storm is 1.4 inches total.

\subsubsection{Subsurface Investigation and Surveying}

Surveying and subsurface investigation for design shall be conducted to determine depth of rock, confirm soil characteristics and evaluate existing soil for chemical and radiological contamination. Locations of ground surface interferences and site characteristics shall be determined with a survey of the site.

\subsubsection{Soil Excavation and Shoring}

Specifications for excavation work shall require that excavations comply with OSHA Standards, 29 CFR 1926, Subpart P (and Subpart U if blasting is necessary), Subsection 1926.641. Where major complex temporary support systems such as shoring, cribbing, sheet piling, etc. are required, they shall be fully design by the $\mathrm{AE}$ as part of the design package.

\subsubsection{Paving and Surfacing}

Paving shall be provided around the building for parking areas and access roads. All paved areas adjacent to buildings and structures shall have a $1 \%$ minimum slope away from the buildings or structures. Unpaved areas shall be sloped $2 \%$ minimum.

Design for paved roads shall conform to Idaho State Highway Standard Specifications and AASHTO HS-20 loading. Geometric design of all roads, streets, access drives and parking areas shall comply with AASHTO. Other loadings such as those imposed by transfer cask operations shall be incorporated into pavement design where applicable.

\subsubsection{Slabs, Sidewalks, and Stoops}


Sidewalks, door stoops, and approaches shall be provided at all building personnel exits or vehicle openings. Sidewalks shall be installed to provide a safe and efficient means for personnel to access doorways and walk to other nearby facilities. Concrete slabs, door stoops, truck ramps, etc., shall be sloped at least $2 \%$.

\subsubsection{Physical Protection}

The facility shall be located within the ICPP security system and fence. Construction of the new facility may take place outside of the existing main security fence if an equivalent level of security protection is established.

\subsubsection{Underground Utilities}

Existing underground ICPP utilities (sewer, potable and fire water systems) shall be extended as necessary to provide necessary services. Design of potable systems shall be in accordance with the State of Idaho Department of Health and Welfare, Idaho Regulations for Public Drinking Water Systems. Sanitary waste water shall be routed to the ICPP sewage treatment system. Water used for cleaning of the hot cells, if applicable, shall be removed by floor drains or sumps, filtered, contained in double containment tanks, monitored for hazardous materials, and if allowable, routed to the sanitary sewer system.

\subsubsection{Site Demolition}

Site demolition, as required, will be dependent of the final site location.

\subsubsection{Architectural Requirements}

\subsubsection{General}

Architectural designs shall be in accordance with the DOE-ID Architectural Engineering Standards, DOE 6430.1A, and the following design criteria. The facility shall have a minimum design life of 40 years. Interim Storage Facility design life shall be 50 years minimum. The facility shall be planned and laid out on the basis of repetitive or discrete processing steps. The need for safe normal and emergency access, egress and internal traffic flow shall be considered.

Energy conservation shall be given attention during planning and design in accordance with 10 CFR 435, Energy Conservation Voluntary Performance Standards for New Buildings, Mandatory for Federal Buildings.

\subsection{Hot Cell.}

Hot Cell design shall be based upon a Uniform Building Code (UBC) occupancy classification of Group H, Division 7. Occupancy separations and construction types shall be designed in accordance with the UBC. 
Layout of the Hot Cell area shall include a buffer area for personnel entering and exiting the cell and shielded viewing windows for remote operations.

The Hot Cell shall include shielded, impervious and decontaminable walls, floors and ceilings as appropriate. The hot cell walls shall provide sufficient shielding to protect personnel from gamma and neutron radiation. The dose rate at the exterior of the Hot Cell wall in the operating gallery shall be below $0.1 \mathrm{mrem} / \mathrm{hr}$.

\subsection{Buffer Area.}

A Buffer Area shall be provided between the Hot Cell and other areas. Design shall be based upon a UBC occupancy classification of Group $H$, Division 7. Facilities for changing anti-c clothing and personnel monitoring (frisking) devices shall be provided adjacent to the Hot Cell. A shielding labyrinth leading from the Hot Cell to the Buffer Area and then to an Anti-C Change Room shall be provided. These areas shall be separated from each other and the pressure barriers maintained.

The Buffer Area shall provide space for discarded protective clothing used in the Hot Cell and a step off pad for frisking of contamination by PCM machine. All surfaces in the Buffer Area shall be impervious and decontaminable as well as the floors and walls of the Anti-C room.

\subsection{Operating Galleries.}

Operating galleries shall be provided as required by view angles and retraction/repair of remote equipment. Space and utilities shall be provided to accommodate remote equipment operations. Operating galleries shall be separated from the Hot Cell by a concrete shielded wall.

\subsection{Utility Support Areas.}

Utility Support Areas design shall be based upon a UBC occupancy classification of $\mathrm{H}-7$ and shall be designed to accommodate remote and contact maintenance of equipment.

\subsection{Equipment Maintenance Areas.}

Crane maintenance areas shall be provided to support maintenance of in-cell equipment.

\subsection{Administrative Areas.}

The Administrative Area design, which includes office and support areas, shall be based upon a UBC occupancy classification of Group B.

The Administrative Area shall include a minimum of three offices for a shift supervisor and HP support personnel. A Ready Room shall be provided for conduct of meetings and work breaks. Men's and women's lavatories, showers, lockers, and change facilities shall be provided. Storage space and a janitor's room shall also be provided. 


\subsubsection{Building Features}

Materials selected for the walls shall address durability, low maintenance, shielding, insulation and decontamination. The walls shall meet the recommended $R$ value of the DOE-ID AVE Standards. The UBC Construction Type of II-N shall be used for the Facility.

The entire surface area of the contaminated work areas shall be decontaminable. Where wash down or decontamination activities are to be located, the floors shall be sloped to drains that lead to appropriate holding tanks.

Devices (such as door types or air lock arrangements) shall maintain pressure barriers for the hot cell and operating gallery aręas.

\subsubsection{Structural-Requirements}

\subsubsection{General}

Structural design shall be in accordance with the DOE-ID Architectural Engineering Standards, DOE O 420.1, and DOE-STD-1020.

\subsubsection{Classification and Design Loads}

The performance categories for SSCs shall be established using DOE-STD-1021, Natural Phenomena Hazards Design and Evaluation Criteria for Department of Energy Facilities." Sitespecific studies and hazard assessments of the site, as needed, shall be developed in accordance with DOE-STD-1022, "Natural Phenomena Hazards Site Characterization Criteria" and DOE-STD1023, "Natural Phenomena Hazards Assessment Criteria."

All permanent and transient loads that could exist or be developed during normal operations of the facility shall be considered in the design of the facility. Loads to be considered shall include: dead, live, thermal, lateral soil, snow, natural phenomena, seismic, wind, flood, off-normal operating and accident loads, and load combinations.

Dead and live loads shall be determined in accordance with ANSI/ASCE 7, "Minimum Design Loads for Buildings and Other Structures." Loadings due to natural phenomena hazards (wind, seismic, flood, etc.) shall be determined in accordance with DOE-STD-1020, Natural Phenomena Hazards Design and Evaluation Criteria for Department of Energy Facilities."

In accordance with DOE-STD-1020, the Uniform Building Code shall be used as the basis for seismic design for Performance Category 1 and 2 SSCs. The seismic input control motion for the INEEL for Performance Category 3 SSCs is specified by appropriately scaling the USNRC R.G. 1.60 horizontal spectra $(0.18 \mathrm{~g})$. The input motion is assumed to occur in the free-field at the top of a real or hypothetical rock outcrop near the facility location. The vertical input spectra shall be taken as $2 / 3$ of the horizontal spectra. A detailed soil amplification analysis or the soil surface spectra shall be taken to equal the rock outcrop spectra multiplied by: 
(a) 1.2 for soil overburden up to $20 \mathrm{ft}$.

(b) 1.5. for soil overburden between $20 \mathrm{ft}$ and $50 \mathrm{ft}$.

Snow loads shall be determined in accordance with ANSVASCE 7, with a ground snow load of 35 psf and a minimum roof snow load of 30 psf. Tornado loads are not anticipated and need not be included. Load combinations shall be determined in accordance with ANSUASCE 7.

3.2.4.2.I NRC Specific-To meet NRC requirements, seismic loads shall be determined in accordance with 10 CFR 72, Subparts D and E, 10 CFR 100, and USNRC Reg. Guide 1.6. Tornado loads shall be determined in accordance with ANSU/ANS-2.3. Load combinations shall be designed using applicable load combinations and stress limits stipulated in ANSI/AISC N690 and ANSI/ACI349.

\subsubsection{Footings and Foundations}

Footings shall be designed to support the structure and keep differential settlement within allowable limits. Design frost depth shall be 5-ft below grade. The Hot Cell and shielded storage areas shall be provided with continuous reinforced grade beams or wall footings as required for shielding.

\subsubsection{Structural Features}

The Hot Cell walls and roof design shall be consistent with shielding and loading requirements. Other shielded area walls and roofs shall be designed consistent with shielding and loading requirements. The structural design must support crane systems.

\subsubsection{Handling Requirements}

\subsubsection{Cranes (Critical Lift Devices Only)}

All crane designs shall meet the ASME NOG-1 and where applicable, CMAA 70, Crane Manufacturers Association of America, Inc., Specification for Electric Overhead Traveling Cranes and CMAA 74-1987, Specifications for Top Running and Under Running Single Girder Electric Overhead Traveling Cranes Utilizing Under Running Trolley Hoist.

In addition, all cranes shall meet the requirements of NUREG-0612, Control of Heavy Loads at Nuclear Power Plants.

Cranes shall have true vertical lift on the hoist and all motions shall be the slowest that are commercially available to allow for more precise control when placing or picking objects.

\subsubsection{Work Platforms}


The facility shall be equipped with decontaminable work platforms that shall provide a safe and convenient elevated work area for personnel as required. Design of the platforms and their means of access shall be in accordance with OSHA 1910. "Removable guard rails may be utilized as necessary to meet process and handling requirements.

\subsubsection{HVAC Requirements}

All HVAC systems shall be in accordance with Regulatory Guides RG 1.140 Design, testing, and maintenance for normal ventilation systems, RG 1 Design, testing, and maintenance criteria for post-accident engineered safety feature ventilation systems, NUREG-0̀800 Section 9.4.3 Auxiliary and radioactive waste area ventilation, NUREG-0800 Section 11.3 Gaseous waste management systems, NUREG 0800 Section 11.5 Process and effluent radiological monitoring, NUREG-1567 Offgas treatment and ventilation, NUREG-1567 (Draft) Section 11.4.1.3, Ventilation offgas system design features.

HVAC systems shall be in accordance with 29 CFR 1910, Occupational Safety and Health Standards for General Industry, Subpart G (Occupational Health and Environmental Control) and Subpart Z (Toxic and Hazardous Substances).

The HVAC systems shall meet the air quality requirements addressed in 40 CFR 50-53, and 58 .

The HVAC systems shall be in accordance with ANSI/ASME N509-1989, Nuclear Power Plant Air Cleaning Units and Components and ANSI/ASME N510-1989, Testing of Nuclear AirCleaning Systems.

The HVAC systems shall meet the requirements of Idaho Administrative Procedures Act (IDAPA) 16.01.01000-01999.

The HVAC systems shall be in accordance with MIL-F-51068C (Filter: Particulate High Efficiency, Fire Resistant) and MIL-F-51079A (Filter Medium: Fire Resistant, High Efficiency).

The Hot Cell atmospheric pressure shall be controlled during hot operations to $-0.6 \mathrm{~W}$. G. (or lower) below atmospheric pressure.

Heating loads shall be based on a minimum winter outdoor design temperature of $-14^{\circ} \mathrm{F}$. Cooling loads shall be based on temperatures of $93^{\circ} \mathrm{F}$ dry bulb and $61^{\circ} \mathrm{F}$ wet bulb. The HVAC system should maintain a minimum temperature of $65^{\circ} \mathrm{F}$ in the winter and approximately $76^{\circ} \mathrm{F}$ in the summer in the operations area (not including the vitrification cell). The HVAC system must maintain a minimum temperature of $65^{\circ} \mathrm{F}$ in the winter and approximately $72^{\circ} \mathrm{F}$ in the summer in the Administrative areas. HVAC design for indoor temperature conditioning shall be based on ASHRAE 90. 
Air shall flow from areas of least contamination potential to areas of highest contamination potential. The HVAC system shall collect exhaust air from contamination control areas and pass it through HEPA filters prior to discharge to the atmosphere.

\subsubsection{Mechanical Utilities Requirements}

Mechanical utilities systems shall meet the requirements of the ASME Code for Pressure Piping B31.

\subsubsection{Compressed Air}

Compressed air for plant and instrument air shall be provided for pneumatically operated HVAC system equipment and other pneumatic operations in the facility. The system design for compressed air shall be in accordance with 29 CFR 1910, Occupational Safety and Health Standards for General Industry, Subpart M (Compressed Gas and Compressed Air Equipment). Instrument air shall be ISO-141 Grade or better.

\subsubsection{Compressed Gas}

Argon compressed gas shall be supplied for welding processes

Helium compressed gas shall be supplied for pressure testing and inerting operations.

The system design for compressed gas shall be in accordance with 29 CFR 1910, Occupational Safety and Health Standards for General Industry, Subpart H (Hazardous Materials) and Subpart M (Compressed Gas and Compressed Air Equipment).

\subsubsection{Potable Water}

Potable water, including hot water where applicable, shall be provided to the facility to service water closets, urinal(s), sinks, showers, shower/eyewash facilities, evaporative coolant units, drinking fountains, and miscellaneous ports.

Cross-connection control shall be in accordance with the Idaho Code (IDAPA 16.01.08), "The Cross Connection Control Manual, Accepted Procedure and Practice" (Pacific Northwest Section of American Water Works Association), and the Foundation for Cross Connection Control and Hydraulic Research (University of Southern California.)

\subsubsection{Waste Systems}

3.2.9.4.1 Liquid Waste-Liquid waste system(s) shall be provided for in the Hot Cells and other process areas. The liquid waste systems shall be designed in accordance with NUREG-0800 Section 11.2 Liquid waste management systems. Condensate from HVAC equipment shall be disposed of using the liquid waste system. Liquid waste shall be collected and tested prior to being pumped into the waste line 
3.2.9.4.2 Sanitary Systems-The sanitation system design shall be in accordance with 29 CFR 1910, Occupational Safety and Health Standards for General Industry, Subpart J (General Environmental Controls). Sanitary sewer drains, cleanouts, and vents shall be provided as needed

\subsubsection{Fire Protection}

Fire water shall be provided in accordance with DOE 6430.1A, DOE Order 420.1, and the DOE-ID Architectural Engineering Standards. Fire protection systems shall ensure nuclear criticality and suppressant-HLW chemical reactions cannot occur. All underground fire water lines shall be cathodically protected and meet State of Idaho requirements for minimum distances from potable water piping.

\subsubsection{Steam} insulated.

Steam shall be provided and routed to the HVAC system as required. The steam lines shall be

\subsubsection{Electrical Requirements}

The criteria for the electrical design of the WTF is based on requirements from NFPA, ANSI, Factory Mutual (FM), DOE O 420.1 and 29 CFR 1910, Occupational Safety and Health Standards for General Industry, Subpart $S$ (Electrical).

Electrical design and installation shall incorporate the most efficient methods of penetration, shielding integrity retention, efficiency, and operational convenience.

The facility shall require an electrical room a communications room, and an Uninterruptable Power Supply (UPS) room.

\subsubsection{Power}

The electric power system shall be designed to provide standard power to the facility and emergency electrical supply to essential instrumentation, emergency lighting, emergency communications, and physical security systems. Standby power shall be supplied for the Hot Cells, process areas, and HVAC system exhaust fan.

An Uninterruptable Power Supply (UPS) shall provide emergency power. The UPS shall support the Fire Alarm, Voice Paging, HVAC, Radiation Monitoring and Alarm, and security systems. There shall sufficient battery capacity to carry the rated load for a minimum of 30 minutes.

\subsubsection{Grounding} standards.

Grounding shall be provided in accordance with the DOE-ID Architectural Engineering 


\subsubsection{Cathodic Protection}

Utility piping shall be protected through connection to the existing ICPP cathodic protection system. A testing/bonding station shall be included to periodically monitor the cathodic protection system.

\subsubsection{Lighting}

Interior and exterior lighting shall be designed and included in accordance with current Illuminating Engineering Society (IES) recommendations. Emergency and exit lighting shall be provided at each means of egress. Hot Cell lighting shall be provided by high-pressure sodium fixtures.

\subsubsection{Lightning Protection}

A lightning protection system shall be included and shall be designed in accordance with NFPA 780.

\subsubsection{HVAC Controls}

A HVAC control system shall be provided. It shall be a smart system that can automatically generate control signals to change HVAC equipment operating parameters based on signal received from various monitors. A computer monitor shall be provided in the Shift Supervisor's office for reviewing the operating status of the system and making adjustments to control setpoints.

Instrumentation shall. be provided to detect and alarm both high and low differential pressure across filters in the HVAC system. Instrumentation shall be provided to initiate isolation of the HVAC system filters in the event of fire detection.

\subsubsection{Equipment Controls}

Facility control, process control, and data acquisition systems shall be provided.

Remotely controlled CCTV cameras shall be provided in the Hot Cells and process areas for general visual observation, operations, inspection, and documentation. Each Hot Cell window shall be equipped with a visual inspection station which shall include two high resolution cameras; a monitor; camera controls for pan, tilt, and zoom functions; and recording capability for archival purposes. earthquake.

Instrumentation shall be provided to measure and record the facility structural response to an

A system shall be provided for the collection of alarms from the HVAC system and other alarms. This shall be located in the Shift Supervisor's office. 


\subsubsection{Radiation Monitoring and Alarms}

Radiation detection instrumentation shall be provided to warn operating personnel of radiation and airborne radioactivity levels above set limits. The RAMs shall alarm locally and remotely in the RadCon office.

Stack monitoring shall be provided for the detection of radioactive particulates in the air exhaust stream. These instruments shall comply with ANSI-N42.17B-1989.

Provisions shall be made in the design for monitoring groundwater in the vicinity of the storage area for radioactive contamination.

Activity monitors shall be provided in the wash water collected from the Hot Cells and process areas.

\subsubsection{Communications and Alarms}

Voice and data telecommunications lines shall be provided throughout the occupied areas of the facility. The existing Broadband Local Area Network (LAN) shall be made available in the facility. Access ports shall be provided in all normally occupied offices.

Fire alarm, emergency voice paging, and evacuation alarm systems shall be compatible with existing systems at ICPP.

\subsubsection{Data Acquisition and Recording}

A data entry station shall be provided to record and monitor all fuel movements. The stations shall be linked for data communications.

\subsubsection{Security Systems}

Physical protection of the facility shall be in accordance with 10 CFR 73 and 10 CFR 72, Subpart H.

\subsubsection{Design Life Requirements}

Design life of the facility and equipment shall be 30 years and have maintainable or replaceable life of 60 years

\subsubsection{Safety Requirements}

\subsubsection{Safety Classification}

The facility is assumed to be a Hazard Category 2 . 


\subsubsection{Construction}

The design of utility services and distribution systems that are important to safety shall include redundant systems to the extent necessary to maintain, with adequate capacity, the ability to perform safety functions assuming a single failure.'

The facility and its systems important to safety ${ }^{2}$ shall be designed to be evaluated by appropriate tests or by other means acceptable to the NRC to demonstrate that they will reasonably maintain confinement of radioactive material under normal, off-normal, and credible accident conditions.

Structures, systems, and components important to safety shall be designed and located so that they can continue to perform their safety functions effectively under credible fire and explosion exposure conditions.

The design of the facility shall include provisions to protect against nuclear criticality that might otherwise result from the operation or the failure of fire suppression or decontamination systems.

Material handling, packaging, transfer, and storage systems shall be designed to be maintained subcritical under the worst case moderated and reflected conditions, and to ensure that, before a nuclear criticality accident is possible, at least two unlikely, independent, and concurrent or sequential changes must occur in the conditions essential to nuclear criticality safety.

Each entrance or access point into a high radiation area shall have either a control device that energizes a conspicuous visible or audible alarm signal so that the individual entering the high radiation area and the supervisor of the activity are made aware of the entry; or entryways that are locked, except during periods when access to the areas is required, with positive control over each individual entry.

Process materials that are reactive with water or other chemicals shall be protected from exposure to those materials.

The facility shall be designed to prevent the dropping of critical loads under normal and off normal conditions including the design basis accidents (DBAs) that they shall withstand.

1. A single failure is an occurrence that results in the loss of capability of a component to perform its intended safety function(s). A multiple failure, i.e., loss of capability of several components, resulting from a single occurrence, is considered to be a single failure. Systems are considered to be designed against an assumed single failure if neither (1) a single failure of any active component (assuming passive components function properly) nor, (2) a single failure of any passive component (assuming active components function properly) results in loss of the system's capability to perform its safety function(s).

2. Structures, systems, and components important to safety mean those features of the Storage Facility whose function is: (1) To maintain the conditions required to store spent fuel safely, (2) To prevent damage to the spent fuel waste container during handling and storage, or (3) To provide reasonable assurance that spent fuel can be received, handled, packaged, stored, and retrieved without undue risk to the health and safety of the public. 
The facility shall be designed to prevent the dropping of critical loads under normal and off normal conditions including the design basis accidents (DBAs) that they shall withstand.

The facility shall be designed to be able to recover from accidents involving dropping of critical loads.

In-cell equipment shall be designed for recovery from all possible conditions to the extent that manned entry into the cell, for maintenance, can be accomplished.

Fire doors shall be provided as required by UBC, UFC, NFPA-80, and NFPA-101. In addition, all fire doors and frames shall meet all requirements of the Underwriters Laboratories and shall bear the UL or FM label. Fire doors and frames shall be constructed from metal. Structural members, such as steel channels embedded in wall openings, shall not substitute as door frames. All fire doors shall be provided with fitted frames which are anchored to, but separate from, the building structural members. The fire doors shall contain windows fitted with UL approved safety glass which is not removable from the outside of the door. Their installation shall meet all of the requirements of NFPA-80 and NFPA-101.

The facility design shall mitigate natural phenomena hazards. The design shall address common cause effects and interactions for: earthquakes, volcanic events, tornadoes, hurricanes, high winds, floods, excessive rains, excessive snow, ice cover, lightning, and fires. The secondary natural phenomena include drought, fog, frost, high temperatures, low temperatures, landslides, subsidence, surface collapse, uplift, storm surges, and waterspouts. Damage and failure will be considered for systems, structures, and components. In addition, the facility shall have instrumentation or other means to detect and record the occurrence and severity of seismic events.

\subsubsection{Operation}

Radiation protection for occupational workers shall be per 10 CFR 835 (Occupational Radiation Protection) and the INEEL Radiological Control Manual

Facility design features and physical controls shall ensure occupational exposure is maintained ALARA during normal and off-normal operations

Personnel radiation exposure levels throughout facility shall not exceed $0.1 \mathrm{mr} / \mathrm{hr}$ for continuously-occupied areas.

Safe access will be provided to all packages, vehicles, and installed components for purposes of testing, inspection, and maintenance.

\subsubsection{Environmental Requirements}

Facility emission limits shall be per requirements listed in EDF-WTS-003, Section 5. 
Administrative controls and Best Available Control Technology shall be used to minimize the impacts of air emissions

The facility processes and equipment shall be designed to limit solid waste generation of LLW and industrial (cold) waste

Solid radioactive waste produced by operations shall be packaged in standard RWMC $4 \times 4$ $\times 8-\mathrm{ft}$ plywood boxes for contact-handled $(\mathrm{CH})$ LLW or INEL Mark III concrete containers for remote-handled $(\mathrm{RH}) \mathrm{LLW}$, and shipped to RWMC for disposal

Means for measuring the amount and concentrations of radionuclides in effluents during normal operations, and under accident conditions, shall be provided for effluent control systems

Warm liquid waste shall be controlled and verified to meet the criteria for existing ICPP handling systems, and shall be transferred to those systems

If all or part of the facility is located outside of existing ICPP fences, the use of new land shall not exceed 551 acres when combined with other storage systems included in DOE/EIS-0203-F.

\subsubsection{Safeguards and Security}

The materials are not attractive as defined in DOE Order 5633.3B.

A data management system shall be provided to keep records. The data management system shall meet the requirements of 10 CFR 72, Licensing Requirements for the Independent Storage of Spent Nuclear Fuel and High-Level Radioactive Waste, Subpart D (Records, Reports, Inspections, and Enforcement).

Dual records shall be maintained to ensure an off-normal event cannot result in the loss of the sole records. These records shall be retained for as long as the material is stored, and for a period of five years after the material is disposed of or transferred.

The following are NRC requirements that may or may not apply

Equipment shall be provided to conduct a physical inventory of all material in storage at intervals not to exceed 12 months unless otherwise directed by the Commission. A copy of the current inventory shall be retained as a record until the Commission terminates the license.

Physical protection of the facility and materials shall be in accordance with 10 CFR 72, Licensing Requirements for the Independent Storage of Spent Nuclear Fuel and High-Level Radioactive Waste, Subpart H (Physical Protection); 10 CFR 73, Physical Protection of Plants and Materials; and 10 CFR 1046, Physical Protection of Security Interests.

\subsubsection{Quality Assurance Requirements}


The applicable portions of DOE/RW-0333P, Quality Assurance Requirements and Description, shall be invoked as the baseline requirements document for developing and implementing quality assurance programs. These requirements apply to activities related to interim storage or disposal, including characterization for data collection, conditioning, or placing into a form for disposal. In addition, the EM-WAPS Rev. 01, Waste Acceptance Product Specifications for Vitrified High-Level Waste Forms, May 1995, also imposes a QA Program consistent with the QA requirements under the DOE/RW-0333P.

All purchased items will be restricted to those not suspect/counterfeit, misrepresented, used, or other than represented/advertised in accordance with INEL-95/227, "Guidelines for Identifying Suspect/Counterfeit Material."

Records, reports, and inspections shall be done in accordance with $10 \mathrm{CFR} 72$, Licensing Requirements for the Independent Storage of Spent Nuclear Fuel, Subpart D (Records, Reports, Inspections, and Enforcement).

Training of personnel shall be performed in accordance with 10 CFR 72, Licensing Requirements for the Independent Storage of Spent Nuclear Fuel, Subpart I (Training and Certification of Personnel). 


\subsection{References}

Nuclear Regulatory Commission (NRC) Licensing Assessment for the Idaho National Engineering and Environmental Laboratory (INEEL) High-Level Waste Program, prepared by R. G. Morgan and S. E. Leroy, Duke Engineering Services, Inc., April 23, 1997. Referenced in Idaho Chemical Processing Plant High Activity Waste Treatment Project Regulatory Assessment Report - SEL-11-97, prepared by S. E. Leroy, dated April 25, 1997. 


\section{Appendix B}

\section{Drawings and Sketches}




\title{
Contents
}

\author{
HWO-00 \\ HWO-01 \\ HWO-02 \\ HWO-03 \\ HWO-04 \\ HWO-05 \\ HWO-06
}

HWO-C-1

HWO-A-2

HWO-A-3

HWO-A-4

HWO-A-5

HWO-A-6

HWO-HV-1 


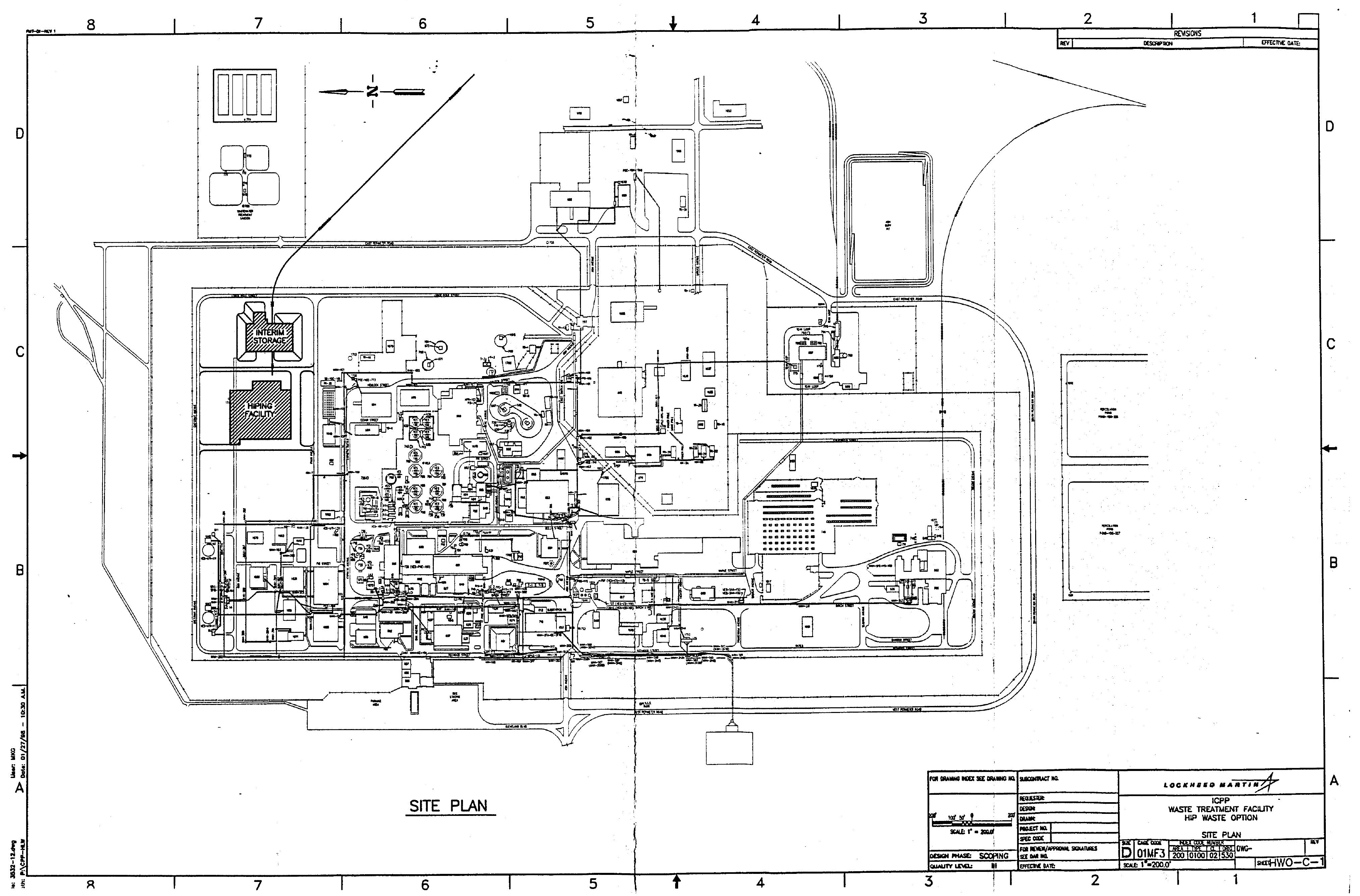




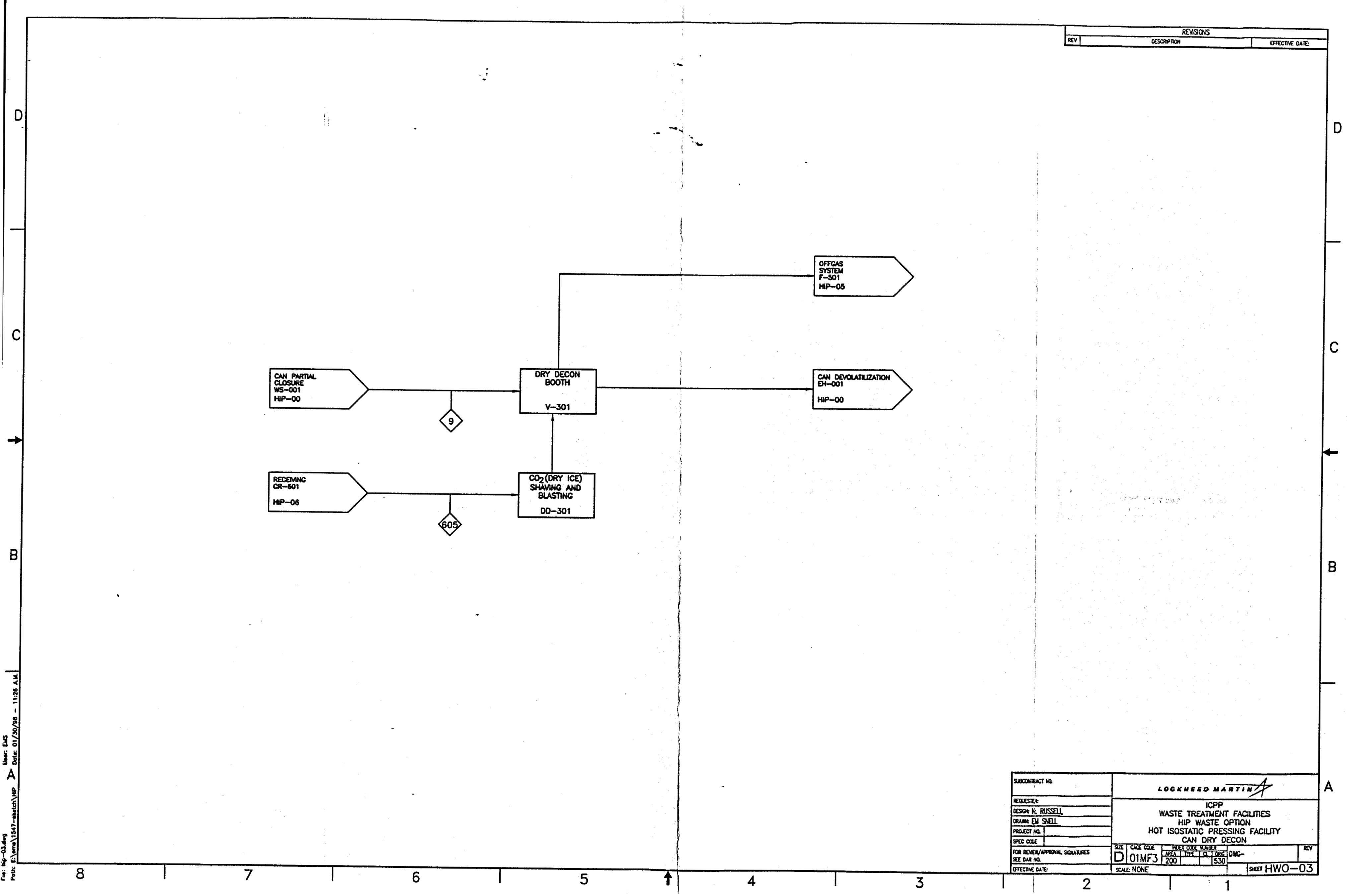




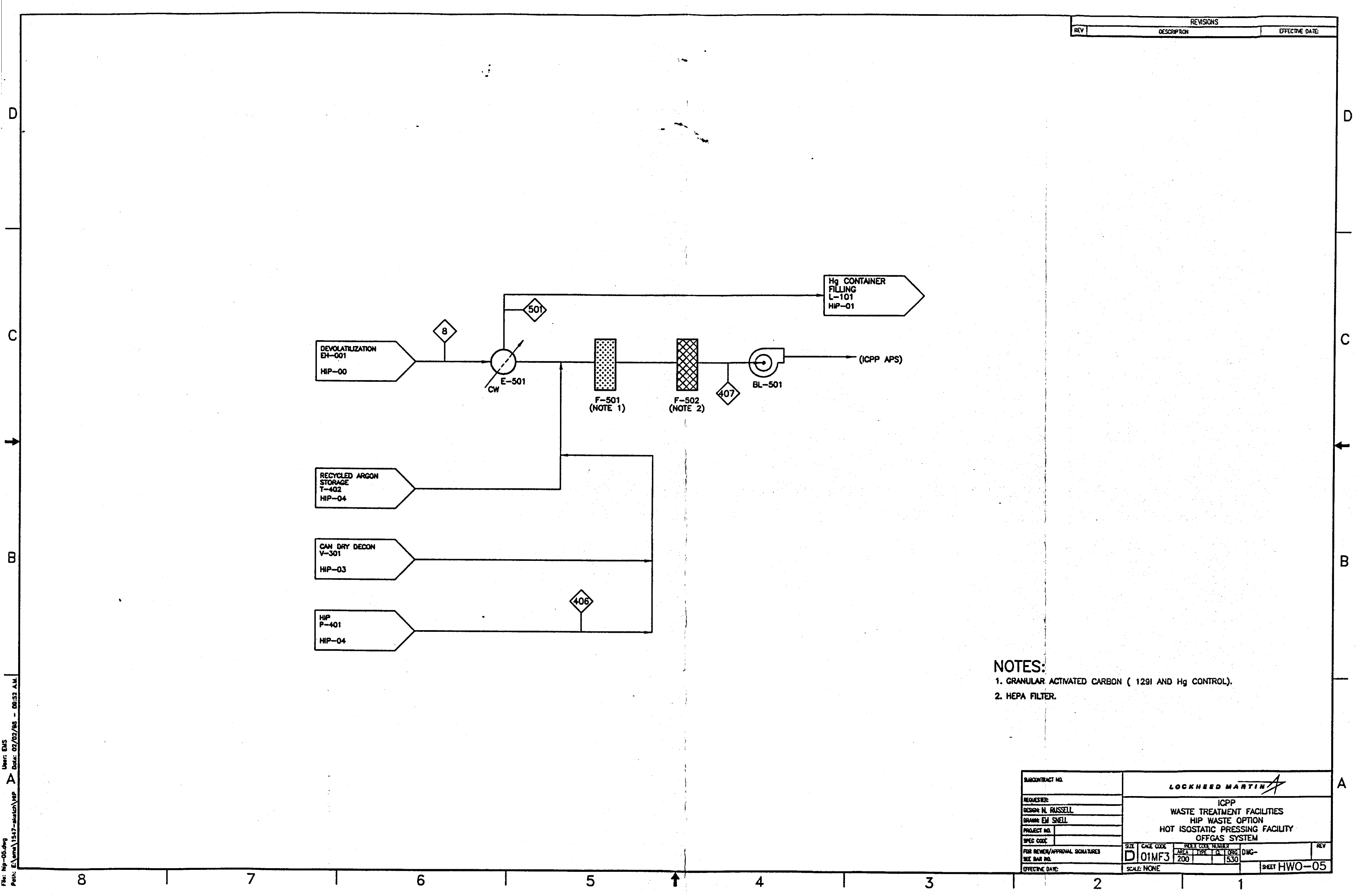



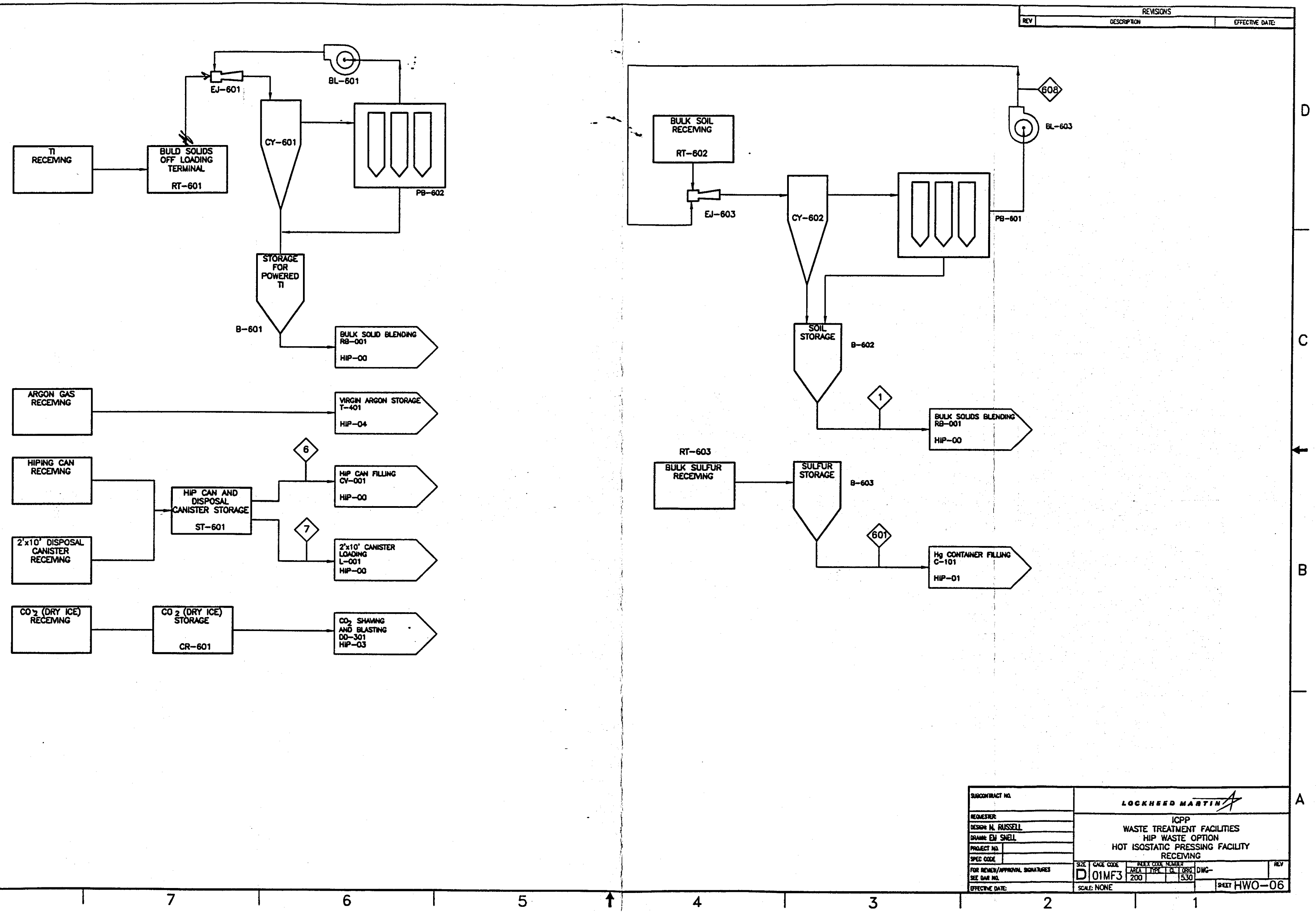


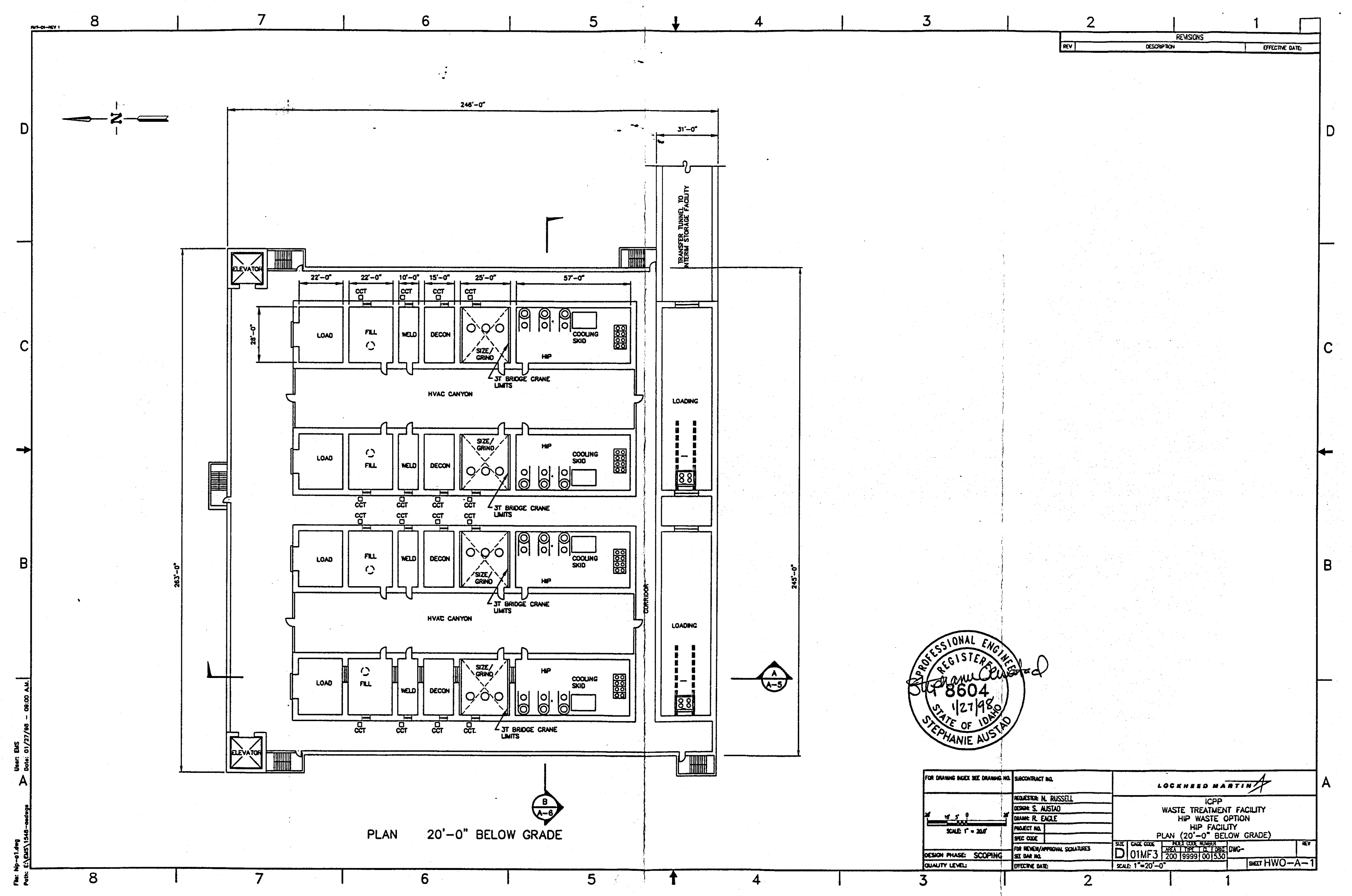




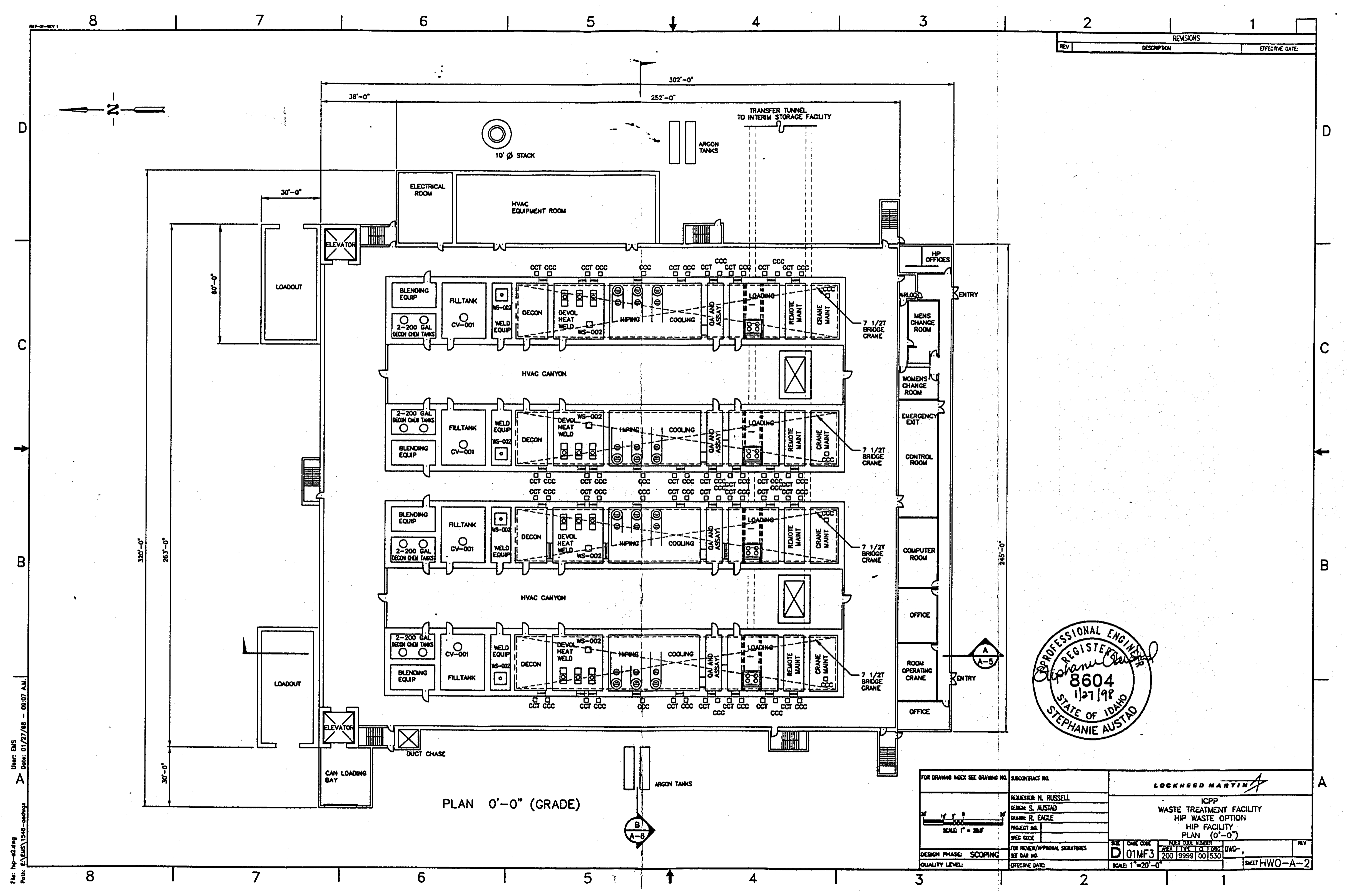




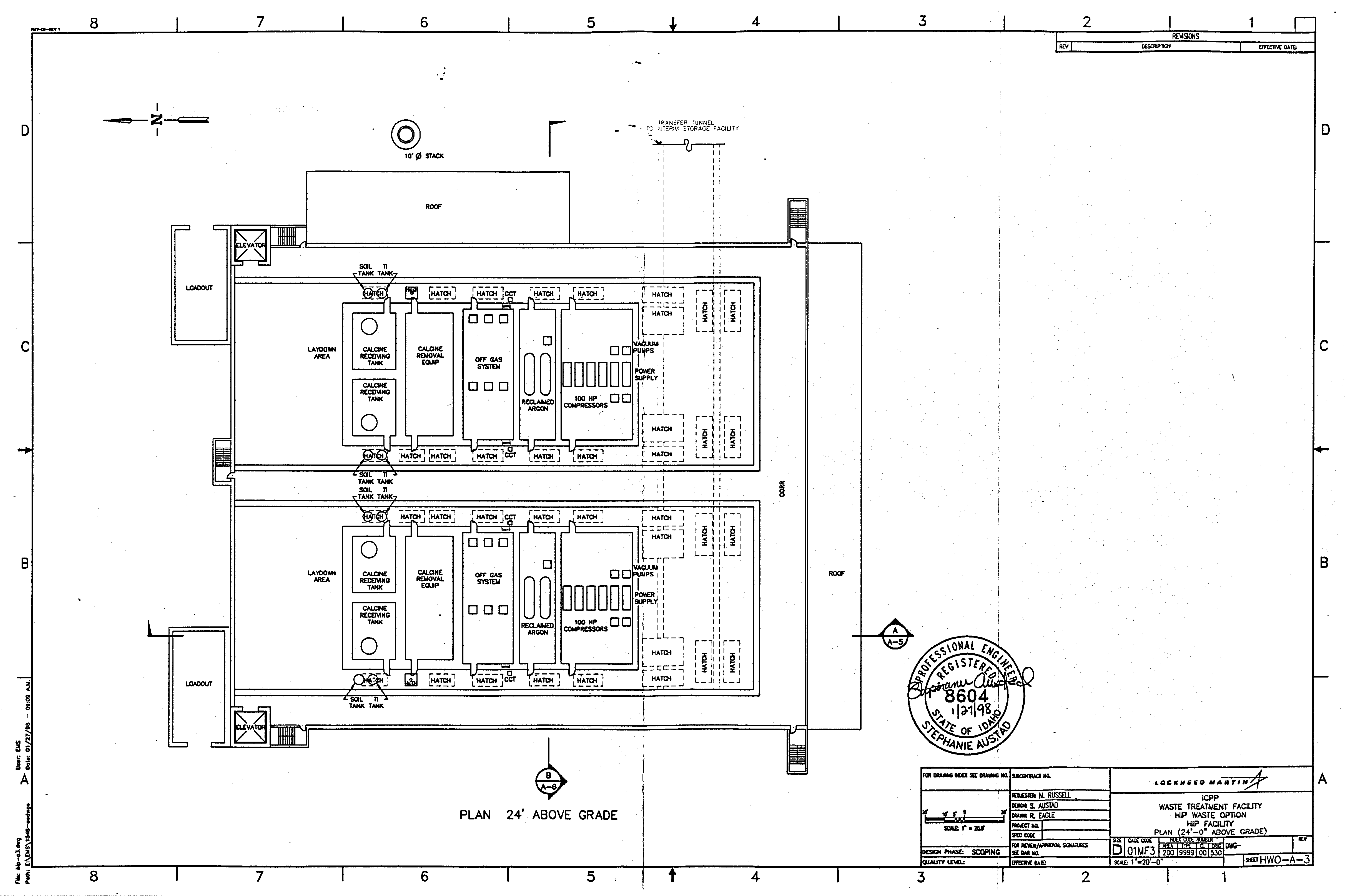




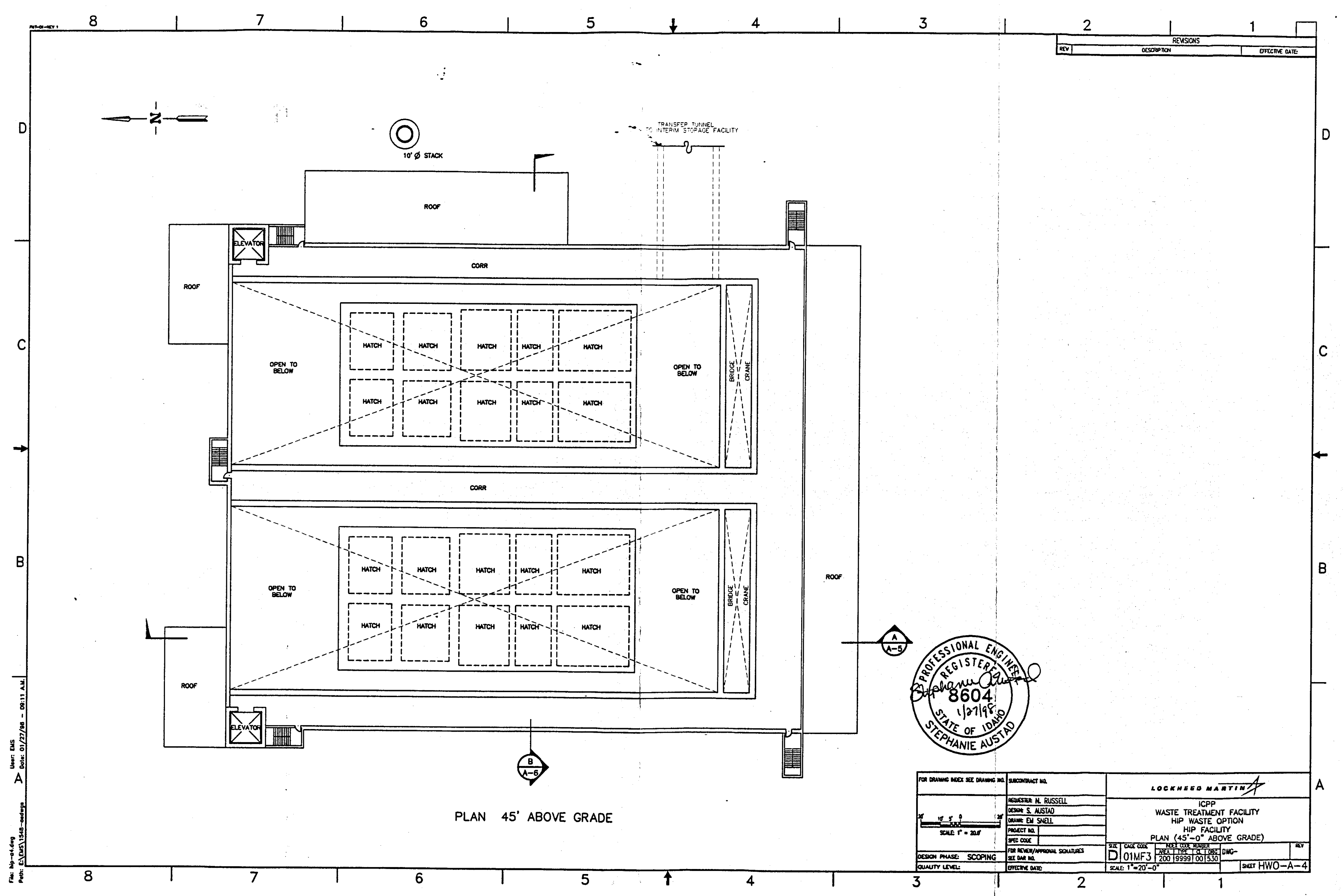




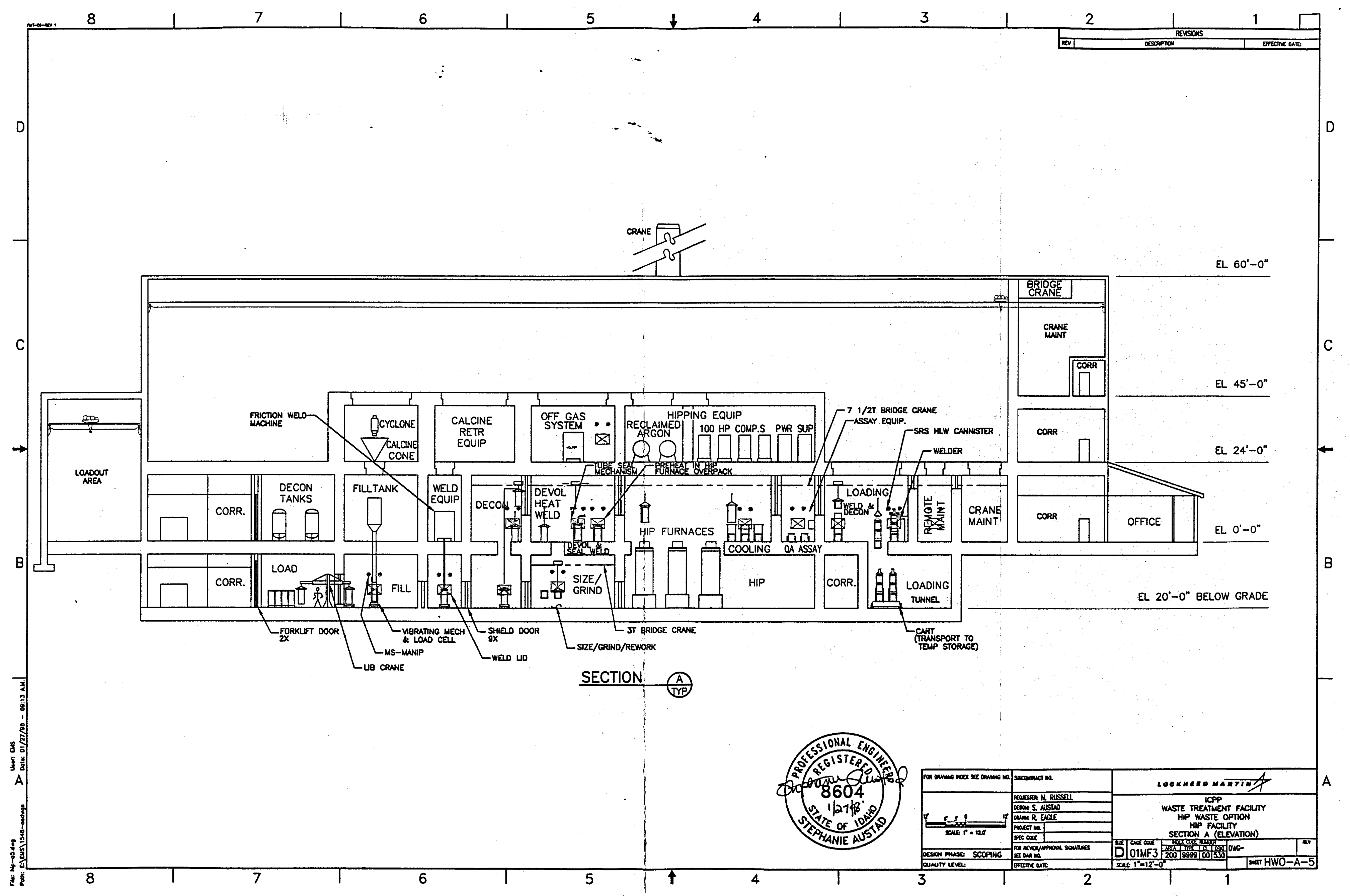




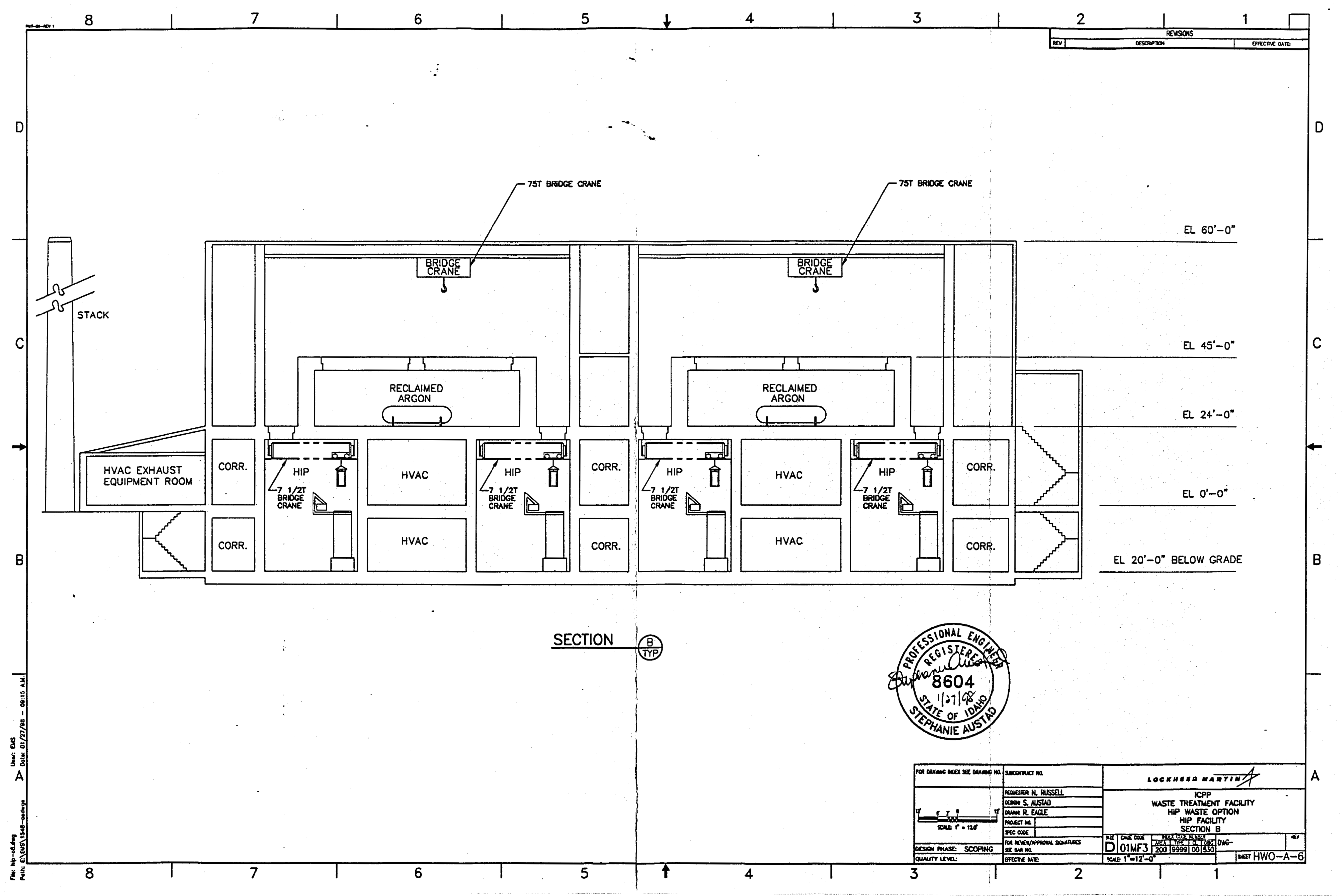




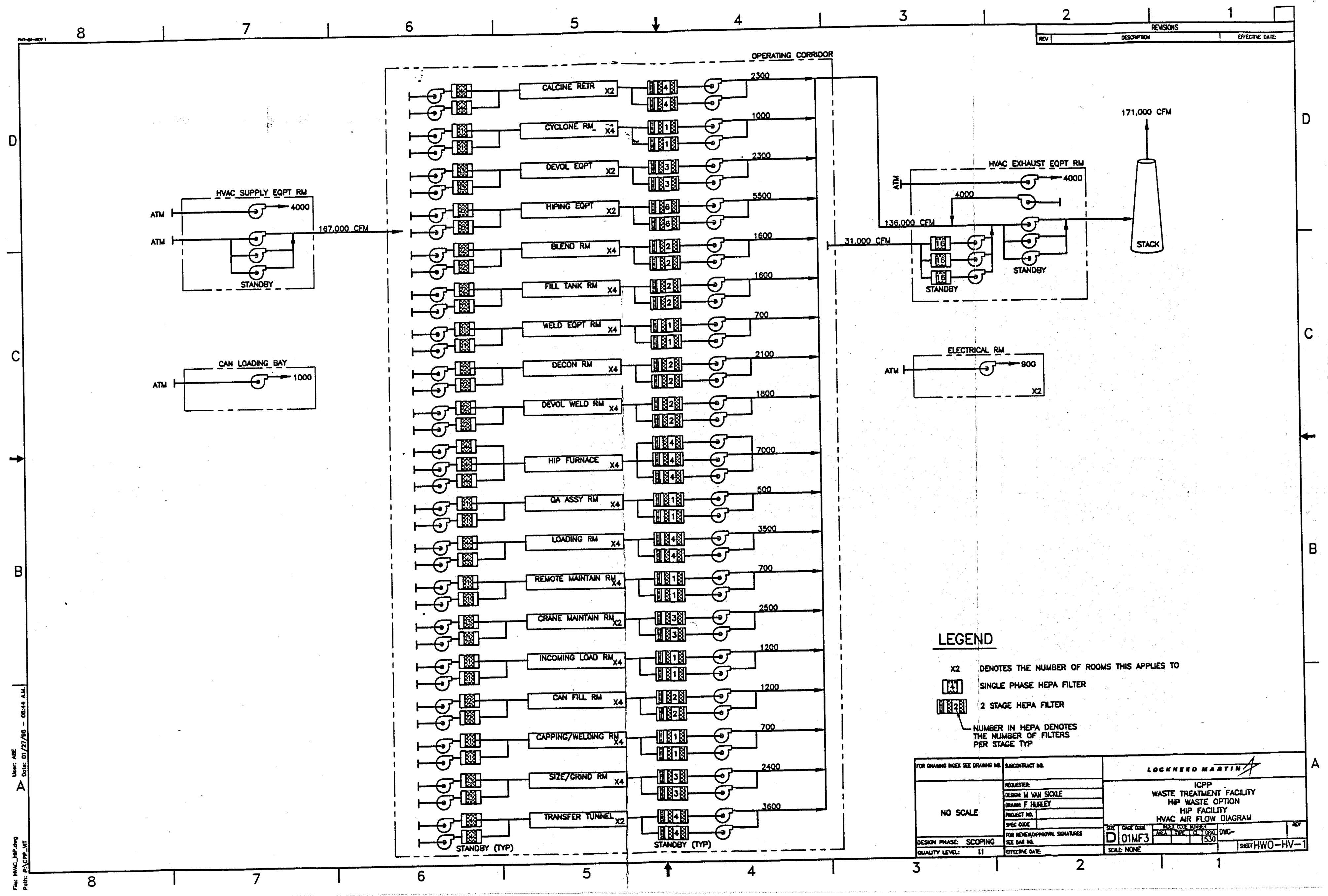




\section{Appendix C}

\section{Additional Assumptions}


HWO STUDY ASSUMPTIONS

\begin{tabular}{|c|c|c|c|c|}
\hline $\begin{array}{c}\text { Number } \\
\text { Latest Rev } \\
\text { Initinls }\end{array}$ & Assumption & References & Application to Volumes & Application to \\
Alternatives & Contact and Date \\
\hline
\end{tabular}

\begin{tabular}{|c|c|c|c|}
\hline $\begin{array}{c}1 \\
1023 / 97\end{array}$ & \multicolumn{3}{|c|}{ 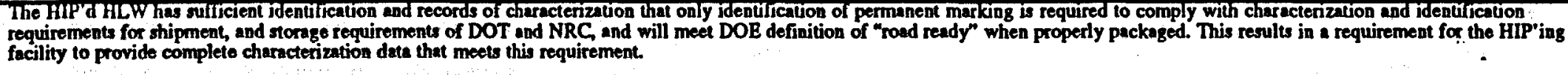 } \\
\hline Basis & $\begin{array}{l}\text { This assumption is necessary to support the conlention that the Hitr'd } \\
\text { waste product is "road ready" at the completion of its processiog } \\
\text { cycle. It also drives an important process requirement for } \\
\text { characterization and identification. }\end{array}$ & & $\begin{array}{l}\text { P.M.Rice } \\
\text { (208) } 526-2884 \\
\text { pmpQinel.gov }\end{array}$ \\
\hline $10 / 23 / 97$ & \multicolumn{3}{|c|}{$\begin{array}{l}\text { The physical characteristics of the HIP'dHLW as delivered from the HIP" ing facility will meet or exceed shipment, and siorage requirements of DOT and NRC, and will meet DOEE } \\
\text { definition of "road ready" when properly packaged. It is also assumed that the HIP'd HLW will meet all of the physical requirements necessary to be accepted by the repository. This results } \\
\text { in a requirement for the HIP'ing facility to provide a final wate form product that meets this requirement. }\end{array}$} \\
\hline Busis & $\begin{array}{l}\text { This assumption is necessary to support the contention that the HIP'd } \\
\text { waste product is "road ready" at the completion of its processing } \\
\text { cycle, It also drives an important process requirement for physical } \\
\text { property specifications. }\end{array}$ & & $\begin{array}{l}\text { P.M. Rice } \\
\text { (208) 526-2884 } \\
\text { pmpQinel.gov }\end{array}$ \\
\hline $1023 / 97$ & \multicolumn{3}{|c|}{$\begin{array}{l}\text { The RCRA Iisted wastes in the HII'd product will be delisted prior to shipment of the HLW to the repository. The HIP'jng process will tulfil the LDR requirements for BDA Treatment for } \\
\text { certain RCRA constituents in the waste. A waiver will be granted by the EPA to allow the HIP' ing process to be used as BDAT for other hazardous constituent which need LDR technology- } \\
\text { specific treatment other than vitrification. }\end{array}$} \\
\hline Basis & $\begin{array}{l}\text { An assumption provided in reference Istates that a fral waste form } \\
\text { for HAW will be developed only after the system performance } \\
\text { requirements and Wasto Acceptance Criteria for HLW requiring } \\
\text { permanent isolation in geological repository are issued. } \\
\text { The key component of the INEEL waste management plan is the de- } \\
\text { listing of various hazardous wastes in the various waste streams such } \\
\text { that RCRA requirements do not apply (reference 2). }\end{array}$ & $\begin{array}{l}\text { (I) DOEID-10544, Regulatory Analysis } \\
\text { and Proposed Path Forward for tho Idaho } \\
\text { National Engineering Laboratory High- } \\
\text { Level Waste Program, U. S. Department } \\
\text { of Energy, Idaho Operntions Office, } \\
\text { Idaho Nalional Engineering Laboratory, } \\
\text { Nuclear Operations Division High-Level } \\
\text { Waste Directorate, October 1996. } \\
\text { (2) Idaho Chemical Processing Plant } \\
\text { High Activity Waste Treatment Project } \\
\text { Regulatory Assessment Report, prepared } \\
\text { by R. G. Morgan and S. E. Leroy, Duke } \\
\text { Engineering Services, Inc. S. E. Leroy } \\
\text { letter to V. L Jacobson, dated April 25, } \\
\text { 1997). }\end{array}$ & $\begin{array}{l}\text { P.M.Rice } \\
\text { (208) 526-2884 } \\
\text { pmpeinelgov }\end{array}$ \\
\hline
\end{tabular}


HWO STUDY ASSUMPTIONS

\begin{tabular}{|c|c|c|c|c|c|}
\hline $\begin{array}{c}4 \\
1023 / 97\end{array}$ & The storage of HIP'd HLW will be licensed under TO CFR 72 & & & & \\
\hline Basis & $\begin{array}{l}\text { An assumption was made that the storage facility would be licensed } \\
\text { under } 10 \text { CFR 72, (reference 1) } \\
\text { The key component of the INEEL waste managemeat plan is the de- } \\
\text { listing of various hazardous wastes in the various waste streams such } \\
\text { that RCRA requirements do not apply (reference 2). }\end{array}$ & $\begin{array}{l}\text { (I) Idaho Chemical Processing Plant } \\
\text { High Activity Waste Treatment Project } \\
\text { Regulatory Assessment Report, prepared } \\
\text { by R. G. Morgan and S. E. Leroy, Duke } \\
\text { Engineering Services, Inc. S. E. Leroy } \\
\text { letter to V. L Jacobson, dated April 25, } \\
1997 \\
\text { (2) Idaho Chemical Processing Plant } \\
\text { High Activity Waste Treatment Project } \\
\text { Regulatory Assessment Report, prepared } \\
\text { by R. G. Morgan and S. E. Leroy, Duke } \\
\text { Engineering Services, Inc. S. E. Leroy } \\
\text { letter to V. L Jacobson, dated April 25, } \\
\text { 1997). }\end{array}$ & $\begin{array}{l}\text { This reters to EIS } \\
\text { volume mumbers and } \\
\text { will be completed by } \\
\text { others }\end{array}$ & $\begin{array}{l}\text { This refers to the Els } \\
\text { alternatives and will be } \\
\text { completed by others. }\end{array}$ & $\begin{array}{l}\text { P.M. Rice } \\
\text { (208) } 526-2884 \\
\text { pimpeinel.gov }\end{array}$ \\
\hline
\end{tabular}

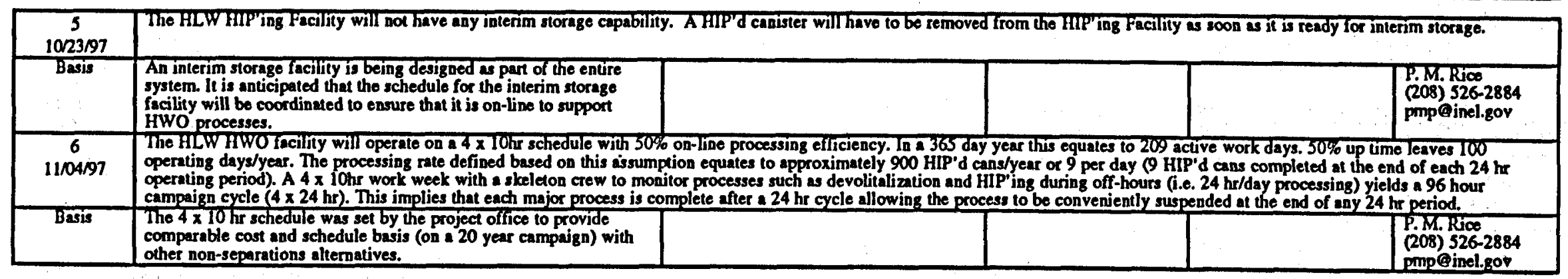

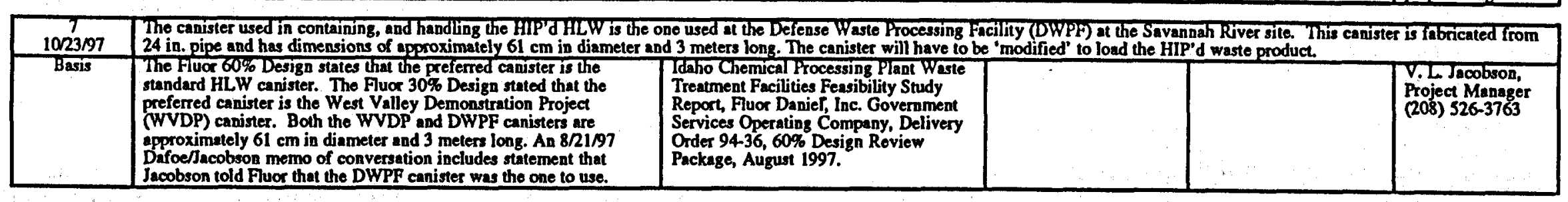

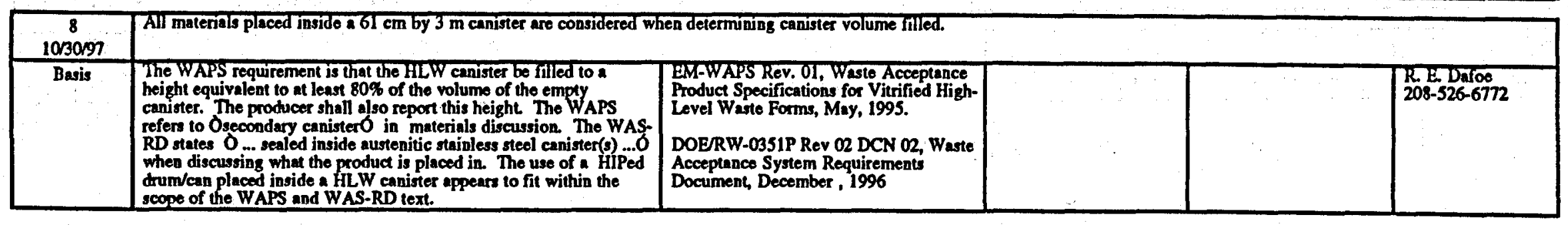


Appendix D

\section{Detailed Cost Estimates}




\section{Lockheed Martin Idaho Technologies Company INTERDEPARTMENTAL COMMUNICATION}

Date: January 27, 1998

To: $\quad$ N.E. Russell

MS 3765

6-8619

From: D. R. James

MS 3655

6-7139

Subject: HWO HIP FACILITY - DRJ-02-98

As requested, Cost Estimating has completed the Planning Cost Estimates for the project referenced above. Listed below are the various types of estimates prepared and the associated estimated cost:

$$
\begin{array}{ll}
\text { Total Estimated Cost - Escalated } & \$ 644,000,000 \\
\text { Total Estimated Cost - Unescalated } & \$ 512,000,000 \\
\text { Other Project Cost - Escalated } & \$ 265,200,000 \\
\text { Other Project Cost - Unescalated } & \$ 247,000,000
\end{array}
$$

Attached please find the Estimate Summary, Support Data Recapitulation and Detail Sheets for your reference. These documents should adequately describe the scope of work, assumptions and unit cost associated with the project.

If you have any questions or comments, please do not hesitate to contact me at 526-7139 or Office Vision-ID NIE.

DRJ

Attachments

cc: Estimate File $\$ 2419$

D. R. James Files

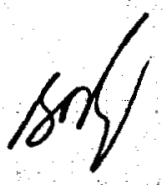


Lockheed Martin Idaho Technologies Company

(Rev. 06/96)

\section{COST ESTIMATE SUPPORT DATA RECAPITULATION}

Project Title: HWO HIP FACILITY

Type of Estimate: Planning

File No: 2419

Estimator: D. R. James

Date: Jan, 27, 1998

Approved By:

I. SCOPE OF WORK: Brief description of the proposed project.

Construct a Hot Isostatic Press (HIP) facility to accept, process and transport calcined waste. The facility will be complete with all internal utilities and process equipment necessary to accomplish the HIP process.

II. BASIS OF THE ESTIMATE: Drawings, Design Report, Engineers notes, and/or other documentation upon which the estimate is originated.

1. Sketches, equipment lists and descriptions from cognizant project personnel.

2. Discussions with the individuals responsible for the various components of the facility.

3. Historical data on waste processing facilities.

4. Raytheon Engineers and Constructors, Inc., Cost Estimate dated Nov. 7, 1994.

III. ASSUMPTIONS: Condition statements accepted or supposed true without proof or demonstration. An assumption has a direct impact on total estimated cost.

1. The soil containing low level radioactivity, encountered during excavation, will be stockpiled and used as backfill or processed at a later date.

2. Open cut excavation with a $11 / 2 / 1$ slope will be used.

3. Costs for utilities to the facility will be evaluated in a different study.

5. Modifications to the existing facilities that will support the HIP Facility will be evaluated in separate studies.

6. A concrete batch plant will be mobilized at the INEEL for construction of this facility.

7. The exhaust stack will be fabricated from carbon steel material.

8. Excess clean soil will be spread outside the facility within 1 mile. 
Lockheed Martin Idaho Technologies Co.

\section{COST ESTIMATE SUPPORT DATA RECAPITULATION} (CONTINUATION)

File No: 2419

Page 2 of 2

\section{ASSUMPTIONS: (Continued)}

9. Construction will begin in January, 2006 and complete in December, 2011.

10. Costs for the Transfer Tunnel from the HIP Facility to the Interim Storage Facility (ISF) will be included in the ISF Cost Estimate.

11. It is assumed that the process will work as designed. Costs have not been estimated to compensate for the incorporation of an alternative process in the event the current process does not work.

IV. CONTINGENCY GUIDELINE IMPLEMENTATION: The percentage used for contingency as determined by the contingency allowance guidelines can be altered to reflect the type of construction and conditions that may impact the total estimated cost.

The estimate was prepared from limited information. In some instances the details are based on the estimator's best judgement of the requirements to construct this facility. Areas of major risk are the process equipment, mechanical systems and electrical systems. Therefore the contingency for these areas has been increased accordingly.

The estimated contingency for this project of $43.5 \%$ is within the guidelines for a project at this stage of design. Please refer to the Contingency Analysis sheet for the breakdown of contingency.

\section{OTHER COMMENTS/CONCERNS SPECIFIC TO THE ESTIMATE:}

1. G\&A and PIF have been applied to the estimated costs in accordance with current guidel ines.

2. Considering the magnitude of the project, a $1 \%$ Procurement Fee was applied rather than the standard $3 \%$. 
Lockheed Martin Idaho Technologies Co.

PAONECT NAME: HWO HIP FACIUTY

LOCATION 1:

TOTAL ESTIMATED COST - ESC.

REQUESTOR:

JOB LOCATION

N Russel

COST ESTIMATE SUMMARY

TYPE OF ESTIMATE: PLANNING

PROAECT NO: 2419

PAEPARED BY: D. R. James

REPORT NAME: Cost Estimate Summary
DATE: 26 -Jan-1998

TIME 15:42:31

CHECKED BY

APPRD BY:

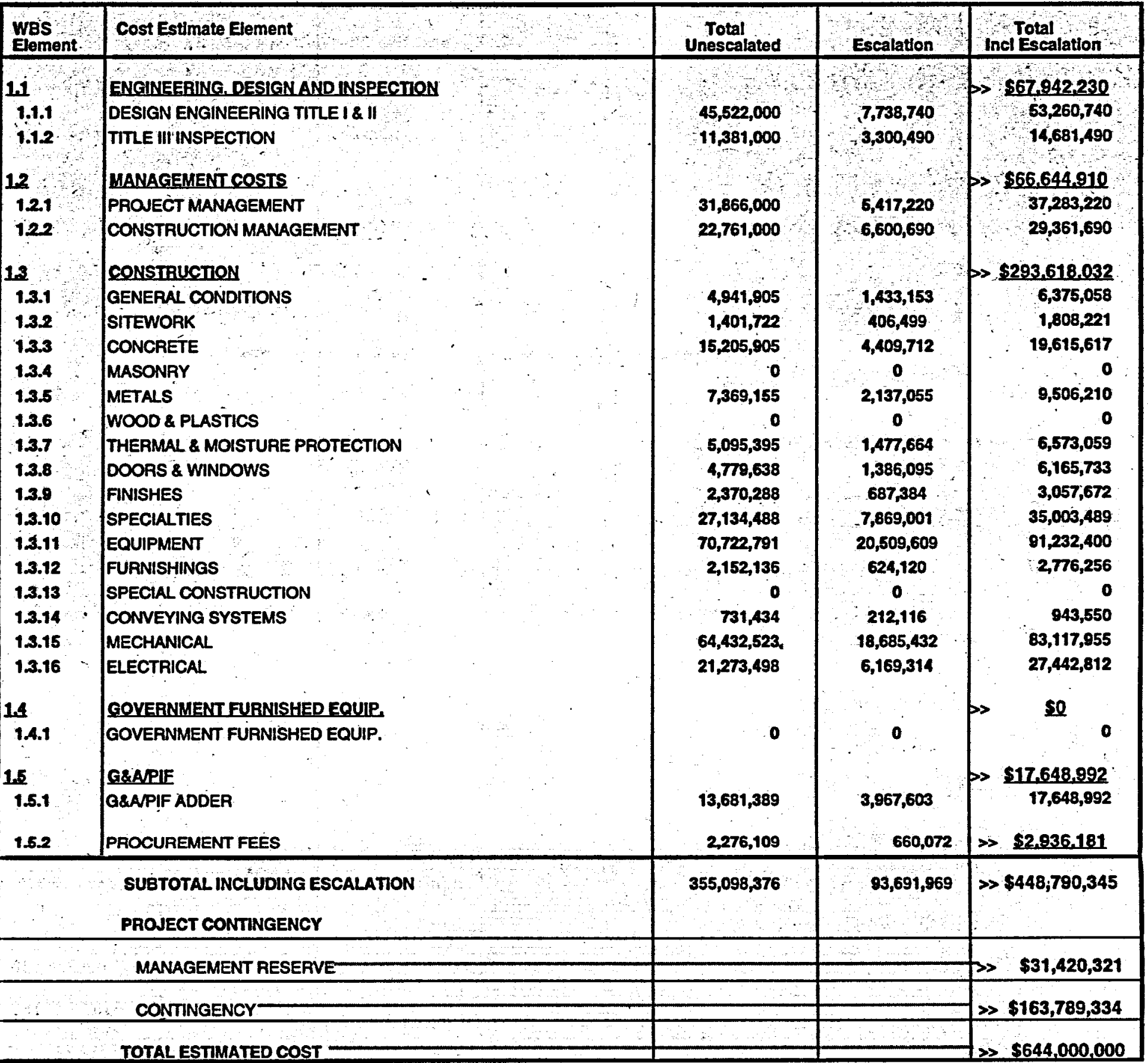

\section{BRONECT COST PARAMETERS}

EDI AS A $\%$ OF CONST. + GFE $=23.00 \%$ 
Lockheed Martin Idaho Technologies Co.

PROAECT NUME: HWO HIP FACILTY

TOTAL ESTMMATED COST - UNESC.

LOCATION 1: JOB LOCATION

REQUESTOR: NRUSSEl
COST ESTIMATE SUMMARY

TYPE OF ESTIMATE: PLANNING

PROJECT NO: 2419

PREPARED BY: D. R. James

REPORT NAME: Cost Estimate Summary
DATE 26-Jan-1998

TIME: 16:02:31

CHECKED BY

APPRD BY:

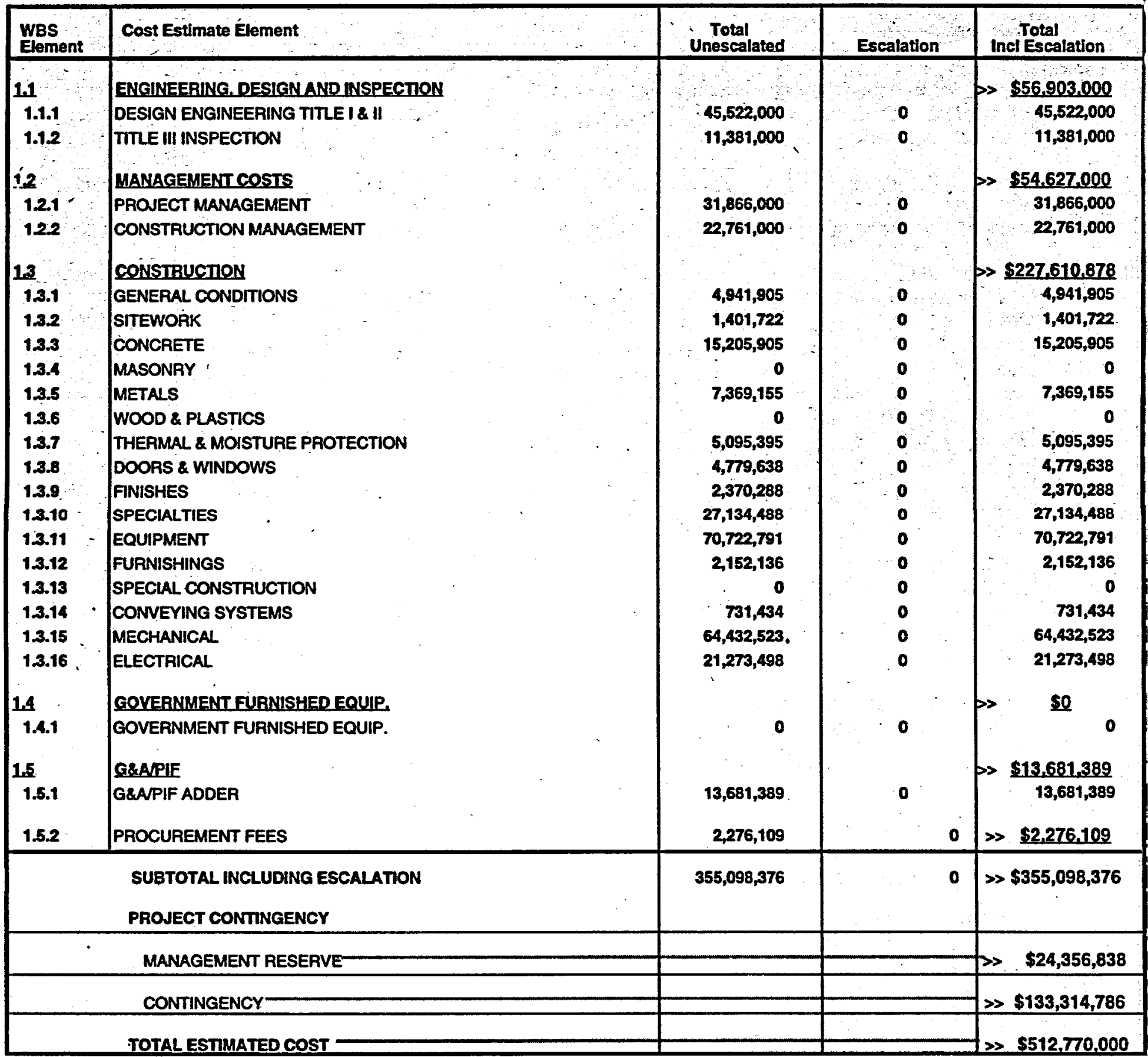

\section{PRONECT COST PARAMETERS}

EDI AS A \% OF CONST. + GFE $=25.00 \%$

CONTINGENCY $=44.40 \%$ 
Lockheed Martin Idaho Technologles Co.

$$
\text { Rov o-96 }
$$

PAOJECT NAME: HWO HIP FACILTY

TOTAL ESTIMATED COST - ESC

LOCATION 1: JOB LOCATION

REOUESTOR: N RUSSOI

\section{DETAILED COST ESTIMATE SHEET}

TYPE OF ESTIMATE: PLANNINC

PAOUECT NO: 2419

PREPARED BY: D. R. James
- PABE 1

DATE 26-Jan-1998

TIME: 15:42:46 REPOAT NAME: Detall Cost Eotimato Sheot

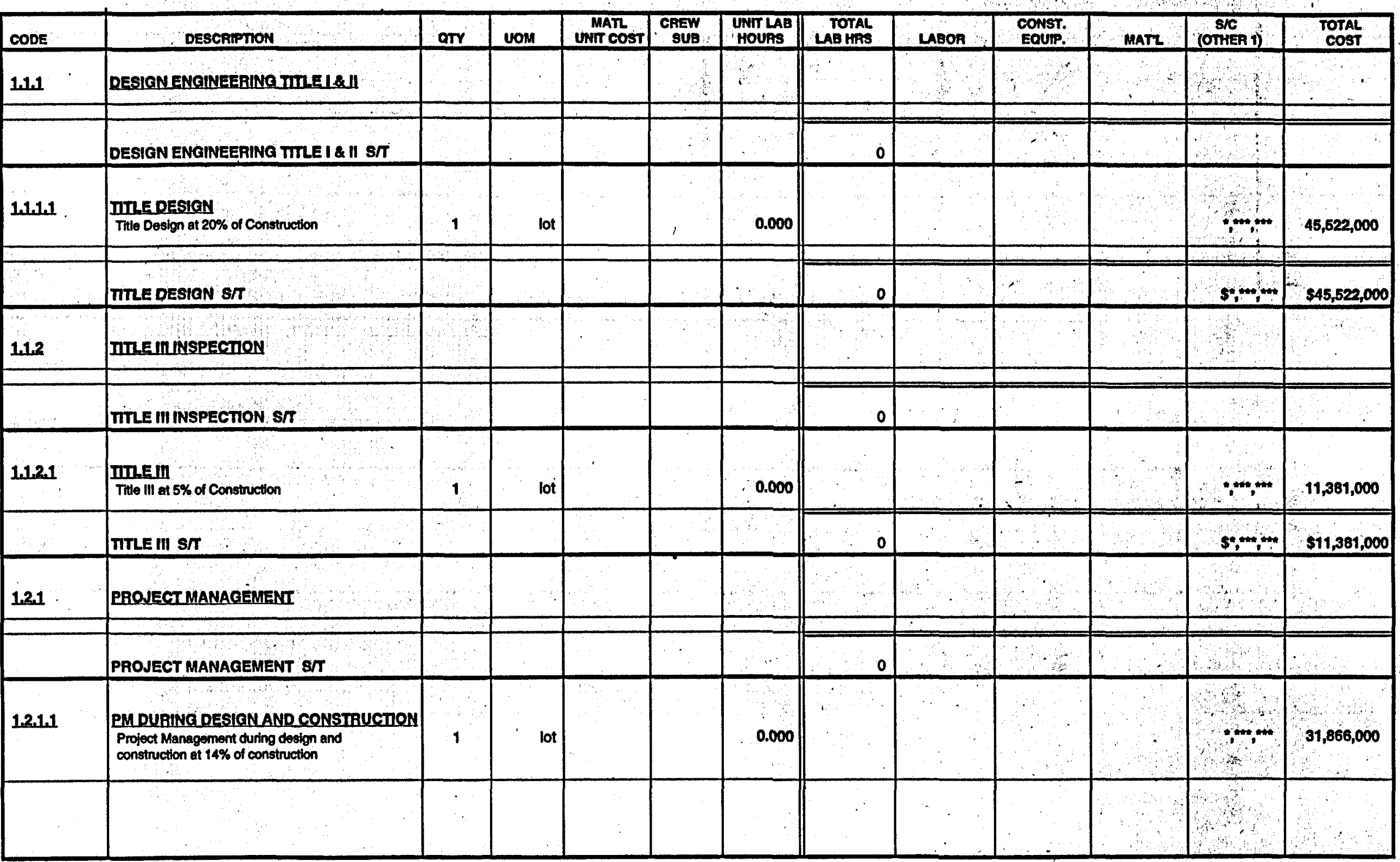


Lockheed Martin Idaho Technologles Co. Rov 0.98

PROEECT NAME: HWO HIP FACILITY

TOTAL ESTIMATED COST - ESC.

LOCATION 1: JOB LOCATION

REOUESTOR: N Russel
DETAILED COST ESTIMATE SHEET

TMPE Of ESTIMATE: PLANINING

PROAECT NO:: 2419

PREPARED BY: D. R. James
PAGE: 2

DATE 26-Jan-1998

TIME: 15:42:46

REPORT NAME: Detall Cost Eotimate Shoet

\begin{tabular}{|c|c|c|c|c|c|c|c|c|c|c|c|c|}
\hline CODE & DESCRIPTION & arr & \multirow[t]{3}{*}{ UOM } & \multirow[t]{3}{*}{$\begin{array}{c}\text { MAT } \\
\text { UNI COST }\end{array}$} & \multirow[t]{3}{*}{$\begin{array}{l}\text { CAEW } \\
\text { SUB }\end{array}$} & \multirow[t]{3}{*}{$\begin{array}{c}\text { UNT LAB } \\
\text { HOURS }\end{array}$} & $\begin{array}{l}\text { TOTAL } \\
\text { LAB HAS }\end{array}$ & LABOA & $\begin{array}{l}\text { CONST. } \\
\text { EOUiP. }\end{array}$ & MATL & $\begin{array}{l}\text { SKC } \\
\text { (OTHER 1) }\end{array}$ & $\begin{array}{c}\text { TOTAL } \\
\text { COST }\end{array}$ \\
\hline \multirow[t]{2}{*}{12.11} & \multirow{2}{*}{$\begin{array}{l}\text { PM DURINC DESIONAND CONSTRUCTION } \\
\text { PM DURING DESTON AND CONSTRUCTION }\end{array}$} & \multirow[b]{2}{*}{$5 \pi$} & & & & & & & & & & $\because \because$ \\
\hline & & & & & & & 0 & & & & $5 \%$ & $\$ 31,866,000$ \\
\hline 122 & CONSTRUCTONMANAGEMENT & & & & & & & & & & & $\because$ \\
\hline & & & & & & & - & & & & & \\
\hline & CONSTRUCTION MANAGEMENT S/T & & & & & & 0 & & & & & \\
\hline 122.1 & $\begin{array}{l}\text { CONSTRUCTION MANACEMENT AND SUPE } \\
\text { Construction Management Q } 10 \% \text { of } \\
\text { Construction }\end{array}$ & 1 & lot & & & 0.000 & & & & & & $22,761,000$ \\
\hline & CONSTRUCTION MANAGEMENT AND SUPP & ORT $s / T$ & & & & & 0 & & & & & $\$ 22,761,000$ \\
\hline 1.3 .1 & GENERALCONDMONS & & & & & $\therefore$ & & & & & & 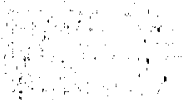 \\
\hline & & & & & & & 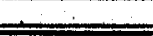 & 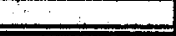 & & 0 & & $\therefore$ \\
\hline & GENERAL CONDITIONS ST & & ' & & & $\because$ & 0 & & & & & \\
\hline 1.3 .1 .1 & $\begin{array}{l}\text { IRAINING AND SUPEAVISION } \\
\text { Training - } 2 \%\end{array}$ & 1 & allow & & PIPE & 20000.0 & 20,000 & $\mathbf{7 3 5 , 8 0 0}$ & & & & 735,800 \\
\hline & Supervision - 5 men 4 years & 1 & allow & & $\begin{array}{l}\text { PIPE } \\
\text { MECE }\end{array}$ & 41600.0 & 41,600 & $1,530,464$ & & & mes & $1,530,464$ \\
\hline & TRAINING AND SUPERVISION ST & . & & & & & 61,600 & $\$ 2,266,264$ & & & & $\$ 2,268,264$ \\
\hline 1.3 .12 & $\begin{array}{l}\text { EQUPPMENT SUPPORI } \\
\text { Crano Suppont }\end{array}$ & 1 & allow & & $\begin{array}{c}\text { EQHV } \\
\text { GEN }\end{array}$ & 4160.00 & 4,160 & 131,248 & $1,000,000$ & se & 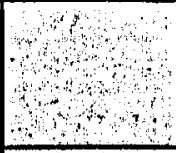 & $\begin{array}{r}1,131,248 \\
\end{array}$ \\
\hline$\ldots$ & $\begin{array}{ll}\therefore \\
\cdots\end{array}$ & & & & & & & & 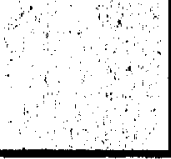 & कित्य & कित्य & कि \\
\hline
\end{tabular}


Lockheed Martin Idaho Technologles Co.

$$
\text { Rev 6-90 }
$$

PROUECT NAME: HWO HIP FACILTY

- TOTAL ESTMATED COST - ESC.

LOCATION 1: JOB LOCATION

REQUESTOR: N RUSSEl

\section{DETAILED COST ESTIMATE SHEET}

TYPE of Estimate: PLANNINC

PAONECT NO.: 2419

PREPARED QY: D. R. James
PAGE 3

DATE 26-Van-1998

TME $15: 42: 46$

REPORT NAME: Detall Cosi Estimate Sheel

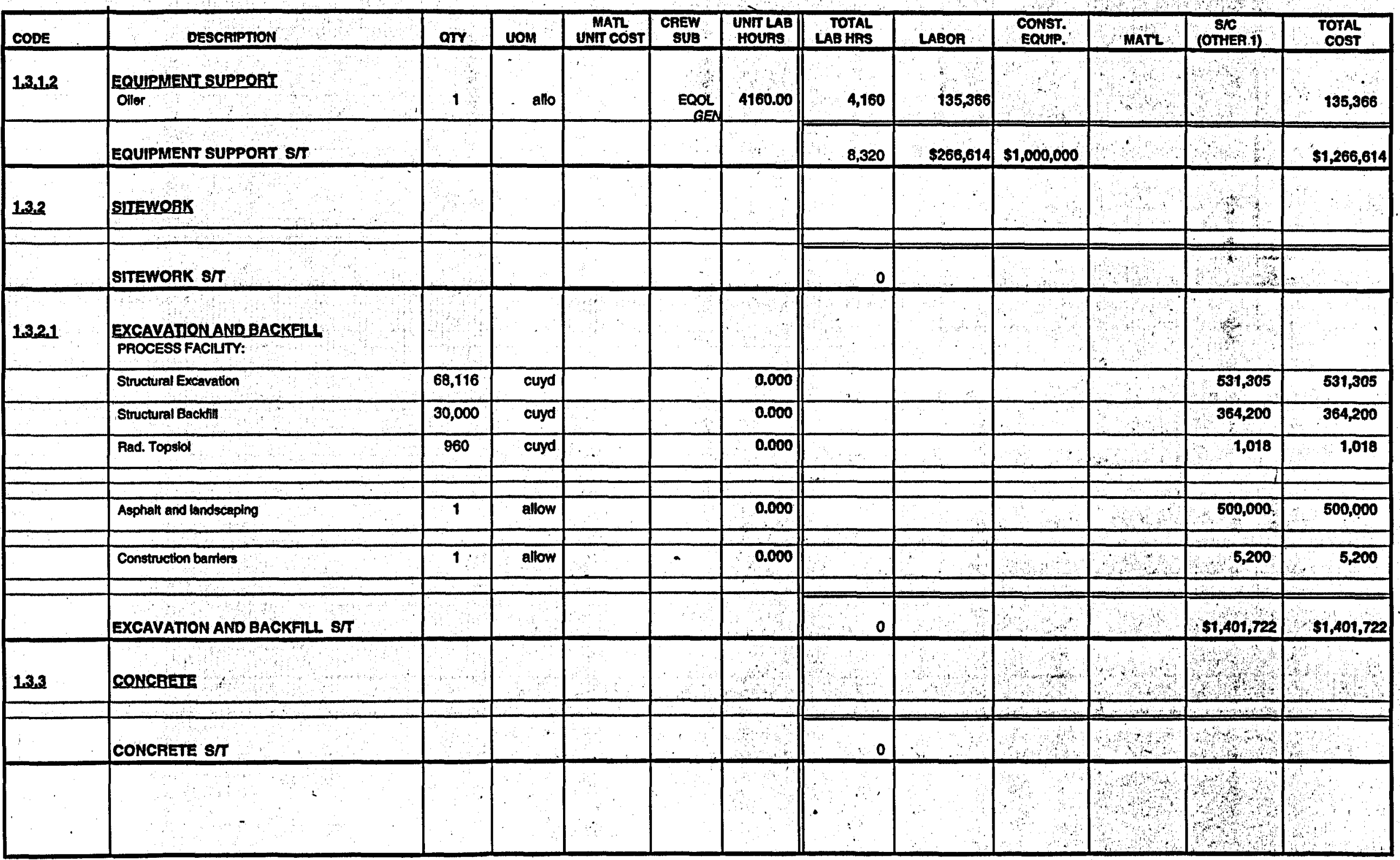


Lockheed Martin Idaho Technologles Co. Rov $8-90$

PAOJECT NAME: HWO HIP FACILITY

TOTAL ESTIMATED COST - ESC.

JOB LOCATION

REOUESTOR: N RUSSEI
DETAILED COST ESTIMATE SHEET

TYPE OF ESTIMATE: PLANNING

PROUECT NO.: 2419

PAEPAAED BY: D. R. James
PAGE 4

DATE 26-Jan-1998

TIME: 16:42:46

REPOAT NAME: Detall Cost Eotlmato Sheer

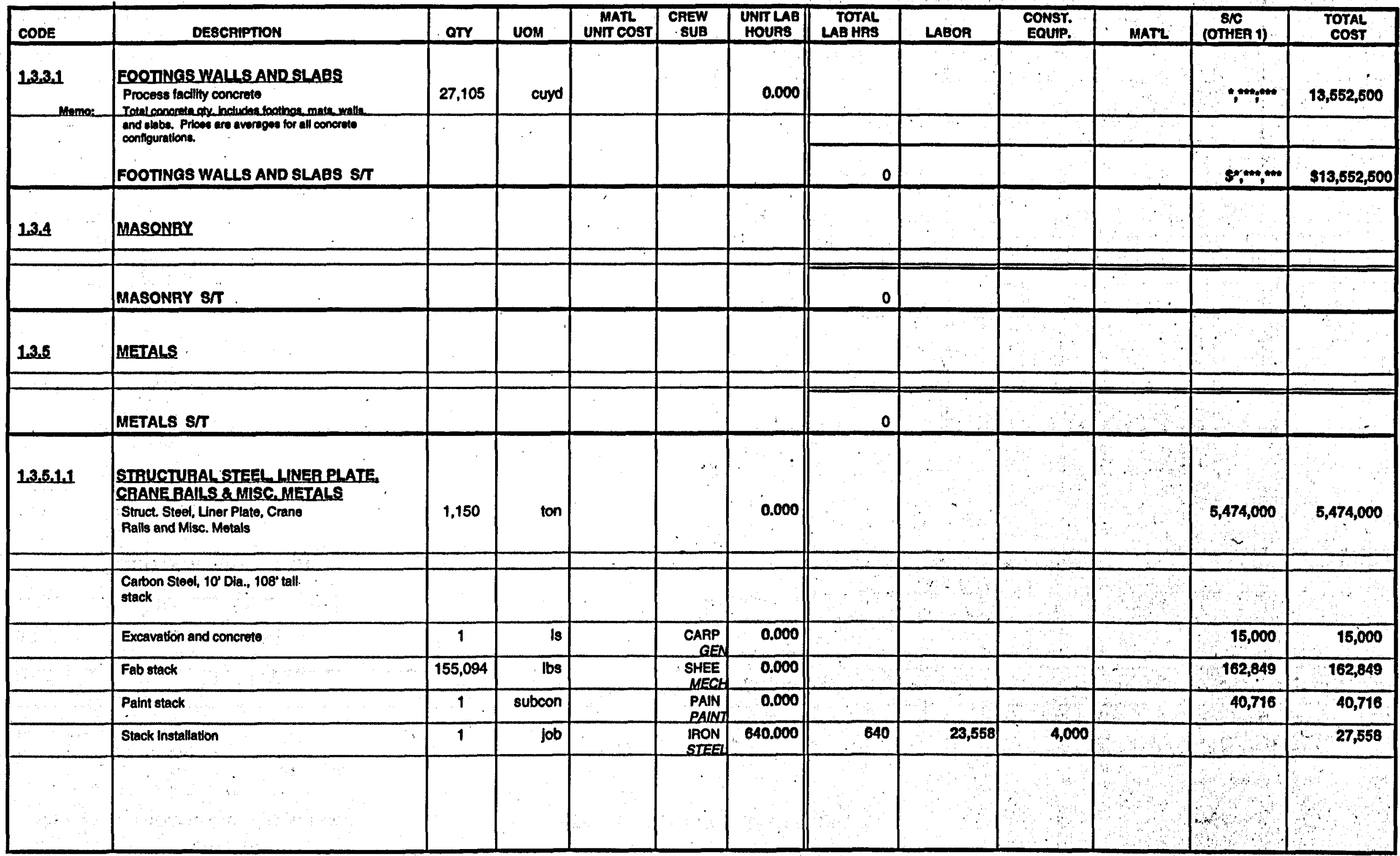


Lockheed Martin Idaho Technologles Co.

Aevers

PAOEECT NAME: HWO MIP FACILTY

TOTAL ESTIMATED COST - ESC.

LOCATION 1: JOB LOCATION

REOUESTOR: N Russel
DETAILED COST ESTIMATE SHEET

TYPE OF ESTIMATE: PLANNINC

PAOUECTNO: 2418

PAEPARED BY: D. R. James
PAGE 5

DATE 26Jan-1998

TME: 15:42:46

REPORT NAME: Detall Cost Estlmato Sheet

\begin{tabular}{|c|c|c|c|c|c|c|c|c|c|c|c|c|}
\hline CODE & DESCRIPTION & aTy & yom & $\begin{array}{c}\text { MATL } \\
\text { unm cost }\end{array}$ & $\begin{array}{c}\text { CREW } \\
\text { SUB } \\
\end{array}$ & $\begin{array}{l}\text { UNT LAB } \\
\text { HOURS }\end{array}$ & $\begin{array}{l}\text { TOTAL } \\
\text { LAB HAS }\end{array}$ & LABOR & $\begin{array}{l}\text { CONST. } \\
\text { EQUIP. }\end{array}$ & MATL & (OTHER 1) & $\begin{array}{l}\text { TOTAL } \\
\text { COST }\end{array}$ \\
\hline 1.3.5.1.1 & $\begin{array}{l}\text { STRUCTURAL STEEL_LWER PLATE } \\
\text { CAANE RAILS \& MISC.METALS } \\
\text { Stack shielded probo }\end{array}$ & 1 & $e a$ & $500,000.00$ & $\begin{array}{l}\text { PIPE } \\
\text { PEEC }\end{array}$ & 120.000 & 120 & $\mathbf{4 , 4 1 5}$ & क & 500,000 & $\therefore$ & 504,415 \\
\hline & $\begin{array}{l}\text { STRUCTURAL STEEL, LINEA PLATE, CRAN } \\
\text { METALS ST }\end{array}$ & RAILS : & Misc. & r & & & 760 & $\$ 27,973$ & $\$ 4,000$ & $\$ 500,000$ & $\$ 5,692,565$ & $\$ 6,224,538$ \\
\hline 13.5 .12 & $\frac{\text { METAL DECK }}{\text { Metal Decking }}$ & 38,660 & sqft & & & 0.000 & & & & & 91,624 & 91,624 \\
\hline 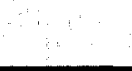 & METAL DECK S $/ T$ & & & & & & 0 & & & & $\$ 91,624$ & $\$ 91,624$ \\
\hline 13.6 & WOOD \& PLASTCS & & & & & & & & & & 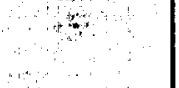 & \\
\hline & WOOD \& PLASTICS S/T & & & & & & 0 & & & & 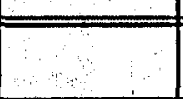 & \\
\hline 1.3.7 & THEAMAL \& MOISTURE PAOTECTON & & & & & & & & & & & \\
\hline & THERMAL \& MOISTURE PROTECTION ST & & & & $=$ & & 0 & & & & & \\
\hline 13.7 .1 & $\begin{array}{l}\text { INSULAMON } \\
\text { Pipe, Tank and Duct Insulation }\end{array}$ & 1 & Is & & $\begin{array}{l}\text { ASBE } \\
\text { INSUI }\end{array}$ & 0.000 & & & & & 135,000 & 135,000 \\
\hline & INSULATION ST & & & & & & $\therefore$ & & & & $\$ 135,000$ & $\$ 135,000$ \\
\hline 1.3 .7 .2 & $\begin{array}{l}\text { BOOFING AND SIDING } \\
\text { Foofing and extertor wall siding }\end{array}$ & 1 & is & & $\begin{array}{l}\text { ASBE } \\
\text { INSUI }\end{array}$ & 0.000 & & & & & $\begin{array}{r}3,455,000 \\
3\end{array}$ & $3,455,000$ \\
\hline & $\therefore$ & & & & & & & & & & 2 & \\
\hline
\end{tabular}


Lockheed Martin Idaho Technologies Co.

$$
\text { Rov 6-86 }
$$

PROIECT NAVE: HWO HIP FACILTY

TOTAL ESTIMATED COST - ESC.

LOCATION 1:

REOUESTOR: N RUSSOI

\section{DETAILED COST ESTMMATE SHEET}

TYPE OF ESTMMATE: PLANNINC

PAONECT NO: 2418

PREPARED BY: D. R. James
PAGE 6

DATE 26-Jan-1998

TME: 15:42:46

REPORT NAME: Dotall Cost Estlmato Shoot

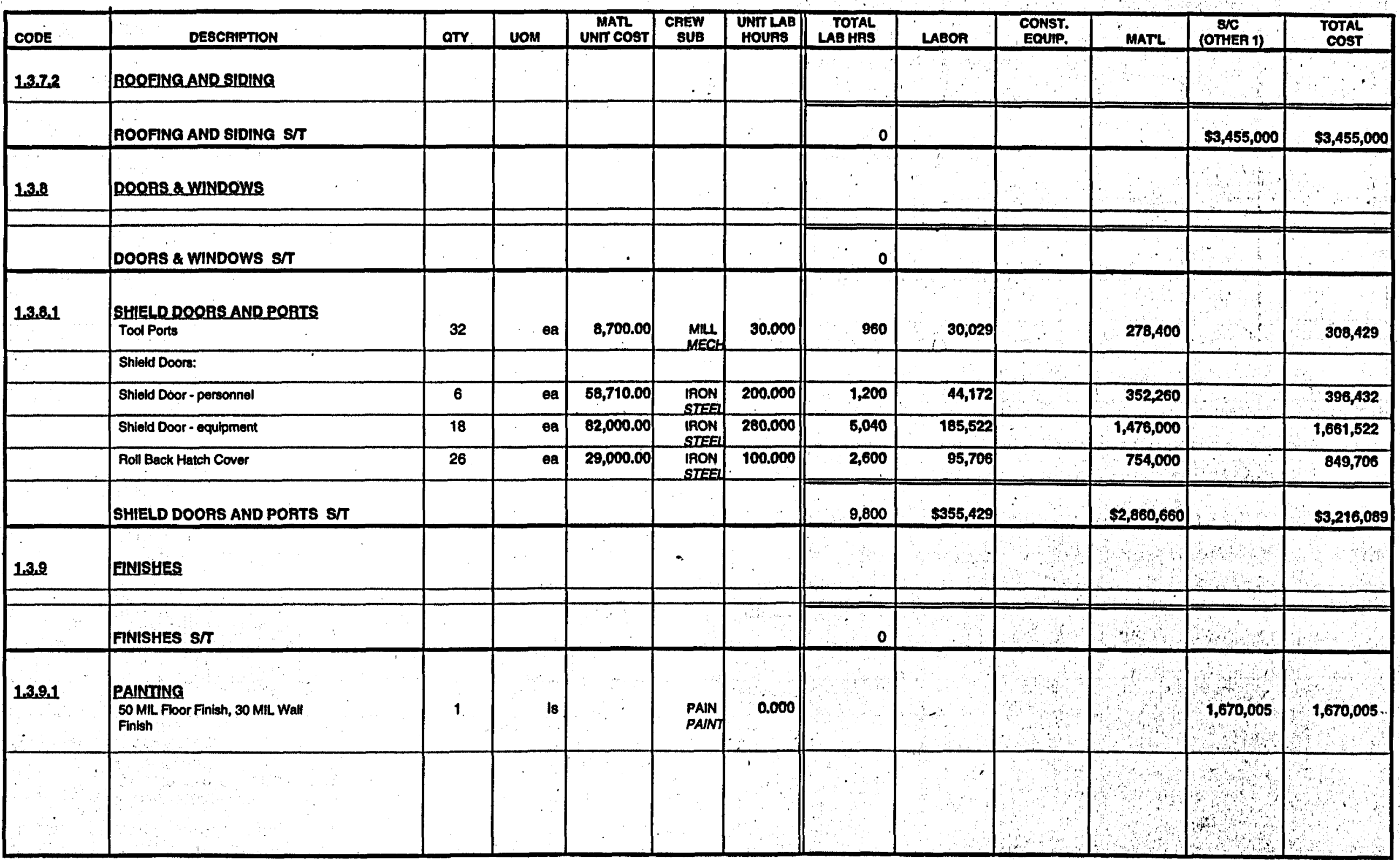


Lockheed Martin Idaho Technologles Co. Aov 6-9s

PAONECT NAME: HWO HIP FACHITY

TOTAL ESTMMATED COST - ESC.

LOCATION ::

JOB LOCATION

REOUESTOP: N Russel

\section{DETAILED COST ESTIMATE SHEET}

TYPE OF ESTMATE: PLANNING

PROUECT NO.: 2419

PREPARED BY: D. R. James
PAGE 7

DATE 26-Van-1998

TIME: 16:42:46

REPORT NAME: Detall Cost Esthmate Sheet

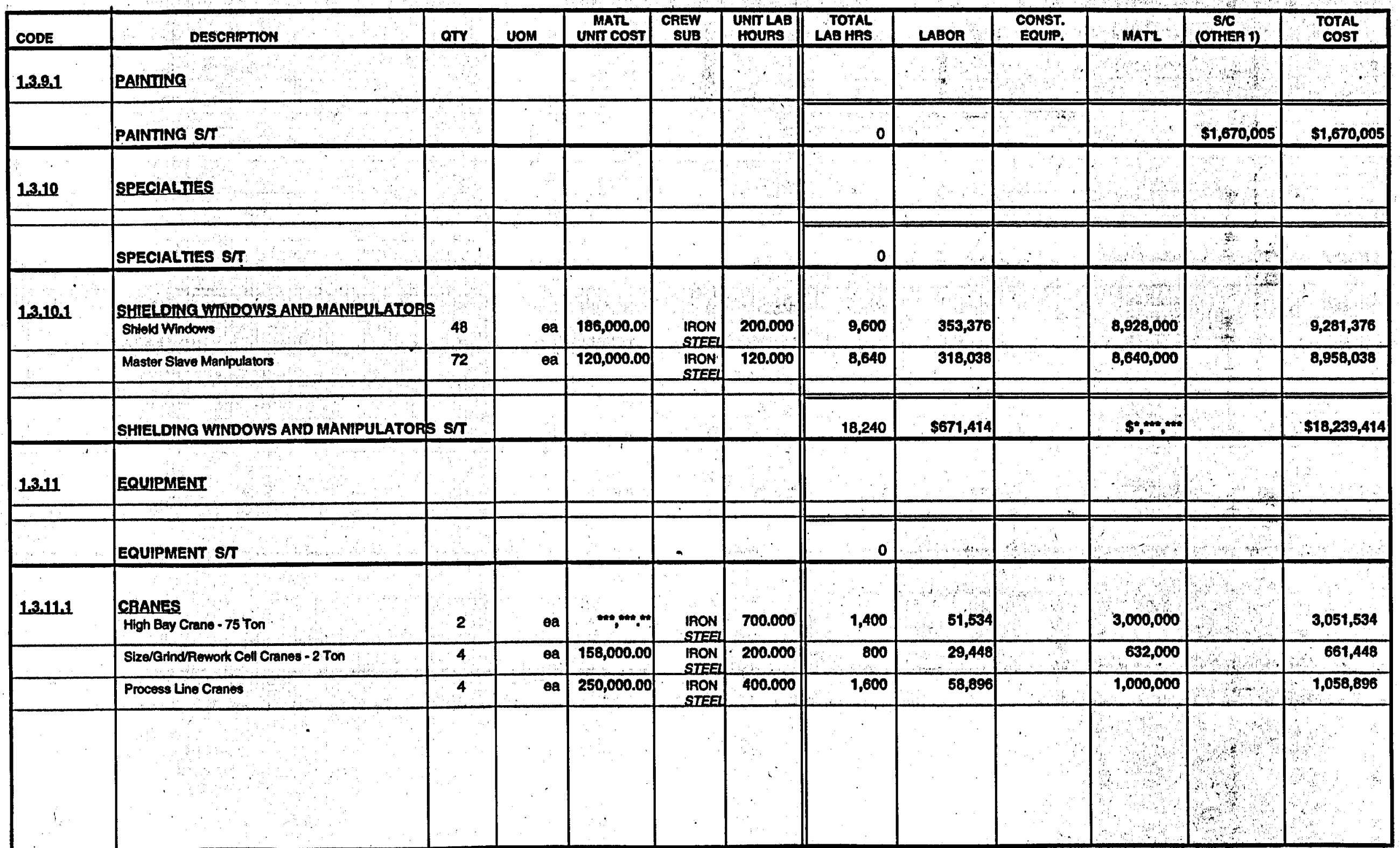


Lockheed Martin Idaho Technologles Co. Aov 8-98

PROIECT MAME: HWO HIP FACILITY TOTAL ESTIMATED COST - ESC.

LOCATION 1: JOB LOCATION N Russel

REOUESTOR: N Russel
DETAILED COST ESTIMATE SHEET

TYPE Of Estimate: PLANiNING

PAONECT NO:: 2419

PREPARED BY: D. R. James
PAGE 8

DATE 26 Jan-1998

TIME: 15:42:46

REPOAT NAME: Dotall Cost Estlmato Sheot

\begin{tabular}{|c|c|c|c|c|c|c|c|c|c|c|c|c|}
\hline CODE & DESCRIPTION & ary & UOM & $\begin{array}{l}\text { MATL } \\
\text { uNIT Cost }\end{array}$ & $\begin{array}{l}\text { CREW } \\
\text { 8U日 }\end{array}$ & $\begin{array}{l}\text { DNTT LAB } \\
\text { HOUAS }\end{array}$ & $\begin{array}{l}\text { TOTAL } \\
\text { LAB HAS }\end{array}$ & LABOR & $\begin{array}{l}\text { CONST. } \\
\text { EOUIP. }\end{array}$ & MATL & (OTHER I) & $\begin{array}{l}\text { TOTAL } \\
\text { COST }\end{array}$ \\
\hline 1.3 .111 & $\begin{array}{l}\text { CAANES } \\
\text { Grapples }\end{array}$ & 4 & ea & $60,000.00$ & $\begin{array}{c}\vdots \\
\text { IRON } \\
\text { STEE4 }\end{array}$ & 80.000 & 320 & 11,779 & & 200,000 & & 211,779 \\
\hline & CRANES S/T & & & & & & 4,120 & $\$ 151,657$ & & $\$ 4,832,000$ & & $\$ 4,983,657$ \\
\hline 13.112 & $\begin{array}{l}\text { RROCESS EQUIPMENT, } \\
\text { Electro-Mechanical Manipulators } \\
\text { w/Trolleys }\end{array}$ & 12 & $\mathbf{e a}$ & $350,000.00$ & $\begin{array}{l}\text { MILL } \\
M E C H\end{array}$ & 120.000 & 1,440 & 45,043 & & $4,200,000$ & & $4,245,043$ \\
\hline 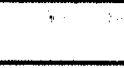 & HIP Can Lid Weldìng Equipment & 4 & allow & $250,000.00$ & MLL & 220.000 & 880 & 27,526 & & $1,000,000$ & $\because$ & $1,027,628$ \\
\hline & HIP Can Sealing Equipment & 4 & allow & $68,000.00$ & MML & 80.000 & 320 & 10,010 & & 232,000 & & 242,010 \\
\hline & Decontamination Equipment: & & & & & & & & & & $\because$ & $\therefore$ \\
\hline & CO2 Pellet Blasting Equlpment & 4 & ea & $120,000,00$ & MML & 120.000 & 480 & 15,014 & & 480,000 & & 495,014 \\
\hline & Chemical Decon. Equipment & 4 & ea & $180,000,00$ & $\begin{array}{c}\text { MML } \\
\text { MEC4 }\end{array}$ & 200.000 & .800 & 25,024 & & 720,000 & & 745,024 \\
\hline & NDE QAAssay Equipment & 12 & units & $85,000.00$ & MLL & $\frac{1}{60.000}$ & 720 & 22,522 & & $1,020,000$ & & $1,042,522$ \\
\hline & Devolatilization Fumaces & 12 & ea & 50.000 .00 & & 0000 & & & & 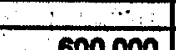 & & angmens \\
\hline & & & & & sue & & & & & . ovou,ưu & & 600,000 \\
\hline$\therefore$ & Vacuum Pumps & 4 & ea & $2,125.00$ & & 0.000 & & & & 8,500 & & 8,500 \\
\hline wis. & Control Systems & 1 & allow & $125,000.00$ & & 0.000 & & $\overline{6}$ & & 125,000 & 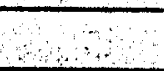 & 125,000 \\
\hline & HIP Pressure Vessel & 12 & ea & $m,+\infty+\infty$ & MIL & 200.000 & 2,400 & 75,072 & & $y^{6+0+1+\infty+1}$ & & $14,475,072$ \\
\hline & Spere HIP Pressure Vessels & 2 & ea & $+\cdots,+\infty$ & & 0.000 & & & & $2,400,000$ & & $2,400,000$ \\
\hline$\therefore$ & Kanthal Fumaces & 12 & ea & $500,000.00$ & MILI & 200.000 & 2,400 & 75,072 & 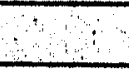 & $6,000,000$ & 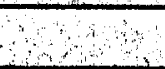 & $6,075,072$ \\
\hline & Spare Kanthal Fumaces & 4 & ea & $500,000.00$ & sue & 0.000 & & & & $2,000,000$ & 4 & $2,000,000$ \\
\hline & Pressure Vessel Vacuum Pump & 8 & ea & $40,000.00$ & MLL & 120.000 & 960 & 30,029 & & 320,000 & 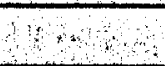 & 350,029 \\
\hline & 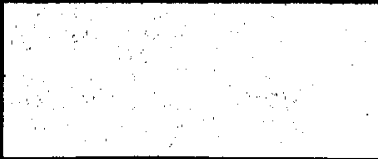 & & & & $\because>$ & & & & & & 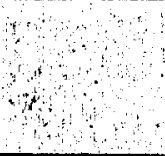 & as \\
\hline
\end{tabular}


Lockheed Martin Idaho Technologles Co.

PROUECT NAME: HWO HIP FACILITY

TOTAL ESTIMATED COST - ESC

LOCATION 1: JOB LOCATION

AEQUESTOR: N Russel :
DETAILED COST ESTIMATE SHEET

TYPE OF ESTMMTE: PLANNING

PAONECT NO: : 2419

PAEPARED BY: D. R. James
PAGE ? 9

OATE 26 Jan-1998

TIME: 15:42:46

AEPORT NAME Detall Cost Eotlmate Sheet

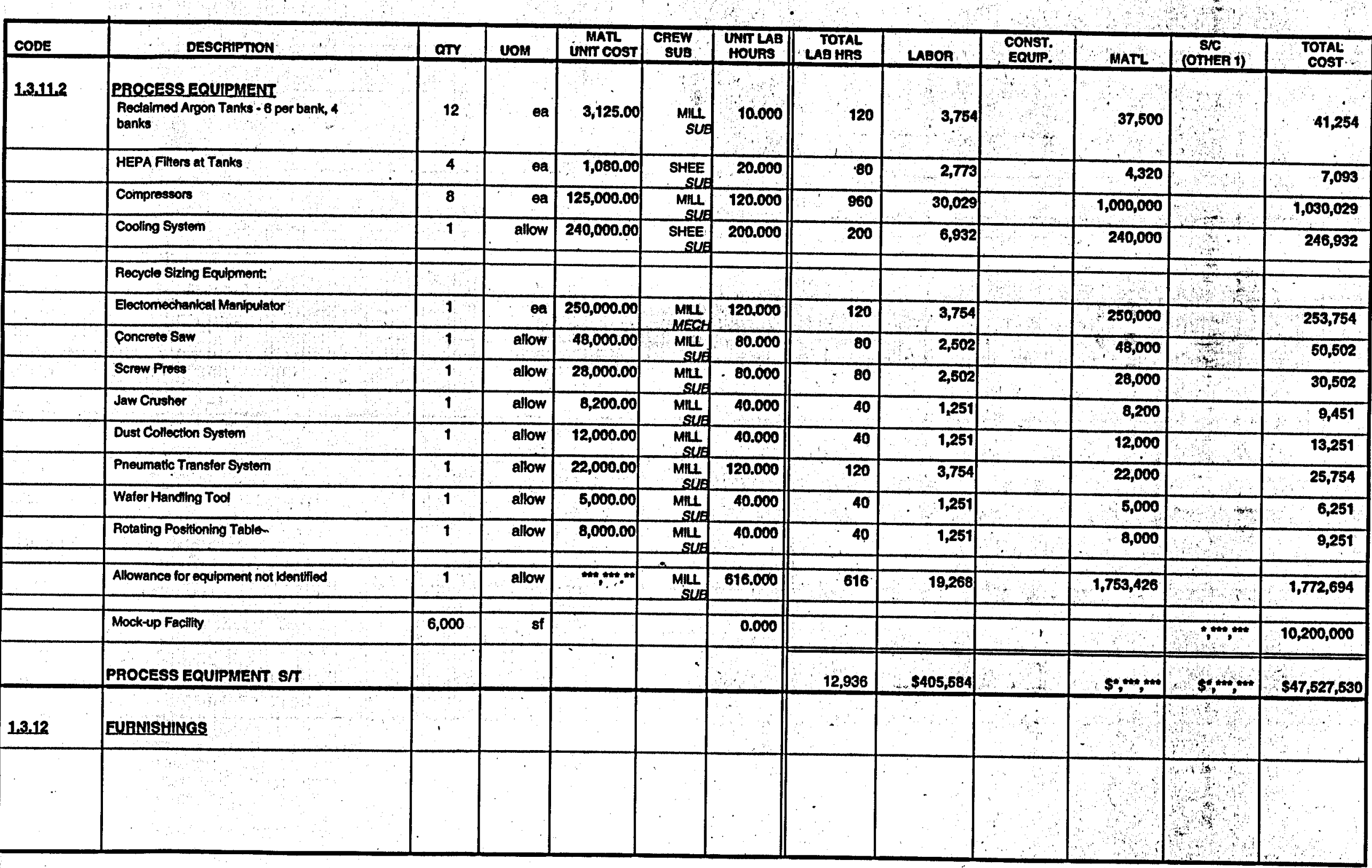




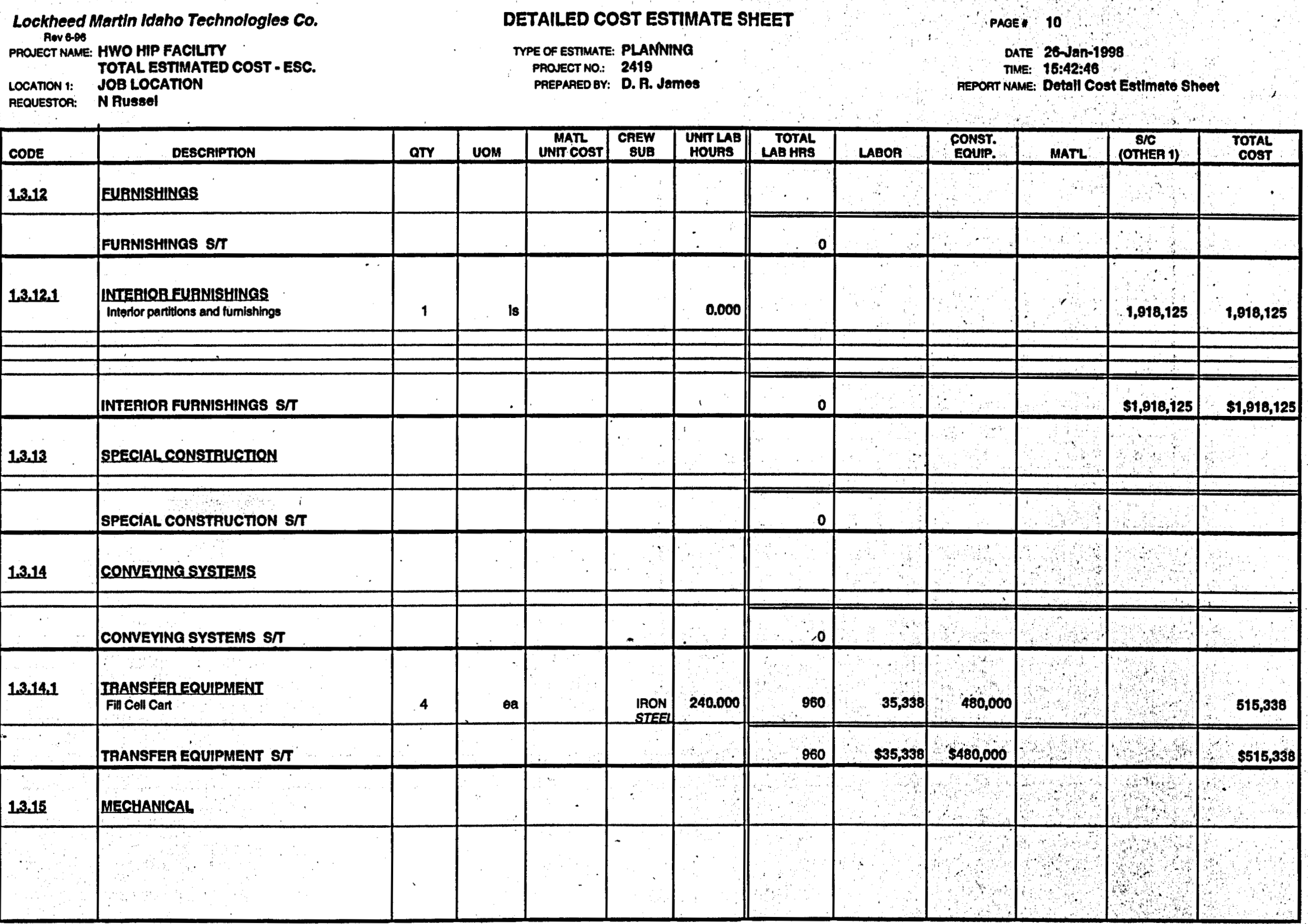


Lockheed Martin Idaho Technologies Co. PAOUECT NAME: HWO HIP FACILTYY

TOTAL ESTIMATED COST - ESC.

LOCATON 1:

REQUESTOR: NRUSSOI
DETAILED COST ESTIMATE SHEET

TMPE OF ESTMATE: PLANNING

PAOJECT NO:: 2419

PREPARED BY: D. R. James
PAGE: 11

DATE 26-Jan-1998

TIME: 15:42:46

AEPORT NMME: Detall Cost Estimate Sheet

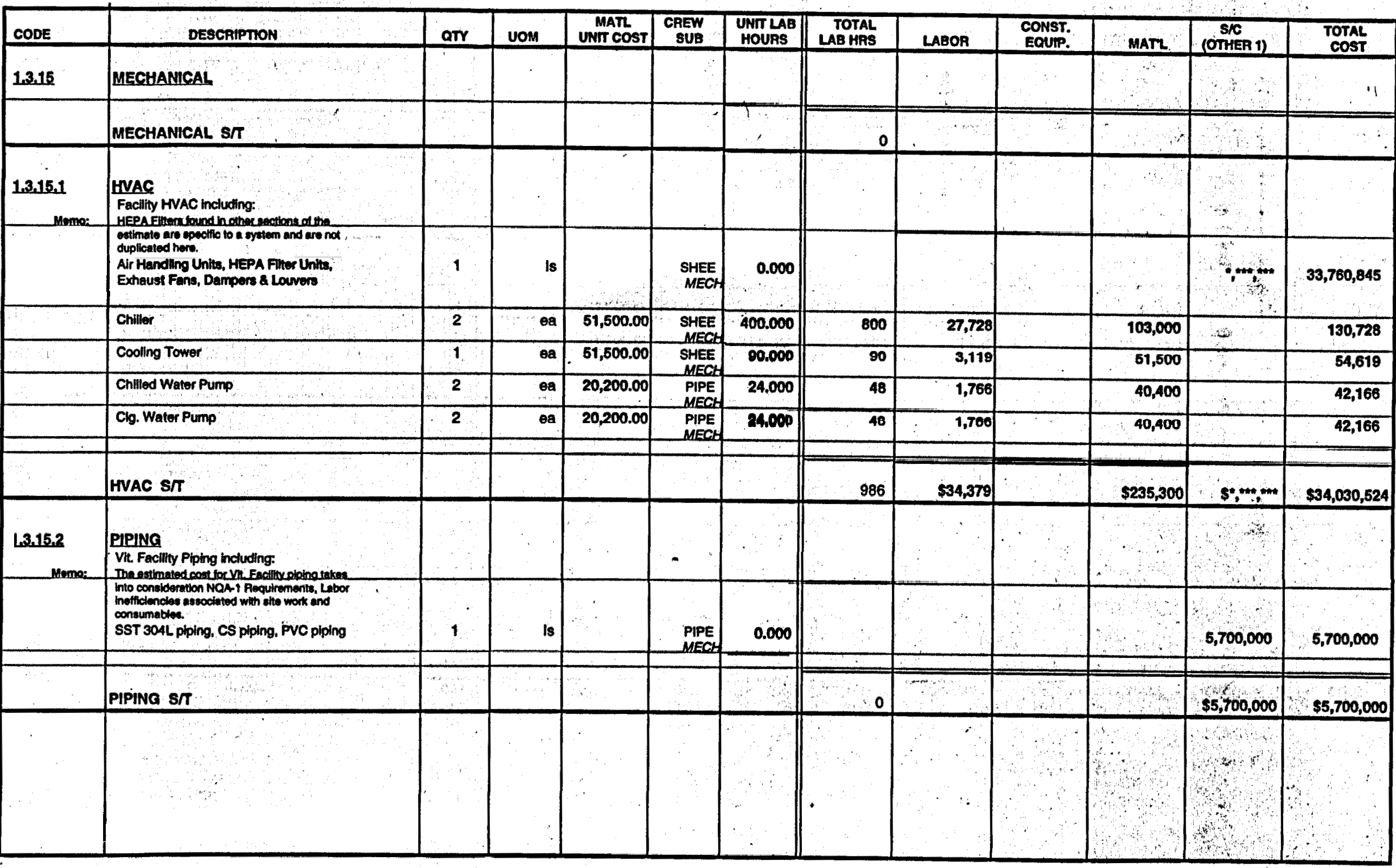




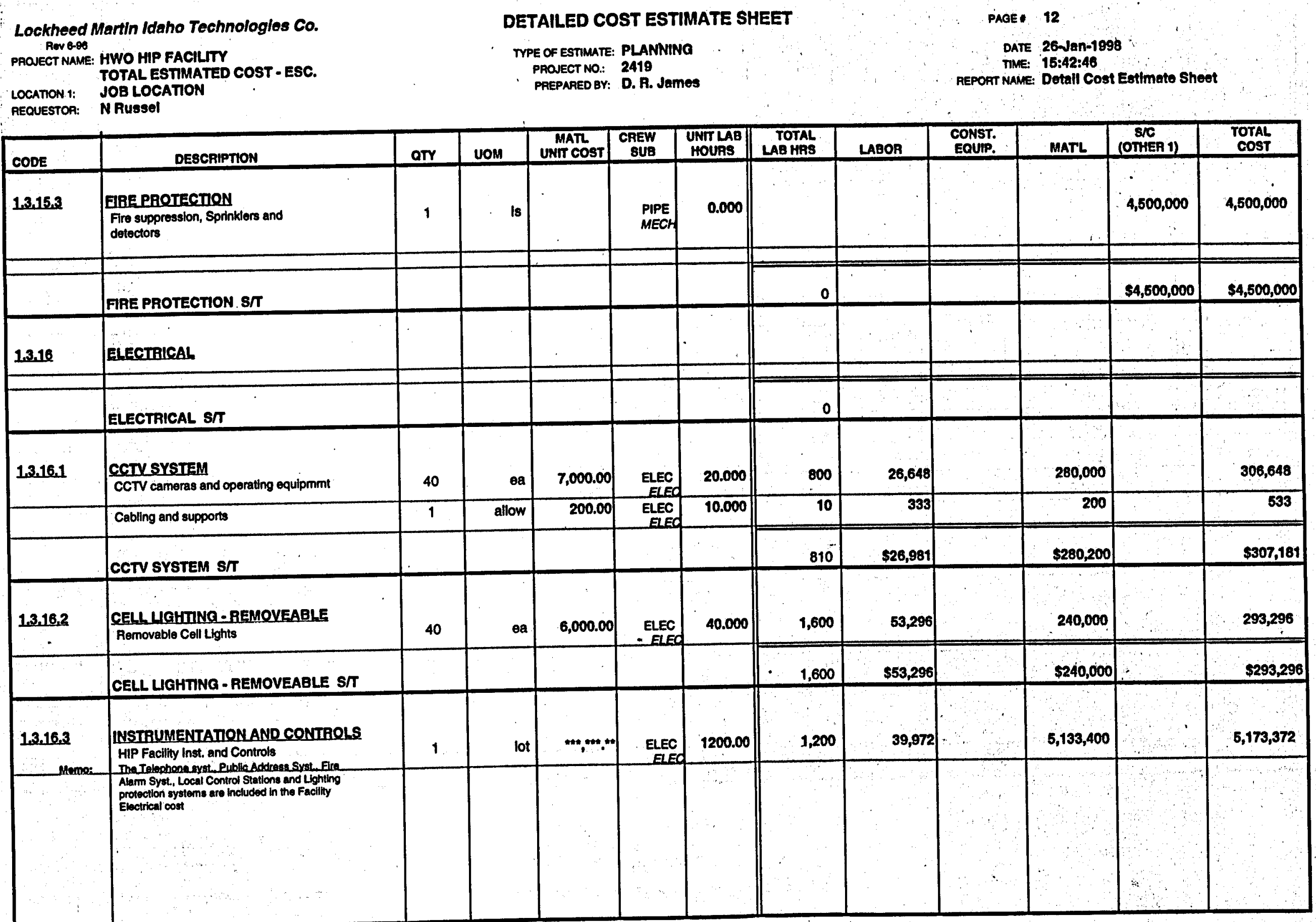


Lockheed Martin Idaho Technologles Co. Rov 6-90

PROUECT NAME: HWO HIP FACILTY

TOTAL ESTIMATED COST - ESC

LOCATON 1: JOB LOCATION

REOUESTOR: N RusSel

\section{DETAILED COST ESTMATE SHEET}

TYPE OF ESTIMATE: PLANNING

PAONECT NO: 2419

PREPARED BY: D. R. James $\therefore$ PAGE 13

DATE 26-Jan-1998

TIME: 15:42:46

REPORT NUME: Detall Cost Estlmate Sheet

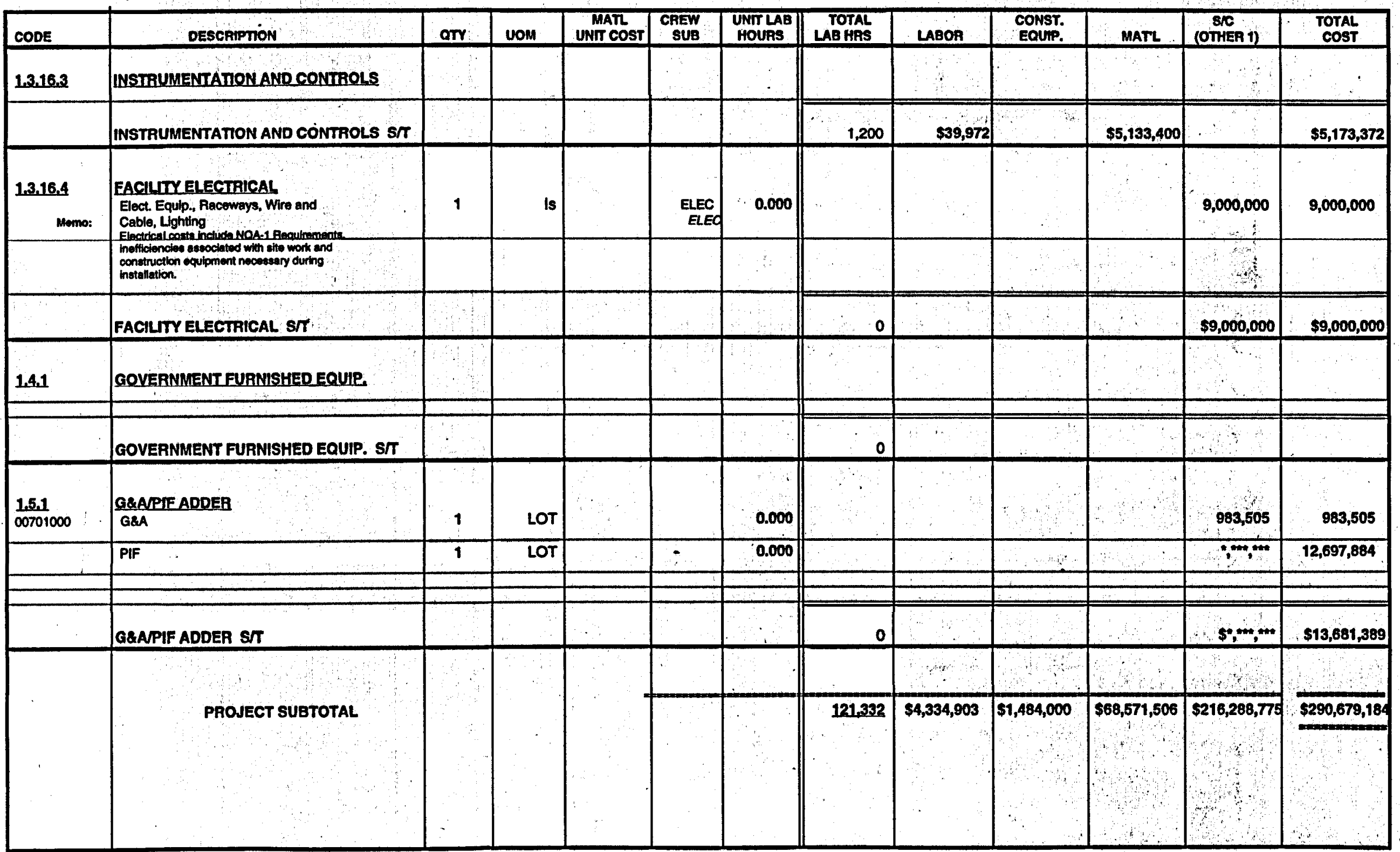


Lockheed Martin ldaho Technologies Co.

PRONECT NANE: HWO HIP FACILTY " TOTAL ESTIMATED COST - UNESC.

LOCATION 1: JOB LOCATION

RECUESTOR: N RuSSEI

CONTINGENCY.ANALYSIS TPE OF ESTINATE: PLANNING
PROAECT NO: 2419

PREPARED BY:
D. R. James
DATE: 26-Jan-1998

TIME: 16:02:19

REPORT NAME: Contingency Analysis

\begin{tabular}{|c|c|c|c|c|c|c|c|c|c|c|c|}
\hline \multirow{3}{*}{\begin{tabular}{|l|} 
\\
WaS \\
Element \\
\end{tabular}} & \multirow{3}{*}{ Cost Estimate Eement } & \multirow{3}{*}{$\begin{array}{l}\text { Total Cost w/o } \\
\text { Contingency }\end{array}$} & \multirow{3}{*}{$\begin{array}{l}\text { X Total } \\
\text { Cost }\end{array}$} & & & & & 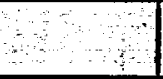 & \multicolumn{2}{|c|}{$\begin{array}{l}\text { PROJECT } \\
\text { CONTINGENCY }\end{array}$} & \multirow{3}{*}{$\begin{array}{l}\text { SUMMAA) } \\
\text { Total Cost } \\
\text { by Element }\end{array}$} \\
\hline & & & & \multicolumn{2}{|c|}{$\begin{array}{l}\text { Prob. \% Var: } \\
\text { Frpm Est }\end{array}$} & \multicolumn{2}{|c|}{ Wh $\%$ of Prob. } & \multirow{2}{*}{ Contingency } & \multirow{2}{*}{$\%$} & \multirow{2}{*}{ Cost } & \\
\hline & & & & - & \pm & $=$ & + & & & & \\
\hline 1.1 .1 & DESIGN ENGINEERING TILEI \&U & $45,522,000$ & 1282 & 15 & 30 & 1282 & 3.05 & $3.269 \%$ & $736 \%$ & $11,608,172$ & $57,130,17$ \\
\hline 1.12 & TIIE UII INSPECTION & $11,381,000$ & 321 & 15 & 30 & 0.48 & $0.06^{\circ}$ & $0.817 \%$ & $1.84 \%$ & $2,902,171$ & $14,283,17$ \\
\hline 1.2 .1$. & PRONECT MANAGEMENT & $31,866,000$ & 8.97 & 15 & 30 & 1.35 & 2.69 & $2288 \%$ & $5.15 \%$ & $8,125,873$ & $39,891,87$ \\
\hline 122 & CONSTRUGTION MANAGEMENT & $22,761,000$ & 6.41 & 15 & 30 & 0.96 & 1.02 & $1.634 \%$ & $3.68 \%$ & $5,804,086$ & $28,565,08$ \\
\hline 13.1 & GENERAL CONDITONS & 4,941,805 & 139 & 10 & 45 & 0.14 & 0.63 & $0.550 \%$ & $124 \%$ & $1,852,063$ & $6,893,96$ \\
\hline 1.32 & \begin{tabular}{|l} 
SITEWORK \\
\end{tabular} & $1,401,722$ & 0.39 & 5 & 60 & 0.02 & 0.24 & $0.211 \%$ & $0.48 \%$ & 749,925 & $2,151,64$ \\
\hline 1.3 .3 & CONCRETE & $15,205,905$ & 4.28 & 5 & 60 & 0.21 & 2.57 & $2.291 \%$ & $5.16 \%$ & $8,135,203$ & $23,341,10$ \\
\hline 134 & MASONRY & 0 & 0.00 & 5 & 45 & 0.00 & 0.00 & $0.000 \%$ & $0.00 \%$ & 0 & \\
\hline 1.3 .6 & METALS & $7,369,155$ & 2.08 & 5 & 60 & 0.10 & 125 & $+1.110 \%$ & $250 \%$ & $3,942,519$ & $11,311,67$ \\
\hline 1.3 .6 & WOOD \& PLASTICS & 0 & 0.00 & 5 & 30 & 0.00 & 0.00 & $0.000 \%$ & $0.00 \%$ & & \\
\hline 1.3 .7 & THERMAL \& MOISTURE PROTECTION & $8,095,395$ & 1.43 & 8 & 60 & 0.07 & 0.86 & $0.768 \%$ & $1.73 \%$ & $2,726,051$ & $7,821,441$ \\
\hline 1.38 & DOORS \& WINDOWS & $4,779,638$ & 1.35 & 5 & 65 & 0.07 & 0.87 & $0.781 \%$ & $1.76 \%$ & $2, \pi 72,205$ & $7,551,84$ \\
\hline 13.8 & FINISHES & $2,370,288$ & 0.67 & 5 & 50. & 0.03 & 0.33 & $0.297 \%$ & $0.67 \%$ & $1,054,784$ & $3,425,07$ \\
\hline 1.3.10: & SPECLALTIES & $27,134,488$ & 7.64 & 5 & 40 & 0.38 & 8.06 & $2.713 \%$ & $6.11 \%$ & $0,632,795$ & $36,767,28$ \\
\hline 1.3 .11 & EOUIPUENT & $70,722,701$ & 19.92 & 5 & 65 & 1.00 & 12.95 & $11552 \%$ & $26.02 \%$ & $41,019,438$ & $111,742,22$ \\
\hline 1.3 .12 & FURNISHINGS & $2,152,136$ & 0.61 & 5 & 45 & 0.03 & 0.27 & $0.242 \%$ & $0.55 \%$ & 860,859 & $3,012,99 !$ \\
\hline 13.13 & SPECIAL CONSTRUCTION & a & 0.00 & 5 & 45 & 0.00 & 0.00 & $0.000 \%$ & $0.00 \%$ & of & \\
\hline 13.14 & CONVEYING SYSTEMS & 731,434 & 0.21 & 5 & 45 & 0.01 & 0.09 & $-0.082 \%$ & $0.19 \%$ & $-292,575$ & $1,024,008$ \\
\hline 13.15 & MECHANICAL & $64,432,523$ & 18.14 & 5 & 65 & 0.91 & 11.78 & $10.524 \%$ & $23.70 \%$ & 87,371,063 & $101,803,58 i$ \\
\hline 1.3 .16 & EIECTRICAL & $21,273,498$ & 5.99 & 5 & 65 & 0.30 & 3.89 & $3.475 \%$ & $7.03 \%$ & $12,338,695$ & $33,612,19:$ \\
\hline 1,4 & GOVERNMENT FURNISHED EQUIP. & 0 & 0.00 & 5 & 45 & 0.00 & 0.00 & $0.000 \%$ & $0.00 \%$ & 0 & \\
\hline 1.5 .1 & G\&NPIF ADOER & $13,681,389$ & 3.85 & 5 & 45 & 0.10 & 1.73 & $1.541 \%$ & $-3.47 \%$ & $5,472,585$ & $18,153,974$ \\
\hline \multirow[t]{2}{*}{1.52} & PROCUREMENT FEES & $2,276,109$ & 0.64 & 5 & 45 & 0.03 & 0.29 & $0.256 \%$ & $0.58 \%$ & 910,448 & $3,186,55$ \\
\hline & ESCALATION & 0 & 0.00 & 5 & 45 & 0.00 & 0.00 & $0.000 \%$ & $0.00 \%$ & 114) & 11 \\
\hline & SUBTOTAL & $355,098,376$ & 100.00 & & & $\cdot$ & & $44.402 \%$ & & & \\
\hline & CALCULATED CONTIIGENCY & $157,670,667$ & & & & & & & & & \\
\hline & RESULTANT TEC & $512,769,043$ & & & & & & & - & & \\
\hline & ROUNDED TEC & $512,770,000$ & & & & & & & & & \\
\hline & PROJECT CONTINGENCY & $157,671,624$ & & & - & & & $44.40 \%$ & & & \\
\hline & MANAGEMENT RESERVE & $24,356,838$ & & & & & & & & & \\
\hline & CONTINGENCY & $133,314,786$ & & & & & & & & & \\
\hline & TOTAL ESTMMATED COST & $512,770,000$ & & & & . & & : & & $157,671,624$ & $512,770,00$ \\
\hline
\end{tabular}

CONFIDENCE LEVEL AND ASSUMED RISKS:

The Lockheed Idaho Technologies Co. Cost Estimate Contingency Analysis Model is based on the applied contingency and the assumptions upon which the estimate was predicated. The model is applied with a suggested risk level of $18 \%$ and a level of confidence of $90 \%$ the estimate will fall within the bid range. The Contingency Analysis is based on a weighted average to provide a

$90 \%$ probability of underrun and a $10 \%$ probability of overnun.
CONTINGENCY ANALYSIS GUIDE BY TYPE OF ESTIMATE

Guidelines established by DOE/FM 50 , Cost Estimating Guide, Vol. 6 Cost Guide, and as presented in the INEL Cost Estimating Guide.
PLANNING
$20 \%-30 \%$
Experimental/Special Conditions...........Up to $50 \%$ Conceptual $15 \%-25 \%$ TITLE I
experimental/Special Conditions...........Up to $40 \%$
TITLE I
TITLE II/AFC
$10 \%-20 \%$
$5 \%-15 \%$
Market Conditions 
Lockheed Martin Idaho Technologies Co. PROJECT NAME: HWO HIP FACILTÝ

TOTAL ESTIMATED COST - ESC. REQUESTOR: NRUSSel
CONTINGENCY ANALYSIS

TYPE OF ESTMMATE: PLANNING
PAOECT NO:
PREPARED BY:

DATE: 26-Jan-1998

TIME: 15:42:18

PEPORT MAME: Contingency Analysis

\begin{tabular}{|c|c|c|c|c|c|c|c|c|c|c|c|}
\hline & $-\quad+3+4$ & BLE\% YABIA & & & & & 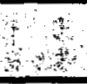 & $\ldots$ & $\begin{array}{l}\text { PRO } \\
\text { CONTI }\end{array}$ & CT & SUMMARY \\
\hline $\begin{array}{l}\text { WaS } \\
\text { Element }\end{array}$ & Cost Estimate Eement & Total Cost w/o & $\begin{array}{l}\text { \% Total } \\
\text { Cost }\end{array}$ & & $\begin{array}{l}\text { XVar. } \\
\text { mEst. }\end{array}$ & Wh $\%$ & Prob. & Contingency & $\%$ & Cost & Total Cost \\
\hline & & Contingency & & - & + & $\div$ & + & & . & & by Element \\
\hline 1.11 & DESIGN ENGINEERING TILE I \& II & $45,522,000$ & 10.14 & 15 & 30 & 1.52 & 3.04 & $2.587 \%$ & $5.95 \%$ & $11,611,807$ & $57,133,807$ \\
\hline 1.12 & TIILEIII INSPECTION & $11,381,000$ & 254 & 15 & 30 & 0.38 & 0.76 & $0.647 \%$ & $1.49 \%$ & $2,903,070$ & $14,284,078$ \\
\hline 12.1 & PROJECT MANAGEMENT & $31,866,000$ & 7.10 & 15 & 30 & 1.07 & 213 & 1.811\% & $4.16 \%$ & $8,128,418$ & $39,094,418$ \\
\hline 122 & CONSTRUCTION MANAGEMENT & $22,761,000$ & 5.07 & 15 & 30 & 0.76 & 1.52 & $1.293 \times$ & $2.97 \%$ & $6,805,903$ & $28,566,903$ \\
\hline 13.1 & GENERAL CONDITIONS & $4,041,905$ & 1.10 & 10 & 45 & 0.11 & 0.50 & $0.435 \%$ & $100 \%$ & $1,952,674$ & $6,894,579$ \\
\hline 132 & SITEWORK & $1,404,722$ & 0.31 & 5 & 60 & 0.02 & 0.19 & $0.167 \%$ & $0.38 \%$ & 750,160 & $2,151,882$ \\
\hline 1.3 .3 & CONCRETE & $15,205,905$ & 3.39 & 8 & 60 & 0.17 & 203 & $1.813 \%$ & $4.17 \%$ & $6,137,750$ & $23,343,655$ \\
\hline 1.34 & MASONRY & 0 & 0.00 & 5 & 45 & 0.00 & 0.00 & $0.000 \%$ & $0.00 \%$ & 0 & 0 \\
\hline 13.5 & METALS & $7,369,155$ & 1.64 & 5 & 60 & 0.08 & 0.99 & $0.878 \%$ & $202 \%$ & $3,943,754$ & $11,312,009$ \\
\hline 13.6 & WOOO \& PLASTICS & 0 & 0.00 & 5 & 30 & 0.00 & 0.00 & $0.000 \%$ & $0.00 \%$ & 0 & 0 \\
\hline 1.3 .7 & TMERMAL \& MOISTURE PROTECTON & $8,095,395$ & 1.14 & E & 60 & 0.06 & 0.68 & $0.607 \%$ & $1.40 \%$ & $2,726,904$ & $7,822,299$ \\
\hline 1.3 .8 & DOOAS \& WINDOWS & $4,779,638$ & 1.07 & 5 & 65 & 0.05 & 0.69 & $0.618 \%$ & $112 \%$ & $2,773,073$ & $7,552,711$ \\
\hline 1.3 .9 & FINISHES & $2,370,288$ & 0.53 & 5 & 50 & 0.03 & 0.26 & $0.235 \%$ & $0.54 \%$ & $1,055,114$ & $3,425,402$ \\
\hline 13.10 & SPECIALTIES & $27,134,488$ & 6.05 & 5 & 40 & 0.30 & 2.42 & $2146 \%$ & $404 \%$ & $9,635,811$ & $36,770,299$ \\
\hline 13.11 & EQUIPMENT & $70,722,791$ & 15.76 & 8 & 65 & 0.79 & 10.24 & $0.140 \%$ & $21.02 \%$ & $41,032,282$ & $111,755,073$ \\
\hline 13.12 & FURNISHINES & $2,152,136$ & 0.48 & 5 & 45 & 0.02 & 0.22 & $0.192 \%$ & $0.44 \%$ & 661,129 & $3,013,265$ \\
\hline 1.3 .13 & SPECIAL CONSTRUCTION & 0 & 0.00 & 5 & 45 & 0.00 & 0.00 & $0.000 \%$ & $0.00 \%$ & . &.$\quad 0$ \\
\hline 1.3 .14 & CONVEYING SYSTIEMS & 731,134 & 0.16 & 5 & 45 & 0.01 & 0.07 & $0.065 \%$ & $-0.15 \%$ & 292,667 & $1,024,101$ \\
\hline 1.3 .15 & MECHANICAL & $64,432,523$ & 14.36 & 5 & 65 & 0.72 & 0.33 & $8.327 \times$ & 19.15\% & $37,382,765$ & $101,815,288$ \\
\hline 13.16 & ELECTRICAL & $21,273,498$ & 4.74 & 5 & 65 & 0.24 & 3.08 & $2749 \%$ & $6.32 \%$ & $12,342,558$ & $33,616,056$ \\
\hline 1.4 .1 & GOVERNMENT FURNISHED EQUIP. & 0 & 0.00 & 5 & 45 & 0.00 & 0.00 & $0.000 \%$ & $0.00 \%$ & 0 & 0 \\
\hline 1.5 .1 & G\&APIF AODER & $13,681,389$ & 3.05 & 5 & 45 & 0.15 & 1.37 & $1.219 \%$ & $200 \%$ & $8,474,298$ & $19,155,687$ \\
\hline 1.52 & PROCUREMENT FEES & $2,276,109$ & 0.51 & 5 & 45 & 0.03 & 0.23 & $0.203 \%$ & $0.47 \%$ & 010,734 & $3,186,843$ \\
\hline & ESCALATION & $93,691,969$ & 20.88 & 5 & 45 & 1.04 & 9.39 & $8.351 x$ & $1920 \%$ & $37,488,775$ & $131,180,744$ \\
\hline & SUBTOTAL & $448,790,345$ & 100.00 & & & & & $43.483 \times$ & & & \\
\hline & CALCULATED CONTINGENCY & $195,147,454$ & & & & & & & & & \\
\hline & RESULTANT TEC & $643,937,799$ & & & & & & & & & \\
\hline & ROUNDED TEC & $644,000,000$ & & & & & & & & & \\
\hline & PROUECT CONTWGENCY & $195,209,655$ & & & & & & $43.50 \%$ & & & \\
\hline & MANAGEMENT RESERVE & $31,420,321$ & & & & & & & & & - \\
\hline & CONTINGENCY & $163,789,334$ & & & & & & & & & \\
\hline & TOTAL ESTIMATED COST & $644,000,000$ & & & & & & & & $105,209,655$ & $644,000,000$ \\
\hline
\end{tabular}

CONFIDENCE LEVE AND ASSUMED RISKS:

The Lockheed Idaho Tectinologies Co. Cost Estimate Contingency Analysis Model is based on the applied contingency and the assumptions upon which the estimate was predicated. The model is applied with a suggested risk level of $18 \%$ and a level of confidence of $90 \%$ the estimate will fall within the bid range. The Contingency Anatysis is based on a weighted average to provide a $90 \%$ probability of underrun and a $10 \%$ probability of overrun.
CONTINGENCY ANALYSIS GUIDE BY TYPE OF ESTIMATE

Guidelines established by DOEIFM 50, Cost Estimating Guide, Vol. 6 , Cost Guide, and as presented in the INEL Cost Estimating Guide. PLANNING $20 \%-30 \%$ Experimental/Special Conditions...........Up to 50\% Conceptual $15 \%-25 \%$ Experimental/Special Conditions............. Up to $40 \%$ TITLE I

TITLE II TITLE IVAFC
$10 \%-20 \%$

$5 \%-15 \%$ Market Conditions 


\section{G\&A/PIF ADDER CALCULATION SHEET}

\section{PROCUREMENT FEE:}

CONSTRUCTION $=$

$\$ 227,611,000$

GFE =

Subtotal

$\$ 227,611,000$

FEE $1 \%=$

$\$ 227,611,000 \cdot 0.01=$ $\$ 2,276,110$

G\&A $\bigcirc 23 \%$ (with a ceiling of $\$ 500,000$ imposed per year

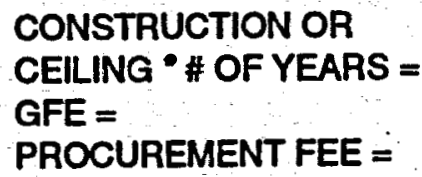

Subtotal

FEE @ 23\% =

$\$ 2,000,000$

$\$ 0$

$\$ 2,276,110$

$\$ 4,276,110$

$\$ 4,276,110 * 0.23=$
$\$ 983,505$

PIF $3.5 \%$

CONSTRUCTION $=$

GFE =

PROCUREMENT FEE $=$

G\&A =

FEE $5.5 \%=$
Subtotal
$\$ 227,611,000$

$\$ 2,276,110$

$\$ 983,505$

$\$ 230,870,615$

$\$ 12,697,884$

$\$ 2,276,110$

$\$ 983,505$

TOTAL G\&A FEE:

$\$ 12,697,884$

TOTAL PIF: 
Lockheed Martin Idaho Technologles Co. PAONECT NAME: HWO HIP FACILTY

OTHER PROJECT COSTS - ESC.

LOCATION i: REQUESTOR:

INEEUACPP

N. E. Russell
COST ESTIMATE SUMMARY

TYPE OF ESTIMATE: PLANNING

PROJECT NO: 24190

PREPARED EY: D. R. James

REPORT NAME: Cost Estimate Summary
27-Jan-1998

CHECKED BY:

APPAD BY:

\begin{tabular}{|c|c|c|c|c|}
\hline $\begin{array}{l}\text { WBS } \\
\text { Element }\end{array}$ & Cost Estimate Element $\quad-\quad$ & $\begin{array}{l}\text { Total } \\
\text { Unescalated }\end{array}$ & Escalation & $\begin{array}{l}\text { Total } \\
\text { Incl Escalation }\end{array}$ \\
\hline $\begin{array}{l}111 \\
1.1 .1 \\
1.2 .1 \\
1.3 \\
1.3 .1 \\
1.4 \\
1.4 .1 \\
\end{array}$ & $\begin{array}{l}\text { CONCEPTUAL } \\
\text { CONCEPTUAL DESIGN } \\
\text { MANAGEMENT } \\
\text { PM FOR PROUECT DEVELOPMENT } \\
\text { RERMITING } \\
\text { PERMTTING \& DOCUMENTATION } \\
\text { SOTEST \& STARTUP } \\
\text { SOTEST \& START-UP } \\
\text { PROCUREMENT FEES }\end{array}$ & $\begin{array}{r}131,881,000 \\
13,881,000 \\
2,904,000 \\
39,663,000 \\
0\end{array}$ & $\begin{array}{r}7,912,860 \\
4,025,490 \\
842,160 \\
2,379,780 \\
0\end{array}$ & $\begin{array}{r}p \frac{\$ 139,793,860}{139,793,860} \\
p>\frac{\$ 17906,490}{17,906,490} \\
p \quad \frac{\$ 3,746,160}{3,746,160} \\
\Rightarrow \quad \frac{\$ 42,042,780}{42,042,780} \\
\Rightarrow \quad \frac{\$ 0}{4}\end{array}$ \\
\hline$\because$ & $\begin{array}{l}\text { SUBTOTAL INCLUDING ESCALATION } \\
\text { PROJECT CONTINGENCY }\end{array}$ & $188,329,000$ & $15,160,290$ & $>>203,489,290$ \\
\hline & MANAGEMENT RESERVE & & & 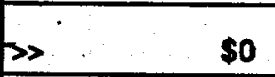 \\
\hline & CONTINGENCY & & 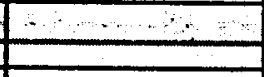 & $\gg \quad \$ 61,710,710$ \\
\hline$i$ & TOTAL ESTIMATED $\operatorname{cosT}$ & & & $\gg \$ 265,200,000$ \\
\hline
\end{tabular}

\section{PROJECT COST PARAMETERS}

EDI AS A \% OF CONST + GFE $=\%$ 
Lockheed Martin Idaho Technologles Co. Rov. 6-96

PRONECT NAME: HWO HIP FACILTY

LOCATION 1:

OTHER PROJECT COSTS - UNESC.

NEELICPP

REQUESTOR
COST ESTIMATE SUMMARY

TYPE OF ESTIMATE PLANNING PROVECT NO: 24190 PREPARED BY: D. R. James REPOAT NANE: Cost Estimate Summary
CHECKED BY

DATE 27 Jan-1998 08:45:410OA

APPROBY:

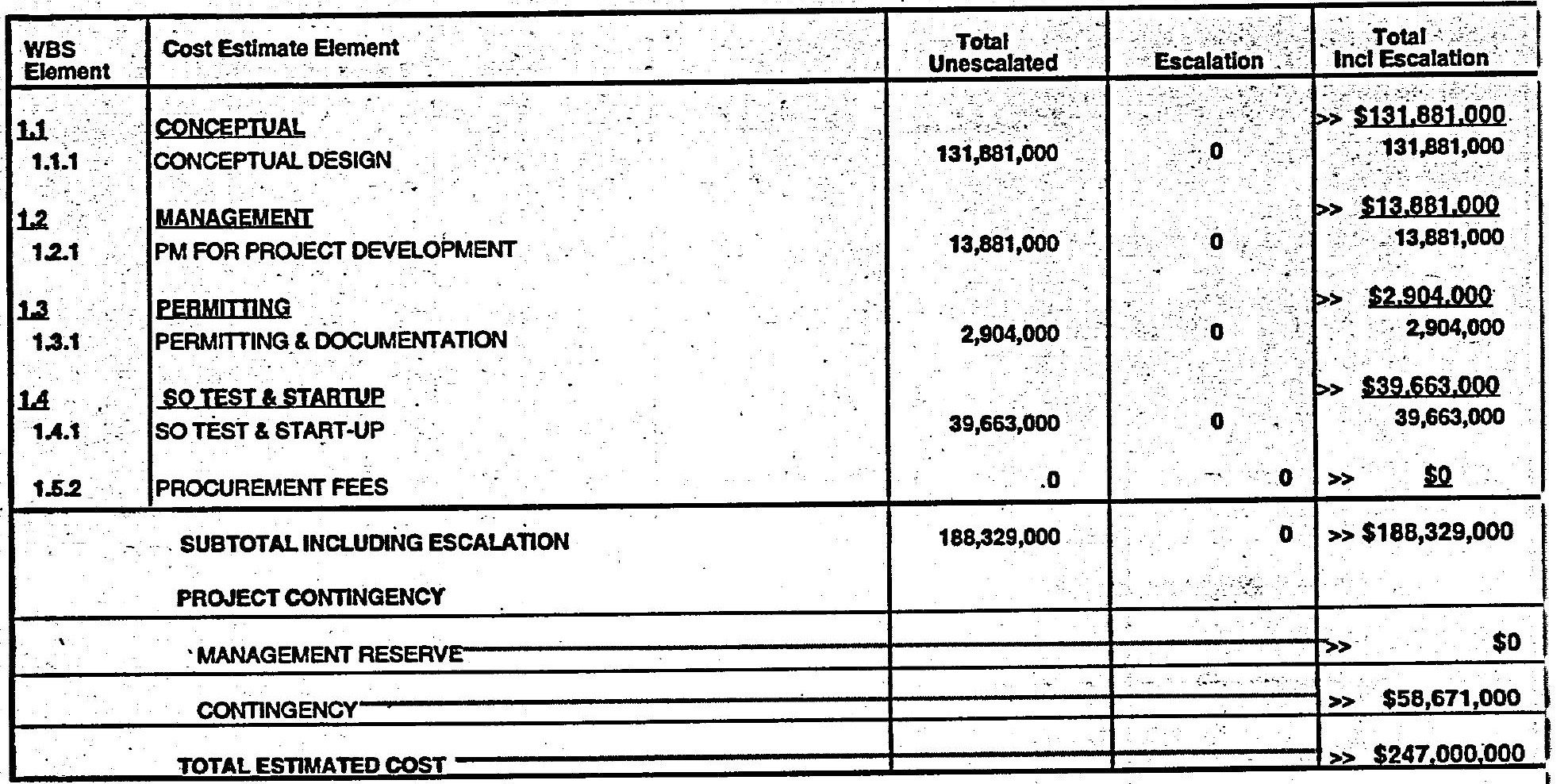

PRONECT COST PARAMETERS

EDI AS A \% OF CONST. + GFE $=" \because * \%$ 
Lockheed Martin Idaho Technologles Co. Rov 6-90

PAOJECT NAME: HWO HIP FACIUTYY OTHER PROJECT COSTS - ESC.

LOCATION 1: INEELICPP

REQUESTOR: N. E. Russell
DETAILED COST ESTIMATE SHEET

TYPE OF ESTMMATE PLANNING

PAOUECT NO: 24190

PAEPARED BY: D. R. James
PAGE 1

DATE 27Jan-1998

TIME: 08:18:16

REPORT NAME: Detail Cost Estimate Sheet

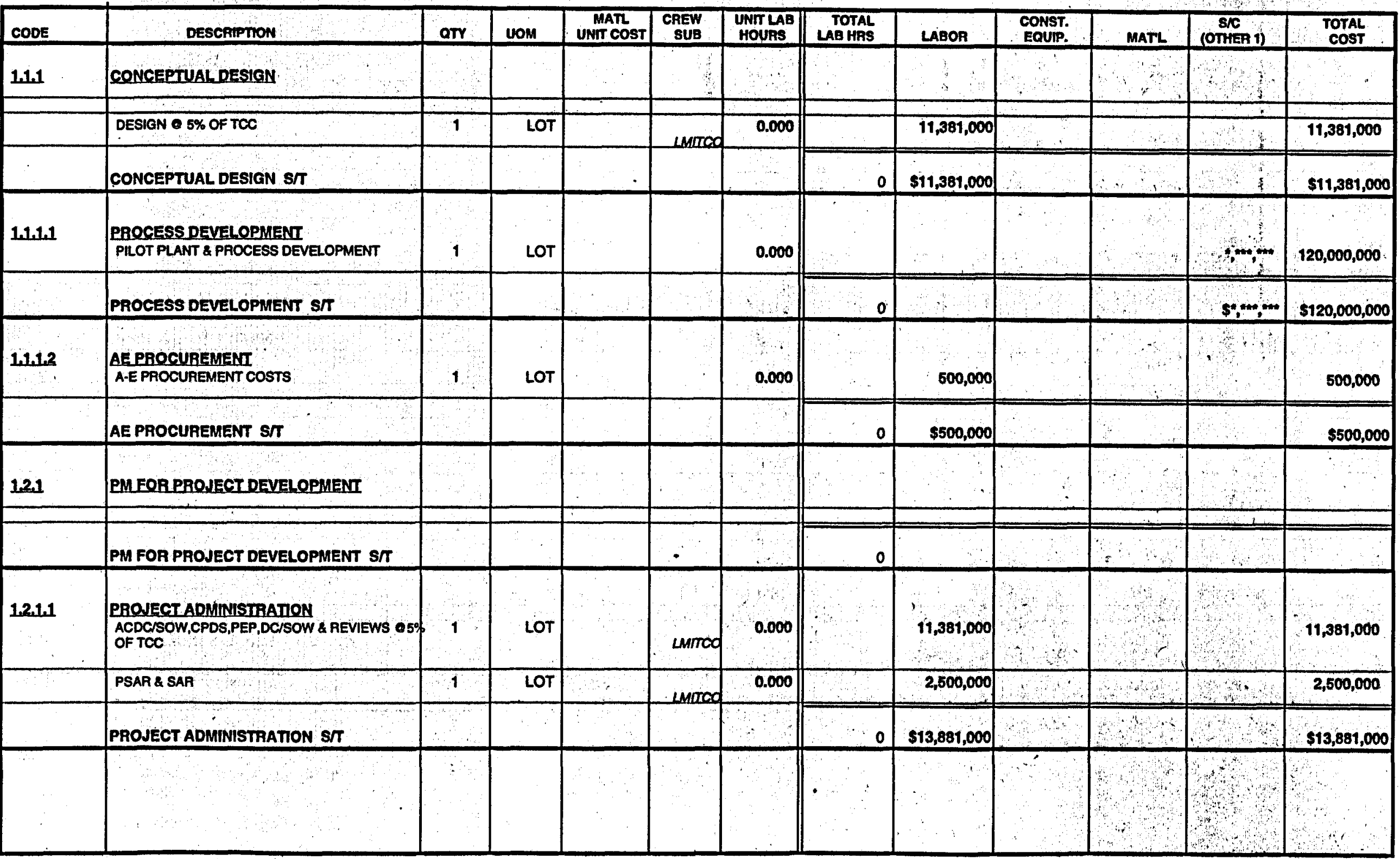


Lockheed Martin Idaho Technologles Co.

$$
\text { Rov 8-96. }
$$

PROUECT NAME: HWO HIP FACILITY

OTHER PROJECT COSTS - ESC.

LOCATION 1:

REOUESTOR: N. E. Russell
DETAILED COST ESTIMATE SHEET

TYPE OF ESTIMATE: PLANNING

PRONECT NO: 24190

PAEPARED BY: D. R. James
PAGE 2

DÁtE 27Jan-1998

TME: 08:18:16

AEPOAT NAME: Detall Cost Estimato Sheof

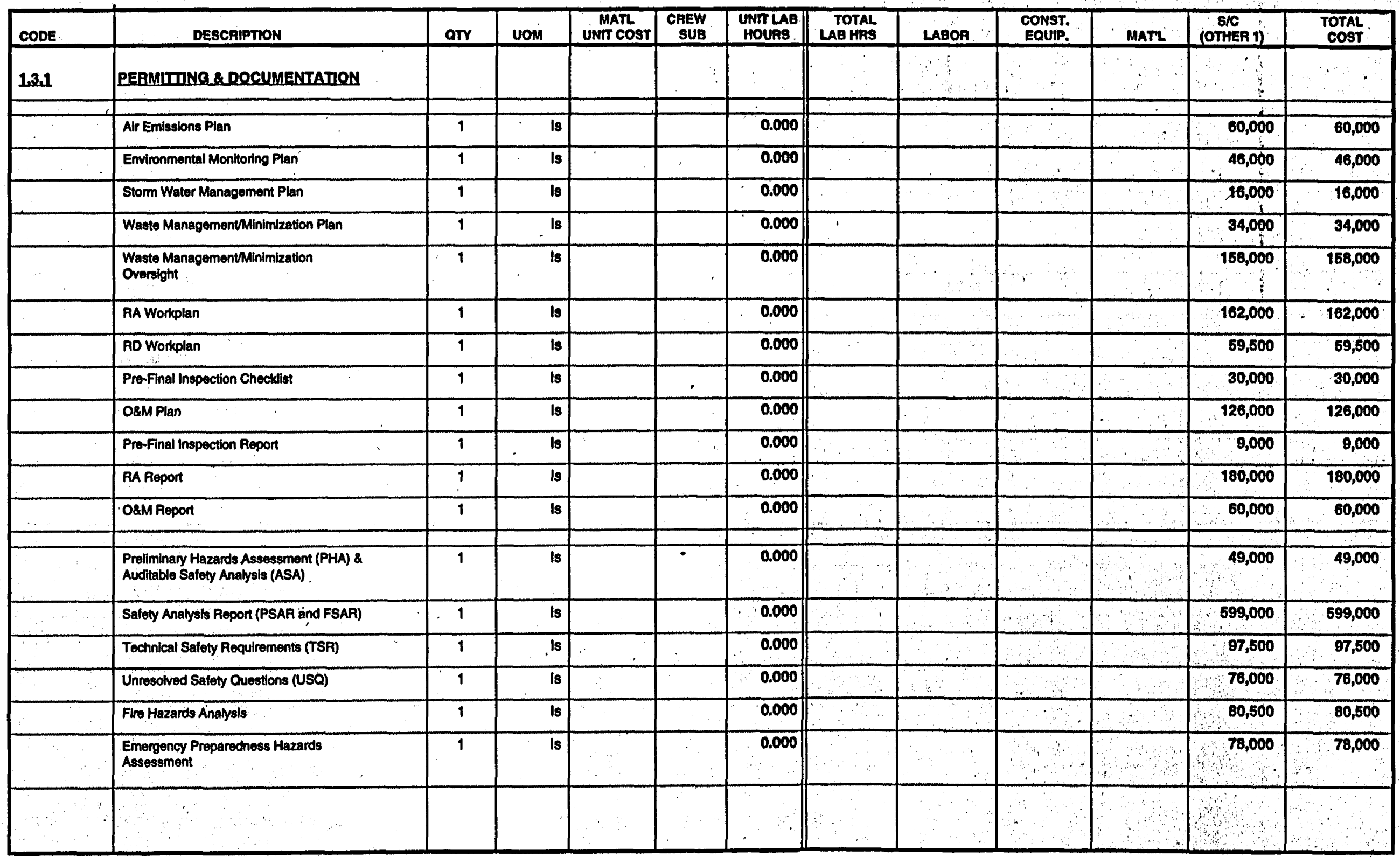


Lockheed Martin Idaho Technologles Co. Rov 6-90

PAONECT NAME: HWO HIP FACIUTY OTHER PROJECT COSTS - ESC.

LOCATION 1: INEELACPP

REQUESTOR: N. E. Russell

\section{DETAILED COST ESTIMATE SHEET}

TYPE OF ESTIMATE: PLANFING

PRONECT NO: 24190

PAEPARED BY: D. R. James
PAGE 3

DATE 27-Jan-1998

TME 08:18:16

REPOAT NAME: Detell Cost Estimate Sheet

\begin{tabular}{|c|c|c|c|c|c|c|c|c|c|c|c|c|}
\hline CODE & DESCRIPTION & aTy & vom & $\begin{array}{l}\text { MATR } \\
\text { UNIT Cost }\end{array}$ & $\begin{array}{l}\text { CREW } \\
\text { SUB } \\
\end{array}$ & $\begin{array}{l}\text { UNTTLAB } \\
\text { HOURS }\end{array}$ & $\begin{array}{l}\text { TOTAL } \\
\text { LAB HAS } \\
\end{array}$ & LABOA & $\begin{array}{l}\text { CONST. } \\
\text { EQUIP. }\end{array}$ & MATL & $\begin{array}{l}\text { S/C } \\
\text { (OTHER 1) }\end{array}$ & $\begin{array}{l}\text { TOTAL } \\
\text { COST }\end{array}$ \\
\hline \multirow[t]{3}{*}{1.3 .1} & $\begin{array}{l}\text { PERMiIIING \& DOCUMENTATION } \\
\text { Nuclear Criticality Saloty Program }\end{array}$ & 1 & Is. & & & 0.000 & & 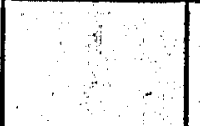 & & & 70,000 & 70,000 \\
\hline & Radiation Protectlon Program & 1 & is & & & 0.000 & & & & & 611,000 & 611,000 \\
\hline & $\begin{array}{l}\text { Industrial and Occupational Safety } \\
\text { Programs }\end{array}$ & 1 & is & & & 0.000 & & & & & 132,500 & 132,500 \\
\hline \multirow{4}{*}{\begin{tabular}{|l} 
\\
\\
\\
\\
\end{tabular}} & Emergency Plan & 1 & is & 1 & & 0.000 & & & & & 70,000 & 70,000 \\
\hline & Quality Program Plan & 1 & $=$ is & & & 0.000 & & & & & 100,000 & 100,000 \\
\hline & & & & & & & & & & & 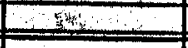 & \\
\hline & PEAMITTING \& DOCUMENTATION ST & & & & & & 0 & & & & $\$ 2,904,000$ & $\$ 2,904,000$ \\
\hline \multirow[t]{5}{*}{1.4 .1} & SQTEST \& STARTUP & & $\therefore$ & & & & & 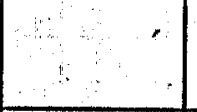 & & & & \\
\hline & & & & & & & & & & & & 8 \\
\hline & ORR & $\therefore 1$ & LOT & & & 0.000 & & $3,000,000$ & & $\because$ & $\therefore$ & $3,000,000$ \\
\hline & SO TEST \& TRAINING $3 \%$ OF TEC & 1 & LOT & & Lmired & 0.000 & & $16,152,000$ & & & & $16,152,000$ \\
\hline & SO TEST \& STARTUP S/T & & & & & & 0 & $\$ 19,152,000$ & & & $x$ & $\$ 19,152,000$ \\
\hline \multirow[t]{2}{*}{1.4 .1 .1 .1} & $\begin{array}{l}\text { PRQNECT SUPPORT } \\
\text { SUPPORT DURING DESIGN, CONSTRUCTION } \\
\text { STARTUP Q 4\% OF TEC }\end{array}$ & 1 & LOT & & LMrrod & 0.000 & & $20,511,000$ & & & & $20,511,000$ \\
\hline & PRONECT SUPPORT $\mathrm{s} / \mathrm{r}$ & $\because$ & & & & & 0 & $\$ 20,511,000$ & 3 & 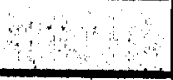 & +1 & $\$ 20,511,000$ \\
\hline & PRONECT SUBTOTAL & & & & & & & leg5 $195 \mathrm{~mm}$ & & 1 & & \\
\hline & $\begin{array}{lll} & \\
& & \end{array}$ & & & & & $*$ & & $\because$ & 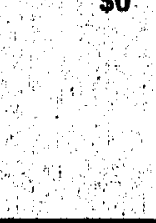 & 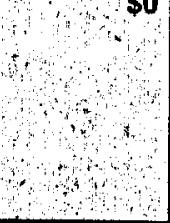 & 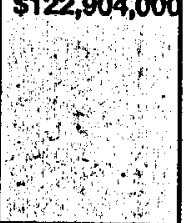 & 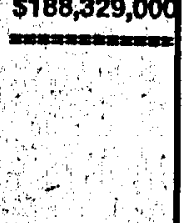 \\
\hline
\end{tabular}



Lockheed Martin Idaho Technologies Co.

PROVECT NAME: HWO HIP FACILTY OTHER PROJECT COSTS - UNESC.

LOCATION :: INEELCPP

RECUESTOR: N. E Russell

\section{CONTINGENCY ANALYSIS}

TYPE OF ESTMATE: PLANNING

PAONECT NO: 24190

PREPARED BY: D. R.James
DATE - 27- 1998

TME: 08:45:53

REPOFT NAME: Contingency Analysis

$+2$

PROBABLE \% VARIATION

\begin{tabular}{|c|c|c|c|c|c|c|c|c|c|c|c|}
\hline $\begin{array}{l}\text { WBS } \\
\text { Element }\end{array}$ & Cost Estimate Eement & Total Cost wo & $\begin{array}{l}\text { * Total } \\
\text { Cost }\end{array}$ & & $\begin{array}{l}\text { KV Var. } \\
\text { om Est. }\end{array}$ & Wt. $\%$ & ob. & Contingency & & 8 & Total cast \\
\hline$-\cdots$ & -4 & Contingency & & - & + & - & + & a & 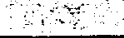 & & \\
\hline 1.1 .1 & CONCEPTUALDESIGN & $131,881,000$ & 70.03 & 5 & $.35 \cdots$ & 350 & 24.51 & $21.708 \%$ & $70.01 \%$ & $41,074,095$ & $172,955,898$ \\
\hline 121 & PM FOR PRQUECT DEVELOPMENT & $13,881,000$ & 737 & 5 & 35 & 0.97 & 2.58 & $2285 \%$ & $737 \%$ & $4,323,296$ & $18,204,296$ \\
\hline $13.1 \div$ & PERMTTING \& DOCUMENTATION & $-2,904,000$ & 154 & 0 & 35 & $0.00 \mathrm{x}$ & 0.54 & $0.486 \%$ & $157 \%$ & 919,051 & $\therefore 3,823,051$ \\
\hline 1.4 & SO TEST \& STAFTUP & $39,663,000$ & 21.06 & 5 & 35 & 1.05 & 737 & $6.529 \%$ & $21.06 \%$ & $12,353,209$ & $52,016,209$ \\
\hline 1.52 & PROCUREMENT FEES & $\therefore \quad 0^{\circ}$ & 0.00 & $\theta$ & 30 & 0.00 & 0.00 & $0.000 \%$ & $0.00 \%$ & 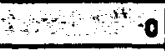 & 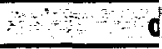 \\
\hline$=$ & ESCALATION & 0 & $0.00^{\circ}$ & 5 & 25 & 0.00 & 0.00 & $0.000 \%$ & $\therefore 0.00 \%$ & 549 & \\
\hline & suatotal & $188,329,000$ & 100.00 & & 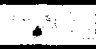 & & & $31.008 \%$ & 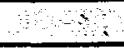 & & 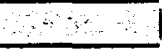 \\
\hline$\because$ & CALCULATÉ CONTWGENCY. & $58,396,510$ & $\therefore$ & & 8 & & $\because$ & & 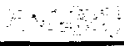 & & \\
\hline & RESULTANT TEC & $246,725,510$ & & & & & $\therefore$ & & 6 & & \\
\hline$\therefore$ & ROUNDED TEC & $247,000,000$ & & & $\therefore$ & $\cdots$ & & $\because$ & & $\%$ & $\because-$ \\
\hline & PROVECT CONTINGENCY & $58,671,000$ & $\because$ & & 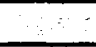 & $\therefore \ldots$ & & $31.15 \%$ & 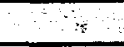 & $\because$ & . \\
\hline & MANAGEMENT RESERVE & 0 & & & & & & & $\because$ & & $\therefore$ \\
\hline & CONTINGENCY & $88,671,000$ & & & & & & & $\therefore \ldots$ & & \\
\hline. & $\therefore$ TOTAL ESTILATED COST & $247,000,000$ & & & & & & & & $58,677,000$ & $247,000,00$ \\
\hline
\end{tabular}

CONFIDENCE LEVEL AND ASSUMED RISKS:

The Lockheed Idaho Technologies Co. Cost Estimate Contingency Analysis Model is based on the applied contingency and the assumptions upon which the estimate was predicated. The model is applied. with a suggested risk level of $18 \%$ and a level of confidence of $90 \%$ the estimate will fall within the bid range.

The Contingency Analysis is based on a weighted average to provide a

$90 \%$ probability of underrun and a $10 \%$ probability of overnun.
CONTINGENCY ANALYSIS GUIDE BY TYPE OF ESTIMATE Guidelines established by DOE/FM 50, Cost Estimating Guide, Vol. 6 Cost Guide, and as presented in the INEL Cost Estimating Guide. PLANNING Conceptual

Experimental/Special Conditions. $15 \%$ up to $40 \%$

TITLE!

TITLE II

TITLE II/AFC
$10 \%$... $40 \%$

$5 \%-15 \%$

Market Conditions 
Lockheed Martin Idaho Technologles Co.

PROVECT NAME: HWO HIP FACILTY

LOCATION 1: INEEI RCPP

REQUESTOR: N. E. RuSSEll
CONTINGENCY ANALYSIS

TYPE OF ESTIMATE: PLANNING
PROAECT NO: 24190
PREPARED BY: D. R. James

DATE $27-$ Jan-1998

TIME: 08:17:39

REPORT NAME: Contingency Analysis

\begin{tabular}{|c|c|c|c|c|c|c|c|c|c|c|c|}
\hline \multicolumn{4}{|c|}{ PROBABLE \% VARIATION } & \multicolumn{5}{|c|}{ ( } & \multicolumn{2}{|c|}{$\begin{array}{l}\text { PRONECT } \\
\text { CONTINGENCY }\end{array}$} & \multirow{3}{*}{$\begin{array}{l}\text { SUMMARY } \\
\text { Total Cost } \\
\text { by Element }\end{array}$} \\
\hline \multirow[t]{2}{*}{$\begin{array}{l}\text { WBS } \\
\text { Element }\end{array}$} & \multirow{2}{*}{ Cost Estimate Element } & \multirow{2}{*}{$\begin{array}{l}\text { Total Cost w/o } \\
\text { Contingency }\end{array}$} & \multirow[t]{2}{*}{$\begin{array}{c}\text { \%Total } \\
\text { Cost }\end{array}$} & \multicolumn{2}{|c|}{$\begin{array}{l}\text { Prob. } \% \text { Var. } \\
\text { From Est. }\end{array}$} & \multicolumn{2}{|c|}{ Wt $\%$ of Prob. } & \multirow[t]{2}{*}{ Contingency } & \multirow{2}{*}{$\%$} & \multirow[t]{2}{*}{ Cost $=$} & \\
\hline & & & & - & + & - & + & & & & \\
\hline 1.t.1 & CONCEPTUAL DESIGN & $131,081,000$ & 64,81 & 8 & 35 & 324 & 22.68 & $\mid 20.091 \%$ & $66.14 \%$ & $40,814,834$ & $172,695,834$ \\
\hline 12.1 & PM FOR PROAECT DEVELOPMENT & $13,881,000$ & 6.02 & 5 & 35 & 0.34 & 2.39 & $2115 \%$ & $6.96 \%$ & $4,295,024$ & $18,176,924$ \\
\hline 131 & PERMITIING \& DOCUMENTATION & $2,904,000$ & 1.43 & 0 & 35 & 0.00 & 0.50 & $0.450 \%$ & $1.48 \%$ & 913,232 & $3,817,232$ \\
\hline 1.4 .1 & SO TEST \& START-UP & $39,663,000$ & 18.49 & 5 & 35 & 0.97 & 6.02 & $6.042 \%$ & $10.89 \%$ & $12,274,996$ & $51,937,996$ \\
\hline 1.5 .2 & PROCUREMENT FEES & 20 & 0.00 & 0 & 30 & 0.00 & 0.00 & $0.000 \%$ & $0.00 \%$ & 50 & 8,0 \\
\hline$\cdots$ & ESCALATKON & $15,160,290$ & 7.45 & 5 & 25 & 0.37 & 1.86 & $1.639 \%$ & $5.10 \%$ & $3,411,724$ & $18,572,014$ \\
\hline & SUBTOTAL & $203,489,290$ & 100.00 & & $\because$ & & & $30.337 \%$ & . & & 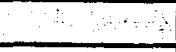 \\
\hline & CALCULATED CONTINGENCY & $61,731,774$ & & & & $\therefore$ & $\therefore$ & $8+2$ & $4 x$ & & \\
\hline$\therefore$ & RESULTANT TEC & $265,221,064$ & & & & & & & $\therefore \cdots$ & & 8 \\
\hline & ROUNDED TEC & $265,200,000$ & & & & & & $\because$ & & & ? \\
\hline & PRONECT CONTINGENCY & $61,710,710$ & & 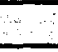 & & $\therefore$ & & $30.33 \%$ & . & - & \\
\hline & MANAGEMENT RESERVE & 0 & & & & & & & & & \\
\hline & CONTINGENCY & $61,710,710$ & & & & & & & & & \\
\hline & TOTAL ESTIMATED COST & $265,200,000$ & & & & & & & & $61,710,710$ &, 000 \\
\hline
\end{tabular}

CONFIDENCE LEVEL AND ASSUMED RISKS:

The Lockheed Idaho Technologies Co. Cost Estimate Contingency Analysis Model is based on the applied contingency and the essumptions upon which the estimate was predicated. The model is applied with a suggested risk level of $18 \%$ and a level of confidence of $90 \%$ the estimate will fall within the bid range. The contingency Analysis is based on a weighted average to provide a $90 \%$ probability of underrun and a $10 \%$ probability of overrun.
CONTINGENCY ANALYSIS GUIDE BY TYPE OF ESTIMATE

Guidelines established by DOE/FM 50, Cost Estimating Guide,Vol. 6. Cost Guide, and as presented in the INEL Cost Estimating Guide.

PLANNING

Experimental/Special Conditions $20 \%-30 \%$ Conceptual

Experimentalspecial Conditions $15 \%-25 \%$ TITLE :

TITLE ॥

TITLE IIAFC
U... Up to $40 \%$

$10 \%-20 \%$
$5 \%-15 \%$

Market Conditions 
Date: January 30, 1998

To: $\quad$ Neal E. Russell $\quad$ MS $3765 \quad 6-8619$

From: R. J.Turk Refent MS 3875 6-3611

Subject: $\quad$ ECONOMIC AND LIFE CYCLE ANALYSIS CONDUCTED for the HOT ISOSTATIC PRESSING (HIP) WASTE OPTION-R IT-10-98

Purpose:

As requested an Economic and Life-Cycle Cost (LCC) has been conducted to evaluate for the HOT ISOSTATIC PRESSING (HIP) WASTE OPTION. This facility will accept all raw calcined waste, or other solid waste to convert to a glass-ceramic waste form, cast into a HIP can, then placing three cans into an SRS-Type canister. The canisters will be sent to an interim storage facility until transport to final disposition.

This economic analysis is based on information provided by S. Gifford, D. Taylor, A. Pinto, S. Alstad and other team members. D. James and R. Adams provided cost estimates. J. Prendergast provided process personnel modeling.

\section{Methodology:}

The Economic Evaluation assumed a 36-year period (2001-2036) since this is the estimated time required to complete all of the anticipated remediation activities. The LCC identifies evaluated the initial development, construction, operation and post operation costs over the life-cycle. A discounted LCC analysis assumes a current-dollar basis, discounted to 1998 using a discount rate of 6.30\% per the Office of Management and Budget (OMB) Circular A-94. All costs are conservatively discounted assuming the end-of-year convention.

\section{Assumptions:}

The scope of work and requirements of all related activities are vague at this time. Facility and processing costs were developed from historical experience associated with DD\&D work at the INEEL. The LCC analysis was generated to match cost estimating cost structure. These costs include Permitting, Direct and Indirect Construction, G\&A, Procurement Fee, Engineering, 
N. E. Russell

January 30, 1998

RJT 10-98-Rev.3

Page 2

Inspection, Project Management, Construction Management, Escalation and Contingency costs.

The design period is assumed to be accomplished in four years with construction completed in four years. Labor rates were assumed as follows: Managers, \$125/hr; Engineers, \$108 \$/hr; Other Technicians \$ 85/hr; Administration/support staff \$ 65/hr; Operators and Maintenance personnel $\$ 65 / \mathrm{hr}$. The operational period for this facility was assumed to be twenty years, followed by three years of post-operations activities. Due to this projects lack of complexity and relative cleanliness this analysis assumed a decommissioning cost equal to $20 \%$ of the engineering design cost, decontamination costs equal to $5 \%$ of total pre-operation cost, and demolition costs equal to $8 \%$ of total pre-operation cost. Utilities calculated assuming a S.0824per $\mathrm{kWh}$. Procurement costs for HIP cans $\$ 2,500$ each and SRS Canisters at $\$ 10,000$ each. Material blending costs were developed by several sources to cost as follows: Amorphous Silica Frit $\$ 1.00 / \mathrm{kg}$ and Titanium $\$ 22.00 / \mathrm{kg}$.

Results:

The HOT ISOSTATIC PRESSING (HIP) WASTE OPTION has a Discounted LCC of $\$ 1.106$ billion.

Attachments:

cc: R. J. Turk File 


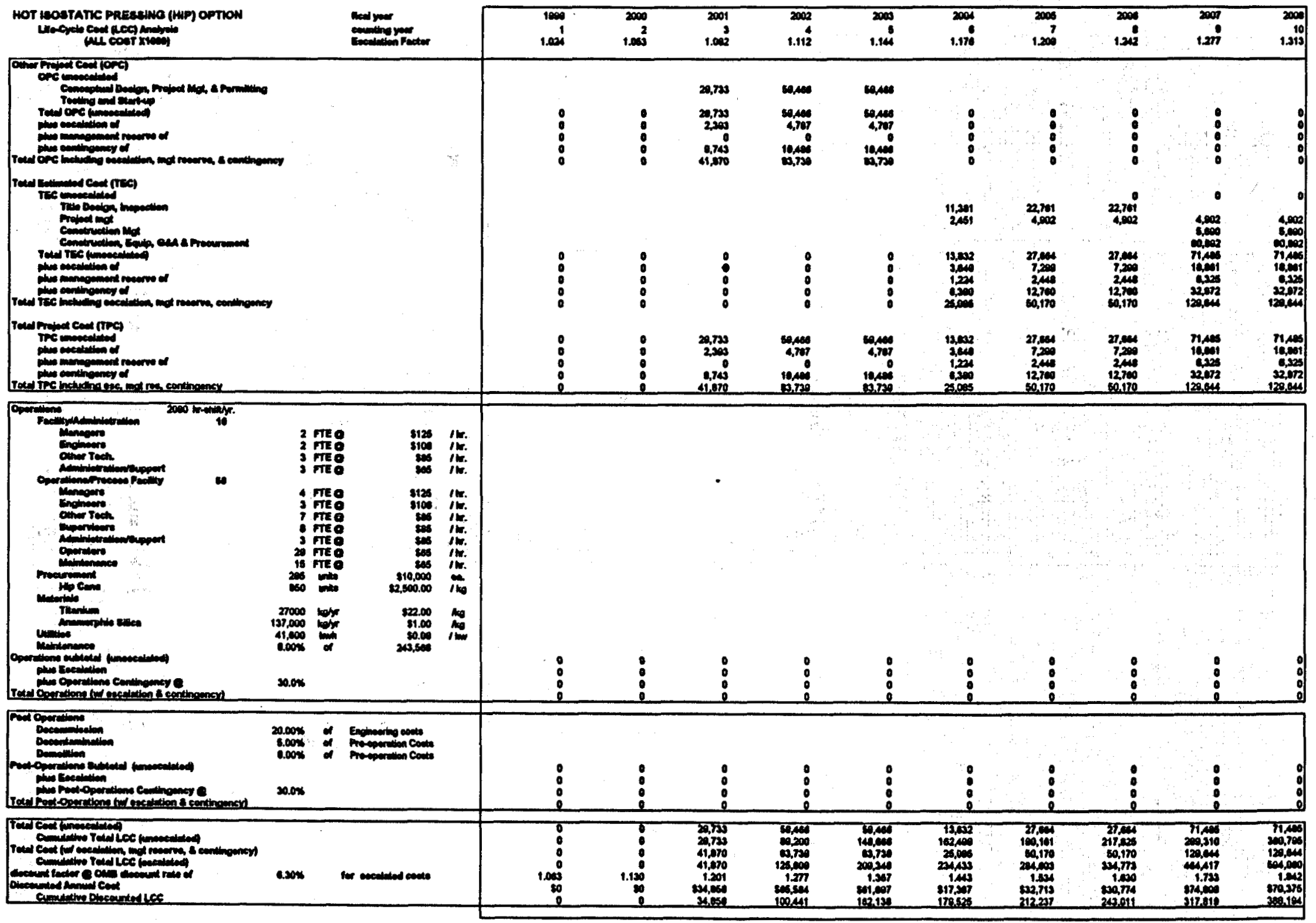

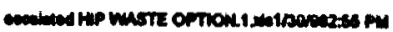




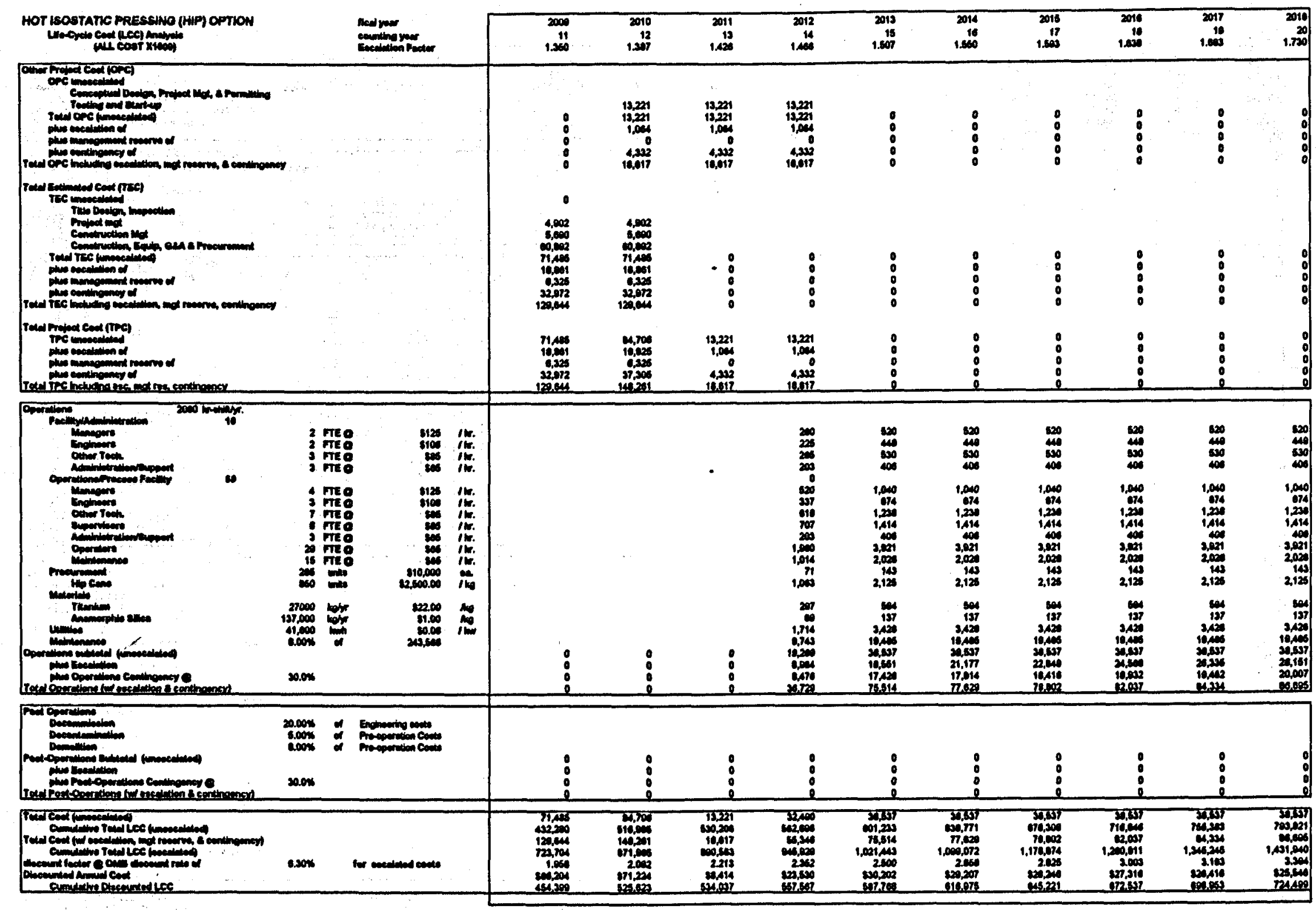




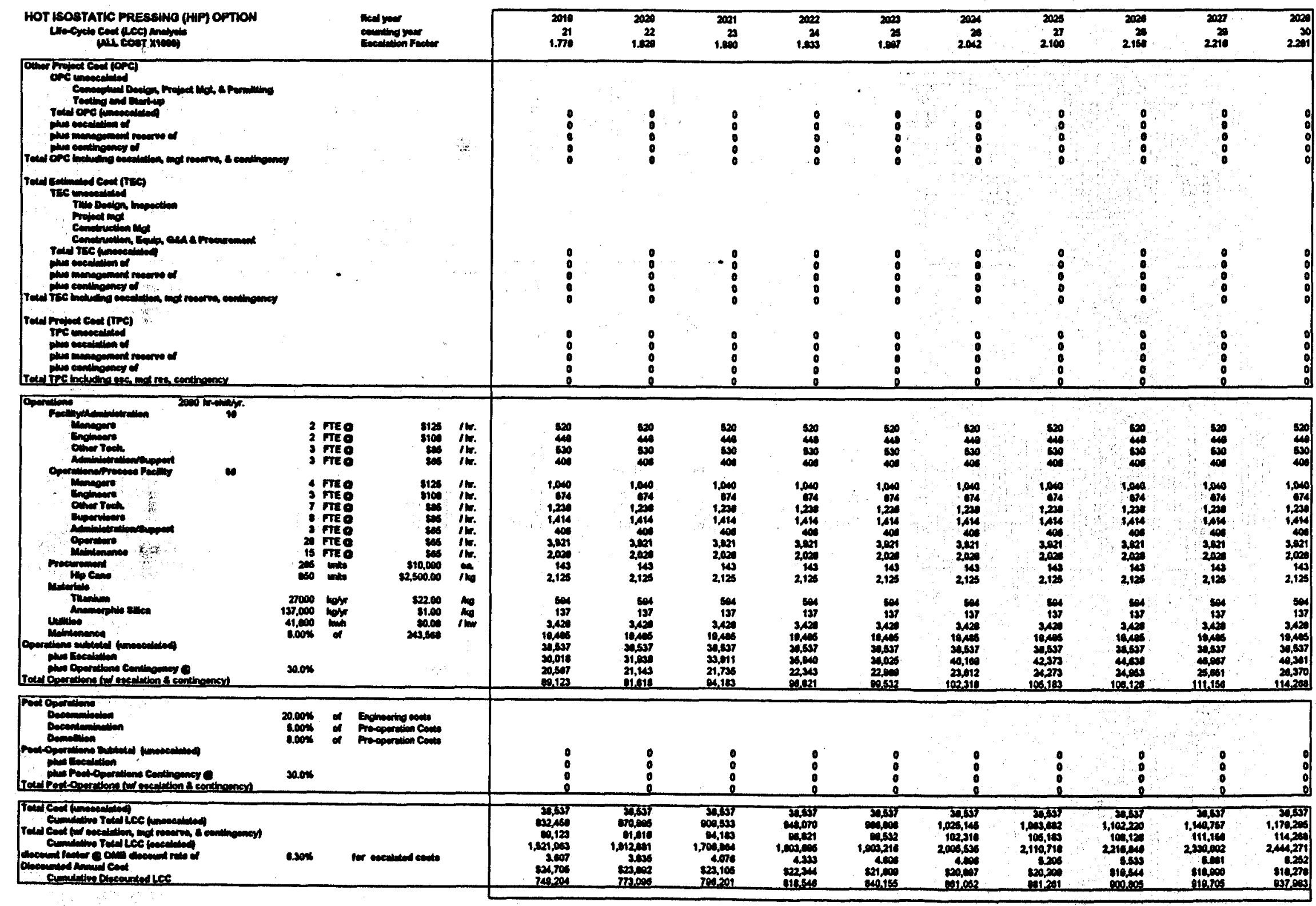




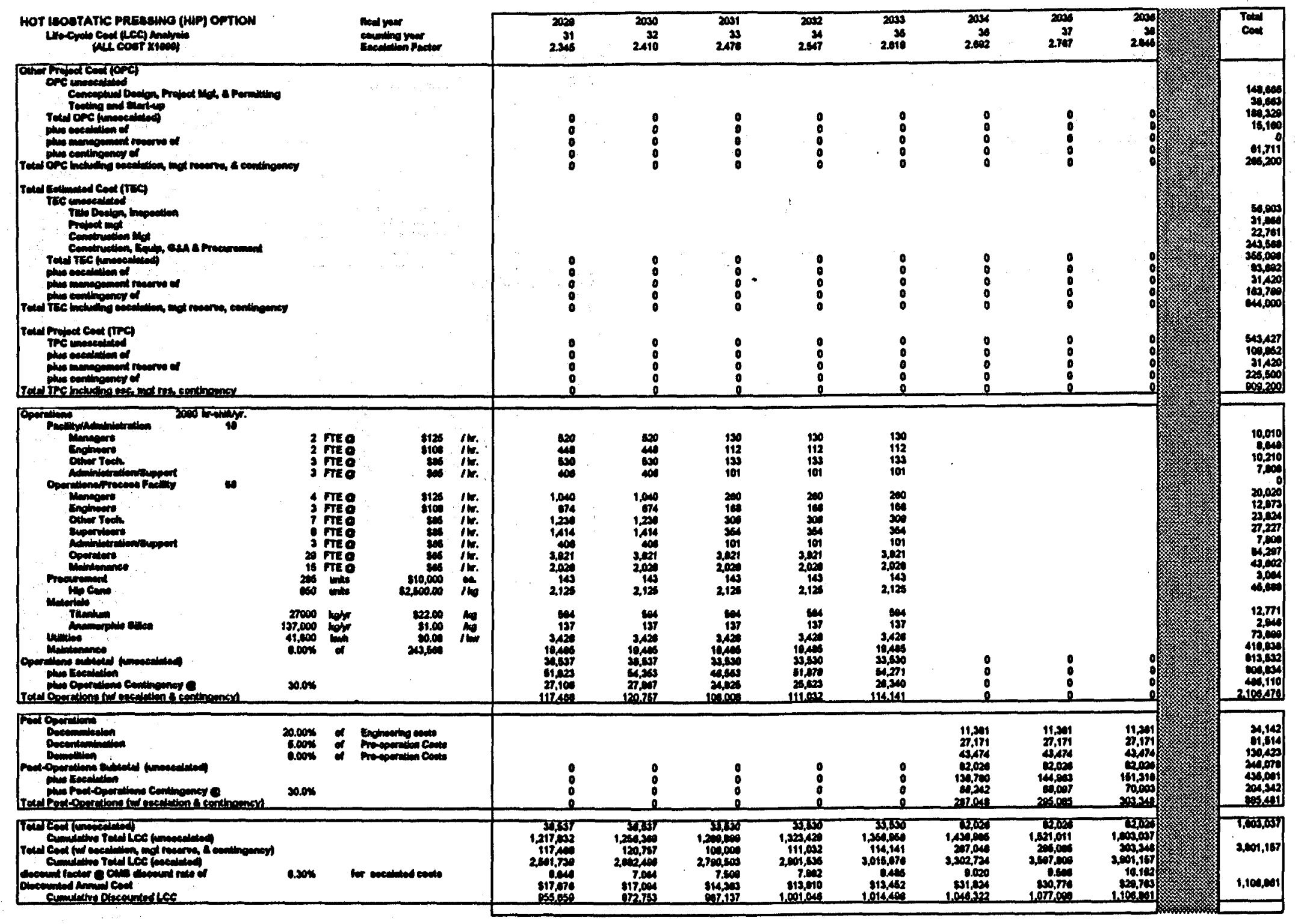




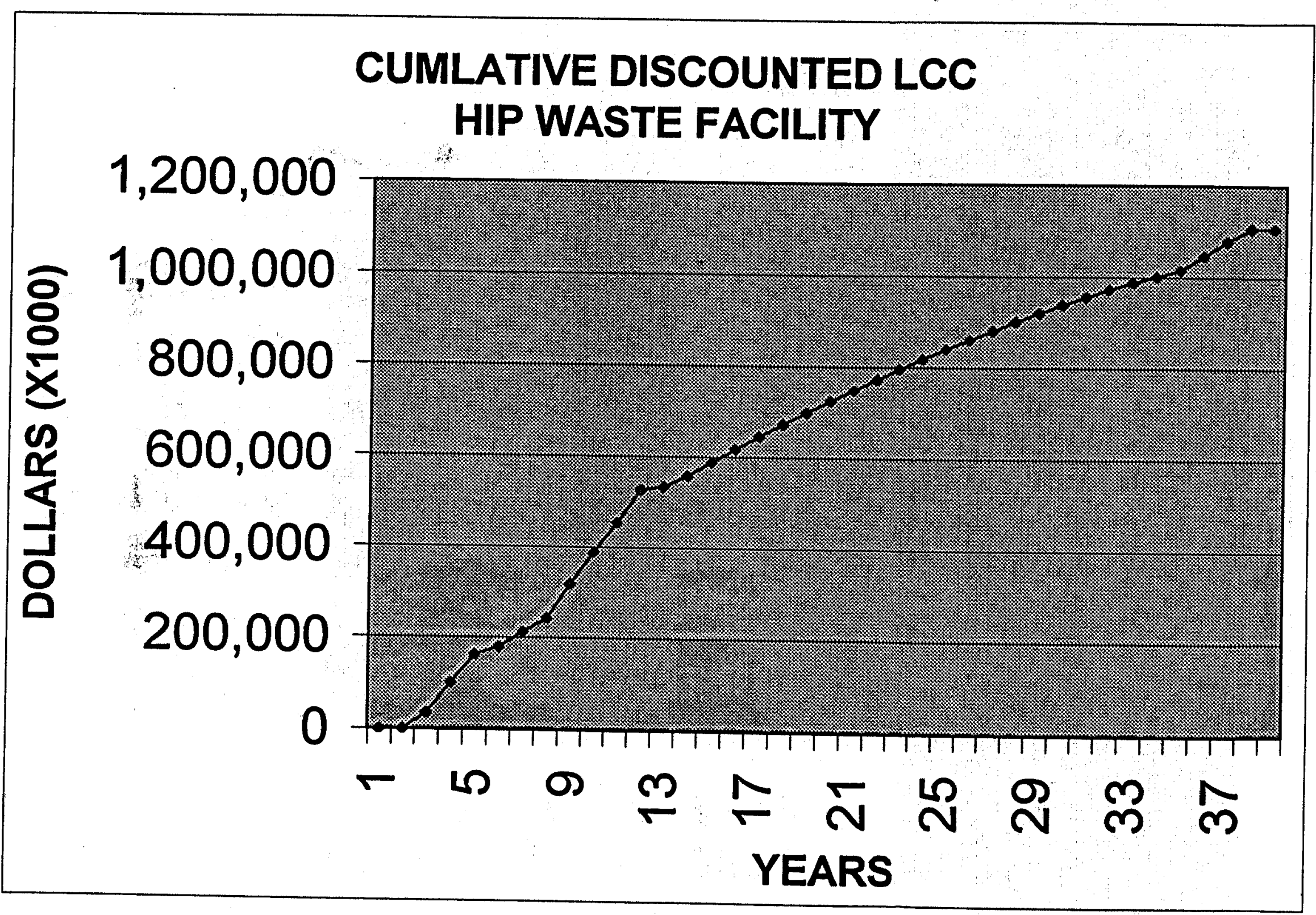




\section{TOTAL ANNUAL COST (escalated) HIP WASTE FACILTY}

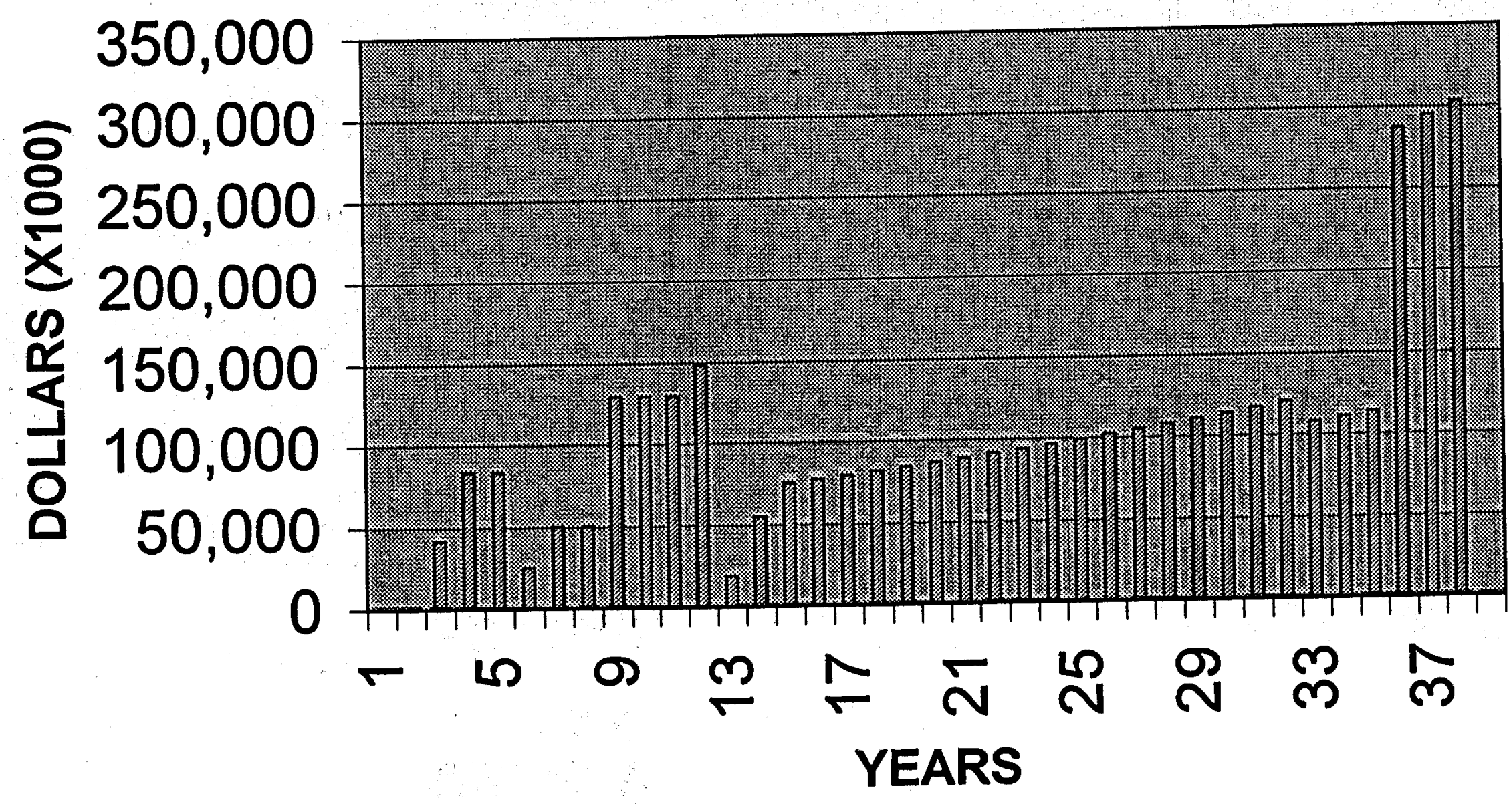


HIP OPTION

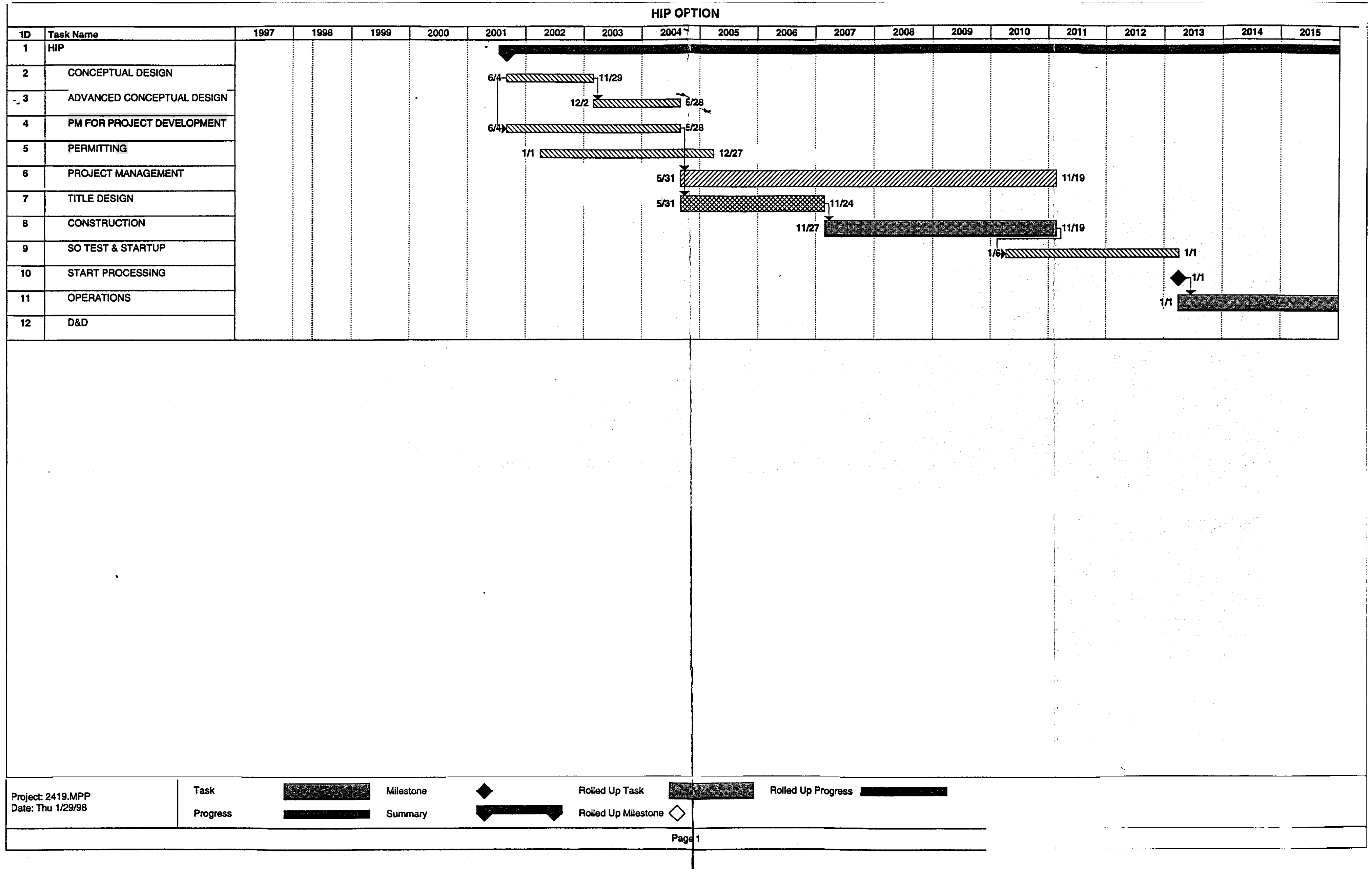




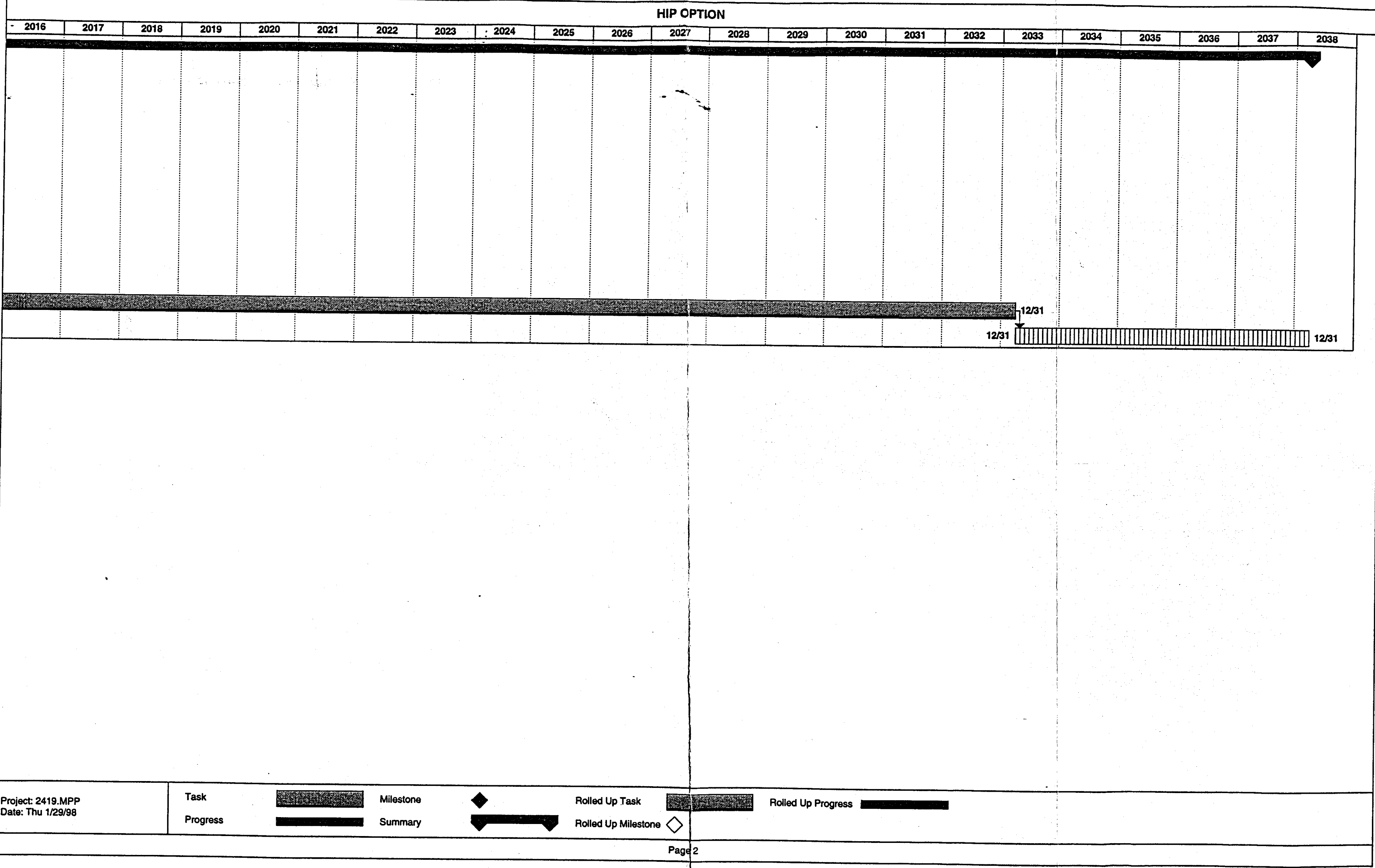




\section{Appendix E \\ Backup Information for Project Data Sheet}




\section{Introduction to Project Data Sheet Backup Information}

This Appendix provides the backup information for the project data sheet, Section [TBD]. The information is divided into five parts:

- Construction estimates and assumptions

- Operations estimates and assumptions

- D\&D labor estimates

- Other D\&D estimates and assumptions

- Diesel emission estimates for construction, operations, and D\&D

Cost information presented in the data sheet comes directly from the capital and life cycle cost estimates in Appendix D. 


\begin{tabular}{|c|c|c|c|c|c|c|c|}
\hline Construction duration = & 4 & years & & & & & \\
\hline SO testing = & 3 & years & & & & & \\
\hline Total years $=$ & & Lone year of overk & ap... see life cycle a & ost estimater & & & \\
\hline Labor - use a total of & 100 & new workers/yr & & & & & \\
\hline from Dan James & & & & & & & \\
\hline Sanitary Wastewater = & 562,500 & gal/yr $=$ & $12,774,375$ & liters (total) & & & \\
\hline (based on 25 gal/person-day and 2 & 25 days/year of con & istruction) & & & & & \\
\hline $\begin{array}{l}\text { Biological Process Design for } \\
\text { Wastewater Treatment, InPrint, }\end{array}$ & & & & & & & \\
\hline & & & & & & & \\
\hline Water used for dust control = & 2000 & gal/wk = & 605,600 & liters (total) & & & \\
\hline (assumes dust control required 20 & weeks/yr...R. Kimmit & & & & & & \\
\hline & & & & & & & \\
\hline Electrical usage assumed to be 3,00 & $0 \mathrm{kWh}$ from John D & Juggan) & & & & & \\
\hline 156 & MWhis & & & & & & \\
\hline $\begin{array}{l}\text { Assume } 3 \text { gallons of lubricating oil } \\
\text { and hydraulic fluid generated for } \\
\text { every } 60 \text { hours of operation of } \\
\text { heavy equipment = }\end{array}$ & & & & 1,417 & liters (total) & & \\
\hline & & & & & & & \\
\hline Square footage $=$ & 208,249 & isq.ft I & 19,347 & $\mathrm{~m}^{2}$ & & & \\
\hline (Stephanie Austed, 1/12/98). & & & & & & & \\
\hline & & & & & & & \\
\hline Acres disturbed $=$ & 161,170 & sq.ft. $=$ & 14,973 & $m^{2}=$ & 3.7 & acres (previ & ous) \\
\hline (Stephenie Austed, 1/12/98) & & 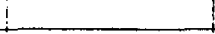 & & & & & \\
\hline & & 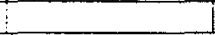 & & & & & \\
\hline Heary equipment = & 3 vehicles @ $624 \mathrm{~h}$ & hrs/yr during constr & uction $=$ & 7,488 & hrs total & & \\
\hline Equipment fuel usage (see http://hn & ww/deere.com/ind) & $E$ & & 6 & $\mathrm{gal} / \mathrm{hr}$ & & \\
\hline Total heavy equipment fuel usage = & & 44928 & gal $=$ & 170,052 & liters (total) & & \\
\hline & & & & & & & \\
\hline Dust during construction $=1.2$ lons & s/month-acre $=$ & & 213 & tons (total) & & & \\
\hline (from USEPA Office of Ar Quality Pla & unning and Standards & & & & & & \\
\hline & & & & & & & \\
\hline Construction costs are from life cycl & e cost estimate (R. T) & Turk) & & & & & \\
\hline & & & & & & & \\
\hline Air emissions from fuel usage are ba & sed on the diesel em & nissions spreadshee & & & & & \\
\hline & Ti & I & & & & & \\
\hline Air emissions during SO \& start-up t & esting are based on & non-radioactive ope & erations for 3 years: & & & & \\
\hline Flow rate $=$ & 11,632 & $1 \mathrm{bs} / \mathrm{yr}=$ & 17 & tons (total) & & & \\
\hline (based on 1 sctm, 24 hours/day for & 100 days $(y r)$ & & & & & & \\
\hline & & & & & & & \\
\hline Construction trash = & 6,200 & $y d 3$ (total) $=$ & & 4,742 & $m^{3}$ (total) & & \\
\hline (Use $15.5 \mathrm{yd} 3 / \mathrm{y}$ per capita. This is & twice the generation & in rate of trash from & site operations) & & & & \\
\hline & & & & & & & \\
\hline Hazardous waste generation = & 275 & gal/week = & & 217 & $m^{3}$ (total) & & \\
\hline $\begin{array}{l}\text { rate of } 5 \text { 55-gallon drums of waste } \\
\text { per week, } 52 \text { weeks } / y \text { r, and } 4\end{array}$ & & $i$ & & $\therefore$ & & & \\
\hline & & & & & 1 & & \\
\hline Hazardous waste storage $=$ & 3300 & $g a l=$ & 13 & $m^{3}$ & & & \\
\hline $\begin{array}{l}12 \text { weeks [ } 84 \text { days] in a } 90-d a y \\
\text { accumulation area, then picked up }\end{array}$ & & & & & & & \\
\hline & & 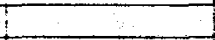 & & & & & \\
\hline 1 man-year of labor $=$ & $1800 !$ & manhours & & & & & \\
\hline & & & & & & & \\
\hline SO testing liquid effluent = & $81,360,000$ & gallons total = & & $307,947,600$ & liters (total) & & \\
\hline (based on $452 \mathrm{gpm}$ for 10 hours/da) & $y, 100$ days/yr, and $s$ & 3 years... see EDF & F-HWO-012) & & & & \\
\hline & & & & & 1 & & 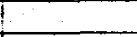 \\
\hline Hazardous waste (SO testing) $=$ & & & $\mathrm{m}^{3}$ (total) & & & & \\
\hline (based on an assumed 50 cu.ft. of & spent activated carbc & on/yr) & & & & & \\
\hline & & $!$ & & & & & \\
\hline SO testing process water usage $=8$ & ame as process wate & ter effluent (once th & rough cooling water) & & & & \\
\hline & & & & & 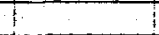 & & \\
\hline Excavation: Excavated earth will be s & pread in a spoil area & a adjacent to ICPP, & except for backfill so & & & & \\
\hline & & & & & 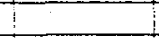 & & \\
\hline Concrete: & & & & & & & \\
\hline
\end{tabular}




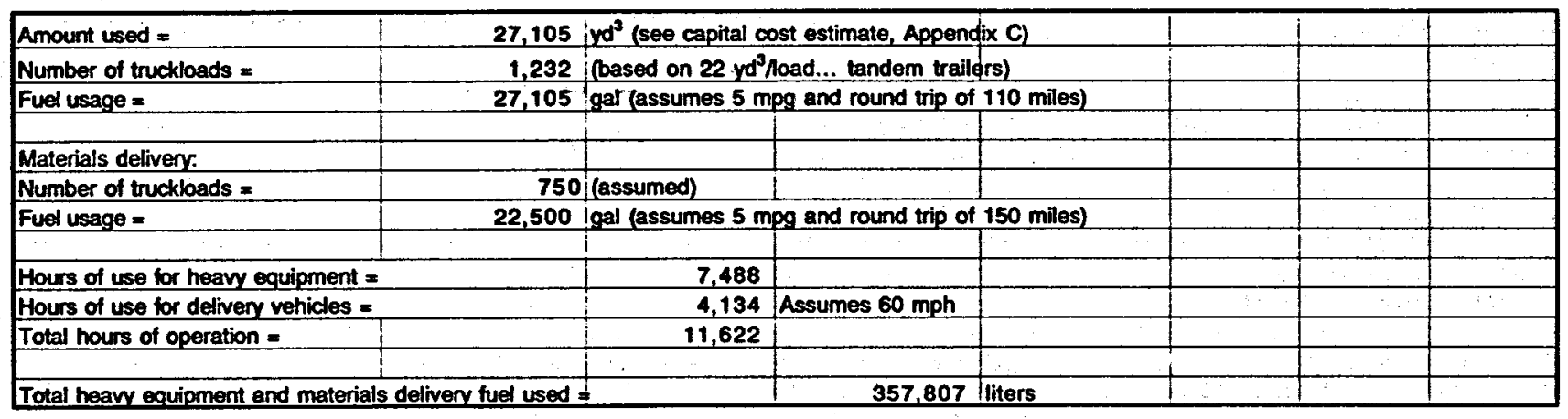




\begin{tabular}{|c|c|c|c|c|c|c|c|}
\hline Llabor: & 78 & & & & & & \\
\hline \multirow{2}{*}{\multicolumn{7}{|c|}{ Gerrating costs are taken from the life cycle cost estimate. }} & \\
\hline & & & & & & & \\
\hline \multicolumn{8}{|l|}{$\begin{array}{l}\text { Radiation } \\
\text { worker } \\
\text { annual }\end{array}$} \\
\hline $\begin{array}{l}\text { air } \\
\text { emissions }\end{array}$ & & 118 & Hos/yr $=$ & 0.1 & Tons/yr & & \\
\hline \multicolumn{8}{|c|}{ (pased on HIPing off gas rate of 1 sctm or 100 ders $/ v$ r) } \\
\hline \multicolumn{3}{|c|}{ Process water (non-radiotctivo) = } & $27,120,000$ & & & & \\
\hline \multirow{2}{*}{\multicolumn{8}{|c|}{ (leased on $452 \mathrm{gmm}$ of onco-though cooling water for $10 \mathrm{hr} / \mathrm{day}$ and 100 dars/yr - EOF-HW0-012) }} \\
\hline & & & & & & & \\
\hline Senitary wa & stewater = & & 405,600 & oalkr $=$ & $1,535,196$ & liters/ur & \\
\hline \multicolumn{8}{|c|}{ (oesed on 25 gal/doy per worker, facility occupied yoar-round, i.e. 52 wks/yr, 4 doys/wk) } \\
\hline & & & & & & & \\
\hline \multirow{2}{*}{\multicolumn{8}{|c|}{ Domestic wator usages same es senitary wrastewater rate. }} \\
\hline & & & & & & & \\
\hline \multicolumn{2}{|c|}{ Sanitarylndustrial tash } & & 588 & $y \alpha^{3} / Y^{r}$ & 433 & $\mathrm{~m}^{3} / \mathrm{xr}$ & \\
\hline \multicolumn{8}{|c|}{ 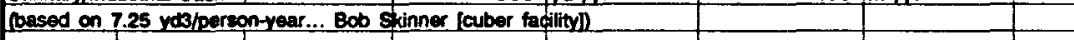 } \\
\hline & & & & & & & \\
\hline \multicolumn{8}{|c|}{ Padionective solid waste: } \\
\hline \multicolumn{2}{|c|}{ Mercury amaloam = } & 1 & $m^{3} / y r$ & & & & \\
\hline \multicolumn{8}{|c|}{ (based on 1.5 gal per day of operation) } \\
\hline \multicolumn{2}{|c|}{ Product canisters $=$} & 186 & $m^{2} / y r$ & & & & \\
\hline \multicolumn{8}{|c|}{ (soe EDF-HWO-012, page $n$} \\
\hline \multicolumn{8}{|c|}{ HEPA Mter: } \\
\hline & \multicolumn{2}{|c|}{ Bullding ventilation - } & 1378 & $n^{3} / v r=$ & 39 & $m^{2} / \mathrm{rr}$ & \\
\hline & $\begin{array}{l}\text { fitters with a } \\
\text { volume of } 4\end{array}$ & & & & & & \\
\hline & \multicolumn{2}{|c|}{ Calcine trenster systom = } & 288 & $t^{3} / v r=$ & 8 & $m^{3} / v r$ & \\
\hline & $\begin{array}{l}12 \text { fitters } \\
\text { with a }\end{array}$ & & & & & & \\
\hline & \multicolumn{2}{|c|}{ Process off-oas tystem = } & & 48 & $n^{2} / r=$ & 1 & $m^{3} / 4 r$ \\
\hline Total volum & of of HEPA nit & $6=$ & 48 & $m^{3} / 2 r$ & & & \\
\hline $\begin{array}{l}\text { red waste } \\
\text { (oxclusive } \\
\text { of HEPA }\end{array}$ & & 167 & $\mathrm{~m}^{3} / \mathrm{rr}$ & & & & \\
\hline Hazardous & waste $=$ & 100 & $t^{2} / h r=$ & 3 & $m^{3} / v r$ & & \\
\hline (essumedv & olume - R. KMm & nmitt. Herns euch & in es pain, epent & solvents, etc.) & & & \\
\hline & & & & & & & \\
\hline $\begin{array}{l}\text { activated } \\
\text { carbon }\end{array}$ & & & 50 & $n^{3} / \mathrm{rr}=$ & 1 & $m^{3} / r r$ & \\
\hline & & & & & & & \\
\hline & & & & & & & \\
\hline Process wa & ter usage $=8$ & ane es process & water efliuent (on & nce-through cooli & ling water? & & \\
\hline & & & & & & & \\
\hline Electric pow & er usage : & & $8,472,000$ & $k W h / x=$ & 8,472 & MWh/yr & \\
\hline beased on 8 & $A 72 \mathrm{~kW}-E D F$ & F-HWO-012, p. & (5) & & & & \\
\hline & & & & & & & \\
\hline Stram Una & & 16,000 & $1 \mathrm{bs} / \mathrm{hr}=$ & $63,709,091$ & $\mathrm{~kg} / \mathrm{sr}$ & & \\
\hline EDF-HWO- & 012, D. 151 & & & & & & \\
\hline & & & & & & & \\
\hline Redianctivit & $x$ essociate with & th waste materig & & & & & \\
\hline & 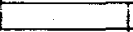 & & & & & & \\
\hline HEPA Fitter & & 35 & Cilyr & & & & \\
\hline $\begin{array}{l}\text { is based on } \\
\text { the } \\
\text { assumption } \\
\text { that only } \\
\text { the fiters } \\
\text { associated }\end{array}$ & 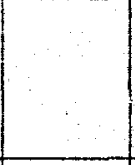 & : & . & $\therefore$ & & & \\
\hline Spont ectiv & ated carbon $=$ & & $<1$ & clor & & & \\
\hline $\begin{array}{l}\text { assumed } \\
\text { that }\end{array}$ & & $\therefore$ & 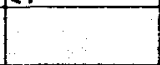 & ene & & & \\
\hline & & & & & & & \\
\hline Mercury am & $\operatorname{algam}=$ & 0 & $\mathrm{Ci} / \mathrm{yr}$ & $\begin{array}{l}\text { No radioactivity } \\
\text { is evelved } \\
\text { during the } \\
\text { devolatilization } \\
\text { process. }\end{array}$ & & & \\
\hline & & 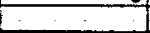 & & $T=1$ & & & . \\
\hline Vitrified wa & ste : & $1,152,000$ & Cilrr & 1 & & , & \\
\hline $\begin{array}{l}\text { processing } \\
\text { aporoximat }\end{array}$ & & 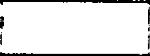 & 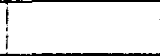 & $!$ & .. & & \\
\hline
\end{tabular}




\begin{tabular}{|c|c|c|c|c|c|c|c|c|c|}
\hline \multirow{2}{*}{\multicolumn{10}{|c|}{ D\&D Labor }} \\
\hline & & & & & & & & & \\
\hline Crew : & Crew Function & Total MH/day & Totel \$/day & Material \$/day & $\begin{array}{l}\text { Equipment } \\
\text { s/day }\end{array}$ & Total \$/day & $\begin{array}{c}\text { D\&D Cost } \\
\text { Allocated (FY } 97 \\
\text { dollars) }\end{array}$ & \multirow{2}{*}{$\frac{\text { Total MH }}{43,200}$} & \multirow{2}{*}{$\begin{array}{r}\text { Man-hours/y! } \\
8,640\end{array}$} \\
\hline D & Documentation & 18 & $\$ 1,136$ & $\$ 114$ & $\mathbf{s}$ & $\$ 1,250$ & $3,000,000$ & & \\
\hline 1 & Characterization & 44 & $\$ 2,302$ & $\$ 460$ & $\$ 691$ & $\$ 3,453$ & $6,994,000$ & 89,121 & 17,824 \\
\hline 2 & Rad Demoltition-Systems & 77 & $\$ 4,091$ & $\$ 818$ & $\$ 1,023$ & $\$ 5,932$ & $30,000,000$ & 389,413 & 77,883 \\
\hline $2 \mathrm{~A}$ & Rad Demolition-Building & 99 & $\$ 5,319$ & $\$ 1,064$ & $\$ 1,598$ & $\$ 7,979$ & $18,000,000$ & 223,336 & 44,667 \\
\hline 3 & Demolifion-Systems & 72 & $\$ 3,762$ & $\$ 752$ & $\$ 941$ & $\$ 5,455$ & $8,951,000$ & 118,143 & 23,629 \\
\hline 3A. & Demoltion-Building & 88 & $\$ 4,808$ & $\$ 862$ & $\$ 1,442$ & $\$ 7,212$ & $2,000,000$ & 24,404 & 4,881 \\
\hline 4 & Asbestos Abatement & 77 & $\$ 3,753$ & $\$ 375$ & $\$ 188$ & $\$ 4,316$ & $\$$ & - & - \\
\hline 5 & Decontamination & 77 & $\$ 3,753$ & $\$ 751$ & $\$ 1,126$ & $\$ 5,630$ & $30,094,000$ & 411,588 & 82,318 \\
\hline 6 & Prop/Fabrication & 61 & $\$ 3,217$ & $\$ 643$ & $\$ 965$ & $\$ 4,826$ & $2,000,000$ & 25,280 & 5,056 \\
\hline \multirow[t]{2}{*}{7} & RADCON SUNEYS & 50 & $\$ 2,596$ & $\$ 519$ & $\$ 779$ & $\$ 3,894$ & $8,000,000$ & 102,722 & 20,544 \\
\hline & & & & & & & & & \\
\hline Total & $\ldots$ & $\ldots$ & & & & & s $109,039,000$ & $1,427,208$ & 285,442 \\
\hline & $\ldots$ & & & & & & & & \\
\hline \multirow[t]{2}{*}{ Available } & $\ldots . . .$. & & & & & & \& $109,039,000$ & & \\
\hline \multirow{2}{*}{\multicolumn{10}{|c|}{ Notes: }} \\
\hline & & & & & & & & & \\
\hline & \multicolumn{3}{|c|}{ Crew functions and dally estimates are from the D\&D program (Dave Haycraft) } & & & & & & \\
\hline 2 & Total costs are based on life cycle estimate by $R$. Turk & & & & & & & & $-\infty . . .+1$. \\
\hline 3 & \multicolumn{2}{|l|}{ Assume all workers in crews 2, 2A, 5, and 7 are rad workers } & & & & & & & \\
\hline 4 & Assume a man-vear is 1800 hours. & & & & & & & & \\
\hline
\end{tabular}




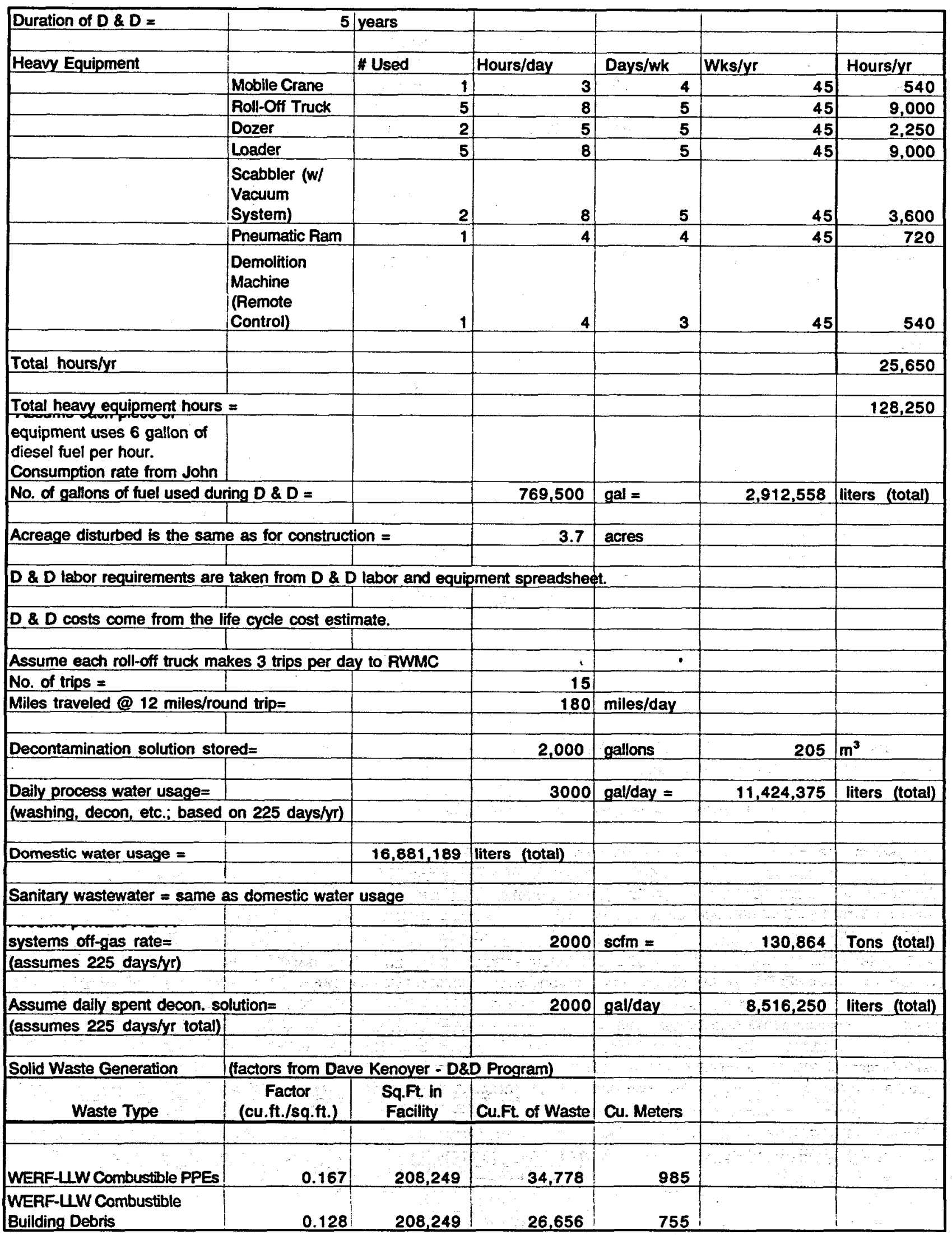




\begin{tabular}{|c|c|c|c|c|c|c|}
\hline $\begin{array}{l}\text { WERF-UW Compactable } \\
\text { Building Debris }\end{array}$ & 0.195 & 208,249 & 40,608 & 1,150 & & \\
\hline $\begin{array}{l}\text { RWMC-UWNon- } \\
\text { Compactable Equipment }\end{array}$ & 0.513 & 208,249 & 106,832 & 3,026 & & $\because$ \\
\hline $\begin{array}{l}\text { RWMC-LW Non-Compt } \\
\text { Building Debris }\end{array}$ & 0.684 & 208,249 & 142,442 & 4,035 & & \\
\hline $\begin{array}{l}\text { RWMC-LWW Non-Compt } \\
\text { Concrete Rubble }\end{array}$ & 3.44 & 208,249 & 716,375 & 20,294 & $\begin{array}{l}\text { twice as large as } \\
\text { that } \\
\text { recommended by } \\
\text { the D\&D program } \\
\text { to account for } \\
\text { that large }\end{array}$ & \\
\hline $\begin{array}{l}\text { RWMC-ULW Non-Compt } \\
\text { Scrap Metal }\end{array}$ & 0.778 & 208,249 & 162,017 & 4,590 & & \\
\hline $\begin{array}{l}\text { RWMC-UW Asbestos/ACM } \\
\text { Covered Pipe }\end{array}$ & 0 & 208,249 & - & - & & \\
\hline $\begin{array}{l}\text { CFA Landfill Non-Compt } \\
\text { Building Debris }\end{array}$ & 1.99 & 208,249 & 414,415 & 11,740 & 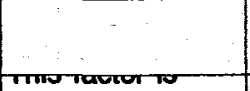 & \\
\hline $\begin{array}{l}\text { CFA Landtill Non-Compt } \\
\text { Concrete Rubble }\end{array}$ & 2.45 & 208,249 & 510,209 & 14,454 & $\begin{array}{l}\text { twice as large as } \\
\text { that } \\
\text { recommended by } \\
\text { the D\&D program } \\
\text { to account for } \\
\text { that large }\end{array}$ & \\
\hline CFA Landfill Asbestos & 0 & 208,249 & - & $\because$ & 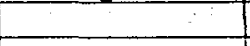 & \\
\hline $\begin{array}{l}\text { HWSF Hazardous Mirls } \\
\text { (Hg/PCBs/etc) }\end{array}$ & 0.002 & 208,249 & 416 & 12 & & \\
\hline Metal Recycle & 0.022 & 208,249 & 4,581 & 130 & & \\
\hline & & & & & & \\
\hline $4 W=$ & & & $1,229,708$ & 34,836 & & \\
\hline Non-Rad = & & & 924,624 & 26,193 & & \\
\hline Hazardous $=$ & 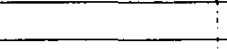 & 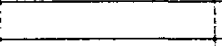 & 416 & 12 & & \\
\hline Metal $=$ & & & 4.581 & 130 & & \\
\hline Electric power usage = & 156,000 & kWh/yr & 156 & MWh/yr & & \\
\hline \multicolumn{7}{|c|}{\begin{tabular}{|l|l|l} 
(based on 3,000 kWh/wk - John Duggan) \\
\end{tabular}} \\
\hline \multicolumn{7}{|c|}{ Air emissions from fuel are based on the diesel emissions spreadsheet. } \\
\hline & & & & & & \\
\hline 1 manyear of labor = & 1800 & manhours & & & & \\
\hline & & & & & & \\
\hline Lube oil = & 24,271 & liters (total) & & & & \\
\hline \multicolumn{7}{|c|}{ (based on 3 gal for every 60 hours of operation) } \\
\hline & 1 & & & & & \\
\hline Mixed waste $=$ & 61,875 & gal (total) $=$ & 234 & m3 (total) & & \\
\hline \multicolumn{7}{|c|}{ (based on an assumed 5 55-gallon drums generated per week... work only 45 weeks/yr) } \\
\hline & & & & & & \\
\hline \multicolumn{7}{|c|}{ Radioactivity associated with waste materials: } \\
\hline & 4 & & & & & \\
\hline \multicolumn{7}{|c|}{\begin{tabular}{|l:l|l|l} 
Spent decontamination solution $=$ & 8,516 & $\mathrm{a}$ \\
\end{tabular}} \\
\hline \multicolumn{7}{|c|}{ (based on an assumed average activity concentration of $1 \mathrm{uCi} / \mathrm{ml})$} \\
\hline & & & & & & \\
\hline Radioactive solid waste $=$ & & 348 & $\mathbf{a}$ & & & \\
\hline \multicolumn{7}{|c|}{ (based in an assumed activity concentration of $0.01 \mathrm{uCi} / \mathrm{cc}\left[0.01 \mathrm{Ci} / \mathrm{m}^{3}\right]$ ) } \\
\hline & & & & & & \\
\hline Mixed waste $=$ & & 2 & $\mathbf{a}$ & & & \\
\hline \multicolumn{6}{|c|}{ (based on an assumed activity concentration of $0.01 \mathrm{uCi} / \mathrm{cc}\left[0.01 \mathrm{Cl} / \mathrm{m}^{3} \mathrm{l}\right.$ ) } & \\
\hline
\end{tabular}




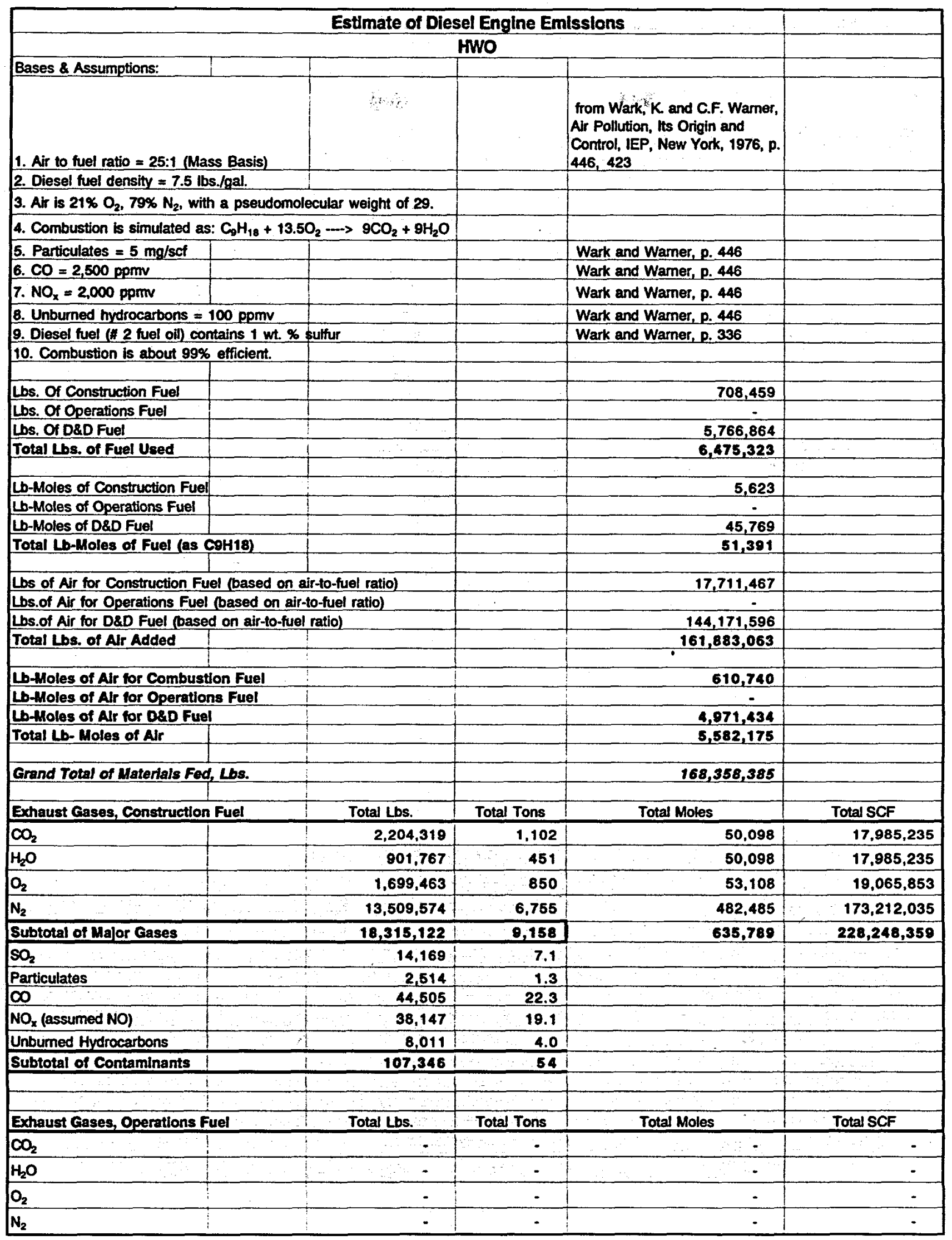




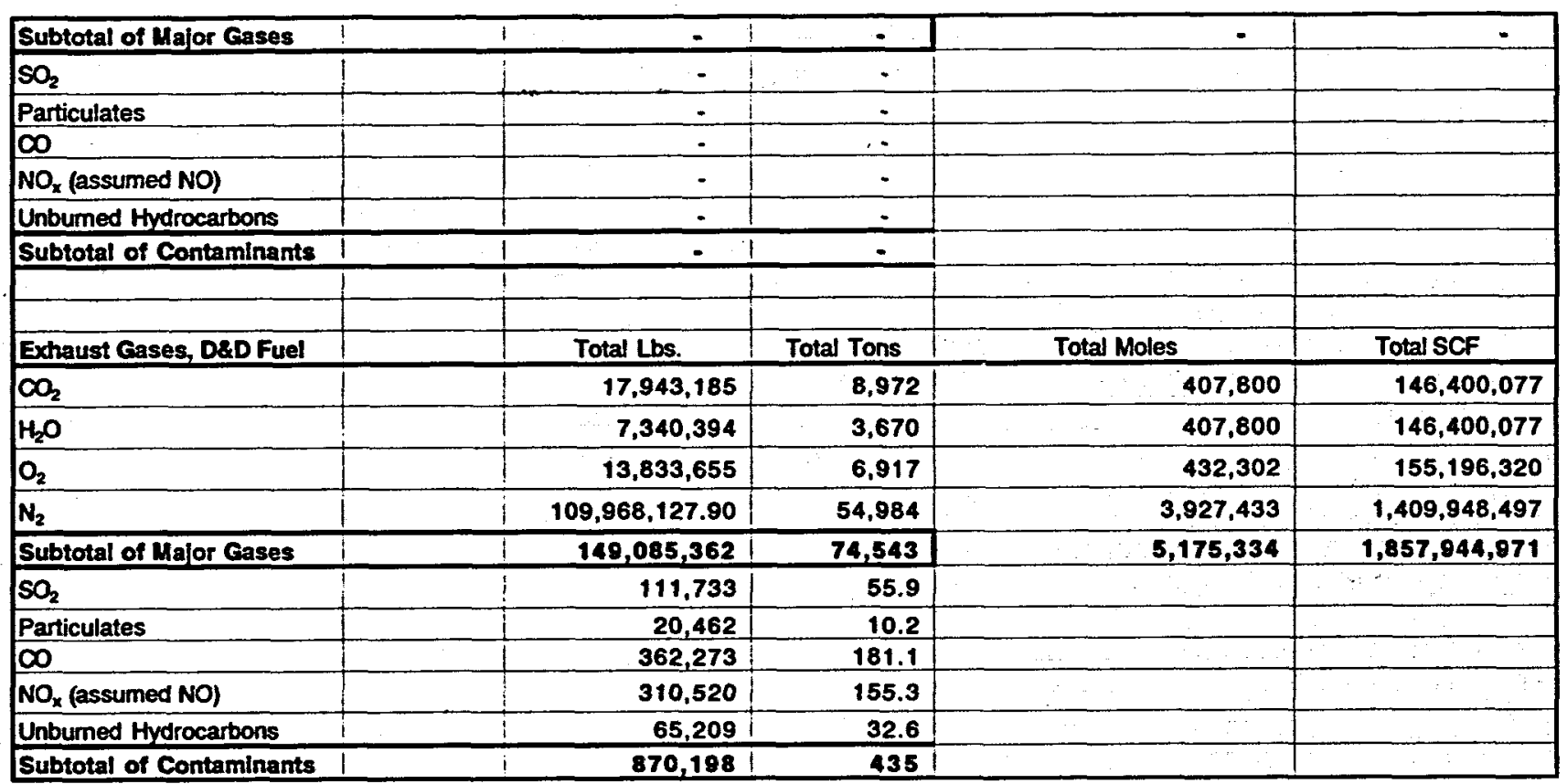

